\title{
Mailehen - Erlebnis des "Überlebten"
}

\section{Ein Brauch als Medium}

Dissertation

zur Erlangung des philsophischen Doktorgrades an der Philosophischen

Fakultät der Georg-August-Universität zu Göttingen

\author{
vorgelegt von \\ Hans-Willi Wey \\ aus Münstermaifeld
}

Göttingen 2002 
Vorwort

Den 37 namentlich ungenannt gebliebenen Personen, die mir ihre Mailehenerlebnisse und Einsichten in vielen Gesprächen mitteilten, gehört mein herzlichster Dank. Ohne ihre lebhafte Mitarbeit wäre die Promotion ganz anders verlaufen und das subjektzentrierte Kapitel der Mailehenforschung würde weiterhin brachliegen. Den Mitgliedern des Junggesellenvereins in Oeverich möchte ich besonders dafür danken, daß sie mir verständnisvoll in viele Bereiche des Brauchgeschehens Einblick gewährten, der gewöhnlich dem ortsfremden, nichtinitiierten, verheirateten Familienvater verschlossen bleibt. Mit der teilnehmenden Beobachtung wurden die Schilderungen meiner GesprächspartnerInnen noch plastischer.

Zudem gilt mein Dank Prof. Rolf Wilhelm Brednich. Er hat mein Dissertationsvorhaben von Anfang an mit Interesse verfolgt und auf vielfältige Weise unterstützt. Sein Blickwinkel eröffnete mir stets wichtige Anregungen und Perspektiven.

PD Dr. Dr. Gudrun Schwibbe danke ich für die engagierte Übernahme des Zweitgutachtens. Ebenso danke ich den übrigen Mitgliedern der Prüfungskomission: Prof. Brigitta Benzing, Prof. Wolf-S. Rosenbaum und Prof. Dieter Stellmacher.

Die Arbeit wurde mit Mitteln der Graduiertenförderung des Landes Niedersachsen gefördert. Auch hierfür sei gedankt.

Nicht genug kann ich meiner Familie und meinen Freunden danken, die mich während der Promotion begleitet und unterstützt haben.

Bonn, im Januar 2002

H.-W.W. 
In ha $1 \mathrm{t}$

VORWORT TH

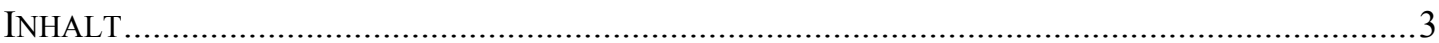

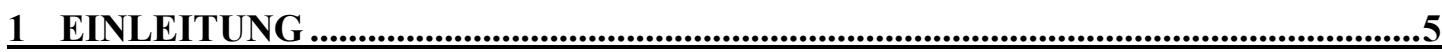

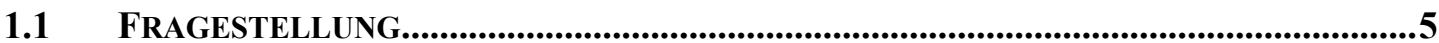

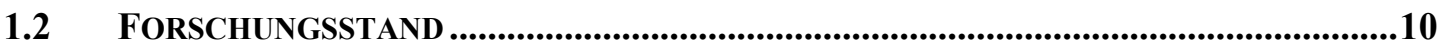

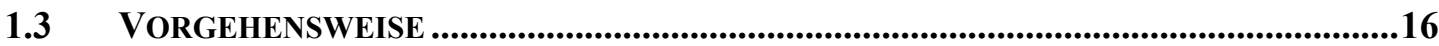

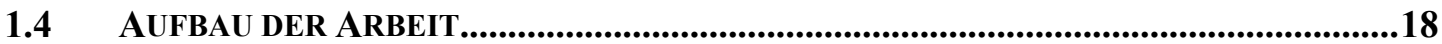

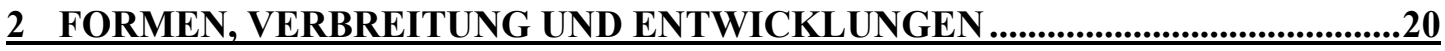

2.1 URSPRUNGSSUCHE: BABYLONIER UND GERMANEN .............................................20

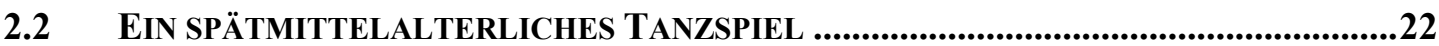

2.3 NACHRICHTEN AUS DEM STÄDTISCHEN MILIEU DES 15./16. JAHRHUNDERTS........24

2.4 UNTER DEM DRUCK FRÜHNEUZEITLICHER MACHTINTERESSEN ...........................27

2.5 AUF DEM WEG ZU EINER FORMALISIERTEN BRAUCHORGANISATION (19. JH.) ....36

2.6 AUSWIRKUNGEN DER INDUSTRIALISIERUNG.........................................................55

2.7 KONFRONTATION MIT DEM NATIONALSOZIALISMUS..............................................60

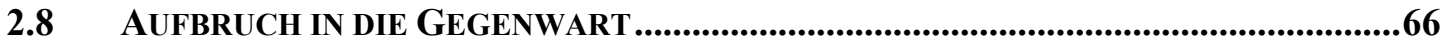

2.9 ENTWICKLUNGSGESCHICHTLICHE DIMENSIONEN DER RITUELLEN

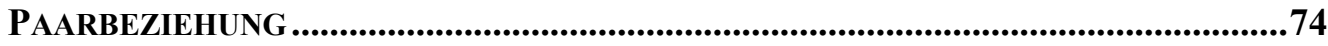

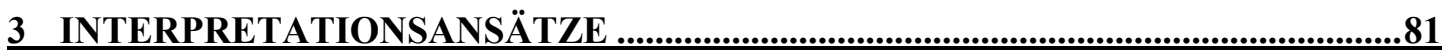

3.1 KULTISCHES - ZAUBER DER DÄMONEN UND IMITATION DES GÖTTLICHEN ........81

3.2 RESIDUALES - WIDER FROMMEN EIFER, EISENBAHNEN UND

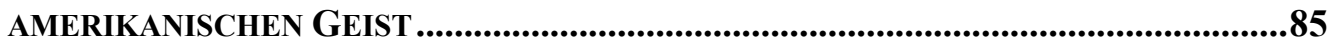

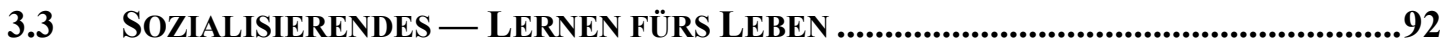

3.4 REBELLISCHES - KONFLIKT UND AUSGLEICH .................................................100

3.5 EXISTENTIELLES — ÖKONOMISCHES KALKÜL .....................................................103

3.6 DIONYSISCHES — AMBIVALENZ DER FREUDE ...................................................109

3.7 PLAUSIBILITÄT VON MAILEHENDEUTUNGEN_...................................................125

4 FALLBEISPIEL: MAILEHENPRAXIS IN OEVERICH ...................................129

4.1 DER ORT UND DAS "FELD": ZUR SPEZIFIK DER ERHEBUNG .................................129

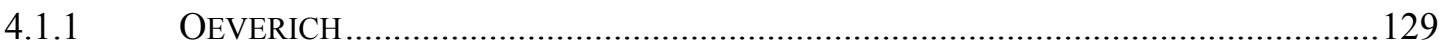

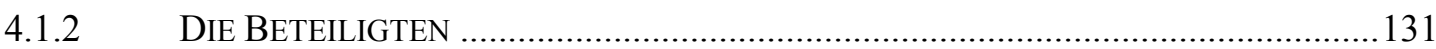

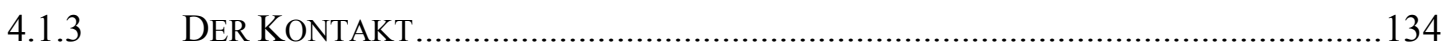

4.1.4 BEMERKUNGEN ZUR AUSWERTUNG UND WIEDERGABE DER EMPIRIE ................140

4.2 RÜCKBLICK: OEVERICHER MAILEHENGESCHICHTE ............................................142

4.2.1 GRÜNDUNG UND AUFBAU DES JUNGGESELLENVEREINS (1889-1920) ..................142

4.2.2 KONFRONTATIONEN MIT DEN DORFAUTORITÄTEN (1920-1945) .........................145 
4.2.3 ZURÜCKGEWONNENE LEBENSFREUDE (1945-1960)

4.2.4 MODERNES BRAUCHMANAGEMENT (1960-1995)

4.3 MOMENTAUFNAHME: ETHNOGRAPHISCHE BEOBACHTUNGEN IM JAHRE 1993..164

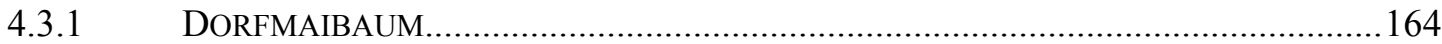

4.3.3 AUFNAHME NEUER MITGLIEDER IN DEN JUNGGESELLENVEREIN ........................168

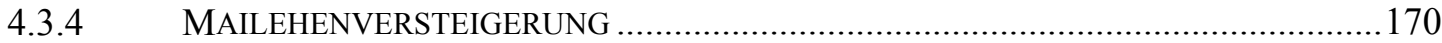

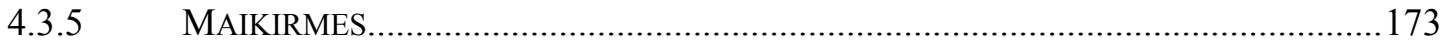

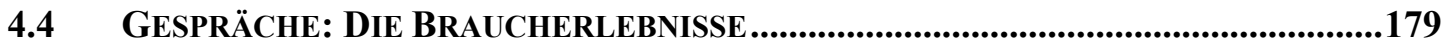

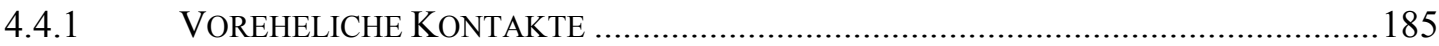

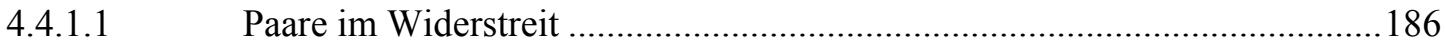

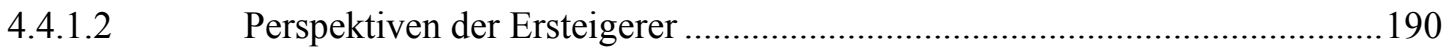

4.4.1.3 Anbahnung sexueller Beziehungen................................................................ 194

4.4.2 SOZIALE ROLLEN UND DIE ERSCHLIEßUNG ANDERER WELTEN ...........................200

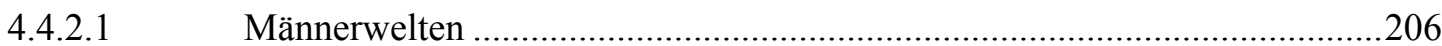

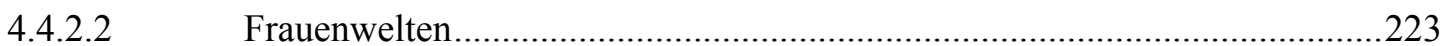

4.4.3 SOZIALE BRAUCHÖKONOMIE: VERDIENEN UND VERDIENSTE ................................23

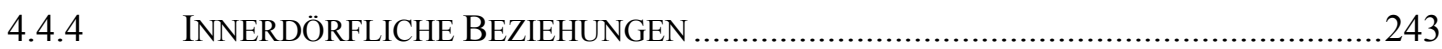

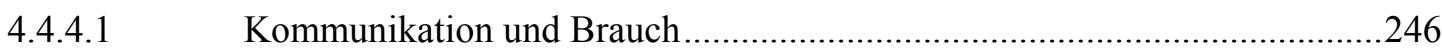

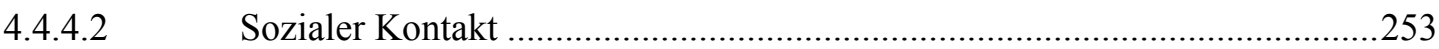

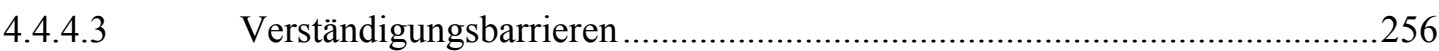

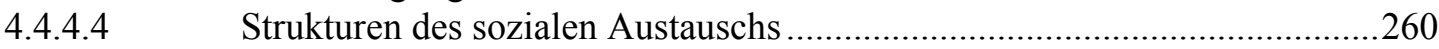

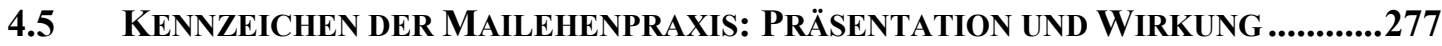

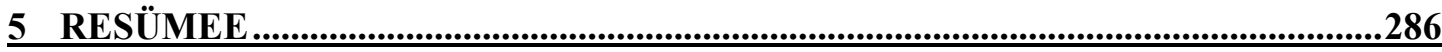

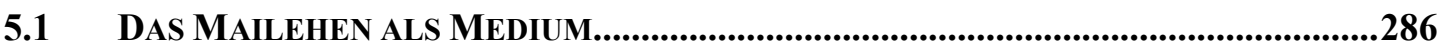

5.2 BRAUCHFORSCHUNG UND DAS ERLEBNIS DES "ÜBERLEBTEN"..............................293

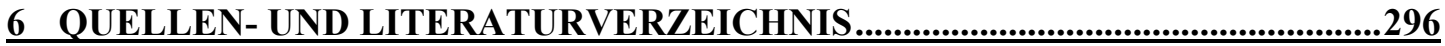

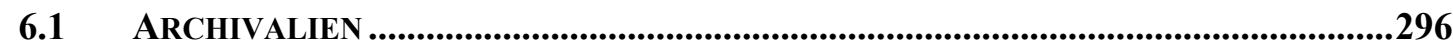

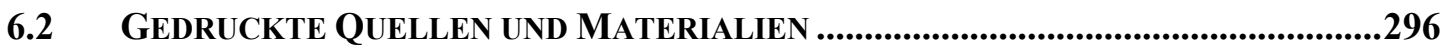

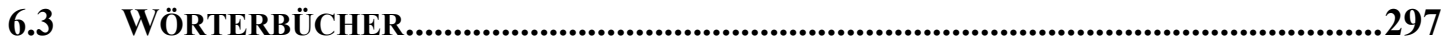

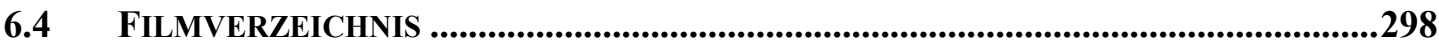

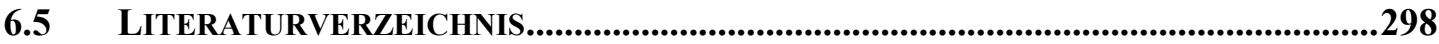

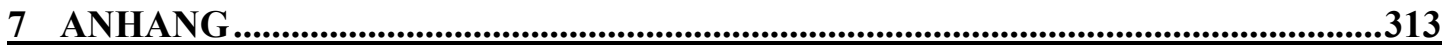

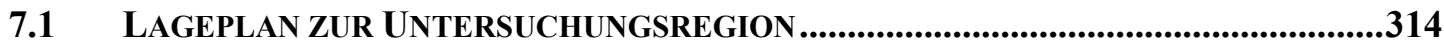

7.2 STATISTISCHE DATEN ZUR UNTERSUCHUNGSREGION ...........................................315

7.3 MATERIALIEN ZUR DURCHFÜHRUNG DER GESPRÄCHE .........................................316

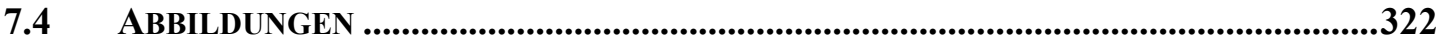




\section{Einleitung}

1.1 Fragestellung

Mit dem Begriff Mailehen verbindet sich seit dem 19. Jahrhundert ein Brauch, der hauptsächlich unter den unverheirateten Jugendlichen eines Ortes praktiziert wurde. Dabei versammelten sich häufig in der Nacht zum 1. Mai die im Junggesellenverein organisierten jungen Männer, um die sogenannte Mailehenversteigerung vorzunehmen. Hierbei kam es zur Zuteilung der Mailehenpaare sowie zur Ermittlung eines Maikönigspaares. Wenn ein Mädchen keinen Ersteigerer fand, konnte es in den sogenannten Rummel gelangen, der alle Übriggebliebenen vereinigte und einen Ausschluß aus der Gruppe der aktiven BrauchträgerInnen bedeutete. Aus der rituellen Verpaarung ergaben sich sodann spezielle Aufgaben: die Mädchen erhielten einen Maibaum, die Paare gingen zusammen zum Tanz, das Maikönigspaar sorgte für ein feierliches Gepränge und ähnliches mehr. Nicht selten bildete das Mailehen auf diese Weise den festgefügten Rahmen eines mehrtägigen Festes der gesamten Gemeinde. Da diese Aktivitäten vielerorts im Monat Mai ausgeübt wurden, lag die Bezeichnung Mailehen für den Brauch nahe. Der Ausdruck Lehen erklärt sich aus der Geschichte des Brauchs, wobei die ursprüngliche Wortbedeutung des althochdeutschen lêhan "etwas dargeliehenes" (Deutsches Wörterbuch 1854-1960) meint. Damit präsentiert sich der Brauch als ein Akt einer leihweisen Überlassung von etwas Unbestimmtem. Die Konkretisierung dieses "Leihobjekts" ist ein zentrales Thema der vorliegenden Arbeit: Wer oder was wurde ritueller Gegenstand der Leihgabe und wer sind die handelnden Subjekte - Geber und Nehmer - dieser Transaktion? Kurz, wer erhält innerhalb des rituellen Geschehens was von wem geborgt?

Auf eine präzise Beantwortung dieser Fragestellung ist in der Literatur leider nicht immer genügend Wert gelegt worden. Daher haben sich unweigerlich Probleme in der Deutung des Brauches eingestellt. Mit der weitverbreiteten Ansicht, daß dem Junggesellen das rituell abgesicherte Recht gebühre, über seine ledigen Altersgenossinnen nach eigenem Belieben und Ermessen zu verfügen, wurden grundlegende Bestimmungsfaktoren des Mailehens achtlos übergangen. Die Prämisse einer eklatanten asymmetrischen Machtverteilung unter den aktiven Brauchträgern und passiven "Brauchträgerinnen" läßt sich bis ins Jahr 1836 zurückverfolgen. Ein anonymer Autor nahm in besonders deutlicher Weise Stellung zur Brauchpraxis, indem er resümierte: "Glücklich für mich, daß ich kein Mädchen bin!"1 Damit ist die

\footnotetext{
${ }^{1}$ Siehe Anonymus (1836c:85). Der unbekannte Autor reagierte auf einen Aufruf in den Rheinischen Provinzial=Blättern, der unter der Überschrift "Seltsamer Gebrauch in der Gegend von Uelmen" abgedruckt worden war und zur Mithilfe bei der Dokumentation von "Volks=Gebräuchen" anregen sollte. Vgl. Anonymus (1836a:122-123).
} 
Behauptung der massiven Benachteiligung von Frauen durch den Brauch im 19. Jahrhundert deutlich ausgesprochen worden, und sie begegnet uns in abgewandelter Form bis in die Gegenwart. Einige Beobachter und Beobachterinnen sahen das Mailehen in unverständlich krassem Widerspruch $\mathrm{zu}$ den allgemeinen gesellschaftlichen Verhältnissen. Wie war es möglich, daß sich jener unverhohlene männliche Besitzanspruch gegenüber dem weiblichen Geschlecht so stark manifestieren konnte? Ohne diesem Problem ernsthaft nachzugehen, wurde von den AutorInnen häufig der unmittelbar bevorstehende Untergang des Mailehens angekündigt. Aus der Sicht des aufgeklärten Bildungsbürgertums war das Mailehen nicht mehr zeitgemäß. Man ging davon aus, daß die tradierten Handlungskomplexe, die in der sich formierenden modernen Gesellschaft keine erkennbare Funktion einnahmen, sich in absehbarer Zukunft auflösen würden. Niessen (1900:95) sprach deshalb davon, daß "für unsere Zeit der Brauch sich überlebt haben [dürfte] und [er] geht denn auch wirklich mehr und mehr seinem Ende entgegen". ${ }^{2}$

Seither ist viel Zeit vergangen. Der durch die Moderne forcierte gesellschaftliche Fortschritt hat weiter um sich gegriffen. Die Gleichberechtigung der Geschlechter ist mittlerweile so weit gediehen, daß die politische Beteiligung der Frauen auf den allerhöchsten Ebenen gesellschaftlicher Machtausübung denkbar und auch möglich ist. Und dennoch hat das Mailehen überlebt, wie auch das Etikett des Relikthaften überlebt hat. So bemerkten Elke und Herbert Schwedt (1989:146) zum Mailehen unlängst, daß es "dort, wo es nicht bekannt und gewohnt ist, als besonders exotisch [gilt]: kann es denn im 20. Jahrhundert eine Versteigerung von Mädchen geben? Es kann", so wird den LeserInnen sogleich versichert, "und die Mädchen haben nicht einmal etwas dagegen einzuwenden".

Aussagen über die Erscheinung und die Verbreitung des Mailehens sind zwar für die phänomenologische Betrachtung eines Brauches wertvoll, sie lassen aber die Motive der Brauchbeteiligten im allgemeinen unberührt und reduzieren somit den Deutungsspielraum um die Perspektive des Braucherlebnisses. Das Verstehen des Mailehens scheint aber von der Überwindung dieser Schwachstelle abzuhängen, wie kürzlich noch einmal bemerkt wurde:

"Es ist klar, daß ein solcher Brauch sehr sorgfältig interpretiert werden muß, wenn man ihm gerecht werden will, und die Roben der Maiköniginnen lassen ahnen, daß viele Mädchen ihn durchaus nicht als Repressionsinstrument oder gar als Nebensache verstehen. Aber von Jünglingsversteigerungen hat man eben doch nie gehört" (Schwedt 1999:165).

\footnotetext{
${ }^{2}$ Schon in den Rheinischen Provinzialblättern von 1836 wurden Vermutungen zum Niedergang des Mailehens laut: "Schreiber dieses [...] wünscht sehr, daß die folgende Mittheilung [zum Mailehen, H.W.W.] dazu beitragen möge, die Aufmerksamkeit auf diesen seltsamen, anscheinend mehr und mehr verschwindenden Gebrauch hinzulenken" (Anonymus 1836b:3).
} 
Unter den weiblichen Mailehen ${ }^{3}$ wurde derjenigen die Königswürde zuteil, die den höchsten Preis bei der Mailehenversteigerung erzielen konnte. Das hervorstechende Kleidungsverhalten der Regentinnen diente an dieser Stelle als Indikator einer persönlichen Akzeptanz des Brauches. Gewagt wäre es, von der Ambivalenz solcher Zeichen abzusehen. Denn der Glanz jener zur Schau getragenen Pracht kann immer nur die Oberfläche einer individuellen, sozialen und kulturellen Disposition zur Brauchpraxis widerspiegeln. Derartige Zeichen referieren auf einen äußerst begrenzten und voraussetzungsvollen Ausschnitt gelebter Wirklichkeit, der zu Recht das volkskundliche Interesse weckt und eine angemessene Herangehensweise verlangt. Das Einbeziehen der handlungsleitenden Motive bei der Brauchausübung führt an dieser Stelle zu einer bedeutsamen Erweiterung der oben angeführten erkenntnisleitenden Fragestellung: $Z u$ welchem Zweck und unter welchen Bedingungen erfolgt die durch das Mailehen angestoßene rituelle Leihgabe?

Untersucht wird also nicht nur das Erscheinungsbild, die Formen, die vordergründige Präsentation des Brauches, sondern auch seine kulturellen, sozialen und psychosozialen Voraussetzungen. Hierbei kann der historische Rückblick die Erwartungen nur bruchstückhaft erfüllen, da die damals drängenden Fragestellungen und erfolgversprechenden Methoden eine andere Ausrichtung besaßen. Gerade deshalb kommt der eigenen Erhebung vor Ort eine wichtige Aufgabe zu. Eine Mikrostudie ermöglicht die intensive Auseinandersetzung mit den Hintergründen von Oberflächenphänomenen. Sie birgt die Chance, die Entstehungsbedingungen von Handlungen in ihrer lebensweltlichen Einbettung zu erfassen. Freilich muß man sich bei der Analyse der Ergebnisse der Gefahr einer unzulässigen Verallgemeinerung des Einzelfalls bewußt sein. Dort, wo sich jedoch Erlebnis-, Verhaltens- und Verarbeitungsstrukturen abzeichnen, läßt sich immerhin abwägen, inwieweit diese Strukturen mit der bisher dokumentierten Mailehenpraxis auf synchroner oder diachroner Ebene korrespondieren.

Die vorliegende Untersuchung gewährt nicht den Raum für eine grundsätzliche Aufarbeitung wissenschaftstheoretischer Positionen volkskundlicher Brauchforschung. ${ }^{4}$ Dennoch ist für die Interpretation der im Zusammenhang mit dem Mailehen

${ }^{3}$ Der Begriff Mailehen läßt sich auch unmittelbar auf die BrauchträgerInnen beziehen (s. Stichwort Mailehen Rheinisches Wörterbuch, 1928-71). In der Literatur wird oftmals stillschweigend davon ausgegangen, daß die Bezeichnung sich lediglich auf die weiblichen Brauchträger übertragen lasse. Mithin wird oft schon vor der eigentlichen Analyse auf begrifflicher Ebene eine einseitige Perspektive eingenommen.

${ }^{4}$ Trotz bestehender Ansätze, die einen allgemeinen Zugang zu Brauchthemen versprechen (z.B. Trümpy 1970, Wolfram 1972; Weber-Kellermann 1984, 1985 und Pop 1984), macht Bimmer (21994:392) auf das noch unzureichend behandelte Problem der Brauchtheorie aufmerksam. Aus der anglo-amerikanischen Perspektive geht man ebenfalls in jüngerer Zeit mit Grundsatzfragen an die sogenannten "ritual studies" heran. Vgl. dazu etwa Bell (1992), Humphrey/Laidlaw (1994) und den Aufsatzband von Belliger/Krieger (1998). 
gewonnenen Erkenntnisse die Darlegung eines epistemologischen Fundaments sinnvoll. Ausgangspunkte der Brauchforschung bildeten immer wieder Begriffe wie Sitte, Tradition, Gemeinschaft. ${ }^{5}$ Sie leisteten nicht selten einer zu kurz greifenden Phänomenologie und einer pseudowissenschaftlichen Objektivierung von Ursprungsund Funktionszusammenhängen Vorschub. Eine Definition von Brauch, die vielfach rezipiert wurde, die noch in jüngerer Zeit als Orientierungsmarke gegolten hat, ${ }^{6}$ ist die folgende:

"Brauchtum ist gemeinschaftliches Handeln, durch Tradition bewahrt, von der Sitte gefordert, in Formen vorgeprägt, mit Formen gesteigert, ein Inneres sinnbildlich ausdrückend, funktionell an Zeit oder Situation gebunden" (Dünninger ${ }^{2} 1962$, Spalte 2575).

Durch eine wiederholte Verwendung des Wortes Form in dieser Definition erhält der Gegenstand Brauch eine Überbetonung des Formellen. Selbst das Handeln, das durch Überlieferung und Sitte geradezu zwingend vorgegeben sein soll, macht das Brauchgeschehen anscheinend $\mathrm{zu}$ einem Ort, an dem das Subjekt und seine innere Disposition alleine an der Ausführung des Brauches fixiert bleiben. Wenn aber davon auszugehen ist, daß "Brauch zuallererst eine soziale Kategorie [ist]" (Bimmer 21994:375), dann kann es nicht bei einer subjektreduzierten und damit inhaltsleeren Bestimmung des Gegenstands bleiben. ${ }^{7}$

Für wesentlich gehaltene epistemologische Grundannahmen konnten vom Verfasser bereits in einer inhaltsanalytischen Bearbeitung von Presseerzeugnissen zum Mailehen dargelegt werden. Brauch wurde dort verstanden "als ein differenziertes System aufeinanderbezogener Handlungen und Erwartungen, das seinen turnusmäßigen Aufbau im wesentlichen durch vorgezeichnete, tradierte Strukturen erfährt, die von alternierenden Brauchträgern aufgegriffen, reorganisiert sowie modifiziert und von dem übergeordneten Sozialsystem kontrolliert, bewertet,

\footnotetext{
${ }^{5}$ Die Kritik dieser Terminologie, welche auf die Ahistorizität und die unzureichende soziale und räumliche Differenzierung historischer Befunde aufmerksam machte, hatte in Hermann Bausinger einen vehementen Verfechter. Vgl. z.B. Bausinger (1986:94-134). Auch die jüngere Diskussion um den z.T. wieder modisch gewordenen "Volkskultur"-Begriff fordert erneut zu einer Auseinandersetzung auf, allerdings dieses Mal mit dem Ziel, eine "Minimalplattform" (Schindler 1984:54) eines volkskulturlichen Selbstverständnisses in Abgrenzung zur Herrschaftskultur aufrechtzuerhalten. Siehe dazu auch Kaschuba (1986:500-501) und Zimmermann (1992:239-247). Letzterer warnt vor einer Zwei-Kulturen-Dichotomie und zieht das von Tönnies begründete evolutionstheoretische Gesellschaftsmodell vor. Ferner s. Bausinger (1985:12f), Bimmer (1990:150ff) und Scharfe (1991:10f) zur Verwendung der problematischen Bezeichnung Brauchtum.

${ }^{6}$ Vgl. Hartinger (1992:37-62), der auch über die Definition hinaus Vorgaben von Dünninger fast vollständig übernimmt.

${ }^{7}$ Zur sozialen Dimension des Brauches siehe ferner Scharfe (1991:17f). Vgl. die methodologische Bedeutung der Subjektorientierung, die Lipp (1988:29-46; bes. 30-32) im Kontext der volkskundlichen Frauenforschung hervorgehoben hat.
} 
gefördert oder gehemmt werden" (Wey 1999:313) ${ }^{8}$. Bei der Anlehnung an den systemtheoretischen Ansatz aus der Soziologie kam es mir vor allem darauf an zu zeigen, daß die Brauchaktivitäten keineswegs den grundsätzlich wirksamen Bedingungen und Möglichkeiten sozialer Kommunikation und Interaktion verschlossen sind. Im Braucherleben geht es um mehr als um den Gebrauch einer Grammatik (Trümpy), es geht auch um mehr als in dem klassischen SenderEmpfänger-Modell verdeutlicht werden kann. Weder schematische Regelanwendung, noch die einseitige Informationsübertragung kann der Brauchpraxis gerecht werden. Bei der brauchspezifischen Kommunikation handelt es sich dagegen um einen voraussetzungsvollen Prozeß der Mitteilung. ${ }^{9}$

Um diese Voraussetzungen, die in jeder Kommunikation und damit auch im Mailehen wirksam sind, zu begreifen, wurde das reflexive Moment der doppelten Kontingenz herangezogen. ${ }^{10}$ Danach produziert das soziale Verhalten in jeder Situation eine kontingente Ausgangsposition und damit "etwas, was weder notwendig ist noch unmöglich ist; was also so, wie es ist (war, sein wird), sein kann, aber auch anders möglich ist. Der Begriff bezeichnet mithin Gegebenes (Erfahrenes, Erwartetes, Gedachtes, Phantasiertes) im Hinblick auf mögliches Anderssein; er bezeichnet Gegenstände im Horizont möglicher Abwandlungen. Er setzt die gegebene Welt voraus, bezeichnet also nicht das Mögliche überhaupt, sondern das, was von der Realität aus gesehen anders möglich ist" (Luhmann 1987:152). Aufgrund der Kontingenzerfahrung, welche die generelle Instabilität von sozialen Beziehungen impliziert, erhält der Aufbau von Verbindlichkeiten und Strukturen seinen Sinn. Allerdings schafft die soziale Produktion von Ordnungen, Traditionen oder Ritualen keineswegs unbegrenzte Verhaltenssicherheiten. Sie führt lediglich dazu, daß die Kontingenz auf einem anderen Niveau sozialer Komplexität fortgesetzt wird. ${ }^{11}$

\footnotetext{
${ }^{8}$ Vgl. dazu eine ähnliche Konzeption der Begriffe Ritual und Ritualisierung bei Belliger/Krieger (1998:28-31), die auf Bell (1998:37-48) und Platvoet (1998:173-190) fußen.

${ }^{9}$ Dazu Luhmann (1987:193-201).

${ }^{10}$ Siehe Luhmann (1987:148-190).

${ }^{11}$ Siehe Luhmann (1987:171-172). Die soziologische Systemtheorie hat bisher kaum Eingang in die volkskundliche Brauchforschung gefunden, obwohl funktionalistische bzw. strukturfunktionalistische Erklärungsmodelle in den Arbeiten von Bausinger (1979:210-242), Weber-Kellermann (1984:23-29) oder Gerndt (1973:22 und 1976:34-49) in ihrer Bedeutsamkeit immer wieder hervorgehoben wurden. Aus meiner Sicht erscheint eine "Supertheorie", wie die Systemtheorie verstanden werden möchte (Luhmann 1987:19), innerhalb der empirischen Forschung tatsächlich nur bedingt von Vorteil. Sich der Größe eines sogenannten Riesen anvertrauen zu wollen, um dann von dessen Schultern mit Adlerblicken auf das bewegte Leben herabzublicken, dessen Praxis zu über- oder gar dessen "Logik" zu durchschauen. Die Systemtheorie bietet einerseits in ihrer Geschlossenheit und differenzierten Begrifflichkeit Vorzüge bei der Beobachtung und Beschreibung von funktionalen Zusammenhängen innerhalb einer eingrenzbaren sozialen Situation. Andererseits erscheinen ihre Möglichkeiten, Machtkonstellationen in ihren subtilen Differenzierungen und ihren übergreifenden Proportionen aufzuspüren, gegenüber anderen soziologischen Erkenntnistheorien eingeschränkt (Bourdieu/
} 
Diese Verortung der Möglichkeiten und Grenzen der individuellen Spielräume vor dem Hintergrund präformierter, ritueller Verhaltenszumutungen war mir wichtig, da der Blick der Brauchforschung oftmals auf einer allzu statischen Konstellation sozialer Rollen und einer strengen Ausübungsmechanik verharrte. Daß unter hohem Druck, den die organisierten Brauchträger und ihre UnterstützerInnen auszuüben wußten, die soziale Kontrolle für den einzelnen bedrängend werden konnte, ${ }^{12}$ muß dabei nicht in Vergessenheit geraten. Aber die vorliegende Untersuchung bringt eine Reihe von Belegen dafür, daß auch in den brauchbedingten Momenten der Repression die Kreativität menschlicher Reaktionsweisen keineswegs ins Aus manövriert wird. Die Flexibilität sozialer Relationen sowie Aspekte der Spontaneität, Innovation oder die Wirkung von Unerwartetem muß in einer Analyse, die das Verstehen des Brauches am Erlebnis der Beteiligten orientiert, ebenso antizipiert und verfolgt werden wie die Normativität der tradierten Erscheinungsform des Mailehens und der Strukturen, die das soziale Umfeld prägen. ${ }^{13}$ In der Arbeit wird somit die Forderung einzulösen versucht, den Brauch auf den Betroffenen in seinen individuellen Erlebnisweisen, in seinen gesellschaftlichen Beziehungen und in seiner kulturellen Eingebundenheit $\mathrm{zu}$ beziehen, um somit das notwendige Maß an Deutungsmöglichkeiten zu gewinnen. ${ }^{14}$

\subsection{Forschungstand}

Der Feststellung von Schrick (1992:32), daß das Mailehen "in der volkskundlichen Literatur gerne beschrieben [wird], jedoch beschränkt sich das Interesse hauptsächlich auf seine Ausführung, regionale Gestaltung und auf die organisierenden

Wacquant 1996:134-135). Auch die Externalisierung des Menschen aus dem Gegenstandsbereich der Theorie wirft Probleme auf, die inzwischen von den Systemtheoretikern intensiv bearbeitet werden (Fuchs/Göbel 1994:7-14). Eine wechselseitige Offenheit gegenüber den jeweiligen Stärken der Luhmannschen Systemtheorie (analytisch tiefenscharfe Begrifflichkeit), der Praxeologie von Bourdieu (Sensibilität gegenüber sozialen Machtgefällen) und dem Lebensweltansatz von Schütz (Nähe zum empirischen Alltagshandeln) mag zwar der jeweiligen Orthodoxie schaden und bietet auf diese Weise Angriffsflächen. Kritik sollte die Brauchforschung jedoch nicht scheuen, denn: "Methodischer Aufgabenstreit und wissenschaftliche Grenzziehung haben zurückzustehen, wenn es sich um ein Forschungsgebiet handelt, bei dem die Grenzen flüssig sind" (Dünninger 1967:9).

${ }^{12}$ Vgl. z.B. Scharfe (1970:45-68).

${ }^{13}$ An dieser Stelle besteht eine Beziehung zum Habitusbegriff Bourdieus, bei dem die Dichotomie von Subjekt-Objekt überwunden werden soll (s. Bourdieu 1992:43, 116-117 bzw. Wacquant 1996:19-22), und dem Luhmannschen Kontingenzbegriff, welcher den sozialen Strukturen Dynamik verleiht. Der Subjektbegriff wird aber dennoch beibehalten, weil er dazu geeignet ist, den individuellen Träger der sozialen und kulturellen Objektivationen kenntlich zu machen.

${ }^{14}$ Lipp (21994:316) hat die Brauchforschung gegenüber einem "quasi geschlechtsneutrale(n) Code" sensibilisiert. Analog dazu wäre hier vor der Unterstellung eines quasi subjektneutralen Codes zu warnen; s. auch Wey (1999:315). Vgl. hierzu auch Bausinger (1980:10) mit Bezug auf Nelson Brooks (1968). 
Junggesellenvereine", kann im wesentlichen zugestimmt werden. Zudem wurde die fragwürdige Qualität einer Reihe von Arbeiten aus den 1930er Jahren kritisiert. Trotz der zum Teil überdeutlichen rassistischen und sexistischen Einfärbungen fanden diese Abhandlungen immer wieder einen unangemessenen Raum in der späteren Rezeption. Anscheinend bürgte bereits das Etikett Dissertation für eine Verläßlichkeit, bei der die präsentierten Forschungsergebnisse nur noch von dem ideologischen Wortgeklingel bereinigt werden müßten, um zu den noch brauchbaren Fakten oder Sachargumenten $\mathrm{zu}$ gelangen. ${ }^{15}$ Das Hauptwerk der bisherigen Mailehenforschung muß zu diesen problematischen Quellen gezählt werden. Mit der Arbeit "Das rheinische Mailehen nach seinem Wesen, seiner Verbreitung und seiner Stellung in der Gemeinschaft" promovierte Friedrich Dierker 1939 an der Kölner Philosophischen Fakultät. Dierker hat dabei eine Fülle von Material zusammengetragen, wobei er sich besonders auf den sogenannten Rheinischen Fragebogen von 1922 stützte. ${ }^{16}$ Dieser enthielt Angaben zum Mailehen nach dem Prinzip der Korrespondentenbefragung. Man hatte vor allem Dorfschullehrer aus dem gesamten Gebiet der preußischen Rheinprovinz gebeten, sich schriftlich über den Restbestand des althergebrachten Volkslebens zu äußern. Obwohl Dierker die Grenzen seiner Quellen methodenkritisch einzuordnen wußte und dabei auch erkannte, daß beispielsweise die zeitliche Bestimmung der erhobenen Daten teilweise unmöglich ist, hat er das Material wenig sachgemäß verwertet. Neben formalen Mängeln besteht ein schwerwiegendes Problem in der inhaltlichen Bewältigung der Forschungsaufgabe. Die Aussagekraft von plausiblen Deutungsansätzen ging durch die eklektische Aneinanderreihung unhaltbarer Spekulationen über Ursprünge und Funktionen des Brauches verloren. Man vermißt eine geordnete Synthese. Statt tragfähiger Erkenntnisse häufen sich am Ende der Lektüre viele Fragen, Tautologien und Widersprüche. ${ }^{17}$

\footnotetext{
${ }^{15}$ In diesem Punkt ist die Trennung von ideologisch beeinflußtem Erkenntnisinteresse und inhaltlichen Sachverhalten problematischer, als man zunächst annehmen möchte. Insbesondere die Auslegung der Daten über die Rügepraxis zeigt die Gefahr der Fehlinterpretation auf der Basis ideologischer Theoreme, wie in Kap. 2 festgestellt werden kann.

${ }^{16}$ Hintergründe zum Rheinischen Fragebogen finden sich bei Cox (1989/90:32) und Zender (1966:232).

${ }^{17}$ Die Kritik sei an signifikanten Beispielen verdeutlicht. Bei der zeitlichen Einordnung des Brauches heißt es lapidar: "Doch ist der Brauch viel weiter [als das 16. Jahrhundert] hinaufzurücken, er ist sicher sehr alt" (1939:17; vgl. 103) oder in bezug auf die moralische Bewertung von Rügebräuchen, die im Zusammenhang mit dem Mailehen aufgetreten sind: "Diese unnachsichtliche Art gibt Zeugnis von der sittlich gesunden Grundlage des ganzen ländlichen Maiwesens. Alles, was sich nicht im Rahmen ihrer ungeschriebenen, blutmäßigen Gesetze hält, brandmarkt das Landvolk und stößt es als unwürdig ab" (1939:105). Was die Funktion des Mailehens betrifft, so finden sich zwar eine lange Reihe von Versatzstücken aus vorangegangen Arbeiten, aber letztlich zieht sich Dierker auf die sogenannte "innere Berechtigung" der Brauchpraxis zurück, aus der nicht klar wird, woraus sie sich letztlich konstituiert: "Man hat schon vor Jahrhunderten vor dem Mailehen gewarnt, wie die
} 
Zwei Jahre vor Dierkers Dissertationsschrift erschien in Schweden die vielfach rezipierte Studie über die Sitten der Eheeinleitung von Karl Robert V. Wikman (1937). Auch hier gründete der methodische Zugang zur Empirie auf einer Fragebogenaktion, bei der vor allem der Brauch des Kiltgangs (Nachtfreierei) in Schweden beleuchtet werden sollte. Zusätzlich zog der Autor Daten aus Deutschland, Estland, Litauen, Lettland, Polen, Ungarn und der Schweiz heran und ließ sie in eine "vergleichend ethno-soziologische Untersuchung" einfließen. Neben diffusionstheoretischen Ansätzen zur räumlichen Verteilung des Kiltgangs wurden dem Beziehungsaspekt zwischen Jugendlichen beiderlei Geschlechts große Aufmerksamkeit geschenkt, was zur Klärung des "Funktionsmilieus" der Brauchpraxis beitrug. ${ }^{18}$ Im Rahmen unserer Fragestellung wird der Nutzen von Wikmans Analyse jedoch dadurch geschmälert, daß das Mailehen nur am Rande einbezogen wurde und daß die Ergebnisse unter einem notorischen Mangel an Transparenz zustande gekommen sind. ${ }^{19}$ Aufgrund der fehlenden Angaben über die Erhebungssituation bleiben manche der dargestellten Ergebnisse nicht nur unklar und fragwürdig, sondern sie werden einer weiteren wissenschaftlichen Nutzung mehr oder weniger entzogen. Gleichzeitig stellt sich auch in Wikmans Arbeit das Problem spekulativer Ätiologie, die noch zu dieser Zeit von der Brauchforschung kaum hinterfragt worden ist. ${ }^{20}$

Nach 1945 setzte sich allmählich die Erkenntnis durch, daß etliche Themen der Volkskunde einer Revision unterzogen werden müssen, um sie einer kritisch-rationalen Analyse zugänglich zu machen. Es war der Zeitpunkt, sich von dem angehäuften Ballast ideologisch befangener Interpretationen der Romantiker, der Mythologen, der Völkischen und der Nationalsozialisten zu trennen. Wenngleich diese Notwendigkeit auch für das Mailehen erkannt wurde, so unterblieb eine gründliche Aufarbeitung des Brauches auf längere Sicht. Daher war man auch immer wieder versucht, die fragwürdigen Ergebnisse aus den einschlägigen Publikationen für die eigenen Maileheninterpretationen $\mathrm{zu}$ verwerten, was unmittelbar die Überzeugungskraft der aktuellen Forschungen schmälern mußte. Hans Moser, ein virtuoser Könner auf dem Gebiet der nüchternen Entideologisierung überkommener Wissensbestände, nahm sich 1961 dem Maibrauch an. Der Umstand, daß er sich bei seiner Analyse hauptsächlich auf den Maibaum konzentrierte und das Mailehen deshalb nur streifte, trug dazu bei, daß eine kritische Durchmusterung der historischen Mailehenbelege weiterhin noch ausstand. Moser ging es nicht um kleinliche Faktenhuberei, sondern um die Prüfung der Verläßlichkeit historischer

mitgeteilen Verbote ausweisen; aber dennoch besteht der Brauch bis heute, ein Zeichen, daß ihm eine innere Berechtigung zukommt" (1939:150). Vgl. auch die Kritik von Zender (1972:251).

${ }^{18}$ Vgl. Korff (1984:251-252).

${ }^{19}$ Zur Bedeutung der methodologischen Transparenz aus ethnologischer Sicht s. Wey (1994:892-894).

${ }^{20}$ Zur problematischen Überkreuzung von diffusionstheoretischer oder ätiologischer Spekulation und fundierter funkionalistisch inspirierter Analyse s. Wikman (1937:44-45). 
Quellen $^{21}$ und um die damit verbundene Richtigstellung von sinnentstellenden Entwicklungslinien. ${ }^{22}$

Paarzuteilung, reziproke Geschenk- und Besuchspflichten, Fest- und Tanzveranstaltungen haben ein komplexes rituelles Handlungsgefüge entstehen lassen. Daher war eine analytische Betrachtungsweise sinnvoll, bei der die historische Entwicklung von Brauchelementen und Deutungen zunächst möglichst auseinandergehalten wurden. Der Vorteil dieser Vorgehensweise wurde darin gesehen, daß die sukzessive Abfolge von Daten mit ethnographischem Gehalt das Werden und den Wandel besser verdeutlichen kann, wenn im ersten Schritt ablenkende Ausschmükkungen wissenschafts- und zeitgeschichtlich bedingter Maileheninterpretationen bewußt ausgeblendet werden. Brauchbeschreibungen aus erster Hand sind deshalb für den historischen Teil der Arbeit von besonderem Wert (s. Kap. 2). Glücklicherweise findet sich eine Reihe von derartigen Zeugnissen. Erwähnen möchte ich hier zumindest das sogenannte Gedenkbuch von Hermann Weinsberg (1518-1597), das Zender (1979:763) als "Krone" der frühen volkskundlichen Quellen bezeichnete und ihm somit einen hohen Stellenwert bei der Erforschung des Rheinlands eingeräumt hat. Die Quellengattung der frühneuzeitlichen Verordnungen wurde von der Volkskunde häufig herangezogen und bietet auch heute noch bei sorgfältiger, d.h. quellenkritischer Betrachtung einen reichen Fundus an Informationen zu unserem Gegenstand. Im 19. Jahrhundert folgen dann bereits Zeugnisse der Vereine, die für die Ausübung des Mailehens mitverantwortlich waren, oder aber ethnographische Notizen von interessierten Beobachtern.

Obwohl sich die teilnehmende Beobachtung als wissenschaftliche Erhebungsmethode durch die Trobriandermonographie von Malinowski (1922) in der Ethnologie bewährt hatte, war eine vergleichbare Vorgehensweise innerhalb der Volkskunde vorerst wenig verbreitet. ${ }^{23}$ Als Dissertation erschien 1931 unter der Ägide des Kölner Soziologen Leopold von Wiese die empirische Untersuchung über den

\footnotetext{
${ }^{21}$ In Verbindung mit dem Wirken von Karl-S. Kramer wurde der Ansatz Hans Mosers in der Fachgeschichte mit dem Prädikat "Münchner Schule" gewürdigt. Jeggle ( ${ }^{2} 1994: 66$; s.auch 69) resümierte kürzlich, daß die beiden Volkskundler "mit strenger Quellenkritik ... den Ursprünglichkeits- und Ewigkeitsvorstellungen der traditionellen Volkskunde de(n) Giftzahn gezogen" hätten und fügte hinzu, daß eine radikale Abkehr von den Irrlehren nach 1945 nicht überall auf positive Resonanz stieß. Diese Einschätzung kann hier nur bestätigt werden. Vgl. auch Brückner (1985:X).

22 Moser hat angemerkt, daß seine Analyse des bayerischen Maibrauchs durch weitere Untersuchungen zu ergänzen seien: "es empfiehlt [sich], auch in anderen Landschaften und Ländern eine planmäßige volkskundliche Quellenforschung für kein vergebliches Bemühen zu halten" (Moser 1985:207).

${ }^{23} \mathrm{Im}$ 19. Jahrhundert existierten bereits sorgfältig erarbeitete Monographien, die den Standards der Feldforschung Malinowskischer Prägung vorgriffen. Dazu z.B. Probst (1983:51-52). Als instruktive Orientierungen über den Stellenwert der Feldforschung innerhalb der Volkskunde s. Brednich (21994:83-85) und Kaschuba (1999:195-213).
} 
Junggesellenverein in der Eifel. Leo Hilberath war für diese Aufgabe aus mehreren Gründen gut vorbereitet. Er wuchs in Remagen und Bad Neuenahr-Ahrweiler auf, arbeitete mehr als fünf Jahre in der örtlichen Gemeindeverwaltung und sammelte somit Erfahrungen, die ihm für seine spätere Erforschung des Junggesellenvereins und des Mailehens nützlich sein konnten. Leider fallen seine methodologischen Bemerkungen äußerst knapp aus. Genauere Informationen über die Auswahl des Untersuchungsortes, den Forschungsrahmen, den -verlauf und seine Probleme erhalten wir nicht, ${ }^{24}$ aber die Arbeit bietet detaillierte Einblicke in das Verhältnis der Junggesellen zur altersgleichen Gruppe der Mädchen und zur übrigen Dorfbevölkerung. Darüber hinaus hat Hilberath weiterführende Überlegungen zur Funktion des Mailehens angestellt und konnte dabei den Ansatz von Schurtz (1902) zur biologistischen Erklärung sozialer Institutionen überwinden. ${ }^{25}$

Zenders große Erwartungen an eine volkskundliche Revision des Mailehens ${ }^{26}$ wurden auch durch die Bemühungen Dierkers nicht umfassend befriedigt, so daß er selbst während seines langjährigen Schaffens am Atlas der Deutschen Volkskunde immer wieder das Thema aufgriff. Da er sich in erster Linie auf die Feststellung und Erklärung der räumlichen Diffusion kultureller Ausprägungen im gesamten Rheinland konzentrierte, blieben die drängenden Erkenntnisprobleme, die sich einer idiographischen Analyse auf der Gemeindeebene stellten, nach wie vor unberücksichtigt. Indessen gelang es ihm, die historische Entwicklung des Mailehens teilweise zu ordnen. ${ }^{27}$ Dem Glauben an einen "magisch-zaubrischen" Ursprung des Mailehens blieb er jedoch bis zuletzt verhaftet. ${ }^{28}$

1964 startete das ehemalige Institut für mitteleuropäische Volksforschung, Abteilung Hessen, unter der Mitwirkung von Ingeborg Weber-Kellermann eine schriftliche Befragung zu "Maibaum-Bräuchen", die an 2688 Gemeindebürgermeister gerichtet

${ }^{24}$ Man muß sich mit der Anmerkung begnügen, daß die Arbeit "sich [...] auf die systematisierte Anordnung e i g e n e r Beobachtungen und Erfahrungen, die durch eingehende Studien während eines längeren Aufenthaltes innerhalb der betreffenden sozialen Lebenssphäre gewonnen werden konnten, [beschränken muß]" (Hilberath 1931:1). In einer Rezension hat Zender (1933:374-376) wenig Anerkennung für die fachfremde Dissertation ausgesprochen. Zudem wies er darauf hin, daß alle aufgeworfenen Fragen in einer weiteren Untersuchung zum Junggesellenverein und zum Mailehen erneut behandelt werden müßten. Vgl. dagegen die positiv ausgefallene wissenschaftsgeschichtliche Einordnung innerhalb soziologischer Vereinsforschung bei Siewert (1984:162-163).

${ }^{25}$ Hilberath (1931:19-23, 2-3). Vgl. auch die Schurtz-Kritik bei Gennep (1909:93f, 160) und in den jüngeren Veröffentlichungen von Reulecke (1990:3-10) und Schweizer (1990:23-30).

${ }^{26}$ Siehe Fn. 17.

${ }^{27}$ Siehe Zender (1972:249-255).

${ }^{28}$ Zuletzt in Zender (1979:837). Obwohl der Autor sich ausdrücklich gegen eine ahistorische Ätiologie abzugrenzen versuchte, interpretiert Zender (1977:133) die Ergebnisse, die Moser (1985) in seiner fundierten Maibrauchrevision vorlegte, mit Blick auf eine archaische Religion: "Seine [Mosers] Erkenntnis schließt nicht aus, daß ursprünglich Brauch eine magisch-zaubrische, ja religiöse Funktion hatte". 
wurde. Ulrich Löber (1972) wertete nicht nur diese Fragebogenaktion in seiner Studie zu den dörflichen Burschenvereinigungen der "Marburger Landschaft" aus, sondern fügte dem noch eigene Beobachtungen hinzu. Dabei hatte er es sich zum Ziel gemacht, die Entwicklung der Burschenschaften seit 1945 aufzugreifen und insbesondere den Organisations- und Brauchformen besondere Aufmerksamkeit zu schenken. Sicherlich unter dem Einfluß der aufkommenden Konjunktur empirischer Sozialforschung setzte er eine Random-Befragung ein, mittels der er Daten über die "Faktenkenntnisse und Beurteilungswerte" (Löber 1972: Vorwort ohne Paginierung) der Dorfbevölkerung zum Forschungsgegenstand erheben wollte. Die Arbeit zeigt deutlich die Grenzen der standardisierten und halbstandardisierten Befragungstechniken auf und hält interessantes Material zur hessischen Ausprägung des Mailehens bereit, wenngleich die Hintergründe der Brauchausübung in vielen Punkten ungeklärt bleiben. ${ }^{29}$ Löber (1972:171) weist darauf hin, daß es den Einsatz anderer Methoden bedurft hätte, um die Diskrepanzen zwischen den normativen Forderungen zur Rollenübernahme im Brauch und den darauf bezogenen Handlungen in der Praxis offenlegen zu können.

Ende der 1970er Jahre ist der Bericht von Michael Faber und Torsten Ziegler über die Aktivitäten Bonner Junggesellenvereine erschienen. In erster Linie stützte sich das Autorenduo auf die Auswertung einer teilnehmenden Beobachtung der Maibräuche und der Gespräche, die mit aktiven und ehemaligen Vereinsmitgliedern geführt wurden. Aufgrund der Vorarbeiten einer studentischen Arbeitsgruppe am Volkskundlichen Seminar der Universität Bonn sah man eine erste Möglichkeit zu einer PanelUntersuchung, welche zur Erfassung des Brauchwandels über den kurzen Zeitraum von 1975 bis 1978 dienen sollte. ${ }^{30}$ In einem Forschungsprogramm verwies man damals auf folgende Aspekte: "ausführliche Beschreibungen (Ablaufdiagramme der Aktionen, Vorbereitungen und Feste, Soziogramme der Festbeteiligten, Basisinformationen über die Aktionsorte), Fragen nach den Hintergründen (soziokulturellen Prädispositionen, Motivationen) und Herausarbeiten von Entwicklungen (Kontinuitäten, Fixierungen, Rupturen, Innovationen und Revitalisierungen, folkloristische Tendenzen)" seien für eine Bestandsaufnahme der Junggesellenaktivitäten in den heutigen Erscheinungsformen dringend gefragt. Das selbst gesetzte Erkenntnisziel konzentrierte sich auf "die Erstellung eines detaillierten Ablaufdiagramms", und daher sei die Abhandlung "lediglich als Grundlage weiterer Studien anzusehen" (Faber/Ziegler 1979/80:148f). Somit sind seit geraumer Zeit viele Lücken und Probleme der Mailehenforschung bekannt, ohne daß sie zwischenzeitlich eine umfassende Bearbeitung erfahren haben. Aus dem Blickwinkel der Brauchforschung, aber auch aus wissenschafts- und landesgeschichtlicher

${ }^{29}$ Hierzu Löber (1972: Vorwort o. Pag.; 29-32, 43-47, 115-116, 147-157, 189).

${ }^{30}$ Siehe Faber/Ziegler (1979/80:148-149). 
Perspektive, eröffnete das Phänomen Mailehen ein geeignetes und vielversprechendes Forschungsfeld.

\subsection{Vorgehensweise}

Das Mailehen präsentiert sich als Brauch, dessen Spuren sich bis in die Frühe Neuzeit zurückverfolgen lassen, dessen Verbreitung territoriale und soziale Grenzen vielfach überschritten und der im Laufe seiner Geschichte unterschiedlichste Ausprägungen erfahren hat. Angesichts dieser Dimensionen war es unerläßlich, den Gegenstandsbereich der Arbeit auf das Wesentliche zu konzentrieren. Zunächst mußte es um die Aufarbeitung des publizierten forschungsrelevanten Materials gehen. Ein Überblick über die historisch gesicherten Daten, eine kritische Erörterung ätiologischer Ansätze und eine Zusammenschau der vorgebrachten Brauchdeutungen sollten eine hermeneutische Basis für das Verständnis der gegenwärtigen Mailehenpraxis bieten. ${ }^{31}$

Ein Hauptproblem der Untersuchung bestand darin, einen angemessenen Zugang zur rezenten Mailehenpraxis und speziell $\mathrm{zu}$ den sich subjektiv ausdifferenzierenden Erlebnis- oder Erinnerungsweisen der Brauchbeteiligten $\mathrm{zu}$ finden. Um die Interpretation der Daten nicht von unterschiedlichen Standortgegebenheiten abhängig zu machen, war eine intensive Fallstudie auf Gemeindebasis die richtige Wahl. Die Ortschaft Oeverich im Kreis Ahrweiler (Rheinland-Pfalz), etwa zwanzig Kilometer westlich von Bonn entfernt, wurde Hauptstützpunkt der Erhebungen. Das unmittelbar benachbarte Niederich wurde miteinbezogen, weil die beiden Dörfer durch eine gemeinsame Mailehengeschichte und -praxis miteinander verbunden sind. ${ }^{32}$ In der Untersuchungsregion wie in vielen angrenzenden Gebieten läßt sich der Brauch über lange Zeit verfolgen. Als Glücksfall stellte sich die recht intensive Bearbeitung archivalischer Quellen durch vorangegangene Forschungen heraus. ${ }^{33} \mathrm{Sie}$

\footnotetext{
${ }^{31}$ Dieses Vorgehen trägt darüber hinaus der Beobachtung Rechnung, daß das volkskundliche Wissen über Ursprung und Wesen eines Brauches nicht zuletzt von den BrauchträgerInnen selbst aufgegriffen wurde, "daß es", so Scharfe (1991:14f), längst Bestandteil der Bräuche selbst geworden ist, weshalb eine vollkommene Beschreibung auch die gängigen Interpretationen 'folkloristischer' Phänomene zu umfassen hätte".

${ }^{32}$ Die Ausrichtung der Maikirmes und der Junggesellenverein haben in Oeverich ihren Austragungsort. Daher wird in der Arbeit zumeist nur dieser Ort genannt. Treten lokalspezifische Einzelzüge der Brauchausübung auf, wird darauf selbstverständlich eingegangen.

${ }^{33}$ Neben den Arbeiten und Quellensammlungen von Becker (1989), Frick (1933), Redlich (1911), Schug (1952) oder Bous und Klein (1998) sei auf die sorgsam recherchierten Studien des ortsansässigen Heimatforschers Ottmar Prothmann (hier besonders: 1982, 1988, 1989, 1990, 1992 u. 1998) verwiesen.
} 
ermöglichten eine rasche Einarbeitung in die geschichtsbildenden Prozesse von lokaler Bedeutung.

Da die Reflexion über die persönliche Motivation und die Umstände bei der Teilnahme am rituellen Geschehen einen großen Raum in der Untersuchung einnehmen sollte, wurde von vornherein eine Hinwendung $\mathrm{zu}$ einer subjektorientierten qualitativen Sozialforschung für angebracht gehalten. ${ }^{34}$ Hilfreich erschien neben der teilnehmenden Beobachtung zunächst das themenzentrierte Interview, da es versucht, sowohl der Komplexität des Gegenstands, der Vergleichbarkeit der Daten als auch den subjektiven Positionen der Befragten Rechnung zu tragen. Während der Erarbeitung eines komplexen Leitfadens wurde allerdings deutlich, daß eine rasterhafte Eingrenzung der anzusprechenden Themen oder die detaillierte Erfassung relevanter Fragen sich im Widerstreit mit dem Forschungsziel befand. Der Eindruck, daß bereits der Inhalt einer Fragestellung - auch bei geschickter Formulierung - eine bestimmte Antwortvorgabe implizieren kann, veranlaßte dazu, das methodische Konzept umzustellen. ${ }^{35}$ Ziel war es, die asymmetrische Rollenverteilung zwischen Forscher und Beforschten $\mathrm{zu}$ entschärfen, indem die Befragten als GesprächspartnerInnen ernst genommen und nicht als DatenlieferantInnen betrachtet werden sollten. ${ }^{36}$ Die künstliche Befragungssituation, die unweigerlich durch die Präsenz des Forschers, durch das artikulierte Erkenntnisinteresse oder in meinem Fall auch durch den Einsatz der Tonbandaufnahme aufkam, sollte im Verlauf einer

${ }^{34}$ Eine qualitative Sozialforschung, welche den Erhebungsprozeß als eine wechselseitige Interaktion zwischen den Beteiligten auffaßt und die Begegnung mit den InformantInnen auf Augenhöhe für möglich hält, hat inzwischen breite Zustimmung innerhalb der Volkskunde gefunden, so daß sie zu den methodischen Standards zählen darf. Vgl. resümierend dazu Brednich (21994:75-76). Bourdieu (1993:365-374 bzw. 1990:75-81) hat zu einer kritischen Methodenanwendung geraten, bei der sowohl eine reflexive (Selbst-)Beobachtung als auch eine differenzierte Analyse von objektiven Hierarchien im Vordergrund stehen sollte. Das heißt auch, daß die Wahl der Methode weder die Produktion einer triftigen Datengrundlage noch eine gelungene Auslegung des erhobenen Materials garantiert. Vielfache Anforderungen sind an die Forscherin bzw. den Forscher gestellt, wenn die gewonnenen Erkenntnisse, eine ernsthafte Annäherung an die reale psychische, soziale und kulturelle Situation sein sollen. Die Methode kann hier nur eine mehr oder weniger geeignete Hilfestellung geben. Sie als ein Mittel zur beschwörenden Harmonisierung zwischen Forschenden einerseits und Beforschten andererseits zu gebrauchen, gliche einer Zweckentfremdung. Zudem hätte die Methode ihre anregende Wirkkraft in der Erforschung sozialer Beziehungen ausgereizt, wenn sie als ein mustergültiges Rezept aus numinosen "Handwerksgeheimnissen" handhabbar wäre (s.u. Kap. 4.1.3). Vgl. zur aktuellen Kritik der Präsentation volkskundlicher Forschungsstrategien Löffler (1999:99-114).

${ }^{35}$ Präjudizierende Implikationen von Fragestellungen (Affirmationen bzw. Ablehnungen) bilden nicht nur ein zentrales Problem im Rahmen empirischer Erhebungen, sondern auch in der historischen Volkskulturforschung. Darauf hat Schindler (1984:77) mit Rekurs auf eine bedeutsame Argumentation Bourdieus (1982:797) hingewiesen.

${ }^{36}$ Wichtige Anregungen liefert oftmals weniger die Standardliteratur zu qualitativen Forschungsmethoden als ihre konkreten Anwendungen in Monographien. Den methodischen Zugang zum Gegenstand prägten daher nicht nur Arbeiten wie: Devereux (31992, [1967]), Arbeitsgruppe Bielefelder Soziologen (1973, 1976a,b) oder Hermanns (1981), sondern auch Nadig (1986) und Chernoff (1979). 
gelungenen Sitzung in den Hintergrund rücken. ${ }^{37}$ Dabei wurde versucht, sich auf die GesprächspartnerInnen einzulassen. Offenheit, Transparenz und Redlichkeit über die Forschungshintergründe ${ }^{38}$ sowie die Beachtung alltäglicher Kommunikationsformen waren eine $\mathrm{zu}$ erfüllende Grundvoraussetzung, um sich dem Ziel einer zwischenmenschlichen Begegnung auf Augenhöhe anzunähern. Nur auf diese Weise erschien es möglich, tiefreichende, verläßliche Kenntnisse über subjektive Verarbeitungsprozesse im Zusammenhang mit dem örtlich ausgeübten Mailehen zu erheben. In einer möglichst vertrauensvollen, machtneutralen Atmosphäre des gegenseitigen Respekts wurden günstige Bedingungen für den kommunikativen Austausch geschaffen. ${ }^{39}$ Hierin konnten die persönlichen Erlebnisse mit dem Mailehen gewissermaßen nacherlebt, -gefühlt und besprochen werden. Mit der Veröffentlichung der Ergebnisse wird versucht, diesen menschlichen Erfahrungshorizont - die Beweggründe und den subjektbezogenen Sinn der Beteiligung am Brauch - auch einem außenstehenden Leserkreis näher zu bringen. ${ }^{40}$

\subsection{Aufbau der Arbeit}

Die vorliegende Untersuchung setzt sich aus fünf Kapiteln zusammen. Nachdem in der Einleitung ausführlich die Fragestellung, der Forschungsstand und die Vorgehensweise diskutiert wurden, werden in den beiden folgenden Kapiteln die Ergebnisse einer eingehenden Sichtung der Forschungsliteratur präsentiert. Zunächst geht es darum, anhand der Sekundäranalyse einen sicheren Überblick über die Formen, Verbreitung und Entwicklung des Mailehens $\mathrm{zu}$ gewinnen. Irreführende oder ungenaue Darstellungen sowie vorhandene Forschungslücken sollen dabei aufgezeigt

\footnotetext{
${ }^{37}$ Hierzu auch Leiris (1977:54).

${ }^{38}$ Vgl. dazu Lindner (1981:54f).

${ }^{39}$ Eine detaillierte Auseinandersetzung mit der Erhebungssituation beinhaltet Abschnitt 4.1.

${ }^{40}$ Die wissenschaftliche Präsentation von Feldforschungsergebnissen ist mit einem Dilemma konfrontiert, das den Abstraktionsgrad und die Verständlichkeit von Texten berührt. So ist die Forderung, daß die Auswertungen auch für die Erforschten leicht zugänglich und verständlich sein sollten (z.B. Hugger 21994:286-287), mit gewissen Vorbehalten zu versehen. Lipp (1994:88) hat darauf hingewiesen, daß es in der kulturwissenschaftlichen Analyse nicht um die "Verdoppelung von Wirklichkeit" gehen kann. Ein Hervorbringen paradigmatischer ethnologischer Erkenntnisse - etwa in der Tradition von Bourdieu - erscheint unter vorgenannter Forderung unrealistisch. Gleichwohl ist es berechtigt, darauf hinzuweisen, daß Forschung nicht als "Einbahnstraße" gesehen wird und der Rückfluß der gewonnenen Erkenntnisse nicht verlorengeht. Hierfür sollten jedoch verstärkt Medien (TV- oder Rundfunkbeitrag, Lokalzeitung, Heimatjahrbuch) in Erwägung gezogen werden, welche nicht nur in bezug auf Anschaulichkeit über Vorteile verfügen, sondern auch der alltäglichen Praxis der Informationsgewinnung am nächsten kommen. Ansätze einer filmischen Aufbereitung der Mailehenthematik sind zwar vorhanden (siehe unter Kap. 6: Filmverzeichnis). Aber den Ansprüchen einer visuellen Anthropologie, wie sie von Ballhaus (1989:183-185) formuliert wurden, können sie vor allem deswegen nicht gerecht werden, weil sie den formalen Ablauf der Brauchhandlungen in den Vordergrund rücken und die sozialen Rahmenbedingungen dabei weitgehend außer acht lassen.
} 
werden. Die verschiedenen Interpretationsansätze sind Gegenstand des dritten Kapitels. Hier wird die Stichhaltigkeit der Interpretationen im einzelnen geprüft. Die Zusammenhänge der Hypothesenbildung werden ergründet, das Beweismaterial wird ausgebreitet und auf der Grundlage der geschichtlichen Hintergründe besprochen. Überzeugende Deutungsansätze können in den hermeneutischen Wissensbestand einbezogen werden und somit bei der Analyse des Fallbeispiels als zusätzliche Beurteilungsgrundlage dienen. Im vierten Kapitel folgt die eingehende Betrachtung der Mailehenpraxis in Oeverich. Die Erklärungen der Betroffenen stehen hier im Mittelpunkt und sollen durch ausführliche Gesprächswiedergaben und -analysen genügend Raum erhalten. Nach einer einführenden historisch-ethnographischen Standortbeschreibung wird die Bedeutung des Mailehens erstmals anhand der Äußerungen der Brauchbeteiligten eruiert. Grundlage ist dabei die Analyse der erhobenen Gespräche. Beim Resümee werden die erarbeiteten Ergebnisse nochmals gebündelt mit jener forschungsleitenden Problemstellung konfrontiert: wer erhält bei der Mailehenausübung was von wem zu welchem Zweck und unter welchen Bedingungen als Leihgabe? Darüber hinaus ist zu zeigen, an welche der aufgezeigten Perspektiven volkskundliche Brauchforschung in Zukunft anknüpfen kann. 


\section{Formen, Verbreitung und Ent- wicklungen}

\subsection{Ursprungssuche: Babylonier und Germanen}

Herodot, ein griechischer Historiograph, der im 5. Jahrhundert v. Chr. lebte, gilt als ein ausgezeichneter Beobachter und Analytiker seiner Zeit. Auch Kenner haben seinen verbreiteten Ruf als "Vater der Geschichte" als gerechtfertigt angesehen (Stein 81968:XXVI-XXXI). Die Suche nach Traditionslinien bewährt sich gewöhnlich dadurch, daß historische Rekonstruktionen auf solidem Grund stehen. Hieraus erklärt sich schon zu einem Teil die Attraktivität, welche Herodot in der früheren Mailehenforschung zugekommen ist. ${ }^{41}$

Herodots Nachlaß informiert über zeitlich, räumlich wie kulturell sehr entlegene Begebenheiten. Unter anderem wird ein Brauch erwähnt, der im assyrischen Raum vor 539 v. Chr. Verbreitung gefunden haben soll. Hierbei ist die Rede von einem jährlich wiederkehrenden Ritual, bei dem unverheiratete Mädchen zur Ehe an zahlungskräftige Männer versteigert wurden. Da die Schilderung tatsächlich gewisse Parallelen zum Mailehen aufweist, sei sie in Auszügen wiedergegeben:

"Nun ließ der Ausrufer ein Mädchen nach dem andern aufstehen und bot es aus, zuerst die Schönste von allen, dann, wenn diese um viel Geld verkauft war, rief er die nächste aus, die nach dieser die Schönste war. Es galt aber die Bedingung, daß der Käufer sie heiratete. Die heiratslustigen Babylonier nun, die wohlhabend waren, überboten einander, um die Schönsten zu bekommen, die heiratslustigen aber aus dem gewöhnlichen Volk, denen es nicht um die Schönheit zu tun war, die bekamen die häßlichen Mädchen und noch Geld dazu. Denn sowie der Ausrufer mit den wohlgestalteten Mädchen durch war und die alle verkauft hatte, ließ er die aufstehen, die am schlechtesten gebaut war oder einen körperlichen Fehler hatte, sofern welche dabei waren und bot die aus, nämlich wer mit der kleinsten Zugabe zufrieden wäre, wenn er sie zur Frau nahm, bis sie dem Mindestfordernden zugeschlagen wurde [...] Erlaubt war hingegen, daß der Kaufwillige auch aus einem anderen Dorf kam. Das war also ihr bester Brauch, jedoch hat er nicht gedauert, und heute gibt's ihn nicht mehr, sondern neuerdings sind sie auf etwas anderes verfallen. Seit der Einnahme der Stadt nämlich sind sie heruntergekommen und ist ihr Besitz geschwunden, und nun gibt jedermann aus dem Volk, der in Not ist, seine Tochter für Geld preis" (Herodot 1973:109f; Hervorhebung durch H.-W.W.).

Die Authentizität der vorangehenden Zeilen bedarf einiger Erläuterungen. Herodots Schilderung bezieht sich auf die Verhältnisse vor dem Einfall des Perserkönigs Kyros II. Damit ist also die geschichtliche Situation vor dem Jahr 539 v. Chr. gemeint. Der Geschichtsschreiber bereiste Babylonien 449 v. Chr. Aus der zeitlichen Differenz ergibt sich, daß er und sein Informant den Brauch nicht aus unmittelbarer Anschauung kennengelernt haben können. Aber selbst im Falle, daß die

${ }^{41}$ Vgl. Radermacher (1886:151f), Usener (1902:228), Becker (1904:122), Zinzius (1925:44), Dierker (1939:17f, 69), Rockenbach (1954:27), Barlen-Ebert (1960:6) und Zender (1972:251). 
Gegebenheiten nicht treffend wiedergegeben worden wären, so resultiert allein aus dem Notierten ein Erklärungsbedarf für diese Sonderart der Eheschließung. Wie beim Mailehen wurden im alten Babylon Paare durch Versteigerung zusammengegeben. Dies geschah in der Antike mit dem ernsthaften Hintergrund der Verehelichung bei gleichzeitigem Bestreben, nicht nur für die schönsten Frauen, sondern auch für die weniger attraktiven oder gar für die gebrechlichen einen Lebenspartner zu finden. Der fragwürdige Akt der auktionären Veräußerung einer Frau erscheint in einem geradezu moralisch geläutertem Gewand. Denn die Versteigerung diente dazu, jeder Frau zu einem Ehemann zu verhelfen. Die Sinnfälligkeit des Brauches und nicht seine reale Durchführung und Verbreitung mögen Herodot bewogen haben, diesen eigenartigen Prozeß babylonischer Eheschließung festzuhalten. Sowohl die lehrreiche als auch die unterhaltsame Komponente erzählter Geschichte sollte an dieser Stelle berücksichtigt werden (Herodotos ${ }^{8} 1968$ :XX-XXII, XLII-XLIV).

Was ätiologisch orientierte Spurensucher oft nicht bemerkt haben, war eine zu beobachtende Funktionsverschiebung zwischen babylonischem und rheinischem Ritual. Während es dort eindeutig und manifest um Hochzeit mit allen ernstzunehmenden Konsequenzen ging, galt es hier, lediglich die Paare für die bevorstehenden Tanzfeste spielerisch zusammenzugeben. Mag für den wissenschaftlichen Anspruch des ausgehenden 19. Jahrhunderts das Defizit diffusionistischer Belegreihen hinnehmbar gewesen sein, so haben für den rheinischen Bereich die weitaus präziseren Forschungsergebnisse der Kulturraumforschung im Gefolge von Aubin, Frings und Müller (1926) die Standards neu gesetzt. Spätestens zu diesem Zeitpunkt durften die an Hyperdiffusionismus grenzenden Spekulationen als obsolet betrachtet werden.

Ein weiterer problematischer Anknüpfungspunkt betrifft die Rekonstruktion des Mailehens aus der lokalen Frühgeschichte. Eine Reihe von Autoren möchte das Mailehen in die Zeit unserer germanischen Vorfahren verlegen, ${ }^{42}$ was die besondere Schwierigkeit mit sich bringt, daß in diesem Fall kein Kronzeuge vom Range Herodots angeführt werden kann. Nachdem die Berichte von Tacitus nicht die gewünschten Erkenntnisse zum Mailehen lieferten, wurde nach weiteren Quellen

\footnotetext{
${ }^{42}$ Die Zahl der Autoren, die einer germanisierenden Deutung des Mailehens anhängen, ist kaum überschaubar. Zählt man diejenigen Texte hinzu, die den Brauch mit ahistorischen Attributen, wie z.B. uralt, zäh, archaisch, magisch, kultisch, zaubrisch, erhalten aus ferner Vergangenheit etc. versehen, ließe sich leicht eine Liste von ca. fünfzig Verfassern zusammenstellen. Sie würde nach meinen Recherchen bei Laven (1834:ohne Paginierung) beginnen und bei Moser (1993:242) enden. Anspruchsvollere Forschungen (Zender 1958:38f; 1977:133; 1979:858) sind von substanzlosen ahistorischen Aussagen ebenso betroffen wie populärwissenschaftliche Abhandlungen in Heimatblättern (Krämer 1954:24). Aufgrund der ideologischen Vorgaben trifft man in der nationalsozialistischen Zeit verstärkt auf germanische bzw. heidnische Ursprungsdeutungen (Meyer 1934:65; Theme 1938:88), allerdings nicht unbeeinflußt von den Erkenntnissen der romantisch und mythologisch beeinflußten Forschungsrichtung. Vgl. Uhland (1984,4:339f, 316f), Zuccalmaglio (1854-58:29f), Reinsberg-Düringsfeld (1863:134), Simrock (51878:578, 580, 584) oder Mannhardt (1875-77, 1:462 und ${ }^{2} 1905,2: 12$ ).
} 
gesucht. Geblieben ist die Exegese einer vermeintlich vorchristlichen Religion, die man in der nordischen Mythologie zu erkennen glaubte. Nun hatte man die Grundlage, die dem mythologisch Bewanderten vielfältige Möglichkeiten der Interpretation eröffnete. Ausgehend von den Romantikern hin zur mythologischen Forschungsrichtung der Volkskunde war es ein kleiner Schritt, die "verblichenen Reste des germanischen Volkstums" in den Bräuchen des 19. Jahrhunderts aufzudecken und wiederherzustellen; darunter fehlte das Mailehen nicht. Für den Mythologen war es unbedeutend, wenn nicht gar unerwünscht, die sozialen Zusammenhänge des Brauches den Möglichkeiten entsprechend in Raum und Zeit zu verankern. Er war mehr bestrebt, ein zeitloses germanisches Weltbild auferstehen zu lassen. Dementsprechend liegen die betreffenden Forschungsergebnisse oftmals abseits der historischen Realität. ${ }^{43}$ Sie gehören vorwiegend zum Spektrum der Deutungen (s. Kap. 3).

\subsection{Ein spätmittelalterliches Tanzspiel}

Mittelalterliche Quellen tragen zur historischen Erhellung des Mailehens nur wenig bei. Dennoch konnte die Mailehenforschung auf die Fährte eines "grotesk-komischen Bauernepos" (Wießner 1931:6) stoßen, das durchaus ernstzunehmende Annahmen über den Entstehungszusammenhang des Brauches erlaubt. Hierbei handelt sich um den "Ring" von Heinrich Wittenwiler. Nach der neueren literaturgeschichtlichen Forschung entstand das Werk vermutlich um 1408/1410 in Konstanz (Brunner 1991:653-658). Zentraler Gegenstand des auf Unterhaltung und Belehrung abzielenden Stückes ist der Gang einer Hochzeit unter Bauernfamilien im süddeutschen Raum. Das Geschehen spielt sich in drei aufeinanderfolgenden Stadien ab: (1) der Lappenhauser Bertschi Triefnas wirbt um die Bauerndirne Mätzli Rüerenzumph, (2) die konkrete Einleitung der Hochzeitsfeier bis zum Hochzeitstanz und (3) Abbruch der Feier durch einen Raufexzeß während des Tanzes. Die Intention des Autors war nach Wießner (1931:5-9) weniger die idiographische Wiedergabe eines süddeutschen Hochzeitsbrauches als vielmehr die sittliche Belehrung einer Klientel, deren Ansehen über dem des Bauernstands rangierte. Das bäuerliche Milieu sollte in seiner Derbheit den grotesk-komischen Hintergrund für den lehrreichen Stoff damaliger Bildung, wie z.B. Paternoster, Ave-Maria, Credo, Beichtformel und Schülerspiegel, abgeben.

An bestimmte Ausprägungen des Mailehens erinnert eine einzelne Stelle im letzten Drittel des Schwanks. Sie beschreibt die Situation, als die Festgesellschaft damit

${ }^{43}$ Scharfe (1991:23) hat in diesem Zusammenhang deutlich gemacht, daß die "Mythologie als Hypothese genauso plausibel (ist) wie vieles Spätere und vielleicht Heutige". Unhaltbar sei dagegen das in den Deutungen zugrundeliegende Menschenbild - "das Konstrukt eines Menschen, der sich niemals und durch nichts verändert." 
beginnt, Paare für den Hochzeitstanz zusammenzustellen. Ganz ähnlich, wie es beim Lehenausrufen in jüngerer Zeit praktiziert wurde, ${ }^{44}$ stellte Wittenwiler die Paare Mithilfe eines Zuteilungsspruchs bzw. -lieds zusammen, dessen Text folgendermaßen lautet:

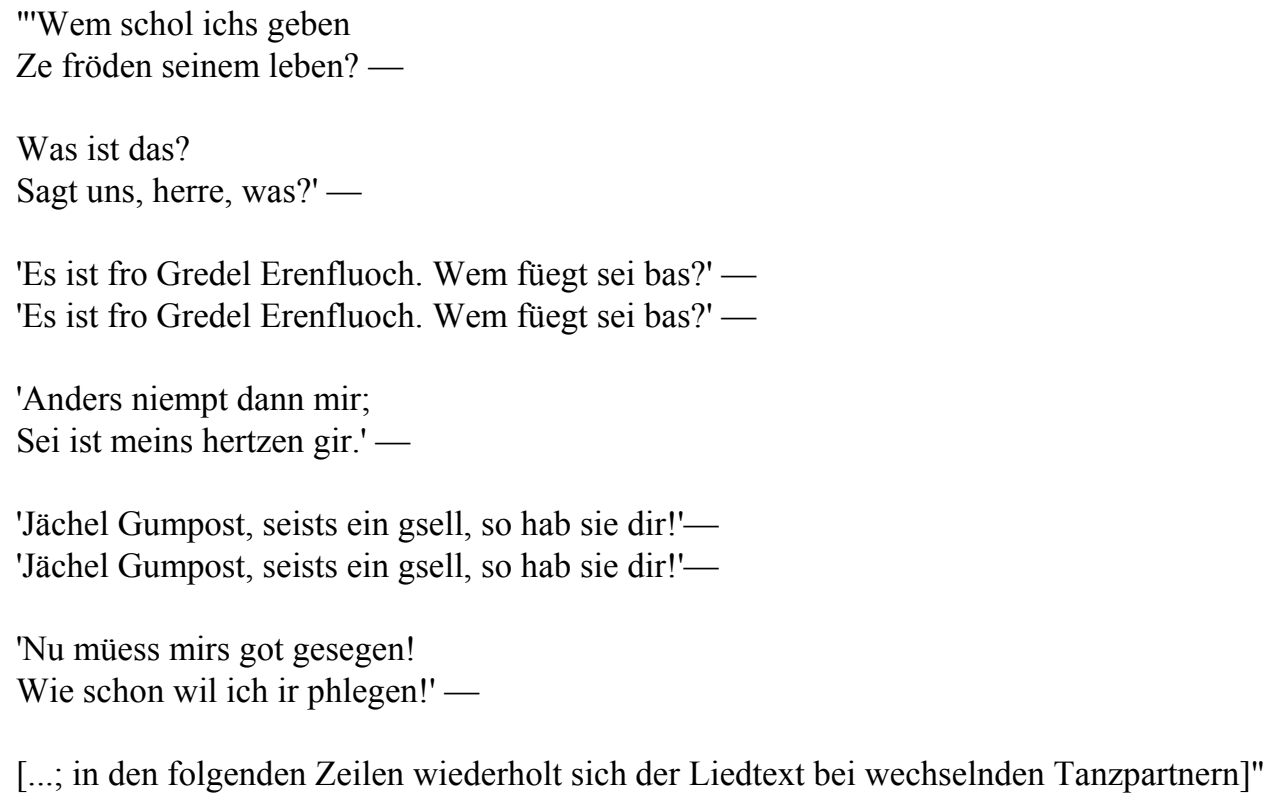

Die Ähnlichkeit der Texte im spätmittelalterlichen Lied und rezenten Spruch zur Zusammenfügung des Mailehenpaare ist unbestritten, dennoch darf der Kontext der jeweiligen Ausprägungen nicht außer acht gelassen werden. Während in Wittenwilers Tanzlied die jungen Paare in ein Spiel hineingezogen werden, bei dem Paare für den bevorstehenden Tanz erwählt werden, so wurde beim Lehenausrufen mittels des förmlichen Spruches ein Paar ausgerufen, das über einen längeren Zeitraum miteinander verbunden wurde und dessen Aktivitäten über das Tanzen noch hinausgegangen sind. Ein unmittelbarer Zusammenhang von Mailehen und Wittenwilers Tanzpaarermittlung besteht somit nicht, indes erscheint eine Entwicklung des sozial komplexeren Mailehenbrauches aus dem einfachen Tanzspiel denkbar. ${ }^{45}$

\footnotetext{
${ }^{44}$ Vgl. das Saarhölzbacher Beispiel aus der Mitte des 19. Jahrhunderts zum Ablauf des Lehenausrufens in Abschnitt 2.5.

${ }^{45}$ Vgl. auch die von Wießner (1936:225f) im Kommentar gegebenen Hinweise.
} 


\subsection{Nachrichten aus dem städtischen Milieu des 15./16. Jahrhunderts}

Eindeutige Nachweise über die Existenz des Mailehens datieren von der Neuzeit. Zwei rheinische Belege, die in die städtische Lebenswelt des 15. und 16. Jahrhunderts hineinführen, müssen beleuchtet werden. Der frühere, aus St. Goar stammend, verblaßt vor der Detailfülle, die uns der Kölner Ratsherr Hermann Weinsberg (15181597) aufgrund seiner tagebuchartigen Chronik über die Verhältnisse in der rheinischen Metropole hinterlassen hat.

Laut Alexander Grebel soll es bereits im 15. Jahrhundert eine "Versteigerung der St. Goarer Jungfrauen" gegeben haben. Angaben dazu würden die städtischen Rechnungen enthalten, da die Einnahmen der Versteigerungen jeweils in die Stadtkasse geflossen seien. 20 bis 30 Taler seien auf diese Weise jährlich in die Hände des Fiskus gelangt. $\mathrm{Zu}$ den Hintergründen hat Grebel bemerkenswerte Angaben geliefert:

"Auf Ostermontag wurden alle Jungfrauen öffentlich auf dem Rathhause an die jungen Männer versteigert, was dann die Folge hatte, daß die angesteigerte Jungfrau das ganze Jahr hindurch nur mit ihrem Erwerber tanzen durfte, und dieses hatte sodann wieder die weitere Folge, daß aus der lieblichen Tänzerin sehr häufig die geliebte Gattin wurde" (Grebel 1857:95).

Da sich die Informationen zur sozialen Funktion des Mailehens schwerlich aus den St. Goarer Rechnungsbüchern entnehmen lassen dürften, stellt sich das Problem der Authentizität zu derartigen Schlußfolgerungen. Analog zur Praxis anderer zeitgenössischer Berichterstatter ist zumindest denkbar, daß Grebel zu diesem Punkt unvermerkt Angaben anderer Autoren - z.B. von Kinkel (1846:160-162) übernommen hat. ${ }^{46}$ Der Versuch, Klarheit über die genauen Zusammenhänge zu bekommen, erscheint jedoch als aussichtsloses Unterfangen, weil die in Frage kommenden Archivalien nicht verfügbar sind. ${ }^{47}$

In Köln herrschte eine andere Situation. Die freie Reichsstadt, deren kulturelle, religiöse, wirtschaftliche und politische Vorreiterrolle im Rheinland über Jahrhunderte unangefochten blieb, steht für überraschende Facetten der Mailehenpraxis. Nahezu mit der Intimität eines vertraulichen Tagebuchs zeichnete Hermann Weinsberg ein ungewöhnlich anschauliches Bild. An verschiedenen Stellen berührt er dabei ein fastnachtliches Brauchgeschehen, das sich eindeutig auf das Mailehen beziehen

\footnotetext{
${ }^{46}$ Aus Kinkel (1946:160-162) oder Anonymus (1836c:83-85) teilweise wörtlich übernommene Angaben zum Mailehen finden sich ohne Quellenverweis etwa bei Schannat (1852, 3:478f) oder Mering (1837, 4:8f).

${ }^{47}$ Die Stadt St. Goar hat die älteren Archivbestände an das Landeshauptarchiv Koblenz abgegeben. Eine Recherche dort ergab, daß erst für die Zeit nach 1561 entsprechendes Archivmaterial vorliegt (Bestand 638, Nr. 77).
} 
läßt. Die erste relevante Eintragung fällt in das Jahr 1538. Als Zwanzigjähriger schrieb Weinsberg:

"Ein jonfer, heisch Fridrich, ein basterzdochter van Nuwenar und Mors [Kind, das aus einer sozial ungleichen, nicht standesgemäßen Verbindung hervorgegangen ist], wart mein lehen; die schickte mir ein britzel, ich schickte ir den mei. Noch ein, zum Loickentlant ein dochter, wart min geistliche suster, ich moist allet etwas geben" (Weinsberg 1886-1926,I:133).

Obwohl bei diesen ersten Informationen noch viele Brauchaspekte unaufgedeckt bleiben, erkennt man das Lehensverhältnis zweier lediger Personen: ein junger Mann und eine "jonfer", deren Bekanntschaft Weinsberg im Zusammenhang mit dem Klosteraufenthalt seiner zehnjährigen Schwester machte. Es ist nicht auszuschließen, daß dieses Lehensverhältnis auf eine eher geschwisterliche als auf eine voreheliche Beziehung abzielte, wie der Schreiber selbst angibt. Damit wäre der Geschenketausch - primär ist von Brezeln und Maien die Rede - eher eine warmherzige Sympathiebekundung gegenüber einer jungen Bekanntschaft als ein symbolischer Liebesbeweis mit sich daran anknüpfenden Folgen. Beide Tauschgegenstände lassen diesen weiten Deutungsspielraum durchaus zu. Durch den Nachsatz "ich moist allet etwas geben" wird die Gabe nachdrücklich betont, so daß man zu der Ansicht neigt, daß der Austausch von Geschenken ein zentrales Element im kölnischen Mailehen darstellte. ${ }^{48}$

Zum 5. April 1579 folgt eine weitere Meldung:

"[...] dominica Laetare zu halffasten uff der Rosentag hat mir jonfer Elisabetha Horns, die bei uns wonte und den lest fastabent mir zu einem lehne wie in Coln bruchlich, geben war, ein britzel geschickt. Derhalb sin mir den abent zu Weinsberch samen frolich gewest" (Weinsberg 1886-1926,V:141).

Bemerkenswert ist zunächst die Tatsache, daß die Akteure des Mailehens nicht wie gewohnt als jugendliches, unverheiratetes Paar auftreten. Bei den zusammengefügten BrauchträgerInnen handelte es sich um bereits gestandene Persönlichkeiten: der 61jährige, zum zweiten Mal verehelichte Jurist und Ratsherr Hermann Weinsberg und die zukünftige Ehefrau ${ }^{49}$ seines elf Jahre jüngeren Bruders. Die Brezel als Signum des Brauches wurde benannt. Die Gegengabe des Mannes, der Maien, taucht erst in einer Eintragung vom 10. Mai 1579 auf, aus der hervorgeht, daß der eigentliche Termin zum Maienstecken bzw. Maienschenken gewöhnlich auf den Monatsersten fiel (Weinsberg 1886-1926,V:143). ${ }^{50}$ Festzuhalten sind die Brauch-

\footnotetext{
${ }^{48}$ Eingehend zur sozio-kulturellen Funktion von Geschenkritualen vgl. Mauss (1968).

${ }^{49}$ Vgl. die im Band V des Buches Weinsberg (1886-1926,5) beigefügte Stammtafel.

${ }^{50}$ Der Maien in Verbindung mit der Ausübung des Mailehens war offensichtlich noch kein dezidiertes Symbol für das gegengeschlechtliche Begehren. Er trat hier in den Zusammenhang der Bezeugung einer familiär-freundschaftlichen Beziehung. Für die gegenwärtige Praxis des Maiensteckens, wie ich es im Bonner Umland in den letzten fünf Jahren beobachten konnte, würden derartige
} 
termine Fastnacht, Fastnachtdienstag und Laetare, der vierte Fastensonntag. Während an Fastnacht die Paarzuteilung vorgenommen wurde, beging man zum Höhepunkt der Fasten (Mittfasten), offensichtlich im Kreise seiner Nächsten, die abendliche Feier des Lehensverhältnisses.

Demzufolge darf der Mailehenbrauch in den vorösterlichen Fest- und Brauchzyklus eingereiht werden, wobei der Ort des Geschehens sowie die Zusammensetzung der Brauchbeteiligten im Vergleich zu jüngeren Verhältnissen ungewohnt ist. Weinsberg berichtete über das Mailehen als einen fastnachtlichen Familienbrauch, bei dem sich die wesentlichen Funktionen im Rahmen von Bestätigung und Konsolidierung familiär-freundschaftlicher Beziehungen und des "samen frolich"-Seins konzentrieren. Diese Charakterisierung des kölnischen Mailehenbrauchs findet auch in späteren Anmerkungen von Weinsberg (1886-1926,IV:163f, 185, 253) weitere Bestätigung. Darüber hinaus erfährt man, daß die Brezeln der "jonfern" und "frauwen" schön verziert wurden, bevor die "jonge gesellen oder man" sie erhielten. Zudem wurden am ersten Mai nicht nur die Maien geschenkt, sondern es wurde wieder im Familien- und Freundeskreis ordentlich gefeiert. Dabei bekamen die "Lenen" (hier die weiblichen Brauchträger) von den jeweils zugehörigen Männern in silbernen Kannen ein mit Zimt gewürztes Getränk, den sogenannten "Meikneildrank" (Weinsberg 1886-1926,IV:163f). Auch die Mägde hatten Anteil am Geschehen zumindest was die besondere Art des Lehenausrufens betraf:

"Die macht Ail und Eifgin reifen die lienen widder des stoiblins dur aus, alle in geheim" (Weinsberg 1886-1926,IV:185).

Hinter der verschlossenen Türe, vor die die männlichen Brauchteilnehmer vermutlich einzeln herantreten mußten, um den Namen ihrer Partnerin zu erfahren, riefen die beiden Mägde Ail und Efgen die Lehen aus. Auf diese Weise entstanden zufällig und geheim ausgewählte Lehenpaare. 1596 im Alter von 76 Jahren folgte die letzte Notiz über das Mailehen. Sie erbringt keine neuen Informationen, aber sie zeigt, daß der Mailehenbrauch über den Zeitraum von fünf Jahrzehnten in einem frühneuzeitlichen kölnischen Ratsherrenhaushalt fest installiert war. Weinsberg unterließ es dabei nicht, auch das Ausbleiben der Mailehenpraxis zu bemerken, das er auf die kölnischen Krisen- und Kriegszeiten im Gefolge der reformorientierten Machtpolitik des Erzbischofs Truchseß von Waldburg zurückführte (Weinsberg 1886-1926,IV:163f).

Verhaltensweisen zumindest Gerüchte über etwaige Liebschaften auslösen. Ausführlich behandelt und exzellent historisch belegt ist der Brauch des Maibaumstellens bei Moser (1985). 


\subsection{Unter dem Druck frühneuzeitlicher Machtinteressen}

Sichere Anhaltspunkte bei der Beurteilung der geschichtlichen Genese des Mailehens gründen in den Prozessen der Reformation, der Gegenreformation und des Ausbaus der Territorialmächte. Die Glaubensspaltung und religiöse Erneuerung, die im 16. Jahrhundert grundlegende Impulse erhielten, sorgten für weitreichende Eingriffe in religiöse, soziale, wirtschaftliche und politische Sphären der städtischen wie ländlichen Lebenswelt. Die damalige Situation spiegelt sich in zahlreichen Dokumenten, z.B. Kirchen-, Polizei-, Dorfordnungen oder Protokollen der Kirchenvisitationen und Sendgerichte wider. Bis ins 19. Jahrhundert hinein lassen sich die Spuren dieser von Staat und Kirche gemeinsam gelenkten Umwälzung deutlich verfolgen. Die ubiquitäre Überwachung der Rechtgläubigkeit durch staatliche wie weltliche Instanzen führte vom Öffentlichen ins Private, ja bis ins intimste Innere menschlicher Psyche, das bei jeder Beichte hervorgelockt und einer möglichst gründlichen pastoralen Prüfung unterzogen werden sollte. Der allgemeine Lebenswandel auf Gemeindeebene stand unter der Observation ausgewählter Kirchenältester oder Sendschöffen und war in den Kirchenvisitationen seit dem 16. Jahrhundert keineswegs eine Marginalie. ${ }^{51}$ Stets achteten die Kirchenmänner bei späteren Folgeinspizierungen auf etwaige (Fehl-)Entwicklungen, Verbesserungen oder Verschlechterungen.

Auch der Brauch des Mailehens, der in seiner Geschichte häufig im Lichte unmäßiger, unsittlicher Lebensführung betrachtet wurde, taucht seit dem 16. Jahrhundert in einer Reihe von offiziellen Mitteilungen, Protokollen und Edikten auf. In manchen Regionen wurden Verbote der Brauchausübung unter Strafandrohung über Jahrzehnte hinweg mehrfach bestätigt oder gar verschärft. Das Mailehen stellte generationenübergreifend in den Augen der Obrigkeiten ein Ärgernis dar. Anderwärts lassen sich lediglich Einzelfunde nachweisen. Dieser Tatbestand geht auch aus der nachfolgenden Tabelle deutlich hervor. Zugunsten einer übersichtlichen Darstellung, die sich auf die zeitliche und räumliche Ausdehnung des Mailehens konzentriert,

\footnotetext{
${ }^{51}$ Die Überwachung der Privatsphäre wurde von der Bevölkerung nicht akzeptiert. Die Sendschöffen, die selbst ortsansässig waren, wurden als Spitzel angesehen und waren nicht gelitten. Die vom Pfarrer und der Kirchenleitung eingesetzten Sendschöffen übernahmen wohl selbst ungern diese Kontrollfunktion, weshalb sie von der Obrigkeit unter Druck gesetzt wurden. In einem Edikt des Kölner Kurfürsten Joseph Clement des Jahres 1700 heißt es, daß "[...] die so hochnöthige Anordnung einiger Send-Scheffen eine zeitlang an vielen Oertheren unterlassen worden, solchen Dienst auch deswegen bald niemand übernehmen wollen, weilen selbige von ihren Mitnachbahren hierüber geschmähet, verspottet und davon abgeschreckt werden, derhalben dan allerhand Unthaten und Laster eingerissen [...] wodurch Gottes Zorn Rach und Straff ungezweiffelt über dem Ertzstifft gezogen werden dörffte" (Vollständige Sammlung... 1772-73 siehe 265. Stuck). Vgl. auch die kurtrierische Kirchensendordnung von 1589 (Scotti 1832 siehe Nr.142; ferner Nr.290).
} 
treten die inhaltlichen Aspekte der jeweiligen Meldungen vorläufig in den Hintergrund. ${ }^{52}$ Die Auflistung erbringt einen Überblick zu zeitlichen, räumlichen und typologischen Verteilungen sicherer Mailehenbelege in Tabelle 1.53

Tabelle 1:

ÖFFENTLICHE VERBOTE UND EINWENDUNGEN GEGEN DAS MAILEHEN (16.-19. JH.) ${ }^{54}$

\begin{tabular}{|c|c|c|c|c|c|c|c|c|}
\hline D-nr. & Jahr & Ort & Region & Urtext & Bezeichnung & Urheber & Strafmaß & Quelle \\
\hline 1 & 1544 & Kusel & 2 & VP & LA & 1 & 6 & Fröhlich (1934) \\
\hline 2 & 1558 & Zweibrücken & 2 & VP & LA & 1 & 5 & Schunck (1926) \\
\hline 3 & 1560 & Kusel & 2 & PK & $\mathrm{LAH}$ & 1 & 6 & Dierker (1939) \\
\hline 4 & 1563 & Amt Hüttenberg & 3 & $\mathrm{~V}$ & LA & 1 & 5 & HNass. VWb. (1927ff) \\
\hline 5 & 1566 & Leiningen & 2 & $\mathrm{PO}$ & LA & 3 & 2 & Biundo (1960) \\
\hline 6 & 1567 & hintere Gft. Sponheim & 1 & VP & LA & 1 & 0 & Back (1872-74) \\
\hline 7 & 1569 & Badenheim & 3 & $\mathrm{~V}$ & LA & 1 & 2 & Krebs (1973) \\
\hline 8 & 1574 & Völklingen & 1 & $\mathrm{KO}$ & LA & 1 & 0 & Conrath (1962) \\
\hline 9 & 1575 & Enkirch & 1 & VP & LG & 1 & 0 & Back (1872-74) \\
\hline 10 & 1576 & Völklingen & 1 & $\mathrm{KO}$ & LA & 1 & 0 & Fox $(1935 / 6)$ \\
\hline 11 & 1578 & Isenburg. Amt Dreieich & 3 & 0 & LA & 1 & 5 & Dierker (1939) \\
\hline 12 & 1579 & Zweibrücken & 2 & VO & LA & 1 & 0 & Fox $(1935 / 6)$ \\
\hline 13 & 1580 & Birkenfeld & 1 & VP & LA & 1 & 0 & Back (1899) \\
\hline 14 & 1589 & Lichtenberg & 2 & $\mathrm{Pl}$ & LA & 1 & 0 & Dierker (1939) \\
\hline 15 & 1589 & Grünberg & 3 & V & LA & 2 & 0 & Barlen-Ebert (1960) \\
\hline 16 & 1590 & Enkirch & 1 & 0 & LA & 1 & 3 & Back (1872-74) \\
\hline 17 & 1593 & Völklingen & 1 & $\mathrm{KO}$ & LA & 1 & 0 & Conrath (1962) \\
\hline 18 & 1597 & Gft. Leiningen & 2 & VP & LA & 1 & 0 & Becker (1939) \\
\hline 19 & 1598 & Katzenelnbogen & 3 & V & LA & 1 & 0 & Back (1872-74) \\
\hline 20 & 1598 & Herrstein & 1 & PK & LA & 1 & 0 & Back (1872-74) \\
\hline 21 & 1599 & Reichenbach & 3 & $\mathrm{PC}$ & LA & 1 & 0 & Dierker (1939) \\
\hline
\end{tabular}

(Fortsetzung siehe nächste Seite)

${ }^{52}$ Zur inhaltlichen Analyse s. Abschnitt 3.6.

${ }^{53}$ Die begrenzte Grundgesamtheit der aufgelisteten Fälle sowie die inhaltliche Diversität der Quellen sind ungeeignet, um anhand der gewonnenen Daten statistische Operationen durchzuführen. Dennoch können die Häufigkeitsverteilungen der einzelnen Merkmale dazu dienen, Tendenzen in der Entwicklung des Mailehens zu erkennen und Fehlurteilen vorzubeugen.

${ }^{54}$ Abkürzungen und Schlüsselnummern:

Kopfzeile: Datensatznummern.

Region: Die regionale Zuordnung dient hier der geographischen, nicht politisch-territorialen Orientierung: 1=Rheinland (mit Saarland); 2=Pfalz; 3=Hessen; 4=Lothringen.

Urtext: $\quad \mathrm{KV}=$ Kirchenvisitation; $\quad \mathrm{VP}=$ Visitationsprotokoll; $\quad \mathrm{VO}=$ Visitationsordnung; $\mathrm{KO}=$ Kirchenordnung; $\quad \mathrm{PK}=$ Pfarr-/Kirchenkonvent; $\quad \mathrm{GP}=$ Generalpunkte; $\quad \mathrm{PI}=$ Pfarrinstruktion; $0=$ unspezifisch (z.B. Befehl, Bericht des Amtsmanns); V=Verordnung (Anordnung); $\quad \mathrm{PO}=$ Polizeiordnung; $\quad \mathrm{PC}=$ Pfarrchronik; $\mathrm{E}=\mathrm{Edikt;} \quad \S=$ Strafverfahren.

Bezeichnung: LA=Lehnausrufen; $\quad$ LS=L.schenken; LAH=L.ausheischen; $\quad L G=$ L.ausgeben; LW=L.schwinken; LT=L.austeilen; S="Soldée"; MF=Maifeier; MLV=Mailehenversteigerung.

Urheber: $\quad 1=$ kirchliche Obrigkeit; $2=$ weltliche Obrigkeit; $3=$ Mischform.

Strafmaß: $\quad 0=$ keine Angabe; 1=religiöse Buße; 2=Geldbuße; 3=Arrest; 4=komplexe Strafandrohung; $5=$ diffuse Strafandrohung; $6=$ ohne Strafandrohung.

Quelle: HNass.VWb.=Hessen-Nassauisches Volkswörterbuch; Pfälz./Südhess.Wb.=Pfälzisches/Südhessisches Wörterbuch; Vollst. Slg.=Vollständige Sammlung. 


$\begin{array}{ll}1608 & \text { hintere Gft. Sponheim } \\ 1609 & \text { Konken } \\ 1612 & \text { Glehn/Liedberg } \\ 1613 & \text { Reichenbach } \\ 1617 & \text { Kfsm. Köln } \\ 1617 & \text { Niederrhein } \\ 1624 & \text { Glehn/Liedberg } \\ 1628 & \text { Longuyon } \\ 1629 & \text { Gilverath } \\ 1641 & \text { Overath, Kaarst, Glehn } \\ 1654 & \text { Gilverath } \\ 1657 & \text { Hessen } \\ 1668 & \text { Hessen } \\ 1669 & \text { Neuss } \\ 1670 & \text { Aachen } \\ 1680 & \text { Marburger Umgebung } \\ 1683 & \text { Marburger Umgebung } \\ 1683 & \text { Rheinsheim } \\ & \\ 1706 & \text { Aachen } \\ 1716 & \text { Kfsm. Köln } \\ 1718 & \text { Sinzig } \\ 1749 & \text { Kfsm. Köln } \\ 1762 & \text { Kfsm. Köln } \\ 1767 & \text { Amt Amöneburg } \\ 1779 & \text { Stadtkyll } \\ 1780 & \text { Konvente Kirtorf } \\ 1793 & \text { Hzm. Berg } \\ 1830 & \text { Siegkreis } \\ 1851 & \text { Troisdorf } \\ & \end{array}$

$\begin{array}{cc}\text { GP } & \text { LA } \\ \text { VP } & \text { LA } \\ \text { VP } & \text { LS } \\ \text { V } & \text { LA } \\ \text { V } & \text { LW } \\ \text { VP } & \text { LS } \\ \text { KV } & \text { (LS) } \\ \text { VP } & \text { S } \\ \text { VP } & \text { LS } \\ \text { VP } & \text { LS } \\ \text { VP } & \text { LS } \\ \text { KO } & \text { LA } \\ \text { KO } & \text { LA } \\ \text { V } & \text { LS } \\ \text { E } & \text { LA } \\ 0 & \text { LA } \\ \S & \text { LA } \\ \text { VP } & \text { LA } \\ & \\ \text { E } & \text { LA } \\ \text { V } & \text { LA } \\ \text { V } & \text { LA } \\ \text { V } & \text { LA } \\ \text { V } & \text { LA } \\ 0 & \text { LA } \\ \text { V } & \text { LT } \\ \text { PK } & \text { LA } \\ \text { E } & \text { MF } \\ 0 & \text { MLV } \\ 0 & \text { MLV }\end{array}$

Back (1872-74)

Pfälz.Wb. (1965ff)

Giersberg (1883)

Südhess. Wb. (1965ff)

Schuegraf (1856)

Giersberg (1883)

Bremer (1930)

Kaiser, J.B. (1928)

Giersberg (1883)

Keussen (1922-24)

Giersberg (1883)

Landau (1840)

Dierker (1939)

Faber (1985)

Faber (1985)

Landau (1840)

Landau (1840)

Becker (1913)

Dierker (1939)

Vollst. Slg. ... (1772-73)

Eckertz (1863/1864)

Vollst. Slg. ... (1772-73)

Vollst. Slg. ... (1772-73)

Heeger (1965)

Oster (1927)

Baur (1856)

Schwall (1922)

Gansen (1931)

Gansen (1931)

Bereits aus der Frühphase der Ausbreitung reformatorischen Gedankenguts stammen die ersten Belege über die beobachtete Praxis des Lehenausrufens: im Jahre 1544 hält ein pfälzisches Visitationsprotokoll der protestantischen Kirche das Mailehen für die Stadt Kusel fest. Darin heißt es:

"Item [Herr Ulricus Weigandt, Pfarrer zu Kusel; H.-W.W.] zeigt an, ob man die Faßnacht dantz, so man sie halten wil, zulassen wolle, desgleichen das Radbrennen, Lehenusrufen und Maienstecken. (So sollichs one Gotzlesterunge zugeeht, laß man es bleiben.)" (die Bemerkung in runden Klammern wurde durch die Obrigkeit dem Bericht nachträglich hinzugesetzt; Fröhlich 1934:321).

In der Tabelle finden sich die wesentlichen formalen Merkmale dieses Zitats wieder, nämlich Jahreszahl und Urheber des Visitationsprotokolls, Ausübungsort, geographische und typologische Einordnung des Brauches. Die Ziffer 6 in der Spalte zum Strafmaß besagt, daß auf eine Strafandrohung verzichtet wurde. Diese Daten konnten für 49 weitere Fälle (Datensätze) ermittelt werden, die sich in einem Zeitraum von 
vier Jahrhunderten bewegen, wobei der überwiegende Anteil in das 16. und 17. Jahrhundert fällt. Lediglich zwei Meldungen stammen aus dem 19. Jahrhundert. ${ }^{55}$

Der überwiegende Anteil der Eintragungen bezieht sich auf das Lehenausrufen (35 Nennungen zwischen 1544 und 1780). Siebenmal taucht der ausschließlich am Niederrhein gebräuchliche Begriff Lehenschenken auf (1612-1669). Möglicherweise steht hierzu der Ausdruck Lehnschwinken in einem Zusammenhang (vgl. Datensatznr. 26). Jeweils mit einer Meldung sind Lehnausheischen, Lehnausgeben, Lehnausteilen und Soldée vertreten. Die Bedeutungen der bisher genannten Brauchbezeichnungen dürften sich decken; ob sie zwingend mit der Brauchausübung des heutigen Lehenausrufens - insbesondere mit der Praxis der Paarermittlung durch Los oder willkürliche Festsetzung - in Einklang steht, kann allerdings nicht eindeutig festgestellt werden. Was die Beurteilung erschwert, sind in erster Linie die Ausführungen eines kurkölnischen Edikts aus dem Jahre 1749, das unter den Begriff Lehenausrufen sowohl das Prinzip der freien Auswahl als auch der Versteigerung faßt. Die entscheidende Stelle heißt:

"[...] zudeme unter besagten jungen Leuthen die Söhn und Töchtere so wohl, als Knecht und Mägde sehr ärgerliche Gesellschafften und Gelacher anzuordnen, fort diese alljährlich in denen May-Zeiten und Pfingst-Feyrtägen die so genante Lehne oder junge Töchter und Mägde per sortem, aut licitationem für jeden Purst, Sohn und Knecht außzutheilen, und öffentlich außzuruffen, [...]" (Vollständige Sammlung... 1772-73 siehe das 272. und 273. Stuck).

Insoweit rekurriert die allgemeine Brauchbezeichnung zumindest bis ins 19. Jahrhundert auf die Form der Bekanntmachung der Lehen und nicht auf die Form der Zusammengebung der Lehenpaare. Begriffe wie Maifeier und Mailehenversteigerung tauchen erst spät auf (1793 und 1830, 1851), setzen sich aber im Sprachgebrauch zunehmend durch. Mit der Zurückdrängung feudaler Strukturen durch die Säkularisierung scheint auch ein Teil feudalzeitlicher Terminologie zu verschwinden. Die Maifeier ${ }^{56}$ läßt auf einen größeren Brauch- und Festkomplex

\footnotetext{
${ }^{55} \mathrm{Um}$ zu entscheiden, ob sich in den Häufigkeitsverteilungen die Höhen und Tiefen reformatorischer bzw. gegenreformatorischer Visitationstätigkeit spiegelt, müßte eine Gesamtbetrachtung der in dieser Zeit absolvierten Visitationen erfolgen. Dies war jedoch in diesem Rahmen nicht möglich.

${ }^{56}$ Bei der Verwendung derart allgemeiner Brauchbezeichnungen muß genau geprüft werden, ob ein Zusammenhang zum Mailehen tatsächlich besteht. Wenn in der "Pollicey Ordnung des Ertzstiffts Cöllen" des Jahres 1595 unter $§ 19$ "Von ubrigen unkösten der Faßnachten und anderen Geselschafften, Brautlofft, Kindertauff und Begrebnissen" die Rede vom "Meygelage" ist (Scotti 1830-31, Nr.37 vgl. Nr.358), so ist darunter nicht die Vereinigung der Junggesellen zu verstehen, die das Mailehen ausübt, sondern vielmehr eine Gesellschaft, deren vorrangiges Interesse in "kostbare(r) und unnütze(r) Gestery" lag. Wäre das Mailehen an dieser Stelle gemeint, so dürfte man vor dem Hintergrund gleichartiger Verbote annehmen, daß die Charakterisierung des Brauches eine andere Richtung eingeschlagen hätte: die Völlerei wäre den sittlichen Gefahren untergeordnet worden. Ganz ähnliche Vorbehalte betreffen das May-Spiel (Becker 1989:296f), das in einem kurkölnischen Edikt von 1665 Erwähnung findet, oder den sogenannten "Schluitgang", der mit dem Kommabend in Verbindung gebracht wurde (Vollständige Sammlung... 1772-73, 442. Stuck). Assoziationen zum Mailehen sind
} 
schließen, als dies alleine im Lehenausrufen zum Ausdruck kommt. Sie darf als Vorläufer der städtischen und stadtnahen Brauchformen des ausgehenden 19. Jahrhunderts gelten. ${ }^{57}$

Beachtlich bei der räumlichen Verteilung ist, daß der Brauch vornehmlich in den Gebieten des Rheinlandes (27 Nennungen), der Pfalz (9 Nennungen) und in Hessen (13 Nennungen) Verbreitung gefunden hat. Auch in dem lothringischen Archidiakonat Longuyon wurde der Brauch ausgeübt. Der mittelrheinische Großraum mit seinen Zentren Köln, Aachen, Mainz und Trier tritt hier als Kerngebiet des Mailehens hervor. Verbunden mit der geographischen Verteilung ist auch der jeweilige territorialpolitische Machteinfluß, dem die Brauchausübung unterlag. Dabei wird ersichtlich, daß die Bekämpfung keineswegs nur von protestantischer Seite aus betrieben wurde, obgleich das pfälzisch-zweibrückische Herrscherhaus mit zahlreichen Ordnungsmaßnahmen vertreten ist. Sie reichen von relativ geringfügiger "Geldbuße" (z.B. ein Gulden in Datensatznr. 5) bis zu einer harten Bestrafung, die gegen den Delinquenten, aber auch gegen seine Eltern gerichtet war. So führen darüber die von Back (1872-74:401) erwähnten Generalpunkte aus:

"'Obschon vor vielen Jahren das Lehenausrufen verboten worden, sei doch in vielen Kirchspielen der schädliche Brauch noch in Übung. Pfarrer und Amtleute sollten es aber strafen, die Eltern, die solches ihren Kindern gestatteten, mit einer Geldpön ansehen und das junge Volk mit dem Thurm zum Gehorsam bringen"'.

Auch die Rheinländer bekamen im Zuge der Gegenreformation mehrfach die starke Hand des Kölner Kurfürsten zu spüren, und es ergingen in seinem Herrschaftsgebiet nach vorangegangenen Mahnungen zumindest zwei Verbote, die mit der Androhung von Freiheitsentzug dem Mailehen gegenüber eine unmißverständliche Haltung einnahmen (vgl. Datensatznr. 43 und 44). Strafrechtlich interessant ist dabei eine Differenzierung der Strafe je nach Art und Häufigkeit der Beteiligung. Demnach wird ein einmaliges Vergehen noch mit einer Geldstrafe von "drey Goltgülden" belegt, wohingegen die dreifache Übertretung "mit dem Stockhauß zu Kayserswerth gestraffet werden sollen". Dem Wirt oder demjenigen, der die Junggesellen in ihrem Tun unterstützt, droht jeweils das doppelte Strafmaß (Vollständige Sammlung... 1772-73 siehe das 272. und 273. Stuck).

Die im hessischen Raum verhängten Strafen zeugen von geringerer Härte. So wird zum Ende des 17. Jahrhunderts eine bereits mit Strafe gerügte Brauchpraxis im Urteilsspruch der höheren Instanz als straffrei beurteilt:

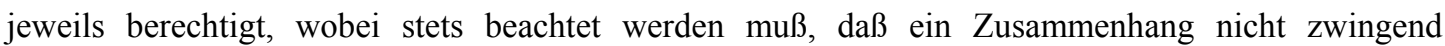
abzuleiten ist.

${ }^{57}$ Dazu Abschnitt 2.6. 
"Im Jahre 1683 wurden die Bursche des Dorfes Rod im schenkischen Eigen wegen des Lehnausrufens vor den Schultheißen gefordert. Einer der Angeklagten erzählt im Verhör, wie sie 'in der Walpersnacht vmb $10 \mathrm{Vhr}$ vber den Steg gegangen vff dem Staden, da hetten sie die Lehn ausgeruffen aus Kurtzweil, solchergestalt, der N. vndt die N. sollen lehn seyn, hetten drausen ein fewer angemacht vnd darbei geschossen, - nachgehends wern sir wieder zurück vnd ins Wirtshaus gangen, hetten des Nachts im Wirtshaus gesessen, geschossen vnd gesoffen bis es tag worden, hetten auch dabei weltliche Lieder gesungen, hetten darbei 4 zu Knechten gemacht, welche 4 Virtel zum Besten haben geben müssen etc.' Als sie gestraft wurden, wendeten sie sich an die Regierung zu Marburg, welche die Strafe wieder aufhob, weil das Lehnausrufen, obgleich es nicht zu gestatten, doch noch nicht verboten sey" (Landau 1840:273f).

Eine allgemeine Interpretation der Strafverfolgung anhand der Daten ist problematisch. Es liegt ein sehr hoher Anteil von Zeugnissen vor, die - zumindest der zitierten Quelle zufolge - keinerlei Angaben zur Bestrafung der Mailehenausübung enthalten. Die Erwägung eines Ausübungsverbotes verbunden mit einer Strafandrohung beginnt mit der ersten Meldung von 1544, wenngleich man hier noch die Angelegenheit auf einer aufmerksamen Beobachtung des Geschehens beruhen läßt. Die Tabelle macht deutlich, daß die jeweiligen Machthaber über den gesamten Belegzeitraum von drei Jahrhunderten die Bereitschaft zeigten, das Strafregister bei der Delinquentenverfolgung weitgehend auszuschöpfen. Kirchliche Bußen (1680) $)^{58}$ tauchen ebenso auf wie Geld- (1566-1851) und Freiheitsstrafen (1608-1793) oder komplexe Strafen (16081793), bei denen je nach Schwere und Verantwortlichkeitsgrad Abstufungen und Mischformen auftreten.

$\mathrm{Zu}$ bezweifeln ist, ob die Strafandrohung und selbst die Strafverfolgung - sofern sie überhaupt eingeleitet wurde - die geeigneten Mittel zur Abschaffung des Brauches darstellten. Bemerkenswert sind die Wiederholungen bestehender Anordnungen bzw. Verbote. Besonders charakteristisch erscheinen hierbei Ortschaften der hinteren Grafschaft Sponheim, die in der Tabelle sechsmal auftauchen (1567-1608) ${ }^{59}$, oder auch der Kurkölner Bereich, wo einzelne Edikte zum Teil eine wortwörtliche Neuauflage erfuhren (zehn Eintragungen im Zeitraum von 1612-1762) ${ }^{60}$. Somit wird zum einen der Eindruck erweckt, daß den Verordnungen der nötige Nachdruck fehlte, um die wirksame Abschaffung des Mailehens zu erreichen und/oder zum anderen der Widerstand in der brauchtreibenden Bevölkerung in seiner Hartnäckigkeit über lange Zeit hinweg ungebrochen blieb. Die Renitenz der Untergebenen konnte dabei sowohl gewaltsame als auch subtilere Formen angenommen haben. Aus dem vorliegenden Quellenbefund ist darüber keine klare Aussage ableitbar. Die Einbettung der Verordnungen in ein übergeordnetes Maßnahmenbündel von Kirche und Staat läßt aber eine Haltung der Landeshoheit erkennen, die sich an einer allgemeinen Hebung von

${ }^{58}$ Es ist anzunehmen, daß die kirchlichen Bußen (Ablaß, Ehrenstrafen) weitere Verbreitung hatten, als dies hier zum Ausdruck kommt. Da die Beichte in katholischen Gebieten zur regelmäßigen Pflicht eines Gläubigen gehörte, konnten sich die Delinquenten der Kirchenbuße kaum entziehen.

${ }^{59}$ Vgl. Datensatznr. 6, 9, 13, 16, 20, 22.

${ }^{60}$ Vgl. Datensatznr. 24, 26-28, 30-32, 41, 43, 44. 
Ordnung, Stabilität, Frömmigkeit und Wohlfahrt orientiert. Die Abschaffung des Mailehens mag sich hier einfügen, wobei anzunehmen ist, daß sie innerhalb der restriktiven obrigkeitlichen Politik einen relativ geringen Stellenwert eingenommen hat. ${ }^{61}$

Die Mailehengeschichte wurde in der nachreformatorischen Zeit jedoch nicht nur aus den bereits analysierten obrigkeitlichen Bestimmungen, sondern auch aus Chroniken oder persönlichen Aufzeichnungen erhellt. Bei Kriegk (1868:420f) heißt es, daß der Brauch in Frankfurt (Main) ausgeübt wurde, jedoch um 1700 in einen Umzugsbrauch der Kinder Eingang gefunden hat.62 Die Quelle erlangt insoweit eine gewisse Plausibilität, als das Mailehen zu dieser Zeit in der Frankfurter Umgebung bekannt war. Zudem haben die Beispiele aus St. Goar und Köln gezeigt, daß das Mailehen durchaus im städtischen Umfeld ausgeübt wurde.

Mit Skepsis muß eine singuläre Nachricht betrachtet werden, die sich bei Dünninger und Schopf (1971:74f) findet. Die beiden Autoren geben einen Auszug aus einem Kopialbuch des Katholischen Pfarramts Pülfringen in Franken wieder. Zwar läßt der Text den Brauch des Lehenausrufens erkennen, aber fehlende Angaben über die zeitlichen, räumlichen und sozialen Zusammenhänge der Brauchpraxis verhindern eine weitergehende Bewertung der Quelle und des Inhalts. ${ }^{63}$

Die zwei folgenden Mitteilungen gewähren Einblicke in die Verhältnisse des niederrheinischen Brauchlebens an der Wende des Ancien régime. Die zeitliche Einordnung der früheren legt Meisen (1935:77-79) zwischen 1760 und 1773 fest. Der Autor dieser handschriftlichen Beschreibung der Herzogtümer Jülich und Berg bleibt dagegen unbenannt. Es darf davon ausgegangen werden, daß er aus dem oberdeutschen Sprachgebiet stammte und somit Land und Leute aus einer gewissen kulturellen Distanz heraus betrachtete. Über das Mailehen berichtet er knapp:

\footnotetext{
${ }^{61}$ An dieser Stelle sind eine vergleichende Analyse verschiedener Delikte und die jeweilige Festsetzung des Strafmaßes erhellend. Besonders drastisch scheinen religiöse Vergehen im Bereich des Schwörens, Fluchens oder der Gotteslästerung und Sonntagsentheiligung geahndet worden zu sein. Neben vielen Beispielen, die sich in den umfangreichen Gesetzessammlungen von Scotti (1830-31 siehe Nr. 37, 54, 62 und 65) sowie derselbe (1832 siehe Nr.132, 142 und 497) häufen, sei in erster Linie auf die Kirchen-, Polizei- und Dorfordnungen des 16., 17. und 18. Jahrhunderts verwiesen. Vgl. Lüdtke (1992:7-33) zur allgemeinen Entwicklung des Polizeiwesens und dessen Erforschung.

$62 "[\ldots .$.$] die Kinder fuhren in einem grünen Wägelchen von Haus zu Haus und riefen das Mai-Lehen$ aus, d.h. sie sangen Worte, mit denen vor 1232 ein Herold zuweilen einer Bürgerstochter angekündigt hatte, daß der Kaiser sie einem seiner Leute zur Ehe verliehen habe" (Kriegk 1868:421). Bothe (1941:34) nennt als Quelle von Lersner: Chronik. 2 Bände 1709-34. Unter dem Stichwort Mailehen im von W. Brückner herausgegebenen Frankfurter Wörterbuch (1971-85) werden diese Angaben bestätigt, wenn auch nicht weiter präzisiert.

${ }^{63}$ Vgl. Moser (1985:247), der einen Fall beschreibt, bei dem das Mailehen fälschlich als traditionsreicher "altbayerische(r) Brauch" etikettiert wurde; dabei hatte der Tourismus dafür gesorgt, daß das Mailehen 1906 in Schäftlarn folkloristische inszeniert worden war.
} 
"Auch der erste tag im monath Mäy giebt den Bergischen und Gülischen zu einiger ergözlichkeit anlaß: Ehe noch die sonne aufgehet, werden schon unter dem schall des kuhehorns oder eines andern dergleichen wohl klingenden instruments die Mäyschäze ausgerufen, das ist, es machet ein jung mit erhabener stimme bekannt, welches mädgen ein jeder junggesell diesen sommer hindurch als seinen würdigen Mäyschaz verehren, bedienen und liebkosen soll. Hierauf laßet ein jeder an der thür seiner schönen mäyen stecken, nachmittags aber begiebt sich das [...] gesamlete junge volck zum Mäyspiel oder tanz" (Meisen 1935:95).

Die Art und Weise der Mailehenverteilung läßt dieser frühe ethnographische Bericht außer acht, aber die Form der Bekanntgabe ist das bis dahin oft genannte Lehenausrufen; hier durch einen männlichen Ausrufer und unter Einsatz von lautstarken "Instrumenten" während der ersten Mainacht. Dazu gehörten auch das Maiensetzen und der Maitanz. Als zentrales Element des Brauches wird die Pflege der Paarbeziehung deutlich angesprochen. Damit sind in aller Kürze wesentliche Bestandteile des Mailehens genannt, welche die Brauchentwicklung über lange Zeit bis in die Gegenwart geprägt haben. ${ }^{64}$

Die zweite Notiz, die oben angesprochen wurde, läßt sich der Dorfchronik des Joan Peter Delhoven aus Dormagen (1783-1823) entnehmen. Hinter der chronologischen Aufzählung von Fakten verbergen sich oft nähere Angaben zum lokalen Tagesgeschehen und zur Autobiographie des Autors (Cardauns et al. 1966:7, 179). ${ }^{65}$ Der charakteristische Unterschied der vorangestellten Ethnographie zum BergischJülichen Territorium, in der ein regionaler Gesamteindruck vermittelt wurde, besteht in der direkten Berührung Delhovens zum Lebensalltag des brauchausübenden Dorfverbandes. Delhoven beobachtete nicht nur, sondern er erlebte das Mailehen aus nächster Nähe, wenngleich er sich selbst aus dem aktiven Geschehen heraushielt. So vermerkte der noch ledige Siebenundzwanzigjährige:

"1. [Majus 1793; H.-W.W.] Diese Nacht um 12 Uhr versammelten sich die Dorfjungen und riefen die Meylehnen aus. Es wird dann jedem Jüngling ein Mädchen zur Meyfrau ausgerufen, dreimal in ein Horn geblasen, und dann gefragt, obs allen lieb wäre".

In dieser Beobachtung stimmen die Belege der beiden Regionen überein. Die Situationsbeschreibung wird jedoch um die empathische Anteilnahme bereichert, mit welcher der Dormagener seine Eintragung zum 1. Mai 1793 beschließt:

"Die Alten müssen sowohl als wir die Schönheiten des Lenzes empfunden haben; denn ihre Feyer des Wonnemondes beweiset dieses, als da sind: das Meyleuthen, das Beyeren mit den Klocken, Sonn- und Feyertagabends das Meysingen, wo die Mädcher um hin und wieder im Dorf aufgesteckte grüne Meyen tanzen und Frühlingslieder singen, oft bis in die späte Nacht. Die Lieder sind einfach und nach alter Sitte, meistens Lobgesänge auf den Mey, und von Lieb und Treu der Jugend. Fast in allen herrscht Anmuth und viele Empfindung und Zartgefühl. Diese Gesänge mögen viele vor manch hundert Jahren zur Feyer des Frühlings bestimmt und

${ }^{64}$ In der neueren Jugendforschung finden sich vielfältige Parallelen zu den hier aufgezeigten rituellen Ausdrucksformen. Vgl. hierzu Fabre (1997:56-96) und Schindler (1996:319-382).

${ }^{65} \mathrm{Vgl}$. auch Streckenbach (1992:122, 133-137). 
von unsern schon zu Staub gewordenen Vorfahren in der Blumenzeit ihres Lebens gesungen worden seyn" (Cardauns et al. 1966:81f).

Die nüchternen Angaben zur Brauchausübung werden durch eine emotionale Komponente ergänzt: der Brauch scheint die sinnlich wahrnehmbaren Reize des Frühlings, die besonders in der sich wandelnden Vegetation und im wärmeren Klima spürbar werden, aufzunehmen und gleichsam aufzuladen, um sie dann wieder durch Aktion (z.B. Tanz) weiterzubilden. ${ }^{66}$ Dies gilt auch noch in einer Situation, in der gravierende soziale, politische und wirtschaftliche Umwälzungen ausgehend von der Französischen Revolution ihren Lauf nahmen und schon bald für das linke Rheinufer Wirklichkeit werden sollten. ${ }^{67}$

Die Verve in der Darstellung des Brauchgeschehens erhöht zusätzlich die Verwunderung über den passiven Beobachterstatus Delhovens. Erklärungen für die Zurückhaltung des Junggesellen liegen möglicherweise in seiner Bindung an ein religiöses Elternhaus begründet. Er selbst weist an einer Stelle seiner Chronik darauf hin, daß die kirchliche Missionsarbeit vehement gegen den "Bauren Reyen" vorgegangen sei, wenn auch erfolglos, denn die Männerreih als ein Vorläufer des Junggesellenvereins blieb in Dormagen erhalten. Daß der 27jährige Delhoven das zulässige Höchstalter für den Reih überschritten haben konnte, erscheint zweifelhaft. Die Aufnahmebedingungen regeln normalerweise das Eintrittsalter. Alle Junggesellen vom Zeitpunkt des Schulaustritts an hatten die Möglichkeit, der informellen geschlechtsspezifischen Gruppierung anzugehören. Ein Zwang bestand offenbar nicht. Der Dormagener Reih scheint einem organisierten Verein jüngeren Zuschnitts zu ähneln. Dies äußert sich z.B. darin, daß Ämter (Präsident, Korporäls und Läufer), dazugehörige Kleidervorschriften (Uniformen) oder eine eigene Fahne genannt wurden (Cardauns et al. 1966:30, 155f). Ausprägungen dieser Art haben sich im entstehenden Vereinswesen des 19. Jahrhunderts durchgesetzt und sind vielerorts kennzeichnend für das heutige Erscheinungsbild der Junggesellenvereine geblieben. ${ }^{68}$

\footnotetext{
${ }^{66}$ Hierhin gehört ferner die folgende Eintragung vom 21. Mai 1793: "Pfingstdienstag. Viele Menschen feyerten heute. Am Abend erheiterte sich der Himmel und die junge Welt errichtete Meyen im Dorfe[...] . Da stimmten die Mädcher im Dorf ihre Lieder an. Ich kann nicht sagen wie seltsam rührend mir ward. Die harmonische Musik kann bey mir nicht so entzückende Empfindungen hervorbringen, als diese einfachen Lieder der Vorzeit. Ein Knabe mit einer melodischen Flöte begleitete den Gesang, der beym Scheine des lieblichen Mondes bis in die Nacht unterhalten wurde" (Cardauns et al. 1966:82). Was in flüchtigen Quellen als May- und Pfingstspiel bezeichnet worden ist, wird durch Delhovens Chronik anschaulich. Mailehenversteigerung, Maitanz oder Maibaumstecken können jeweils nur einen Teil des gesamten Mai- und Pfingstbrauchkomplexes ausgemacht haben.

${ }^{67}$ Siehe Cardauns et al. (1966:175); ferner zur politischen Einordnung des Chronisten: Streckenbach (1992:113-137).

${ }^{68} \mathrm{Vgl}$. Zender (1972:258-263).
} 


\subsection{Auf dem Weg zu einer formalisierten Brauchorganisation ( 19 . Jh.)}

Offizielle Anordnungen zur Abschaffung des Mailehens nehmen im 19. Jahrhundert deutlich ab. In der oben aufgeführten Tabelle 1 (s. Kap. 2.4) sind lediglich zwei Eintragungen für die Jahre 1830 und 1851 verzeichnet. Beide beziehen sich auf die Siegburger Umgebung. Während die frühere Meldung auf die Beschwerde eines Geistlichen zurückzuführen ist, bezieht sich die spätere auf ein Verbot des Gemeindevorstehers. Auffallend ist ein Wandel in der Diktion der Ordnungsmandate. Hatten die kirchlichen Seelsorger in vorangegangenen Jahrzehnten und Jahrhunderten oft die Landeshoheit auf ihrer Seite, scheiterten die restriktiven Vorstöße bereits auf der vergleichsweise niederen Rangebene der Bürgermeister. Entgegen pastoraler Bedenken erhält das Mailehen tatkräftige Unterstützung durch die Gemeindevertretung, wenn z.B. der Siegburger Bürgermeister am 22. August 1830 erklärt:

"[...] es (ist) nicht angebracht, diesen alten Brauch da, wo er sich in seiner Reinheit erhalten habe, zu stören" (Gansen 1931:18).

Selbst die zuständigen Behörden, der Landrat und der Regierungspräsident, pflichteten dieser Ansicht mit Nachdruck bei, als sie folgenden Wunsch übermittelten:

"[...] die Behörden sollten mitwirken, den alten Brauch auch fernerhin in seinem ursprünglichen Sinne zu erhalten" (Gansen 1931:18).

Diese Stelle ist noch aus einem anderen Blickwinkel aufschlußreich für die Mailehenforschung. Sie belegt, daß bei der Betrachtung des Mailehens spätestens seit 1830 mit einer bewußt gesteuerten "Brauchtumspflege" zu rechnen ist. Und es wird sichtbar, wie konservierende und restaurierende Bestrebungen, die über den Bestandserhalt lokal variierender Brauchpraxen hinausgehen, zu einer Gegenbewegung zu den vielfach verhängten Sanktionen kirchlicher Obrigkeit heranreifen.

Doch kehren wir zurück zur ethnographischen Ausgangslage: Den die Mailehenversteigerungen ausübenden Burschen wurde von der Kirche zur Last gelegt, gegen die guten Sitten zu verstoßen. Zur angemessenen Beurteilung sollte aus allen betreffenden Gemeinden formell Bericht erstattet werden. ${ }^{69}$ Bei den Recherchen stellte sich sodann heraus, daß Mailehenversteigerungen unter Ausschluß der Öffentlichkeit stattfanden. Dies führte in Troisdorf dazu, daß dem Gemeindevorsteher die Teilnahme an der Auktion verwehrt wurde. Dementsprechend hatte der "Brauchgutachter" bewußt auf eine Beurteilung zur sittenverderbenden Wirkung des Mailehens verzichtet (Gansen 1931:18f). Wo in den vorangegangenen Jahrzehnten

${ }^{69}$ Es lagen jedoch bloß die Unterlagen für die Ämter Troisdorf und Wolsdorf vor (Gansen 1931:18). 
oder gar Jahrhunderten allgemeine Unzucht und Sündhaftigkeit des Mailehens und somit der Brauch als Ganzes angeprangert wurde (s. Kap. 3.6), trat nunmehr verstärkt der Akt der Mädchenversteigerung in einen Widerstreit mit anerkannten Moralvorstellungen der Kirchen- oder Gemeindebehörde ein.

Ein wirksamerer Kampf gegen das Mailehen erfolgte zwei Jahrzehnte später in den eben genannten Ortschaften. Die Begebenheit macht deutlich, daß ein personeller Wechsel in der Gemeindeverwaltung nach kurzer Zeit die Verhältnisse umkehren konnte. 1851 trug der neue Troisdorfer Gemeindevorsteher erfolgreich sein Anliegen beim ebenfalls neu eingesetzten Siegburger Bürgermeister vor mit dem Ergebnis, daß für den gesamten Amtsbezirk die Brauchausübung bei Geldstrafe polizeilich untersagt wurde. Als Anlaß für die Beschwerde wurden Exzesse beim Maiensetzen und Alkoholkonsum genannt. Vermutlich hat das Setzen von Schandmaien, die als Symbol für die Unehrenhaftigkeit eines Mädchens deutlich sichtbar von den Junggesellen vor das betreffende Haus plaziert wurden, den Unfrieden in der Gemeinde gestiftet. ${ }^{70}$ Die Annahme wird durch Gansen (1931:19) bestätigt, der auf eine Siegburger Polizeiverordnung von 1851 aufmerksam machte:

"Die Verordnung wies auch darauf hin, daß bei der öffentlichen Versteigerung für mißliebige Mädchen - dies seien gewöhnlich die sittsamsten, die keine Beziehung zu dieser Vereinigung [der Junggesellen; H.-W.W.] unterhalten wollten - entweder kein oder nur ein geringes Gebot abgeben würde, wodurch sie dem Spott und Hohn der Versammlung preisgegeben würden, ferner darauf, daß Mädchen durch das Anbringen der bekannten Spott-Maien (Häckselstreuen und dergl.) öffentlich herabgesetzt würden".

Das Verbot konnte dem Mailehen keinen endgültigen Einhalt gebieten, denn schon bald wurden "die alten Mailehenvereinigungen erneuert oder selbst eigene Vereine [der Junggesellen; H.-W.W.] gegründet, so im Jahre 1863 Maienlust zu SiegburgAulgasse". Gansen (1931:19), der diese Entwicklung verfolgt hat, stellt für die 1930er Jahre schließlich fest, daß diese Vereinigungen "allerwärts" in der Umgebung von Siegburg und Bonn zu finden sind.

Wie es scheint, hat die Säkularisierung nicht nur eine erhebliche Befreiung von kirchlicher Subordination, von rechtlich wie ökonomisch einengenden Hörigkeitsverhältnissen und Fronden bewirkt, sondern auch gleichzeitig die soziale Selbstbestimmung im kommunalen Verband belebt. ${ }^{71}$ Was die gezielte Abschaffung des

${ }^{70}$ Die Quellenlage zur Analyse des Schandmaiens charakterisiert Moser (1985:263) kurz und treffend: "Faktische Nachweise aus älterer Zeit sind noch selten". Einen frühen Beleg von 1630, den Klersch (1965,1:201) für Köln anführt, zieht er zu Recht in Zweifel. Im Zusammenhang mit dem Mailehen kann diese Form des Rügebrauchs erst im 19. Jahrhundert als gesichert gelten, wobei das Häckselstreuen oder Lindescheuern, worauf noch zurückzukommen ist, den Schandmaien anscheinend vorausging.

${ }^{71}$ Über das enorme Ausmaß dieses Wandels, der keineswegs geradlinig zur Errichtung einer modernen Gesellschaft führte, sondern mit vielfältigen Widerspruchsmomenten behaftet war, hat unlängst Doering-Manteuffel (1995:31-62) berichtet. 
Mailehens betrifft, so versagten zwar kirchliche oder weltliche Zwangsmaßnahmen seit dem 16. Jahrhundert in einer nicht näher zu bestimmenden Zahl von Fällen. ${ }^{72}$ Mit dem Beginn des 19. Jahrhunderts beeinflußt ein völlig neuer Gestaltungswille das Brauchgeschehen, woraus dem Mailehen zusätzlicher Auftrieb erwachsen konnte. Erkennbar wird diese Tendenz in der sich wandelnden Organisationsform eines Teils der Brauchträgerschaft. Die Umbildung eines in Zusammensetzung und Verhaltensregelung lockeren Verbandes von Jugendlichen - der in den Quellen selten geschlechtsspezifisch determiniert wird - hatte sich im 18. Jahrhundert Bahn verschafft und führte zu einer strafferen Bündelung, Hierarchisierung und Steuerung der ortsansässigen ledigen Männer. In seiner Führungs- und Exekutionsebene, in seinen Statuten und Kleidervorschriften imitierte der Junggesellenverein die imponierenden Präsentationsformen des Obrigkeitsstaats. Sicher wollte man damit das Ansehen und das Gewicht der Gruppe im Ort erhöhen. Höchstoffizielle Statuten in Kanzleisprache abgefaßt, Titel wie Maikönig, Präsident oder Schultheiß, dekorative, an Uniformen angelehnte Kleidungsstücke sowie feierliche, geordnete Festumzüge zeugen vom Abglanz der mächtigen Vorbilder. Die Kopie, der die Potenz des Originals symbolisch präsent ist, machte somit eine Übertragung der Machtfülle spielerisch und konkret erfahrbar. Genauer betrachtet, wirkt die Uniform oder die formelle Satzung wie ein Analogiezauber, der die Heranwachsenden in wichtige und einflußreiche Herren verwandelt. Für die imitierte Obrigkeit konnte dieses "magisch-ironische Spiel" gleichzeitig eine Anmaßung oder Parodie darstellen. Offensichtlich hat es sich aber erst nach dem Abtreten absolutistischer Landeshoheiten entfaltet.

Die vorhin benannten äußeren Insignien lassen über den gesteigerten jugendlichen Selbstbestimmungsanspruch hinaus noch andere Aspekte erkennen, die für die Beurteilung des Brauchwandels bedeutsam sind. Selbstgegebene Statuten mit verbrieften Rechten und Pflichten für die Mitglieder zeugen nicht nur formal von den Folgen der Alphabetisierung und dem damit einhergehenden Bildungszuwachs in den betreffenden strukturschwachen Regionen. Inhaltlich hinterläßt die vereinseigene Sammlung von Verhaltensvorschriften auch ein Bild von der tatsächlichen Brauchausübung. Bei der Analyse dieser verschiedentlich als "Mottekopp" bezeichneten Satzungen sollte der normative Charakter keinesfalls verdeckt werden. ${ }^{73}$

\footnotetext{
${ }^{72}$ Becker (1989:302) sieht im Zusammenhang des obrigkeitlichen Vorgehens gegen das Brauchgeschehen die Wirksamkeit des absolutistischen Machtapparats in Frage gestellt: "In Kurköln zeigt sich, daß der Staat im Zeitalter des Absolutismus, der uns in unseren Schulbüchern nach wie vor als beängstigend machtvoller Apparat dargestellt wird, in Bezug auf das Brauchtum eine geradezu erstaunlich anmutende Hilflosigkeit an den Tag gelegt hat".

${ }^{73} \mathrm{Vgl}$. zur neueren volkskundlichen Beurteilung von Burschenschaften den Aufsatz von Schwedt/Schwedt (1990:119-124), der auf eine Reihe ungeklärter Fragen zu den Problemen der Genese aufmerksam macht. Die Autoren halten Datierungen von Vereinen bzw. Vereinssatzungen vor das 18. Jahrhundert für ungeklärt. Sie bestätigen den deutlichen Aufschwung der Junggesellenvereine
} 
Für das 18. und 19. Jahrhundert liegen Statuten der Junggesellenvereine aus dem Bonner Vorort Impekoven (1793), ${ }^{74}$ aus Mayschoß an der Ahr (1850) ${ }^{75}$ und aus dem bergischen Lohmar (1878) ${ }^{76}$ in publizierter Form vor; das Körrenziger Junggesellenbuch von 1843 ist allerdings nur in Auszügen bei Meves (1912:139) abgedruckt. Allen gemeinsam ist, daß sie grundsätzliche Angaben zu den Modalitäten des Vereineintritts, zur konstitutiven Vereinshierarchie und zu den Rechten und Pflichten der Mitglieder beinhalten. Ein Mindestalter (17, 18 bzw. 20 Jahre) und eine Einstandsgebühr bei der Aufnahme eines neuen Mitglieds haben alle Vereine gefordert. In Impekoven wurden drakonische Strafmaßnahmen für diejenigen angedroht, die sich dem Verein entziehen wollten:

\footnotetext{
"Wan ein junger Bub wan er anfangt zu sehr hitzig zu werden und bei Nacht und Unzeiten auf Gassen und Straßen schwärmen und all Unheil und frevelntlich Vermessenheit alledieser ist den Junggesellen in Straf verfallen oder er muß achtzehn Jahr alt sein und dann Herrn Junggesellen den Einstand geben, sonst wan er wieder den Junggesellen in die Hände fällt, so ist er gewiß, daß er von den Herrn Junggesellen im Wasser bei der Nacht durch einen großen Weier auf und ab geschwämmet werden muß und in einem Zaunstecken aufgehenkt so werden ihm noch etliche Klabsen mit schwarzem Kirschbäumen Holz hinten auf den Stinker zugesetzt so wird er trocken werden und die große Hitz wird was nachlassen. Dies ist zu seiner Straf es muß aber vernünftig und mit Verstand traktiert werden ohne Unglücker" (Thomas 1979:268).
}

Auch wenn der letzte Satz die Schärfe der Strafmaßnahmen etwas zurücknimmt, so geht aus diesem Satzungsartikel klar hervor, daß unter dem Druck der Sanktionierung durch die Übermacht des Junggesellenvereins ein beachtlicher Zwang bestand, der die jungen Männer des Dorfes ausnahmslos erfaßte und der schließlich dazu führen sollte, daß sich die Betreffenden allesamt am Verein beteiligten. Weniger konformistischen Ortsangehörigen konnte mithin das Leben schwer gemacht werden. Immerhin legt die Satzung in diesem Beispiel nahe, daß es auch potentielle Widersacher des Junggesellenvereins, die ihre persönlichen Freiheiten behaupteten, gegeben hat und denen die angeführten Sanktionen gelten sollten. Die andern drei Statuten sehen von Zwangsmaßnahmen dieser Art ab.

im 19. Jahrhundert und sehen einen Zusammenhang zur Entwicklung des bürgerlichen Vereinswesens (Schwedt/Schwedt 1990:123). Im Hinblick auf die soziale Durchlässigkeit scheinen vor allem die Vereine des städtischen Kleinbürgertums den Junggesellen am nächsten gestanden zu haben, so wie sie für die berufliche Gruppierung der Handwerker eine Rolle gespielt haben. Lenger (1988:104) bemerkt dazu: "Handwerker, sangen, turnten, schossen oder lasen häufig mit Arbeitern, aber nur selten mit Kaufleuten oder Fabrikanten". Der Verein als bürgerliches Organisationsprinzip war somit nicht zwangsläufig an bürgerliche Interessen geknüpft. Sein Verbreitungserfolg gründete sicherlich gerade in dieser "Anwendungsoffenheit", wie Raschke/Opp de Hipt (1983:714) annehmen.

${ }^{74}$ Thomas (1979:268ff); vgl. auch die Kopie des Originals im volkskundlichen Archiv des Amts für rheinische Landeskunde in Bonn (T 170).

${ }^{75}$ Schwall (1922:52f).

${ }^{76}$ Zinzius (1925:45). 
$\mathrm{Da} ß$ der satzungsgemäße Verein Ämter und damit verbundene Aufgabenpositionen für einzelne Mitglieder heraushob und fixierte, bedeutete einen Verlust unformalisierter, möglicherweise egalitärer Strukturen einer vorangegangen, nicht näher spezifizierten Organisation von Jugendlichen. ${ }^{77}$ Die einzelnen Vorschriften haben die Organisation und Verfahrensweisen festgeschrieben und wirkten auf diese Weise einer bislang vorhandenen Spontaneität und Flexibilität entgegen, die in dem Prinzip der erinnerten Tradierung begründet waren. Die rechtmäßige Satzung konnte nun gegen die Erfahrung und das kommunikative Aushandeln von Verfahrensregeln angewandt werden. Wie erwähnt, wurde bereits an den Amtsbezeichnungen der hierarchische Aufbau des Vereins erkennbar. Es tauchten neben der wichtigsten Funktion des Schultheißen noch die der Schöffen, Schreiber, Gendarme, Polizeidiener, Aktuare und Advokaten auf. In Mayschoß und Lohmar wurden diese Dienstposten, mit denen besondere Rechte und Pflichten verbunden waren, versteigert. Was die gewöhnlichen Mitglieder betraf, so schrieben die Satzungen bestimmte Verhaltensregeln vor, die allgemein auf die Einhaltung von Disziplin und Ordnung abzielten. Pünktlichkeit und Vollzähligkeit bei Treffen, Unterordnung unter die Vereinshierarchie, Wahrnehmung von "polizeilichen" und sittenrichterlichen Tätigkeiten sollten von jedermann beachtet werden. Bei den Neulingen strich man die Notwendigkeit der Unterordnung besonders heraus:

"Wann ein junger ankommender Bub oder Jüngling sich das erste mal zu der Gesellschaft der Junggesellen verfüget ein Mai-Lehen zu holen und auf den Tanzboden kommt sich lustig zu machen, so muß er von einem jeglichen Junggesellen in aller Ehrbarkeit instruiert und aufgemuntert werden. Weil er noch blöd und furchtsam ist, und er muß sich auch gefallen lassen, den jüngellen untertänig zu sein und dem Herrn Schultheiß und ganzer Gesellschaft als Bote zu bedienen bis wieder ein neuer zukommt so ist er wie die Anderen" (Thomas 1979:269).

Mit dem ersten Jahr als dienendes Mitglied im Impekovener Junggesellenverein erwarb man sich für die Folgezeit das Recht, von den jeweils neu aufgenommenen Junggesellen bedient $\mathrm{zu}$ werden. Durch diese Regelung sollte das hierarchische Prinzip sinnfällig auf jede Altersstufe appliziert und in fortwährender Rotation tradiert werden.

Zur formalen Aufnahmeprozedur der neuen Mitglieder gehörten mancherorts nicht nur die Einstandszahlungen, sondern auch festgelegte, einer Initiation vergleichbare Rituale. Freyaldenhoven (1914:252) hat die im letzten Drittel des 19. Jahrhunderts bereits aufgegebenen Praktiken im Jülicher Lande als "verschiedenste, oft recht sonderbare Zeremonien" bezeichnet. Präziser führt dazu Meves (1912:139) aus:

${ }^{77}$ Schwedt/Schwedt (1990:123) verweisen auf "ein diffuses Bild" von der Entwicklung burschenschaftlicher Organisation. Ihre Annahme, daß "für sehr informelle, ephemere Zusammenschlüsse die Ausbildung einer Ordnung mit unterschiedlichen Positionen [zweifellos] anzunehmen sein [wird], wenn eine solche Gruppierung überhaupt einen für irgendwelche Aktivitäten erforderlichen Integrationsgrad erreichen soll", führt zu der Frage, wie diese "Positionen" qualitativ zu beurteilen sind. 
"Alsdann soll er [der Neuling; H.-W.W.] sich den Bart barbieren und sich dazu eines Barbierzeugs der besten Art bedienen".

Was unter "Barbierzeug der besten Art" zu verstehen ist, hat der Berichterstatter offengelassen. Möglicherweise ging es hier um einen ganz ähnlichen Vorgang, wie er in einer Antwort auf den Rheinischen Fragebogen von 1922 für den Ort Bengen geschildert wurde:

"Nach dem Maisetzen am 30. April abends zogen die Jungen nach dem Wirtshaus. Dort wurden die Jünglinge unter $18 \mathrm{Jhr}$ verhanst (aus Hänschen wurde Hans) d.h. sie wurden für würdig befunden mit der Gesellschaft zu verkehren. Das ging folgendermaßen: Mit Ruß wurde ihr Gesicht geschwärzt und mit einer alten Sense oder Häbe rasiert. Als Spiegel diente ein Deckel vom Feuerloch des Ofens. Der Bart? [sic] kam in einen großen Korb. Das war keine angenehme Prozedur. Vor dem Verhansen durfte sich keiner abends auf der Straße sehen lassen ohne verhauen zu werden (Nach dem Kriege nicht mehr gemacht.)". ${ }^{78}$

Die "Junggesellentaufe", die oft eine starke psychische und physische Belastung für die Initianden bedeutete, wurde einseitig auf dem Rücken der Neulinge ausgetragen. Alle übrigen Junggesellen ergötzten sich zumeist an dem Schauspiel. Dieser Aufnahmebrauch zeigt ebenso wie die unten folgenden Verhaltensvorschriften, die den Junggesellen durch die Statuten auferlegt wurden, die Nähe zu rituellen Handlungen innerhalb der städtischen Handwerker- und Kaufmannsgilden. ${ }^{79}$ Bei einem solchen Vergleich muß allerdings in Rechnung gestellt werden, daß ein streng gehüteter Ehrenkodex einer berufsständischen Vereinigung - vor dem Hintergrund einer ökonomisch sinnvollen Strategie - mehr Gewicht erlangte ${ }^{80}$ als die unbeständigen spielerischen Nachahmungen der Junggesellen.

Gegenüber den Aufnahmebräuchen dienten eine Reihe der niedergeschriebenen Verhaltensvorschriften zur allgemeinen Belustigung und im Übertretungsfall durch den Einzug von Strafgeldern der Aufbesserung der Vereinskasse. In den Impekovener Statuten von 1793 beziehen sich die Handlungsanweisungen vor allem auf eine ordnungsgemäße Pflege geschlechtlicher Beziehungen; sie unterstützen damit die Paarbildungsfunktion des Mailehens:

"erstens, wenn einer bei seinem Lehen seine richtige Schuldigkeit nicht getan hat. Dies muß er auf ein sechs Stüber Kümpchen Branntwein gestraft werden. zweitens, wenn einer den anderen bei seinem Lehen 'drappiert' hat, daß ist ein Pint Branntwein Strafe und so weiter. drittens, wenn die Schloß der Fenster nicht im Stand und Riegel gehalten werden, daß die Spinnen in das Loch gebaut haben und sich mit allerhand Unreinigkeit befindet [...] so ist derjenige der das Mägtel für ein Lehen hat dem Gericht in ein sechs Stüber Kümpchen Branntwein Straf erfallen. Wieder weiß sich hier jeder vor solcher Verwüstung zu hüten, daß er sein Lehen besser in

\footnotetext{
${ }^{78}$ Vgl. Seminar für Volkskunde Bonn: Rheinischer Fragebogen Nr.: 1665, Ort Bengen (Kr. Ahrweiler).

${ }^{79}$ Vgl. auch die Nähe des Junggesellenvereins zu den Regularien und Ritualen studentischer Verbindungen bei Weber-Kellermann/Stolle (1971:104f) oder Steuten (1998:156-186).

${ }^{80}$ Vgl. Lenger (1988:14f) und Zerwas (1990:33-40).
} 
Stand hält. viertens, wenn einer seinem Lehen im Bösch, Feld oder Weingarten aufhebt und küsst es nicht, wenn das dann nun stimmte oder nicht, uns hierüber Klagen kommen, so ist, daß er im Rückstand zum Schlappmachen in die gerichtliche Straf erfallen auf ein halb Pint Branntwein wenn es mit sicherem Beweis geklagt wird. Es muß aber ein Plappermäulchen, weil es gesehen hat uns auf Beweis dem Mägtel in dieser beschwerlichen Ursach behilflich sein" (Thomas 1979:280f).

Die deutlichen Anspielungen auf eine ungezügelte Sexualpraxis der Brauchträger waren von einer konkreten Umsetzung weit entfernt. Sie entsprachen einer männlichen Verarbeitung der Differenz von normativen Verhaltensschranken und unausgelebten Sexualphantasien, wie sie sich vielfach auch in anderen Bereichen, z.B. skatologischen Witzen und Liedern, äußern konnte. ${ }^{81}$ Zusätzlich zum mailehenspezifischen Verhaltenscode, wie er hier deutlich wurde, enthält das jüngere Lohmarer Statut Artikel, die trotz ihres zweifelhaften Ernstes auf die berufliche Lebenssituation der Junggesellen im Bereich Landwirtschaft und Handwerk verweisen:

"Art. 8. Wer im Felde mit einem Pferde arbeitet, muß des Mittags beim Glockenschlage abspannen.

Art. 9. Wer sein Pferd hinaus- oder hereinbringt, muß Schoß reiten, pfeifen oder singen.

Art. 10. Jeder Handarbeiter muß sein Werkzeug nachschleppen, und darf es nicht tragen" (Zinzius 1925:45)

Ein letztes Beispiel aus Brück, ein Ort in unmittelbarer Nähe zu Köln, markiert die Spitze der Absurdität derartiger Vorschriften:

"§ 12. Keiner darf seine Notdurft gegen den Wind verrichten" (Klein 1909:134). ${ }^{82}$

Wenngleich es sich hier um ausgelassene Späße der Junggesellen handelte, so konnte durch das Aufstellen und Befolgen von derartigen Sonderregeln das Gruppengefühl zusätzlich bestärkt werden. ${ }^{83}$

Darüber hinaus sind die Bestimmungen über Versteigerung, Kommabende und Mailehenpaare zu erwähnen, die ebenfalls statuarisch festgehalten worden sind. In Mayschoß war es üblich, vor der Versteigerung eine "Taxe" des Ansteigerungspreises festzulegen. Damit sollte verhindert werden, daß die ehrenvollen Ämter zu Schleuderpreisen an die Junggesellen fielen. An einer Funktionsübernahme konnten gleichzeitig Prestige und Privilegien geknüpft sein. Hierunter fiel die freie Wahl eines Mailehens:

81 Zur vorehelichen Sexualität vgl. Beck (1983:139-141), Westphal (1988:118-122) und zur "sexual lore" Lövkrona (1993:270-279).

${ }^{82}$ Eine genaue Datierung der Brücker Vereinsstatuten geht aus der Abhandlung von Klein (1909) nicht hervor.

${ }^{83}$ Eine vergleichbare Funktionsweise wird den Ritualen studentischer Verbindungen zugeschrieben (Steuten 1998:181-186, Lucius 1990:376 und Schümann 1990:383). 
"Und der Schultheiß hat auch die Freiheit das beste Mägtel für seine Lehe zu nehmen frei und frank unentgeltlich was ihm am besten gefällt" (Thomas 1979:275).

Ebenso schrieb die Satzung vor, daß der Ersteigerer von seinem Mailehen zu akzeptieren sei, andernfalls habe das abweisende Mädchen bei den Tanzveranstaltungen mit empfindlichen Strafen zu rechnen. In Lohmar und Mayschoß wurden diese Sanktionen verschärft, indem man die nicht willfährigen Mailehen vom Tanz vollkommen ausschloß. Die Impekovener Vereinsrichtlinien gestatteten immerhin noch den Tanz mit Vereinsmitgliedern. Einer Demütigung, die in der Zurückweisung eines Ersteigerers zu erkennen ist, versuchten die Junggesellen am wirkungsvollsten dadurch vorzubeugen, daß sie die potentiellen Vergeltungsmaßnahmen satzungsgetreu - also mit der Gewalt des Kollektivs - androhten. Der Zusammenhalt der Junggesellen untereinander und das zu erwartende Tanzverbot machten es den unorganisierten Mädchen nicht leicht, ihre Vorstellungen gegen die des Vereins durchzusetzen. Demgegenüber räumte die Lohmarer Satzung den Junggesellen explizit das Recht ein, nachträglich von ihren Mailehen Abstand nehmen zu dürfen. Der entsprechende Artikel lautet:

"Wenn einem Mitgliede das angekaufte Mailehen nicht mehr zusagt, so hat er demselben durch den Pieler einen Strauß zuzusenden; es ist dadurch unter Verlust des Kaufgeldes von demselben entbunden" (Zinzius 1925:45).

Die Dominanz der Männer über die Frauen tritt in den hier besprochenen Quellen beständig hervor. Die Junggesellen verfügen darin nicht nur über die Dorfmädchen, sie bestimmen auch über weibliches moralisches Ansehen, indem sie unzüchtiges Verhalten zum Thema ihrer sittenrichterlichen Urteilskompetenz machen. Im Mayschoßer Statut wurden ausnahmsweise einmal dieselben Rechte für beide Geschlechter postuliert:

"Sollte jemand aus unserer Gesellschaft sich gegen die Sittlichkeit verfehlen, so wird er aus derselben ausgeschlossen. (Ein 'gefallenes' Mädchen kommt nicht zur Versteigerung.)" (Schwall 1922:53).

Dennoch darf diese formale Egalität nicht dazu verleiten, die Hürden geringzuschätzen, die bei der Einforderung derartiger Bestimmungen zu überwinden waren. Denn es muß berücksichtigt werden, daß die Junggesellen die entscheidenden Anteile an Legislative, Judikative und Exekutive der sittenrichterlichen Gewalt stets in ihren Händen hielten. Auf der Frauenseite mangelte es an einer vergleichbaren Bündelung weiblicher Interessen durch eine vereinsmäßige Organisation. ${ }^{84}$ Die Mädchen waren somit in viel stärkerem Maße auf sich selbst und ihr unmittelbares soziales Umfeld

${ }^{84}$ Hierzu Wikmann (1937:35f), Lipp (1990:37,40), Schwedt (1999:160f) oder Schindler (1996:336339) Daneben vermerkt König (1990:XXXI) kritisch: "Daß die Frage der Frauenbünde so schwer zu belegen ist, hat unter anderem damit $\mathrm{zu}$ tun, daß es auch zu diesem Problem bisher kaum Untersuchungen gibt". 
(Elternhaus) gestellt. Wie Doppelmoral und Interessenpolitik der Junggesellen sich in Impekoven in den Satzungen niederschlagen konnten, zeigt folgende Stelle:

"Jungfern zu Fall bringen ist keine Kunst doch schimpflich und schändlich. Wenn sie sich aber selbst darnieder legen ists commod und gemächlich. Dann tun sie auch den harten Fall nicht und sind selbst Schuld daran, dafür hat eine jede sich zu hüten" (Thomas 1979:285).

Wie konnte sich ein solches Ungleichgewicht Raum verschaffen und hartnäckig bestehen bleiben? Hätten die Betroffenen im Schulterschluß mit Gleichgesinnten und sich solidarisierenden Parteien nicht sichtbar gegen derartige Auswüchse ankämpfen müssen? Denkbar ist, daß die Junggesellen - wenn überhaupt - nur äußerst zurückhaltenden Gebrauch von ihrer satzungsgemäßen Gewalt machten und dadurch nur wenig Angriffsfläche boten. Der Eindruck, der zum Teil über die Kontrollfunktionen der Burschen erweckt worden ist, bedarf zumindest für die hier angesprochenen Fälle einer Korrektur. Die Stellung der ledigen Burschen wurde gesellschaftlich dadurch gefestigt, daß sie die Bereitschaft zeigten, Aufgaben bzw. Dienstleistungen von allgemeinem Interesse (etwa die Ausrichtung von Dorffeiern und Tänzen) zu übernehmen. Hierzu konnten z.B. auch öffentliche Rügepraktiken gezählt werden. ${ }^{85}$ Abwegig ist es aber, daß die Ausnahmesituation der Rüge zu der stets präsenten und willkürlich handhabbaren Verfügungsgewalt über ein Disziplinierungsinstrument der männlichen Jugend hätte führen können. Die Jugendlichen agierten in dem sozialen Spannungsfeld ihres nächsten Umfeldes. Es existieren keine Anhaltspunkte dafür, daß die statuarischen Anleitungen zur Devianz außerhalb des Vereins gebilligt wurden. Dort, wo sie als Spaß erkannt werden konnten, hat man sie sicherlich jovial übergangen. Dort, wo sie ungerechtfertigt erscheinen mußten, wird man den Grenzüberschreitungen ein Ende bereitet haben. ${ }^{86}$

Ob der Einfluß der Junggesellen auf die jeweiligen vorehelichen Paarbeziehungen auf dörfliche Zustimmung stieß, läßt sich für den Einzelfall schwer entscheiden, aber die Verbreitung und der allgemeine Stellenwert, der den Aktionen zufiel, deutet auf eine weitreichende Tolerierung hin. Prekär war die Situation, wenn Jungen aus Nachbardörfern sich mit Mädchen einlassen wollten. In einem solchen Fall war es üblich, daß der Dorffremde sich bei den Junggesellen die Erlaubnis zum Freien erkaufen mußte, wenn er einer langwierigen aggressiven Konfrontation entgehen wollte. Auch hierzu geben die Satzungen Auskunft:

"Zu wissen ist, daß allhier bei uns Junggesellen zu Imppenkoffen bräuchlich ist, wenn ein Fremder oder auswärtiger Junggesell oder Wittmann eine Jungfer hier aus dem Dorf karessieren will, so muß er sich gefallen lassen mit dem Anfang bei den Imppenkoffer Junggesellen

${ }^{85}$ Vgl. z.B. Schwedt (1999:161).

${ }^{86}$ Die Ausführungen von Hinrichs (1991:450-462), die insbesondere das süddeutsche Haberfeldtreiben beleuchtet haben, zeigen, daß der Bereich des Rügebrauchs in seiner historischen und sozialen Verortung noch intensiver Forschungsarbeit bedarf. 
durch Gunst und guter Freundschaft, mit Respekt und Gebührlichkeit, durch einen mäßigen Trinkpfennig oder Ehrtrunk zu Frieden stellen und sich einen freien Weg und Zugang ohne Hindernis die Freiheit nehmen darf weil viele Berge und Hügel sind und Pfähle sich hier befinden, wo man leicht über straucheln und fallen werden kann, weil es dem Fremden und Auswärtigen unbekannt und fremd ist [...] Hat dieser Fremde [...] aber zu viel stief Jög in seiner Kleidung, so muß solches mit dem schmücken von Holz, worauf die Nachtigall etliche Jahre lang ihre liebliche Musik drauf gesungen hat, das stief durch schlapp gekloppt werden, damit ihm die Kleider an seinem Leib bequemer werden, daß hat er dann seinem Schneider oder Kleidermacher zu danken. Durch diese Veränderung wird der Mensch auch manierlicher wenn er zum zweiten mal kommt, so müssen sich die Junggesellen mit höflicher reverenz melden lassen vor ihnen zu erscheinen" (Thomas 1979:283).

Das Weichklopfen der Kleidung ist die ironische Umschreibung für die Tracht Prügel, mit der ein auswärtiger Eindringling zu rechnen hatte, wenn er die verlangte Erkenntlichkeit gegenüber den eingesessenen Junggesellen vermissen ließ.

Die Überwachung der ortsinternen Mailehenbeziehungen zog ebenfalls Sanktionen nach sich. Pflichtgemäß wurden Besuchsabende festgelegt, d.h. sogenannte "Kommovende", bei denen der Junggeselle zu geregelten Zeiten bei seinem Mailehen erscheinen mußte. Die Pflichterfüllung wurde durch eingesetzte "Gendarmen" kontrolliert und Zuwiderhandlungen zumeist mit Geldstrafen belegt. Gleichfalls wurde Wert darauf gelegt, daß ein Junggeselle ausschließlich bei seinem eigenen Mailehen ans Schlafzimmerfenster ging (Thomas 1979:280f und Zinzius 1925:45).

Einen soliden Einblick in die wichtigsten Brauchabläufe im 19. Jahrhundert gewährt Laven (1834). Er hat sich als Kenner des Saargebietes ausgewiesen und hinterließ in der Tat eine sehr detaillierte Schilderung des Lehenausrufens in Saarhölzbach. Obwohl der Brauch in Variationen im gesamten saarländischen Raum vertreten ist, hält Laven die Auswahl eines Dorfes für gerechtfertigt. Die Ausgestaltungen des Lehenausrufens und die allgemeinen lokalen Verhältnisse seien besonders typisch und hätten eine Ausbreitung von hier wahrscheinlich gemacht (Laven 1834:ohne Paginierung). Nach der Beschreibung fügte sich das Lehenausrufen aus folgenden Teilen zusammen:

- Ausrufen der Lehen durch die Burschen am Abend des Sonntags vor Fastnacht (sogenannter Lehn-Sonntag);

- Tanzveranstaltungen zu Fastnacht;

- Marktbesuch in Mettlach;

- weitere Gelegenheiten zum Besuch von Tanzveranstaltungen.

Am "Lehen-Sonntag" versammelte sich nahezu das gesamte Dorf im Tal. Die Jungen bildeten zwei Gruppen und erkletterten zwei gegenüberliegende Hügel. Von dort aus wurden die Lehenpaare durch einen markanten, immer wiederkehrenden wechselseitigen Spruch ausgerufen. Laven (1834:ohne Paginierung) schildert den Vorgang folgendermaßen: 
"Die Abtheilung auf dem Bachberge beginnt; es ruft Einer von ihnen Denen auf dem Funkenberge zu: Ich geb', ich geb'! Die Funkenberger antworten: Gieb wem du willst! Jetzt schreit die erste Abtheilung ihnen den Namen des ältesten Burschen zu. Nachdem Die auf dem Funkenberge den Namen deutlich vernommen haben, berathen sie sich, welches Mädchen sie ihm bestimmen sollen. Während Dessen herrscht im Dorfe tiefe Stille; die Plaudermäulchen, die bisher vielleicht noch nicht ruhig gestanden haben, schweigen nun, denn es geht um Eine von ihnen. Jetzt erschallt der verhängnisvolle Name des Mädchens von der Höhe her und nach ihm der Ruf: Dies Jahr zum Lehn, Das andere Jahr zur Eh'!".

Alle zur Verfügung stehenden Jungen und Mädchen wurden nach diesem Verfahren zu Paaren vereint. ${ }^{87}$ Bemerkenswert dabei ist, daß die Mädchen ein einmaliges Einspruchsrecht besaßen, wenn ihnen ihr zugeteilter zukünftiger Tanzpartner nicht zusagte. In einem solchen Falle erschallte der Einspruch des Mädchens: "Es ist Nichts, es ist Nichts! und das ganze Dorf stimmt ein" (Laven 1834: ohne Paginierung). Es erfolgte dann ein zweiter Vorschlag der Burschen, den das Mädchen unweigerlich hinnehmen mußte. Aufschlußreich an dieser Stelle ist ein direkter Vergleich zur Situation des Lehenausrufens im Eifelort Einruhr (Kreis Schleiden). Gierlichs (1895:361f) beschreibt die Schwierigkeit, unter der ein gewählter "Hauptjunge" und seine beiden Gehilfen die Zusammenstellung der Paare vornehmen müssen wie folgt:

"Wer weiss, wie eifersüchtig in einem Bauerndorfe jeder auf seinen Rang ist, kann sich eine Vorstellung von der Wichtigkeit und Schwere dieses Amtes machen. Da gilt es wohl zu überlegen, ober [sic] dieser oder jener Jüngling zu dieser oder jener Jungfrau nach Stand und Rang passt. Dass dabei auch auf gegenseitige Neigung Rücksicht genommen werden muss, ist selbstverständlich".

Der Fall aus Einruhr wirft ein anderes Licht auf die Zusammenführung der Mailehenpaare. Spannung und Heiterkeit, die in Saarhölzbach die Atmosphäre des Lehenausrufens beherrschten, werden hier merklich von der Problematik der Entscheidungsfindung überschattet. Der Status- oder Prestigegewinn für die Burschen, der in der Entscheidungsmacht liegt, erfährt durch den Beobachter eine wichtige Präzisierung. Nicht Willkür und Ausgelassenheit, sondern besonnenes Abwägen und Verantwortungsgefühl für die soziale Balance des Dorfes stehen bei Gierlichs im Vordergrund.

Wie bereits angeklungen, sieht Laven die Tanzpartnerschaft neben dem hohen allgemeinen Unterhaltungswert als die wesentliche Funktion des Brauches an. Die Zusammengehörigkeit des Tanzpaares war in der Regel auf ein Jahr festgelegt, bis dann durch erneutes Lehenausrufen neue Konstellationen entstehen konnten. Manches Mal unterblieb der Brauch jedoch aufgrund ungünstiger lokaler Verhältnisse; Laven denkt hier an Zeiten der Mißernte und Folgen wirtschaftlicher Bedrückung, die der

${ }^{87}$ In den Grundzügen des Ausrufespruchs stimmt der Brauch mit dem zur gleichen Zeit in der Grafschaft Ziegenhain geübten Lehenausrufen überein (Landau 1840:274f). Für die Schwalmer Gegend siehe Lange (1895:70f). 
Bevölkerung die Freude am Feiern nehmen konnte. ${ }^{88}$ Die Fastnachtszeit war ein wichtiger Termin für die Lehenpaare, weil an diesen Tagen häufig getanzt und das alltägliche Geschehen vielerorts außer Kraft gesetzt wurde. Dies zeigt sich auch darin, daß die Mädchen für ihre zugeteilten Burschen große Brezeln gebacken hatten, die während eines Treffens am Fastnachtssonntag im Wirtshaus gemeinsam verspeist wurden. Obwohl bereits die asketische Fastenzeit ihren Einzug gehalten hatte, war selbst zu diesem Zeitpunkt das Tanzen ein mehr oder weniger geduldeter Programmpunkt der Heranwachsenden.

Vor dem Hintergrund des reziproken Tauschgebotes hat Laven es als notwendig erachtet, daß die Brezelgabe der Mädchen von den Jungen erwidert werden mußte. Unverzichtbar war deswegen der Kauf von silbernen Ringen oder Schmuckbändern auf dem großen Mettlacher Markt, der am Sonntag nach Christi Himmelfahrt stattfand. Die sozialen Beziehungen der Tanzpartnerschaft erhielten auf diese Weise einen materiellen Ausdruck im Gabentausch. Von einer vergleichbaren brauchmäßigen Zirkulation von Waren im Zusammenhang mit sozialer Beziehungspflege war bereits bei Weinsberg (s. Kap. 2.3) die Rede. ${ }^{89}$ Die solchermaßen geknüpften Verbindungen konnten in ihrer Bedeutung noch gesteigert werden, indem sie tatsächlich zur Eheschließung eines Lehenpaares führten. Laven (1834: ohne Paginierung) bemerkt: "daß viele Paare sich wirklich mit einander verheirathen [...]".90

Ein zweites Beispiel gibt Laven uns aus dem Pfarrort Nalbach, der ebenso im Saargebiet liegt. Er trifft hier auf den Mädchenraub als eine äußerst ungewöhnliche Form der Zusammenfügung der Lehenpaare. Am Tage des Kirchweihfestes rissen sich die betreffenden Burschen beim Verlassen des Gottesdienstes um ihr auserwähltes Mädchen. Der Autor berichtet über tumultartige Zustände im Kirchenraum, die 1826 durch diese Verfahrensweise ausgelöst wurden: "Mehrere (stürmten) zugleich auf ein Mädchen, das sich durch seine Schönheit vor allen andern auszeichnete". ${ }^{11}$ In einem

\footnotetext{
${ }^{88}$ Siehe oben (Kap. 2.3) den Hinweis bei Weinsberg über die zeitweilige Aufhebung der Brauchpraxis. Vgl. auch die hessischen Verhältnisse, die Schulte $(1902: 68,70)$ beschrieben hat. Es war nicht ungewöhnlich, daß die Feierlichkeiten kleinerer ländlicher Ortschaften über mehrere Jahre ausgesetzt wurden. Mit den Festen waren soziale Verpflichtungen gegenüber den Verwandten und dem Freundeskreis verbunden, die z.B. in kostspieligen Bewirtungen bestehen konnten. Auch aus den zeitlich vorangegangenen landesherrlichen Bestimmungen sind wir über eine stattliche Anzahl von Geboten zur Mäßigung bei gemeinschaftlichen Feiern (Taufe, Hochzeiten, Kirmes, Begräbnisse) unterrichtet, die im vorrevolutionären Deutschland vielfach durch "Lokal-Polizei-Verordnungen" erneuert wurden (z.B. Scotti 1832 siehe Nr. 332 und Nr. 806; Vollständige Sammlung... 1771-72 siehe 434. Stuck; Sammlung Erzdiozöse Köln 1837:16f, 127f und Pfeilstücker 1841: Anhang S.8, 17f).

${ }^{89}$ Gaben oder Dienstleistungen, zu denen sich die Mailehen dem anderen gegenüber verpflichtet sahen, werden zwar hin und wieder genannt, jedoch nicht immer in der hier vorgefundenen ausgewogenen reziproken Tauschform (vgl. z.B. Schmitz 1856-58, 1:49).

${ }^{90} \mathrm{Zu}$ den Hintergründen der ehestiftenden Funktion des Mailehens s. Kap. 3.3 und 4.4.1.

${ }^{91}$ Die Exzesse, die Laven im 19. Jahrhundert beim Nalbacher Mädchenraub beobachtete, wurden abgestellt (Zewes 1924:76). Die aus dem Gottesdienst kommenden Jungen und Mädchen mußten sich
} 
oberhessischen Dorf, dessen Name leider nicht mehr angegeben werden konnte, findet sich das Nalbacher Paarbildungsprinzip in Abwandlung wieder. Austragungsort war hier nicht die Kirche, sondern eine Scheune, in der sich Jungen und Mädchen in zwei langen gegenüberliegenden Reihen aufstellten. Nachdem das vereinbarte Signal gegeben worden war, stürmten die Burschen auf die jeweils Auserwählte los, und wer als erster ihre Hand $\mathrm{zu}$ fassen bekam, hatte sie als Tanzpartnerin für die bevorstehenden Kirmestage gewonnen. Auch hier hat der Berichterstatter die "häßlichen Auftritte" als Folgen eines grotesken Rituals beklagt (Schulte 1902:72).

Schließlich stieß Laven auf die Eifeler Variante der Mailehenversteigerung. Im Falle von Niederzissen (Kreis Ahrweiler) versteigerten die im Wirtshaus versammelten Burschen am Maiabend (30. April) die Mädchen. Der Versteigerungserlös wurde offensichtlich unmittelbar in Getränke umgesetzt. Zudem wurden den Mädchen an diesem Abend noch Maien gesetzt. Auch in Niederzissen bewirkte die Mailehenschaft eine Tanzpartnerschaft auf ein Jahr, wobei Laven betont, daß der Ersteigerer nur das Recht auf den ersten Tanz hatte. Gleichzeitig taucht in der Schilderung das Brauchelement des Kommabends auf, bei dem der Junggeselle am Samstagabend sein Mailehen für eine Stunde besuchen mußte. Bemerkenswert sind die Brauchaktivitäten der Mailehenpaare zum Jahreswechsel; sie finden sonst in der Literatur keine Erwähnung. An Neujahr hatte jeder Junge einen musikalischen Beitrag zur Ehre seiner Auserwählten zu erbringen. Außerdem war dieser Tag wieder Anlaß für gemeinsamen Tanz. Aus dem Quellenmaterial stechen in diesem Kontext besonderer Ausprägungen des Mailehens die Aktionen am Dreikönigsabend hervor:

"[...] die Mädchen (bilden) aus ihren Mitteln eine Kasse, dingen sich Spielleute, zieren sich mit Lorbeer und Bändern und durchziehen unter lautem Jubel und Singen das ganze Dorf. Vor den Häusern, worin die Burschen wohnen, wird angehalten, man dringt hinein und nimmt die Tänzer ab. So wälzt sich der Haufen, immer größer werdend, voran. Manchmal verstecken sich jedoch die spröden Liebhaber in den Scheunen und auf den Heuböden, dann sind die Mädchen gezwungen, das Haus zu durchsuchen, bis sie den Schalk aus seinem Schlupfwinkel hervorzieh'n" (Laven 1834: ohne Paginierung).

Die Stelle ist für die Aufarbeitung der Mailehengeschichte, aber auch für die historische Rekonstruktion der jugendlicher Lebensweise bedeutsam,,${ }^{92}$ weil sie sicher und in angemessener Weise belegt, daß die jungen Frauen nicht zwangsläufig die Rolle der schüchternen, passiven Erdulderin des Brauchgeschehens übernehmen mußten. Hier wird sichtbar, daß sie Mädchen durchaus als Brauchträgerinnen angesprochen werden können. Das Erleiden von rituell abgesicherten Demütigungen durch die

nunmehr in entsprechender Reihenfolge links und rechts vor das Kirchenportal geordnet aufstellen. Diejenigen, die sich Gesicht zu Gesicht gegenüberstanden, wurden zu Mailehenpaaren.

${ }^{92}$ Vgl. Fn. 84. 
Burschen stand sicher nicht nur den Mädchen in Niederzissen fern, sondern auch andernorts; auch dann, wenn uns hierüber die Quellenlage im Ungewissen läßt. ${ }^{93}$

In Ergänzung zu den geschilderten Möglichkeiten, über das Mailehen Tanzpaare zu ermitteln, muß noch die Verlosung erwähnt werden. Schulte (1902:70f) hat davon gesprochen, daß die Mädchen "herausgespielt" worden seien und gab diese Zuteilungsform als die ursprüngliche an. Dies geschah in der Weise, daß die Namen aller in Frage kommenden Burschen und Mädchen jeweils auf einen Zettel notiert wurden. Sortiert nach Geschlecht wurden diese als Lose in zwei Gefäße gegeben und gemischt, bevor man nach und nach die Paare durch die Ziehung der Lose ermittelte. Allerdings schienen auch hier die Mädchen sich nicht immer ihrer schicksalsmäßigen Bestimmung willenlos fügen $\mathrm{zu}$ wollen. Sie konnten im nachhinein selbst ihren Namen von der öffentlich ausgehängten Liste der zugeteilten Paare streichen, wobei sie jedoch dann die Strafe des Tanzverbotes auf sich zogen. Ganz ausweglos schien die Situation dennoch nicht zu sein, wie Schulte (1902:75) bemerkt:

"Die Klugheit der Evastöchter bringt es übrigens zu Wege, auch ohne dieses Ausstreichen geheimen Wünschen Rechnung zu tragen. Tauschen ist erlaubt, und so wird für das Nötige gesorgt".

Die Differenz von gesetzter Norm und trickreicher Praxis wird an diesem Beispiel sehr deutlich. Aus meiner Sicht müssen auch andere Fälle, wie z.B. der statuarisch festgelegte Ausschluß der Frauen durch die Junggesellenvereine in Lohmar, Mayschoß und Impekoven (s. oben), auf dieser Grundlage bewertet werden.

Mit der Beschreibung des saarländischen Lehenausrufens und des Mailehens aus der Eifel und aus Hessen konnten die wesentlichen Züge des Mailehenbrauchs festgehalten werden. Auffallend ist, daß die vorkommenden BrauchträgerInnen allesamt als eine lose Vereinigung der Dorfjugend gekennzeichnet wurden. Junggesellenvereine mit ihren straffen Organisationen tauchen noch nicht auf. Es kommt lediglich $\mathrm{zu}$ einer personellen Aufgabenverteilung, dort wo sie unabdingbar notwendig ist. So tritt kurz vor Beginn des Saarhölzbacher Lehenausrufens ein Junge hervor, der in besonderem Maße dazu geeignet erscheint, die Menge zum Stillschweigen $\mathrm{zu}$ bewegen. Bei der Niederzissener Mailehenversteigerung heißt es schlicht: "Einer aus ihrer Mitte wird zum Einnehmer ernannt" (Laven 1834: ohne Paginierung). Der erwähnte Mädchenraub in Nalbach konnte auf etwaige "Führungspositionen" vollkommen verzichten. Ganz ähnlich verhält es sich bei der Brauchausübung in den oberhessischen Dörfern und in den Regionen des Vogels-

${ }^{93}$ Vgl. auch die flüchtige Notiz von Schmitz (1856-58, 1:49) über den Brauch in Faidt (Kr. Cochem), der es am zweiten Kirmestage den Mädchen erlaubte, die Jungen zum Tanz auszuwählen. Der Autor faßte diese Angaben unter die Rubrik Mädchenversteigerung, ohne daß er den Zusammenhang deutlicher gemacht hat. Siehe ferner über den Realitätsgehalt geschlechtsspezifischer Stereotypen, der durch solche Belege relativiert werden muß (Wey 1999:316-318). 
bergs, wobei Schulte (1902:68ff) die Dominanz der Burschen gegenüber anderen BrauchträgerInnen hervorgehoben hat. In einigen Orten seien aber bereits die Burschen von den Gastwirten bei der Organisation der Kirmes abgelöst worden.

Auf den hierarchischen Vereinsaufbau, den die eingangs erwähnten Statuten festhalten, stößt man erst bei Schmitz (1856-58, 1:32-33, 48-49). Für die Ahrgegend und den Ort Blankenheim in der Eifel benutzt er den Begriff "Innung", um die Gruppe der männlichen Brauchträger zu bezeichnen. Hier seien auch die Ämter des Schultheißen, Schöffen und Schreibers geläufig. Einen vergleichbaren Organisationsgrad fände sich außerdem noch in anderen Orten der Eifelgegend, so z.B. in Ulmen und Gerolstein.

In den gemeinnützigen und unterhaltenden Rheinischen Provinzialblättern erschienen 1836 mehrere anonym verfaßte Leserbeiträge, die von einer kleinen Notiz über das Mailehen im Eifelort Ulmen angeregt wurden (Anonymus 1836a:122f, 1836b:3-5 und 1836c:82-86). Es wurde beobachtet, daß die Versteigerung in der Bonner Gegend gewöhnlich nach einer vereinbarten Reihenfolge ablief. Mit abnehmender Schönheit seien alle verfügbaren Mädchen nacheinander den Junggesellen zum Angebot gemacht worden "bis zu den am wenigsten mit körperlichen Vorzügen Ausgestatteten herab und trifft es wohl zu, daß ungeachtet aller Lobpreisungen des Ausrufenden die Häßliche keinen Liebhaber findet" (Anonymus 1836b:4). Hier wurde in der Mailehenliteratur dem Schönheitsmerkmal als Ausgrenzungskriterium erstmals Beachtung geschenkt. Auch Kinkel hat das Phänomen der speziellen Präferenzen bei den Versteigerungsangeboten beschrieben, wobei es in seiner Darstellung keinen Ausschluß aufgrund von Schönheitsidealen gab. Dagegen sah Kinkel das Problem der unterschiedlich verteilten finanziellen Mittel. Er hielt es für symptomatisch, daß der Reichste die Schönste davontrage, "wo nicht eine besondere Herzensneigung zu großen Geldopfern anspornt" (Kinkel 1846:160). ${ }^{94}$ Schulte (1902:71) konstatierte aufgrund seiner Beobachtungen im hessischen Raum, daß die Mädchen ohne nennenswerten Kostenaufwand für die Jungen "verstrichen" worden sind. In einem Widerspruch dazu steht seine Bemerkung, daß der Versteigerungswert den Mädchen je nach Höhe des Betrages Ehre oder Schande bereitet habe (Schulte 1902:72). ${ }^{95}$ Es fehlt hier eine Erklärung dafür, daß die Versteigerungssummen, die für die

\footnotetext{
${ }^{94}$ Korff (1984:252) hat Kinkels Beobachtungen auf den Ort Altenahr bezogen, wenn auch diese Festlegung nicht eindeutig aus der Quelle hervorgeht. Vorsicht ist zudem bei der Behauptung, Kinkel sei Zeuge der Mädchenversteigerung geworden, angebracht. Nach den Berichten von Gansen (1931:19) und einem anonymen Leserbriefschreiber (Anonymus 1836c:83f) für die "Rheinischen Provinzial-Blätter", welche die Versteigerung zum gegebenen Zeitpunkt als interne und geheime Angelegenheit der Junggesellen schildern, ist es eher wahrscheinlich, daß Kinkel seine Kenntnisse über den Mailehenbrauch von ungenannten Informanten bezogen hat. Siehe ferner Bearbeiter Georg Bärsch in Schannat (1852,3:478f), der den Text von Kinkel fast wörtlich übernommen hat.

${ }^{95}$ So wie das Mailehen in den rheinischen Beispielen oft beschrieben wurde, hat Schulte (1902:73) für den Ort Nieder-Gemünden den Brauch mit Wahl von Bügermeister und Polizeidiener, diskriminierender Anpreisung der Mädchen und Rummel festgehalten.
} 
Junggesellen aufgrund ihrer Höhe belanglos waren, für die Ersteigerten von persönlich hohem Wert sein konnten. Schulte erweckt den Eindruck, daß das spielerische Moment der Mailehenversteigerung von den Mädchen nicht erkannt wurde, daß das Ehr- und Selbstwertgefühl von Pfennigsbeträgen abhängen konnte und daß die Gekränkten dem rituellen Treiben wehrlos ausgeliefert waren. Derartige Darstellungen entsprechen einem distanzierten Blickwinkel, der die Brauchhandlungen und -rollen von vornherein in ein vorgefaßtes Muster zwängt, ohne daß der aufscheinende Widersinn tatsächlich geklärt wird.

Erwähnenswert ist überdies die Form der Ausbietung. Eine besondere Anforderung an den Auktionator schienen seine Verkäufereigenschaften und damit seine Redegewandtheit zu sein. Keines der Mädchen sollte bei den bevorstehenden Ortsfestlichkeiten ohne Tanzpartner sein, und daher sei der Auktionator zuletzt auch dazu bereit, "mit eben nicht zarten Ausdrücken die Vorzüge und Mängel der einzelnen Dorfschönen hervorzuheben" (Anonymus 1836b:4). ${ }^{96}$ Der beträchtliche Versteigerungsgewinn wird hier anders als in Niederzissen für die Bezahlung der Tanzmusik zur Kirmes verwendet. Kinkel (1846:160f) stimmt hierin überein und fügt noch hinzu, daß das überschüssige Geld zur Verköstigung der ersteigerten Mailehen gedient habe. Von Radermacher (1886:149) erfährt man, daß der real erzielte Preis für ein Mailehen bloß ein Bruchteil des Zuschlaggebotes ausmachte, weil in Talern gesteigert, der Nennbetrag letztlich aber in Pfennigen ausbezahlt wurde.

Die Eigenart des sogenannten Rummels, der bei der Mailehenversteigerung dann entstand, wenn die nicht versteigerten Mädchen zu einem Angebot vereinigt und schließlich von einem einzelnen Jungen ersteigert wurden, kommt in folgenden Zeilen zum Ausdruck. Der Verfasser sieht in dem Ersteigerer der "Übriggebliebenen"

"[...] ein(en) Speculant(en), der noch etwas werthvolles im 'Rummel' kennt, oder irgend einer der glaubt, wenn er Viele habe, weniger gebunden zu seyn. - Denn wie an diesem Tage jedem die Bahn geöffnet ist, diejenige Tänzerin zu erwerben, die er zu haben wünscht, so tritt auch für ihn die Verpflichtung ein, derjenigen die er erworben, das Jahr hindurch, ein getreuer Chapeau zu seyn" (Anonymus 1836c:84). ${ }^{97}$

Die Tanzpartnerschaft hat in diesem Beispiel einen für die weibliche Seite verpflichtenderen Charakter als in vorhin genannten Fällen, da das Mädchen den Jungen um Erlaubnis bitten muß, wenn sie mit einem anderen tanzen möchte (Anonymus 1836c:84). ${ }^{98}$

\footnotetext{
96 Ähnliche Merkmale zu Versteigerung und zum Auktionator beschreibt Gierlichs (1895:363) im Zusammenhang mit dem Mailehen in Golbach bei Kall.

${ }^{97}$ Andernorts firmiert der Rummel unter anderen Bezeichnungen, wie z.B.: Knubbel, Sack, Rötzchen u.a. Siehe dazu Dierker (1939:76ff).

${ }^{98}$ Landau (1840:276f) konstatiert für einzelne Gebiete Hessens, daß es eine gegenseitige Verpflichtung zur Tanzpartnerschaft gebe: "Beide [Junge und Mädchen; H.-W. W.] sind nun für die ganze
} 
Das moralisch korrekte Verhalten der Jugend wurde in vielen Mailehenquellen thematisiert. Während in den (gegen-)reformatorischen Visitationsberichten häufig eine allgemeine Aburteilung des Brauches vorgenommen wurde, geben die späteren Quellen Anhaltspunkte zur Differenzierung. Als lokaler Sonderfall wird im Zusammenhang des Eifeler Mailehenbrauchs das Scheuern der Linde betrachtet. Dieses Brauchelement komme nur dann zum Tragen, wenn einem Mailehen vorehelicher Kontakt mit Schwangerschaftsfolge angelastet werden könne. Habe die Delinquentin unter Vortäuschung makelloser Sittlichkeit dennoch am feierlichen Vortanz um die Dorflinde teilgenommen, so müsse im nachhinein "die Linde, oder das etwa um dieselbe befindliche Geländer rein gewaschen und gescheuert, und das Pflaster ringsum, aufgebrochen und erneuert" werden (Anonymus 1836c:85). ${ }^{99}$ Über vergleichbare Sanktionen gegenüber den männlichen Delinquenten schweigt der Verfasser in diesem Zusammenhang. ${ }^{100}$ Immerhin ist er der Auffassung, daß der Brauch des Mailehens keineswegs zur Unsittlichkeit verführe, "vielmehr glaubt derselbe bemerkt zu haben, daß die Orte, wo diese Sitte beobachtet wird, sich in umgekehrter Richtung vor vielen andern auszeichnen" (Anonymus 1836c:86). ${ }^{101}$

Im Gegensatz dazu stehen die Ausführungen von Schulte (1902:82), der insbesondere im Zusammenhang mit den Tanzveranstaltungen Gefährdungen für die Jugend sieht:

"Es kommt da viel vor, daß sich die Burschen den Mädchen, die sie gern haben, auf den Schooß setzen, sie um den Hals nehmen und küssen[...] . Der Bauer sagt uns zwar: 'In solchem Brauche findet nur der Städter etwas; was geschieht, geschieht ganz öffentlich. Kein Vater und keine Mutter werden deshalb die Tochter auch nur schief ansehen.' Er verweist uns in diesen Worten auf den allerdings sehr großen Unterschied in der Empfindungsweise des Bauern und des Städters".

Und schließlich berichtet derselbe Autor über die Gefahren des Nachhauseweges, der die innerlich nicht gefestigten Mädchen unterliegen könnten unter dem Einfluß der "Gesellschaft schlechter Burschen, die das Dorf ebenso gut hat, wie die Stadt" (Schulte 1902:82f).

Ein weiterer Aspekt, der schon in den besprochenen Statuten auftauchte, ist bei Kinkel (1846:161) zur Sprache gekommen: die Ausgrenzung von Ortsfremden im Mailehenbrauch. Kinkel hat ein Bild von äußerst engen sozialen Beziehungen vor Augen, die durch das Mailehen geschaffen wurden. Diese würden für alle Feste des

Dauer des Festes miteinander verbunden und nur vorübergehend, aber nicht ohne Erlaubniß, ist es ihnen gestattet, während des Tanzes zu wechseln". Dort, wo ein absolutes Verbot des Wechselns herrsche, scheint der Junge genauso daran gebunden zu sein wie das Mädchen.

${ }^{99}$ In Übereinstimmung hierzu vgl. Schmitz (1856-58, 1:32).

${ }^{100}$ Gierlichs (1895:362f) bemerkt in einem ähnlichen Fall sittlicher Verfehlung darüber, daß die öffentliche Rüge genauso dem Mann galt.

${ }^{101}$ Hierzu auch Kinkel (1846:161). 
Sommers gelten, an denen der Junge sein Mailehen zum Tanz auszuführen und auch zu bewirten habe. Dem alleinigen Tanzrecht, das er von seinem Mailehen verlangen dürfe, entsprach eine manifeste Abneigung der Dorfburschen gegenüber nicht ortsansässigen Freiern. Wollte ein Auswärtiger mit einem Dorfmädchen eine Liebesbeziehung anbahnen, so mußte er sich dazu in vielen Fällen erst einmal bei den Junggesellen das Recht förmlich erkaufen. War der betreffende "Wilderer" nicht bereit, Geld- oder Sachleistungen (meistens alkoholische Getränke) gegenüber der männlichen Dorfjugend zu erbringen, konnten starke Spannungen und ein ernsthafter Konflikt zwischen den beiden Parteien entstehen, die sich in aggressiven Gewaltausbrüchen oder schmählichen Rügebräuchen entluden. ${ }^{102}$

Was Landau (1840:276f) über das Mailehen in Niederhessen und in der Umgebung von Hersfeld berichtet, ist wohl als eine Abschwächung des Brauches zu verstehen, insofern hier gruppenbezogene Aktionen unterblieben. In den betreffenden Gebieten kam es zwar auch zu einer rituellen Zusammenfügung von jugendlichen Tanzpaaren, allerdings lebte der Brauch nunmehr von der Initiative einzelner Burschen, die einen förmlichen Besuch bei der jeweils Auserwählten abstatteten und dort um die Bestätigung einer festen Tanzpartnerschaft baten. Zum Rheinland, wo die Entstehung von vereinsmäßigen Strukturen zu verzeichnen ist, läßt sich somit eine gegenläufige Erscheinung festmachen.

Nachzutragen sind noch die Ergebnisse Radermachers (1886 und 1893-1896), die eine Bestandsaufnahme des Mailehens im Großraum Köln für den Ausgang des 19. Jahrhunderts erbringen. Ansatzweise ist bei den Feierlichkeiten eine Struktur und Organisation vorzufinden, die den erörterten Satzungen entspricht. Ein Richter und ein Sergeant übernahmen Aufsichtsfunktionen, aber wohl nur für die zeitlich begrenzte Phase der Maiaktivitäten (Radermacher 1896:149f). Neben den bekannten Einzelelementen des Mailehenbrauchs, wie z.B. Versteigerung, Kommabend, Maiensetzen, Tanzveranstaltungen, vermerkt Radermacher noch weitere Brauchkomponenten: ${ }^{103}$ die Ermittlung einer Maikönigin, das symbolische Verbrennen der vormaligen Mailehen, das Aufstellen von Schandmaien sowie die Errichtung eines Dorfmaibaums und den festlichen Umzug der Mailehenpaare im Rahmen eines besonderen Maifestes. Das Mädchen, das bei Versteigerungsende das Höchstgebot erzielte, sei für den Zeitraum eines Jahres Maikönigin gewesen. Leider erfährt der Leser aus der Quelle nichts über die Rechte und Pflichten, die mit diesem hohen Repräsentationsamt verbunden waren. Selbst die Existenz eines Maikönigs als

${ }^{102}$ Siehe z.B. Schmitz (1896/97:108ff) und Radermacher (1893:231); vgl. ferner die Darstellung und Interpretation der am Fall Hütten (Eifel) populär gewordenen Eselshochzeit (Lutz 1960:74-88).

${ }^{103}$ Die jeweiligen Einzelzüge des Mailehenbrauchs weisen in ihrer Gesamtheit eine gewisse Variabilität auf, d.h. sie waren nicht unbedingt konstitutiv für die Brauchausübung. Dagegen können eine Form der Paarbildung (z.B. Versteigern), Wege zur Bekanntgabe der Mailehenpaare (z.B. Kommabend) und eine Möglichkeit paarbezogener Aktionen (z.B. Tanz) als elementar gelten. 
männliches Pendant wird mit keinem Wort belegt (Radermacher 1886:150). ${ }^{104}$ Ein eigenartiges Phänomen innerhalb des Brauchkomplexes stellt die Verbrennung einer Strohpuppe dar, die nach Radermacher (1886:151) in der Mainacht vor dem Maienstecken stattfindet. ${ }^{105}$ Nach seinen Angaben würden sich die Junggesellen in der Gegend des Siebengebirges auf diese Art und Weise symbolisch ihrer ehemaligen Mailehen entledigen und ein Recht auf eine Erneuerung der Mailehenbeziehung begründen. Daß im Zusammenhang mit dem Brauch des Mailehens Liebes- bzw. Ehrenmaien genannt wurden, ${ }^{106}$ ist bereits angemerkt worden. Bei Radermacher (1886:153f) ist ein Verweis auf die sittenrichterliche Anwendung von sogenannten Schandmaien festzuhalten. Die Altenrather Junggesellen verwendeten Zweige von verschiedenen Baum- oder Straucharten, ${ }^{107}$ die sie sichtbar am Hause der betreffenden Delinquentinnen anbrachten, um deren sozial bedenklichen Lebenswandel zu brandmarken. Zum gleichen Zweck diente auch das Streuen von Häcksel (Stroh) vor der Haustür des Mädchens. Ebenso aus dem Siebengebirgsraum kommt die Nachricht, daß die Schandmaien auch als persönliche Vergeltungsmaßnahme benutzt wurden, wenn der Junge von einem Mädchen abgewiesen wurde (Schmitz 1896/97:109). ${ }^{108}$ Bemerkenswert ist, daß nunmehr von einem besonderen Maifest die Rede ist, das sonntags nach dem ersten Mai stattfand und sich

${ }^{104}$ Becker (21994:71) führt die Maikönigschaft auf die "Wahl des 'Maigrafen' im Bürgertum der mittelalterlichen Städte" zurück. Die Darstellung des Maigrafenbrauchs durch Pabst (1865) macht es wenig plausibel, daß hier ein Zusammenhang besteht. Ebenso problematisch ist eine romantisch verklärende Rückführung auf altdeutsche Volksversammlungen und Gerichtstage durch Zucchalmaglio (1854-58:29f), wobei eine ethnographische Beschreibung Einblick in die ehrenvolle Sonderstellung des Maikönigpaares des 19. Jahrhunderts gibt. Erste sichere Nachrichten über einen Maikönig erhalten wir durch Back (1872-74, 3:400f). Danach existierte das Repräsentantenamt seit 1575 in Enkirch und war dem Anschein nach mit der Aufgabe der Mädchenzuteilung verbunden. Der Hinweis auf einen früheren Zeitpunkt durch Bellinghausen (1923-25, 1:97f) und König (1938:28) beruht wohl auf einem flüchtigen Übertragungsfehler. Überraschenderweise bleibt das weibliche Pendant, die (Mai-)Königin, in der Literatur lange Zeit unbekannt. Zender (1972:251) hält sie für eine späte "Zutat" aus den zwanziger Jahren des 20. Jahrhunderts. Hier kann eine kleine Korrektur erfolgen (s.o. Zucchalmaglio). Obzwar unter anderer Amtsbezeichnung, so verkörperten der Schultheiß und seine Tänzerin, die in der Mitte des 19. Jahrhunderts für Ahr- und Eifelgegend belegt sind, die saisonalen Würdenträger spiegelbildlich (Schmitz 1856-58, 1:32). Der heute gängigen Ermittlung des Maikönigpaares durch das höchste Gebot, das ein Mailehen während einer Versteigerung erzielt, liegt eine über hundertjährige Tradition zugrunde (Radermacher 1886:150). Schon damals genoß der Herrscher über die Junggesellen die Freiheit, sein Mailehen nach Belieben auszuwählen (Korth 1892:94; Klein 1909:135; Mütter 1912:102). Ruland (1968:235) hat am Fall Mayschoß explizit ausgeführt, daß der Schultheiß "neuerdings" als Maikönig tituliert werde — hier handelte es sich offenbar nur um die Präsentation eines zeitgemäßeren Titels. Bemerkenswert ist auch das Phänomen der weiblichen Alleinherrschaft. Im Kreis Bergheim wählten die Junggesellen eine würdige Titelinhaberin und ehrten sie mit einem schmucken Maibaum (Gierlich 1895:363f; Müller 1936:22).

${ }^{105}$ Durch Schell (1900:40) erhielt dieser Vorgang die irreführende Bezeichnung Autodafé.

${ }^{106} \mathrm{Vgl}$. Abschnitt 2.3.

${ }^{107}$ Einen umfangreichen Katalog der Schandmaiensymbolik hat Müller (1911:72f) geliefert.

${ }^{108}$ Derselbe Autor berichtet über einen Brauch, wonach Burschen, die erfolglos um die Gunst eines Mädchens warben, zum Spott eine Art Schandmaien gesetzt bekamen (Schmitz 1896/97:109). 
nach der Auffassung Radermachers (1886:155f) mit der Mailehenversteigerung verbunden hat. Dieses Fest gipfelte in einem Ball. Aber vorher traten die Mailehenpaare noch gemeinschaftlich in Aktion, wenn sie z.B. den Dorfmaibaum herrichteten, der vor dem Tanzsaal plaziert wurde, oder wenn sie den feierlichen Umzug durch den Ort gestalteten. Schon zu Zeiten Rademachers präsentierte sich der Festzug mit der Musikbegleitung und den berittenen Funktionsträgern der Junggesellen als eine parademäßige Schau. ${ }^{109}$

Eine Mischform von Mailehenversteigerung und Lehenausrufen hat Ferdinand Schmitz (1896/97:107f) aus dem rechtsrheinischen Raum bei Bonn überliefert. Dort wurden am Maiabend die betreffenden Mädchen zuerst von den Junggesellen versteigert. Nach der Auktion teilte sich die Burschenschar in zwei Gruppen, wovon die Ausrufer einen ortsnahen Berg bestiegen und die anderen im Tal zurückblieben. Dann wurden die durch die Versteigerung ermittelten Paare öffentlich ausgerufen und anschließend die Maien vor den Häusern der Auserwählten aufgestellt.

\subsection{Auswirkungen der Industrialisierung}

In den dokumentarischen Berichten des frühen 20. Jahrhunderts zum Mailehen lassen sich die einzelnen Formen der Brauchausübung aus vorangegangener Zeit unschwer wiederfinden. So setzte sich die Hauensteiner "Märevestäging" in der südwestlichen Pfalz aus den bekannten Komponenten zusammen: die Bestimmung von Notar, Schreiber und Ausrufer, die zum Bieten anspornende Anpreisung der jeweiligen Mailehen und nicht zuletzt der gesellige Charakter der Veranstaltung bei erhöhtem Alkoholkonsum. Hier lag das brauchspezifisch Unerwartete jedoch in einer besonderen Gestaltung der Versteigerung. Die einzelnen Mailehen wurden als sogenannte Gemeindehölzer feilgeboten. Kreuter (1910:185), der selbst Augenzeuge einer solchen Auktion wurde, gibt den Vorgang in ungewohnt transparenter Weise wieder, wie der untenstehende Auszug belegt:

"Handelt es sich um ein vermögendes, rechtschaffenes Fräulein, so wird dasselbe angepriesen:
'Ein Eichenstamm erster Klasse, ganz ohne Aeste', ist das Mädchen außergewöhnlich groß, so
wird es eine 'Hopfenstange' oder 'Bohnenstange' genannt, ist es von kleiner Figur und korpu-
lent, so wird etwa ausgerufen: 'ein Baumstumpf, einen Meter Umfang, sonst solid', ist es bleich
aussehend, dann heißt es: 'ein Ster birken Scheitholz', gilt es als 'Betschwester', so ist 'das Holz
zuhöchst auf dem Gipfel des Kirchenwaldes gewachsen'[...]. Allgemeine Heiterkeit erfolgt,
wenn mißliebige, nicht zum besten beleumundete oder als nicht besonders reinlich geltende
Jungfrauen älterer oder jüngerer Generationen unter den Hammer kommen. Es sind dies 'von
früher her sitzen gebliebene alte Wellen, die schon im vorigen Jahrhundert hätten abgefahren
werden sollen', 'altes dürres Geäst', 'stachlige Akazienhecken', 'knorriges Prügelholz letzter

${ }^{109} \mathrm{Vgl}$. den feierlichen Umzug der Mailehenpaare in Hessen bei Schulte (1902:77f). 
Qualität', 'Krappen von der Rußekupp', 'Klotzholz vom Mistberg, wo man aber noch den Grund und Dreck runter machen muß', 'morsches Abfallholz vom Saubuckel' u.s.w.".

Auch wenn an anderen Stellen bereits von etikettierenden Anpreisungsformeln der Mailehenauktionatoren die Rede war, so kommt der diffamierende Charakter, den die Veranstaltung gegenüber den Brauchträgerinnen annehmen konnte, selten so deutlich wie hier zum Vorschein. Eine Erklärung dafür bieten womöglich die speziellen Rahmenbedingungen, unter denen das Hauensteiner Mailehen stattfand. Der Ort selbst unterlag Kreuters Angaben (1910:184f) zufolge einem durchgreifenden Wandel. Die prosperierende Schuhindustrie sorgte für einen wirtschaftlichen Aufschwung und einen demographischen Zuwachs. Gleichzeitig hat der Berichterstatter einen Niedergang verschiedener Brauchtraditionen beobachtet, wobei die Mailehenversteigerung eine Ausnahme bildete. Das Mailehen war unter diesen Bedingungen nur durch eine besondere Attraktivitätssteigerung $\mathrm{zu}$ erhalten. Die Erhöhung des Schau- und Unterhaltungswertes des Brauches dürfte mit einer öffentlichen Versteigerung der "Gemeindehölzer" gelungen sein, in der die Hauptakteure mit Hilfe bestimmter Requisiten (Brillen, Aktenbündel) möglichst glaubwürdig ihre Rolle als Notar, Schreiber und Ausrufer spielten. Wie es so oft in vergleichbaren Fällen geschehen ist, wurde versäumt, die Situation bzw. die Reaktionen der Frauen zu erfassen. Den Beobachter interessierten die "Kosten" dieser abgewandelten Form der Mailehenversteigerung mit ihrem anscheinend "reich(en) Feld der Betätigung für Humor und Mutterwitz" nicht im geringsten (Kreuter 1910:185).

Beobachtungen, die Hilberath (1931:67f) unter feldforschungsähnlichen Untersuchungsbedingungen im Kreis Ahrweiler machte, bestätigen den unaufhaltsamen Brauchwandel unter den Einflüssen von Verstädterung und Industrialisierung. Die primär soziologisch ausgerichtete Analyse kommt zu dem Schluß, daß der Eifeler Junggesellenverein und seine Institutionen, insbesondere die der Mailehenversteigerung, sich in einer Phase der Umbildung, Auflösung und Revitalisierung befänden. Da die Schaffung von Paarbeziehungen unter ledigen Frauen und Männern durch den gesellschaftlichen Wandel vielfach erleichtert worden und auch auf persönlicher Ebene möglich sei, erübrige sich die brauchmäßige Zusammenfügung der Mailehenpaare durch die Junggesellen. ${ }^{110}$ Der Brauch könne dort sogar als besonders störend empfunden werden, wo bereits mit einer verstärkten Herausbildung von Interessenvielfalt und Individualisierung der Bevölkerung zu rechnen sei. Hilberath

${ }^{110}$ Was die Regelung von Paarbeziehungen in der Eifel anbelangt, ist diese Darstellung, die dem Junggesellenverein eine Monopolstellung einräumt, zu vereinfachend und generalisierend. Auch vor dem 20. Jh. existierte für die ländliche Jugend vielfach die Möglichkeit, ohne den Verein und seine Bräuche Liebes- bzw. Ehebeziehungen einzugehen. Die Aktivitäten der Junggesellen bezogen sich auf den Heimatort. Die außerörtlichen Liebesbeziehungen versuchte der Verein zwar zu sanktionieren, aber unterbinden konnte er sie deswegen nicht. 
(1931:68) hat dabei nicht verkannt, daß die Position der Frauen unter den Zwängen der Mailehenversteigerung in stärkerem Maße von diesem Wandel betroffen wurde:

"Hinzu kommt auch eine Art Emanzipation der Mädchen; ihre Mehrzahl opponiert dagegen, daß sie versteigert wird und infolgedessen Verpflichtungen haben soll. Die Institution Junggesellenverein wird infolge der differenzierteren Individualität unbequem. Wenn sie früher auch für die weibliche Jugend eine Annehmlichkeit war, ist sie jetzt für sie eine Last".

Neben diesen gravierenden Veränderungen erkannte der Soziologe auch jene Anpassungstendenzen, die dazu führten, daß der Junggesellenverein zur Pflege der Geselligkeit oder zur Prestigeerhöhung der Mitglieder ${ }^{111}$ weitergeführt wurde. Schließlich komme es auch nicht selten zur erneuten Einführung des Mailehen, wenn die Aufgabe traditioneller Brauchstrukturen von den Beteiligten als Verlust empfunden worden sei (Hilberath 1931:67).

Eine Darstellung des Mailehens aus Bouderath (Kreis Schleiden) hat grundsätzliche Übereinstimmung mit dem für das 19. Jahrhundert skizzierten Ablauf des Brauchgeschehens, aber auch lokale Eigenarten ins Blickfeld gerückt. Der Versteigerung wurde hier ein Heischebrauch, das sogenannte Maieierholen, vorgeschaltet. Dabei zogen die Junggesellen von Haus zu Haus, und unter einem speziellen Liedvortrag heischten sie um eine großzügige Eierspende. Spreu oder Häcksel erhielten diejenigen, die eine Gabe verweigerten; den übrigen sprach man seinen Dank aus. Schließlich zog man gemeinsam zum Wirtshaus weiter, um dort die Eier zu verspeisen und das gespendete Geld in Branntwein umzusetzen. ${ }^{12}$ Dann leitete man in bekannter Weise die Versteigerung der Mailehen ein. Eine Neuerung, welche die Spannung während der Versteigerung gewiß erhöhte, stellt die Möglichkeit des "Umwerfens" dar: im gegenseitigen Überbieten konnte es vorkommen, daß ein Junggeselle auf seinem Gebot "sitzen blieb" und er dadurch ein Mailehen ersteigerte, an dem er nicht ernsthaft interessiert war. In einem solchen Fall erlaubte das Bouderather "Umwerfen", den rituellen Kauf gegen die Zahlung einer Gebühr rückgängig zu machen. Die Gebühr erhöhte sich bei wiederholtem "Umwerfen" des Versteigerungsergebnisses. Mütter (1912:100ff), dem wir diese Angaben zu verdanken haben, hat darüber hinaus ein dem Mailehen inhärentes Konfliktpotential beschrieben, das insbesondere dort zum Ausbruch komme, wo der Ersteigerer nicht mit dem Liebhaber des Mailehens identisch sei. Wichtig für die Beurteilung heutiger Verhältnisse ist auch seine Feststellung, daß der Erlös der Versteigerung nicht immer

\footnotetext{
${ }^{111}$ Vgl. hierzu die Umwandlung des schlichten Junggesellenvereins in einen Junggesellen-Schützenverein (Hilberath 1931:67; siehe auch Schütz 1935).

${ }^{112}$ Meyer (1934:66) bestätigt diesen Heischebrauch für den Kreis Schleiden. In der Umgebung von Euskirchen scheint eine ähnliche Praxis geherrscht zu haben. Meyer (1934:67) teilt ein Heischelied aus dem Ort Lessenich mit, in dem die Eierspende als Bedingung für das Setzen eines Maien zu Ehren der Haustochter genannt wurde.
} 
in die Organisation eines Maiballs, sondern hin und wieder in sonntägliche Maiausflüge mit den Mädchen investiert werden konnte (Mütter 1912:103).

Entwicklungen im Mailehenbrauch des Saargebietes wurden ferner durch die Abhandlung von Fox (1929) und das darin enthaltene Kartenmaterial beleuchtet. Fox (1929:244) verzeichnet vor allem im ehemals kurtrierischen Raum einen Rückgang beim Lehenausrufen. Soweit er die pfalz-zweibrückischen und nassausaarbrückischen Territorien miterfaßt, läßt sich erkennen, daß die Brauchausübung bei der Datenaufnahme in diesen Gebieten nicht mehr anzutreffen war. Lediglich beiderseits des Saarabschnitts zwischen Saarhölzbach im Nordwesten und Völklingen im Südosten wurde das Mailehen praktiziert. Dabei ist die Landesgrenze hin zum Lothringischen überschritten worden. Aber auch in diesem Rückzugsgebiet hat Fox lokale Tendenzen des Rückgangs bemerkt. In wenigen Orten westlich von Mettlach wurde das Lehenausrufen gemeinsam mit dem sogenannten Räderschieben ausgeübt, wobei man ein brennendes Wagenrad den Berg hinunterrollen ließ. Geradezu als typisch bezeichnete der Autor die Verbindung mit dem Fastenfeuer, ohne jedoch auf die Revitalisierungsmaßnahmen, die im 19. Jahrhundert stattgefunden haben mußten, einzugehen. Laven (1834:ohne Paginierung) konnte seinerzeit nur den längst erloschenen Brauch des Räderschiebens für die Region konstatieren. Daß jenem Räderschieben nur wenige Zeit später eine Renaissance bevorstand, wurde von Laven noch nicht antizipiert.

Das Mailehen war auch zu Beginn des 20. Jahrhunderts nicht nur auf das BäuerlichDörflich-Ländliche begrenzt. Korff (1984:260f) hat den sich zum Ende des 19. Jahrhunderts weiter ausdifferenzierenden und komplexer werdenden Brauch vor dem Hintergrund sozialer und ökonomischer Bedingungen des städtischen Umfeldes dargestellt. Urbanisierungsprozesse im Aachener, Kölner und Bonner Raum hätten das transformierte Mailehen $\mathrm{zu}$ "ein(em) angemessene(n) Medium der Selbstdarstellung und historischen Selbstvergewisserung" (Korff 1984:261) insbesondere in wohlhabenderen Handwerkerkreisen gemacht.113 "Man brauchte die Historisierung, um mit der Modernisierung der Gesellschaft fertig zu werden", lautet die Erklärung Korffs (1984:261), die eine Verbreitung des Mailehens im städtischen Raum plausibel machen soll. Ein Teil dieser Entwicklung konnte allerdings schon in der ersten Hälfte des 19. Jahrhunderts durch die gravierenden politischen Wandlungen auch im ländlichen Bereich Fuß fassen. Mit der Säkularisierung und der zunehmenden Betonung nationaler Größe ging ein wachsendes Selbstbewußtsein bislang unterprivilegierter Bevölkerungsschichten einher. Sicherlich hatte prunkvolle Festlichkeit bei den städtischen Varianten des Mailehens, die in diesem Zusammenhang oft als Maispiele bezeichnet wurden, einen hohen Stellenwert.

${ }^{113}$ Vgl. Zender (1979:824f). 
Maibaumsetzen, Parodien auf Schieds- und Strafverhandlungen, Maigerichte, Scherzbräuche, Handwerksneckereien, die Korff (1984:260) in den Kontext der "'verbürgerlichte(n)' Umformungen" des Mailehens gestellt hat, sind - wenn auch in abgeschwächter Form - ebenso in den dörflichen Gegenden anzutreffen. Die den Beginn des 20. Jahrhunderts markierende Konstruktion der Stadt-Land-Dichotomie stellt insofern hauptsächlich ein ökonomisches, weniger ein brauchspezifisches Problem dar. Die BrauchträgerInnen unterschieden sich in ihren Aktionen und Vorstellungen weniger als in den finanziellen Möglichkeiten, die jeweils Üppigkeit oder Kargheit in der Brauchausführung bestimmten. Die vorgenommene Perspektivenkorrektur ändert jedoch nichts an der berechtigten Annahme, daß der Mailehenbrauch für soziale Gruppierungen als ein geeignetes Mittel der Selbstdarstellung und historischen Verortung in der kritischen Situation gesellschaftlicher Modernisierung fungieren konnte. Mit anderen Worten: das Mailehen war sowohl für die ländliche als auch die städtische Bevölkerung ein wirksames Medium, in dem für die Beteiligten sozial und kulturell geteilter Raum unmittelbar sichtbar und erfahrbar werden konnte. ${ }^{114}$

Ein wichtiges Kriterium zur Beurteilung des Brauchwandels scheint nach Korff (1984:260) die "Exclusion" der Aktionen zu sein:

"Verändert hat sich vor allem das Verhältnis zur lokalen Öffentlichkeit; durch die Vereinsorganisation wird der Brauch 'excludiert' und nicht mehr von dem gesamten Ort praktiziert. Der Brauch wird in gewisser Weise zelebriert, aufgeführt und nicht mehr ausgeführt".

Daß diese Vorgänge erst mit der vereinsmäßigen Organisation einsetzten, ist jedoch zweifelhaft. So ist zu berücksichtigen, daß die BrauchträgerInnen des Mailehens schon sehr früh mit beiden Mechanismen sozialer Gruppenbildung - Segregation und Integration - konfrontiert waren und damit operierten. Die Vereinsgründungen stellten insofern keine strukturelle Brauchumformung, sondern lediglich eine für die Zeit typische Weiterführung der bewußten Steuerung von Gruppenbildungsprozessen dar. Brauchausübende Vereine existierten folglich schon im ausgehenden 18. Jahrhundert in ruralen wie urbanen Gegenden.

Darüber hinaus muß man berücksichtigen, daß das Mailehen als Instrument vorehelicher Paarbildung sich erst allmählich im 19. Jahrhundert zu einem öffentlichen Festbrauch entwickelte. Eine Beteiligung der gesamten Dorfgemeinschaft, die als heterogenes Gebilde aufzufassen ist, war bei den BrauchträgerInnen zunächst nicht erwünscht. Die verschiedensten Interessenlagen im Ort, die z.B. religiös, ökonomisch oder sozial bestimmt sein konnten, führten von vornherein zu Reibungspunkten und Schranken, die eine Brauchbeteiligung für den einen erschwerten, für den anderen

${ }^{114}$ Hier zeigt sich bereits die Bedeutsamkeit des Begriffes Medium für das Verständnis des Brauches. Ausführlich zum Verhältnis Mailehen/Medium in Abschnitt 5.1. 
wünschenswert machten. Eine traditionelle, homogene dörfliche Gemeinschaft, die alle gleichermaßen am Brauch partizipieren ließ, kann im Rahmen der Mailehenforschung nicht aufrecht erhalten werden. ${ }^{115}$

\subsection{Konfrontation mit dem National- sozialis mus}

Der tiefgreifende Wandel, der sich in nur 13 Jahren nationalsozialistischer Schreckensherrschaft auf allen politischen, sozialen und kulturellen Ebenen der Gesellschaft vollzog, beeinflußte auch die Mailehenpraxis. Bei intensiver Auseinandersetzung mit den Quellen entsteht der Eindruck, daß das formale Erscheinungsbild relativ konstant bleiben konnte. Verändert hatten sich in erster Linie die Rahmenbedingungen der Brauchausübung durch politische, aber auch wissenschaftliche Bewertung oder Einmischung. Darstellungen des Mailehens als germanisches Frühlingsfest bzw. als Fruchtbarkeitszauber, dessen kultischer Ursprung erwiesen sei, sind in dieser Zeit allgegenwärtig. Kultische Kontinuität, Erziehung zur Sittenreinheit, männliche Dominanz und Vollstreckungsgewalt gegenüber weiblicher Fügsamkeit, arteigene Traditionen wider entartende Vermischungen und Modernisierungen, dies sind die immer wiederkehrenden Schlagworte der nationalsozialistischen Ideologie.

$\mathrm{Zu}$ welchen Anschauungen und Geisteshaltungen volkskundliche Wissenschaft in der nationalsozialistischen Epoche fähig war, soll in einer quellenkritischen Geschichtsdarstellung nicht verbrämt werden. ${ }^{116}$ Insbesondere die Abhandlungen von Fox (1937), Wrede (21938) und Weber (1935) zeugen davon, in welchem Ausmaß Bräuche im allgemeinen oder auch Maibrauch und Mailehen im speziellen für gesellschaftspolitische Ziele ideologisch mißbraucht werden konnten. Nach den Vorstellungen von Fox sei es Aufgabe der Volkskunde, in jeder Hinsicht die arteigenen Wesenszüge des deutschen Menschen freizulegen und deutlich von artfremden Einflüssen zu scheiden. Scharf wendet er sich gegen die Verbreitung von religiösen Schriften, die in einem jüdischen Zusammenhang stünden. Aber auch die christliche Glaubensausübung habe zur "Verdrängung und Verfälschung deutscher

115 Vgl. Moser (1985:216), Landau (1840:272f) und Schulte (1902:68); siehe auch oben das Beispiel Delhovens (Kap. 2.4).

${ }^{116}$ Beschwichtigungsformeln zur Bewältigung nationalsozialistischer Vergangenheit, wie sie unlängst zur Friedenspreisverleihung 1998 in der Walserdebatte vorgetragen wurden, rütteln an dieser Überzeugung. Auch in der Beurteilung wissenschaftsgeschichtlicher Themenstellungen ist es stets bedeutsam, sich umfassende Klarheit zu verschaffen über die Ausgangspositionen und Spielräume menschlicher Verantwortung, menschlichen Verhaltens und auch wissenschaftlicher Arbeit unter den Verhältnissen des Nationalsozialismus. 
Sitten und deutschen Brauchtums" geführt (Fox 1937:183). Seine Schrift endet schließlich mit folgendem Appell an die Fachdisziplin:

"Das Schicksal der Saar und die neueste Geschichte unseres Vaterlandes haben die schlummernden nationalen Kräfte in der Bevölkerung geweckt, und die Volkskunde soll diese Kräfte in die richtigen Bahnen leiten für den Kampf gegen das Artfremde und für das Arteigene" (Fox 1937:185).

Wenn auch weniger kämpferisch, so doch inhaltlich in wesentlichen Punkten mit Fox konform agitierte Wrede (21938:137). Der Kölner Volkskundler hob aber nicht so sehr die Mißstände einer vermeintlich verunreinigten, wesensfremden deutschen Lebenswirklichkeit hervor, als vielmehr die überall $\mathrm{zu}$ beobachtenden Verbesserungen, die auf Leistungen der nationalsozialistischen Politik zurückzuführen seien. Eine scheinbar sinngerechte Wiederbelebung von Bräuchen wurde ausdrücklich begrüßt. Hiervon waren auch die Maibräuche und das Mailehen berührt, vor allem dadurch, daß aufgrund eines Erlasses vom 27.02.1934 der 1. Mai zum nationalen Feiertag erhoben worden war (Moser 1985:249). Die staatlich verordneten Feierlichkeiten wurden herausgestellt als "Ausdruck des neuerweckten und wiedererstandenen Tat- und Gemeinschaftswillens des nationalsozialistischen Volkes" (Wrede 21938:152). Der Maibaumbrauch veranschauliche genau diesen Wandel, so heißt es:

"Der Maibaum, ursprünglich Sinnbild und Vorbild der Fruchtbarkeit, dann in den jüngeren Zeiten mehr und mehr lediglich zum Mittelpunkt weltlicher Freude ohne gehaltvollen Sinn geworden, hat heute wiederum einen tiefen, staatspolitisch hochbedeutsamen Sinn erhalten: er gilt als Künder neuen Lebenswillens, neuer Schaffens- und Lebensfreude" (Wrede 21938:153). ${ }^{117}$

Bräuche sollten als sinnstiftende, gemeinschaftsfördernde, Lebenslust und Tatendrang vermittelnde Impulse im deutschen Alltag erkannt und propagiert werden. Insofern schloß auch die bewußte Begehung des Maifeiertages eine Lücke im ehemals sinnentleerten Dasein: hier gehe es nicht mehr um den trivialen "Ausdruck schwärmerischer Gefühle", sondern um ein "Bekenntnis", so Wrede (21938:152).118 Hier kommt zum Vorschein, wie sehr die Autoren von der nationalsozialistischen Ideologie ergriffen waren, wie sehr sie die Phrasen von Überlegenheit und Reinheit der Art, völkischer Gemeinschaft, wahrer Sinnstiftung als Gegebenheit auf die komplexe Realität projizieren und diese damit zur Unkenntlichkeit verzerren oder in eine Scheinwelt umwandeln. Einer solchen Scheinwelt begegnet man zum einen in der konstruierten germanischen Mythologie, zum anderen in brauchspezifischen

${ }^{117}$ Vgl. auch die Darstellung der Errichtung eines nationalen Maibaums in der Reichshauptstadt Berlin 1934. Wrede (21938:155) hat hierzu bemerkt: "Bereits diese Feier war ein weihe- und stimmungsvolles Ereignis und ein ausdruckvolles Zeichen des geeinten und seiner selbst wieder bewußt gewordenen deutschen Volkes".

118 Ähnlich äußert sich Weber (1935:99) dazu. 
Revitalisierungs- und regelrechten Inszenierungsversuchen. ${ }^{119} \mathrm{Da}$ eine ideologisch überfrachtete und instrumentalisierte Brauchrenaissance Stilblüten hervorbringen konnte, die im diametralen Gegensatz zur postulierten völkischen Echtheit und Ursprünglichkeit standen, löste paradoxerweise nicht die geringste Verwunderung aus. So hat Wrede (21938:155) das Aufkommen der Wahl einer Maikönigin innerhalb der Arbeiterschaft eines städtischen Betriebes in direkten Zusammenhang mit der Personifizierung der Maikönigin als Nerthus und damit als germanische, göttliche Segensmacht gebracht. Ein anderer Fall betrifft die Inszenierung des Mailehens als dramatisches Maispiel, bei dem ein Sommerkönig (Maikönig) den Winterkönig besiegte und einen Maigrafen bestimmte, der die Mailehenpaare auswählte und sie zur Sittsamkeit ermahnte (Wrede 21938:155f). ${ }^{120}$

Ein abschließendes Beispiel zur Perfidie der Auswirkungen des Nationalsozialismus auf den Maibrauch und seine wissenschaftliche Bearbeitung:

"Mädchen, die sich während der Besatzungszeit mit Ausländern herumgetrieben haben, wird die Treppenstufe mit Teer bestrichen. Dieser Schabernack ist angesichts der aus der Besatzungszeit stammenden Negerbastarde eine ebenso gerechte wie treffende Kritik der Volksmeinung an einer solchen Kulturschande. In einer derartigen Brandmarkung einzelner minderwertiger Volksgenossen seitens der Gemeinschaft findet das gesunde Gefühl und Rassenbewußtsein des deutschen Bauern deutlichen Ausdruck" (Weber 1935:27). ${ }^{121}$

Gerade dieses Zitat verdeutlicht sehr eindringlich, daß die scheinbar hohlen ideologischen Phrasen, die dogmatisch oder unhinterfragt in ungebrochener Redundanz publiziert wurden, nicht nur Worthülsen darstellten, sondern eine abgrundtief menschenverachtende Konkretisierung erfuhren. Die erschreckende Unmenschlichkeit der nationalsozialistischen Gesellschaft gehörte auch in der Mailehenforschung zur Realität. Hier stellt sich das Problem, inwieweit die Brauchpraxis, d.h. die Empirie von der ideologischen Durchdringung betroffen war.

${ }^{119} \mathrm{An}$ vielen Stellen in der nationalsozialistisch bestimmten Literatur finden sich Bemerkungen zur bereits erfolgten positiven Wiederbelebung der Maibräuche bzw. Appelle zum Erhalt der bestehenden brauchmäßigen Aktionen. Siehe dazu z. B. Weber (1935:1-15, 27, 34-36, 99, 101, 104f), Wrede (1934:47 und 21938:152f, 155), Theme (1938:87f), Fox (1937:181,185), Sels (1938:170) und Zender (1938:108). Die Brauchrevitalisierung mußte sich nationalsozialistischen Normierungsvorstellungen beugen, wie sie beim Maibaumbrauch deutlich wurden. Hatte die Aktion der synchronen Aufstellung des Maibaums am 1.Mai um 00:00 Uhr im ganzen Reichsgebiet bei Wrede (1934:47) einen positiven Anstrich, so hat Müller (1936:18-20) den nicht genuinen Umgang mit dem Brauch kritisiert, wenngleich auch Letzterer die Zusammenhänge und die Verantwortlichen im dunkeln ließ.

${ }^{120}$ Die sittenrichterliche Tätigkeit im Mailehenbrauch wurde in der nationalsozialistischen Zeit lobend herausgestrichen. Zwar handele es sich um ein hartes Gericht, bei dem die Mädchen den unbeugsamen Kriterien der Volksmeinung unterlägen, aber in seiner Durchführung habe es einen positiven erzieherischen Effekt. Hierzu s. Wrede (1934:63 und $\left.{ }^{2} 1938: 153\right)$, König (1938:25-28), Dierker (1939:105), Hurth (1935:55) und Theme (1938:87).

${ }^{121}$ Zur Zwangssterilisierung der sogenannten "Rheinlandbastarde" unter den Nationalsozialisten s. die Arbeit von Pommerin (1979). 
Das Spektrum der Formen, in denen das Mailehen politisch vereinnahmt wurde, muß weiter differenziert werden. Das Mailehen kann dort als politisch mißbraucht angesehen werden, wo es über Jahrzehnte oder Jahrhunderte hinweg verankert war und durch die NationalsozialistInnen eine inhaltliche Gewichtung erfuhr, welche die konkrete Lebenswirklichkeit der Betroffenen nicht nur ignorierte, sondern auch absichtlich korrumpierte. ${ }^{122}$ Dies mag an Orten, die unter dem Einfluß des totalitären Herrschaftsapparates den Brauch neu aufleben ließen oder erstmals einführten, anders zu sehen sein. Hier lag es nahe, daß der Brauch in den unmittelbaren Einflußbereich nationalsozialistischer Strukturen geraten konnte und die Brauchträger identisch mit der Jugendorganisation der NSDAP waren (Theme 1938:87f). Im Rahmen von Neubelebungen des Brauches war es sicherlich schwierig oder unmöglich, Bedingungen zu schaffen und Bereiche zu finden, die vor einem Zugriff der nationalsozialistischen Kader geschützt waren.

Relativ unbehelligt fortsetzen konnten die "AkteurInnen" des Mailehens die gewohnte Brauchausübung wohl nur in Strukturen, die bereits vor 1933 entwickelt waren. Konflikte zwischen Obrigkeit und Bevölkerung waren dort vorprogrammiert, wo ortsspezifische Eigenarten $\mathrm{zu}$ stark nach außen getragen wurden. Allerdings lassen sich diese in den Literaturquellen nicht verfolgen. Möglicherweise können intensive Archivstudien hierüber neue Ergebnisse erbringen. Die Vereinnahmung des Brauches durch den Nationalsozialismus dürfte allerdings weniger Widerstände erfahren haben, als dies unter vorangegangenen politischen und kirchlichen Kontrollbzw. Domestizierungsversuchen der Fall war. Gründe dafür sind darin zu vermuten, daß das egalitärere Beziehungsgeflecht unter den BrauchträgerInnen seit dem 19. Jahrhundert einer vereinsmäßigen Organisation gewichen war (siehe unten Kapitel 2.5) und die Frauen sich mehr und mehr aus dem aktiven Brauchgeschehen zurückzogen. Die heranwachsenden Männer erhielten durch die Anerkennung ihrer "kultisch-religiösen" Praxis und der Aufwertung der sittenrichterlichen Tätigkeit einen positiven Rückhalt, der ihre Sonderstellung im Ort und ihre Dominanz gegenüber dem weiblichen Geschlecht bekräftigte. ${ }^{123}$ Die JunggesellenSchützengesellschaft, die in dem Ort Lantershofen (Kreis Ahrweiler) das Mailehen ausübte, hatte durch eine Festschrift die Transformation in nationalsozialistische Bahnen festgehalten. Die folgende Stelle belegt nochmals die politische Erhöhung einer vormals schlichten Vereinigung von Junggesellen aus einem kleinen Ort in der Ahrgegend:

\footnotetext{
${ }^{122}$ Bei dem von Weber zitierten Beispiel ist ein Mißbrauch der tradierten Brauchstrukturen denkbar, v.a. wenn nationalsozialistische Schergen für die exzessive Anwendung des Rügebrauchs verantwortlich gemacht werden könnten. Diese Möglichkeit birgt eine gewisse Plausibilität, da die sittenrichterliche Brauchpraxis offensichtlich unter den Nationalsozialisten eine "Hochkonjunktur" erfahren hat (vgl. Müller 1936:24). Zur politischen Instrumentalisierung von Rügebräuchen s. auch Hinrichs (1991:460f).
}

${ }^{123}$ Vgl. Hurth (1935:55), Wrede (1934:63 und 21938:153), Schütz (1935:25ff) und Theme (1938:87). 
"Getreu ihrem alten Wahlspruch: 'Religion und Tugend, Arbeitsamkeit und Fleiß, Eintracht und Liebe, Frohsinn und Scherz' stellte sich die Gesellschaft in einer von dem Vorsitzenden einberufenen außerordentlichen Generalversammlung bei der nationalen Erhebung einmütig hinter den Führer und seine hohen Ziele. In einem neuen, starken Deutschland freut sich die Junggesellenschützengesellschaft, an ihrem Platz mitarbeiten zu können zum Besten unserer Heimat, zum Wohle unseres geliebten, herrlichen Vaterlandes" (Schütz 1935:31).

Der Zusammenbruch des nationalsozialistischen Staates und die Folgen des Zweiten Weltkrieges führten zu einer Phase des Wiederaufbaus und der politischen Neuorientierung. Der Totalität des nationalsozialistischen Gedankengutes und Gestaltungswillens, welche sich auch im Brauch des Mailehens äußerten, waren die legitime Basis und die machtvollen Exekutionsstrukturen entzogen. Gleichzeitig war die bis dahin gängige menschenverachtende, verbrecherische Praxis vielfach entblößt und stand vor den Ächtungsinstanzen und der Anklagebank der internationalen Völkergemeinschaft. Sieht man einmal von den Maßnahmen der offiziellen Verbrechensverfolgung $a b$, so konnte sich jeder einzelne aufgrund der totalitären Strukturen im nationalsozialistischen Herrschaftssystem fragen, inwieweit er das Regime und seine Machenschaften - sei es aktiv oder passiv - unterstützt und damit eine konkrete Mitschuld am Verlauf der Geschichte auf sich genommen hatte. Die bis heute nicht abgeschlossene "Bewältigung" dieses Kapitels deutscher Vergangenheit mündete in verschiedene Bahnen: Unverbesserlichkeit und Ignoranz, Verschleierung, Ablenkung, Verdrängung und Flucht oder auch Bekenntnis und Mut zum Neuanfang. Wie auch immer sich der persönliche Umgang mit den Geschehnissen des Dritten Reiches gestaltete, prinzipiell scheinen ähnliche Muster der "Vergangenheitsbewältigung" im Zusammenhang mit den Veränderungen des Mailehens seit den frühen Nachkriegsjahren wirksam zu sein. Ein schwerwiegendes Problem bei der Beantwortung der entwicklungsgeschichtlich bedeutsamen Fragestellungen stellt die Quellenlage dar. ${ }^{124}$ Es mangelt an empirischen Erhebungen für diese Zeit, so daß man auf die Einschätzungen der FachkennerInnen angewiesen ist, die sich zu Wort meldeten. Daneben bietet die spätere, retrospektive Befragung von Zeitzeugen Anhaltspunkte. Hieraus ergibt sich folgendes Bild:

Wrede behauptet in der dritten neubearbeiteten Auflage der Eifeler Volkskunde (31960:217) lapidar und ohne weitere Kommentierung, daß die traditionellen Burschenvereinigungen in der NS-Zeit "neuen Jugendorganisationen weichen (mußten), erstanden aber nach dem 2. Weltkrieg in manchen Dörfern neu". Auch unter den politisch gewandelten Verhältnissen vermochte Wrede nicht, die Gleichschaltung

${ }^{124}$ Zur Bewertung dieses Wandels ist die Frage nach der Nachhaltigkeit nationalsozialistischer Infiltration bedeutsam: Wie tief drang die Ideologie tatsächlich in die Brauchausführung ein, wie sehr wurde sie von den BrauchträgerInnen verinnerlicht, so daß ihr Überleben auch nach dem Zusammenbruch als wahrscheinlich gelten konnte? Zudem läßt sich fragen, mit welchem Bewußtsein und mit welcher Radikalität die manifesten oder latenten nationalsozialistischen Strukturen und Inhalte verworfen wurden. 
unter den Nationalsozialisten und deren Konsequenzen kritisch zu analysieren. Gleichfalls wird an anderer Stelle Wredes (31960:312) undifferenziertes Geschichtsverständnis offenkundig:

"Das mannigfache Brauchtum, das den Mai umrankt und durchzieht, gilt besonders den Dorfmädchen, der Verehrung der Tugendhaften und der Verunglimpfung der weniger Ehrenhaften. Die Mailehen und deren Versteigerung sind noch in vielen Dörfern der Nordeifel üblich wie ehedem am ganzen Mittelrhein und in Hessen".

Bereinigt von dem ideologischen Vokabular, erscheint der Brauch hier unverändert als Ausdruck einer sittenrichterlichen Tätigkeit der männlichen Jugend. Gerade Wredes Urteil hätte in Anbetracht seiner eigenen Aktivitäten und "wissenschaftlichen" Publikationen im Dritten Reich anders ausfallen müssen. Er hätte den politischen Mißbrauch, den Prozeß der ideologischen Vereinnahmung und Wiederbelebung der Maibräuche aus intimster Erfahrung und Kenntnis schildern können. Statt dessen wird das Bild einer bruchlosen Kontinuität, faktisch eines ahistorischen Stillstands des Mailehens gezeichnet. Die realen Verhältnisse der Vergangenheit in ihrem Wechselspiel von Statik und Dynamik werden verfälscht und verschwiegen. ${ }^{125}$

Da exaktere historische Analysen für die frühe Nachkriegszeit fehlen, steht an dieser Stelle die generelle Haltung zu historischen Wandlungsprozessen auf dem Prüfstand, die sich in der Literatur niedergeschlagen hat. Es läßt sich nicht übersehen, daß die Autoren sich nicht mit den konkreten Problemen der Umbruchzeit befaßten, sondern auf allgemeinere Wandlungs- bzw. Beharrungstendenzen ausgewichen sind. Am auffälligsten erscheint dabei ein Einvernehmen im Hinblick auf die grundsätzliche Starrheit von Brauchstrukturen. So ist allgemein die Rede von gegenwärtig bedeutsamen "ursprünglichen, in jahrhundertelanger Entwicklung gewordenen Grundlagen" (Zender 1964:573) oder von einer immer noch "festgefügte(n) Brauchlandschaft" im Kreis Ahrweiler (Ruland 1968:235). Nach Ruland (1972:620) habe sich das Verhalten der Mailehenpaare mit unerheblichen Abweichungen über 120 Jahre hinweg an die normativen Vorgaben der Vereine gehalten, so "wie die Statuten es für 1850 schon aussagen". Den Schlußstein in diesem scheinbar immerwährenden, schon zur Leblosigkeit erstarrten Brauchmonument Mailehen setzte Zender (1979:863):

"Sogar bei Bräuchen, die in den Strudel politischer Ausnutzung hineingezogen waren, hat sich nach 1945 das alte Verbreitungs- und Gestaltbild wieder hergestellt".

${ }^{125} \mathrm{Da} \beta$ seine gleichmacherische Strategie auf fruchtbaren Boden fallen konnte, zeigten z.B. die Ausführungen von Barlen-Ebert (1960:6, 11), die Wredes Darstellung kommentarlos übernommen hat. Aufgrund der häufig zu verzeichnenden Fehler sei hier ausdrücklich darauf hingewiesen, daß Argumentationen, die sich auf Quellen beziehen, die in der nationalsozialistischen Zeit veröffentlicht wurden, in keinem Fall als gesichert gelten und ungeprüft übernommen werden können. 
Verbreitung und Gestalt des Mailehens erscheinen nach 1945 regelrecht bereinigt von jeglicher politischen Umklammerung und Umformung, die es in der nationalsozialistischen Zeit erfahren hat. Wie diese scheinbar flächendeckende "Reinigung" oder fragwürdige Wiedereinsetzung in den vorigen Stand ablief, darüber erhält man jedoch kaum eine Nachricht. Die Vermutung liegt nahe und konnte bisher nicht widerlegt werden, daß weder die Vergangenheit einer korrumpierten Brauchausübung und Brauchträgerschaft noch die Auseinandersetzung mit dieser speziellen Vergangenheit des Mailehens im Interesse der volkskundlichen Forschungsarbeit lag. Die Problematik volkskundlicher Forschungsdefizite verschärft sich zudem an solchen Stellen, wo die nationalsozialistisch erheblich beeinflußten Untersuchungsergebnisse in der jüngeren Literatur unkritisch übernommen und weitergetragen werden.

Hinzu tritt die empirische Problematik, die sich in den beobachteten Haltungen der Befragten ausdrückt und zu berücksichtigen ist. Selbst in jüngerer Zeit, wo die Suche nach Ursachen und Verantwortlichen zunehmend für Betroffene weniger brisant erscheinen muß, hat es Schwierigkeiten bei der Erforschung der nationalsozialistisch geprägten Brauchgeschichte gegeben. Bei den jungen Brauchakteuren stieß man weithin auf Desinformiertheit, was die Vergangenheit des eigenen Vereins betraf (Faber/Ziegler 1979/80:152, 161f), oder die Untersuchungsergebnisse wiesen eindeutig auf ein Verschweigen der nationalsozialistischen Brauchpraxis hin (Löber 1972:29ff). ${ }^{126}$

\subsection{Aufbruch in die Gegenwart}

Bis in die Gegenwart reicht der tiefgreifende Wandel, den das Mailehen der zweiten Hälfte des 20. Jahrhunderts erfaßt hat. Dem Brauch wird nunmehr eine dynamische, flexible Struktur zugeschrieben. Reaktionen des Brauchgeschehens auf Veränderungen in der Gesellschaft werden von den Berichterstattern mit seismographischem Gespür dokumentiert. Somit stehen die Beobachtungen, welche die Forschung etwa 15 Jahre nach Kriegsende anstellt, diametral den Erkenntnissen von einer annähernden Unwandelbarkeit der Gestalt des Mailehens gegenüber. Veränderungen in den übergeordneten Gesellschaftsbereichen von Wirtschaft,

${ }^{126}$ Rückkehr zur besseren, zur unverfänglicheren Vergangenheit, Befreiung von faschistischer Unterdrückung und Ansätze, dort weiterzumachen, wo man ab 1933 gehindert wurde, sind durchaus nachvollziehbare Bewältigungsmechanismen. Dennoch sollte bewußt sein, daß die Folgen 13jähriger nationalsozialistischer Geschichte de facto unauslöschbar sind. Wenn sie nicht in aller Deutlichkeit zutage treten, dann ist zumindest die psychosoziale Disposition des einzelnen betroffen. Insofern bleibt es Illusion oder taktische Geschichtsklitterung zu meinen, daß das Mailehen nach 1945 wieder das Gleiche sei wie vor dem Machtantritt Hitlers. 
Politik, sozialer Organisation und Religion sind nicht folgenlos für das Mailehen geblieben. Je nach Ausmaß von Einflüssen wie z.B. Urbanisierung, Persönlichkeitsbildung, Mobilität, moderne Freizeitgestaltung konnte die Ausübung des Mailehens zum Erliegen kommen. Wiederbelebungsversuche waren aber zu keiner Zeit ausgeschlossen, insbesondere dann nicht, wenn historisch orientierte Sinnstiftung mitspielte. Deutlich haben sich innerhalb des Brauchsystems die beiden entgegengesetzten Strömungen im Verlauf der letzten vierzig Jahre Brauchausübung herauskristallisiert: Einerseits führte eine Tendenz der Vereinfachung, andererseits eine Zunahme von Komplexität und Differenzierung zur Umgestaltung des Mailehens. Diese beiden Grundströmungen haben vielfältige, in der Literatur detailliert beschriebene Erscheinungsbilder hervorgebracht. Die wichtigsten Neuerungen sollen zusammenfassend vorgestellt werden. Sie können im empirischen Hauptteil der Arbeit ein Wegweiser für den historischen Standort des untersuchten Fallbeispiels sein.

Das Mailehen hat durch die Einführung einer öffentlichen und feierlichen Krönungszeremonie des Maikönigpaares eine wesentliche Programmerweiterung erfahren. Bot selbst schon das exponierte Amt des Maikönigs und seiner Mitregentin ein relativ hohes Maß an Reputation, so ist das Prestige der jährlich neu bestimmten Persönlichkeiten samt ihrem Gefolge durch die öffentliche Inszenierung einer Krönung nochmals gestiegen. ${ }^{127}$ Faber/Ziegler (1979/80:172-179, 188ff) berichten erstmals und eingehend über das Zeremoniell. Sie haben in ihrer Abhandlung im Anhang zusätzlich die Festreden hinzugefügt, die ebenso wie die verschiedenen Abbildungen einen nachhaltigen Eindruck von der Feierlichkeit und Würde des Akts hinterlassen. ${ }^{128}$ An Zuschauern schien es bei diesen Anlässen nicht zu mangeln, so ist je nach Ortschaft von etwa 100 bis 300 Festgästen die Rede. Ein repräsentatives Podium als Bühne und der Einsatz verschiedener Redner, welche die Festabfolge einzuhalten hatten, hinterließen wohl insgesamt den Eindruck einer gelungenen Darbietung. Das Mailehen entwickelte sich auf diese Weise zunehmend zum Schaubrauch. Unüberschreitbare Grenzlinien konnten sich daher zwischen inszenierenden Protagonisten und konsumierendem Publikum legen. Die ästhetische Komponente wurde z.B. durch üppigen Straßenschmuck oder durch das aufwendige Äußere der BrauchträgerInnen erheblich gesteigert. Der Brauch entfaltete auf diese Weise die Möglichkeit prachtvoller Selbstdarstellung für den Kreis der Jugendlichen und zuschauergerechter Freizeitgestaltung auf der Seite der passiven

${ }^{127}$ Weder in Dierkers Dissertation (1939) noch in der detailreichen Materialsammlung des Rheinischen Wörterbuchs (1928-71) wird eine Krönungszeremonie erwähnt, obgleich mehrfach von schmuckvollen Insignien oder von feierlichen Umzügen samt Hofstaat die Rede ist (s. unter den Stichwörtern Mai, Maifest, Maigraf, Maiknecht, Maikönig, Maikönigin, Maimagd und Maistrauß). Zum Amt des Maikönigs s. auch Fn. 104.

${ }^{128}$ Vgl. die Abbildung in Faber (1985:444). 
Ortsbevölkerung. Faber/Ziegler (1979/80:156f, 185) haben dabei beobachtet, daß die Brauchaktivitäten, die zwar Engagement erforderten, aber nur von geringem Schauwert waren, bei den Junggesellen kaum akzeptiert wurden. Das Mailehen hat durch die Komponente der Selbstdarstellung weitere Ausdifferenzierungen erfahren, gleichzeitig führten die für den einzelnen unangenehmeren Seiten des Brauches zu einer Einschränkung der Brauchbeteiligung.

Der Aspekt des persönlichen Engagements für den Verein und in der Brauchausübung ist keinesfalls auf einen allgemeinen Trend zurückzuführen. Er wird von persönlichen Einstellungen und von der allgemeinen Gruppenkohäsion stark beeinflußt. So geht aus dem lebendigen Bericht von Ruland (1972:620) hervor, daß gerade die unbequemen Aufräumarbeiten nach dem Maiball eine integrative Funktion übernehmen und den Anlaß zu einer informellen Nachfeier geben konnten:

"Offiziell endet mit diesem Ball das Verhältnis [der Mailehenpaare; H.-W.W.]. Am Tag darauf ist für die Burschen Blautag. Sie räumen den Saal auf, bezahlen die Rechnungen und feiern am Brünnchen [...] nach. Oft sind sie am Ende des Tages so mitgenommen, daß sie mit allen Kleidern durch die Ahr marschieren. 'Die Badesaison ist eröffnet."'.

Zur Komplexitätssteigerung des Mailehens kann auch eine Professionalisierung der Brauchorganisation gezählt werden. Junggesellenvereine wurden inzwischen geschäftsmäßig geführt. Den üblichen Geldquellen (Versteigerung und Tanzveranstaltung) stellte man weitere zur Seite; so flossen Gelder aus Spenden, zusätzlichen Festveranstaltungen oder Wettbewerben neben den regulären Mitgliedsbeiträgen in die Vereinskassen. ${ }^{129}$

Überhaupt haben die Kalkulation der Kosten und die Berücksichtigung des Nutzens bei der Brauchausübung einen festen Platz in der vereinsmäßigen wie privaten Buchführung eingenommen. Denn mit der Etablierung des präsentablen Schaucharakters sind kostspielige Äußerlichkeiten sehr bedeutsam geworden. Glanz und Gloria einer würdevollen Krönungszeremonie müssen ebenso finanziert werden wie beispielsweise die obligatorische Bewirtung zahlreicher Gäste durch die Eltern der Maikönigin.

Die konkrete Brauchausübung hat sich entsprechend der allgemeinen Entwicklung in Wirtschaft, Know-how und Lebensstandard der allgemein verfügbaren technischen Innovationen bedient. Gerade auf dem Terrain, das im allgemeinen mit typisch männlichen Handlungsmustern assoziiert wird, ergab sich ein reichhaltiges

${ }^{129}$ Aus der Buchführung zweier Junggesellenvereine im Bonner Raum geht hervor, daß die Zusatzeinnahmen im Haushalt des Jahres 1978 zwischen 25\% und 40\% lagen. Die vereinsmäßigen Ausgaben zum Maifest schwankten zwischen $42 \%$ und $67 \%$ der Gesamteinnahmen. Mithin ergibt sich eine interessante finanzwirtschaftliche Gewichtung der Maibräuche, da bei dem anonymisierten Verein (Nr.1) maibrauchfremde gegenüber maibrauchspezifischen Ausgaben einen höheren Anteil erzielt haben (Faber/Ziegler 1979/80:154f). 
Repertoire, das sich zwischen dem Einsatz von Kranfahrzeugen beim Aufstellen der Maibäume und der Nutzung des Computers bei der zufallsabhängigen Ermittlung der Mailehenpaare erstrecken konnte. ${ }^{130}$

Bemerkenswert ist auch die Steigerung der vereinsgebundenen Aktivitäten. Die Ausrichtung weiterer lokaler Feste hat als zusätzliche Einnahmequelle oder im Rahmen interner Feiern als wirksames Mittel zur Steigerung des Wir-Gefühls gedient. Darauf wurde oben hingewiesen. Gleichzeitig beteiligten sich die Junggesellen auch an Altenkaffees oder halfen dabei, örtliche Goldene Hochzeiten zu gestalten. Das Mailehen mit Versteigerung, Maiensetzen, Aufstellen des Dorfmaibaums, Organisation des Maiballs ist zu einem Betätigungssegment neben anderen geworden. Daneben fällt auf, daß auch die vereinsinternen Unternehmungen, insbesondere die gemeinschaftlichen Ausflüge, mit erhöhtem Aufwand betrieben wurden. Regelmäßige Fahrten an Rhein, Mosel und Ahr sind inzwischen selbstverständlich, sogar Auslandsreisen nach Mallorca oder Holland wurden genannt. ${ }^{131}$

Doch die Steigerung der Aktivitäten, des Schauwertes einzelner Brauchelemente und das Einbringen moderner Techniken können nicht darüber hinwegtäuschen, daß das Mailehen genauso von einer Aufwandsbegrenzung erfaßt wurde, die sich in einer sorgfältigen Kosten-Nutzen-Abwägung der Beteiligten widerspiegelt. Derartige Kosten-Nutzen-Kalkulationen haben innerhalb des Brauchgeschehens ein Spannungsfeld erzeugt, das nicht nur für Auflösungserscheinungen, sondern auch für weitere Ausdifferenzierungen sorgte. Galt es in früheren Berichten noch als Selbstverständlichkeit, daß eine designierte Maikönigin ihre "Wahl" angesichts der bezeugten Ehre bedenkenlos annahm, so sind nun zeit-, arbeits- und finanzwirtschaftliche Erwägungen der Mädchen ausschlaggebend geworden. Auch die Eltern der jungen Regentinnen wurden von derart pragmatischen Überlegungen beeinflußt: Nicht die Sorge um sittliche Verfehlungen, sondern Überlegungen zu schulischen oder beruflichen Leistungen der Töchter wurden bestimmend, wenn es um die Zustimmung zur Teilnahme an Tanzveranstaltungen ging. Wo ehemals Geschlossenheit und Einmütigkeit in der Erfüllung der Brauchbedingungen herrschte, sind nunmehr diffizile Abstimmungen unerläßlich geworden (Faber/Ziegler 1979/80:163f).

$\mathrm{Zu}$ ähnlichen Auswirkungen hat die emanzipatorische Bewegung geführt, da sie die Mädchen und Frauen gegenüber geschlechtsspezifischer Benachteiligungen sensibilisierte. Die Junggesellen wurden zunehmend zur Berücksichtigung weiblicher Interessen und zur Korrektur ihrer dominanten Position in der Brauchausübung gedrängt. Wenn eine Paarbeziehung durch das Mailehen erfolgreich zustande

${ }^{130}$ Vgl. Faber/Ziegler (1979/80:166), Grasmück (1989:25).

${ }^{131}$ Hierzu Faber/Ziegler (1979/80:154) und Ruland (1972:620). 
kommen sollte, reichten jetzt nicht mehr die Versteigerungsergebnisse aus. Indessen wurde um die Teilnahme der Mädchen am Maiball durch Einladungsschreiben gezielt geworben, den festen Freunden der Mädchen gegenüber verhielt man sich weniger ausgrenzend, Maigepflogenheiten, wie z.B. die Durchführung von Kommabenden, verloren ihren verbindlichen Charakter und wurden den Wünschen der Beteiligten angepaßt. ${ }^{132}$ Es ist nicht zu verkennen, daß die geringere Beteiligung der Frauen am Brauch Zerfallserscheinungen von Brauchelementen zur Folge hatte. Dort, wo diffizile Abstimmungen nicht zum Ergebnis kamen, wurde z.B. der Kommabend aufgegeben. Auch die Palette der Rügeformen ist minimiert worden, wie später noch zu zeigen sein wird. Brauchmodifikationen, die dem sozialen Wandel entsprangen, konnten halbherzig ausfallen, weil sie sich nur zögerlich vom scheinbar "Althergebrachten" distanzierten. Das folgende Beispiel dazu kommt von Ruland (1968:235) und verweist auf den Rummel:

"Die Burschen, die nicht steigern, müssen zahlen und bleiben im Knubbel, wie es hier heißt. (Ehedem blieben die nicht gesteigerten Mädchen im Knubbel, der dann von einem Jungen zu einem Spottpreis ersteigert wurde. Aber das setzte doch böses Blut im Ort.)".

Ein letzter wichtiger Aspekt der Komplexitätssteigerung ist exogen bedingt, insoweit bestimmte Ziele der Brauchausübung von außen an die BrauchträgerInnen herangetragen werden konnten. An diesem Punkt setzte erneut eine Ideologisierung des Mailehens an; zwar nicht in einer doktrinären, zwanghaften Spielart, die dem nationalsozialistischen Zugriff entsprach, sondern in einer zum Teil recht subtilen Vereinnahmung durch die vom Zeitgeist, von Wählerstimmen oder auch von anderen Nützlichkeitserwägungen abhängigen gesellschaftlichen "Meinungsmacher". Ein konkretes Beispiel hierfür haben Faber/Ziegler (1979/80:160ff, 185 und Faber 1985:448) bei ihrer Analyse der Motivation der Junggesellen zur Brauchausübung erwähnt. Die vagen Floskeln von der Förderung der Gemeinschaft, der Geselligkeit und des "Brauchtums", die bei den Brauchträgern registriert wurden, hatten eine direkte Affinität zum Sprachgebrauch der Festtagsredner aus der Kommunalpolitik, der lokalen Heimatforschung oder Presse. Die Brauchausübung diente führenden Kommunalpolitikern als Vehikel, mit dem eine aktive, harmonische und traditionsbewußte Ortsgemeinschaft beschworen wurde. Es entfaltete sich ein schönfärberisches Bild, das durch die jährlich wiederkehrenden Feiern geeignet schien, die Bindungsfähigkeit zur Heimat unter Beweis zu stellen. Stolz hat die lokale Führungselite die Tatkraft der Söhne und die Schönheit der Töchter des Ortes gepriesen und verschwieg wohlweislich kommunale Probleme und Ärgernisse, die letztlich auch mit der Brauchausübung verquickt sein konnten (z.B. Lärmemissionen durch laute Tanzmusik). Regelmäßig entzogen sich Ortsansässige dem rituellen Treiben, das sie nicht ansprach, das ihrem Empfinden nach zu laut oder zu "feucht-

${ }^{132}$ Faber/Ziegler (1979/80:163f, 168) und Löber (1972:115f). 
fröhlich" werden konnte. Der einsetzende Braucheskapismus führte die Verdrossenen über die Feiertage in Urlaubsgegenden fernab von Zuhause (Zender 1979:865).

Mit der Ideologisierung auf psychosozialem, gesellschaftspolitischem Gebiet korrespondiert eine Kommerzialisierung auf der materiellen, ökonomischen Seite. Bereiche kommunaler Wirtschaft bedienten sich des Mailehenbrauches, um finanziellen Profit $\mathrm{zu}$ erheischen. Ob dabei die Belange der BrauchträgerInnen beeinträchtigt wurden, ist nicht von vorrangigem Interesse der Geschäftemacher. Aus der Literatur läßt sich nur ein oberflächlicher Informationsstand über die Formen und Auswirkungen der Kommerzialisierung gewinnen. Zum Teil sind die Aussagen auch widersprüchlich. Einerseits wurde behauptet, daß der prosperierende Fremdenverkehr im Ahrgebiet zu einer Belebung des Brauches geführt habe (Ruland 1968:237f), andererseits heißt es:

"Hier wird nichts für die Fremdenwerbung ausgeschlachtet, wozu sich manches leicht anböte. Maibaumholen und -aufstellen, Mädchensteigerung, Maiball und Liedgut gäben für einen geschickten Arrangeur großartige Möglichkeiten, ganze Busse mit Schaulustigen heranzuschleppen, um hier die 'wahre Volksseele' öffentlich darzubieten" - natürlich gegen Bezahlung, möchte man hinzufügen (Ruland 1972:621).

Die recht detaillierte Untersuchung von Faber/Ziegler (1979/80:186) bietet zu diesem Punkt nur Fragmentarisches. Die folkloristischen Züge des Mailehens, wie z.B. eine Kutschfahrt für das Maipaar, die Beteiligung unspezifischer Ortsvereine am Umzug und die Austragung von Fähndelmeisterschaften, werden aufgezählt, aber nicht eingehender analysiert. Mithin bleibt das Fazit, daß das Mailehen durchaus Ansatzpunkte einer Kommerzialisierung entfaltete. Unklarheit besteht jedoch in den Folgen. Es ließ sich bereits an anderer Stelle zeigen, daß das Mailehen den Charakter eines Schaubrauches annehmen und damit weitgehend seine Bedeutung als Instanz der Partnervermittlung einbüßen konnte. In der Folge kam es unweigerlich zu einer Inszenierung von überlieferten Brauchformen, die zu einem wesentlichen Teil ihrer Funktionen entkleidet sind und in vielfältiger Weise modifiziert und arrangiert wurden, so daß der Eindruck einer gewissen Beliebigkeit des Brauchgeschehens entstehen konnte. Hier muß freilich die Frage nach dem Band, das letztlich die Aktionen und Akteure zusammenhielt, gestellt werden. Führte die festzustellende Beliebigkeit nicht zu Desorganisation und endgültigem Niedergang? Verlangte die bisherige Kontinuität des Mailehens nicht klarere Vorstellungen, Ziele und Konzepte für die Gewährleistung zukünftiger Brauchausübung? Reichte die Unterlegung des Mailehens mit den oben aufgeführten ideologischen Phrasen von Gemeinschaft, Geselligkeit und Tradition als Sinnstiftung für die BrauchträgerInnen und die Menschen aus den betreffenden Ortschaften aus, um weiterhin Jahr für Jahr die notwendigen Akteure und Zuschauer anziehen zu können? ${ }^{133}$

${ }^{133}$ Diesen Fragen wird in Kapitel 4 und 5 nachgegangen. 
Bei der bisherigen systemischen Betrachtungsweise muß darauf geachtet werden, daß vorhandene Spannungsverhältnisse und konkurrierende Entwicklungskräfte angemessene Berücksichtigung finden. So sollte der Prozeß einer fortschreitenden Ausdifferenzierung des Brauches nicht darüber hinwegtäuschen, daß das Mailehen ebenso Tendenzen zur Vereinfachung von Formen und Inhalten in sich getragen hat. Sehr auffällig ist dabei der ersatzlose Wegfall von Pflichten und Rechten, die für die Mailehenpaare Geltung hatten. ${ }^{134}$ Beispielsweise ist der prinzipielle Geschenketausch zwischen den Geschlechtern, der schon bei Weinsberg (s. Kap. 2.3) beschrieben und der in nachfolgenden Berichten durch eine Vielfalt abgewandelter Varianten bereichert wurde, vielfach abhanden gekommen. Das Maiensetzen ist in manchen Gegenden im Rückgang begriffen. Zum Teil wurden die Bäume nicht mehr selbst geschlagen. Statt dessen konnten sie vom Forstamt erworben werden (Faber/Ziegler 1979/80:166). Die Zahl der Blumensträuße für die weiblichen Mailehen nahm ab (Barlen-Ebert 1960:23), von irgendwelchen Schmuckgegenständen als Präsent für die Auserkorene oder auch für den werbenden Junggesellen ist keine Rede mehr. Im Saargebiet ist das Brezelgeschenk an den Jungen zwar "wiederbelebt" worden, doch konnte es sich hier kaum noch um den Ausdruck individueller Zuneigung handeln. Die Brezel wurde zu einem ausdruckslosen Standardgeschenk: das seriell hergestellte Erzeugnis des örtlichen Bäckers ersetzte das individuelle Backwerk der Brauchpartnerin (Grasmück 1989:26). Wenngleich hier lediglich schwache Anzeichen der Veränderung $\mathrm{zu}$ beobachten sind, wird doch deutlich, daß eine Rückbildung und Abnahme von Brauchformen zu verzeichnen ist. Diese Anzeichen stellen keineswegs den Endpunkt der Entwicklung zur Vereinfachung des Mailehens dar. Es sind bereits Fälle beschrieben worden, die eine weitaus stärkere Schwundstufe kennzeichnen. Relativ häufig erhält man Nachricht über die ersatzlose Streichung des Kommabends. Dies war eine brauchrelevante Institution, die das gegenseitige Kennenlernen der Paare förderte. ${ }^{135}$ Gleiches gilt für die Ahndung der Vergehen gegen die Statuten der Junggesellenvereine durch Strafgelder: groteske Gebote, wie sie vielfach in den Regularien festgehalten wurden, haben keinen Bestand mehr, weil sie inzwischen von den Verhältnissen der Zeit völlig überholt wurden, unbekannt sind oder einfach nicht befolgt werden. Löber (1972:266f, 354f) hat im hessischen Fronhausen eine Situation vorgefunden, in der die Mailehenversteigerung unregelmäßig stattfand und etwaige Versteigerungsergebnisse für die ersteigerten Mädchen folgenlos blieben. Es wurden hier offensichtlich Paare nur noch ermittelt, um durch die Versteigerung einerseits die Vereinskasse aufzubessern und um sich andererseits an dem ausgefallenen, exotischen Spaß der Auktion zu erfreuen.

${ }^{134}$ Eine allgemeine Verflachung der gegenseitigen Verpflichtungen haben Zender (1954:27), Rockenbach (1954:27), Ruland (1968:237) Löber (1972:153-157, 354f) und Faber (1985;447f) verzeichnet.

${ }^{135}$ Siehe vor allem Zender (1954:27), Faber/Ziegler (1979/80:163) und Faber (1985:447f). 
Zwischen den beiden beschriebenen Polen hat das Gros der Ausprägungen sicher eine Mittelstellung im Spektrum der Brauchvereinfachung eingenommen. Eine entscheidende Rolle in diesem Prozeß spielte der Ausbau des Mailehens als Wirkungsort für Männer bei gleichzeitigem Rückgang der Beteiligung der Frauen. Während in Fronhausen die Statistenrolle der Frauen nur noch auf dem Papier der Versteigerungsliste nachweisbar ist, genügte in vielen Orten ein gemeinsamer Tanzauftritt auf dem Maiball, um den minimalen Anforderungen zu entsprechen. Sollten die Mädchen trotz dieser Regelung nicht zum Tanz erschienen sein, kam es weder zum Eklat noch zu einer Sanktionierung durch Schandmaien oder ähnlichem. Insbesondere die Rügebräuche, die in der Zeit nach 1933 übermäßig betont wurden, sind nahezu vollständig erloschen. Dort, wo es zu einer Revitalisierung kam, hatten die Brauchträger mit rechtlichen Konsequenzen zu rechnen (Müller 1977:7; Schrick 1992:44 Fn. 46). Dies deutet darauf hin, daß die rechtliche Position der Betroffenen sich insofern gestärkt hat, als die sozialen Barrieren im dörflichen Sozialgefüge nicht mehr ausreichen, um die gerichtlich einklagbare Wahrung von Persönlichkeitsrechten $\mathrm{zu}$ vereiteln. ${ }^{136}$ Gleichzeitig hat das sensibilisierte Bewußtsein der Brauchbeteiligten darüber, daß die Würde des Menschen unantastbar ist, dazu geführt, daß der brauchmäßig legitimierten Praxis der Volksjustiz die Grundlage entzogen wurde. Die Öffnung der dörflichen Gesellschaft und die fortschreitende Individualisierung gewährten dem einzelnen einen Handlungsspielraum, der nicht mehr durch die einschüchternde Wirkung überlieferter Rügebräuche einzugrenzen ist.

Zieht man all diese Auflösungserscheinungen in Betracht, so zeichnet sich immer deutlicher ein Rückzug der Frauen aus dem Brauchgeschehen ab. Dies kann im Einzelfall dazu führen, daß selbst in einem Ort, wo die Mailehen noch versteigert wurden, keinerlei weitere Folgen aus dem Brauch abgeleitet wurden. Lediglich wenn der Ersteigerer ein ganz besonderes Interesse an seinem Mailehen hatte, wandte er noch die Mühe des Maiensetzens auf. ${ }^{137}$ Vielfach wird der Eindruck erweckt, daß der Mailehenbrauch sich allmählich unter der Führung der Junggesellenschaft verselbständigt hat. Ein Brauch vorehelicher Geschlechterzusammenführung hat sich auf die formale Ebene reduziert: die Versteigerung läßt sich ohne das Zutun der Frauen durchführen, dagegen verlangen der feierliche Umzug oder die Kommabende persönliche Beteiligung. Schon die Krönungszeremonie macht nur die Anwesenheit einzelner Mailehen und natürlich die Bereitschaft der Maikönigin erforderlich. Wie schwierig der Erhalt der Zustimmung einer designierten Regentin sein konnte, haben Faber/Ziegler (1979/80:170) angedeutet.

${ }^{136}$ Aus der Literatur geht nicht hervor, wie sehr die gerichtlichen Auseinandersetzungen das dörfliche Zusammenleben erschweren konnten. Auch wenn sich über das Ausmaß nichts in Erfahrung bringen läßt, so wird es Beeinträchtigungen sicherlich in derartigen Fällen immer gegeben haben.

${ }^{137} \mathrm{Vgl}$. Löbers wörtliche Wiedergabe eines Interviews mit zwei Burschenschaftsmitgliedern (1972:353f). 
Hält man sich die gesamte Entwicklung des Mailehens rückblickend vor Augen, so geht der Rückzug der Frauen mit einer Betonung und Festigung der männlich dominanten Stellung in der gesamten Brauchabwicklung einher. Die Formalisierung der Brauchträgerschaft durch eine vereinsmäßige Organisation der Junggesellen trug zu dieser Situation ebenso bei wie die stereotype Verstärkung von Geschlechterrollen durch die gesellschaftlichen und politischen Verhältnisse. Die Zeit des Nationalsozialismus war bereits ein deutlicher Indikator für derartige Einflußnahmen und Wirkungsweisen. Die Steigerung dieser geschlechtsspezifischen Asymmetrie in der Ausübung des Mailehens mußte negativen Einfluß auf das zentrale Element der Paarbildung haben. Als der Zwang zum Mitmachen für die Mädchen unter dem allgemeinen gesellschaftlichen Wandel abnahm, waren die Junggesellen bereit, Zugeständnisse an die weibliche Brauchträgerschaft zu machen. Nicht immer scheinen solche Zugeständnisse Ausdruck eines verständnisvollen Miteinanders zu sein, wie Faber/Ziegler (1979/80:160f) bezeugt haben:

"Bezeichnend für das Verhältnis der Junggesellen zu den Mädchen ist eine Diskussion über die Beteiligung der Dorfschönen [...] gewesen, die sich anläßlich einer Versammlung des Vereins in Niederholtorf mitverfolgen ließ: Als Junggesellen Kritik am Verhalten der männlichen Mitglieder des Maigefolges gegenüber den Gefolgsdamen äußerten und ihnen vorwarfen, sie seien schon zu bequem gewesen, die Mädchen zu den Veranstaltungen abzuholen oder überhaupt mitzunehmen, in diesem Zusammenhang dann forderten, man müsse sie allgemein am Vereinsleben stärker beteiligen und außerhalb des Maigeschehens zu Versammlungen und Ausflügen einladen, wurde ihnen entgegnet: 'Genug, daß man sich im Mai mit denen so oft abgeben muß, müsse man sich dann auch noch das ganze Jahr über mit ihnen beschäftigen?"'.

Die historisch gewachsenen Verhältnisse und besonders die Vereinsstruktur haben das Ungleichgewicht zwischen den Geschlechtern bei der Ausübung des Mailehens verursacht: die Männer entscheiden über Art und Weise des Einsatzes und der Beteiligung der Frauen am Brauch. Der vordergründige Zweck des Mailehens, in der vorehelichen Phase intergeschlechtliche Paarbildungen zu unterstützen, wurde stark ins Abseits gedrängt und - wie gezeigt - von anderen Intentionen überlagert. Die weitere Analyse wird ergeben, welche Motive der Brauchausübung die Mailehenforschung bislang ausfindig machen konnte und wie die gewonnenen Erkenntnisse mit der Empirie zusammenpassen.

\subsection{Entwicklungsgeschichtliche Dimensionen der rituellen Paarbeziehung}

"Der Ring" von Heinrich Wittenwiler, "ein Gipfelwerk des deutschen Spätmittelalters" (Brunner 1991:3), enthält durchaus Hinweise auf eine mögliche Herkunft des Mailehens. Das Epos informiert ausführlich über den Ablauf einer süddeutschen Bauernhochzeit, wobei unsere Aufmerksamkeit einem Tanzspiel galt, das der 
Verteilung und dem Ausrufen der Lehen ähnlich ist. Die Übereinstimmung der Zuteilungssprüche, unter denen bei Wittenwiler Tanzpartner und in der Mailehenausübung die Brauchpartner zusammengegeben wurden, verweist auf eine Verwandtschaft zwischen den betreffenden spielerisch-rituellen Handlungen. Zieht man als Argument hinzu, daß das Tanzen bei der Mailehenausübung von hohem Stellenwert war, dann erscheint ein historischer Zusammenhang von spätmittelalterlichem Tanzspiel und der Entwicklung des Mailehens auch aus der inhaltlichfunktionalen Vergleichbarkeit heraus als denkbar.

Anhand der niedergeschriebenen Erfahrungen des Kölner Patriziers Hermann von Weinsberg (1518-1597) liegt eine Beschreibung des Mailehens vor, die mit weitaus jüngeren Überlieferungen vergleichbar ist: Zwei unverheiratete Leute beiderlei Geschlechts gingen für eine bestimmte Zeit im Jahr eine rituelle Beziehung ein. Der beschriebene Geschenketausch gab dem vorehelichen Paarverhältnis eine eindeutige und formelle Ausprägung. Darüber hinaus hat sich gezeigt, daß die Trägergruppe des Mailehens selbst den Haushalt mitsamt den Mägden und Kindern umfassen konnte. Festliche Speisen und Getränke gehörten zum gemeinsamen Fröhlichsein dazu. Die Art der Lehenverteilung basierte auf dem Zufallsprinzip und konnte von weiblichen Bediensteten vorgenommen werden. Dieses frühe Beispiel hat wichtige Aspekte ins Spiel gebracht, die mit der "typischen" Erscheinungsform des Mailehens unvereinbar erscheinen: 1. der Brauch wurde im städtischen Umfeld ausgeübt; 2. der Brauch fand über die gesamte Fastenzeit bis in den Mai hinein statt; 3. der Brauch präsentierte sich in vornehmen, gehobenen Familien, in denen aber alle Haushaltsmitglieder unabhängig von Alter, Status, Ehestand - teilnehmen durften; und 4. Frauen hatten die Möglichkeit, die Lehenpaare auszurufen.

Seit dem 16. Jahrhundert belegen auch Visitationsprotokolle die Existenz des Mailehens. Ergriffen von der Sorge, daß die Brauchausübung, ähnlich der Nachtfreierei, zu großer "leichtfertigkeit" verleiten würde, ${ }^{138}$ wies die Obrigkeit die Pfarrherren an, die Sache gut im Auge zu behalten. Bald darauf verschärfte sich die ordnungspolitische Reglementierung. Verbote, Edikte, Mandate und dergleichen häuften sich, welche die Abschaffung des Mailehens zum Ziel hatten. Stufenweise hob man das Strafmaß bei Übertretungen des Verbots an und erhöhte somit den Abschreckungseffekt gegenüber den potentiellen DelinquentInnen. Jedoch führten diese Maßnahmen zu zweifelhaftem Erfolg. So wurde an manchen Stellen der Widerstand der Ortsjugend gegenüber den moralisierenden Instanzen sichtbar. Daß hierbei die adoleszenten Brauchträgerinnen und -träger von der Bevölkerung mit dem nötigen Rückhalt rechnen konnten, ist aus einem Teil der Quellen $\mathrm{zu}$ erschließen. Ferner ließ sich festhalten, daß das Lehenausrufen im 16. bis 18. Jahrhundert weite Verbreitung in den Gegenden der ehemaligen Rheinprovinz fand, aber auch in der Pfalz, im Saarland

${ }^{138}$ Dazu ausführlich Abschnitt 3.6. 
und dem lothringischen Grenzgebiet sowie in Hessen anzutreffen war. Dabei war die Brauchausübung keineswegs nur auf den ländlichen Raum eingeschränkt.

Im 18. Jahrhundert schlossen sich die bisher spontan gebildeten männlichen Brauchträgergruppen zu Junggesellenvereinen fester zusammen. Nach dem Muster anderer Vereinigungen existierte fortan ein schriftliches Regelwerk, das beispielsweise Aufnahmebedingungen, die Gruppenstrukturen und die Aufgabenbereiche benannte. Die Kirmesfeierlichkeiten wurden zu einem Betätigungsfeld der Burschen. Hierbei anfallende Kosten, etwa das Honorar der Musiker, mußten beglichen werden. Die Versteigerung der Lehen führte $\mathrm{zu}$ einer Aufbesserung der Junggesellenkasse und entwickelte sich so zu einer willkommenen Möglichkeit, eine finanzielle Lösung für die Organisation des Kirchweihfestes zu finden. Darüber hinaus entsprach das Auktionsverfahren einem gesteigerten männlichen Selbstbewußtsein, das sich auch in der Vergabe von repräsentativen Amtstiteln (Maikönig, Schultheiß oder Präsident) niederschlagen konnte. In gewissem Maße imitierte man jene Vorbilder, die in der Zeit des Ancien régime über die politische Macht verfügten. Daß dabei sarkastische Ironie zum Ausdruck kam, zeigen die aberwitzigen Passagen in den selbstgegebenen Statuten.

Mit dem Vordringen der Mailehenversteigerung im 18. Jahrhundert verloren das Lehenausrufen und die damit verbundenen Varianten der Paarermittlung zunehmend an Bedeutung. In dieser Entwicklung lag eine Einschränkung der Beteiligungsmöglichkeiten von Frauen. Regelte das Lehensverhältnis bisher die gegenseitige Tanzpartnerschaft und den gegenseitigen Geschenketausch, so erfährt man jetzt, daß die Brauchträgerinnen der absoluten Willkür der Junggesellen gehorchen sollten. Übten die Frauen Widerspruch oder verstießen sie gegen die dörfliche Moral, dann besaßen die Junggesellen im Grunde das Recht, die Delinquentinnen zur Rechenschaft zu ziehen. Doch die öffentliche Rüge war im Rahmen der Mailehenausübung nicht von dem Gewicht, das man zwischenzeitlich darin gesehen hat. In den spektakulären Aktionen des Schandmaiensetzens, Kavstreuens oder Lindescheuerns zeigte sich eine wenig subtile und dadurch auch nur partiell wirkungsvolle Möglichkeit der Junggesellen, das Verhalten der Mädchen zu beeinflussen. Von der Drohgebärde wurde sinnvollerweise erst Gebrauch gemacht, wenn massive Verfehlungen der Missetäterin bereits Unruhe im gesamten Dorf ausgelöst hatten. Im übrigen darf nicht übersehen werden, daß die Rügepraxis ebenso den männlichen Delinquenten ins Visier nehmen konnte. ${ }^{139}$

Die Versteigerungspreise und die Institution des sogenannten Rummels konnten die unbeugsamen Mailehenkandidatinnen an einer empfindlicheren Stelle treffen und einschüchtern. Die Burschen gelangten auf diese Weise zu einem Mittel, ihre Wert-

${ }^{139}$ Vgl. auch Thompson (1972:301) und Hinrichs (1991:452-454). 
schätzung öffentlich transparent zu machen. Ganz unten in der Gunst standen diejenigen, auf die kein Gebot abgegeben wurde. Darauf folgten dann ledige Frauen, welche die Junggesellen bei der Versteigerung nur zu niedrigen Geboten herausforderten, während der Maikönigin die höchste Ehre zuteil wurde.

Diese Ausprägungen des Mailehens aus dem 18. und 19. Jahrhundert konterkarieren das Bild von dem frühneuzeitlichen Lehenausrufen. Das gegenseitige informellere Aufeinanderverwiesensein und die gemeinsamen Interessen der Brauchbeteiligten scheinen den statuarisch verbrieften Bestimmungen und damit der gesetzten Dominanz der Junggesellen gewichen zu sein. Demnach ist die Zurückweisung der weiblichen Mailehenrolle durch den in der Einleitung zitierten anonymen Leserbriefschreiber auf den ersten Blick begründet (siehe Kapitel 1.1). Und des weiteren erscheinen auch die sich im 19. und 20. Jahrhundert wiederholenden Prognosen über einen Niedergang des Mailehens schlüssig. Denn Außenstehende konnten den Standpunkt vertreten, daß die betroffenen Frauen sich nicht dauerhaft einer rituell geforderten Subordination aussetzen würden, ohne dagegen zu opponieren. Die Aussagen zur männlichen Dominanz haben sich mit dem Aufkommen der Mailehenversteigerung, des Rummels und anderer Sanktionsmittel verschärft. Hintergründe über diese Brauchformen werden in den Quellen vor dem 19. Jahrhundert nicht aufgedeckt. Die Auffassung, daß die ledigen Frauen dem Junggesellenverein im Rahmen der Mailehenversteigerung zur Verfügung stünden und deshalb den Burschen untergeordnet seien, gewinnt insofern an Gewicht.

Bei genauerer Betrachtung muß dieses Bild der dichotomen Machtaufteilung einem differenzierteren Verständnis für Formen und Inhalte der Brauchpraxis weichen. Anzeichen dafür, daß die Unterdrückung der Frauen keineswegs so weit gediehen war, wie die Berichte des 19. Jahrhunderts und ihre Maileheninterpretationen glaubhaft machen wollen, sind durchaus vorhanden. In Gegenden, wo noch das Lehenausrufen stattfand, war es z.B. üblich, daß bei der Paarzuteilung die Interessen der Brauchträgerinnen berücksichtigt wurden. Und dort, wo die Mailehenversteigerung Eingang gefunden hatte, standen weibliche Schönheit und männliche Zahlungskraft nicht in einer schematischen Wechselbeziehung. Kinkel (1846:160) hat bemerkt, daß auch der Grad der persönlichen Zuneigung für den nötigen Ansporn bei der Ersteigerung einer Mailehenpartnerin sorgen konnte. Möglichkeiten der Einflußnahme junger, lediger Frauen auf die Junggesellen und deren Ansteigerungsstrategien wurden in den Quellen vernachlässigt. ${ }^{140}$

${ }^{140}$ Obgleich der Quellenbestand zur Bewertung informellerer Strategien der Interessenwahrung oftmals dürftig erscheint, darf an der Frage, warum das Potential zur weiblichen Selbstbehauptung in der Vergangenheit so wenig berücksichtigt wurde, keineswegs kommentarlos vorbeigegangen werden. Forschungen, welche die festgefügte Sichtweise auf die Geschlechterrollen zu überwinden trachten, haben differenzierte Ergebnisse erbracht. Es können hier nur einige Hinweise folgen: Maya Nadig 
Die brauchspezifische Institution des Rummels mußte nicht zwangsläufig zur Verunglimpfung von unbeliebten oder weniger hübschen Frauen führen. Geht man von einer zahlenmäßig ungleichen Verteilung der Geschlechter bzw. einer Überzahl unverheirateter Frauen aus, ${ }^{141}$ so zeigt sich dahinter vielmehr auch eine Möglichkeit, soziale Ausgrenzungen abzumildern. Indem die "Übriggebliebenen" im Rummel zusammengefaßt und auf diese Weise an einen Junggesellen versteigert wurden, hatten auch die scheinbar Chancenlosen eine reale, wenn auch nicht die wünschenswerteste Option, am Brauch und an den Tanzfestlichkeiten teilzunehmen. Hinzu kommt, daß wir zwar über die Möglichkeiten der Burschen unterrichtet werden. Sie hätten durch die Ersteigerung des Rummels die freie Wahl über die dort vereinigten Frauen gehabt. Dem wurde aber nicht entgegengehalten, daß für die Frauen, die von dem "Schicksal" des Rummels getroffen wurden, das Verpflichtende der Mailehenbeziehung in den Hintergrund trat. Ebensowenig erfahren wir über widerständige Frauen, die der Norm nicht entsprachen und vielleicht auch nicht entsprechen wollten, denen es möglicherweise zur Auszeichnung gereichte, in den Rummel zu gelangen.

Der "male bias"142 in den Mailehendarstellungen hat auch dazu geführt, daß Fälle, in denen die jungen Frauen die Oberhand gegenüber den männlichen Brauchträgern erringen konnten, unbeachtet blieben. Das Beispiel aus Niederzissen, bei dem die Mädchen am Dreikönigsabend die Brauchorganisation übernahmen, Geld zusammenlegten, Musiker engagierten und die etwas zögerlichen Burschen bis auf den Heuboden verfolgten, um diese als Tanzpartner zu gewinnen, präsentiert eben nicht nur eine seltene oder selten dokumentierte Spielart des Mailehens, sondern auch das weibliche Potential, eine überaus aktive Rolle im Brauchgeschehen einzunehmen.

Die Probleme der Mailehenforschung verstärken sich, wenn es um die Betrachtung der nationalsozialistischen Zeit geht. Unter dem Paradigma, ein authentisches germanisches Wesen aus den "Überresten" der Brauchüberlieferung zu präparieren und schließlich mit neuem Leben zu erfüllen, trugen auch Brauchforscher zu einer ideologisch korrumpierten Wissensvermittlung bei. Es nimmt daher nicht wunder, wenn man aus diesen Quellen männlichen Führungsanspruch und Vollstreckungs-

zum Problem des Machismo (1986:125-162, insbes. 139); Revel zur Überwindung einer isolierten Betrachtung der weiblichen bzw. männlichen Geschlechterrolle (1988:9-13). Vgl. die Beiträge für den Tagungsband zum 31. Kongreß der Deutschen Gesellschaft für Volkskunde in Marburg 1997: "Männlich. Weiblich." herausgegeben von Christel Köhle-Hezinger et al (1999), worin neben historischen und empirischen Ansätzen insbesondere die theoretischen Ausführungen zum GenusKonzept von Babara Duden (1999:66-74) dazu anhalten, eine grundlegende Abkehr von einer starren Geschlechterpolarität herbeizuführen.

${ }^{141}$ Dies konnte z.B. leicht der Fall sein, wenn nicht alle ledigen Männer am Mailehen teilnahmen. Vgl. dazu den Fall Delhoven, der unter Abschnitt 2.4 beschrieben wurde.

${ }^{142}$ Zum Problem des "male bias" in der ethnologischen Literatur bzw. Feldforschung vgl. Thiel (1980:82-85) und Fischer (1980:73). 
gewalt gegenüber weiblicher Gefügigkeit und Keuschheit vorgespiegelt bekommt. Nach 1945 wurde die nationalsozialistische Einflußnahme in ihrer Bedeutung heruntergespielt. Man behauptete, daß die Erneuerungsversuche und die Gleichschaltung von Vereinen keine Veränderungen des Brauchgeschehens bewirkten. Empirische Untersuchungen über die konkreten Auswirkungen scheiterten bislang, weil die Betroffenen über die damalige Situation und den Wandel keine Auskunft gaben. Die Version von der unveränderten Brauchkontinuität trägt allerdings zu einem Widerspruch bei: die be-schworene eingewurzelte Authentizität ritueller Handlungen, z.B. bei der Verwendung von Schandmaien oder ähnlichen Rügebräuchen, fügte sich nahtlos an eine nach 1945 einsetzende allgemeine Bedeutungslosigkeit dieser einschlägigen Brauchformen. ${ }^{143}$

Was den Wandel betrifft, so ging die Brauchforschung und -beschreibung der letzten fünfzig Jahre in der Regel von einer grundsätzlichen sozialen Anpassungsfähigkeit des Brauchgeschehens aus. Aus dieser Position erwuchs die Chance, scheinbar sinnentlehrte Anachronismen, wie z.B. die Mailehenversteigerung, ohne einen Rückgriff auf vorgefaßte Traditionsrhetoriken wertneutral $\mathrm{zu}$ beschreiben. ${ }^{144}$ Wenn unter den Bedingungen einer Gesellschaft, die zunehmend Alternativen der Freizeitbeschäftigung eröffnet hat, ${ }^{145}$ die Organisation des Maibrauchs und -fests weiterhin gelingen sollte, müßten auch die Traditionsträger sich um die Wünsche der Beteiligten und die Attraktivität der Brauchpraxis kümmern. Auch die Interessen der in den Hintergrund gedrängten Frauen wurden unter diesen Umständen zunehmend relevant. Eine relativ freie Entscheidung über die Annahme des Maiköniginnenamtes gilt hier als eine Anpassung des Brauches an veränderte gesellschaftliche Verhältnisse. Das verbreitete Postulat einer absoluten und rituell legitimierten Entscheidungsmacht zugunsten männlicher und zuungunsten weiblicher Brauchträger wäre hier endgültig in Frage $\mathrm{zu}$ stellen. Die Betrachtung der geschichtlichen Entwicklung des Brauches, wie sie sich aus der Forschungsliteratur erkennen läßt, konnte das Problem der scheinbar einseitigen Machtverteilung an einer tieferen Stelle aufgreifen. Wenngleich die einseitige Beobachterperspektive oftmals keinen unmittelbaren Blick auf die sozialen Verhältnisse zuläßt und die Thematisierung des geschlechts- und subjektneutralen Codes erst eine junge Forschungstradition hat, so ließ sich dennoch zeigen, daß die Interessen beider Geschlechter im Rahmen des Mailehens nach ihrer Verwirklichung strebten. Diesen Ansatz findet man in den frühesten Beschreibungen, in denen die Zufallsauswahl ritueller Paarkonstellationen oder der gegenseitige Geschenketausch bedeutsam waren. Selbst dann noch, wenn

\footnotetext{
${ }^{143}$ Siehe auch Wey (1999:307 Fn.48).

${ }^{144}$ Eine ausführliche Auseinandersetzung mit dem Problem der Traditionsrhetorik findet sich weiter oben in Kap. 3.2; vgl. auch Wey (1999:317f).

${ }^{145} \mathrm{Zu}$ einer ernüchternden Analyse der Zunahme von Freizeitangeboten gelangt Lüdtke (1997:368413).
} 
die Burschen die Paare vergeben und ausgerufen haben, kam der Reziprozitätsaspekt unter den Betroffenen zur Geltung, indem die Mädchen das Ergebnis mit ihrem Einspruch für nichtig erklären oder indem sie informell einen Partnertausch vornehmen konnten.

Aus dem Gesagten ergibt sich das Bild von formalen Rollenunterschieden im Mailehen, die aber nicht unbedingt einer geschlechtsspezifischen Hierarchie folgen mußten. Aber die Frage ist, ob die räumliche Verbreitung des Auktionsverfahrens und die Stärkung des Selbstbewußtseins der männlichen Jugend über ihre Vereinsgründungen seit dem 18. Jahrhundert die Geschlechterbeziehungen nicht doch unter erhebliche Spannungen setzte. Ist die oben geschilderte Widerspruchsmöglichkeit von designierten Maiköniginnen nicht das längst überfällige Resultat weiblicher Loslösungsstrategien aus rituell determinierten Rollenzuschreibungen? Nach dem bisherigen Forschungsstand hätte man diese Fragen eindeutig bejahen müssen. Man hätte auf die objektivierenden Selektionsprinzipien qua Mailehenversteigerung und die Instrumente männlicher Verfügungsgewalt (den Rummel, die Schandmaien) hingewiesen. Und immer wieder wäre implizit oder explizit als Schlußakkord der Unterwerfungsthese die Frage aufgetaucht, wie lange denn noch das "mysogyne Treiben"146 seine Fortsetzung finden könnte. Bei einer derartigen Urteilsfindung hätte man jedoch eine angemessene Quellenkritik umgangen. Die Tatsache, daß die Hauptbetroffenen des Brauches immer nur Gegenstand der Betrachtung waren und in ihren eigenen subjektiven Anschauungen und Äußerungen ignoriert wurden, gehört aber nicht an den Rand, sondern ins Zentrum einer sorgfältigen Reflexion (s. Kap. 4).

${ }^{146}$ Näheres dazu in Abschnitt 3.2. 


\title{
3 Interpretationsansätze
}

\author{
3.1 Kultisches-Zauber der Dämonen und \\ Imitation des Göttlichen
}

Der Brauch in Verbindung mit vorchristlicher Religion und (indo-)germanischer Stammesverwandtschaft ist nicht das Thema aktueller Mailehenforschung. Mit dem Hinweis auf die Unhaltbarkeit ahistorischer Traditionslinien, welche die Mailehenpraxis in einen engen Zusammenhang zu Mythologie, Fruchtbarkeitskulten und Initiationsriten der Germanen verwickelten, endet zumeist die Auseinandersetzung mit mythologischen Forschungsergebnissen. ${ }^{147}$ Doch eine derartige Argumentation entkräftet die traditionalistischen Ansätze nur zum Teil. Sie verlangen eine Entgegnung, die auch Klarheit über eine scheinbar vorhandene inhaltliche Plausibilität verschafft. Denn diese inhaltliche Aussagekraft trägt dazu bei, daß heute noch BrauchträgerInnen, LokaljournalistInnen, HeimatforscherInnen wie auch VolkskundlerInnen an den Glauben der mythischen Kontinuität gebunden sind. So hat z.B. Ruland (1987:136) sein Unverständnis darüber geäußert, daß die jüngeren Maileheninterpretationen sich zu stark auf gegenwärtige Verhältnisse stützen und dabei die Nähe des Brauches zu altdeutschen Rechtsformen ignorieren würden. Angeraten sei eine "Rückorientierung auf älteste Belege". Auch Zender hielt eine archaische Vergangenheit des Mailehens für möglich. Aus Mangel an Belegen stellte er die apodiktische Behauptung auf:

"Der Brauch des Kölner Raumes ist [...] eines magisch-irrationalen Gehalts vollständig entkleidet" (Zender 1972:276). ${ }^{148}$

Dieser Unterstellung von vorchristlichen Wurzeln im Brauch liegt jenes einflußreiche volkskundliche Paradigma zugrunde, das seine Wirkung im 19. Jahrhundert entfaltete und erst nach seiner ideologischen Nutzung im Nationalsozialismus ${ }^{149}$ an Bedeutung verlor. Bis dahin ist dem vermeintlichen mythischen Urgrund des Brauches ein völlig anderes Gewicht, wenn nicht gar ein zentraler oder ausschließlicher Stellenwert beigemessen worden. ${ }^{150}$ Die Arbeiten von Jacob Grimm waren zu Beginn richtungsweisend. ${ }^{151}$ Der 1835 von ihm vorgelegten Abhandlung über die "Deutsche Mythologie" kam aber für die Mailehenforschung nur eine Nebenrolle zu. Vergewissert man

${ }^{147}$ Dazu Faber/Ziegler (1979/80:147), Schrick (1992:32f); ferner Grasmück (1989:24).

${ }^{148}$ Darüber hinaus vgl. Zender (1955:288, 291), ders. (1958:30, 38), ders. (1977:133), ders. (1979:837) und Kyll (1975:70).

${ }^{149}$ Bausinger (1979:61ff) charakterisierte die nationalsozialistische Variante dieser Forschungsrichtung als "konsequentes Extrem".

${ }^{150} \mathrm{Vgl}$. die Arbeiten von Hilberath (1931:7ff) und Dierker (1939:139ff).

${ }^{151}$ Vgl. Bausinger (1979:41f). 
sich über die Positionen der Vordenker, stellt man mit einiger Verwunderung fest, daß Grimm ansatzweise das unheilvolle Potential der Mißdeutung seiner mythologischen Quellensammlungen erkannte. Da er die Lückenhaftigkeit des zusammengetragenen Materials zu beurteilen vermochte, wollte er voreiliger Kritik bewußt entgegentreten:

"Vor der verirrung, die so häufig dem studium der nordischen und griechischen mythologie eintrag gethan, ich meine die sucht, über halbaufgedeckte historische daten philosophische oder astronomische deutungen zu ergießen, schützt mich schon die unvollständigkeit und der lose zusammenhang des rettbaren. ich gehe darauf aus, getreu und einfach zu sammeln, was die frühe verwilderung der völker selbst, dann der hohn und die scheu der Christen von dem heidenthum übrig gelassen haben, und wünsche nichts als daß meine arbeit für einen anfang weiterer forschungen in diesem sinn gelten könne" (Grimm 1835:9).

Doch seine Warnungen gegenüber haltloser Interpretation und sein Werben für eine deskriptive Sammeltätigkeit verhallten. Höchst verärgert über ein früh einsetzendes "Ausschlachten" seiner Veröffentlichungen, zog er als Rezensent gegen jene zu Felde, die seine disziplinierte Zurückhaltung auszunutzen wußten. Neun Jahre nach Erscheinen der "Deutschen Mythologie" wandte sich Grimm (1871:336ff) in einer harschen Replik gegen den ersten Versuch einer religionsgeschichtlichen Interpretation der mythologischen Quellen. ${ }^{152}$ Es liegt nahe, daß die bereits von Grimm erkannte Anwendungsoffenheit mythologisch ausgewiesener Quellen zusammen mit einer einseitigen Betonung völkischer Eigenarten eine für den Fortbestand dieser Forschungsrichtung äußerst problematische und folgenschwere Ausgangslage darstellte.

Das Mailehen erfuhr in der mythologischen Forschung nicht bei Grimm, sondern erst bei Mannhardt (1875-77) und Frazer (1890) ein ausführlichere Würdigung. Es zeigte sich bereits, daß die mythologische bzw. mythologisierende Brauchforschung ihr Ideengebäude nicht eng an historischen Befunden entfaltete, sondern vielmehr nach tieferen, sozusagen überzeitlichen Ursprüngen suchte und somit notwendigerweise auf das weite Feld spekulativer Deutungen verfiel. Um diese assoziativen Gedankenspiele zu erhärten, stützte man sich entweder auf die nordische Mythologie, in der man den Urtext germanischer Religion zu erkennen glaubte, oder man erlaubte sich den Rückgriff auf vielfältige Analogieschlüsse beim Vergleich rezenter "Primitivvölker" und germanischer Vorfahren. Herausgelöst aus ihren jeweils kulturgeschichtlichen und sozialen Zusammenhängen ergab sich mithin für die Beweisführung ein schier unbegrenzter Interpretationsspielraum, der für den Brauch des Mailehens zur Etablierung zweier Erklärungsansätze führte. Zum einen galt der Brauch als die jährlich wiederholte Inszenierung einer mythischen Hochzeitsfeier, bei der das Maikönigspaar zugleich das höchste Götterpaar - Wuotan und Frigg -

${ }^{152}$ Anlaß jener Rezension war die 1844 in Göttingen herausgegebene Arbeit eines Grimmschülers: "Geschichte und System der altdeutschen Religion" von Wilhelm Müller. 
vergegenwärtigen sollte (Hochmythologie). Zum anderen wurde behauptet, daß die Brauchausübung eine dämonische Kraft belebe. Im Gegensatz zur vorangehenden Annahme gingen die Mailehenpaare hier auf eine ursprünglichere Verkörperung geisterhafter Wesen mit existentieller wachstumsfördernden Potenz zurück (Niedermythologie). Mannhardt, der die zweite Position vertrat, sah sich keineswegs im Widerspruch zur These der göttlichen Theogamie, aber er glaubte, mit seiner Deutung zu einem tieferen Sinn und gleichzeitig zu einer älteren Schicht des Brauches vorgedrungen zu sein.

$\mathrm{Ob}$ Theogamie oder Vegetationsdämon, die Paradigmen stimmen letztlich darin überein, daß der Mailehenbrauch Ausdruck einer kultischen Handlung sei. Insofern gilt, daß die Brauchakteure zum Wohle der Gemeinschaft in symbolischer Weise einer übermenschlichen Macht huldigen. Der Maikönig wird in der Vergegenwärtigung des Vegetationsdämons selbst als Mittler zwischen weltlicher und sakraler Sphäre erachtet, da die kultische Brauchausübung "dem nach Berührung des Göttlichen sehnsüchtigen Volke" diene (Mannhardt 21905, 2:200). Explizit setzt Mannhardt sich davon ab, in dem Brauch lediglich eine von der Natur inspirierte saisonale Allegorie zu sehen, wie dies vor ihm von Uhland vertreten wurde: ${ }^{153}$

" [...] nur darum wird die Untersuchung sich zu bewegen haben, ob sie als unmittelbare und selbständige Wurzeltriebe aus der Metapher der Liebe, Werbung, Vermählung für das neue Leben in der Natur und der Menschenbrust, das der Frühling hervorruft, emporschossen, oder ob sie als Blüten auf dem Zweige jener mythischen Illusion gewachsen sind, welche die Lenzmonate mit dem Glauben an ein in Wahrheit personhaftes, dämonisches Brautpaar oder junges Ehepaar erfüllte. Alle Anzeichen sprechen für die letztere Annahme [...] und in der Tat, täuscht nicht alles, so sind Mailehen [...] vervielfältigende, den Parallelismus des Menschenwachstums mit dem Pflanzenwachstum bezeugende Darstellungen der Situationen des geisterhaften Lenzpaares gewesen" (Mannhardt 1875-77, 1:492f).

Frazer stimmt fast ausnahmslos mit der Mannhardt'schen Konstruktion des Mailehenbrauchs überein. Zur Vervollständigung und Konkretisierung fügt er noch das Bild der geschlechtlichen Vereinigung der Maipaare hinzu, denn darin kulminiere letztlich eine wirksame Personifikation und Darstellung der Walddämonen:

"They [neben anderen Vermählungen auch die rituelle eines Maikönigspaares] were charms intended to make the woods to grow green, the fresh grass to sprout, the corn to shoot, and the flowers to blow. And, it was natural to suppose that the more closely the mock marriage of the

${ }^{153} 1844 / 45$ entwirft Uhland eine allgemeine Erklärung des intentionalen Hintergrunds der Maibräuche in seiner Abhandlung über hoch- und niederdeutsche Volkslieder: "Die Poesie liegt weniger in den begleitenden Reden und Gesängen, als unmittelbar in den Festgebräuchen selbst. Die Gestalten, welche hierbei auftraten, waren allegorischer Art und eben darum, selbst wenn sie aus heidnischer Zeit stammten, auch der christlichen unanstößig. Aber die sonst übelberufene Allegorie stand hier in ihrem guten Rechte. Wo eine Volksmenge sich festlich bewegt, da bedarf es eines einheitlichen Ausdrucks, welcher den Sinn der Bewegung augenfällig darlegt, eines vernehmlich und unzweideutig ausgesprochenen Gedankens. Das gerade leistet die Allegorie, und ihr eigenes starres Wesen beseelt sich durch das freudige Volksleben, dem sie zur Losung dient" (Uhland 1984,4:339f). 
leaf-clad or flower-decked mummers aped the real marriage of the woodland spirites [sic], the more effective would be the charm. Accordingly we may assume with a high degree of probability that the profligacy which notoriously attended these ceremonies was at one time not an accidental excess but an essential part of the rites, and that in the opinion of those who performed them the marriage of trees and plants could not be fertile without the real union of the human sexes" (Frazer ${ }^{3}$ 1922,II.1:97).

Ausdrücklich unterstreicht Frazer (31920,II.3:266ff) in einem weiteren Teil seiner Ausführungen die Position der sogenannten homöopathischen bzw. imitativen Magie. Er weist darauf hin, daß die geschlechtliche Vereinigung als kultische Praxis der Vorzeit oder auch der "primitiven Kultur" eine notwendige Vorbedingung zum physischen Fortbestehen einer vom Getreideanbau abhängigen Bevölkerung sei.

In seinem kompilatorischen Werk deutet Reinsberg-Düringsfeld auf den Nimbus, welche das Geschehen jener theogamen Vermählung umgab. Geradezu als "heilig" bezeichnet er die ersten zwölf Nächte im Mai, da die Eheschließung in diese Zeitspanne fallen sollte (1863:134). Gleichfalls geht Simrock in seinem Handbuch zur deutschen Mythologie von einer göttlichen Stellvertreterposition des Mailehenpaares aus (51878:578,580,584ff). Das Mailehen erfährt auf diese Weise eine religiöse Überhöhung und braucht bald den Vergleich zu christlichen Feiertagszyklen nicht mehr zu scheuen. Der Grimmschen Tradition folgend, fordert Hahn (1899:45ff, 67) dazu auf, die vorchristlichen Wurzeln der eigenen Geschichte im Brauch zu akzeptieren. Im Verlauf seiner Ausführungen schildert er dabei den germanischen Ursprung des Mailehens besonders eingehend:

"Vielleicht der bedeutsamste Tag im Jahre war für die Germanen der e r s te $\mathrm{M}$ a i, der Hochzeitstag Wuotans und der Freyja. Der Monat Mai war für die Entwickelung der Jahresschöpfung der wichtigste. Von dem Ansatz der Früchte in diesem Monate hing der Reichtum des Erntesegens ab. Alle guten Geister der Erde, der Luft und des Himmels nahmen an der Hochzeitsfeier teil und zogen in der Nacht zum 1. Mai nach einem hohen Berge mit üppigem Baumwuchs; denn nur auf solchen Bergen konnte die Hochzeit stattfinden. Manches Paar mag sich am Hochzeitstage Wuotans zu dauerndem Bunde zusammengefunden haben, und es ist nach dem eben Gesagten kein Wunder, daß sich die Erinnerung an Wuotans und Freyjas Hochzeitstag, zumteil mit den Anschauungen des mittelalterlichen Lehnstaates durchtränkt, bis in die neueste Zeit hinein erhalten hat. An die bedeutungsvolle Vermählung Wuotans erinnert in erster Linie ein höchst merkwürdiger Brauch, das sogenannte Lehnausrufen oder das Mailehn" (Hahn 1899:58f).

Von der germanischen Frühzeit über das Mittelalter bis in die Jetztzeit zieht der Autor eine kontinuierliche Linie und behauptet entgegen der Quellenlage, daß die Junggesellen sich "nach uralter Sitte" zum letzten Tag im April in den Wäldern versammeln würden, um dort eine Wahl oder Versteigerung der Maifrauen vorzunehmen. "Ohne Zweifel ein Rest des alten, namentlich auf den Mailagern vorkommenden Brautkaufes", lautet schließlich die apodiktische Formel (Hahn 1899:59). Die Unhaltbarkeit derartiger Behauptungen wird im einzelnen durch die historischen Befunde sehr deutlich. Der mythologisierende Ansatz vermag weder formale noch 
inhaltliche Aspekte der Brauchausübung hinreichend zu klären. Die Variantenvielfalt von Brauchterminen und Handlungsorten oder der richtungsgebende Zweck des Mailehens als einer spielerischen Vermittlungsinstanz von Tanzpartnern stehen im Widerspruch zum behaupteten mythologischen Gewicht des ersten Mais und der Verpaarung. Die im Mailehen hervorstechende Hinwendung auf profane Freuden und Unbeschwertheit markieren geradezu einen Gegensatz $\mathrm{zu}$ formelhaften kultischen Inszenierungen, wie sie Hahn oben beschrieben hat.

Was die Deutung des Mailehens von hier aus bedingt weiterführen kann, ist eine angemessene Analyse der Brauchsymbolik. Ohne daß die Aktionen der Mailehenpaare als kultische Beschwörung eines Vegetationsgeistes angesehen werden müssen, können sie dennoch als ein symbolischer Gleichklang von schwärmerischen Frühlingsgefühlen aufgefaßt werden, der seinen Widerhall an einer "erwachenden Natur" findet. So gesehen hätten sich die von Mannhardt gesetzten Vorzeichen erneut umgekehrt, und das Mailehen wäre nicht "jener mythischen Illusion" entsprungen, sondern doch eher als "Metapher der Liebe, Werbung, Vermählung für das neue Leben in der Natur und der Menschenbrust, das der Frühling hervorruft, [emporgeschossen]" (Mannhardt 1875-77, 1:492f).

\title{
3.2 Residuales - Wider frommen Eifer, Eisenbahnen und amerikanischen Geist
}

\begin{abstract}
"Wenn nun bald die Eifel, wie sie das nur hoffen kann, dem Verkehr durch Eisenbahnen erschlossen wird, muß das nicht der letzte Nagel am Sarge der heimischen Ueberlieferungen sein? Aber gedenken wir nicht der Eifel allein: in allen deutschen Ländern haben fremde Gesetzgebung, humanistische Schulbildung und falsche Aufklärungssucht seit Jahrhunderten alles eigenthümliche, naturwüchsige Leben ausgetrieben, und was sich noch in abgeschiedenen Gegenden gefristet hatte, das werden auch dort bald die Eisenbahnen verscheuchen. Dazu der Geist, der jetzt aus Amerika zu uns herüberweht, jener Geist, der nur den Dollar achtet und keine höhern Güter mehr kennt [...]" (Simrock 1856-58, 2:147).
\end{abstract}

Widerstanden hätten demnach die "Traditionen" der Eifelbewohner den Unbilden des vormodernen Wandels. Weder landesherrliche Verfügungen, Anfechtungen durch die Kleriker noch kriegsbedingte Verwüstungen vermochten in jenem Gebiet einen kulturellen Exodus herbeizuführen. ${ }^{154}$ Trotz dieser bewundernswürdigen Zählebigkeit des kulturellen Überlieferungsbestands drohe ein finaler Zusammenbruch, wie die kulturpessimistische, wenn auch nicht innovationsfeindliche Vision des namhaften Bonner Germanisten und Dichters Simrock suggeriert. Letztlich bliebe nur die

${ }^{154}$ Parallel zu Simrock, aber mit unmittelbarem Bezug auf das Mailehen hebt Menzel (1856:65) ebenso das Überdauern kultureller Erscheinungen in der Eifel hervor: "Hier, wo noch so viel gutes Alte der modernen schulmeisterlichen und polizeilichen Aufklärung widerstanden hat, werden die Jungfrauen noch gegenwärtig ausgerufen und verbindet sich damit ein sittlicher Zweck". 
Hoffnung, daß zukünftig die völkisch-nationalen Kräfte wieder mobilisiert werden könnten. Dabei wäre es wichtig, auf höhere Mächte, die Kirche, den Staat und "die junge Wissenschaft der deutschen Sprache und Alterthumskunde" zu vertrauen. Denn letztere "allein vermag den deutschen Geist zu erwecken, sie allein verleiht das Bewußtsein was Deutschland war und, wills Gott, wieder werden soll" (Simrock 1856-58, 2:147f). Die Zitatstellen lesen sich nicht nur als Reflex auf die bekannt gewordenen Forschungsziele der Brüder Grimm und deren Suche nach den Wurzeln der germanischen Kultur, in ihnen drängt es nach einer gezielten Anwendung der Wissensbestände. Konzipiert wird eine Wiederbelebung des Deutschseins, bei der den Germanisten und Altertumskundlern die tragende Rolle des Geburtshelfers zukomme.

Und tatsächlich folgte auf die Grimmschen Arbeiten eine Welle von Untersuchungen und ethnographischen Erhebungen, die als "Reliktforschungen" rubriziert wurden. Weithin wurde in diesem Rahmen über kulturelle Ausprägungen, wie z.B. Märchen, Sagen oder Bräuche, gehandelt, die man gleichsam als fossile Reste bzw. Zeugen einer verschütteten, tiefen historischen Schicht deutete. ${ }^{155}$ Doch die sogenannte "Archaismus-Falle", ${ }^{156}$ in welche viele der Adepten hineingetappt waren, wurde von der Romantik allenfalls nachjustiert und verfeinert. Denn während der postreformatorischen Bekämpfung des Mailehens durch die Kirchen kam es schon einmal zu einer interessengeleiteten Enthistorisierung kultureller Überlieferung. Der entstellende und verächtliche Vorwurf seitens der Kirche besagte, daß der Brauch als heidnisches Erbe in einer christlich beherrschten Landschaft nichts mehr tauge. Am weiteren Verlauf der Geschichte läßt sich die radikale Umwertung nachvollziehen, die das Etikett "heidnisch" im Gefolge der Säkularisierung erfuhr. Was im 17. Jahrhundert noch Ausdruck von übelster Herkunft war, erscheint keine zweihundert Jahre später als ausgesprochen weihevoll. So findet sich bei Landau (1840:274) folgende Passage:

"Daß der in den vorstehenden Aktenstücken erwähnte Gebrauch [das Lehnausrufen] uralt ist, möchte wohl kaum eines Beweises bedürfen. Auch schon im 17. Jahrhundert betrachtete man ihn [...] als vorchristlichen Ursprungs und suchte ihn im frommen Eifer als heidnischen Greuel zu vertilgen; doch das, was durch ein Alter vieler Jahrhunderte geheiligt ist, weicht nicht so leicht dem engherzigen Verbote, das gegen jenes nur ein ephemerisches Daseyn hat".

Dem aufmerksamen Geschichtsforscher sollte im Grunde nicht entgangen sein, daß unter der Berufung auf eine zielgerichtete obrigkeitliche Brauchbekämpfung keine verläßliche Darstellung des Mailehens möglich ist. Aber offensichtlich verspürte Landau unter den veränderten machtpolitischen Verhältnissen die verlockende

${ }^{155}$ Besonders deutlich ist die Passage bei Zender (1955:288).

${ }^{156}$ Das Bild der "Archaismus-Falle" verwendet Scharfe (1978:143ff), um die unkritische, oberflächliche Auseinandersetzung mit sogenannten "Konservatismen" und "Archaismen" zu enttarnen. 
Chance, die Argumentation umzukehren: die Zeit immunisiere den Brauch gegenüber allen Widrigkeiten, und somit könnten selbst "frommer Eifer" und "engherzige Verbote" dem anachronistischen Brauchgeschehen nichts anhaben. Wie steht Landau aber zur voranschreitenden Moderne? Wie hält er es mit den bevorstehenden Umwälzungen durch die zunehmende Mobilität und die verkehrstechnische Erschließung der Peripherien, die sein Zeitgenosse Simrock als unvermeidlich einschätzte - ganz zu schweigen von der erstaunlich früh unterstellten und kritisierten "Amerikanisierung"? Stehen sich bei der Deutung des Mailehens die Experten unversöhnlich gegenüber: hier Kulturoptimist, dort -pessimist? Aus der Retrospektive erscheint eine Antwort leicht möglich. Allein die gegenwärtige Fortführung des Mailehens zeugt von der Richtigkeit der Annahme, daß der "überlebte" Brauch eine enorm hohe Widerstandskraft besitzt, um launigen Wechselspielen des Zeitgeistes zu trotzen. ${ }^{157}$ Allerdings sind die Probleme der Konstruktion einer Überzeitlichkeit des Mailehens damit eher verschärft als gelöst. Die Interpretation des Mailehens als "kulturelles Gefäß", das aus einer (noch) nicht näher bestimmbaren Vorzeit schadlos in die Gegenwart befördert wurde, bedarf einer genaueren Betrachtung, um so mehr, als jenes offene "Behältnis" widerstreitende Inhalte aufzunehmen vermag. Die Beispiele belegen, daß sich das Unzeitgemäße scheinbar reibungslos in zwei entgegengesetzten Deutungsmustern verwenden läßt. Dahinter verbirgt sich ein erster Hinweis darauf, daß es den betreffenden Interpreten weniger um die eigentliche Erklärung des Brauches gehen konnte als um eine Vermittlung mehr oder minder verdeckter Botschaften. Ziel wird es daher im folgenden sein, den Mechanismus der "Archaismus-Falle" zu erkennen und die intentionale Verquickung von Brauch und ideologisch aufgesetzter Sinngebung zu erhellen.

Wenn in der Mailehenliteratur das Ungleichzeitige eine Bedeutung erlangt, so wird davon ausgegangen, daß der Brauch sich in Form und Inhalt der Handlungen von den üblichen Denk- und Verhaltensmustern deutlich abhebe und sich nicht in das soziale Gefüge integriere. Anhand einzelner Brauchbeschreibungen gerät eine Trennlinie ins Blickfeld, die eine erhebliche Differenz zwischen althergebrachter Tradition und aktuellem Geschehen aufscheinen läßt. Diese fundamentale Unterscheidung kann sich beiläufig in den Etikettierungen des Mailehens als ein uralter Brauch, der sich "aus der Vorzeit erhalten" (Schannat 1852,3:478) habe, äußern; sie kann aber auch inhaltlich Gestalt annehmen.

Wann immer das Mailehen als Anachronismus aufgefaßt wird, tritt ein spezifisches Verhältnis vom Wandel und von der Beharrung soziokultureller Phänomene und

${ }^{157}$ Dieser Standpunkt wurde bereits bei Dierker (1939:47) vertreten: "Daß unser Mailehenbrauch trotz der vielen Zersetzungskräfte wie städtischer Einfluß (Ausstrahlungskreis der Stadt), weltliche Behörden und Kirchen und Geistlichkeit noch eine weite Verbreitung aufzuweisen vermag, ist aber auch ein Beweis für die Tatsache, daß er noch tief in der Gemeinschaft wurzelt, also ein echt volkstümlicher Brauch des Rheinlandes ist". 
Zustände zum Vorschein. Das heißt, der Brauch als regelmäßige Fortführung, als unendliche Kette tradierter Handlungen fungiert als Träger oder Überlieferer einer zurückliegenden, weithin verlorengegangenen Ordnung - es scheint, als würde die Vergangenheit im Brauch konserviert, als bliebe sie von der Gegenwart unberührt und rage aus der historischen Tiefe in eine umgestaltete Wirklichkeit. Die in dieser Weise produzierte Ungleichzeitigkeit von Brauch und soziokulturellem Umfeld verursacht zwangsläufig Spannungen, Widersprüche bzw. eine Kollision zwischen der im Alltag erfahrenen Gegenwart und der im Brauch innewohnenden Vergangenheit. Mit der aktiven Aneignung und Anwendung von Erfahrungen im Hier und Jetzt kann die rituelle Nachempfindung geschichtlicher Authentizität nicht in Einklang gebracht werden. Aus dieser Unvereinbarkeit erklären sich die konzedierten Vermittlungsprobleme. Weder die Brauchbeteiligten noch die Brauchinterpreten seien in der Lage, die Handlung des fortgesetzten Brauches in ihrem ursprünglichen Sinn und ihrer Intention adäquat $\mathrm{zu}$ erfassen. ${ }^{158}$ Kennzeichnend ist somit für das residuale, anachronistische Mailehen die Beobachtung eines zunehmenden Funktions- bzw. Sinnverlusts, der zur scheinbaren soziokulturellen Randständigkeit des Brauches beiträgt. Dieses marginale Verharren wird nach den oben skizzierten Richtungen gedeutet, wie sich sehr deutlich anhand zweier Beispiele zeigen läßt. Einerseits heißt es:

"Die eigenthümlichen Gebräuche der Bewohner, die in verschiedenen Ahrbeschreibungen angeführt werden, wie die Versteigerung der Mädchen [...] fand fast eben so in der ganzen übrigen Eifel statt, ist aber in neuerer Zeit der immer stärker einbrechenden, aber auch abflachenden, allgemeinen Cultur gewichen" (Wirtgen 1864:123),

andererseits:

"Das Mädchenlehen hat sich, in welcher Form auch immer, im gesamten Rheinland, vor allem aber in den Hochburgen des Köln-Bonner Raums bis in die Gegenwart hinüberretten können. In Anbetracht seiner anachronistischen Züge, die gerade in Zeiten frauenemanzipatorischer Bestrebungen zutage treten, gilt es, hierfür [...] nach Gründen zu suchen" (Faber 1985:446).

Vergleichbar mit den obigen Ausführungen Simrocks, Landaus und Menzels münden die von Wirtgen in eine affirmative Haltung gegenüber der festgestellten Brauchpraxis. Umgekehrt dazu verhält sich die Perspektive Fabers, der dem Brauchgeschehen mit Skepsis begegnet. Geradezu als Wellenbewegung kann die Haltung der Maileheninterpreten seit der Reformationszeit dargestellt werden. In der Bewertung des Brauches richtet man seine Argumentation danach aus, ob die

${ }^{158}$ Selbst Mannhardt (21905, 2:XXVIIff, 301) beurteilt die Erklärungsmöglichkeiten seiner mythologischen Studien als recht begrenzt. Er warnt vor spekulativen Analogieschlüssen. Dagegen erscheinen ihm diffusionistisch-morphologisch orientierte Sammlungen und Vergleiche der kulturellen "Überlebsel" als vordringlich. In diesem Kontext ergibt sich eine Verbindungslinie zu den Anstrengungen jener Kulturraumforschung, welche die "Fossilien einer vergangen Zeit" (Zender 1955:288) aufzuspüren sucht. Dort taucht auch das Konstrukt vom Sinnverlust einer kulturellen Erscheinung häufig auf. 
zeitgenössische soziale Ordnung generell in Frage $\mathrm{zu}$ stellen ist oder nicht. Die Redewendung "(sich) überlebt haben" veranschaulicht diesen Zusammenhang eindringlich. Hat der Brauch z.B. als "Relikt", "Survival", "Überbleibsel", "Fossil" überlebt, dann gilt er als seltener, nur für den Spezialisten einzuordnender und um so wertvoller und erhaltenswerter Zeuge einer einstmals vorhandenen gesellschaftlichen Ordnung. ${ }^{159}$ Daß dieser Brauch allen Wandlungen der Geschichte getrotzt hat, wird als weiteres Kriterium einer machtvollen "Lebenskraft", die dem altehrwürdigen Brauch innewohne, zur Kenntnis genommen. Von dort gelangen die Deutungen rasch $\mathrm{zu}$ einer polaren Bewertung, bei der die Vergangenheit bis hin zur germanischen Prähistorie als Zustand von anmutiger Reinheit, einender Gemeinschaft, hochstehender Sittlichkeit überhöht und die Gegenwart dagegen als verhängnisvoller Krisenherd diskreditiert wird. Unbegründet erscheint die Überlegung, daß nach den Erfahrungen mit der nationalsozialistischen Konstruktion geschichtlicher Zusammenhänge ${ }^{160}$ und mit der danach einsetzenden Problematisierung des Geschichtsbewußtseins die Deutung und vor allem auch der gezielte Gebrauch der positiv gewichteten "Archaismen" heute ein Ende gefunden hätten. Faber und Ziegler (1979/80:162,185) haben dagegen gezeigt, daß der rezente Mailehenbrauch wirksam jenes Wunschbild regionaler Identität untermauern kann, das gerne von kommunalpolitischen Festrednern verbreitet wird. Die Ursprünglichkeit des Brauches und die Treue der BrauchträgerInnen würden alljährlich den vermeintlich gesunden Kern von Landschaft und Bevölkerung belegen. Im Gegenzug rühre aus der Verbeugung der Lokalpolitiker vor dem "ewig währenden Brauch" ein spürbarer Statuszuwachs, dem sich die Jugendlichen wohl kaum verschließen könnten. ${ }^{161}$ Solange die Brauchträger sich als respektable Stützen ehrwürdiger Kultur

${ }^{159}$ Vgl. beispielsweise Usener (1902:221ff, 228), der unter der Aufbietung einer Fülle von Details aus der antiken Geschichte zu der Feststellung kommt: "Die Mädchenversteigerung unseres Rheinlandes ist uralt" und dann als weiteren Beleg Herodots Bemerkungen zur babylonischen Frauenversteigerung anführt (siehe Kap. 2.1).

${ }^{160}$ Den Nationalsozialisten erschien es als wesentliche Aufgabe im Rahmen völkischer Selbstbewußtwerdung, den schlummernden Archaismen gebührende Geltung zu verschaffen: "Es ist ein großes, kulturelles Verdienst der Männer, die das Steuer des neuen Deutschland in fester Hand führen, wenn sie sich die Wiedererweckung alten deutschen Volks- und Brauchtums sehr angelegen sein lassen. Sie wissen, daß sie damit das Volk an die Quellen seines ureigenen Wesens zurückführen, wo es am ehesten zum Bewußtsein seiner völkischen Größe und Art erwachen kann", so lautet Themes (1938:88) Einschätzung der Wiederbelebung des Mailehens. Siehe dazu auch den Einfluß der nationalsozialistischen Politik und Ideologie auf das Mailehen in Kap. 2.7.

${ }^{161}$ Siehe auch Faber (1985:448). Daß das Mailehen schon in der ersten Hälfte des 19. Jahrhunderts behördlich geschützt wurde, konnte unter Abschnitt 3.6 aufgezeigt werden. Auch hier argumentierten die Befürworter des Mailehens mit dem Alter und der "Reinheit" des Brauches; dazu Gansen (1931:18). 
präsentieren können, erscheinen die anachronistischen Züge des Mailehens nicht mehr nur von außen oktroyiert. 162

Diametral entgegengesetzt verläuft die Argumentation im anderen Falle, d.h. immer dann, wenn sich das Mailehen überlebt hat. Nicht als wertvolles Relikt, sondern als exotische Kuriosität, als überkommener Rest oder als antiquiertes "Überbleibsel" tritt der Brauch hier auf. Innerhalb sozialer Evolution kennzeichne das Mailehen Rückständigkeit: eine soziale wie kulturelle Retardierung der am Brauch Beteiligten. Diesen Mißstand gelte es aufzudecken, die aufklärerischen Potenzen seien zu mobilisieren, um der brauchmäßigen Hemmung des sozialen Fortschritts entgegenzuwirken. ${ }^{163}$ In aller Deutlichkeit hat Weber-Kellermann (1985:112) diese Linie vertreten:

"Nur wenige [Brauchträgerinnen] beginnen das Frauenfeindliche und Sexistische eines solchen Brauches in unserer heutigen Gesellschaft zu begreifen und sich dagegen zu wehren. So werden die herkömmlichen Geschlechterrollen mit diesem Brauch fixiert und den Burschen schon von fünfzehn Jahren an männliches Überlegenheitsgefühl mit Bier und Weiwerstrich (d.h. Ausstreichen der Mädchen auf einer Liste) anerzogen - und das Bewußtsein von der Verfügbarkeit der Frauen. So, wie dieser Brauch heute abläuft, ist er nicht nur abstoßend, sondern auch emanzipationsfeindlich und hemmt die dörfliche Entwicklung, was das Verhältnis Männer zu Frauen anbetrifft".

Die Autorin betrachtet das Mailehen in ihrer strukturalistisch beeinflußten Analyse vor dem Hintergrund der jugendlichen Sozialisation, wobei dem Geschlechterrollenbild der männlichen Dominanz, das sich vor allem durch das frauenfeindliche Versteigerungsritual Geltung verschaffe, nicht der erforderliche und zeitgemäße Widerspruch entgegengehalten werde. Ausgerichtet auf ein emanzipatorisches Geschlechterverhältnis folgert sie daher, daß diese Praxis nicht allein abstoßend und sexistisch sei, sondern die dörfliche Gesellschaft daran hindere, am allgemeinen Fortschritt zu partizipieren. Damit sind die Ausführungen an einen Punkt gelangt, wo sich zwei Erklärungsansätze zur Bedeutung des Mailehens kreuzen: einerseits wird von einer hochwirksamen sozialisierenden Funktion des Mailehens gesprochen, andererseits gilt der Brauch als rückwärtsgewandt zur sozialen Entwicklung und insofern als überflüssig. Im Verständnis sozialen Wandels, in einem antizipierten Horizont gesellschaftlichen Progresses, im Rahmen eines vorausgesetzten

${ }^{162} \mathrm{An}$ dieser Stelle tritt eine subtile Wechselwirkung zwischen Brauch und Brauchdeutung zum Vorschein, die Brückner (1986:370f) im Zusammenhang mit der Tracht hervorhob und die zur besonders sorgfältigen Analyse von kulturellen Traditionen verpflichtet.

${ }^{163}$ Auch bei Grasmück (1989:17) taucht der Satz auf: "Mich interessierte, warum Menschen diesen doch ziemlich 'antiquierten' Brauch beibehalten". Obwohl das Erkenntnisinteresse der Forscherin zunächst aus einem Unverständnis für eine Situation erwächst, welches den Brauch nicht nach allen Seiten hin offen, sondern als überkommen und rückständig voraussetzt, wird sich im weiteren Verlauf dieser Untersuchung zumindest von der Voreinstellung distanziert. Es stellt sich allerdings bei derartigen empirischen Erhebungen das Problem, wie nachhaltig z.B. Interviewergebnisse von der unterschwelligen Wertschätzung des Forschers beeinflußt sind (vgl. Kapitel 1.3 und 4.1.3). 
Wertgefüges, gelangen die Kritiker und Brauchgegner zu der Meinung, daß das Mailehen nicht mehr den Anforderungen des sozialen Umfeldes und der Brauchträgerschaft entsprechen könne. Der stumpfe Wiederholungsmechanismus der "Tradition" habe die rituellen Aktionsmuster in die moderne Zeit verfrachtet, ohne daß die Brauchbeteiligten je gefragt hätten, welcher Sinn, welche Bedeutung der gegenwärtigen Mailehenausübung heute noch zukomme. Wenn nicht Bedeutungsverlust bis zur hohlen Sinnentlehrung, so stecke hinter der wiederkehrenden Brauchpraxis ein konservativer Impetus, der schließlich zu unverständlichen Ungleichzeitigkeiten, zu Verhärtungen, zur sozialen Rand- und Rückständigkeit führe und im Widerspruch zu aktuellen gesellschaftlichen Anforderungen stehe. Folgerichtig erklären die Verfechter dieser Brauchdeutung, daß sich das Mailehen in einem unaufhaltsamen Zerfallsprozeß befinde und die regressive Brauchausübung an der allgemeinen gesellschaftlichen Entwicklung und ihrem Tempo scheitern müsse. Der Niedergang des Mailehens sei insofern bereits kalkulierbar, wie Niessen (1900:95) zu Beginn des 20. Jahrhunderts festgehalten hat. Das in der Einleitung bereits wiedergegebene Zitat (siehe Kapitel 1.1) war zurückhaltend im Konjunktiv formuliert. Nach wenigen Jahren wirkt die Aussage entschiedener und von letzten Zweifeln bereinigt, wenn es heißt: "Für unsere Zeit hat der Brauch sich überlebt" (1907:67). Inzwischen, an der Schwelle zum 21. Jahrhundert, kann insofern eine Bilanz gezogen werden, daß eine Traditionsrethorik, wie sie hier am Beispiel des Mailehens seit der Neuzeit aufgedeckt werden konnte, nicht zur Klärung des Gegenstands, sondern zur Maskierung von Geisteshaltungen beiträgt. ${ }^{164}$ In dem Maße wie Brauch und Brauchbeteiligte als beliebig einsetzbares Vehikel bald die "konservative", bald die "progressive" Weltsicht transportieren, in dem Maße liegt gleichzeitig ihre intentionale Instrumentalisierung vor. Deutungen, die dagegen das konkret zeitgeschichtliche Eingebundensein des Brauchgeschehens innerhalb des sozialen Umfeldes in Rechnung stellen, entgehen nicht nur der "Archaismus-Falle" oder der "Mumifikation" lebendiger Kultur, sondern bilden die Basis eines überprüfbaren Erklärungsansatzes, der Sinn, Funktion und Probleme des Brauchwandels zu erfassen vermag. ${ }^{165}$

\footnotetext{
${ }^{164}$ Assion (1986:355ff) weist auf die heute verbreitete identitätsstiftende Wirkung der Traditionsrhetorik hin, der eine spezifische Bedürfnisstruktur vorausgehe.

${ }^{165}$ Siehe Bausinger (1986:112f). Vgl. Bourdieu (1987:38-45, hier 38) zur Unangemessenheit der ethnologischen Interpretation von Riten, die aus einer "falschen intuitiven Sympathie der Nostalgiker" bzw. aus dem "Ethnozentrismus des Beobachters" herrührt. - Ein zusätzlicher Beleg für die Zeittypik und ein plastisches Beispiel zur überregionalen Anwendbarkeit jener "Mumifikation" von Kultur findet sich auch bei Wey (1995a:211ff).
} 


\subsection{Sozialisierendes - Lernen fürs Leben}

"Dies Jahr zum Lehn, Das andere Jahr zur Eh'!"

Die stereotype Ausrufeformel, die von Laven 1834 (ohne Paginierung) überliefert worden ist und nicht nur innerhalb des saarländischen Lehenausrufens verbreitet war, ${ }^{166}$ wurde wenig später in einer allgemeinen Deutung als Abbild der Realität ausgegeben:

"Die Erfahrung soll es bestätigt haben, daß durch diese Sitte die temporairen $\mathrm{L}$ e h e $\mathrm{n}$ sich gewöhnlich allodificiren, indem die Angewöhnung der jungen Leute aneinander, welchen ja hinreichende Gelegenheit geboten ist, sich in allen Beziehungen kennen zu lernen, die Ehe zur Folge hat. Man hätte sonach das Heirathsbureau des platten Landes in einer ganz eigenthümlichen Gestaltung!" (Anonymus 1836b:4f).

Die rituelle Praxis erscheint an dieser Stelle als ein Bindeglied zwischen adoleszenter Statuslosigkeit und zukunftsgerichteter Eheschließung, auf der dann in der Regel die Phase der Familiengründung aufbauen konnte. "Das Mailehn", ein sechsstrophiges Lied von Wolfgang Müller, ${ }^{167}$ stellt dieses Übergangsstadium noch stärker in den Mittelpunkt. Vor dem Hintergrund romantischer Poesie des 19. Jahrhunderts ertönen die einleitenden Verse:

"Es läuten die Glocken ihr volles Geläut, Maiabend war gestern und Maitag ist heut, Und gestern da war ich noch ledig und leer, Heut führ ich mein Mailieb am Arme daher" (Müller 1853:215).

Das soziale und persönliche Unausgefülltsein, das die der Kindheit entwachsenen Jugendlichen bisher beherrschte, wird offenbar durch das Mailehen als sinnstiftender, lebensgeschichtlich bedeutsamer Wendepunkt durchbrochen. Er gipfelt in einer zweigeschlechtlichen Verbindung, die nicht mit dem rituellen Ende des Brauches aufgehoben sein muß, und so klingt das Lied mit der Sehnsucht nach der unvergänglichen Liebesbeziehung, die im Mailehen seinen Anfang genommen hatte, aus:

"Und wenn auch, mein Mailieb, die Bohnen verblühn,

Uns soll nicht mit ihnen die Liebe verglühn,

O nenn dich, Herzlieb, dann ferner auch mein!

Ich bin und ich bleibe in Ewigkeit dein".

${ }^{166}$ Die bei Dierker (1939:87ff) aufgelisteten Beispiele machen deutlich, daß der betreffende Spruch vor allem in Hessen und im Saargebiet angetroffen wurde. Die Pfalz ist nur durch den von Becker (1913:18f) angeführten Beleg für Rheinsheim vertreten.

9 ${ }^{167}$ Zur literaturgeschichtlichen Einordnung des rheinischen Dichters siehe Oellers (1979:597ff). 
Liebes-, Ehe- und Lebensglück scheinen mit dem Mailehen unverbrüchlich verbunden zu sein. Mit dieser Ansicht steht der rheinische Poet der Spätromantik keineswegs allein. Eine Vielzahl von Autoren teilt die Auffassung, daß im Mailehen eine wichtige Funktion im Rahmen der Eingliederung des Individuums in sein soziales und kulturelles Umfeld wirksam sei. Und dabei sei die Reichweite (psycho-)sozialer Integration nicht nur auf den engeren Bereich von Ehe und Familie begrenzt, sie erfasse ebenso Handlungsfelder von allgemeinerem gesellschaftlichem Interesse. Im folgenden werden die verschiedenen Erklärungsansätze zusammengeführt, welche die erzieherischen, die einerseits sozial-integrativen, andererseits sozial-segregierenden Effekte der Brauchausübung betonen. Da die benannten Effekte insgesamt auf eine Steigerung der sozialen bzw. kulturellen Kompetenz und Performanz abzielen, können die Analyseergebnisse unter der Rubrik Sozialisierendes gebündelt werden.

Betrachtet man die Verhältnisse im frühneuzeitlichen Köln, wo die Paare innerhalb des patrizischen Haushalts ermittelt wurden, als Ausnahme, so darf die rituelle Paarbildung von weiblichen und männlichen Jugendlichen in der Tat als konstitutives Element des Mailehens angesehen werden. Demzufolge rückt die Ausübung des Mailehens in die Nähe der Ehevorbereitung, und so verwundert es keinesfalls, daß sich im Laufe der letzten 150 Jahre die Bezeichnung "Heirathsbureau" als Paraphrasierung des Brauches etabliert hat. ${ }^{168}$ Andere Interpreten formulieren etwas vorsichtiger und verweisen stärker auf die ehevorbereitende denn auf die ehestiftende Funktion des Mailehens. Auf dieser Grundlage hat die Mailehenliteratur ein weites Spektrum latenter und manifester Ansätze zur Deutung des Mailehens als kulturelle Institution der Eheanbahnung entfaltet, so daß hier nur die wichtigsten und markantesten Argumentationslinien aufgegriffen werden können.

Anhand des Vergleichs europäischer Jugendbräuche versuchte Wikman nachzuweisen, daß die Heranwachsenden im Brauch Möglichkeiten und Hilfestellungen anstreben würden, die ihnen den vorehelichen Kontakt erleichterten. Wenngleich das Mailehen nicht im Mittelpunkt seiner Untersuchung steht, ${ }^{169}$ so hält er dennoch fest, daß:

168Zunächst von Niessen (1907:65f) ohne Quellenhinweis übernommen, wurde diese Stelle vielfach in der Mailehenliteratur angeführt: Dierker (1939:150), Korff (1984:255), Schrick (1992:34 Fn. 5).

${ }^{169}$ Wikman konzentriert sich auf den sogenannten Kiltgang, d.h. den nächtlichen Besuch junger Männer bei den jungen Frauen. Der Wert seiner Untersuchung beruht auf der ethnographischen Darstellung und der funktionalistischen Analyse des Brauchgeschehens. Daneben hebt er darauf ab, "eine Reihe fest ineinander gefügter Glieder einer althergebrachten Heiratsordnung" herauszustellen, deren Wurzeln er insbesondere im germanischen Europa verfolgen möchte (1937:XIII und 4). Gerade die ahistorisch-diffusionistische Zielsetzung bereitet Probleme bei der Rezeption, da die Ergebnisse nicht konsequent historisch abgesichert wurden. So basiert ein Teil seiner Argumentation auf Fragebogenerhebungen und Archiv- bzw. Literaturstudien, aus denen der realgeschichtliche Bezug (Zeit, Ort, sozialer Kontext) nach gegenwärtigen Maßstäben deutlicher hervorgehen müßte (z.B. 1937:19, 269f, 344,348f, 376ff). 
"[...] Umgangsformen, für die sich die Jugend einsetzte, auf einen Verkehr der Geschlechter mit einander [sic] hinausliefen, der der Jugend sonst verwehrt war. Jugendinstitutionen wie Spielstuben, Mailehen und vor allem der Kiltgang lassen hierüber keinen Zweifel walten. Wohl heisst es im Sprichwort: 'Lekestuvokärlek å hövlekase-ell ä hett, men står snart över' ('Spielstubenliebe und Hobelspanfeuer brennen wohl heiss, verlöschen aber bald'). Dies hinderte aber durchaus nicht, dass derart angeknüpfte Jugendverbindungen oft einen entscheidenden Einfluss auf die Wahl des zukünftigen Lebensgefährten haben konnten" (Wikman 1937:359f).

Genaugenommen widerspricht Wikman hier der verbreiteten Annahme, daß sich über die Zeit Mailehenpaare tatsächlich zu Ehepaaren verwandeln würden. Unter Einwirkung rituell eingeleiteter vorehelicher Begegnungen erscheint die Auswahl der potentiellen Ehepartner tatsächlich faßbar, nicht aber determiniert zu sein. ${ }^{170}$ Tragweite und Ernst, von der zumeist die endgültige Entschließung zur Heirat begleitet wurde, mußte nicht zwangsläufig das Mailehengeschehen beherrscht haben. Mit einer endgültigen Festlegung auf einen speziellen Partner im vorehelichen Brauch hätte man den spielerischen Reiz und das lehrreiche Ausprobieren wohl ins Abseits gedrängt:

"In dem Festmilieu haben die spielerhaften Liebesverbindungen der Jugendzusammenkünfte eine grössere Offenkundigkeit, eine scheinbare Legitimität, und vor allem eine längere Dauer als in dem Spielstubenverkehr bekommen. Dies gilt besonders [für] die Mailehen und mit ihnen verwandtes Brauchtum" (Wikman 1937:145). ${ }^{171}$

Es bestehe also ein Unterschied zwischen solchen Brauchformen, die auf eine konkrete Eheanbahnung und jenen, welche lediglich auf die Vermittlung eines allgemeinen Orientierungsvermögens der Jugendlichen im Rahmen potentieller Heiratsverbindungen und -allianzen abzielten. Gleichzeitig haben die Autoren vor dem Hintergrund der vorindustriellen Situation der Geschlechtertrennung, der strengen Sexualmoral und der überindividuell beeinflußten Heiratspolitik auf dem Lande darauf hingewiesen, daß die die voreheliche Brauchpraxis für das nähere Kennenlernen unter den Heranwachsenden unverzichtbar gewesen sei. ${ }^{172}$ Das spielerische, offene und dynamische Element der Mailehenausübung ist dabei stets zu berücksichtigen, auch wenn auffällig ist, daß es oft bei der Behauptung der unmittelbar ehestiftenden Funktion des Brauches geblieben ist. Eine sorgfältige Quanti-

${ }^{170}$ Vgl. Hilberath (1931:42f). In neuerer Zeit bemerkt Becker ( $\left.{ }^{2} 1994: 72\right)$ dazu: "Durch die Zusammenführung der Maipaare sollte die heiratsfähige Jugend des Dorfes einander zugeführt werden, um so Sympathien zu wecken, die in späterer Heirat münden sollten".

${ }^{171}$ Vgl. Hilberath (1931:56f) und die teilweise wortwörtliche Übernahme des Gedankengangs durch Dierker (1939:146f). Unlängst wurde auch bei Korff $(1984: 254,257)$ das spielerische Moment hervorgehoben. Zender hat den Zusammenhang von Brauch und Spiel anders gewichtet. Er sieht in der gesamten Entwicklung des Mailehens eine Hinwendung vom Magisch-Kultischen zum Spiel; z.B. Zender (1972:276).

${ }^{172}$ Dazu Hilberath (1931:32ff) und Wikman (1937:349ff). 
fizierung von Heiraten, die aus dem Mailehen hervorgingen und welche die Annahme untermauert hätte, steht jedoch weiterhin aus. ${ }^{173}$

Die vorehelichen Orientierungen weisen die unterschiedlichsten Facetten auf. Zunächst wird davon ausgegangen, daß innerhalb einer reglementierten dichotomen Geschlechterordnung eine Funktion des Brauches darin bestehe, die geschlechtsspezifisch weitgehend getrennten Arbeits- und Lebenssphären der Jugendlichen zeitweilig außer Kraft zu setzen, ${ }^{174}$ um damit das gegenseitige Interesse $\mathrm{zu}$ wecken, zu fördern aber auch in vorgegebene, steuerbare, familiär und gesellschaftlich erwünschte Bahnen zu lenken. Auf der nächsten Stufe dringe der sozial institutionalisierte und kulturell vermittelte Brauch bei der vorehelichen Paarbildung noch weiter vor, indem er die konkrete Kontaktaufnahme zum anderen Geschlecht bewirke. ${ }^{175}$ Dabei würden die Jugendlichen auf soziales, interaktives Neuland stoßen, denn die gewohnten Verhaltensmuster und Rollen würden nicht mehr ausreichen, um in einer Paarsituation angemessen auf den anderen zu reagieren. Auf diese Weise würde die Nähe zwischen den Geschlechtern zum Erlernen angemessener Verhaltensweisen zwischen heranwachsenden Männern und Frauen führen. Das äußere Auftreten, das galante Benehmen, ${ }^{176}$ der schickliche Flirt und nicht zuletzt der Umgang mit der Sexualität ${ }^{177}$ böten genügend Lektionen für die

${ }^{173}$ Selten wird der problematische Aussagewert der Behauptung über die ehestiftende Wirkung des Brauches so deutlich wie bei Nießen: Zunächst formuliert er noch: "[...] kamen aus den zeitweiligen Lehen viele Paare dauernd für's Leben zusammen [...]" (1900:94), so heißt es nur sieben Jahre darauf: "[...] kamen aus den zeitweiligen Lehen manche Paare dauernd fürs Leben zusammen" (1907:65; in beiden Fällen Hervorhebung durch H.-W.W.), ohne daß der Leser den Grund dieser Korrektur erfährt.

${ }^{174}$ Erhebliche Barrieren, die bei der vorehelichen Kontaktaufnahme zu überwinden sind, werden bei Hilberath eindringlich beschrieben: "Entsprechend der streng isolierten, religiösen Erziehung der heranwachsenden Geschlechter und der asketischen Lebensführung mit der Forderung, daß alle sexuellen Impulse, alle erotischen Vorstellungen schlechthin als 'Sünde' zu unterdrücken sind, zeigt sich auch äußerlich im Verhalten eine weitgehende Entfremdung und Abschließung der beiden Geschlechtergruppen. Man sieht auf dem Eifeldorfe die beiden Geschlechter an Sonntagen nie zusammen spazieren gehen, sondern findet sowohl die männliche wie die weibliche Jugend, letztere vielfach in Begleitung einer alten Jungfer in Gruppen isoliert voneinander ihre arbeitsfreie Zeit verbringen" (1931:35f).

${ }^{175}$ Hilberath (1931:48f) schildert plastisch, wie die Junggesellen nach erfolgtem Paarbildungsprozedere durch die Versteigerung geradezu in einen Sog brauchspezifisch organisierter Ereignisse hineingezogen würden, aus dem sich selbst die schüchternsten Jugendlichen nicht entziehen könnten. Das entsprechende Plagiat dazu findet sich bei Dierker (1939:134).

${ }^{176}$ Das Erlernen allgemeiner Umgangsformen zwischen den Geschlechtern nimmt vor allem in den älteren Mailehendeutungen einen festen Platz ein. So werde das weibliche Verhalten im Sinne wohlgefälliger Anpassung, Tugendhaftigkeit und adrettem Auftreten durch den Brauch gefördert (z.B. Anonymus 1836c:85; Menzel 1856:65; Nießen 1900:95; Becker 1913:11; Hurth 1935:55). Demgegenüber übe sich der Junggeselle in Ritterlichkeit und Züchtigkeit (z.B. Meisen 1935:95; Nießen 1907:64f; Wikman 1937:259, 343; Dierker 1939:70, 123 et passim; Ruland 1987:136).

${ }^{177}$ In Verbindung mit jugendlichen Flirts und ersten intimen Kontakten wird das Mailehen bei Hilberath (1931:55ff) ausführlich thematisiert. Die Frage, ob der Brauch zu vorehelichen sexuellen Aktionen unter den Jugendlichen geführt hat, ist aufgrund der Quellenlage nicht eindeutig zu klären. Konträr sind die vertretenen Positionen: Obwohl beide Autoren von einer nachhaltigen germanischen 
BrauchträgerInnen. Der äußere Rahmen (z.B. der Lernort) und die innere Ausgestaltung (z.B. Lerninhalte und -ziele) würden vom Mailehen vorgegeben. Sie bestünden etwa in gemeinsamen Zusammenkünften in der elterlichen Wohnungen (Kommabende), beim gemeinsamen Tanz, während des Umzugs zum Maifest oder bei Sonderveranstaltungen, die ein Treffen der Mailehenpaare voraussetzen (Heischebrauch, Ausflüge). In der Summe der jeweiligen Anregungen und Handlungsmöglichkeiten, die vom Mailehen ausgehen würden, gelange der Brauchträger schließlich zu einer gefestigten Entscheidungsgrundlage, auf der die wohlbedachte Auswahl der zukünftigen Lebenspartnerin basieren könne. ${ }^{178}$ Neben einer Reihe anderer Autoren hält der Volkskundler Josef Ruland diese Funktionsweise des Brauches für erwiesen:

"Es kann wohl nicht bezweifelt werden, daß die Mailehenverhältnisse einer rechtzeitigen Ordnung des sittlichen und sexuellen Verhaltens dienen. Sie sind Ventil und Bremse zugleich: Die Jungen steigern die Mädchen fast nur bei ernsthaften Absichten, die Eltern wissen, wer sich bewirbt und wie der Umgang ist. Im Zuge der Mannbarwerdung werden diese lebenswichtigen Erscheinungen wie Liebe und Ehe vorgestellt und zur Entscheidung gestellt. Man braucht sich nicht festzulegen, bringt aber das Mädchen auch nicht ins Gerede. Im Kreise der Gleichaltrigen lernt man einander unbefangen kennen und darf das Mädchen besuchen. Es war eine kluge Einrichtung von Anfang an. Die Jungen und Mädchen bleiben im Dorf, wo sie in einem festen Rahmen so weit einander zugeführt werden, wie sie es seelisch verarbeiten können" (1972:621). ${ }^{179}$

Deutungen des Mailehens, die sich an dem Motiv der bevorstehenden Verehelichung orientieren, greifen in der Regel auf die genannten Bereiche sozialen Verhaltens und sozialer Verhaltenserwartungen zurück. Damit weisen sie dem Brauch eine Funktion $\mathrm{zu}$, die für die Entwicklung der Persönlichkeit und die Eingliederung des Menschen in sein unmittelbares soziales Umfeld von entscheidender Bedeutung ist. Der Brauch

Kontinuität des Mailehens ausgehen, sieht Zuccalmaglio in der beharrlichen Brauchausübung die "noch züchtige Sitte unserer Väter" (1854-1858:30), während Schurtz (1902:113f) das Mailehen im Licht von "freier Liebe" und "zu nichts verpflichtenden" Geschlechterbeziehungen interpretiert. Hilberath (1931:57) betont die Unterscheidung zwischen "losere(n) Beziehungen [...] und solchen, bei denen das Ziel einer späteren Heirat schon vor Augen steht, abgesehen von der Tatsache einer festen Verlobung. Bei den letzteren wird man in der Regel auch auf einen geschlechtlichen Verkehr schließen dürfen". Interessant sind in diesem Zusammenhang die gegensätzlichen Positionen zum Brauchwandel zwischen Schurtz und Wikman. Schurtz (1902:113f) glaubt, daß die ursprünglich sexuelle Ausrichtung des Brauches durch den Prozeß der Zivilisation verformt worden sei. Hingegen macht Wikman (1937:284f) die Beobachtung, daß "sexuelle Laxheit" beim Kiltgang gerade im Gefolge der Modernisierung auftritt. Gegenüber städtisch beeinflußten Bräuchen möchte Klersch das ländliche und moralisch unbedenkliche Mailehen abgrenzen; er schreibt: "Ganz anderem Geist als dieses ursprünglich heidnische Brauchtum, das anstößig wurde, weil es seinen inneren Sinn verloren hatte, entspringt das Mailehen, durch das die Dorfgemeinschaft, in der Sitte und Brauch oft stärker sind als das Gesetz, den Umgang der mannbar gewordenen Mädchen mit den Burschen in Zucht und Sitte regelt" (1965,1:197).

${ }^{178} \mathrm{Vgl}$. Korff (1984:257f).

${ }^{179}$ Vgl. Schmitz (1896/97:107), Oster (1927:89), Hilberath (1931:39), Wrede (31960:218), Ruland (1968:237), Faber (1985:446) und Grasmück (1989:31); ferner unter besonderer Betonung der agrarischen Ökonomie Korff (1984:254). 
bestimme nicht nur das besondere, ja intime Verhältnis der Geschlechter untereinander, er regle auch den zum Teil konfliktbeladenen Umgang mit der jeweiligen Paarbeziehung der Alters- und Geschlechtsgenossen; dadurch könnten sich die Jugendlichen gegenseitig im Wettstreit um potentielle Partner erleben. Gründe für persönliche Niederlagen und soziale Konflikte würden im Mailehen offen zutage treten und forderten somit zu ausgleichenden Lösungen auf. Früh hat Kinkel diese Ansicht vertreten:

"Durch diesen Akt [der Versteigerung] erhält nun der Ansteigerer das Recht, bei allen Festen des Sommers und so besonders bei der Kirmeß mit dem erworbenen Mädchen ausschließlich zu tanzen, sie auch zum Tanzboden abzuholen und zu regaliren. Daß hier Liebe und Intrigue oft in Kampf gerathen, läßt sich denken" (1846:161).

Des weiteren taucht in diesem Zusammenhang die These auf, daß das Mailehen dafür sorge, diesen folgenschweren Wettstreit unter Männern um eine potentielle Heiratskandidatin abzumildern, indem rituell vorgegebene Handlungsanordnungen in ihrer Verbindlichkeit streitbare Alternativen unterdrückten. Somit übe das Mailehen das brauchgesteuerte zeitweilige "Gewinnen" und "Verlieren" von Anrechten auf Paarbeziehungen ein. ${ }^{180} \mathrm{Im}$ Widerstreit dazu steht die Annahme, daß das Mailehen dazu beitrage, das gegnerische Moment bei der vorehelichen Partnersuche geradezu zu verschärfen. ${ }^{181}$

Konfliktvermeidung und -lösung im Rahmen gegenseitig anerkannter Paarzuweisungen würden voraussetzen, daß es unter den Brauchtreibenden eine Verständigung darüber gibt, wer zum Kreis der potentiell möglichen Kandidaten gehört und welche Paarkonstellationen sozial tragbar sind. Das Mailehen ginge insofern über das gleichgeschlechtliche Buhlen um einen favorisierten Partner hinaus, wie es z.B. bei den preistreibenden Bietgefechten während der Versteigerung zum Ausdruck gekommen ist. Auf eine weitreichende Akzeptanz der rituellen Verpaarung müßten vielfältige Überlegungen verwendet werden. Faktoren wie soziale oder lokale Herkunft (Status/Endogamie) würden dabei ebenso bestimmend sein wie der Einfluß der Besitzverhältnisse, des Gerechtigkeitsgefühls und des Affekts. Aus dieser Sicht

${ }^{180}$ Wenn Grasmück meint: "Das Lehensverhältnis schuf klare Verhältnisse unter der Dorfjugend. Ein besonders begehrtes Lehen war vergeben, und der Grund für eventuelle Streitigkeiten und Raufereien war für ein Jahr gebannt" (1989:31), dann vertritt sie denselben Standpunkt, der bereits zu Beginn der ethnographischen Brauchbeschreibung von Laven (1834:ohne Paginierung) behauptet wurde: "Was über den ganzen Gebrauch in sittlicher Beziehung zu sagen ist, das überlasse ich Jedem zum eigenen Nachdenken; nur will ich hinzufügen, daß durch dieses Verpaaren wenigstens manchen Balgereien auf den Tanzböden vorgebeugt wird. Weil jeder schon im Voraus die Tänzerinn, die ihm vor allen angewiesen ist, kennt, darum braucht er nicht erst mit Andern darum zu rechten". Ferner Hilberath (1931:51ff) und Weber-Kellermann (1985:101ff), die in den widerstreitenden Interessen der Brauchträger ein strukturbildendes Prinzip erkennt.

${ }^{181}$ Das Tanzrecht des Ansteigerers gilt für Mütter (1912:103) als Konfliktauslöser, es "führte manchmal infolge der vorhandenen Verschiedenheit des formellen und wirklichen Besitzes eines Mädchens zu Zwistigkeiten und nicht selten zu offenen Streitigkeiten". 
führte das Mailehen zu einer besonderen Geschlechterbeziehung, die zwar individuell ausgetragen und in einem gewissen Rahmen ausgestaltet werden konnte, die aber in erster Linie innerhalb der Brauchträgerschaft und darüber hinaus vom sozialen Umfeld prinzipiell gebilligt werden mußte. ${ }^{182}$

Auch dort, wo das individuelle Wohl- und Fehlverhalten von Brauchbeteiligten zu einem öffentlichen Diskussionsthema gemacht worden ist, dringt die Verankerung des Mailehens im sozialen Umfeld deutlich hervor. Es wurde von Aktionen berichtet, die dazu geeignet waren, das Ansehen von potentiellen BrauchträgerInnen gegebenenfalls zu erhöhen oder zu schmälern. Betroffen von den Urteilen und ihren Folgen, Sanktionen oder Ehrungen, war vorwiegend die weibliche Jugend. Nur vereinzelt ist auch von entsprechenden Maßnahmen bei Männern die Rede. So erhielten die ledigen Frauen bei konformem Lebenswandel eine ehrende Anerkennung in der symbolisierten Form des Maiens. Demgegenüber wurden Mädchen, die des Fehlverhaltens für schuldig befunden worden waren, nicht zum Mailehen erwählt, sie kamen in den anrüchigen Rummel. Es konnten außerdem ein öffentlicher Tadel oder eine Rüge zum Ausdruck gebracht werden, die meist durch aussagefähige Varianten des sogenannten Schandmaiens ${ }^{183}$ publik wurden. Augenscheinlich wurde dem Mailehen in diesem Rahmen eine volks- oder sittenrichterliche Potenz beigemessen, wobei die Handhabe über das moralische Urteil im wesentlichen den Junggesellen zugebilligt worden sei. Die Interpretation dieser ungleichen Verteilung sittenrichterlicher Gewalt, bei der dem Mann die Rolle des Richters und Vollstreckers, der Frau die Rolle der moralisch wie sozial Abhängigen zugewiesen wird, verweist auch an diesem Punkt auf eine sozialisierende, persönlichkeitsbildende Wirkungsweise des Mailehens: die Jugend würde auf die Überlegenheit des Mannes in der Gesellschaft hingeführt und gleichzeitig würde die hieran geknüpfte sozialstrukturelle Asymmetrie weiterhin aufrecht erhalten. ${ }^{184}$

${ }^{182}$ Wikman (1937:148) verknüpft die Mailehenausübung mit der Formel "'Gleich und gleich gesellt sich gern'" und möchte damit die sozio-ökonomische Seite des Brauches hervorheben. Noch stärker treten die Status- und Besitzwahrungsstrategien bei Hilberath (1931:64f) zum Vorschein. Er veranschaulicht, daß die Mißachtung von sozialem Status und Besitz bei der Auswahl des Mailehenpartners zu ernsthaften Benachteiligungen bei Erbschaftsregelungen führen könne. Vgl. auch Hilberath (1931:42ff, 50, 58ff), Barlen-Ebert (1960:20) und Conrath (1962:4); siehe unten Kap. 3.5 die besondere Lesart Korffs (1984).

${ }^{183}$ Zum Schandmaien siehe Kap. 2.5.

${ }^{184}$ Schell (1900:40) betrachtet die germanische Sozialordnung, bei der "das verhältnismäßig hochstehende Weib, die verehrte Jungfrau, fast als Eigentum der Sippe [...] angesehen wurde", als Bedingung für die Entstehung des Mailehens. Die Ansicht, daß die geschlechtsspezifische Dominanz innerhalb der Gesellschaft konsequent im Brauch fortgeführt werde, findet sich vielerorts in der Literatur: vgl. z.B. Menzel (1856:65f) und König (1938:25). Eine erzieherische Wirksamkeit sei den Rügebräuchen trotz aller Härten nicht abzusprechen, meinen z.B. Niessen (1900:95), Becker (1913:11), Theme (1938:87) oder Dierker (1939:103ff). Auch Faber (1985:446f) sieht die Vorrechte 
Aber anhand eines konkret zu behandelnden Vorfalls bzw. Regelverstoßes sei die normativ gesetzte Ordnung des sozialen Terrains erkannt worden, die Burschen hätten sozialregulative Strategien angewandt und die allgemeinen Konventionen anerkannt. Dadurch sei die Bereitschaft, sich in die bestehende soziale Lebensrealität einzufügen, geprüft und trainiert worden. ${ }^{185}$ Vor diesem Hintergrund erscheint der Mailehenbrauch nahezu als ein Modell einer außerschulischen Institution des Lernens. Auf anschauliche, manchmal spielerische und insbesondere handlungsorientierte Weise würden die gesellschaftlich noch nicht vollständig integrierten Jugendlichen auf ihr zukünftiges soziales Aktionsfeld vorbereitet, bei dem Ehe, Familie, öffentliches Ansehen und Wahrung der Ordnung einen hohen Stellenwert einnähmen.

Infolgedessen liegt der Schluß nahe, daß in der Mailehenausübung ein allgemeineres sozial relevantes Prinzip vorherrschend sei, das auch in anderen Bräuchen seine erwünschte Wirksamkeit entfaltet: die Vergabe von machterhaltenden und sozialstabilisierenden Aufgaben und die Aufsicht über gesellschaftliche Verantwortungsund Ordnungsbereiche an nachrückende Generationen. Da diese Übertragung von Kompetenzen im institutionalisierten Rahmen eines Rituals stattfindet, haben die etablierten Machthaber keine Herabwürdigung ihrer Stellung zu befürchten. Demnach würde die Beobachtung von Scharfe (1970:56) zutreffen, wonach im Geltungsbereich des Rügebrauchs "die Kontrollierenden die eigentlich Kontrollierten sind". Wenn dem tatsächlich so ist, so wäre das Mailehen einer subtilen gesellschaftlichen Mechanik zuzuordnen, deren Leistung darin läge, die zur Veränderung, zur Rekombination, zu Chaos, Anarchie und Autonomie fähige Jugend mit der wohldosierten Überlassung einer Pseudomacht zufrieden- und ruhigzustellen. Das Mailehen hätte also einen ausgeprägt sozial konservativen Zug, denn es stünde dysfunktionalen Potenzen der adoleszenten Brauchträgerschaft entgegen. ${ }^{186}$

Deutlich haben die hier analysierten Erklärungsversuche gezeigt, daß die brauchspezifischen Aktionen durchaus in einem wechselseitigen Verhältnis zum gesellschaftlichen Gefüge zu betrachten sind. Am rituellen Geschehen beteiligte Einzelpersonen und Gruppen erscheinen nicht von vornherein als sozial isoliert, als sozial wirkungs- und machtlos. Alltagsweltliche Bezüge und sozialstrukturelle Gegebenheiten der gesellschaftlichen Umwelt sind keineswegs deaktiviert, wenngleich sie im

der Burschen als Folge einer "männerorientierten Gesellschaft", in der den Frauen letztlich nur die Zustimmung zur öffentlichen Bevormundung übrig bleibe.

${ }^{185}$ Dazu Usener (1902:215ff).

186Dazu auch Fabre (1997:82ff). Im Rahmen von Brauchausübung und adoleszenter Sozialisation hat Schindler (1996:348ff) die Ambivalenz zwischen sozialer Anomie und Anpassung betrachtet und dabei mit unterschiedlichen Bezugsgrößen (dörfliche vs. obrigkeitliche Interessen) konfrontiert. Dabei wurde deutlich, daß die "soziale Logik" der Jugendlichen sich nicht immer in den Dienst des übergeordneter Sozialsysteme stellen ließ. 
Rahmen der Brauchpraxis zuweilen etwas in den Hintergrund treten können. Das erleichtert das spielerische soziale Lernen, welches das Auftreten sozialer Delinquenz und ihre Konsequenzen entschärft und soziale Innovationen als virtuelle Möglichkeit sichtbar werden läßt. Werden die BrauchträgerInnen aufgrund ihrer bevorstehenden Hochzeit aus dem Kreis der Aktiven entlassen, so würden sie gut vorbereitet in eine neue verantwortungsvolle Phase ihres Lebens eintreten können. Die Entfaltung und Herausbildung einer Persönlichkeit, die der Loslösung aus der familialen Primärgruppe und zugleich der Ehe, dem intimen Geschlechterverhältnis wie auch dem allgemeinen sozialen Eingliederungserfordernis gewachsen ist, erscheinen nach diesen Interpretationsmustern als zentrale Ergebnisse einer Sozialisation durch das Mailehen.

\subsection{Rebellisches - Konflikt und Ausgleich}

Innerhalb der Tradition der britischen Sozialanthropologie wurde in den 1950er Jahren von Max Gluckman das psychosoziale Konzept eines Rebellionsrituals umrissen. Vor allem anhand empirischer Befunde aus dem südlicheren Afrika machte er die bedeutsame Beobachtung, daß manifeste gesellschaftliche Ordnungen ohne Gefährdung gezielte temporäre Umwandlungen erfahren könnten. So wurde festgestellt, daß in bestimmten Situationen Geschlechterrollen vertauscht oder daß strukturell vorgegebene Machtverhältnisse durchbrochen und eine bestehende Hierarchie regelrecht umgekehrt werden konnten. Gleichzeitig kam es aber bei den scheinbar rebellischen Umsturzversuchen nie $\mathrm{zu}$ einer wirklich ernsthaften Bedrohung des tradierten Normen- und Wertegefüges. Im Gegenteil, die zeitweilige spielerische Vertauschung von Rollen- oder Machtpositionen basiere wesentlich auf der Anerkennung des bestehenden Sozialsystems. Nicht revolutionär, unberechenbar oder anomisch sei das Rebellionsritual, sondern aufgrund der starren sozialen Inversion sei es ein psychosozial wirksames Instrument zur Befestigung der bestehenden Strukturen. Der Ausbruch aus der Normalität entfalte seine Wirkung erst recht, wenn er sich unmittelbar an den realen Gegebenheiten orientiere und ein konkretes Gegenbild sinnlich erfahrbar mache. Die Imitation als verfremdetes Abbild der Normalität führe zu einer emotionalen Entlastung oder gar einer Katharsis persönlicher Unzufriedenheit. Somit blieben zwar problematische Rollen- und Machtstrukturen durchweg bestehen, aber gesellschaftliche Zwänge und politischer Druck würden auch in gewissem Maße für den einzelnen erträglicher. ${ }^{187}$

${ }^{187}$ Siehe Gluckman (1983:266ff). Vgl. Scribner (1984:137ff), der den Begriff Rebellionsritual im Zusammenhang des neuzeitlichen Karnevalsbrauchs anwendet. 
Neuerdings hat Becker (1989:303-305) versucht, das Mailehen im Rahmen ritueller Rebellion zu deuten, aber zunächst muß auf ähnliche, weiter zurückliegende Interpretationsansätze eingegangen werden. Heinrich Schurtz, dessen Thesen zu prinzipiellen Gestaltungsmechanismen der Gesellschaft von seinen zeitgenössischen Kollegen euphorisch aufgenommen wurden, wollte am Brauch des Mailehens die Wirksamkeit altersklassenspezifischer Strukturen nachweisen. Nachdem er eine allgemeine Dreiteilung konstatierte, bei der sich Kinder, mannbare Jugendliche und verehelichte Generationen als Altersklassen herausbildeten, versuchte er folgende funktionale Differenzierung der Ebenen zu verifizieren:

"Die Verheirateten, denen die Aufgabe obliegt, Kinder zu erzeugen und zu erziehen, stehen in festen gesellschaftlichen Verhältnissen und sind vor dem Wettbewerb der Jugend geschützt. Dies ist aber nur dadurch zu erreichen, dass man dem Verkehr der Jünglinge und Mädchen keine Fesseln anlegt, sondern ihnen fre i e $n$ L i e b e s g e n u s s gestattet, aus dem sich dann allmählich festere Verhältnisse bilden und Ehebündnisse entstehen, mit deren Abschluß auch die Zeit der freien Liebe endet" (Schurtz 1902:85).

Das "soziale Gehege" der Verheirateten sollte also durch die Duldung des adoleszenten "freien Liebesgenusses" vor jugendlichen Übergriffen gesichert werden. Genau in diesem Punkt sah Schurtz beim Mailehen eine Bestätigung seiner Theorie: das Mailehen sollte eine Möglichkeit bieten, das sexuelle Verlangen der Heranwachsenden zu kanalisieren. Auf diese Weise ließ sich der Brauch als Instrument des intergenerationalen Spannungsabbaus auffassen. Obwohl die rituellen Aktionen der Jugendlichen anscheinend die geltenden sexuellen Normsetzungen der Erwachsenen in Frage stellen würden, könnten gleichzeitig Gefahren für die matrimoniale Organisation gebannt und allgemeine Sozialstrukturen gefestigt werden. Allgemeiner schließt Schurtz (1902:192):

"Je lustiger sich die Jugend ausgetobt hat, desto mehr kann die Ehe als Geschäft behandelt werden, desto weniger von dem goldenen Schimmer heitren Liebeslebens wird für die Zeit der reiferen Jahre gerettet; der deutsche Bauer steht vielfach noch so recht auf diesem Standpunkt, der ganz geeignet ist, das Gemüt verknöchern zu lassen und den Menschen zur verdrossenen Arbeitsmaschine umzuwandeln, wie sie nun einmal das harte bäuerliche Leben zu erfordern scheint".

Entscheidend an diesen Überlegungen ist, daß aus sozialen Altersklassen ein Gegensatzpaar mit sozial kompensierenden Funktionen gebildet wurde. Danach stünde der exzessiven Ausgelassenheit und sexuellen Ungebundenheit der Jugendlichen der rauhe Überlebenskampf der Erwachsenen gegenüber. Und eine Preisgabe der geltenden Sexualmoral werde mit dem sozialen Frieden entgolten. Kann man sich dieser Logik binärer Antagonismen entziehen? Erfüllte das Mailehen in der Vergangenheit tatsächlich eine sozialtechnische Steuerungsaufgabe, die ein "Dampfablassen" während konfliktträchtiger Momente ermöglichte? 
Mit Hinweis darauf, daß die Jugendlichen gerade bei der Mailehenausübung die Sexualnormen einhalten würden, widersprach Korff (1984:254f) dieser Deutungsvariante. Die altersklassenspezifischen Antagonismen, welche nach Schurtz maßgeblich an der Herausbildung sozialer Strukturen beteiligt sein sollten, werden augenscheinlich von dem "agrarischen Kollektivismus" abgelöst, der unter den kargen Lebensbedingungen und unter dem Einfluß der Kirchenmoral adoleszente Eskapaden in den Hintergrund treten läßt. ${ }^{188}$ An einen Vermittlungsversuch zwischen den widerstreitenden Positionen hatte Becker (1989:303-305) wohl gedacht, als er sowohl die Idee des jugendlichen Ausbruchs aus gesellschaftlichen Zwängen als auch die des Primats ökonomischer Rationalität zusammenführte. Die Verwendung des sozialanthropologischen Terminus Rebellionsritual übernimmt dabei eine Schlüsselrolle. Auch im Mailehen finde eine rituelle Inversion statt, bei der nicht die Familienoberhäupter über die Paarbildung ihrer Kinder entscheiden würden, sondern die Betroffenen selbst. Somit werde eine rigide elterliche Einmischung durch das Verhalten der Jugendlichen unterlaufen. Gemäß der Funktionsweise des Rebellionsritual wird auch für das Mailehen eine Stärkung systemkonformer Prozesse konzediert:

"Die Macht der Eltern, über die Verheiratung ihrer Kinder zu bestimmen, wird durch die gespielte Gegenwelt aber nicht nur in ihrem Recht belassen, sondern sogar gefördert. Es kommt nämlich nicht von ungefähr, daß eine Gesellschaft, die aufgrund ihrer wirtschaftlichen und demographischen Zwänge eine rigide Heiratsnorm ausgebildet hat, ein System relativ freier Partnerwahl überhaupt zuließ. Die Heirat war im frühneuzeitlichen Dorf kein privater Akt, sondern eine Handlung, die den Interessen zweier Familien und darüber hinaus denen der ganzen Dorfgemeinschaft zu dienen hatte." (Becker 1989:304).

Diese Passage konstruiert also einen Zusammenhang zwischen Selbstbestimmungsstreben der Jugendlichen, der elterlichen Verfügungsgewalt und den öffentlichen bzw. dörflichen Interessen. Es fällt also zunächst auf, daß im Gegensatz zur gewohnten Konfliktsituation im Rebellionsritual, wo sich zwei Konkurrenten gegenüberstehen, mittlerweile drei Parteien betroffen sind. Inhaltlich kreist der Streit um die Frage der Berechtigung von (pseudo-)ehelichen Paarbeziehungen. Dabei führt Becker an, daß die Jugendlichen sich in der Mailehenausübung über den Willen der Eltern hinwegsetzten und somit den Interessen der Dorfgemeinschaft genügten. Eine derartige Argumentation verträgt sich allerdings nicht mehr mit den dargelegten Wirkungsweisen der rituellen Rebellion, und zwar aus folgenden Gründen: 1) Wenn die Annahme zutrifft, daß die Interessen der Jugendlichen mit denen der Dorfgemeinschaft bezüglich der ortsbezogenen Partnerwahl übereinstimmen, dann hätten lediglich die Eltern gegen die örtlichen Vertreter "rigider Endogamieregeln"189 rebellieren können. 2) Wenn aber sowohl die Eltern als auch die Dorfgemeinschaft

\footnotetext{
${ }^{188}$ Siehe Kap. 3.5.

${ }^{189}$ Becker (1989:305) mit Bezug auf Korff.
} 
sich im Einklang mit dem bestehenden Heiratspräferenzsystem befunden und die Heranwachsenden bei ihrer Brauchausübung auch keinen sozialen Widerspruch erzeugt haben, dann kann es sich gemäß der Korffschen Interpretation hier nur um eine "Habitualisierung [der Binnenheirat] durch ein plausibles Brauchsystem" (Korff 1984:257) handeln. Das Mailehen hätte unter der Voraussetzung rigider Endogamieregeln nur dann zum adoleszenten Rebellionsritual avancieren können, wenn die Jugendlichen darin eine institutionalisierte Möglichkeit zur Partnerwahl außerhalb der vorgegebenen Normen gehabt hätten. Die These des Rebellionsrituals greift bei Becker deshalb ins Leere, weil der vorgegebene Konflikt zwischen den betroffenen Generationen durch die Einlösung der präferentiellen Heiratsstrategie negiert wird. Von daher ist es auch zu verstehen, daß Korff in seinen Ausführungen nicht auf Konfliktsituationen einzugehen braucht, die auf einer Generationendifferenz beruhen:

"Die dörfliche Gemeinschaft als wirtschaftlicher Not- und Zwangsverband verlangt von jedem einzelnen die Einordnung in den agrarischen Kollektivismus, auch in jenen Handlungsfeldern, die im bürgerlichen Verständnis als 'privat' und 'individuell' gelten" (Korff 1984:259).

Folgt man dieser Sichtweise, dann scheinen egozentrische Handlungsmotive und Generationenkonflikte in der ruralen Gesellschaft des 18. und 19. Jahrhunderts, die hier vornehmlich in den Blick gerieten, zumindest nicht strukturbildend wirksam gewesen zu sein. Das Individuum geht im Kollektiv auf, das Kollektiv reagiert auf die wirtschaftlichen Erfordernisse,

"[der] Brauch übersetzt dabei die Sprache der ökonomischen Rationalität in die der symbolischen Erlebnisformen" (Korff 1984:259).

Bleibt die Frage, wieviel Plausibilität der Annahme eines ökonomischen Determinismus dieser Art zukommt? Welches Ausmaß hatte die wirtschaftliche Notlage der nördlichen Mittelgebirgsränder des Rheinlandes, daß den lebensgeschichtlich miteinander verbundenen Altersgruppen oder gar dem einzelnen merklicher Eigensinn versagt sein sollte? Mit diesen Problemstellungen öffnet sich der Blick für den folgenden Deutungsversuch.

\subsection{Existentielles-Ökonomisches Kalkül}

Entfernt von heidnischem Kult, dionysischen Vergnügungen, jugendlichem Protest, allgemeiner Persönlichkeitsbildung oder diffusen kulturellen Beharrungskräften überrascht die neuere Mailehenforschung mit einer wirtschaftsgeschichtlich orientierten Interpretation. Gottfried Korff (1984:252-259) betrachtete den Brauch vor dem Hintergrund der wirtschaftlichen Existenzsicherung im Rahmen kleinbäuerlicher Lebensbedingungen der Vormoderne. Damit wurde dem Mailehen eine unerwartet 
gewichtige, funktional wirksame Potenz zuerkannt, die eine eingehende Betrachtung erfordert.

Die Deutung basiert auf folgendem Gedankengang: Bis ins 20. Jahrhundert hätten kleinbäuerliche Verhältnisse das dörfliche Leben und die Arbeit in der Eifel vielerorts geprägt. Das den Ackerern zur Verfügung stehende Land sei durch eine Festlegung der Gemeindegrenzen unverrückbar fixiert worden. Solange der Generationenwechsel von einer stetigen Bevölkerungszunahme begleitet würde, verkleinerten sich jedoch infolge des praktizierten Realteilungsrechts die Bewirtschaftungseinheiten fast bei jedem Erbgang. Dennoch bedeute die Grundbesitzzersplitterung nicht zwangsläufig einen unwiederbringlichen Verlust der begehrten Ackerfläche. Um dem unerwünschten Zugriff Fremder auf das geschlossene Gemeindeland einen Riegel vorzuschieben, genüge eine unmißverständliche matrimoniale Strategie: Heiraten und Familiengründungen sollten ausschließlich unter Dorfangehörigen stattfinden. Allerdings seien normative Vernunft und Logik, wie sie sich im Endogamiegebot äußern würden, alleine noch kein Garant für die Errichtung einer stabilen Sozialordnung. Insofern stelle sich schon bei der Formulierung der Regel die Frage nach einem wirksamen Schutz vor anomischer Delinquenz oder jugendlichem Autonomiestreben. Die beiden klassischen präventiven Prinzipien, Bestrafung und Belohnung, könnten eine Lösung des Problems bieten. Genau an dieser Stelle füge sich das Mailehen zweckmäßig in die vormoderne ländliche Lebensrealität ein. Und dort, wo der Brauch dringend gebraucht werde, lasse er sich auch nicht ohne weiteres durch die obrigkeitlichen Verbote außer Kraft setzen. So habe die Bevölkerung landwirtschaftlicher Problemgebiete an den nördlichen Rändern der Eifel erfolgreich die Brauchausübung gegen Staat und Kirche durchgesetzt. Der von der Kirche gerügten sexuellen Laxheit, die der Brauch schüre, sei zwar mit einem durchgreifenden "Entsexualisierungsproze $\beta$ " begegnet worden, dies ändere aber im wesentlichen nichts an dem rituellen Formenbestand des Mailehens, der in besonderer Weise die wirtschaftlich geprägte Heiratsstrategie unterstütze:

"[...] die Interessen der gesamten Dorfgemeinschaft hatten sich mit dem Brauch ein spielmäBiges System geschaffen, dessen Ziel die lokal-gebundene Partnerwahl war [...] Das Mailehen erscheint so als sinnlich-präsentatives Instrument zur Einübung von Endogamieregeln. Der Zweck des Brauches war nicht die individuelle Einleitung einer befristeten oder lebenslangen Sexualbeziehung, sondern die Interaktion und Kommunikation zwischen den Angehörigen eines lokalumgrenzten Heiratskreises" (Korff 1984:254).

Korff greift damit die herrschende Meinung an, daß das Mailehen vorrangig der Rechtfertigung engerer vorehelicher Kontakte gedient und somit konkrete Freundschaften zwischen Jungen und Mädchen hervorgebracht habe. ${ }^{190}$ Auch wenn er

${ }^{190}$ Korff grenzt sich somit gegen weite Teile der Argumentation ab, die in der Herleitung der sozialisationsbedingten Sinndimension des Mailehens unter Kapitel 3.3 sichtbar wurden. Vergleiche z.B. Hilberath (1931:67), Wikman (1937:376) Dierker (1939:146f), Ruland (1972:621), Faber 
einräumt, daß aus den rituell geschaffenen Paarbeziehungen durchaus auch Ehen hervorgehen könnten, so ändere dies nichts am vorrangigen Prinzip, daß "die Einleitung der Ehe unter allen Angehörigen einer Dorfgemeinschaft das Ziel der jährlich inszenierten Brauchübung" gewesen sei (Korff 1984:254f). Von der individuell formulierten Zuneigung, der Emotionalität oder der sexuellen Attraktion unter den brauchtreibenden Jugendlichen scheint die Mailehenausübung dagegen unberührt zu sein. Dies belege auch der Verzicht auf "die ehemals durchaus vorhandenen sexuellkörperlichen Äußerungsformen des Brauches" (Korff 1984:255), die aufgrund der rigiden landesherrlichen Disziplinierungsmaßnahmen im 18. Jahrhundert verschwunden seien. ${ }^{191}$ Der Stellenwert der kollektiven Partnervermittlung, den Korff über die individuellen Dimensionen des Brauches erhebt, ist faktisch, aber auch sozialpsychologisch schwerlich $\mathrm{zu}$ begründen. Auch die zugrundegelegten zeitgenössischen Berichte widerstreben bei näherem Hinsehen einer solchen Deutung. Selbst Kinkel, dessen zuverlässige und sachkundige Ethnographie Korff (1984:252f) lobend würdigt, hebt in seinen Ausführungen jene individualistischen Neigungen und Eifersüchteleien hervor, von denen das geschäftige Treiben der Burschen bei Mailehenversteigerungen schon früh beherrscht wurde:

"[...] ein gewählter Schöffe bietet nun die sämmtlichen Mädchen aus. Das schönste zuerst, und der Reichste trägt sie zumeist davon, wo nicht eine besondere Herzensneigung zu großen Geldopfern anspornt" (Kinkel 1846:160). ${ }^{192}$

Das Primat agrarisch kollektiver Rationalität verleiht dem Mailehen ein überaus instrumentelles, mechanistisches Gepräge. Von einem alles durchdringenden ökonomischen Kalkül scheint die gesamte Landgemeinde, die hier vorrangig "als wirtschaftlicher Not- und Zwangsverband" (Korff 1984:259) aufgefaßt wird, in allen Lebensäußerungen und -sphären vollends beherrscht. Ein wesentliches Problem der Argumentation liegt in den weitgreifenden Generalisierungen, welche die Monokausalität der Deutung stützen. Hinweise auf eine Dynamik der vormodernen landwirtschaftlichen Konjunktur, die Steigerung des Know-how und der damit einhergehenden vielfältigen Meliorationen, die zusammen mit dem Ausbau des Bildungssystems den allmählichen Fortschritt landwirtschaftlicher Produktion

(1985:446). Ferner die Ausführungen zum rezenten Funktionswandel bzw. -verlust, die von einer individuellen Paarbildung im Mailehen ausgegangen sind; dazu Faber (1985:448), Grasmück (1989:32) oder Schrick (1992:39).

${ }^{191}$ Die Widersprüche, die sich im Zusammenhang mit der "Entsexualisierungsthese" ergeben, werden im folgenden Abschnitt (4.6) ausführlich dargelegt. Hierbei wird sich zeigen, daß keine triftigen Aussagen über die Ausschweifungen oder die asexuelle Enthaltsamkeit im Mailehengeschehen vorliegen.

${ }^{192}$ Schon das Versteigerungsprozedere verlangt grundsätzlich nach einer individuell getragenen Entscheidung. Im 5. Jahrhundert v. Chr. verweist Herodot bei der Rekonstruktion der altbabylonischen Versteigerungspraxis bereits auf die unterschiedlichen Versteigerungsergebnisse, die sowohl auf der Finanzkraft des Ersteigerers als auch auf seinen persönlichen Neigungen beruhen würden; dazu Kap. 2.1. 
begründen, der Reformationen von Grundbesitzstrukturen, der Mobilität von Arbeitskräften, der Veränderung ruraler Berufsstrukturen vermißt man bei der Interpretation ebenso wie eine Differenzierung des individuellen Verhaltensspielraums oder zumindest die Darstellung der widerstreitenden sozialen Gruppen. Die Möglichkeit jedweden unkonformen Verhaltens, ob aus jugendlicher Auflehnung, aus individueller Disposition, aus gruppenübergeordneter Überzeugung, wird bei Korff nicht thematisiert und erscheint daher jenseits des Vorstellbaren.

Auf eine weitreichende soziale Homogenität und Konformität verweist das Postulat von den "Interessen der gesamten Dorfgemeinschaft" (Korff 1984:254). Eine derart widerspruchsfreie Bündelung dörflicher Belange klingt aber nicht nur aus einer übergeordneten systemtheoretischen Sicht fragwürdig, ${ }^{193}$ sondern auch die Ergebnisse der historischen Forschung lassen Zweifel aufkommen. Zu Beginn der 1960er Jahre hat bereits Moser (1985:216) die Vorstellung der dörflichen Geschlossenheit im Hinblick auf hochmittelalterliche Siedlungsformen, Besitzverhältnisse und Rechtsstellungen relativiert. ${ }^{194}$ Die großen Bauernaufstände im 16. Jahrhundert blieben für das Standesbewußtsein der rheinischen Bauern wohl ohne nennenswerte Konsequenzen. So behielt - nach der instruktiven agrarhistorischen Skizze von Aubin (1922:129ff) ${ }^{195}$ - die Agrarverfassung, die in der Stauferzeit entwickelt wurde, auch nach zeitgeschichtlichen Irritationen bis ins 19. Jahrhundert ihre Gültigkeit. Obwohl die sogenannte "versteinerte Grundherrschaft" erst in den napoleonischen Reformversuchen um 1800 ein Ende fand, erfolgten in der neuzeitlichen Landwirtschaft durchaus soziale und wirtschaftliche Veränderungen, die das monolithische Gebilde eines rural geprägten "wirtschaftlichen Not- und Zwangsverbands" (Korff 1984:259) ins Wanken brachten. Selbst die einfache Korrelation von Bevölkerungszuwachs und Landteilungen führte nicht zwangsläufig zu verschärften Existenzproblemen der Bauern. Aubin veranschaulicht eindringlich, wie vielgestaltig soziale Entwicklung, gesellschaftliche Bedingungen und landwirt-

\footnotetext{
${ }^{193}$ Hier ist vor allem an den Stellenwert der doppelten Kontingenz zu denken, die maßgeblich an sozialen Interaktionen beteiligt ist. Jede Verständigung - auch die unter den Bedingungen einer schlichten Paarkonstellation - unterliegt der doppelten Kontingenz, die das dynamische Verhältnis von Kongruenz und Auseinanderfallen gemeinsamer Ziele und Handlungen bewirkt. Auch wenn es dabei zu stabilisierenden, widerspruchsfrei erscheinenden Strukturbildungen kommt, so darf nicht übersehen werden, daß dieser Prozeß unter auseinanderstrebenden Kräften abläuft. Vgl. Luhmann (1984:148ff und 488ff). Zur Kollektivismuskritik siehe auch Emge (1953:3-20).

${ }^{194}$ Bei der Beschreibung des Rheinlands aus agrarhistorischer Sicht bemerkt Aubin (1922:132), daß die Realteilung die selbständigen Bauern keineswegs daran hinderte, "Grundstücke allen möglichen Rechts" zu einer rentablen Betriebsgröße zu vereinigen. Die Betrachtung vormoderner Grundbesitzverhältnisse hat insofern über die heiratsbedingten Variationen hinaus noch andere Formen, wie z.B. Pacht, Belehnung und Kauf, in Rechnung zu stellen. Vgl. hierzu aus neuerer Zeit Koll (1984:115) und Staab (1989:150ff).

${ }^{195}$ Jüngere Forschungen bestätigen die richtungsweisenden agrarhistorischen Erkenntnisse Aubins; vgl. z.B. Kellenbenz (1979:31ff) und Milkereit (1979:213ff).
} 
schaftliche Produktionsverhältnisse im Rheinland miteinander gekoppelt sind; z.B. erfolgte schon im 14. Jahrhundert ein Verzicht auf Landgewinnung zugunsten einer intensiveren Bewirtschaftung der vorhandenen Fläche - ein Prozeß, der offenbar bis zur Gegenwart nichts an Aktualität eingebüßt hat. ${ }^{196}$ Die Zuspitzung der Brauchbedeutung auf die dörfliche Ökonomie konnte weder durch die Analyse agrarstruktureller Prozesse noch durch die fortbestehende Relevanz weiterer, z.B. sozialisationsbedingter Sinndimensionen bestärkt werden. ${ }^{197}$

Dieses Resultat läßt sich auch nicht durch eine anscheinend charakteristische geographische Verteilung des Mailehens im 19. Jahrhundert entkräften. Insbesondere die wirtschaftlich benachteiligten Regionen an den nördlichen Mittelgebirgsrändern hätten das Mailehen aus den benannten Gründen bewahrt (Korff 1984:257). Abgesehen von der geringen Genauigkeit der zugrundegelegten Karte oder der unbegründeten Behauptung, daß das Mailehen im 15. Jahrhundert allgemeine Verbreitung im Rheinland gefunden und insofern für den Erhebungszeitraum nur noch Reliktcharakter habe, folgen bereits aus der unterstellten Brauchverteilung erhebliche Erklärungsschwierigkeiten. So wird nicht darauf eingegangen, warum der Brauch selbst in Gegenden verstärkt vorkommt, die nicht den Merkmalen kleinbäuerlicher Landwirtschaft entsprechen. Das fruchtbare Ackerbaugebiet zwischen Köln und Aachen, das Vorgebirge bei Bonn - eine Region wohlhabender Obst- und Gemüsebauern mit extremer Güterzersplitterung 198 - sind offenbar nicht weniger brauchtypische Landschaften als strukturschwächere Regionen. Umgekehrt ergeben sich gerade dort, wo die wirtschaftlichen Zustände am ehesten für einen "Erhalt" des Brauches gesprochen hätten - also jene "weißen Flecken" der volkskundlichen Kartographie, welche die kargen Eifelgegenden markieren - keine Anhaltspunkte für das Mailehen. Unverständlich erscheint auch das Fehlen eines Hinweises auf eine frühe Verbreitung des Mailehens im städtischen Raum. Die

${ }^{196}$ Die subtile Ausdifferenzierung landwirtschaftlicher Produktionstechniken darf für den vorindustriellen Zeitraum keineswegs als marginal erachtet werden. Kürzlich konnte z.B. Hildebrandt (1989:103ff) beachtliche Entwicklungen innnerhalb dieses Bereichs für das 9.-11. Jahrhundert aufzeigen. Das dynamische Wachstumspotential der Landwirtschaft in der Frühen Neuzeit hat Koll (1984) eingehend analysiert. Darüber hinaus machen die heutigen Tendenzen agrarischer Entwicklung deutlich, daß selbst Produktionsüberschuß und die Stillegung von Nutzflächen eine scheinbar unaufhaltsame Steigerung der landwirtschaftlichen Produktivität nicht hemmen können; hierzu Selter

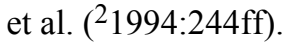

${ }^{197}$ Siehe Kap. 3.3.

${ }^{198}$ Das Beispiel der Vorgebirgsbauern läßt vermuten, daß die Landzersplitterung weniger mechanistisch als oben dargelegt ablief. Nicht nur Bevölkerungsdruck und Erbteilungsregeln, sondern auch die Bonität des Bodens, das Spektrum der erzeugten Güter, die erreichte Produktivität und die Elastizität der Nachfrage wirkten anscheinend auf die Landbesitzverhältnisse ein. Bemerkenswert auch der Hinweis von Aubin (1922:136), daß im Vergleich zu den Splisseninhabern, die extreme Landteilung "stärker noch von den Grundherren als Last empfunden [wurde]", und zwar sowohl wegen eines schleichenden Kontroll- und Eigentumsverlusts als auch wegen der enorm ansteigenden Verpflichtungen (Bewirtung, Holzrechte) gegenüber den Abhängigen. 
urbanen Verhältnisse stehen nicht nur geographisch, sondern auch wirtschaftlich und sozial abseits der hier konzedierten Zusammenhänge. Der Bezug zur räumlichen Verteilung des Brauches ist somit eher dazu geeignet, die Signifikanz der These vom "agrarischen Kollektivismus", der "die Binnenheirat und deren Habitualisierung durch ein plausibles Brauchsystem [erheischt]" (Korff 1984:257), in Frage als unter Beweis zu stellen.

Doch alleine die Offensichtlichkeit persönlicher Bedürfnisse der Brauchakteure und die grobe Verallgemeinerung agrarischer Strukturen haben nicht unbedingt eine völlige Entkräftung des ökonomischen Erklärungsansatzes zur Folge. Da die Argumentation aber zu einer Überbetonung kollektiv motivierter Bedürfnislagen und gleichzeitig zu einer Vernachlässigung individueller Bestrebungen führt, muß vor allem ein Justieren der Perspektive vorgenommen werden. Die Belange der Jugendlichen sind nicht gegen die kollektiven Zielvorgaben der Dorfgemeinschaft auszuspielen; vielmehr zeigen sich neben der jugendlichen Fügsamkeit auch Widersetzlichkeiten, denen der Brauch ein Forum verschafft und zur Artikulation verhilft (siehe insbesondere Kap. 3.3). Anders gesagt: Jene konzedierte wirtschaftliche Bedeutung des Mailehens darf den Blick auf andere, zum Teil auch widerstreitende sinnstiftende Bedingungsfaktoren des Brauches nicht versperren.

Wenn auch die vorrangige funktionale Verknüpfung des Mailehens mit kollektiven Wirtschaftsinteressen und endogamen Heiratspräferenzen nach ausführlicher Analyse einer willkürlichen Konstruktion gleichkommt, stand die Endogamie der Brauchausübung keinesfalls im Wege. Die Verpflichtung der BrauchträgerInnen auf die lokalen Grenzen sorgte freilich für eine Verdichtung der innerdörflichen Kommunikation und Interaktionen. Und ohne die Phantasie übermäßig strapazieren zu müssen, wurde den örtlichen Mailehenpaaren eine unmittelbare Vorstellung von einer virtuellen Ehe eröffnet. Nicht nur den Mailehenpaaren, muß sogleich hinzugefügt werden, denn das geschäftige Treiben der Jugendlichen und ihre aufeinander bezogenen Neigungen entbehrten nicht der gesteigerten elterlichen Aufmerksamkeit. Eheentscheidungen der erbberechtigten Nachkommen waren für die Bauernfamilie von enormer Tragweite. Demgegenüber erscheinen zwischenmenschliche Neigungen der potentiellen Heiratskandidaten in der Tat wie nebensächliches Beiwerk einer generationenübergreifenden Existenzsicherungs- und Vermögensaufbaustrategie. Indessen ist nicht zu verkennen, $\mathrm{da} ß$ gerade die emotionalen Vorlieben der Jugendlichen oft genug zu einem neuralgischen Punkt der agrarischen Rationalität vordrangen, indem sie das ökonomische Kalkül grundlegend anfochten und nach Kräften in seine Schranken wiesen. ${ }^{199}$ Hilberath (1931:64f) und Wikman (1937:148, 356ff) haben gezeigt, daß die voreheliche Paarbildung durch die konkreten Vorstellungen der Erblasser maßgeblich berührt

${ }^{199}$ Rosenbaum (1982:75f) machte auf die z.T. subtile Verflochtenheit von sozialen und ökonomischen Beweggründen bei der Wahl des Ehepartners aufmerksam. 
wurden. Dem Merkmal der Endogamie lassen sich daher Kriterien des materiellen Besitzstandes und des sozialen Ansehens unmittelbar an die Seite stellen. Daß die verschiedenen Interessen sich zu einem harten innerfamiliären Konflikt oder gar zu dauerhaften Zerwürfnissen zuspitzen konnten, wird von den genannten Autoren nicht bezweifelt. Den Jugendlichen, die sich ihre (Lebens-)Partnerwahl nicht von ihren Vätern und Müttern abnehmen lassen wollten, böte das Mailehen die Rückendeckung der Peer-group. Die Möglichkeit der rituellen Paarbildung birgt somit für den Umgang mit konfligierenden ökonomischen und affektgeladenen Interessen nicht nur ein zur Anpassung hinführendes Bewährungs-, sondern auch ein zu verschiedenen Seiten hin offenes persönlichkeitsbildendes Lernfeld. ${ }^{200}$

\subsection{Dionysisches - Ambivalenz der Freude}

In den Auseinandersetzungen über den Sinn des Mailehens taucht das Motiv der menschlichen Freude an Geselligkeit, Unterhaltung, Ausgelassenheit und Feierlichkeit am häufigsten auf. Dabei ist jedoch nicht zu übersehen, daß die Intention und Beweisführung der Interpretationen von unterschiedlicher Qualität und unterschiedlichen Empfindungsweisen geprägt sind. Die Deutungsversuche über jene lustbetonte Entspannung, die eine Teilnahme am Brauchgeschehen gewähren soll, lassen sich keineswegs auf eine gemeinsame Argumentationslinie reduzieren, vielmehr bergen sie Unebenheiten, zuweilen auch bezeichnende Gegensätze. Generell herrscht Einigkeit darüber, daß das Mailehen die Routine und die Mühsal des Alltags zu durchbrechen vermag. Diese grundlegende Erkenntnis führt aber keineswegs zu übereinstimmenden Beurteilungen der lustvollen Aktionsformen, der außergewöhnlichen Geselligkeit, der intensivierten Kommunikationsmöglichkeiten, die im Brauchgeschehen ihren verfestigten Rückhalt finden und die Transzendierung des Gewöhnlichen ausmachen. Während auf der einen Seite freundschaftliches Gespräch oder jugendliche Tanzfreude positiv auf Widerhall stoßen, werden auf der anderen Alkoholmißbrauch und sittliche Entgleisung als unliebsame Begleiterscheinungen der Freude mißbilligt. Die polare Spannungslage wird bei der Durchmusterung des gesamten Quellenbestands sichtbar und läßt in ihren ambivalenten Auslegungen an eine Ästhetik der Freude denken, die je nach Standpunkt des Betrachters durch Anmut besticht oder durch Widerwärtigkeit abstößt. Daß die in Frage kommenden Perspektiven nicht zufällig sind, sondern jeweils mit spezifischen historischen Verhältnissen und Geisteshaltungen korrespondieren, ist hierbei bemerkenswert. Dies wird vor allem dort deutlich, wo der Versuch unternommen wird, die Wirkungen der Brauchausübung auf einen allgemeinen gesellschaftlichen Zustand zu beziehen.

${ }^{200}$ Siehe auch Kap. 3.3. 
Anhaltspunkte dafür, daß das Mailehen als Ausdruck der Lebensfreude anzusehen ist, finden sich bereits in der literarischen Bearbeitung eines mailehenartigen Tanzspiels in Wittenwilers Ring, wo die Zuteilung eines Tanzpartners unter dem Ausspruch "ze fröden seinem leben" erfolgt. ${ }^{201}$ Auch der Chronist Weinsberg zögerte nicht, diesem Aspekt gleich mehrfach Geltung zu verschaffen. Das Mailehen stellte die Voraussetzung für die Vergnügungen dar, welche die Feiergesellschaft im Hause Weinsberg bei "gebrait und wein" erlebte: "derhalb sin mir [...] samen frolich gewest". 202 Und selbst die Obrigkeit, unterstützt von reformwilligen Seelsorgern, sah im Mailehen zunächst nichts Dämonisches. Man solle die Brauchtreibenden ruhig gewähren lassen, "so sollichs one Gotzlesterunge zugeeht", heißt es in einem Kuseler Visitationsprotokoll von 1544.203 Obwohl die Jugendlichen noch einmal verschont blieben, so handelt es sich hier keineswegs um einen klerikalen Freibrief zur ungehemmten Brauchausübung. Die Konzession erfolgte wohlgemerkt unter einer Einschränkung, die nicht nur den Ruf nach einer kontrollierenden Aufsicht, sondern auch einen weiten Deutungsspielraum der Urteilenden umfaßte. Kontrolle und Bewertung des Mailehens haben in der Folgezeit Konturen angenommen. In einem Gutachten zur Zweibrücker Kirchenordnung von 1557 firmiert das Mailehen unter "unzuchtige bruch" und hat eine vernichtende Kritik auf sich gezogen:

"'Solche abgötterey sol warlich in keiner christlichen kirchen auch von keiner christlichen oberkeit geduldet werden"' (zitiert nach Koch 1957:95f).

Seither haben die Kirchen und ihre Befürworter mannigfach ihrer brauchfeindlichen Haltung Ausdruck verliehen. ${ }^{204}$ Herzog Wolfgang von Pfalz-Zweibrücken griff in einem offiziellen Schreiben umgehend die in dem soeben erwähnten Zweibrücker Gutachten festgestellten sozio-religiösen Mißstände auf und veranlaßte die Beseitigung einer Reihe von Brauchhandlungen. Darunter fielen das Johannisfeuer im Zusammenhang mit Trunkenheit und erhöhter Brandgefahr, die gemeinsamen nächtlichen Trinkgelage von Männern und Frauen wie auch das "'Lesen [sic] ausrufen. dabey von Jungen gesellen und Mägden alle leichtfertigkeit gebraucht wurdt [...]"' (zitiert nach Schunck 1926:56). In der Kennzeichnung des Mailehens als einer Angelegenheit, die zwischen den Geschlechtern zu jeglicher "leichtfertigkeit"

${ }^{201}$ Wießner (1931:223, Zeile 6334); vgl. Kap. 2.2.

${ }^{202}$ Weinsberg (1886-1926, 5:141, 143), derselbe (1886-1926, 4:163f) und ferner Hofmann (1963:92ff). Vgl. Kap. 2.3.

${ }^{203}$ Siehe Biundo (1951:53).

${ }^{204}$ Vgl. Tab. 2-1 und Kap. 2.4. Die Unvereinbarkeit von Brauch und Glaube bildet nicht nur die Legitimationsgrundlage zur Abschaffung geächteter Verhaltensformen, sondern gibt auch den interpretativen Rahmen vor, in dem das kirchlich Unerwünschte zu betrachten ist. Da es bei den Verbotstexten in erster Linie nicht um eine wertfreie Zustandsbeschreibung der Gesellschaft geht, sondern um eine wirkungsvolle, politische Entlarvung und Bekämpfung von parteilich empfundenen Fehlentwicklungen, müssen die Inhalte behutsam analysiert werden. Kurzum: intentionale Sichtweisen und apologetische Sinnstrukturen sollten als solche nachvollziehbar aufgedeckt werden. 
führe, ${ }^{205}$ wird der Gruppe der unverheirateten Brauchträger selbst die geringste Einhaltung sittlicher Umgangsformen abgesprochen. Unweigerlich entsteht der Eindruck, als ob die persönliche Verhaltenskontrolle durch die Brauchpraxis erheblich verringert werde. Der brauchmäßig organisierte voreheliche Kontakt der Jungen und Mädchen hatte offenkundig zu diesem Zeitpunkt ein für die Obrigkeit erträgliches Maß überschritten. Daß dabei die Einschätzungen der hegemonialen Kontrollinstanzen am substantiellen Kern des Brauchgeschehens vorbeizielen konnten, ist aus heutiger Sicht nicht auszuschließen. Folglich drängt sich die entscheidende Frage auf, ob und inwieweit dem Klerus die einzelnen Brauchhandlungen tatsächlich vertraut und verständlich waren. ${ }^{206}$ Dort, wo sich die Brauchträgerschaft hartnäckig zur Wehr setzte und gegen die rigiden Sanktionen opponierte, lag nicht zwangsläufig mutwilliger Widerstand gegen die Herrschenden vor, sondern es bestand durchaus die Möglichkeit des begründeten Gegensteuerns im Hinblick auf willkürliche Machtausübung und Sozialdisziplinierung. Der Mangel an unmittelbaren Äußerungen der Betroffenen lenkt die Aufmerksamkeit zunächst auf kontextuelle Informationen. Erwähnt wurde bereits, daß die mehrmalige Auflage von Verbotstexten und das permanente Fortbestehen des Mailehens nicht für eine bereitwillige Unterordnung der Betroffenen sprechen kann. ${ }^{207}$ Es kann von einem grundsätzlichen Rückhalt der Jugendlichen im Kreis der familiären und lokalen Bezugsgruppe ausgegangen werden. Ohne eine derartige Unterstützung erscheint das jugendliche Auflehnen gegen Kirchen- und Staatsgewalt als wenig aussichtsreiches Unterfangen. ${ }^{208}$

Ein Beispiel aus einem vergleichbaren Zusammenhang erhellt den Sachverhalt aus einer zusätzlichen Perspektive. In der Schweiz waren nächtliche Besuche der unverheirateten Männer bei den Mädchen mit gemeinsamem Bettlager weithin verbreitet und durch den sogenannten "Chilt"209 institutionalisiert. Zahlreiche

${ }^{205}$ Vgl. dazu ferner die kirchliche Verordnung zum Verbot des Lehnausrufens im rheinhessischen Badenheim von 1569 (Krebs 1973:228) und das aus dem Jahre 1780 stammende Protokoll der Kirchenkonvente Kirtorf, Alsfeld und Homberg (Baur 1856:568).

${ }^{206}$ Die Einschaltung von Sendgerichten und -schöffen, bei der die Kontrolle und Einhaltung von normativen Verhaltensregeln im Vordergrund standen, belegt die Distanz zwischen Kirche und Glaubensgemeinschaft. Zum einen schien der Ortsgeistliche hierbei selbst einer Überprüfung durch seine Vorgesetzten zu bedürfen, zum anderen war er selbst wohl nicht hinreichend in der Lage, unmittelbar zwischen seinen Parochialen zu vermitteln.

${ }^{207}$ Vgl. Kap. 2.4.

${ }^{208}$ Dazu auch Schindler (1996:344, 355).

${ }^{209}$ Vgl. Wikman (1937:4); er verwendet den Terminus Kiltgang als regional übergreifenden Begriff für den vorehelichen Jugendbrauch, bei dem die jungen Männer die jungen Frauen nachts besuchen. Als Sonderformen der Freierei bzw. Werbung werden Nachtfreierei und das Fensterln genannt. Zu den Schweizer Knabenschaften existiert eine reichhaltige Literatur, die allerdings ähnlich wie die Mailehenforschung in der Frage der Geschlechterbeziehungen einseitig auf die männliche Perspektive referiert. Siehe Hoffmann-Krayer (1905), Caduff (1932), Lutz (1957) oder Cromberg (1970). 
Mandate stellten sich auch gegen diesen Brauch. Wie beim Mailehen wenden sie sich vornehmlich gegen die Unsittlichkeit der Aktionen. ${ }^{210}$ Wobei sich im vorliegenden Fall konkrete Anhaltspunkte zur Klärung jener Frage finden lassen, warum die obrigkeitlichen Brauchrestriktionen nicht zum Erfolg führten:

"das Volk entgegnet: 'Die Herren verstehen Das nicht; sie halten den Kiltgang nur deshalb für böse, weil sie nicht im Stande wären, auf ehrliche Weise bei einem Mädchen zu liegen'". ${ }^{211}$

Aus dieser selten anzutreffenden, aber dennoch bezeichnenden Aussage spricht eine unüberwindbare Kluft zwischen der Kultur der Herrschenden und der Kultur der Beherrschten. Eine Übertragung dieses Verhältnisses auf die Mailehenausübenden und seine Gegner bietet sich an. Insbesondere die sittlich-moralisch gefärbten Verurteilungen des Mailehens, welche die Assoziation zur rituell legitimierten sexuellen Freizügigkeit unter den Jugendlichen nahelegt, entstellen entweder aus einer fundamentalen Distanz zwischen den betroffenen Parteien und einer damit verbundenen Ignoranz bzw. aus einer gezielten Übertreibung die reale Situation. Auf dieser Grundlage entfaltete und festigte sich der anscheinend dämonische Zug rituell erzeugter Freude bis hin zur Personifizierung des Mailehens als Mutter vieler Sünden. Der Kampf gegen das Mailehen wird somit gleichermaßen zum Kampf gegen Teufel und Teufelswerk, wie die folgende Passage aus einem Pfarrersbericht von 1680 an die Marburger Regierung veranschaulicht:

"'Denn alß ich hier zu Ebsdorff gesehen, wie der Teuffel den längst veralteten brauch mit dem $\mathrm{L}$ e $\mathrm{h}$ e $\mathrm{n}$ a $\mathrm{u} \beta \mathrm{r}$ u f f e $\mathrm{n}$, so in der Walpurgis-Nacht soll vorgehen vnd zu grosser Uppigkeit vnd Unzucht Anlaß geben kann, wieder hervorgesucht, also habe ich Amptswegen solchen Muthwille der Jugent nicht gestatten können [...]"'; geradezu "'[...] eine ärgerliche Kuppeley [hätten die Lehnpaare] unter sich gemacht, deßwegen ich am vergangenen Pfingstsonntag in der Nachmittagpredigt, alß sie neben anderen beichten wollen, sie vorher vnd zwar zu letzt, alß die andern alle gebeichtet, in gegenwart meiner Senioren zur Rede gesetzt vnd beweglich ermahnet, von solchem leichtfertigen bösen Brauch abzulassen, widrigen falls ich sie nicht könnte zur Comunion zu lassen, da sie denn angelobet, dergleichen abzustellen, auch darauf gebeichtet vnd die h. Absolution empfangen"'.

Die Wirkung der seelsorgerlichen Disziplinierungsmaßnahme war indes nicht so anhaltend und heilsam, wie es sich der Pastor versprochen hatte, denn der Bericht führt weiter aus:

"'Wie ich nun verhofft hätte, sie würden sich als Heil begierige Comunikanten neben andern den folgenden Tag zum heil. Abendmahl einfinden, bleiben nicht allein ihrer sechs aussen -sondern lassen mir noch dazu -- ins Pfarrhauß trotzig entbieten, da $\beta$ sie sich eines andern bedacht vnd wollten nun nicht zu Gottes Tisch gehen, wie auch geschehen, haben also das gottlose $\mathrm{L}$ e h n a u s r u f f e $\mathrm{n}$ dem heiligen Abendmahle vorgezogen, wie sie denn mir zum trotz ihre Lehnsträ u $\beta$ e a u f den $\mathrm{H}$ ü te n behalten, ob sie nuhn solches auß

${ }^{210}$ Dafür liefert das Schweizerische Idiotikon (1881ff) eine Vielzahl von Hinweisen; s. besonders die Stichwörter "Chilt" und "Stube".

${ }^{211}$ Siehe Schweizerisches Idiotikon (1881ff Stichwort "Chilt", Spalte 244). 
eigenem Willen gethan, oder von den alten darzu angereitzet worden, kann ich noch nicht erfahren."' (nach Landau 1840:272f). ${ }^{212}$

Kuppelei, Unzucht, Mutwille beschreiben die Gesellschaft der Brauchtreibenden in einem Licht ungezügelter, heilloser Ekstase. Die sittliche Ordnung sowie die Gebote Gottes scheinen durch das Mailehen verletzt: "der Teufel hat den Brauch hervorgesucht". Mutwilligkeit, Sittenlosigkeit und Trotzigkeit der Heranwachsenden ergeben auf den ersten Blick ein einleuchtendes, stimmiges Bild. Und wenn es zunächst den Anschein hat, als ließen sich die weltlichen Brauchträger in Ehrfurcht vor den Sakramenten, der Absolution und den Kirchenältesten eines Besseren belehren, so folgte bald bei einem Teil der Missetäter der Rückfall. Das Erstaunliche an dieser Regression ist, daß der Seelsorger es nicht für ausgeschlossen hielt, daß die Jugendlichen in ihrem gleichsam dämonischen Treiben von der Gemeinde unterstützt worden seien. Gerade dieses Moment der Unsicherheit verweist einmal mehr auf die Diskrepanz und Unvermitteltheit, die selbst auf lokaler Ebene die Beziehungen zwischen den Pfarrern und der Bevölkerung prägten. Die Überbrückung jenes sozialen und kulturellen Orientierungsdefizites ist nur unter der Schaffung einer gegenseitigen Vertrauensbasis denkbar. Auch die maßlose Übertreibung gesellschaftlicher Zustände, wie sie in den Archivalien zum Ausdruck gekommen sind, hätten nur durch den Willen zur Sachlichkeit eingedämmt werden können. Solange allerdings beide Maßnahmen nur dazu führen, die neuzeitlichen Formen der Sozialdisziplinierung in Abrede zu stellen, wird man in dem obrigkeitlich gesteuerten Rechtsbereich vergeblich nach einer ausgewogenen Darstellung der gesellschaftlichen Zustände im allgemeinen oder der ekstatischen Elemente des Mailehens im besonderen suchen. ${ }^{213}$ Folgerichtig sagen die einzelnen Fundstellen weniger über die

${ }^{212}$ Den jugendlichen Behauptungswillen in einer zunehmend reglementierten Lebenswelt belegt ein weiteres Beispiel aus dem schweizerischen Brauchkontext der Spinnstuben aus dem Jahre 1716. Der Protest entlarvt die allzu bildhafte Glaubensvorstellung, bei dem die Delinquenten letzten Endes allesamt in der Hölle schmoren würden. Trotzig entgegnet man dem Pfarrer, der die Folgen einer sündhaften Brauchausübung in der Predigt behandelte: "'doch werd es nit so übel sein, wan so hübsche Meitli in der Hel seigind, sy welind dann braff zu ihnen z Liecht [Spinnstube] gahn"' (zit. nach Schweizerischem Idiotikon $1881 \mathrm{ff}$ Stichwort "Stube", Spalte 1185).

${ }^{213}$ Der kulturellen und sozialen Distanz, die im erörterten Rahmen nur unterschwellig zum Ausdruck kommt, läßt sich eine aufschlußreiche Parallele zur Seite stellen. Vergleicht man die Christianisierung in Europa mit der überseeischen Missionstätigkeit, so zeigt sich hier wie dort das Unverständnis der Kirchenmänner gegenüber den Bräuchen, selbst gegenüber alltäglichen Gewohnheiten. Theologisch untermauerte Moralvorstellungen treten zum wiederholten Male in einen Gegensatz zur Lebenspraxis der Bevölkerung. Bei außereuropäischen Kulturen wurde dieser Gegensatz womöglich verschärft, da vom Missionar in der Fremde eine anspruchsvollere Integrationsleistung abverlangt wurde als vom einheimischen Gemeindepfarrer. Zahlreiche Beispiele aus einer Region, die mir aus intensiver Forschungstätigkeit vertraut ist (Wey 1991), veranschaulichen die überregionalen strukturellen Grundzüge der Auswirkungen einer fremdartigen Kirchenmoral; das Resultat war auch auf Palau (Mikronesien) die Bekämpfung traditioneller Tänze, Bräuche oder Kleidungsgewohnheiten, die als Ausdruck vermeintlicher autochthoner Unzucht angesehen wurden. Dazu siehe Krämer (1926,3:20); Jernigan (1973:134ff); Hezel (1980:376); Parmentier (1987:47); Christmann et al. (1991:115ff); ferner Leclerc (1973:152ff). 
Bedeutung des Brauches, über seinen "Sitz im Leben"214 aus als über die spezifischen Interessen der Interpreten.

Damit sind wichtige tendenziöse, wirklichkeitsverzerrende Voreinstellungen aufgedeckt worden, denen man im 19. Jahrhundert unter entgegengesetzten Vorzeichen bei den romantisch-mythologisch ausgerichteten Sinnkonstruktionen wiederbegegnet und die deshalb unten noch einmal aufgegriffen werden sollen. Zunächst muß die Verdammung und Verteuflung des Mailehens als Wurzel des Bösen, als Anstifter zur sexuellen Normenüberschreitung betrachtet werden: Zum ersten ist die Parole von der Leichtfertigkeit und Unzucht, die mit dem Mailehen anscheinend aufs engste verbunden ist, in den meisten Fällen unspezifiziert. Das durch den Brauch ausgelöste sexuelle Fehlverhalten wird selten so deutlich ausgesprochen wie in dem Bericht eines Kirchenmannes an das Gießener Konsistorium im Jahre 1780:

"'Wirklich sind mir Exempel von gefallenen Weibspersonen vorgekommen, die über diese Dinge [das Lehnausrufen betreffend] geklaget, daß ihre Unschuld seie berückt, und sie in Leichtfertige Wege verleitet worden'", worauf der protokollierende Pfarrer resümiert, "'Die Sache ist an sich selbst Böse, und wird zu einer Mutter vieler Sünden"' (zitiert nach Baur 1856:567).

Das Thema jugendliches Verhalten und voreheliche Sexualität taucht seit dem 16. Jahrhundert beständig in den Quellen zum Mailehen auf und sorgt an der Schwelle zum 20. Jahrhundert ebenso für erregte Gemüter. Dabei ist die Stichhaltigkeit der vorgebrachten Vorwürfe aus den bekannten Gründen problematisch. Die Anlage des Brauches als Instrument vorehelicher Kontaktaufnahme spricht dafür, daß das Mailehen zusätzliche Möglichkeiten für einen gezielten sexuellen Umgang unter den Heranwachsenden schuf. Andererseits konnte den neuzeitlichen Familienverbänden, die in der Landwirtschaft ihr Brot verdienten, an unkontrollierten Familienneugründungen kaum etwas gelegen sein. Aus dieser prinzipiellen Überlegung heraus gewinnt eine Reihe von Argumenten zur sittlichen Unbedenklichkeit des Mailehens durchaus an Plausibilität. Und dennoch wird niemand dafür garantieren können, daß eine Grenzüberschreitung im Sinne einer punktuellen Verletzung allgemeiner Verhaltensregeln im Rahmen routinierter Brauchpraxis von vornherein ausgeschlossen war und ist. ${ }^{215}$

Zum zweiten verfolgten die kirchlichen und staatlichen Institutionen das Ziel, ordnend in das soziale Leben einzugreifen. $\mathrm{Zu}$ beachten ist dabei, daß der Normierungsbedarf religiös und daher nicht unbedingt empirisch begründet ist. Gleichgültig

${ }^{214}$ In Anlehnung an Bodemann verwendet Scharfe (1986:347) diesen Ausdruck zur Betonung von funktionalen Dimensionen, die durchweg im Brauchgeschehen wirksam seien.

${ }^{215}$ Auffälligerweise ist der Erfolg eines hartnäckig auftretenden Stereotyps an eine Sinnkonstruktion mit Realitätsbezug und simplifizierender Wirkung gekoppelt (Bausinger 1988:13). Vgl. Wey (1999:316-318). 
ob es sich um grundlegende Kirchenordnungen oder um ein einzelnes Edikt handelt, die Anordnungen und Beschwerden bringen oft mit besonderem Nachdruck die Ernsthaftigkeit und Dringlichkeit eines religiösen Anliegens zum Ausdruck. Dies vermag wiederum ein Beispiel aus dem schweizerischen Brauchmilieu zu verdeutlichen:

"'Es ist auch menklichen noch unvergessen, wie uns der allmächtige Gott, wenn die Stubeten in Alpen und Wähden sind gsyn, uns wieder mit Hagel und Ungewitter und großem Wasser hat gestraft, von wegen unserm sündigen, boshaften, ruchen Leben; deswegen haben wir einhellig uf- und angenommen [...] daß fürohin am Sonntag und an denen Fyrtägen in Alpen und Wähden die gemeinen großen Stubeten verbotten sein sollen."'.216

Das brauchgeleitete Verhalten der "Stuben-" bzw. "Kiltgänger" wurde hier für das Wohlergehen der gesamten Gemeinde verantwortlich gemacht. Unwetterkatastrophen jener Zeit (um 1590) brachten für die vom primären Wirtschaftssektor stark abhängige Bevölkerung verheerende Folgen mit sich. Folgt man der im Stubenverbot zugrundeliegenden Glaubensanschauung, so mußte die vom Hagelschlag verdorbene Ernte nahezu für jeden der sicht- und fühlbare Beweis einer Strafe Gottes sein. Die obrigkeitliche Intervention gegen den Brauch wollte demnach nicht nur das Seelenheil der Delinquenten, sondern gleichsam die dörfliche Existenz und das Gemeinwohl sichern und fördern. Feiern, Feste, Rausch, Tanz oder Ekstase boten den Untertanen die Möglichkeit zur Grenzüberschreitung und damit zu Unmutsäußerungen. Gleichzeitig handelte es sich um wirtschaftlich unproduktive Phasen, deren Minimierung ein Ziel der fortschritts- und wohlfahrtsorientierten Ordnungsmacht war. ${ }^{217}$

Zum dritten sprechen schließlich die Reaktionen der Beteiligten ebensowenig für eine massive, rituell ausgelöste Entgleisung, welche die grundlegenden Regeln des sozialen Miteinanders vollends zu Fall bringen könnte. Die erkennbare Unterstützung der Jugendlichen durch die Erwachsenen zeugte von einem gegenseitig respektierten Bereich gesellschaftlicher Regeln und Pflichten, die sich nicht aufgrund temporärer bzw. ritueller Aktionen aushebeln lassen würden. Matrimoniale Strategien, Erbschaftsregeln, Prestige und Ächtung erscheinen als übergeordnete Verhaltensregulative, deren Gültigkeit durch das Mailehen wohl in ähnlich geringem Maße wie durch vergleichbare Bräuche (Kiltgang, Fensterln, Spinnstuben) in Frage gestellt wurde. ${ }^{218}$ Doch der spielerisch provokante Umgang mit der Sexualität, die

${ }^{216}$ Zitiert nach dem Schweizerischen Idiotikon (1881ff Stichwort "Stube", Spalte 1179f).

${ }^{217}$ Dies illustrieren die zahlreichen Verbote, die von der Obrigkeit des Ancien régime erlassen wurden, um Exzesse zu unterbinden und sowohl die Ordnung als auch die allgemeine Wohlfahrt zu heben; siehe Kap. 2.4, Fn. 61. Vgl. zudem Roeck (1993:125f) über die verbreitete "absurde Logik" der sündhaften Verursachung von Katastrophen im Zusammenhang mit göttlichen Strafen.

${ }^{218}$ Hierzu Wikman (1937:316f), Beck (1983:140f, 112ff, 131f et passim), Rosenbaum (1982:77f) und Medick 1991:392ff). 
scheinbar legitime Verfügbarkeit über die eigene Sexualität und Eheschließung mußte der Kirche spätestens zu dem Zeitpunkt ein Dorn im Auge sein, als sie für sich festlegte, alleinige Entscheidungsmacht über die Gültigkeit einer Ehe zu beanspruchen. ${ }^{219}$

Resultat dieser Betrachtung ist demnach eine vage, unspezifische Empirie, welche die Funktion normenverletzender Interaktionen, insbesondere auf dem Gebiet der sexuellen Annäherung, dem Mailehen zuzuschreiben versucht. Dagegen spricht vieles dafür, daß von einer Beachtung normierender Verhaltensregelungen ausgegangen werden kann, die weniger von moralisch richtiger Anschauung als von Fragen ungewollter Nachkommenschaft und ihren erbrechtlichen sowie statusmäßigen Folgen motiviert war. Als die wirtschaftliche Unabhängigkeit des einzelnen allmählich zunahm, erschien gleichzeitig der sexuelle Umgang in freieren Gestaltungsformen. Wikman (1937:284f) und Hilberath (1931:66ff) haben betont, daß im Zusammenhang mit der Industrialisierung und Verstädterung einerseits der Brauch seine Bedeutung zur Förderung vorehelicher Kontakte zusehends eingebüßt habe, andererseits hätten die Mailehenbeziehungen nunmehr zur Aufnahme sexueller Kontakte dienen können. Aber der Wandel ökonomischer Zwänge ziehe nicht gleichermaßen die Lockerung tradierter Normvorstellungen nach sich. Daher erkläre sich auch, daß dort, wo die Verstöße gegen ehemals elementare Voraussetzungen des Brauches (etwa die Wahrung der Sittlichkeit) vorlägen, der Fortbestand des Brauches gefährdet sei.

Harmlose Lebensfreude wie in Wittenwilers Ring, gesellige Fröhlichkeit wie in der Kölner Chronik bei Weinsberg, sündige Ekstase oder zügellose Sexualität wie in den Zeugnissen neuzeitlicher prohibitiver Zurechtweisung verweisen auf das Mailehen als lustvollen, dionysischen Zeitvertreib. Dennoch sind die Variationen über dieses Thema - die vom Mailehen initiierte Freude - damit nicht erschöpfend behandelt. Die Romantiker und Mythologen stellten im 19. Jahrhundert eine weitere Erklärung auf und reinigten dabei unversehens den Brauch vom Ruch des Unsittlichen. Ihnen gelang geradezu eine Kehrtwendung in der bisherigen Sinndeutung, indem sie das Mailehen nicht mit der Roheit heidnischen Treibens, sondern jetzt mit der Naturverbundenheit und kultischen Nähe zu höheren Wesen des germanischen Götterkanons in unmittelbare Berührung brachten. Ansätze zu einer solchen Sichtweise finden sich bereits in den Tagebuchaufzeichnungen Delhovens, wo die Maibräuche als geronnene sinnliche Erfahrung der Vorfahren vorgestellt wurden. In den Mailiedern erklinge seit jeher "Anmuth und viele Empfindung und Zartgefühl"; die Feiern im Mai seien schließlich Ausdruck dafür, daß "die Schönheiten des Lenzes" seit geraumer Zeit das menschliche Gemüt bewege (Cardauns et al.

${ }^{219}$ Von einschneidener Bedeutung im katholischen Einflußbereich waren in diesem Zusammenhang die Ergebnisse des Tridentinums (1545-63); dazu Becker (1989:279ff). 
1966:81f). Auch Uhland entwirft 1844/45 in seiner Abhandlung über hoch- und niederdeutsche Volkslieder eine zeitlos universale Anthropologie der Frühlingsgefühle, wenn er über die Maibräuche und ihre allegorischen Figuren spricht:

"Alle trockene Absichtlichkeit schwindet, wo die jugendliche Gestalt mit dem lachenden Frühlingsschmucke sich eint. [...] In solch anmutreichen Vertretern wird der Frühling leibhaftig, sie selbst aber gelangen zur festlichen Geltung dadurch, daß sie den Mai bedeuten. Pulsschlag dieser Volksspiele, der einfachen wie der prunkhafteren, ist die jauchzende Herzenslust lebensfrischer Geschlechter" (Uhland 1984,4:339f).

Vincenz v. Zuccalmaglio (1854-58:I) hat offenbar diese Gedanken aufgegriffen, um sie in seinem völkischen Konzept einer geeinten deutschen Nation aufgehen zu lassen. Die überschwengliche Freude am Feiern mutiert dabei von einem allgemein menschlichen Anliegen zu einem außergewöhnlichen, sittlich und politisch unbedenklichen völkischen Erlebnis:

"Nichts schließt die Herzen so lauter aneinander als g e m e i n s a m e F r e u d e. Sie ist der sicherste Damm gegen die Schlechtigkeiten, gegen sittliche und politische Entartungen. Wahre Volksfeste [...] sind die lohnendste Erhebung und vollgültigste Entschädigung für die mit Druck und Sorgen um den leiblichen Unterhalt umwölkte Alltäglichkeit".

Nicht das Geringste von dem, worüber jahrhundertelang zwischen klerikalen Ordnungshütern und parochialen Brauchträgern gestritten wurde, kommt in diesen Beispielen zum Vorschein. Unverdorben, keusch, ja geradezu heilsam seien Geselligkeit und Vergnügen, die aus rituellen Aktivitäten herrühren. Als geläutert erscheint das Mailehen und die an ihm Beteiligten. Der Brauch konnte anscheinend dem Volk zu einem besseren Dasein verhelfen. Diese paradigmatische Umdeutung findet in den ethnographischen Notizen aus dem 19. Jahrhundert ihre Entsprechung. Somit entsteht der Eindruck, daß die Brauchdeutung sich tatsächlich an der Realität mißt. 1836 heißt es in einem anonym verfaßten Bericht:

"Wie sehr auch auf den ersten Blick, diese althergebrachte Sitte als ein Spiel der Leichtfertigkeit erscheinen mag, der dabei Thür und Thor geöffnet wären, so muß Einsender doch erklären, daß dies in der That durchaus nicht der Fall ist, vielmehr glaubt derselbe bemerkt zu haben, daß die Orte, wo diese Sitte beobachtet wird, sich in umgekehrter Richtung vor vielen andern auszeichnen" (Anonymus 1836c:86).

Nur zehn Jahre später hat Kinkel (1846:161) diese Einschätzung wiederholt, wobei er die Sittlichkeit im Rahmen der Mailehenausübung in Abgrenzung zu süddeutschen und schweizerischen Brauchformen besonders hervorhob. ${ }^{220}$ An anderer Stelle wurde

${ }^{220}$ Wie aber die bereits ausgeführten Beispiele aus dem schweizerischen Brauchmilieu vermuten lassen, bewegten sich auch die Kiltgänge im süddeutschen Raum und in der Schweiz durchaus im Rahmen allgemeiner Verhaltensregelungen. Wikman (1937:316f) tritt den Anwürfen mit Vehemenz entgegen: "Gerade die Tatsache, dass trotz allem das Brauchtum der Nachtfreierei die Forderung der Enthaltsamkeit in sich schliesst, widerspricht auf das bestimmteste der Möglichkeit, den Kiltgang als bewusst auf Begattung und Fruchtbarkeit abzielend zu erklären. [...] Es muss betont werden, dass es im Bereich des Kiltgangs, so weit wir diesen kennen, einem Mädchen niemals und nirgends gestattet 
resümiert, daß beim Mailehen "alles in Zucht und Ehren hergehen" müsse, und man erinnerte rückblickend an einen einzigen Fall, in dem "ein Mädchen sich vergangen hatte". Das bekanntgewordene Vergehen des unverheirateten Paares sei öffentlich gerügt worden. Auf diese Weise würden die Bräuche ihre sittenveredelnde Wirkung auf das jugendliche Treiben ausüben (Gierlichs 1895:362f).

$\mathrm{Daß}$ die Freude, welche die Brauchausübung bereitete, nichts mit weltlicher, trivialer Bedürfnisbefriedigung gemein habe, davon scheinen Autoren wie Mannhardt ( ${ }^{2} 1905$, 2:XXXV) und Frazer (31920,II.3:266ff) überzeugt, obwohl sie von einer geschlechtlichen Vereinigung als rituellem Formenbestandteil des Mailehens ausgegangen sind. Hier diene die Sexualität lediglich dem Kult um die alljährliche Wiederbelebung der Natur. ${ }^{221}$

Gegen Usener (1902:195-228) gewandt, artikuliert Schurtz (1902:113f) seine Zweifel an der Diktion der vorherrschenden Sittsamkeit im Mailehen. Nachdem er die Brauchaktivitäten vor dem Hintergrund eines sexuell freieren Umgangs der Jugendlichen gedeutet hatte, relativiert er aber seine These von den "zu nichts verpflichtenden, nur auf Zeit geschlossenen Verhältnisse(n) der Unverheirateten":

"Möglich allerdings, dass in einer Zeit grösserer Ungebundenheit diese Beschränkung [der sittlichen Verpflichtungen der Mailehenpaare] schon als eine würdige Vorbereitung zu einer Kultfeier gelten konnte".

An dieser Stelle ist noch einmal auf die Probleme zurückzukommen, auf die bereits die Analyse der neuzeitlichen Verbotstexte gestoßen ist. Bei aller Gegensätzlichkeit der romantisch-mythologischen Auffassungen zur geschichtlich vorangegangenen Perspektive kirchlicher Machthaber ergeben sich strukturelle Gemeinsamkeiten, die sich auf die Argumentationsbasis und -zielrichtung beider Seiten beziehen. Das durch das Mailehen hervorgerufene lustvolle, freudenstiftende Treiben und die damit assoziierten sexuellen Ausschweifungen wurden konträr gedeutet, aber den Interpreten war es nicht möglich, ihre "Erkenntnisse" auf eine verläßliche empirische

war, mit einem Liebhaber nach dem anderen geschlechtlich zu verkehren. Schon allein ein diesbezüglicher blosser Verdacht hätte ihr für immer jede Aussicht auf eine ehrbare Heirat verbaut. Geschah es aber, dass ein Mädchen von ihrem Liebhaber, der als ihr Verlobter galt, verlassen wurde, so erregte dies allgemeinen Unwillen und es war sehr die Frage, ob es ihr jemals wieder gelingen würde, einen anderen Freier zu finden. War das Mädchen noch dazu während der Verlobungszeit von ihrem Verlobten geschwängert und dann verlassen worden, so wartete ihrer meistens das Los, für immer ledig zu bleiben. In dieser Hinsicht gehen die den Probenächten und der Probeehe zu Grunde liegenden Theorien bestimmt fehl. Schon psychologisch sind sie ein Unding; sind doch Begattung und Schwangerschaft das Ergebnis eines langen, instinktiv begründeten Vorgangs, dessen stufenweise Entwicklung in den Sitten und Einrichtungen der Eheschliessung ihren Ausdruck findet. Der Kiltgang ist nur ein Glied in der Kette dieses psychologischen und sozialen Vorgangs. Wäre das Gegenteil richtig, so könnte man das Ganze etwa mit einem Musikstück vergleichen, das vom Schlussatz beginnend, rückwärts gespielt wird".

${ }^{221}$ Vgl. Kap. 3.1. 
Beweislage zu stützen. Wie unter einer theologisch-ordnungspolitisch motivierten Verdammung die Ausprägungen der Feierfreude einseitig beurteilt wurden, verengt auch eine auf das völkisch-nationale ausgerichtete Perspektive in der Glorifizierung des Mailehens menschliche Erfahrung und gelebte Realität. Dementsprechend vermögen weder rituelle Entgleisung hier noch kultische Ekstase dort das Vergnügen am Brauch angemessen wiederzugeben. Deutungen dieser Art unterliegen gleichsam einer Schwarzweißmalerei, welche die Ambivalenz des Geschehens systematisch ausblendet.

Auch für die Zeit eines konstatierten Umbruchs, die eine Versittlichung, "Entsexualisierung" oder Läuterung des Brauches seit dem 18. Jahrhundert bewirkt habe, ${ }^{222}$ läßt sich nicht stichhaltig belegen, daß der Brauch sich zu einer Bestätigung jugendlicher Asexualität gewandelt habe. Dem widersprechen selbst die normativen Satzungen der Junggesellenvereine, die ansonsten gerne als Zeugnisse jener "entsexualisierten" Moral herangezogen wurden. Erinnert sei hier an die bereits zitierten Passagen aus dem sogenannten Impekovener "Mottekopp" von 1793, in denen von der Beziehungspflege bis hin zum sanktionierten vorehelichen Geschlechtsverkehr die Rede ist. ${ }^{223}$ Dabei wurde das männliche gegenüber dem weiblichen Fehlverhalten statuarisch in Schutz genommen und als geschlechtsspezifische Doppelmoral greifbar: Würde eine "'Jungfrau'" der Attraktivität des jungen Mannes oder dem Reiz des Verbotenen unterliegen, so "'ists commod und gemächlich"' für den Junggesellen; ihn treffe keine Schuld, denn "'eine jede hat sich zu hüten"' (Thomas 1979:285). ${ }^{224}$

Auch aus anderen Fällen spricht jugendlicher Übermut, der deutlich zeigt, daß ein bedenkliches Potential sittlicher Entgleisung bei der Mailehenausübung nach wie vor diskussionswürdig geblieben ist. Die Intervention gegen das Mailehen im Raum Siegburg in der Mitte des 19. Jahrhunderts brachte seitens der Kirchen- und Kommunalbehörden Bedenken gegen die Sittlichkeit der Mailehenversteigerung hervor. Nach einer in diesem Zusammenhang erlassenen Polizeiverordnung wurden diejenigen Mädchen als "die gewöhnlich sittsamsten" ausgewiesen, die sich bewußt dem Mailehen fernhielten (Gansen 1931:19). Aus dieser behördlichen Sicht sind die Brauchtreibenden und ihre Verhaltensweisen auch im 19. Jahrhundert noch weit entfernt von jugendlichem Wohlverhalten und Asexualität.

${ }^{222}$ Korff (1984:255) und Becker (1989:307ff); vgl. auch Peuckert (1955:354f, 358f), dessen Argumentation allerdings auf einer vergleichsweise groben Differenzierung sozialhistorischer Zusammenhänge basiert.

${ }^{223}$ Vgl. Kap. 2.5.

${ }^{224}$ Bezeichnend für den problematischen Realitätsgehalt derartiger Quellen ist, daß jenes Statut von Korff (1984:256) und von Becker (1989:312f) herangezogen wird, um den Prozeß der "Entsexualisierung" des Mailehens im 18. und 19. Jahrhundert zu belegen. 
Sofern die Beobachtungen und Einschätzungen von Schulte (1902:74ff) verläßlich sind, herrschten ganz ähnliche Verhältnisse beim hessischen Mailehen. Der Autor sieht im Mailehen ein ursprünglich verankertes Tanzrecht, das die Tanzpartnerschaft für die Kirmesfeierlichkeiten regelte. Doch die ehemalige Ordnung schien in der Auflösung begriffen: der Brauch entpuppte sich nunmehr als ein ausgelassener Spaß, bei dem die Tanzpartner nahezu willkürlich wechseln konnten. Die Tanzveranstaltung wurde als ein rauschendes Fest beschrieben, bei dem nicht nur unermüdlich getanzt, sondern auch gesungen wurde, "eine Thatsache, die sehr wenig zur Gemütlichkeit und Nachtruhe des anwohnenden Nachbars" beitrug (Schulte1902:79). Die sittliche Gefährdung der Jugendlichen durch den Brauch finde allerdings vor allem in der öffentlichen Akzeptanz geschlechtlich motivierter Annäherung ihren Niederschlag. Schulte (1902:82) hat in diesem Zusammenhang über "eine große Unsitte" geklagt, das sich ungenierte Küssen zu später Stunde auf dem Tanzboden:

"Es kommt da viel vor, daß sich die Burschen den Mädchen, die sie gern haben, auf den Schoß setzen, sie um den Hals nehmen und küssen".

Generell schien der schickliche Umgang unter den jugendlichen Paaren im Brauchgeschehen stärker gefährdet zu sein als unter gewöhnlichen Alltagsbedingungen; so heißt es:

"[...] die Kirmes [bringt] beim Nachhausewege, wie auch vorher, für solche Mädchen, die innerlich nicht feststehen und unbehütet von den Eltern sich selbst überlassen bleiben, wenn sie in die Gesellschaft schlechter Burschen, die das Dorf ebenso gut hat, wie die Stadt, geraten oder sich selbst bringen, s i t t l i c h e G e f a h r e n mit sich" (Schulte 1902:82f).

Wenngleich Schulte (1902:83) in diesem Zusammenhang versichert hat, daß "die Volkskunde das eigenartige Leben unseres Landvolkes [...] weder zu beschönigen noch zu verdammen hat", so zeigt er auch aus seiner eigenen Erfahrung als Pfarrer Verständnis für die Geistlichen, die den Brauch verurteilten und ablehnten.

Die geschilderten Bedenken gegenüber der Brauchausübung ähneln in bemerkenswerter Weise den Einschätzungen, die sich aus den reformatorischen bzw. gegenreformatorischen Zeugnissen gewinnen lassen. Vom religiösen Standpunkt aus vermochte die Entwicklung gesellschaftlicher und politischer Verhältnisse von der Neuzeit bis hin zur Industrialisierung kaum an der Vorstellung zu rütteln, daß das jugendliche Treiben im Brauch zwangsläufig die herrschende Sexualmoral unterwandere. Deutlich verändert hat sich allerdings die Machtposition der Kirche. So führt die diagnostizierte Unsittlichkeit nicht unmittelbar zur "von oben" verordneten Brauchabschaffung. Der kirchliche Kampf gegen das Mailehen und die darin lauernden Gefahren vorehelicher Unzucht wurde im 19. Jahrhundert keineswegs 
aufgegeben, er nahm nur weniger machtvolle und daher auch weniger aufsehenerregende Formen an.

Die Ausführungen lassen sich mit den Deutungsansätzen nicht mehr vereinbaren, welche die Mailehenausübung bis zum 18. Jahrhundert zunächst als eine Angelegenheit darstellen, bei der die Bevölkerung mit Ausnahme des Klerus wohlwollend den sexuellen Ausschweifungen der Brauchtreibenden zugeschaut hätten. Ebenso bedarf die Annahme einer im 19. Jahrhundert erfolgreich abgeschlossenen "Entsexualisierung der ländlichen Jugendkultur durch herrschaftlich-sittenpolizeiliche Eingriffe" (Korff 1984:255) einer Relativierung. Becker (1989:305ff), der die Perspektive Korffs übernommen hat, scheute sich nicht, die Wirksamkeit der Versittlichungsstrategien bis in die Gegenwart fortzuschreiben:

"Zwischen den Mai-Paaren, die heutzutage alljährlich durch Versteigerung zusammenkommen, sexuelle Beziehungen zu vermuten, wäre etwas, das die Mitglieder von Junggesellenvereinen zurecht höchst verärgern würde. Die heutige Form der Maiversteigerung mit ihren anschließenden Pflichten vollzieht sich nach strengen Anstandsregeln, die von der 'Maipolizei' überwacht und geahndet werden. Das war auch schon gegen Ende des 18. Jahrhunderts so, wie sich aus den Satzungen [...] ablesen läßt" (Becker 1989:307)

Eine derartige Argumentation kann sich jedoch nur auf eine vordergründige Quellenanalyse stützen, die einer gängigen, aber fragwürdig gewordenen Einordnung ländlicher Sexualkultur entspricht. Die zeittypischen Angriffe oder Verklärungen gegenüber den Brauchtreibenden sind aufgrund ihrer Einseitigkeit relativ wertlos, wenn ihnen nicht die Haltung der Betroffenen entgegengestellt werden kann. Auch die statuarischen Floskeln sind nur dann aussagekräftig, wenn ihre normative Beschaffenheit sich im Widerschein der gelebten Brauchpraxis ermessen läßt. Diesen Schwierigkeiten hat sich die vorliegende Auseinandersetzung über die Ambivalenz der Freude zu stellen versucht. Dabei war zu bemerken, daß das lustvolle Braucherlebnis im wesentlichen von zwei Sichtweisen gekennzeichnet wird: Am offensichtlichsten trat ein ideologisch-gesellschaftskritisch motivierter Deutungsansatz hervor, der die Freude je nach Standort als verwerflich oder als heilsam etikettierte. Die häßliche oder schlechte Seite des Mailehens betonten vor allem die hegemonialen Ordnungshüter des Ancien régime, während die diametral entgegengesetzte, schöne oder gute Seite beispielhaft von den Romantikern und Mythologen des 19. Jahrhunderts beleuchtet wurde. Das ausschließlich Schlechte respektive Gute am Mailehen verliert auf der anderen Seite, bei idiographischphänomenologisch geleiteten Interpretationen, merklich an Stellenwert. In den Blick gerät zunehmend der Grad der erfahrenen Freude. Nah am Menschen und am Erlebnis des Mailehens werden die Vergnügungen als menschliches Bedürfnis sichtbar: ob in unbändigem Exzeß oder in unauffälliger, gemäßigter Form, die Freude mag sowohl positive als auch negative Begleiterscheinungen bergen. Damit grenzt 
sich dieser Erklärungsansatz von der unvermeidlichen Schwarzweißmalerei ab, welche die ideologisierenden Empfindungsweisen beherrscht.

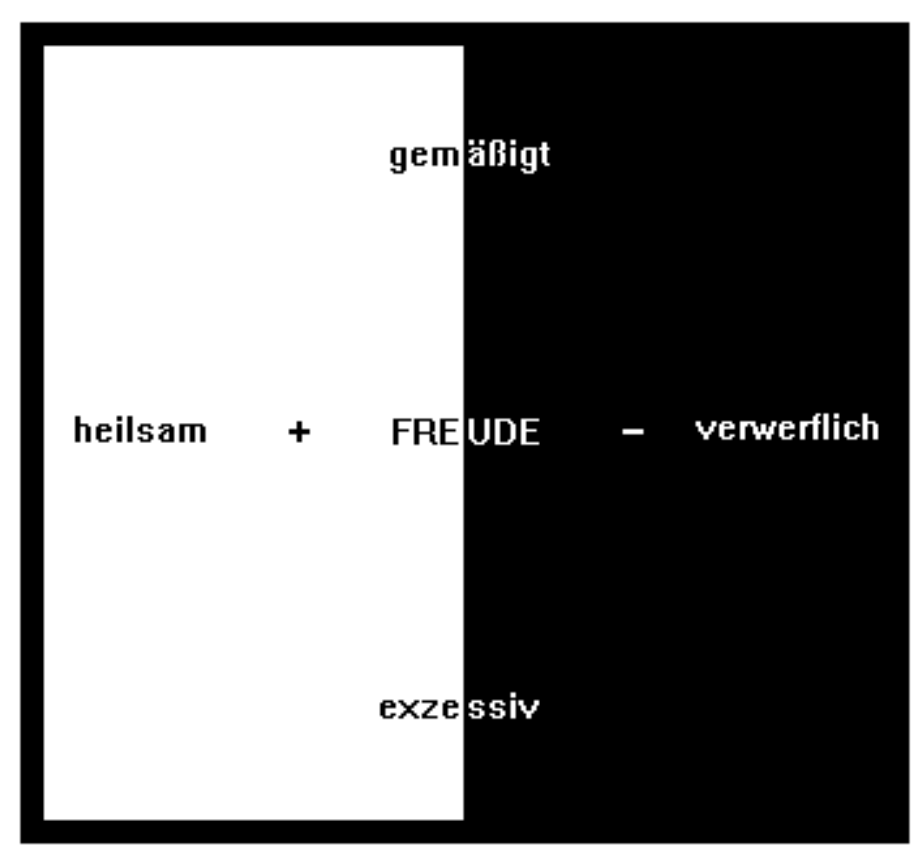

Schema 1: Ästhetik der Freude

Der Schwarzweißkontrast macht hier noch einmal besonders deutlich, daß die lustvolle Transformation des Gewöhnlichen durch den Brauch von einer strukturellen Ambivalenz geprägt wurde, die sich am ehesten in einer idiographisch-phänomenologisch orientierten Interpretation (vertikale Achse) widerspiegelt. Der ideologisierende Ansatz (horizontale Achse) betreibt dagegen das zielgerichtete Ausblenden je eines der beiden widerstreitenden, konstitutiven Merkmale der "Freude".

Die Auseinandersetzung mit der Ästhetik der Freude wurden auch in jüngerer Zeit fortgesetzt. Auffallend ist, daß die vier vorgestellten Leitlinien auch in der letzten Hälfte des 20. Jahrhunderts vertreten sind. Dabei tauchen die problematischen einseitigen Wertungen ebenso auf wie die deskriptiv orientierten Argumentationen. Die Werthaltungen richten sich nunmehr an den gewandelten gesellschaftlichen Verhältnissen aus. Gegenwärtig verwendete Etikettierungen der Brauchhandlungen haben mit dem neuzeitlichen Sprachgebrauch daher wenig gemein. Theologische Kategorien der Wahrnehmung und Beurteilung wurden durch sozialpsychologische ersetzt; ${ }^{225}$ die Parole von Sünde, Teufel, Bösem wich der Darstellung geschlechtsspezifischer Exzesse als Ausdruck von sozialer Ungleichheit und Unterdrückung:

${ }^{225}$ So Weber-Kellermann et al. (1971:109f): "Der Sozialpsychologe kann das gesellschaftliche Phänomen der Mädchenversteigerung, wie es heute noch in vielen Dörfern Hessens lebendig ist, nur mit äußerstem Erstaunen zur Kenntnis nehmen". 
"Nach vorbereitenden Reden und der Initiation der Neuen mit reichlich Bierkonsum beginnt in bereits animierter Stimmung die Mädchenversteigerung. Kein Fremder und schon gar keine Frau ist zu dieser Sache zugelassen, die gewissermaßen als eine Geheimaktion der Burschen behandelt wird. Ähnlich wie hier werden an vielen anderen Orten alle ledigen Mädchen des Dorfes versteigert: Sie werden - Name bei Name - mit ihren angeblichen Qualitäten auf die ordinärste, obszönste Weise angeboten. Dem ausschweifendsten Vokabular ist der größte Beifall sicher" (Weber-Kellermann 1985:112).

In vorindustrieller Zeit wollten die Kirchenmänner ähnlich "amoralischem" Treiben ein Ende setzen, in der Moderne kommt die Kritik vor allem aus den Reihen bürgerlicher Mittelschichten. Selten wurde sie so pointiert vorgetragen wie bei Weber-Kellermann (1985:112), die den Brauch als sexistisch, frauen- und emanzipationsfeindlich oder gar als fortschrittshemmend bezeichnet hat. Läßt das Phänomen der rituellen Frauenversteigerung auf den ersten Blick Zweifel an der Seriosität der Brauchhandlung aufkommen, so erscheinen die vorgebrachten Werthaltungen vor allem deshalb problematisch, weil sie auf einer dürftigen empirischen Grundlage fußen, bei der die Betroffenen kaum zu Wort kommen. Insofern eignet sich die Deutung des Mailehens als männlich dominierter frivoler Exzeß oder gar als "[...] eine so misogyne, unemanzipierte Lebensvorstellung, daß man sie kaum im letzten Drittel des 20. Jahrhunderts suchen würde" (Weber-Kellermann et al. 1971:109f) eher dazu, die stereotype Polarisierung der Geschlechterdifferenz durch die Medien zu bestärken, nicht aber zur realitätsnahen Erklärung der Vorgänge, die im Mailehen sichtbar werden. ${ }^{226}$

Auch auf der Gegenseite, dort, wo die romantisch-mythologische Verklärung die schöne und gute Seite des Brauches herausstrich, wirkt die Schwarzweißmalerei nach obigem Muster noch fort. Auf die Anhänger der schönfärberischen Perspektive trifft man allerdings weniger in wissenschaftlichen Publikationen als im Zusammenhang mit Vereinsfestschriften. In Vorworten werden frohe Stunden und geselliges, vergnügtes Beisammensein beschworen; in den Hintergrund gedrängt werden Alkoholmißbrauch, Lärm, Exzeß. Das Mailehen erscheint hier im erhabenen Licht von der "Liebe zur Heimat", der "Bewahrung der Traditionen" und der "Förderung des Ortsgeschehens".227

Aktuelle Deutungen des Brauchgeschehens im Licht maßvoller Freude, die weder als besonders gut noch schlecht charakterisiert wird, liegen von einer Reihe von wissenschaftlichen Autoren vor. Künßberg (1922:333f) hatte das Mailehen in die Nähe einer inszenierten parodistischen Veranstaltung gerückt und markierte damit eine zuge-

${ }^{226} \mathrm{Zu}$ berücksichtigen ist dabei, daß der zitierten Veröffentlichung eine dreizehnteilige Fernsehfolge vorausging; siehe Weber-Kellermann et al. (1971:V). Die Rolle von Stereotypen in der Mailehenberichterstattung auch bei Wey (1999).

${ }^{227}$ Prothmann (1989:5ff); ferner die Rede des Vorsitzenden vom Ramersdorfer Bürgerverein zu den lokalen Maifeierlichkeiten in Faber und Ziegler (1979/80:193f). 
spitzte Position, bei der die Belustigung der Zuschauer ihr höchstes Gewicht erhielt. Diese Betrachtung wies Wikman (1937:148, 69f) zurück, indem er die lustvolle Unterhaltung als einen unter mehreren wirksamen Effekten der Brauchausübung betrachtete. Diese Betrachtungsweise floß in jüngere Interpretationen ein. Dort wurde das Mailehen "als Teil der Erholung" (Zender 1972:276) oder als ein Brauch mit besonderem Unterhaltungswert beschrieben. So sehen Faber/Ziegler (1979/80:162) "[...] das primäre Bedürfnis des einzelnen Junggesellen, mit anderen Gleichgesinnten die Freizeit zu gestalten, in ihrer Gruppe Geselligkeit zu finden. Dabei bieten die Maitraditionen willkommene Möglichkeiten, Feste zu feiern, die von der Öffentlichkeit akzeptiert werden". Die jugendliche Lust am Feiern erhalte "in der Interpretation als 'Brauchtum' einen höheren Stellenwert". Noch einen Schritt weiter ist Schrick (1992:39) gegangen. Sie hat die Freude, die im Brauch ihren attraktiven Ausdruck finde, nicht ausschließlich auf die Junggesellen begrenzt:

"Festliche Umzüge in bunten Farben, Tanz und Geselligkeit, das Königspaar u.ä. Dies entspricht unseren Bedürfnissen nach 'schöner heiler Welt"'.

Der Unterhaltungswert des Mailehens verweist hier anscheinend auf eine besondere Kompensationsleistung: Zumindest für einen kurzen Augenblick im Jahr scheint die Teilnahme am Brauch Ablenkung und Entlastung von den drückenden Sorgen oder von der schlicht als Belastung empfundenen Monotonie des Alltags zu versprechen. Eine empirische Konkretisierung dieser Erklärungsversuche hatte bereits Grasmück (1989:32f) im Hinblick auf eine Renaissance des saarländischen Lehenausrufens geliefert. Drohende Massenarbeitslosigkeit, Landflucht und "Bauernsterben" würden zu einem "kulturellen Vakuum" in strukturschwachen Regionen führen, so daß ein Rückhalt über die in der Brauchausübung erfahrene lokale Identität und den ästhetischen Genuß erfolge.

Der gegenwärtige Stand einer Ästhetik der Freude bliebe unvollständig, wenn an dieser Stelle der Kontrapunkt zur gemäßigten Freude, die exzessiv vergnügliche Ausschweifung, keine Berücksichtigung fände. Äußerungen über die lustvolle Berauschung am unmäßigen Alkoholgenuß, übertriebenen Lärm, an nicht abreißenden Tänzen und Gesängen oder der "freien Liebe" sind in den ethnographisch-wissenschaftlich orientierten Quellen zur Seltenheit geworden. Fündig wird man dagegen an anderen Stellen: Die journalistische Behandlung des Mailehens lebt geradezu von der Vorstellung einer ausufernden, erregenden Lust, welche der Brauch scheinbar entfesselt. Allerdings lassen bereist die Art der Darstellung und die mangelhafte empirische Fundierung Zweifel an einer seriösen Maileheninterpretation aufkommen. ${ }^{228}$ Selbst in Veröffentlichungen mit populärwissenschaftlichem Anspruch begegnet dem Leser der suggestive und stereotype Charakter der den meisten Zeitungsberichten eigen ist:

${ }^{228}$ Siehe Wey (1999). 
"So brav und sittsam, wie das von den Brauchtums-Vätern dargestellt und von BrauchtumsAutoren geschildert wird, geht die Sache nicht vor sich. Sofern die Mai-Jungfrau bei der Versteigerung tatsächlich noch Jungfrau sein sollte, ist sie es vielerorts nach Ersteigerung und nach dem schönen Monat Mai nicht mehr" (Müller 1977:7).

Damit wäre die "freie Liebe" unter den Jugendlichen, die Schurtz (1902:113f) als fortdauernder Bestandteil germanischer Sozialisationspraxis im Mailehen interpretiert hat, bis auf den heutigen Tag bestätigt, wenn nicht ein begründeter Zweifel über eine derartige Behauptung herrschte. Unverfänglicher erscheint dagegen eine allgemeinere Bewertung, die im Zusammenhang rheinischer Heimatpflege von Nellessen (1974:137) vorgetragen wurde:

"Es gibt in unseren Landen kaum einen anderen Brauch von solchem Zauber und überschäumender Jugendlust wie das Mailehen!".

Auch hier werden leider nur Fragmente einer Deutung sichtbar; so vermag nur die folgende Analyse empirischer Beobachtungen und Befragungen, den "Zauber" und die "überschäumende Jugendlust" am Mailehen zu konkretisieren.

\subsection{Plausibilität von Mailehendeutungen}

Widersprüche und Defizite, die den Mailehenbeschreibungen anhafteten und aus dem zugrundegelegten Tatsachenmaterial hervorgegangen sind, wurden bei dem Versuch, die Hintergründe der Aktionen aufzudecken, nur selten entschärft. Im Gegenteil, die Explikationen reichten von jener Inkarnationsthese, bei der das Maikönigspaar die theogame Verbindung von Wuotan und Frigg repräsentieren sollte, über die Versinnbildlichung archaischer Vegetationsdämonen bis hin zu einer polarisierenden Traditionsrhetorik, die auf den vermeintlichen "Überresten" eines Brauches schließlich Visionen einer besseren Welt aufbauen konnte. Das entscheidende Kriterium für die Analyse der Deutungen war die Plausibilität konstruierter Sinnzusammenhänge. Ansätze, die weniger von einer instrumentalisierenden bzw. hoch- oder niedermythologischen Ätiologie beherrscht wurden, gewannen bereits dadurch an Überzeugungskraft, daß sie sich weitaus stärker an den empirischen Befunden orientierten.

Was konnte auf dieser Grundlage dafür sprechen, das Mailehen als ein Rebellionsritual gegen die Generation der Eltern anzusehen? Geht man davon aus, daß die Jugendlichen infolge der Mailehenausübung die endogame Heiratsregelung, die innerhalb der Dorfgemeinschaft galt, unterstützt hätten, dann stünde der Brauch für eine offene Bestätigung der Sozialordnung. Unter dieser Annahme wären also nicht die Jugendlichen die Rebellen, sondern allenfalls die Eltern, weil ihre Dispositionen über die Heiratsallianzen der Nachkommen gegen das Dorf und die dort geltenden Normen vorgebracht werden müßten. Die von Becker (1989:303-305) aufgestellte 
Rebellionsthese fußte auf der Annahme, daß sich hinter dem spielerischen Mailehengeschehen die intelligible Lösung der Probleme verberge, die mit der traditionellen Erbfolgeregelung in Realteilungsgebieten einhergegangen seien. Denn durch den Brauch würde "die gesamte Junggesellenschaft eines Dorfes durch den Jahr für Jahr wiederholten Versteigerungsakt und die sich daran anschließenden Geselligkeitsformen auf einen örtlich definierten Kreis von Heiratsfähigen eingeschworen" (Korff 1984:254), was weitere Besitzzersplitterungen des Ackerlandes verhindert habe.

So, wie die Rede vom agrarischen Kollektivismus der Vormoderne eine Verkürzung der sozialen Heterogenität des Dorfes impliziert, so führt auch der unterstellte ökonomische Determinismus in eine Verengung, aus welcher sich die Entwicklung der landwirtschaftlichen Produktionsfaktoren sowie die Ausprägungen des Mailehens nicht mehr angemessen erklären lassen. Bei der Austeilung der Lehen in Saarhölzbach wie auch andernorts verkündeten im 19. Jahrhundert die Junggesellen: "Dies Jahr zum Lehn, das andere Jahr zur Eh'!" Daß der Brauch die Jugendlichen eines Ortes in einen kommunikativen Handlungszusammenhang verwickelte, der letztlich auch Einflüsse auf eine bevorstehende Heirat haben konnte, wurde oftmals und zu Recht festgestellt. Die Charakterisierung des Mailehens als ein "plausibles Brauchsystem", das darauf angelegt sei, "die Binnenheirat und deren Habitualisierung [zu erheischen]" (Korff 1984:257), krankt jedoch an einer eindimensionalen ZweckMittel-Relation. Zunächst kann man einwenden, daß hier die Möglichkeiten normativer Verhaltensregeln in Hinsicht auf das Ziel der präferentiellen Heiratsregelung überschätzt wurden. ${ }^{229}$ Gleichzeitig verkennt eine Zuspitzung des Mailehens auf die Endogamie das Spektrum der Erfahrungswelten, welches die Brauchausübung den Jugendlichen erschlossen hat und welches über die ökonomisch-matrimoniale Bedeutung weit hinausgehen konnte.

Eine umfassendere Wirkung des Brauches, die auf Sozialisation, Sozialverhalten und Persönlichkeitsbildung der einzelnen Brauchträgerin bzw. des Brauchträgers abzielt, wurde vielfach in der Forschungsliteratur belegt. Bei den Jugendlichen spielte nicht nur die Integration in übergeordnete Sozialstrukturen eine große Rolle, sondern auch deren psychische Bewältigung. Die Loslösung aus den relativ engen, vertrauten familialen Bindungen, die Verankerung in der geschlechtsspezifischen Altersgruppe und das Eingehen von rituellen Pseudoehen erhielten im Mailehenbrauch einen formalisierten Rahmen. Dieser konnte in jenem Augenblick der adoleszenten Liminalität zur Orientierung verhelfen. Insofern erfüllte das Mailehen die Bedingungen eines

${ }^{229}$ Diese Kritik lehnt sich an Bourdieu (1992:99), der sich z.B. gegen den "Juridismus" strukturaler Analysen behauptet hat. Um den wissenschaftlich begründeten formelhaften Verengungen sozialer Praxis zu entgehen, verweist er auf eine besondere Berücksichtigung der Interessen der AkteurInnen: "Die sozial Handelnden gehorchen einer Regel, wenn das Interesse an ihrer Einhaltung stärker ist als das, sie zu mißachten". 
Übergangsrituals, dessen Handlungsabläufe mit dem berühmten "schéma des rites de passage" korrespondierten. Danach wurden "rites de séperation", "rites de marge" und "rites d'agrégation" unterschieden.230 Mit sechzehn, achtzehn oder einundzwanzig Jahren wechselten die Jugendlichen meistens das Lager. Das Kindsein endete im Grunde dort, wo der Einflußbereich des Elternhauses verlassen wurde. Bei den Junggesellen konnte sich der Übergang durch die vom Neuling geforderten Leistungen formalisieren. An die Aufnahme in den "Männerreih" oder den Junggesellenverein ließen sich Bedingungen, z.B. Mutproben, knüpfen. Demgegenüber wurde bei den Mädchen kein Initiationsritual beobachtet, aber bei ihnen markierte der gesellschaftlich geduldete Umgang mit den Jungen bei Festen den Statuswechsel deutlich. Die Phase des Übergangs endete letztlich bei der Heirat.

Vor dem Hintergrund des Dorfes wurde dem Brauch eine integrative Funktion zugewiesen. In diesem Sinne wirkte das Mailehen als soziale Institution. Die aufeinanderfolgenden Generationen der Unverheirateten schlossen sich im Brauch zusammen. Dies geschah in dem für die Betroffenen prekären Lebensabschnitt der Adoleszenz. In einem Moment relativer Orientierungslosigkeit konnte das Mailehen als ein kulturell probates Instrument eingreifen und somit die Herauslösung aus den familiären Bindungen erleichtern. Charakteristisch hierbei ist, daß im Stadium der Liminalität "deviantes" Verhalten auftreten kann, das einer Eingliederung ins Sozialgefüge strenggenommen entgegensteht, aber durch die Brauchpraxis gesellschaftlich handhabbare Formen annimmt. ${ }^{231}$

Gerade das Moment der Entgrenzung scheint im Mailehen besonders wirksam zu sein, vor allem wenn man die in den Brauchabhandlungen ausgelegte Spur des Dionysischen verfolgt. Der ideologisch bzw. ordungspolitisch motivierte Verwertungszusammenhang, in den die empirische Realität der Brauchpraxis gestellt wurde, läßt sich an dieser Stelle besonders deutlich erkennen, denn hinter der Darstellung von Exzessen - auch im sexuellen Bereich -, zu denen das Mailehen verführt haben soll, verbirgt sich nicht so sehr jugendliche Triebhaftigkeit oder Aggression. Vielmehr kommt in den Verdammungen religiöser Seelenretter oder den Glorifizierungen der romantischen Volksmystifizierer eine jeweils unterschiedlich gewichtete Ästhetik der Freude zum Vorschein. Das hier jeweils einseitig ausgelegte dionysischen Treiben sollte nach Maffesoli (1986:128f) einer differenzierteren Bewertung weichen. Einer "unzeitgemäße(n) Vorherrschaft apollinischer Werte", welche die gesellschaftliche oder jugendliche Entgrenzung oft in verhängnisvoller

${ }^{230}$ Dazu Gennep (1909:13f, 93-163 und 271-279).

${ }^{231}$ Zur Ambiguität des Dazwischenseins mit ihren besonderen Möglichkeiten s. auch Turner (1974:232) und Levi/Schmitt (1996:9). Die Bedeutung von Bräuchen im Rahmen jugendlicher Sozialisation und Persönlichkeitsbildung wird bei Fabre (1997:56-96) in ähnlicher Weise gesehen. Zur entwicklungspsychologischen Spezifik der Adoleszenz s. Erikson (1988), dessen Ansatz von Zinnecker (1997:470f) erneut bestätigt wurde. Vgl. auch Wirth (1984:24-28). 
Weise $\mathrm{zu}$ ordnen, $\mathrm{zu}$ reglementieren, ja in eine tyrannische Moral umzukehren versucht hat, wäre abzulehnen. Die Wallung (effervescence) erhält damit einen neuen Stellenwert, wobei das Mailehen als Auslöser der Vergnügungen weder ausschließlich von verwerflichen noch heilsamen Zügen gekennzeichnet war. Sieht man von den Bewertungen der rituell legitimierten Freuden ab, so öffnet sich das Verständnis für die Funktion der rhythmischen Aufwallungen. Der Orgiasmus nimmt eine wichtige gesellschaftliche und psychosoziale Bedeutung ein, soweit er "ermöglicht [...], jene Angst auszuleben, die vom 'Da-sein', wie Heidegger sagt, und der 'Geworfenheit' herrührt. Eine solche Gespaltenheit machen die Promiskuität und die Wirrung, in die der Körper fällt, für eine Zeitlang vergessen. Sicherlich ist dies die wichtigste Lehre, die uns die Unordnung und der Unruhestifter Dionysos zu geben haben. Im Aufwallen der Bacchanalien oder in sanften Abenden, die man zurückgezogen und in Gefühle versunken verbringt, liegt ein Erinnern und zugleich eine Linderung der gemeinsam erfahrenen Verlassenheit. Sie helfen uns lernen, daß das Leben in seiner leichten Schwere von der Endlichkeit gezeichnet ist, daß es aber, wenn es kollektiv gelebt wird, zugleich auch unendlich ist" (Maffesoli 1986:153f). 


\section{$4 \quad$ Fallbeispiel: Mailehenpraxis in Oeverich}

4.1 Der Ort und das "Feld": Zur Spezifik der Erhebung

\subsubsection{Oeverich}

Zwei Aspekte haben die Auswahl der Untersuchungsregion maßgeblich beeinflußt: 1. die historische Dimension der Mailehenausübung und 2. die Zugänglichkeit zur rezenten Brauchpraxis vor Ort. Oeverich und Niederich, zwei dicht beieinanderliegende Dörfer der Gemeinde Grafschaft, erwiesen sich in dieser Hinsicht als geeignete Standorte für das Forschungsvorhaben. In der Mitte des 19 Jahrhunderts hatte Kinkel (1846:160f) bereits darauf aufmerksam gemacht, daß das Mailehen einen festen Platz im kulturellen Leben der Ahrbevölkerung einnehme. Knapp 150 Jahre darauf haben Schwedt/Schwedt (1989:150) sowie Ginzler (1993:241) die Lebendigkeit der hier anzutreffenden Brauchaktionen nochmals bestätigt. Was den zweiten Punkt und damit die Aufgeschlossenheit der Betroffenen gegenüber einem empirischen Forschungsvorhaben anbelangt, so erwiesen sich weitläufige Beziehungen zu einer Familie im Dorf als vorteilhaft (s.u.).

Oeverich und Niederich liegen im Norden von Rheinland-Pfalz, unweit der Landesgrenze zu Nordrhein-Westfalen. Der rurale Untersuchungsraum profitierte in vielfältiger Weise von infrastrukturellen, wirtschaftlichen und verkehrstechnischen Ausstattungen der umliegenden Mittel- (Bad Neuenahr-Ahrweiler, Meckenheim, Remagen) und Oberzentren (Bonn, Köln). Im Zuge der kommunalen Neuordnung des Jahres 1974 wurden die Dörfer Oeverich, Niederich und Leimersdorf zu dem Ortsbezirk Leimersdorf der Gemeinde Grafschaft im Landkreis Bad NeuenahrAhrweiler zusammengefaßt. Diese grundlegende Reform hat die historisch gewachsenen Strukturen berücksichtigt, so daß die über einen gemeinsamen Pfarrbezirk seit dem 14. Jahrhundert eng verflochtenen Dörfer auch weiterhin verbunden geblieben sind. ${ }^{232}$

Die Einwohnerzahlen vermitteln dem Außenstehenden ein Bild über die Größenordnung der betreffenden Ortschaften. Im Jahre 1996 hatte Oeverich 510 Einwohner. Dagegen zählte man in Niederich nur 176 DorfbewohnerInnen. In beiden Dörfern stieg die Bevölkerung aufgrund von Zuwanderung und hohen Geburtenraten in den

${ }^{232}$ Siehe Anhang 7.1 Lageplan zur Untersuchungsregion. Die Hintergründe zu der historischen, politisch-territorialen Einordnung der Untersuchungsregion hat Prothmann (1990 und 1992) bearbeitet. 
vergangenen Jahren relativ stark an. ${ }^{233}$ Die Kommunalpolitik versuchte, die wirtschaftliche Prosperität der Region durch gezielte Maßnahmen zu verbessern. Schon in einem Entwicklungsplan von 1977 war die Rede von der Schaffung eines Gewerbeparks in der Oberen Grafschaft, der in erster Linie durch die verkehrsgünstige Lage (Autobahnanschlüsse zur A 61 und A 565) investitionsbereite UnternehmerInnen anziehen sollte (Geist et al. 1977:210). Tatsächlich siedelten sich in den folgenden zwölf Jahren achtzehn Firmen auf einer Gewerbefläche von rund 20 Hektar an. ${ }^{234}$ Das Standbein der lokalen Wirtschaft schien damals in den Augen der GutachterInnen aber immer noch der Agrarsektor zu sein. So wurde in Aussicht gestellt, daß hier die landwirtschaftlichen Produktionsbedingungen (Klima, Bodenqualität) den erfolgreichen Fortbestand des primären Sektors sichern würden (Geist et al. 1977:13, 56, 124 und 210). Auch in der Gegenwart wirbt die Gemeinde in offiziellen Anzeigen mit dem Etikett "Kornkammer des Kreises Ahrweiler", 235 wobei sich gerade in den beiden letzten Jahrzehnten hier ein vehementer Wandel vollzogen hat. Die Zahl der Betriebe und der Beschäftigten in diesem Sektor ging unaufhaltsam zurück. Die bis 1950 fast ausschließlich agrarisch geprägten Dörfer entwickelten sich zunehmend zu reinen Wohn- und Schlafstätten der Pendler, die im sekundären und tertiären Wirtschaftssektor ihren Lebensunterhalt verdienten. Das produzierende Gewerbe, die Handwerksbetriebe und der Einzelhandel, die ursprünglich auf dem Land angesiedelt waren, verloren mit dem landwirtschaftlichen Strukturwandel und der aufkommenden Mobilität ihre Bedeutung. Somit verschwand in der letzten Hälfte des 20. Jahrhunderts das diversifizierte Wirtschaftsleben mit einer Rübenkrautfabrik, einer Bäckerei, einer Metzgerei, einer Schmiede, einer Sattlerei und einer Stellmacherei. Bislang konnten sich ein Lebensmittelladen und eine Gaststätte in Oeverich behaupten. ${ }^{236}$ Wie im übrigen Bundesgebiet wurde das Auto in den letzten dreißig Jahren für viele DorfbewohnerInnen mehr und mehr zu einem unverzichtbaren Gut. Fahrten zum Arbeits- und Ausbildungsplatz nach Bad Neuenahr-Ahrweiler, Bonn oder Köln gehören inzwischen ebenso zum Alltag wie die Einkäufe, die fernab vom Wohnort stattfinden. Mit der Mobilität ging auch ein verändertes Freizeitverhalten einher. So ziehen die Jugendlichen z.B. Kino- oder Diskothekenbesuche am Wochenende dem heimischen Wirtshaus vor. ${ }^{237}$

Die kommunale Verwaltung wirbt in ihren Broschüren um den Zuzug:

\footnotetext{
${ }^{233} \mathrm{Vgl}$. Anhang 7.2, Tabelle 7.1.

${ }^{234}$ Kischkewitz (1990:37).

${ }^{235}$ Heimatjahrbuch Kreis Ahrweiler (1990:239) und (2000:233).

${ }^{236}$ Vgl. Prothmann (1995:3) und siehe Anhang 7.2, Tabelle 7.2.

${ }^{237}$ In dem Zeitraum von 1963-1992 stieg die Zahl der zugelassenen PKW im Kreis Ahrweiler um $562 \%$ von 9.432 auf 53.044 PKW (Geist et al., 1977 und Statistisches Jahrbuch für Rheinland-Pfalz 1992/93).
} 
"Am Rande des hochverdichteten Ballungsraumes Köln/Bonn ist die Gemeinde Grafschaft ein attraktiver Wohnstandort mit einer guten infrastrukturellen Ausstattung, einer überregionalen Verkehrsanbindung und einem ausreichenden Potential an Wohnbauflächen" (Kreisverwaltung Ahrweiler 1999b:5).

Das ausreichend vorhandene Bauland und die Fertigstellung der Bundesautobahn A $61 \mathrm{im}$ Jahre 1974 haben sicherlich viele Bauwillige angezogen. Die Grafschaft ist seit den 1980er Jahren auf einem Weg demographischer und wirtschaftlicher Entwicklung, welche die Rede von einer "Boomtown" aufkommen läßt.238 In der Tat sind die Veränderungen im traditionell agrarisch geprägten Dorfgefüge keineswegs an einen Ruhepunkt angelangt. Ein im Zuge des Bonn-Berlin-Ausgleichs geplanter "Technologiepark" für die Grafschaft zeigt, daß die begonnene Entwicklung fortgesetzt wird: die Gemarkung Oeverich wird erneut einen hohen Anteil landwirtschaftlicher Flächen gegen Gewerbegebiet eintauschen.239

Vor dem Hintergrund der demographischen Entwicklung, der Ausweisung von Neubaugebieten, dem Zuzug ortsfremder Familien und dem drastischen Rückgang von Beschäftigten in der Landwirtschaft wird deutlich, daß die Erforschung des Mailehens in den Jahren 1993 bis 1995 zu einer Zeit stattfand, als in der Grafschaft die wirtschaftlichen und sozialen Verhältnisse stärker als zuvor im Fluß waren. Diese Umwälzungen betrafen die Erwerbsmöglichkeiten von Befragten. Dadurch, daß die Sicherung der Existenz in vielen Fällen nicht mehr am Heimatort erwirtschaftet werden konnte und dadurch, daß die unmittelbare Nachbarschaft durch die Ansiedlung der NeubürgerInnen unübersichtlicher wurde, veränderte sich aber auch das soziale Miteinander im Ort. Es verwundert daher nicht, wenn von dem skizzierten Wandel zugleich die Brauchausübung beeinflußt wurde. Die Gespräche über das Engagement der Jugendlichen, den Beteiligungswillen der älteren Dorfbevölkerung oder die Integration von Zugezogenen wurden häufig in diesen Rahmen gestellt.

\subsubsection{Die Beteiligten}

Die empirische Untersuchung eines Brauches gewinnt an Aussagekraft, wenn die Perspektiven und die möglichen Positionen zum Gegenstand nicht durch die Auswahl der InformantInnen eingeschränkt werden. Das heißt, die Forschung sollte sich nicht von vornherein nur auf den engsten Kreis der BrauchträgerInnen stützen, sie muß auch die übrigen Betroffenen im Blick behalten. Bei der vorliegenden Untersuchung des Mailehens war prinzipiell jedes Dorfmitglied geeignet, um ins Sample der Befragten aufgenommen zu werden. Da der Brauch als Dorffest zelebriert wurde,

${ }^{238}$ Siehe Prothmann (1995:24).

${ }^{239}$ Durch die im Bonn-Berlin-Ausgleich zugesicherten Bundeszuwendungen wurde der Etat des Landkreises um 243 Millionen DM aufgestockt (Weiler 1999:48). Mit einem Teil dieser Mittel wird der erwähnte "Technologiepark" finanziert, der 42 Hektar Gewerbefläche umfassen soll (Landkreis Ahrweiler Wirtschaftsförderung o.J., o.Pag.). 
konnte sich die gesamte Bevölkerung durch das Maifest angesprochen fühlen. Darüber hinaus sind die auswärtigen Verwandten und Gäste einzubeziehen, welche die Kirmes als Anlaß eines Besuchs verstehen konnten.240 Um Brauchwandel feststellen zu können, ist es notwendig, einen möglichst breiten Zeitraum über die Befragung von Angehörigen unterschiedlicher Generationen zu erfassen. Die Auswahl der intensiv geführten Gespräche wurde durch diese Vorüberlegungen gelenkt. Es stellte sich aber heraus, daß aufgrund der mangelnden Bereitschaft potentieller GesprächspartnerInnen einige Einbußen hingenommen werden mußten. Personen, die nur wenig Berührung zur Brauchpraxis hatten, waren z.B. relativ schwer für ein Interview zu gewinnen. Insgesamt wurde in neun Fällen eine Absage erteilt. Dennoch konnte in einem Befragungszeitraum von annähernd zehn Monaten eine hinreichend differenzierte Befragtenstruktur erreicht werden. Die Auflistung in Tabelle 2 (s.u.) legt dar, daß sich insgesamt 37 Brauchbetroffene, 16 Frauen und 21 Männer, an ausführlichen Erhebungsgesprächen beteiligt haben. Die altersmäßige Zusammensetzung der Informantengruppe beginnt bei 17 und endet bei 90 Jahren. Die Schilderungen zu den frühesten Braucherlebnissen reichen daher bis in die 1920er Jahre zurück. Der überwiegende Anteil der InformantInnen bestand aus "Brauchaktiven". Sechs von 25 BrauchträgerInnen engagierten sich zum Zeitpunkt der Befragung unmittelbar am Brauchgeschehen. Ebenfalls sechs GesprächspartnerInnen waren dagegen dem Kreis der Passiven zuzurechnen, wobei zwei von ihnen zum Befragungszeitpunkt die formalen Voraussetzungen der Rollenübernahme erfüllten. In weiteren sechs Fällen fehlt eine Angabe zum Brauchträgerstatus, da die Betreffenden in ihrer Jugendzeit weder in Oeverich noch in Niederich beheimatet waren. Eine weitere Hintergrundinformation zur Beurteilung der GesprächspartnerInnen und deren Verhältnis zur lokalen Brauchpraxis ist die Herkunft. Aufgrund der Tatsache, daß bereits ein Elternteil in der Untersuchungsregion geboren wurde, konnten 23 Befragte in der Untersuchung als Alteingesessene oder Einheimische charakterisiert werden. Die Verbleibenden wurden einerseits als Zugezogene, andererseits als Neubürger in zweiter Generation angesprochen. Auch wenn die Letztgenannten von Geburt an oder in frühen Kindesjahren in Oeverich oder Niederich aufgewachsen sind, besteht ein merklicher Unterschied in der sozialen Integration zur Referenzgruppe der Alteingesessenen.

Hohe Stundenangaben bei der Gesprächsdauer sind ein Indiz für die Bereitschaft, sich auf das Thema, die Forschungsmethode und den Gesprächspartner einzulassen. Ein Zeitrahmen von ein bis zwei Stunden Interviewdauer, der von mir in den Vorgesprächen abgesteckt wurde, reichte in den meisten Fällen nicht aus. In 27 von insge-

\footnotetext{
${ }^{240}$ Vgl. Weltz (1998:177-194), die eine mobile und flexible Feldforschungsstrategie einfordert, um eine möglichst umfassende Perspektive auf die relevanten Handlungsfelder zu erschließen.
} 
samt 31 Sitzungsterminen dauerte die Befragung zwei bzw. mehr als zwei Stunden. Dreimal ergab sich mit Befragten ein zweites Gespräch.

\begin{tabular}{|c|c|c|c|c|c|c|}
\hline \multicolumn{7}{|c|}{ Tabelle 2: Liste der InformantInnen } \\
\hline $\mathrm{Nr}$. & Name $^{241}$ & Altersgruppe $^{242}$ & $\begin{array}{c}\text { Brauch- } \\
\text { träger- } \\
\text { status }^{243}\end{array}$ & $\begin{array}{c}\text { Geburtsort eines } \\
\text { Elternteils liegt in } \\
\text { der U.-region }\end{array}$ & $\begin{array}{l}\text { Gesprächs- } \\
\text { dauer (Std.) }\end{array}$ & Anmerkungen \\
\hline 1 & Hr. Beck & 5 & aktiv & ja & 3 & Partnergespräch \\
\hline 2 & Fr. Beck & 5 & aktiv & nein & - & Partnergespräch \\
\hline 3 & Hr. Böhlke & 5 & aktiv & nein & 5,5 & Gruppengespräch II \\
\hline 4 & Hr. Decker & 5 & aktiv & ja & 2,25 & \\
\hline 5 & Fr. Dietz & 4 & aktiv & ja & 3 & \\
\hline 6 & Fr. Eder & 1 & aktiv* & ja & 2 & \\
\hline 7 & Fr. Evers & 3 & aktiv & ja & 2 & \\
\hline 8 & Hr. Fischer & 4 & aktiv & nein & 9,5 & Einzel- u. Gruppengespräch II \\
\hline 9 & Hr. Franken & 4 & o.A. & nein & 1,5 & \\
\hline 10 & Fr. Gebhard & 2 & aktiv* & ja & 2 & \\
\hline 11 & Hr. Gerber & 4 & passiv & ja & 5 & \\
\hline 12 & Hr. Goltz & 3 & aktiv* & ja & 5,75 & zwei Gesprächstermine \\
\hline 13 & Hr. Hagen & 5 & aktiv & ja & - & Gruppengespräch II \\
\hline 14 & Fr. Heuerdorf & 5 & aktiv & ja & 2 & \\
\hline 15 & Fr. Jansen & 2 & passiv* & nein & 3,5 & \\
\hline 16 & Hr. Kastner & 4 & aktiv & ja & - & Gruppengespräch II \\
\hline 17 & Fr. Kruse & 3 & aktiv & nein & 6 & Partnergespräch; 2 Termine \\
\hline 18 & Hr. Kruse & 3 & o.A. & nein & - & Partnergespräch; 2 Termine \\
\hline 19 & Hr. Lange & 4 & aktiv & ja & 4,5 & \\
\hline 20 & Hr. Marx & 6 & aktiv & ja & 4 & Gruppengespräch I \\
\hline 21 & Fr. Marx & 6 & aktiv & nein & - & Gruppengespräch I \\
\hline 22 & Hr. Nolden & 6 & o.A. & nein & 1 & \\
\hline 23 & Fr. Pfeiffer & 2 & aktiv & nein & 2,5 & \\
\hline 24 & Fr. Randow & 2 & passiv* & ja & 2,25 & \\
\hline 25 & Fr. Rosen & 6 & aktiv & ja & - & Gruppengespräch I \\
\hline 26 & Hr. Schmelz & 5 & o.A. & nein & 1 & \\
\hline 27 & Hr. Schmitz & 6 & aktiv & ja & - & Gruppengespräch I \\
\hline 28 & Fr. Schmitz & 6 & o.A. & nein & - & Gruppengespräch I \\
\hline 29 & Hr. Schuster & 5 & aktiv & ja & - & Gruppengespräch II \\
\hline 30 & Hr. Selk & 6 & passiv & ja & 4 & \\
\hline 31 & Hr. Stein & 6 & aktiv & ja & 6,5 & \\
\hline 32 & Hr. Stoll & 5 & o.A. & nein & 6 & \\
\hline 33 & Fr. Theisen & 6 & passiv & ja & 1,5 & \\
\hline 34 & Fr. Thiel & 2 & aktiv* & nein & 4 & zwei Gesprächstermine \\
\hline 35 & Hr. Weiden & 2 & aktiv* & ja & 3 & \\
\hline 36 & Fr. Weiß & 4 & passiv & ja & 3 & \\
\hline 37 & Hr. Winzer & 1 & aktiv* & ja & 2 & \\
\hline $\begin{array}{l}\text { Häufig- } \\
\text { keiten: }\end{array}$ & $\begin{array}{l}16 \text { Frauen } \\
21 \text { Männer }\end{array}$ & $\begin{array}{l}1 \text { (unter } 20 \mathrm{~J} .): 2 \\
2(20 \text { bis } 29 \mathrm{~J} .): 6 \\
3(30 \text { bis } 39 \mathrm{~J} .): 4 \\
4(40 \text { bis } 49 \mathrm{~J} .): 7 \\
5(50 \text { bis } 59 \mathrm{~J} .): 9 \\
6 \text { (60 J. u. älter): } 9\end{array}$ & $\begin{array}{c}\text { aktiv: } 25 \\
\text { passiv: } 6 \\
\text { o.A.: } 6\end{array}$ & $\begin{array}{c}\text { ja: } 23 \\
\text { nein: } 14\end{array}$ & 98,25 Std. & $\begin{array}{l}\text { In } 31 \text { Sitzungen wurden } 2 \\
\text { Gruppen-, } 3 \text { Partner- und } 26 \\
\text { Einzelgespräche geführt. In } \\
\text { drei Fällen kam ein } 2 . \\
\text { Gesprächstermin zustande }\end{array}$ \\
\hline
\end{tabular}

Da einige GesprächspartnerInnen Bedenken über die Verwendung persönlicher Daten zur Schulbildung, Berufs- oder Religionszugehörigkeit geäußert haben, wird aus Gründen der Gleichbehandlung und der Wahrung der zugesicherten Anonymität auf

${ }^{241}$ Aufgrund der zugesicherten Anonymisierung der Daten wurden sämtliche Namen geändert.

${ }^{242}$ Es wurden sechs Altersgruppen aufgestellt: 1 (unter 20 Jahre), 2 (20 bis 29 Jahre), 3 (30 bis 39 Jahre), 4 (40 bis 49 Jahre), 5 (50 bis 59 Jahre) und 6 (60 Jahre und älter).

${ }^{243}$ Die Spalte bezieht sich auf das persönliche Engagement als Junggeselle oder Mailehen, wobei der Asterik $(*)$ den Status des/der Betreffenden zum Zeitpunkt der Befragung anzeigt. Ohne Angabe ist als o.A. abgekürzt. 
personenbezogene Angaben verzichtet. Die Bevölkerungsstruktur der Region wird durch das Sample in ihren Grundzügen widergespiegelt: Befragte lassen sich sowohl den landwirtschaftlichen als auch den handwerklichen Erwerbszweigen und dem Dienstleistungsgewerbe zuordnen. Vom Volks- bzw. Hauptschulabschluß bis zum Abitur sind die geläufigen Bildungslaufbahnen vertreten.

\subsubsection{Der Kontakt}

Die erfolgreiche Interaktion des Forschers mit den InformantInnen hat entscheidenden Einfluß auf die Erzielung fundierter Untersuchungsergebnisse. In der vorliegenden Erhebung waren zunächst entfernt verwandtschaftliche Beziehungen zu einer Familie im Dorf wertvoll. Sie ermöglichten den Zugang zu einer Brauchpraxis, die sich gewöhnlich Außenstehenden entzieht. Der Junggesellenverein setzte Ledigenstatus und Residenzpflicht bei seinen Mitgliedern voraus. An einzelnen Aktionen, wie z.B. dem Maibaumsetzen, nahmen keine Fremden teil. Bei der Mailehenversteigerung zeigten sich deutlich die Grenzen der Partizipationsmöglichkeiten. Um der Gefahr eines Präzedenzfalles und zukünftiger Anfragen von Nichtmitgliedern $\mathrm{zu}$ entgehen, fand die Mailehenversteigerung im strikt geschlossenen Kreis der Vereinsmitglieder statt. Mithin schützten die Junggesellen einen sensiblen Bereich vor Beobachtung und jeglichem Einfluß von außen. Bei der Maikönigstitelversteigerung sah man dagegen einen größeren Handlungsspielraum. Daher konnten die Junggesellen meinem Wunsch einer möglichst allumfassenden Teilhabe an ihren Aktionen entgegenkommen (siehe unten Kapitel 4.3).

Über das Bekanntwerden im Junggesellenverein verzweigte sich die Kontaktaufnahme in viele Richtungen. Zudem führte die Teilnahme an der Maikirmes zum Kennenlernen der aktiven Brauchträgerinnen. Die Beteiligung am rezenten Brauchgeschehen schuf insofern gute Bedingungen bei der Suche nach InformantInnen. Um auch Zugang zu DorfbewohnerInnen zu finden, die sich dem Mailehen entzogen haben, wurde die Chance ergriffen, den in Gesprächen erhaltenen Hinweisen über Außenstehende weiter nachzugehen. Hilfreich war ferner die Unterstützung des Gemeindepfarrers. In einem von ihm verteilten Schreiben konnte insbesondere bei der älteren Bevölkerung um Mitarbeit geworben werden.244 Sukzessive wurde durch dieses Vorgehen ein breites Spektrum von InformantInnen erfaßt.

Eine aussagekräftige Befragung setzt jedoch mehr als die relativ formelle Zusage einer Zielgruppe zur Mitarbeit voraus. Das Beispiel der exklusiven Versteigerungspraxis hat gezeigt, daß in einer "face-to-face"-Erhebung ForscherInnen keinesfalls alleine über die Modalitäten der Informationsgewinnung entscheiden.

${ }^{244}$ Siehe Anhang 7.3: 1) Schreiben zur Werbung potentieller GesprächspartnerInnen. 
Stets sind sie auf die Offenheit ihrer InformantInnen angewiesen. Der Prozeß, die volle Unterstützungsbereitschaft der GesprächspartnerInnen zu gewinnen, ist diffizil und abhängig von objektiven wie subjektiv-persönlichen Gegebenheiten. Einfühlungsvermögen, Anteilnahme, Interesse, Wohlwollen und Sympathien spielen im Alltag und somit auch in der ethnomethodologisch orientierten Forschung eine wichtige Rolle, um Einblicke in andere, fremde Gedanken-, Gefühls- und Lebenswelten zu erhalten. Vor allem aber müssen gegenseitige Respektierung und der Aufbau eines gegenseitigen Vertrauensverhältnisses als unverzichtbare Voraussetzungen qualitativer Erhebungsverfahren im Vordergrund stehen. ${ }^{245}$ Für das narrative Interview, das der vorliegenden Untersuchung in modifizierter Form als Befragungsinstrument diente, hat Hermanns (1981:131) den hohen Anspruch der Methode und die Problematik der Umsetzung treffend herausgestellt:

Der Abbau von Machtstreben im Gespräch ist [...] eine nicht beliebig herbeiführbare Situation - er stellt ja gerade das Gegenteil von strategischem Handeln dar und ist durch keinen Kunstgriff und keine Tricks herbeizuführen: Vertrauengewinnen und Verständnis finden ist keine manipulierbare 'Verhaltensvariable', sondern Ergebnis eines Interaktionsprozesses, der Handeln und Akzeptieren umfaßt, also nicht nur von einem Akteur abhängt". 246

Der Widerspruch in der Durchführung des narrativen Interviews tritt klar hervor: einerseits werden in einschlägigen Methodenhandbüchern zielorientierte rhetorische Befragungskünste propagiert, um günstige Interviewbedingungen erzeugen zu können, andererseits stehen die Voraussetzungen zwischenmenschlicher Kommunikation der Steuerbarkeit von empirischen Erhebungen grundsätzlich entgegen. Während der Kontaktaufnahme und in den Informantengesprächen wurde die oben wiedergegebene Aussage von Hermanns immer wieder faßbar: die Anwendung strategischer Hilfsmittel zur Erzeugung von Datenmaterial kann das Finden einer gemeinsamen Vertrauensbasis mit den GesprächspartnerInnen keinesfalls ersetzen. ${ }^{247}$

Die konzeptionellen Besonderheiten offener Interviews wirken sich bereits bei der Vorbereitung auf bevorstehende Gesprächstermine aus. Statt eines umfangreichen

${ }^{245}$ Einführende Darstellungen mit umfangreichen Literaturangaben zur qualitativen Sozialforschung finden sich in Lamnek (1988, 1989), Mayring (1990) oder Garz und Kraimer (1991).

${ }^{246}$ Brednich (1982:59-64) nimmt aus der Perspektive einer stationären volkskundlichen Feldforschung bei Mennoniten und Hutterern eine vergleichbare Position ein. Die jüngsten Überlegungen zu störenden Machtkonstellationen in sogenannten "research up"- und "research down"-Erhebungen (Warneken/Wittel 1997:7, 15f), in denen insbesondere formale Statusdifferenzen zwischen ForscherInnen und Erforschten (z.B. Bildungsgrade) diskutiert werden, verwischen m.E. das vordringliche Problem der gegenseitigen Akzeptanz und der Gestaltung eines wechselseitigen "Lernprozesses" (Brednich 1982:60f).

${ }^{247}$ Die Methodenliteratur kann manchmal den Eindruck erwecken, daß die Hinwendung zum Qualitativen verbunden mit der Einhaltung methodologisch durchdachter Prozeduren per se die Erhebung realitätsnäherer Daten ermöglichen. Wenn die Befragung als zwischenmenschliche Interaktion aufgefaßt werden soll, stehen dem vorschnellen Methodenpragmatismus Bedenken entgegen. Grundlegend dazu Devereux ( $\left.{ }^{3} 1992: 22\right)$; vgl. Lindner (1981). 
Frageleitfadens, der den Gegenstand aus vielfältigen Perspektiven beleuchtet hätte, genügte eine vor dem Gespräch zu verinnerlichende Stichwortsammlung, die speziell auf den jeweiligen Gesprächspartner ausgerichtet werden mußte. ${ }^{248}$ Das Leitthema war hierbei stets das persönliche Verhältnis zum Brauch: Welche Erlebnisse, Gedanken und Gefühle verbanden die Befragten mit dem Mailehen? Und: Wie hatte sich diese Sichtweise entwickelt? Neben diesen allgemeinen Fragen spielte das konkrete Eingehen auf die individuelle Situation der Gesprächpartnerin bzw. des Gesprächpartners eine Rolle. Bei Alteingesessenen stand z.B. die Übernahme der Brauchhandlungen im Vordergrund, während sich aus der Sicht der Zugezogenen weniger Fragen zur Brauchgestaltung als nach den Partizipationswünschen und -möglichkeiten ergaben. Damit wurde die zentrale Rolle der InformantInnen gegenüber dem Facettenreichtum eines Brauches auch von methodischer Seite in den Vordergrund der Arbeit gerückt. 249

Die Auswahl der ersten vier GesprächspartnerInnen orientierte sich bewußt an Personen, zu denen verwandtschaftliche Kontakte bestanden haben. Aufgrund der geringeren Fremdheit konnten in dieser "Pilotphase" alle Beteiligten sich leichter über Unklarheiten oder Irritationen verständigen. Gerade der Einsatz des narrativen Interviews in der Mailehenforschung birgt aufgrund der relativen Begrenztheit des Themas spezifische Probleme. So riß oftmals schon nach wenigen Sätzen der Erzählfluß ab. Eine unterschiedliche Mitteilsamkeit der Betroffenen war zu bemerken. Es stellte sich heraus, daß die Position des mehr oder weniger passiven Zuhörers keine erstrebenswerte Interviewerrolle sein konnte. Sowohl ein deutliches Beteiligtsein am Kommunikationsprozeß mit Signalen der Zugewandtheit, wie nonverbalen Gesten, Ausdruck von Verwunderung, Unverständnis oder Zustimmung, als auch vertiefende Fragen bereiteten den Weg zu einer nachhaltigen inhaltlichen Auseinandersetzung. Auch spontane Äußerungen, wie z.B. ein unverstelltes Lachen, sorgten für eine gelöste Gesprächsatmosphäre, die der Alltagskommunikation glich. Sehr deutlich konnte das reziproke Element des kommunikativen Austauschs im Dialektgebrauch beobachtet werden. Nicht geschliffene, sondern dialektgefärbte Frageformulierungen zeigten den GesprächspartnerInnen an, daß eine Befragung keine künstlichen Sprachbarrieren beinhalten muß. Sobald sich die alltagsgemäße Redeweise eingestellt hatte, war eine wichtige Hürde auf dem Weg zur Normalisierung der Kommunikationssituation genommen. Das Interview gewann nun entscheidende

\footnotetext{
${ }^{248}$ Zur Kritik des Leitfadens vgl. Breckner (1994:201). Auch Brednich (21994:86) hat vom Gebrauch eines Interviewleitfadens in narrativen Gesprächssituationen abgeraten. Er schlägt dagegen ein flexibleres Verfahren vor, bei dem ein "'thematische(s) Bewußtsein' des Fragenden" vorauszusetzen ist.

${ }^{249}$ Der Ansatz von Rosenthal (1994:128-132) zur Korrektur methodischer Perspektiven auf biographische Texte zielt in die gleiche Richtung. Dort geht es auch darum, die erfragten Ereignisse in direkter Verbindung mit dem subjektiv Erlebten und Erinnerten zu verstehen.
} 
Merkmale des Alltagsgesprächs, bei dem subjektive Positionen und nicht offizielle, druckreife Verlautbarungen formuliert werden konnten. ${ }^{250}$

Die Befragungen verliefen nach einem Grundmuster, bei dem Einstieg, Hauptteil und Ausklang aufeinander folgten. Der Einstieg verlangte zunächst nach einer Darstellung des Projekts und meiner Person. Hierzu wurde unterstützend ein Begleitschreiben von dem Betreuer des Promotionsprojekts eingesetzt, das die Bedeutung der Mithilfe der ortsansässigen Bevölkerung bei der Untersuchung unterstrich und auf den sinnvollen Nutzen einer Tonbandaufzeichnung hingewiesen hat. In einem Fall wurde die Aufnahme abgelehnt und daher ein Protokoll angefertigt. ${ }^{251}$

Der Hauptteil wurde eingeleitet, indem ich die Befragten dazu aufforderte, in aller Ausführlichkeit über ihre persönliche Brauchgeschichte zu berichten. Es wurde erwähnt, daß dabei die ersten Berührungspunkte zum Brauch, die Erlebnisse in der Kindheit, in der Jugend und im Erwachsenenalter zur Sprache kommen könnten. Aber auch Gedanken und Gefühle, die mit dem Mailehen verbunden waren und sind, sollten keineswegs ausgeblendet werden. Wie oben angemerkt, konnte der Erzählfluß der InformantInnen nach wenigen Sätzen bereits abbrechen. Die GesprächspartnerInnen signalisierten, daß das Wesentliche zum Thema bereits gesagt sei und daß von nun an Fragen nach dem üblichen Interviewschema folgen müßten. Versuche mittels relativ allgemein gefaßter Fragestellungen zum Thema die rein narrative Phase des Interviews weiter auszudehnen, führten oftmals nicht weiter. Die GesprächspartnerInnen sahen sich trotz der weitgehenden Offenheit des narrativen Erhebungskonzepts in einen latent einengenden, zielgerichteten Forschungsproze $\beta$ eingebunden; nunmehr mußte ein Weg gefunden werden, diesen eingegrenzten Rahmen zu verlassen. Hier zeigte eine stärkere Hinwendung zum alltagskommunikativen Forschen ihre Stärken. Solange die unausgesprochene Frage nach Fakten bzw. nach vermeintlich "harten Daten" zur Mailehenpraxis im Raum stand, solange erhielten die Äußerungen der InformantInnen eine deutlich offizielle Komponente, die wenig von den inneren Anschauungen zu erkennen gab. ${ }^{252}$ Sollte es in der Befragung aber weniger um ein außenwirksames Brauchstereotyp gehen,

${ }^{250}$ Die sprachliche Verständigung bereitete keine Schwierigkeiten. Hier wirkte sich meine Herkunft aus einem kleinen Eifelort, meine Vertrautheit mit der ländlichen Lebenssituation und der Landwirtschaft spürbar positiv aus. Der im Untersuchungsgebiet vorherrschende Dialekt ist ripuarisch geprägt, wohingegen meine Mundart vom verwandten Moselfränkischen beeinflußt ist.

${ }^{251}$ Siehe Anhang 7.3: 2) Begleitschreiben des Seminars für Volkskunde der Universität Göttingen.

${ }^{252} \mathrm{Vgl}$. hierzu die Bemerkungen Bourdieus (1987:165): "Alles weist darauf hin das der Handelnde, sobald er über seine Praxis nachdenkt und sich damit sozusagen theoretisch in Positur wirft, keine Chance mehr hat, die Wahrheit seiner Praxis und vor allem die Wahrheit des praktischen Verhältnisses zur Praxis zu formulieren: die wissenschaftliche Fragestellung verführt ihn, gegenüber seiner eigenen Praxis einen Standpunkt einzunehmen, der nicht mehr der des Handelns ist, ohne deswegen der Standpunkt der Wissenschaft zu sein". 
sondern um die individuelle Braucherfahrung, dann mußte für das Interesse an der Person und ihrer speziellen Sicht der Dinge maximaler Raum geschaffen werden. Die wirksamen "Ideologien der Rollen"253 von Befragtem und Interviewer sollten über das Interesse am Subjekt und über die zwischenmenschliche Begegnung entkräftet werden, um schließlich als Gesprächspartner in einen offenen Dialog mit unterschiedlichen Wissenshintergründen eintreten zu können. Nur auf diese Weise war eine Atmosphäre zu erwarten, bei der die GesprächspartnerInnen schrittweise Einblicke in die subjektive Braucherfahrung zuließen. ${ }^{254}$ Zur Abrundung einer Befragung blieb meist etwas Raum für die Klärung von Unverständlichem oder Widersprüchlichem, es konnten auch noch letzte Ergänzungen und Anregungen aufgenommen werden. In der Regel führten die abschließenden Gesprächsinhalte auf gewöhnlichere Themen der Alltagskommunikation zurück.

In jeder Sitzung wurde erwogen, ob der Einsatz zusätzlich vorbereiteter Anregungen zur Befragung sinnvoll sein könnte. So kam die Technik des Polaritätsprofils in Betracht. Die GesprächspartnerInnen konnten aufgefordert werden, Entwicklungskurven in zwei vorbereitete Bögen einzutragen, bei denen die persönliche Einstellung und das persönliche Engagement zum Mailehen im Verhältnis zum Lebensalter in Beziehung gesetzt werden sollte. ${ }^{255}$ Wenn dieses Verfahren zur Anwendung kam, wurde damit oft zusätzlicher Raum gewonnen, den Gesamtverlauf der persönlichen Beziehung zum Brauch im allgemeinen zu rekapitulieren und einzelne markante Stationen herauszuheben. Brüche, Kontinuitäten, allmähliche Veränderungen konnten angesprochen werden. Auch eventuell auftretende Unklarheiten zur vorangegangenen erzählenden Darstellung ließen sich hier feststellen und thematisieren.

Zur Beurteilung subjektiver Präferenzen gegenüber einzelnen Brauchhandlungen konnte eine einfache Ratingskala ${ }^{256}$ angewendet werden. Den Befragten wurden in dem Fall zehn Karten vorgelegt, auf denen Bereiche des Mailehens einzeln aufgeführt worden waren. ${ }^{257}$ Die Aufgabe bestand nun darin, die Karten in eine Reihenfolge zu bringen, welche den persönlichen Vorlieben entsprechen sollte.

\footnotetext{
${ }^{253}$ Zur Bedeutung der "Ideologie der Rolle" siehe Parin (1992:112-133).

${ }^{254}$ Bausinger (1980:20f) hat in diesem Zusammenhang vom dialogischen Aushandeln und Ausfechten von Interessensrichtungen unter den Erforschten und Forschern gesprochen.

${ }^{255}$ Siehe Anhang 7.3: 3) Beispiele für Entwicklungskurven der persönlichen Einstellung und des persönlichen Einsatzes in bezug zur Mailehenpraxis.

${ }^{256}$ Siehe Friedrichs (121984:172-174).

${ }^{257}$ Die Stichwörter auf den Karten lauteten wie folgt: "geselliges Beisammensein im Festzelt", "Aufrichten des Dorfmaibaumes", "Kirmesmann", "Walzer des Maikönigpaares", "Maibutz", "Aufnahme neuer Mitglieder in den Junggesellenverein", "Maienstecken für die Mailehen", "Versteigerung der Mailehen", "Umzug der Maipaare" und "Musik- und Tanzveranstaltungen".
} 
Eine weitere Befragungsoption bestand darin, die InformantInnen um ihre Stellungnahme zur aktuellen journalistischen Darstellung des Mailehens in einer benachbarten Region (Berrenrath, ein Vorort von Köln) zu bitten. Dazu wurden sechs Auszüge ausgewählt und vorgestellt, welche weithin verbreitete Stereotypen zum Mailehen widerspiegelten. In gleicher Weise wurde ein Teil der Befragten mit einem verwandten Brauch im nordhessischen Istha bekannt gemacht. Unter der spektakulären Schlagzeile "Junggesellen unterm Hammer" deutete der kurze Artikel darauf hin, daß das Mailehen auch unter vertauschten Rollen praktiziert werden kann. ${ }^{258}$ Hieran schlossen sich in der Regel weiterführende Gespräche an, welche die Differenz der eigenen Erlebnisse $\mathrm{zu}$ den medienwirksamen Ausführungen markierten. ${ }^{259}$

Die genannten Techniken dienten nicht dazu, Datenmaterial zur quantitativen Auswertung zu gewinnen. Wenn genügend Zeit vorhanden war und die Bereitschaft zur Mitarbeit von den GesprächspartnerInnen signalisiert wurde, dann konnten derartige gesprächsbegleitende Instrumente in angemessenen Situationen als zusätzliche Anreize zur Themenreflexion eingeflochten werden. Gütekriterien der quantifizierenden Sozialforschung spielten bei dieser Anwendung keine Rolle. Gegenüber der Vollständigkeit, der Repräsentativität, der Reliabilität oder Validität der erhobenen Daten waren hier kritische Äußerungen und freiwillige Beteiligung von Bedeutung. In der Tat war $\mathrm{zu}$ beobachten, daß manche InformantInnen mit Skepsis bzw. Ablehnung an solche scheinbar objektiven Erhebungsinstrumente herangingen. Demgegenüber konnten andere darin eine spielerische Anregung erblicken, das Thema Mailehen von allen möglichen Seiten zu betrachten. ${ }^{260}$

Die empirische Forschung stellt sich als äußerst voraussetzungsvoll dar. Forschungsziele, -inhalte und -methoden müssen einerseits sorgfältig aufeinander abgestimmt werden, andererseits ist von vornherein damit zu rechnen, daß jegliche theoretische Vorbereitung auf eine empirische Erhebung mit der Eigendynamik der Lebenspraxis

${ }^{258}$ Siehe Anhang 7.3: 4) Auszüge aus einem Artikel der Lokalpresse zum Mailehen (Bonner GeneralAnzeiger 2./3. April 1994) und 5) Zeitungsbericht über eine Männerversteigerung in Istha/Nordhessen (). Vgl. auch Wey (1999). Die freundlichen Hinweise auf die Brauchausübung in Istha verdanke ich Frau Angelika Reinhard und Herrn Prof. Brednich.

${ }^{259}$ Hin und wieder brachten die GesprächspartnerInnen den Vorschlag ein, mittels eigener Photoalben und Zeitungsausschnitte die Erinnerungen aufzufrischen. Dies trug häufig zur weiteren Perspektivierung des Erzählflusses bei.

${ }^{260}$ Auch unter der Anwendung der genannten Instrumente aus der empirischen Sozialforschung endet die Notwendigkeit zur Selbstreflexivität nicht. Die Wahl einer anscheinend bewährten Methode kann die Mitverantwortung des Forschers für die Erhebungssituation und den Gesprächsverlauf nicht außer Kraft setzen. Wie aktuell diese von Devereux $\left({ }^{3} 1992: 17-22\right)$ und Cicourel (1974:312-317) seit den 1960er Jahren maßgeblich geförderten Einsichten sind, bringen die Bemerkungen zur volkskundlichen Empirie von Kaschuba (1999:195-213, besonders 204-212) erneut zum Ausdruck. 
konfrontiert werden wird. ${ }^{261}$ Ferner ist auch in Untersuchungsprojekten, wie dem hier dargestellten, der Aspekt der Konstruktion sozialer und kultureller Realität zu berücksichtigen. Trotz der vom Forscher gesuchten Alltagsnähe darf nicht verkannt werden, daß auch das narrative Interview keineswegs Aussagen im Sinne einer "wiederholten Wirklichkeit einer vergangenen Situation" erbringt (Breckner 1994:209). ${ }^{262}$ Viel hängt von einer weitgehend offenen Gesprächssituation ab. Von ihr kann aber nur dann ausgegangen werden, wenn ein Bemühen um gegenseitige Anerkennung herrscht und die Erhebung nicht durch gegenseitige Manipulationen und Vereinnahmungen beeinträchtigt wird.

\subsubsection{Bemerkungen zur Auswertung und Wiedergabe der Empirie}

Aus dem oben Gesagten wurde bereits deutlich, daß den Gesprächstexten eine eigene spezifische Realität zukommt. Die in den Äußerungen der GesprächspartnerInnen reaktivierten Situationen, Erlebnisse, Gefühle, Eindrücke und Gedanken können die Vergangenheit nicht abbilden, sie können diese aber mehr oder minder bewußt und ernsthaft reflektieren. Auf diese Weise entstehen Texte, die man mit Breckner (1994:209) als "dialektische Verknüpfung des Erlebens zum Zeitpunkt des Geschehens auf das die Erzählung bezug nimmt, von der Verarbeitung des Erlebnisses im Verlauf der weiteren Zeit- und Lebensgeschichte bis zum Zeitpunkt der Erinnerung und Erzählung sowie von den Erwartungen für eine noch offene Zukunft" charakterisieren kann. Das bedeutet für die Analyse der Texte, daß die jeweiligen Aussagen unter der zeitlichen Perspektive von Ereignissen, der persönlichen Involvierung und Bewußtwerdung gesehen werden müssen. Um dieser Erkenntnis gerecht $\mathrm{zu}$ werden, ist es notwendig, die Interpretation von Gesprächspassagen immer im Hinblick auf den biographischen Hintergrund der bzw. des Befragten und den Gesamtkontext des Gespräches vorzunehmen. Zur Auswertung mußten daher alle Gespräche inhaltlich transkribiert und zu allen GesprächspartnerInnen ein soziales Profil erstellt werden. Zudem wurden Notizen einbezogen, die Angaben über die jeweilige Gesprächssituation enthielten. Daraufhin wurde jeder Gesprächstext nach inhärenten Schwerpunktsetzungen befragt. Die hierbei gewonnenen thematischen Aspekte reflektierter Brauchpraxis sollten dabei so weit wie möglich differenziert werden. Hieraus resultierte eine Liste mit 32 Stichpunkten, ${ }^{263}$ die abschließend $\mathrm{zu}$ folgenden thematischen Feldern arrondiert wurden: 1. Brauch und Paarbeziehung, 2. Brauch und Geschlecht, 3. Brauch und Gefühle, 4. Brauch in Relation zu Begegnung und Abgrenzung, 5. Brauch und Organisation und 6. Brauch

${ }^{261}$ Dazu auch Wey (1995b:44-48).

${ }^{262} \mathrm{Vgl}$. Fuchs (1985:462), der ebenfalls vor dem Fehlschluß warnt, daß das narrative Interview unmittelbar zu "authentischer" und "frei erzählender Selbstdarstellung" führe.

${ }^{263}$ Lamnek (1989:114f) hat in diesem Zusammenhang vom Erstellen einer Themenmatrix gesprochen. 
und Identität. Auf dieser Basis konnte nach wiederkehrenden Strukturen gesucht werden, welche die Zugangsweisen zum Mailehengeschehen geprägt haben. Bei einer abschließenden Betrachtung des Untersuchungsrahmens und der Analyseergebnisse, wobei nochmals interpretierte Einzelaussagen auf der Folie der jeweiligen Erhebungssituation betrachtet wurden, ergab sich eine Feststellung, welche die Ausrichtung der Analyse bestätigte und somit als ein vorsichtiges Zwischenergebnis angesehen werden konnte. Es handelte sich um die Beobachtung, daß in dem unten detailliert wiedergegebenen Transkript (siehe die Hinführung zu Kapitel 4.4) die erarbeiteten Kernpunkte der Gesamtanalyse zum Gegenstand eines kontroversen Gruppengesprächs geworden sind.

Anzumerken sind noch einige Hinweise zur Verschriftlichung der Gespräche. Bei der wissenschaftlichen Auseinandersetzung mit Interviewtexten hat sich eine Transkribierung bewährt, welche einerseits die Spezifik der Kommunikation kenntlich macht und in wesentlichen Teilen bewahrt, andererseits eine Bewältigung oder Lesbarkeit der kommunikationsbeeinflussenden Text- und Zeichenfülle nicht übermäßig erschwert. Unter dieser Voraussetzung wurde bei der Wiedergabe der Gesprächspassagen darauf geachtet, daß Gesprächsinhalte durch Weglassungen dargestellt durch [...] - keinesfalls entstellt wurden. Besonders hervorgehobene Wörter (Lautstärke, Betonung) wurden durch Kursivschrift, markante Sprechpausen durch Gedankenstriche ("-") und Satzabbrüche durch Auslassungszeichen ("...") kenntlich gemacht. Beginnt ein Satz mit Auslassungszeichen, so liegt ein abrupter Sprecherwechsel vor, bei dem die Vorrednerin bzw. der Vorredner ihren/seinen Satz (noch) nicht beenden konnte. Dort, wo parasprachliche Äußerungen oder von außen herbeigeführte Interventionen bedeutsam für den Gesprächsverlauf waren, wurden sie in runden Klammern näher bezeichnet: "(lachen)". Grammatikalische Regeln und Satzzeichen ließen sich nur dort sinnvoll anwenden, wo sie sich dem Sprachduktus der GesprächspartnerInnen fügten. Auf sprachliche Korrekturen wurde verzichtet. Ergänzungen, die jeweils in eckige Klammern gesetzt wurden, erfolgten lediglich, um an mißverständlichen Stellen die im Gesprächsverlauf deutlich gewordenen Bezüge aufzuzeigen. Mundartliche Färbungen und Mundart konnten im Transkript ebenfalls berücksichtigt werden. Unter weitgehender Beibehaltung der Ausspracheregeln, die für das Schriftdeutsch gelten, wurde zugunsten der Lesbarkeit auf die Verwendung lautsprachlicher Sonderzeichen verzichtet. Einige Anmerkungen zu Wortbedeutungen erschienen hin und wieder angebracht. Sie finden sich in den Fußnoten, um den Lesefluß möglichst wenig zu beeinträchtigen. Hier wurden auch nach Zitatende die durchweg anonymisierten Angaben zu den GesprächspartnerInnen bzw. zur Identifizierung der Quelle in Klammern hinzugestellt. 
4.2 Rückblick: Oevericher Mailehengeschichte

4.2.1 Gründung und Aufbau des Junggesel1envereins ( $1889-1920)$

Jubiläen werden von Vereinen häufig zum Anlaß genommen, Festschriften herauszugeben, die über das Vereinsleben berichten. Neben vielen Grußworten und den Terminen zum Ablauf anstehender Festivitäten werden darin meist wissenswerte Hintergrundinformationen über die Geschichte, die Aufgabenbereiche und die Mitglieder des jeweiligen Vereins festgehalten. 1989 führte das 100jährige Bestehen des Junggesellen-Vereins Oeverich auch zur Veröffentlichung einer solchen Festschrift, die sich durch eine außergewöhnlich engagierte und professionelle Recherche auszeichnet. ${ }^{264}$ Man erfährt darin, daß der Verein 1889 unter der damaligen Bezeichnung Junggesellen=Verein Leimersdorf offiziell gegründet wurde. Prothmann (1989:20f) nimmt jedoch an, daß bereits vor dieser amtlich dokumentierten Vereinsgründung von einer Vereinigung junger Männer ausgegangen werden kann. Einen Hinweis für deren Existenz erkennt er darin, daß der zuständige Landrat in einer Verfügung aus dem Jahre 1831 Maßnahmen zur Eindämmung des Maibaumfrevels gefordert hatte. Da die Ausübung des Maiensteckens zumeist in den Händen der unverheirateten Burschen lag, erscheint Prothmanns These als begründet.

Ein überliefertes Schriftstück aus dem Jahre 1869 bringt die historische Rekonstruktion einen Schritt weiter. Der damals zuständige Bürgermeister erhielt zu diesem Zeitpunkt vom Landrat die Aufforderung zu einer Stellungnahme über die Verbreitung des Mailehens in der Region und die jugendgefährdende Wirkung der Brauchaktivitäten. Damit versuchte der Landrat denselben Beschwerden auf den Grund zu gehen, die vorher im benachbarten Siegburger Raum die Behörden beschäftigt hatten (vgl. Kap. 2.5). Die entscheidende Passage im Antwortschreiben des Bürgermeisters wird bei Prothmann (1989:86f) wiedergegeben:

"'Der Gebrauch des Ansteigerns von Mädchen unter den Junggesellen am Vorabend des ersten Mai jeden Jahres durch Meistgebot hat früher in sämtlichen Gemeinden hiesiger Bürgermeisterei stattgefunden und hat nunmehr aber in den Gemeinden Holzweiler, Eckendorf, Lantershofen ganz aufgehört, während in mehreren anderen Gemeinden dieser Gebrauch im Abnehmen begriffen ist. Die Junggesellen versammeln sich am Abend des letzten Tages im April, und es findet die Versteigerung der Mädchen nach den Hausnummern durch Meistgebot statt. Der Ansteigerer hat das Recht und die Pflicht, sein angesteigertes Mädchen jeden Sonnabend zu besuchen und zwar in der Zeit vom ersten Mai bis zur Blüthe der sogenannten dicken Bohnen. Gleichfalls im Wege des Meistgebots wird ein Schultheiß sowie ein Feldhüter ernannt, welche das Recht haben nachzusehen, ob jeder Bursche auch seinem Mädchen getreu ist und diesem die vorgeschriebenen Besuche abstattete. Der Erlöß des Geldes wird unter den betheiligten Burschen gemeinschaftlich verzehrt. Der altherkömmliche Gebrauch hat, wir [sic] mir allgemein versichert wird, nichts Unsittliches im Gefolge, er gibt Gelegenheit, den

${ }^{264}$ Siehe Prothmann (1989). 
Mädchen eines Dorfes erkennen zu lassen, in welchem Werthe sie überhaupt und insbesondere bei ihrem Ansteigerer stehen, indem öfters mehrere Mädchen, auf die man nicht viel hält, zusammen ausgesetzt und für einen Spottpreiß zugeschlagen zu werden pflegen. Der Gebrauch wird sich übrigens mit der Zeit selbst abstellen und liegt durchaus keine Veranlassung vor, dies im polizeilichen Wege zu thun'".

Die Gemeinde Leimersdorf wurde nicht explizit im Schreiben aufgeführt, aber immerhin ist von einer allgemeinen regionalen Verbreitung des Brauches die Rede. Danach fand wohl auch in den Ortschaften Oeverich und Niederich nach der protokollierten Art und Weise das Mailehen statt. Die Beschreibung des Brauchablaufs ähnelt den zeitgenössischen Darstellungen (vgl. Kap. 2.5). Wichtigstes Element war das Versteigern, das mit dem Aspekt der gemeinschaftlichen Kasse und des Vertrinkens der eingenommenen Gelder verbunden wurde. Hinzu kommt die Besuchspflicht, die den Junggesellen dazu anhielt, das von ihm ersteigerte Mailehen am Kommabend zu besuchen, und der sogenannte Rummel, bei dem unbeliebte Mädchen durch die Geringschätzung der Bieter sanktioniert werden konnten. Daß die gegenseitige Tanzpartnerschaft in dem behördlichen Schreiben keine Erwähnung gefunden hat, muß seinen Grund in einer oberflächlichen Wahrnehmung der Berichterstatter haben. Denn aus dem folgenden Eintrag des ortsansässigen Lehrers Johannes Watzig im Rheinischen Fragebogen ${ }^{265}$ geht hervor, daß die Mailehen an den Festtagen der Kirmes zusammen zum Tanz gingen:

"Das Mailehen ist noch im Gebrauch. Die Versteigerung findet am Maiabend statt. Es wird ein Schultheiß und ein Schreiber gewählt. Die Mädchen über 17 Jahre wurden in eine Liste eingetragen. Die Jungen müssen über 18 Jahre alt sein. Der Schultheiß hat das Recht, sich ein Mädchen zu wählen, ebenso der Schreiber. Nun beginnt die Versteigerung. Der Junge steckt seinem Mailehen einen grünen Buchenzweig ans Fenster. Er hat die Pflicht, jeden Samstag abend zwischen 9 und $10 \mathrm{Uhr}$ sein Mailehen zu besuchen, andernfalls zahlt er 50 Pfg. Strafgeld. Ebenso muß am Kirmesmontag jeder Junge sein Mailehen zum Tanze holen. Die Mailehnschaft dauert, bis die dicken Bohnen blühen" (Rheinischer Fragebogen Nr. 1546).

Ergänzend zur Kirmes wurde ausgeführt, daß die Junggesellen - auch "Reihjungen" genannt - die Tanzveranstaltung zusammen mit dem Gastwirt organisiert haben. In dieser Zeit waren auch Festumzüge mit Musik üblich, wobei die Burschen offensichtlich ohne die Mailehen am Kirmessonntag und -montag durch die Ortsstraßen gezogen sind.

Detaillierte Durchführungsbestimmungen zum Mailehen, wie sie in den Satzungen anderer Junggesellenvereinigungen öfter erwähnt worden sind (s. Kap. 2.5), gehen aus dem erhaltenen Statut von 1889 nicht hervor. Sprache und Inhalt dieses Dokuments geben im wesentlichen Auskunft über die allgemeine Zielsetzung des Vereins. So definiert Artikel 1:

${ }^{265}$ Näheres zum Rheinischen Fragebogen in Kap. 1.2. 
"Der Junggesellen=Verein hat den Zweck, eine größere Einigkeit unter den Junggesellen hiesiger Gemeinde anzustreben. Es soll dies ein Verband sein, der die einzelnen Mitglieder aus den verschiedenen Ortschaften der Gemeinde anspornen soll, in heiteren wie in ernsten Stunden zusammen zu halten und auch nach Außen hin die Achtung eines jeden Einzelnen zu fördern".

Dem Aspekt einer gemeinschaftsstiftenden Pflege sozialer Beziehungen zwischen unverheirateten Männern aus drei benachbarten Dörfern wurde damit ein hoher Stellenwert eingeräumt. Bereits in der Wahl der offiziellen Bezeichnung "Junggesellen=Verein Leimersdorf" orientierte man sich zunächst an der übergeordneten Pfarrgemeinde, zu der neben dem bevölkerungsreicheren Ort Oeverich, die Dörfer Niederich und Leimersdorf zählten. Die Belange des Vereins wurden aber schon damals maßgeblich von Oeverichern bestimmt, da sie stets den überwiegenden Teil der Mitglieder stellten. ${ }^{266}$ Für die Aufnahme in den Verein war ein Mindestalter von achtzehn Jahren Bedingung. Die formelle Festlegung eines Höchstalters existierte nicht. In den Händen des Präsidenten, der drei Vorstandsmitglieder und des Kassierers lag die Vereinsführung. Für die Veranstaltung von Festen sollte ein "Comité" gewählt werden, das den Bestimmungen zufolge für Ordnung sorgen mußte. In dem später erneuerten Statut von 1907 wurde auf die Ausübung der Maibräuche auch nicht eingegangen. Die Wiederauflage wurde als Beleg für die Neugründung des Vereins verstanden. Mithin war der Verein bereits 18 Jahre nach seiner ersten Erwähnung in existentielle Schwierigkeiten geraten, die eine Erneuerung erforderlich machten. ${ }^{267}$

Auch das Oevericher Fallbeispiel läßt erkennen, daß die Vereinsstatuten und der darin formulierte offizielle Rahmen der Brauchausübung nicht immer mit der tatsächlichen Praxis übereinstimmen muß. Bereits der Wortlaut einzelner Passagen deutet auf schematische Redewendungen hin, die lediglich den amtlichen Auflagen genügen sollten. Einen weiteren Hinweis auf den interpretationsbedürftigen Realitätsgehalt dieser Art von Quellentext haben die Beobachtungen von Lehrer Watzig geliefert. Er berichtete über Schultheiß und Schreiber als wichtige Funktionäre der Junggesellenversammlung. Dies deutet darauf hin, daß die modernen Vereinsfunktionsbezeichnungen, wie sie in der Satzung verwendet wurden, sich im Alltag nicht durchgesetzt hatten. Zudem bevorzugte Berichterstatter Watzig den Begriff "Reihjunge" gegenüber Junggeselle. Im Zusammenhang mit den Kirmesaktivitäten spricht er auch von "Gelog" (Gelage), womit die informelle Art der Gruppenbildung bei älteren Burschenvereinigungen zum Ausdruck kommt (s. Kap. 2.4/2.9).

Seit den 1920er Jahren werden für Oeverich und Niederich stellenweise Maikönigspaare namentlich nachgewiesen. Dabei ist zu bemerken, daß die frühesten

${ }^{266}$ Vgl. dazu auch Prothmann (1989:23, 27, 61-64).

${ }^{267}$ Siehe Prothmann (1989:27). 
Nennungen aus den Jahren 1923 (oder später) und 1924 (oder später) nur ungenau datiert sind und gewissermaßen als Ausnahmeerscheinungen hervortreten. Erst nach 1936 sind die Paare lückenlos aufgeführt und deuten auf eine stabile Institutionalisierung des Regentenstatus hin. ${ }^{268}$ Wahrscheinlich hat sich die bis in die Gegenwart wirkende Repräsentationsfunktion des Maikönigs und seiner Partnerin allmählich aus dem privilegierten Amt des Schultheißen entwickelt. Dabei kam es zu einer Aufspaltung von ursprünglich einheitlich gefaßten Kompetenzbereichen in zwei voneinander getrennte Wirkungsfelder der Vereinsorganisation und Repräsentation. Das heißt, aus den ursprünglich in Personalunion ausgeübten Funktionen des Schultheißen entstanden die heute bedeutsamen Ämter des Präsidenten und Maikönigs. ${ }^{269}$ Die Sonderstellung eines gewählten Schreibers, der ebenso wie der Schultheiß von der Versammlung gewählt wurde und berechtigt war, sich ein Mädchen frei zu seinem Mailehen zu küren, findet sich zuletzt in den Angaben zum Rheinischen Fragebogen. Im weiteren Verlauf der Vereins- und Brauchgeschichte scheint die Stellung des Schreibers oder Schriftführers allerdings in den Hintergrund zu treten.

\subsubsection{Konfrontationen mit den Dorfautoritäten ( $1920-1945$ )}

Aus den Gesprächen mit den InformantInnen ist hervorgegangen, daß die Aktivitäten des Junggesellenvereins in den ersten Jahrzehnten des 20. Jahrhunderts nicht zwangsläufig zu jedem einzelnen Dorfbewohner vordringen konnten. Die hohe Arbeitsbelastung in der Landwirtschaft und sicherlich auch die persönlichen Vorlieben sowie innerfamiliäre Auffassungen zu Volksfesten, Tanzveranstaltungen und Geselligkeit beeinflußten die Wahrnehmung der lokalen Gegebenheiten. Frau Theisen berichtete aus ihrer Jugendzeit in den 1930er Jahren:

Ich weiß, dat do in Oeverich die Jungjeselle, dat woar en janz Teil, die haben da so en Umzug jemacht, ne. Ob dat damals en Verein war oder ob sie sich so zusammenjetan hatten, weiß ich net. Un die ha'm dann Umzug jemacht un hann ne Kirmesmann su auf ne Bahre jedonn un hann die mit rundjetragen, ne. Dat kann ich mich'ens erinnere, dat so wat da war. [...] Dat die da durch et Dorf jingen un mir dann do so hinterher, die Kinder.

War der Umzug da auch schon mit Mailehen?

Nä, nix, nix, nix, nix. Dat woaren dann nur jet Jungjeselle ${ }^{270}$ [...] Dat wierd Anfang der 30er Jahre jewias sinn. - Nä, awwer ${ }^{271}$ su met Mädschje un jet, dat es später jekommen. Also dat weiß ich net, ob dat überhaupt früher war, wenn die da su jejangen sin. Ich glaub dat aber net, ich weiß et wirklich net. [...]

\section{Und später?}

\footnotetext{
${ }^{268}$ Siehe Prothmann (1989:112).

${ }^{269}$ Die formalen Anforderungen an vereinsmäßige Zusammenschlüsse haben die Eigenart der ehemals vorzufindenden Männerreih allmählich nivelliert. Vgl. dazu Kapitel 2.5.

270 "jet Jungjeselle": einige Junggesellen.

271 "awwer" ("awer" oft auch "äwwer"): aber.
} 
Siste, wie Ende der 40er, da war die Regina, der Peter klein, ne un jet, un jeboren. Nä, da sin mir jarnet doa, ja überhaupt jarnet doazo kunn, für noa Oefferich ze joan, ne. Heut sinn dat die "Pampers". Doa hatte mir ken Zitt für. Mir hann noch schön Windeln jewaschen, ne. ${ }^{272}$

Die Liste der Maikönigspaare, die Prothmann (1989:112) in der Vereinsfestschrift vorgelegt hat, weist in der Zeit zwischen 1923 und 1937 nur zwei Paare auf. Diese ungleichmäßige Verteilung kann nicht mehr eindeutig erklärt werden. Die oben angeschnittenen Besonderheiten der landwirtschaftlichen Arbeitswelt traten sicherlich zusätzlich zu den allgemeinen Startschwierigkeiten von Neuerungen hemmend hinzu. Auch der beharrlich und überregional geführte Kampf der katholischen Ortsgeistlichen gegen die Ausübung des Mailehens kann zur Erklärung herangezogen werden. Die Auseinandersetzungen im Fall Oeverich wurden durch eine in allen Pfarreien des Dekanats zu verlesenen Weisung vom April 1927 aktenkundig:

"'Der bevorstehende 1. Mai veranlaßt die Pfarrgeistlichen des Dekanates Ahrweiler öffentlich Stellung zu nehmen zu der Unsitte des sogenannten Mailehens. Es mag sein, daß dieser Gebrauch zu Zeiten mit hochstehender Sittlichkeit und mit gesundem moralischem Empfinden sich in harmlosen Formen vollzogen hat, heute ist das nicht mehr der Fall. Nicht allein, daß bei der Versteigerung selber in zotenhafter Weise geredet wird, haben auch die sogenannten Pflichtbesuche [Kommabende] im Laufe des Monats sich vielfach so gestaltet, daß sie eine nächste Gelegenheit zur Sünde genannt werden können. Als unmittelbar nach dem Mai des letzten Jahres der Oberhirte unserer Diözese die hiesigen Pfarreien durchzog, hat er an verschiedenen Orten auf das Mailehen hingewiesen, es als eine Unsitte bezeichnet und mit eindringlichen Worten die Jünglinge gebeten, von jetzt ab das Mailehen zu unterlassen. Die Pfarrgeistlichen [...] erinnern ihre Pfarrkinder an diese Worte und weisen darauf hin, daß alle, die sich darüber hinwegsetzen und in diesem Jahr trotzdem das Mailehen veranstalten, dadurch ihr Gewissen belasten'". 273

Neun Jahren darauf hielten die Pastoren der Gemeinde Leimersdorf und Nierendorf es für nötig, die Jugendlichen erneut zu ermahnen. Die einschüchternden Appelle an das reine Gewissen potentieller Mailehenkandidatinnen und -kandidaten hielten aber nicht an. Etwa zwei Jahre nach dem wiederholten Disziplinierungsversuch der Geistlichen kam es 1937 wieder zu einer Ernennung eines Maikönigspaares in Oeverich. ${ }^{274}$ Dieser Vorgang ist den damals Betroffenen durchaus bewußt geblieben:

Herr Schmitz: Ja, paßt mol of, da moß ich eich ebbes... Ich weß net, ob ihr et daran erinnere künnt: Da hatten wir doch dumals den Pastur Knopp. Der wollt doch denne Junggeselle verbede dat Steijere.

Frau Rosen: Ja, ja. Das war ne Abwertung für die anderen Mädchen, die nix kosteten, ne, die könnte man nicht verkaufen.

Herr Schmitz: Dat wär wie - wie en Viehmarkt. Dat woar der Pastur dumals, der wollt dat verbieten. Dat kann ich mich noch erinnere...

Frau Rosen:...der is '39 weggegangen. Da war dat vorher noch.

${ }^{272}$ Frau Theisen (06/06/1a:309-424).

${ }^{273}$ Zitiert nach Prothmann (1989:90); vgl. derselbe (1998:52-54).

${ }^{274}$ Siehe Prothmann (1989:112) und (1998:111-113). 
Herr Schmitz: Ich sinn '36 us de Schuol kumme und du woar dann die iaschte Joahr ${ }^{275}$ wie man dann sechzehn, sibbzehn woar, da is man ja dann och alt mitjeloafe, ne. Un da woar de Knopp. Dumals ha'm mir ni'mie jesteijert - vor'm Kreech. Weeß ich noch. [...]

Frau Rosen: Ja, der Knopp, dat war en bißchen eigenwilliger Pastor.

Frau Marx: Ein Prediger! Fantastisch! Ehrlich: fantastisch!

Frau Rosen: Ein Eiferer für das Heil Gottes. Und wenn der dann wütend wurd, dat war dann "heilijer Zorn im Dienste Christi". [...]

Also wär jetzt die Frage, ob der Pastor Knopp sich '39 vielleicht durchgesetzt hat, zur Maikirmes, daß...

Herr Schmitz:...nee, da war noch Kirmes. Also die Kirmes, da hatt der nix dajejen einzuwenden. Der hat bloß jejen dat Versteijern von der Mädchen, da hat er wat einzuwenden jehat.

Frau Marx: Das wär wie, wie als wenn man Vieh versteigert. Das wär menschenunwürdig. ${ }^{276}$

Die Vertreter der Kirche hatten nicht generell etwas gegen die Maikirmes einzuwenden. Aber die Mailehenversteigerung in Verbindung mit den vorehelichen Kontaktmöglichkeiten (z.B. die Kommabende) war den Geistlichen ein Dorn im Auge.

Interesse an der Reglementierung des Brauches gab es zu diesen Zeiten auch seitens der nationalsozialistischen Machthaber, wenn auch in wenig ausgeprägter Form. Herr Stein konnte sich daran erinnern, daß die Nationalsozialisten ebenso an die Junggesellen appellierten, die Sittlichkeitsnormen bei der Brauchausübung einzuhalten:

Da gab's och diese Mailehenversteigerunge und so weiter, das gab's och [vor dem Krieg]. Natürlich wurde da och hinjewiesen drof, also bei den Versteijerungen, keine Entgleisungen und so, ne.

Von den Nazis?

Ja, ja. Von den Nazis aus, net nur von der Kirch aus diese Entgleisungen: "Die Würde der Frau muß jewahrt werden un so, ne.

Ha'm die auch gesagt?

Ja, ja. Un da weiß ich, da ha'm mir dann überlegt, wat solln mir denn da sagen, ne. Da ha'm mir dann zusammenjesetzt. Da muß doch wat in die Kasse kommen. Och, dann ging's da los. Dat jab's ja früher in der Landwirtschaft keine Miststreuer, ne. Da wurde der Mist aufn Wagen oder Karren jeladen und dann wurden da so Haufen jemacht und dann wurd en Stückchen weiterjefahren, so acht, neun oder zehn Meter, un dann wurd widder so en Haufen jemacht. Der wurd dann mit der Mistgabel runterjezogen, ne. Un dann wurd der nachher von Hand verteilt, eh man den eingepflügt hat. Un dann wurd jesagt, da waren dann noch zwei Mädels, die waren bekannt, die konnten ganz schnell un sehr gut, un genau, präzise mistspreiten. Aber sonst hatten se so Revolverschnauzen, ne. Ja, un da hab ich jehört: "Weißt du wat, die tust du anbieten, dat die de Rheinlandmeisterschaft im Mistspreiten hann!" ne. Hatte dat dann och so

275 "die iaschte Joahr ": die ersten Jahre.

${ }^{276}$ Gruppengespräch I (38/23-27/1b:410-477). 
jemacht, ne. Un da konnten ja och die Nazis nichts gegen sagen. Fleißig sein war ja nu kein... da war die Würde der Frau ja net verletzt un so, ne. ${ }^{277}$

Allgemein scheint aber der Einfluß der Nationalsozialisten auf die Durchführung des Mailehens eher unerheblich gewesen zu sein, was sich z.B. auch an der sozialen Außenseiterposition von Dorfbewohnern ablesen läßt, die sich während der Kirmes in NS-Uniformen präsentierten. Dazu äußerte Herr Stein:

Hier waren auch paar Verrückte, die da och Kirmes mit der SA- oder SS-Uniform rumliefen, ne. Aber die wurden so e'bißjen für blöd anjesehn - waren och teilweise die meisten davon. Denn bei so'nem weltlichen Fest da läuft man doch net in Uniform erum! Ich hätt noch verstehen können, wenn se sonst, ne - na ja. Aber die Leute waren ja och damals überhaupt net [...] politisch interessiert, ne: "Die machen in Berlin ja doch, wat se wolln."278

Die Aussagen deuten darauf hin, daß die Brauchübenden durch ihr unauffälliges Verhalten keinerlei Schwierigkeiten mit den Nationalsozialisten hatten. Man paßte sich der Sittlichkeitsforderung an und hielt seine Meinung gegenüber den politisch motivierten Zumutungen zurück. Entsprechend den Machtverhältnissen wurde versucht, Konfrontationen möglichst auszuweichen. Probleme bereitete dagegen die Neugründung des Junggesellenvereins nach dem Zweiten Weltkrieg, wie Herr Stein berichtet:

Aber im großen und ganzen kann ich mich da nich erinnern, dat da [die Veränderung der Brauchausübung betreffend] irjendwie von Seiten der Nazis da irjendwie was unternommen wurde, ne. Das war nachher bei den Allierten war dat schon strenger, ne. Die hatten da immer noch Angst, et würde wieder Militarismus oder paar Heckenschützen entstehen und so weiter. Die Nazis hatten ja, der Goebbels, der hat ja so gute Propaganda jemacht, ne - Werwolf und so weiter, "der Kampf geht weiter bis zum Schluß" ne. Scheinbar hann die das jeglaubt, oder wenistens en Teil davon jeglaubt, ne, sonst hätten se sich bestimmt net so verhalten. ${ }^{279}$

\subsubsection{Zurückgewonnene Lebensfreude (1945-1960)}

Das Mißtrauen der französischen Besatzungssoldaten gegenüber den Jugendlichen mußte Schritt für Schritt abgebaut werden, bis es gegen Ende der 1940er Jahre gelang, den Junggesellenverein wieder zu installieren. Weiter führt Herr Stein aus:

Un die hatten ja immer Angst, die Franzosen, da würd sich - nun war's hier bei Junggesellenvereinen net so schlimm wie bei Sportvereinen - da könnte Sport jetrieben werden un dann Militaristen wieder entstehen, ne. [...] Ja, un da gab's dann die Auflagen, ne: Also in den Vorstand durfte keiner, der nicht nur amtlich, der nur einfaches "PG", also Parteigenosse war. [...] Wir hatten einen Gastwirt, der war Berufssoldat; un die wollten se ja och net. Berufssoldaten durften och keine Führungsrolle übernehmen. Denen ha'm se net jetraut, ne. Ja, un da ha'm wir damals, ha'm wir das anders gemacht. Wir ha'm diejenijen jenommen auf den Formularen, die han dann unterschrieben, ne, daß sie weder Soldat waren... Die Jüngsten unter uns, die ha'm wir jenommen un han die der Militärrejierung jemeldet, daß die die Führung des

${ }^{277}$ Herr Stein (14/11/2a:350-379).

${ }^{278}$ Herr Stein (14/11/2a:244-258).

${ }^{279}$ Herr Stein (14/11/2a:379-397). 
Vereins hätten, ne. [...] Ja, un da wurd das jenehmigt. Un wie wir den Verein hatten, ne, dann ha'm natürlich die anderen widder, die vorher jewählt waren, ne, die han dann die Arbeet des Vereins in die Hände jenommen. Ja, su is das dann jelaufen, ne. ${ }^{280}$

Es zeigte sich, daß die Jugendlichen in Oeverich und Niederich nach 1945 wieder schnell zusammenfanden, um die Ausrichtung der Kirmes und der Maibräuche fortzusetzen. Die eindringlichen Appelle des Pastors Knopp, das Mailehen fallen zu lassen, beschäftigte die Nachkriegsgeneration nicht mehr. ${ }^{281}$ Ein Nachfolger, der die Pfarrei Leimersdorf von 1952 bis 1965 betreute, nahm dies zum Anlaß, den Kampf gegen den Brauch erneut aufzunehmen. Herr Stein erinnerte sich:

Da ha'm wir immer mit'm Pfarrer immer Jedön ${ }^{282}$ jehabt, ne.

Ärger gehabt.

Der war da strikt dagegen, ne. Un der is mal hier jewesen un hat hier jetobt, ne. Da hab ich dem die Satzungen vorjelesen: "Hier sehen se mal, Herr Pastor, das sind doch Satzungen, die fast hundert Jahre alt sind." [...] Un da hab ich dem die Satzungen da jejeben [...] Un da wollte der von mir, ich sollte dafür sorgen, daß dieser Unbrauch aufhören würde, ne. Na, damit ich ihn los würde, hab ich jesacht: "Herr Pastor, ich werd das den Junggesellen von Niederich un Öfferich sagen, daß das ihr Wunsch is, un dann müssen wir darüber abstimmen." - "Abstimmen!?", sagt der, ne. "Ja, wir leben jetzt in'ner Demokratie, da wird abgestimmt." - "Da gibt's nix abzustimmen. Das is genau wie auf'm Viehmarkt!" ne, der war oben von Polch auf'm Maifeld. Da kennt man den Brauch anscheinend net. [...] Un da hab ich dat denen jesacht: "Der war bei mir, der war recht grob zu mir, hat die Dür zujeschlagen, is rausjejangen." Da hab ich jesagt: "Jetzt müßt ihr entscheiden" ne, da ha'm die nur jelacht, ne. Da war der Fall erledigt. Et wurd wieder jesteigert. ${ }^{283}$

Herr Stein hob aber deutlich hervor, daß nicht alle Junggesellenvereine der Umgegend den Mut hatten, den Vorstellung damaliger Autoritäten zu trotzen:

In Birresdorf is ein Jahr die Versteigerung ausjefallen. Die hatten Angst damals vor'm Pastor. Dat war ja auch früher auf'm Land so: Der Pastor und der Lehrer, wenn die sagten: "Aachen liegt am Rhein", da war... kein Mensch hatte den Mut zu sagen: "Herr Lehrer, sie irren sich; Aachen liegt nicht am Rhein!"284

Diese Ausführungen erhalten durchaus Bestätigung in den Berichten weiterer Zeitzeugen. Dabei gewinnt man den Eindruck, als sei das Verhalten der Erwachsenen und die Erziehung der Jugendlichen bis in die 1950er Jahre hinein vom Normen- und Wertegefüge der Kirche und ihrer lokalen Würdenträger maßgeblich beeinflußt worden. Insbesondere was den Bereich intimer Beziehungen betraf, wurde sowohl die damalige Maßreglung als auch die Tabuisierung als besonders eklatant und als ungerechtfertigte Gängelung empfunden:

\footnotetext{
${ }^{280}$ Herr Stein (13/11/1a:452-550).

${ }^{281}$ Vgl. die ähnliche Situation in Nierendorf (Prothmann 1998:257, 269, 271, 273f und 292).

282"Jedön": Ärger.

${ }^{283}$ Herr Stein (13/11/1a:574-606).

${ }^{284}$ Herr Stein (13/11/1a:606-612).
} 
Frau Rosen: Es herrschte eine ganz strenge, fromme Erziehung. Wenn wir gesündigt hätten [unehelicher Geschlechtsverkehr], mußten wir da in dat Gitter [Beichtstuhl] kriechen, mußten bekennen - das is schwer.

Herr Marx: Es war ja auch die Kirche viel Schuld.

Frau Rosen: Die Kirche saß uns auch im Genick und die Eltern: "Wenn! Wenn! Wenn!" Da ging doch nur der Finger: "Wenn! Wenn! Wenn!" (drohende Handbewegung mit vorgestrecktem Zeigefinger) Das war Druck von allen Seiten. Da hatten wir doch Angst.

Also, geredet wurde schon auch darüber [voreheliche Sexualität]. Das wurde nicht totgeschwiegen?

Frau Rosen: Ja, sicher. Die Eltern hatten doch nur Angst vor Schande...

Frau Marx:...ach, was. Sex wurde totgeschwiegen. Nie wurde da ein Wort von gesagt.

Frau Rosen: "Wenn du mit'm Könd anjezore küß!"

Frau Marx: Das war es einzigste, aber... Also meine Mutter, die hat mir erzählt, daß der Vater sie nie nackend gesehen hätte. Da hab ich zu ihr jesagt: "Wie häst du dann die Könder met'm Bap jemaat?" Da hat die mich... bald keine Luft mehr gekriegt, daß ich wagte, so etwas zu erzählen, überhaupt zu fragen. Wir waren schon verheiratet und hatten Kinder, da sagte mein Vater zu meiner Mutter: "Lena, wie kannst du dat bei der Kinner sagen." [...] Also, das war Tabu. Sex war Tabu bei uns Zuhause. Ich habe nie gesehen, daß mein Vater meine Mutter mal umarmt hätte. Nie, nie.

Herr Marx: Ja, wir mußten ja auch Beichten gehen. Da ha'm wir schon wieder Angst vor'm Pastor. [...]

Frau Rosen: Un Kellers Gret sacht - da war ich jung verhirot - sacht sie: "Anna, ja, als jung Frau bichte joan, das is'e Problem."

Frau Marx: Das is wahr.

Frau Rosen: Et Buschs Antonie sacht, "Ich hann mir Strichelchje jemaat!" Die wollten ja och noch wissen, wie oft, wie oft jefusch wued. Wat woar dat dan, wat hat die dan für en Macht die Kirch? (leicht erregt)

Herr Marx: Ja, sicher.

Frau Marx: Und ich finde: Früher waren ja bei uns viele ältere Pastöre. Ich mein, die hätten sich immer nur in den Beichtstühlen aufjegeilt an diesen Erzählungen. ${ }^{285}$

Neben diesen so eindrücklichen wie leidvollen Erfahrungen einer strengen, repressiven Erziehung durch Pastoren, Lehrer und Eltern bestehen auf der anderen Seite die lebhaften Erinnerungen an Geselligkeit, Vergnügen, Tanz und jugendliche Ausgelassenheit. Unverhohlen forderten die Jugendlichen ihr Recht zum ausgelassenen Feiern schon in den ersten Nachkriegsjahren ein. Nachdem wieder ein vereinsmäßiger Status hergestellt worden war, aus dem die Friedlichkeit und der allgemeine Nutzen der Gesellung hervorging, stand von offizieller Seite der Wiederbelebung der Kirmesfeierlichkeiten und des dazugehörigen Brauchgeschehens nichts mehr im Wege. Gerade diese Phase des Wiederaufbaus ist den damals Beteiligten noch deutlich im Gedächtnis geblieben:

${ }^{285}$ Gruppengespräch I (39/23-27/2b:41-105). 
Herr Marx: Bei uns fing et [das Mailehen] ja wieder an. Das war ja mal weg. Im Krieg war ja nix. Dann fing et wieder an...

Frau Rosen:...wir waren voller Übermut.

Herr Marx: Pioniere waren mir. [...] Der Vorgang [die Ausübung des Brauches], der war ja am Ende. Durch den Krieg war alles am Ende. Un da sind wir wieder hin un ha'm wieder anjefange '46. Da ging es wieder langsam aufwärts. Das waren - ja, wieviel Jungjeselle waren da? Zehn, zwölf...

Frau Rosen:...so, da muß ich noch wat ergänzend sagen zu dem Maikönigsklied, -kleid, dat is ja heut...

Herr Marx:...häste dat noch? Vielleicht sinn meine Fingerabdrücke noch drauf?

Frau Rosen:...ich hab noch Bilder davon; das hat mich einen Sack Weizen gekostet, der Stoff. Un wir sind nach Fritzdorf gefahren. Da war so ein Bauersmann, der mäkelte so was und hatte da so jemanden an der Hand. Un dann hab ich dann dieses Stück Stoff bekommen. Ich weiß, daß es ein dunkelblauer grober Stoff war - nicht feine Seide, wie heute die Prinzessinnen anjezogen sinn auf'm Wagen. Dann hat meine Näherin hier ein ganz breites Band gemacht, und dann wurde alles weiß gestickt. Und hier die Ärmel so en Karo hier rein, alles mit weißen Blumen - es war wunderschön, nur vom Stoff her nicht so schön. Es war aber wunderschön gearbeitet. Und da war man doch so selig damit. Das Kleid mußte ja auch noch "hinjemaggelt" werden, daß ich noch en würdiges Kleid hatte zu dem Tag. ${ }^{286}$

In einer weiteren Passage heißt es:

Frau Marx: Überhaupt war dat nach dem Krieg, war man ja richtig süchtig nach Musik, nach Rausgehen, Alkohol - selbstjemacht, jebrannt...

Herr Marx:...ha'm mir mit auf den Saal jenomme [...]

Frau Rosen: Ich erzähl jetzt mal meine Bekanntschaft mit der ersten Musik. Ich bin '39 aus der Schul jekommen und '44 fiel mein Bruder. Un da mußt ich ein Jahr Trauer tragen und noch sechs Wochen. Das war bis '45 im August. Und dann bin ich '39 aus der Schule gekommen un '46 [im Alter von 22 Jahren] das erste Mal nach Fritzdorf auf die Musik. Fastnach. Un da han ich jedaach, die janze Welt is verrück. Ich han mich überhaupt nich wohljefühlt - war mir idiotisch. Un das war eine Fülle, ein Andrang [von Leuten]; wie sie jetzt sachte, wie süchtig alle nach Musik un nach Zerstreuung un so was waren. Wir hatten ja Nachholbedarf. - Un was haben die Leute heute schon erlebt, die in der Zeit jung sind? Und für uns war gar nichts da.

Frau Marx: Das kann man wohl sagen. 287

Die Gespräche zur unmittelbaren Nachkriegssituation konzentrierten sich im wesentlichen auf drei Gesichtspunkte, die nicht nur das allgemeine Lebensgefühl, sondern auch die Art und Weise der Brauchdurchführung prägten. Die besondere Schwierigkeit lag in dieser Zeit darin, daß die vielfach erlittene Zerstörung, Armut und Not, daß die teilweise überkommenen, rigiden Werte-, Normen- und autoritären Erziehungsmuster mit den persönlichen Bedürfnissen und Erwartungen der Jugendlichen in einem spannungsgeladenen Gegensatz zueinander standen. Während der Kriegsjahre waren Tanzveranstaltungen offiziell untersagt. Auch danach hielt eine entbehrungsreiche Zeit an. Die Landbevölkerung schien in der

${ }^{286}$ Gruppengespräch I (38/23-27/1b:114-171). Vgl. auch die Ausführungen von Herrn Stein (13/11/1b:213-240).

${ }^{287}$ Gruppengespräch I (38/23-27/1a:76-105). 
Nahrungsbeschaffung immerhin noch gegenüber der Hunger leidenden Stadtbevölkerung begünstigt. Die Knappheit der Lebensmittel ließ den Schwarzhandel blühen und trug dem ein oder anderen Bauern Vorteile ein. Aber die scharfen Kontrollen der Militärregierung und die Zwangsabgaben von Naturalien an die behördlichen Stellen standen den illegalen Auswüchsen entgegen. Frau Rosen, Herr und Frau Marx, Herr und Frau Schmitz und Herr Stein haben betont, daß zu dieser Zeit ein hohes Maß an Durchhaltevermögen, "Pioniergeist", Einfallsreichtum und Genügsamkeit gefordert war. In der trostlosen Nachkriegssituation, welche die Folge eines politisch, ökonomisch wie auch sozial zerrütteten Landes war, ließen sich dennoch Perspektiven entwickeln, die den damals Zwanzigjährigen Mut und Kraft gaben, einerseits ihren schwierigen Alltag $\mathrm{zu}$ bestehen, andererseits ihre vorhandenen Bedürfnisse nach Zerstreuung, nach Ausgelassenheit und Selbstdarstellung oder nach Vergnügen und Freude zu stillen. Der Brauch des Mailehens und die mit ihm verbundene Maikirmes boten hierzu eine willkommene Gelegenheit. Bereits 1946 regierte eine zweiundzwanzigjährige Maikönigin an der Seite ihres fünf Jahre älteren Maikönigs für die Dauer der Kirmes. Eindrücklich haben die Betroffenen geschildert, wie sie unter erschwerten Bedingungen versucht hätten, die Erwartungen an ein würdiges Festbegehen zu erfüllen. Mühevoll wurde die festliche und kostspielige Kleidung erstanden. Ferner stammte ein hoher Anteil der alkoholischen Getränke, die auf einer zünftigen Kirmes nicht fehlen durften, aus eigener Produktion. Schnäpse und Weine wurden von den Gästen zum Tanz mit ins Wirtshaus gebracht. Für jede mitgebrachte und geleerte Flasche erhielt der Wirt das sogenannte "Stoppejeld". Der Tanzgroschen, den die Tanzwilligen $\mathrm{zu}$ entrichten hatten, ging dagegen an die Junggesellen. ${ }^{288}$

Angesichts von Äußerungen darüber, daß unglaubliche Mengen an Alkohol vertilgt, daß ganze Nächte im Tanzsaal und bei Freunden zugebracht worden seien oder daß man die verrücktesten Streiche gespielt habe, tritt das Bild von der sorgenerfüllten, bleiernen Nachkriegszeit in den Hintergrund. Dort, wo es relativ gefahrlos möglich schien, wurden selbst die französischen Besatzer zur Zielscheibe ausgelassenen Spotts. Detailliert schildert Herr Stein die Lust an den teils hintersinnig konterkarierenden Eskapaden:

Ja, dann kamen dann die ersten Tanzveranstaltungen - mußte man och widder jenehmijen lassen durch die Militärrejierung. Da kamen die kontrollieren, ne, ob alles nich militärisch zujing, ne. Da hatten wir hier ne Musikkapelle, vun Unkelbach war die, un die spielten damals die erste Jazzmusik, ne. Bis dahin war ja alles Blasmusik of'm Land, ne. Un die spielten schon mal Jazzmusik. Un dann hann die - z.B. wenn die Stimmung gut war, et ging so gejen Mitternacht oder noch was später - dann hann die Nationalhymne oder "Die Fahne hoch", dat NSLied, ne, hann die dann immer Jazz jespielt un dann so im Jazz-Ton jespielt un dann immer widder so'ne Ruck dadrin, ne. Allerdings da durften keine Franzosen da sein. Da standen en paar Mann an der Saaltür un hann ofjepaß. Aber dat war kein, sage mal... dat war mehr en

${ }^{288}$ Gruppengespräch I (39/23-27/1a:636-648). Vgl. auch Prothmann (1989:40). 
Spaß, ne. Dat war verboten, ne. Un alles, was verboten is, macht ja im Grund jenommen in etwa Spaß. ${ }^{289}$

Das Streben der Jugendlichen aus dem strengen Werte- und Normensystem auszubrechen, schien das soziale Gleichgewicht zwar zu strapazieren, aber doch nicht nachhaltig zu mißachten oder ernsthaft zu gefährden. "Auf jeden Fall war mir kein Fenster zu hoch, daraus zu klettern", 290 so beschrieb Frau Marx eindrücklich ihre Flucht aus der Enge der elterlichen Gewalt und der Begrenztheit eines als autoritär empfundenen Ordnungsgefüges. Obwohl das von den Eltern verhängte Ausgehverbot umgangen worden ist, indem man unbemerkt aus der Wohnung schlich und so dem elterlichen Zugriff entwischte und obwohl bei den Kirmesfeiern die Nacht zum Tag gemacht wurde, ${ }^{291}$ erinnerte Frau Rosen daran, daß man die geltenden Pflichten anderntags trotzdem zu erfüllen hatte:

Es war eijentlich unerläßlich: man konnte gefeiert haben wie man wollte, man mußte montags früh in der Kirche sein. ... Ich moot och drin john, ejal ob der Kopp weh tat, oder wat. ${ }^{292}$

Die Beispiele zeigen, daß in der Brauchpraxis manche Grenzüberschreitung der Heranwachsenden von den Eltern geduldet wurde. Jugendliche Streiche, Alkoholkonsum oder freizügiger Ausgang eröffneten Freiräume, die im Mailehen geschaffen wurden und die das im Alltag bestehende Normen- und Wertgefüge regelrecht flexibilisierten. Tabu blieb für die Mailehenpaare allerdings der Bereich der vorehelichen Intimität. ${ }^{293}$ Die Brauchtreibenden fügten sich offensichtlich diesen Konventionen, sie waren aber nicht dazu bereit, den kirchlichen Maßstäben von Sittlichkeit gerecht zu werden. Die damals Betroffenen erklärten dazu, daß die Akzeptanz der Brauchausübung eher von der Persönlichkeit und dem "Gusto" der klerikalen Brauchgegner abhing als von der Substanz des Vorwurfs der Verwerflichkeit oder Verderbtheit des jugendlichen Treibens. ${ }^{294}$ In schonungslosen Urteilen der Nachkriegsgeneration sind die betreffenden Dorfautoritäten in die Nähe boshafter Militaristen gerückt worden, während gleichzeitig wohlwollend über die Lockerungen der heutigen Zeit im Bereich von Kirche, Schule und Erziehung gesprochen wurde. ${ }^{295}$ Damit zeigten die älteren GesprächspartnerInnen durchaus ein breites Verständnis für die Möglichkeiten, die von den heutigen Jugendlichen zur persönlichen Entfaltung

\footnotetext{
${ }^{289}$ Herr Stein (13/11/1a:550-574).

${ }^{290}$ Gruppengespräch I (39/23-27/2a:704-714).

291"Mir hann immer nach dem Grundsatz jehandelt: 'Anständije Mensche jehn im Hellen nach Hause'", so Frau Rosen, Gruppeninterview I (39/23-27/2a:691ff). Dieselbe Maxime nimmt die etwa 40 Jahre jüngere Frau Kruse (25/17/1a:207-213) für sich in Anspruch: "Unser Motto is ja Kirmes immer: 'Anständige Leute kommen im Hellen nach Hause!'"

${ }^{292}$ Frau Rosen (39/23-27/2b:340-345).

${ }^{293}$ Gruppengespräch I (39/23-27/2b:465-478); vgl. Kapitel 4.4.1.3.

${ }^{294}$ Herr Stein (13/11/1b:365-410). Siehe auch Kapitel 4.4.2.1.

${ }^{295}$ Gruppengespräch I (39/23-27/2a:41-570), Herr Stein (15/11/3a:100-170).
} 
ergriffen werden können und die in der veränderten Mailehenpraxis auch beobachtet werden konnten.

\subsubsection{Modernes Brauchmanagement (1960-1995)}

In der ersten Hälfte der 1960er Jahre erlahmte das Vereinsgeschehen. Zwischen 1962 und 1967 kamen keine Maikönigspaare zustande. Die genauen Hintergründe, die zum Zusammenbruch führten, konnten von den Befragten nicht mehr angegeben werden. Deshalb ist die Rede von einem allgemeinen Desinteresse der Junggesellen oder von vereinsinternen Zwistigkeiten. Seit 1966 haben sich die Oevericher Junggesellen aber dem Mailehen und der Maikirmes mit großem Erfolg zugewandt. Man paßte einzelne Brauchformen und die Feierlichkeiten den Verhältnissen und Bedürfnissen der Zeit an. Formale Aspekte, z.B. Veranstaltungsort und -termin, blieben hiervon ebensowenig unberührt wie die effektive und straffe Kirmesgestaltung. Mittels der professionellen Organisation des jährlich wiederkehrenden Dorffestes hatte der Verein sich eine gewinnbringende Geldquelle erschlossen. Somit konnten die Burschen anfangs kleinere Tagestouren und später sogar Flugreisen (teilweise) mit Vereinsmitteln finanzieren. Mit einer Terminveränderung entsprach man dem Trend, die Haupttanzveranstaltung auf den Samstagabend zu verlegen. Von nun an wurde das große Festzelt, das ausschließlich für die Dauer der Kirmes in Oeverich aufgeschlagen wurde, zum zentralen Ort des Geschehens. In guten Zeiten hielten sich im Zelt über 500 Gäste auf. Bis zu 600 Eintrittskarten konnten die Junggesellen für den großen Kirmesball am Samstagabend verkaufen. Nach 23.00 Uhr erhielten weitere Besucher freien Eintritt. Im Rahmen der Gesprächsrunde der Junggesellengeneration von 1966 herrschte Einigkeit darüber, daß die Kirmes von damals in der Umgebung als etwas Besonderes galt:

Herr Keller: Es wurd immer gesagt: "Die Oevverijer Kirmes ist die beste Kirmes in de janze Jäjend!"

Herr Kastner: War die och weit'erum. Da hatte sich einfach so einjebürjert, dat... Ich weiß et och net, woher dat kommt.

Herr Fischer: Auf 300 Einwohner waren dat 600 Jäste dadrinne [im Zelt].

Herr Böhm: So unjefähr.

Herr Kastner: Da kamen och die ganzen Birresdorfer. Ich kann mich noch erinnern, die janze junge Mädcher von Birresdorf, die waren doch all hier of de Kirmes. Die waren alle da. Heute siehst du keine mehr.

Herr Keller: Von der Ahr...

Herr Böhm:...Neuenahr, Ahrweiler kommen se. Von Karwiler kom en janze Hoofe.

Herr Hagen: Villip, die janze Eck.

Herr Böhm: Fritzdorp, Villip, jenau, aus der Kant koamen vill, ne. 
Herr Keller: Mir hatten doch Schausteller, [...] zehn Bude, manchmal noch miehte ${ }^{296}$, dat Karussell. Un hök? Weiowei, wenn de Maie net im Dorp jestanne hättn, hätt man jemäant et wär kein Kirmes. ${ }^{297}$

In den 1970er Jahren blühte die Popmusik auf und mit ihr verbreiteten sich die bei den Jugendlichen beliebten Diskoabende auf dem Land, so daß eine derartige Veranstaltung seit 1974 in Oeverich zum Kirmesprogramm gehört. Der Freitagabend wurde speziell für die Dorfjugend zu einem besonderen Ereignis, denn ein professioneller Discjockey ("DJ") sorgte für aktuelle Tanzrhythmen. Unversehens hatte sich die Kirmes zu einem viertägig gut besuchten Lokalereignis entfaltet. Die Oevericher Kirmes war zeitweise weit über die Gemeindegrenzen bekannt. Gerne erinnerten sich die heute Fünfzigjährigen an die damalige Popularität und Beliebtheit der Kirmes und bemerkten gleichzeitig unter Anerkennung der Bemühungen der aktiven Vereinsmitglieder, daß die gegenwärtigen Flauten bei Kirmesveranstaltungen nur schwerlich überwunden werden könnten, weil die Konkurrenz durch den modernen Diskothekenbetrieb zu hart sei. ${ }^{298}$

Während die Nachkriegsgeneration gewissermaßen die Unantastbarkeit einer genuinen Mailehenversteigerung ins Feld führte und mit dem Bewußtsein einer langjährigen Tradition gegen die Bedrohung des Brauches durch die Kirche ankämpfte (s.o.), so verfuhr man zum Ende der sechziger Jahre recht unorthodox mit überlieferten rituellen Verfahrensregeln. Der Versteigerungsmodus wurde von einer sogenannten amerikanischen auf die reguläre Form umgewandelt. Das bedeutete, daß von nun an nur noch das abgegebene Höchstgebot vom Steigernden zu entrichten war. ${ }^{299} \mathrm{Da}$ die Bereitschaft unter den Junggesellen gesunken war, die Pflichten des Maikönigamts auf sich zu nehmen, erlahmte das gegenseitige Hochtreiben der Gebote und machte die Mailehenversteigerung $\mathrm{zu}$ einem zähen, finanziell uninteressanten Geschäft. Aus Angst vor einem zu hohen Zuschlag und der daraus resultierenden Gefahr, Maikönig zu werden, fielen die Steigerungsbeträge immer niedriger aus. Hieraus entwickelte sich die Idee, den Maikönigstitel separat zu versteigern:

Herr Keller: Noher is nimmie jebodde wurde. Doa ha'm mir jesagt, mir don iascht de Maikönig steijere un dann wierd hernoah ne janz annere Summ erennjesteijert.

Herr Kastner: Ja, janz ienau. Es och su jewese, weil keiner de Maikönig mehr mache wollte.

296"miehte": mehr.

${ }^{297}$ Gruppengespräch II (48/33-37/1a:505-519), vgl. (48/33-37/2a:544-660), Herr Lange (29/19/2a:498-546), Herr Beck (08/08/1a:483-568 und 1b:325-436).

${ }^{298}$ Gruppengespräch II (49/33-37/2a:626-639). Vgl. (49/33-37/3b:647-660 und 4a:378-397).

${ }^{299} \mathrm{Im}$ Rahmen der amerikanischen Versteigerung ist jedes Gebot unmittelbar mit einer Zahlung in die Kasse verbunden. Dabei erhöht sich der Betrag bei jedem Gebot um einen festgelegten Mindestbetrag. Allen Mitsteigernden entstehen somit Kosten, obwohl letztlich nur einer den Zuschlag erhalten kann. 
Herr Keller: Ja, ja. Un dou kunn nämlich sinn, dat de Maikönig vielliech fuffzig Mark ze bezahle hatt un die Teuerste [unter den ersteigerten Mailehenkandidatinnen] sechs, siebbe hunnert Mark. ${ }^{300}$

Doch einige Zeit später war der Junggesellenverein erneut mit dem Problem konfrontiert, daß sich nur mühsam Mitglieder zur Ersteigerung des Maikönigstitels bewegen ließen. Mit dem sogenannten "Bier op de Maikönig" richtete der Verein eine Art Solidarfonds ein. Spendierwillige Mitstreiter legten während der Versteigerung einen unbestimmten Betrag zusammen, der als finanzieller Ausgleich für einen Teil der Kosten gelten sollte. Dabei ging man davon aus, daß potentielle Titelanwärter sich nicht durch hohe Ausgaben, die bei der Ausübung des hohen Repräsentationsamtes gewöhnlich anfielen, von ihrem Ziel, Maikönig zu werden, abhalten lassen sollten. Hierzu Herr Goltz:

Et sinn at Joahre jeweas, da joaf ${ }^{301}$ et kene ze kreje, ne, der dat maache soallt. Da is ene hinjejange: "Jod, ${ }^{302}$ wenn du Maikönig wirst, dann kriste vun mir fuffzehn Litte Bier!" Kütt de nächste: "Vun mir kriste zwanzig Litte Bier!" - "Vun mir kriste zehn Litte Bier!" - "Vun mir kriste drißig!" - "Vun mir kriste fuffzig!" - "Un vun mir kriste dat un dat!" Dat wier ofjeschrivve. Sounsoviel Litte Bier vun demm un demm. Un da hiesch et noahher: "Ja, et sinn at hunnertfuffzig Litte Bier jebodde für dejenije, de Maikönig wird." Jod, dat der dat Bier net all drinke kann, dat es wohl kloar. Da hiesch et noahher, ja, fuffzig Litte Bier, de Litte dumols zwei Mark, hätt'sch hunnert Mark jenn. Da jing et nur um et Jeld, verstehste.

Wann war dat?

[...] Mitte der achzijer Jahre es dat kunn, wo die da och jet jebodde - heut waaden ja verschiedene droop, verstehste. [...] Hök hann ich baal dat Jeföhl, dat da verschiedene saren:303 "Weeßte wat, da lasse ma heut abend... wenn jenooch Bier kütt, da maachen ich dat", verstehste.

Un am Anfang wurd auch wirklich noch Bier jejenn?

Nä, wurd immer in Jeld umjerechnet. Das is richtig. - Jod, der Maikönig hätt och immer noch jet ijenn ${ }^{304}$. Wenn et Zelt affjebout wued, da hätt de Maikönig ze Esse holle. Dat heescht, wat jegrillt wued, bezahlt de Maikönig. Hätt jenoch afjesahnt, da kann'n jet bezahle, oder net? Woar vürher äwwer och su, woll'mer su sare. Die Maikönijin joaf dann jet de iaschte Mai, un de Maikönig joaf dann jet beim Zeltafbaue nur vereinintern. So is es jewesen. ${ }^{305}$

Das "Bier op de Maikönig" hat sich einerseits bewährt. Es entwickelte sich zu einem verlockenden Angebot, das dazu geführt hat, daß die Maikönige sich inzwischen finanziell erheblich besser stellen als in früheren Jahren. Andererseits ließen sich die Hemmungen der Vereinsangehörigen bei der Bestimmung des Maikönigs selbst mit Geld nicht immer kompensieren.

\footnotetext{
${ }^{300}$ Gruppengespräch II (48/33/1b:599-609).

301 "joaf": gab.

302"jod" (auch "juut" oder "joot"): gut.

303"hök": heute; "saren": sagen.

304"jet ijenn": etwas (aus-)gegeben.

${ }^{305}$ Herr Goltz (20/13/2a:90-139).
} 
Veränderungen bei der technischen Realisierung der Maibräuche wurden insbesondere von den älteren Informanten genannt. Die Maien seien damals mit der Axt geschlagen und anschließend auf den Schultern vom Wald in den Ort geschleppt worden. ${ }^{306}$ Mit den Innovationen in der Landwirtschaft oder auch im Handwerk ging gleichzeitig eine Modernisierung des Maibaumsetzens einher. Traktoren, Baumaschinen und Motorsägen erledigen heutzutage relativ schnell und mühelos die Arbeit, die Jahrzehnte zuvor hohen körperlichen Einsatz der Junggesellen erforderte. Die voranschreitende Technisierung brachte der Autor der eingangs erwähnten Vereinsfestschrift mit einem Verlust dörflichen Kulturguts in folgenden Zusammenhang:

"Das Aufrichten des Maibaumes geschah bis Anfang der 70er Jahre nach Altvätersitte mit Hilfe von Leitern und Seilen. [...] Um 1973 kam man auf die Idee, diese mühselige und gewiß nicht ungefährliche Arbeit mit Hilfe eines am Traktor befestigten Frontladers auszuführen. [...] Der ganze Vorgang dauert kaum zehn Minuten. Wer einmal die herkömmliche Art des Aufsetzens mitgemacht hat, ist erstaunt, wie spielerisch leicht ein Traktor diese Arbeit schafft. Ginge es nur um das möglichst schnelle Aufrichten des Baumes, wäre dieses Verfahren unbedingt vorzuziehen. Damit aber wird ein wesentlicher Bestandteil dieses Brauches aufgegeben. Wie beeindruckend ist es dagegen mitanzusehen, wie eine Schar von Junggesellen mit vereinten Kräften und nur wenigen Hilfsmitteln einen solchen mächtigen Stamm hochstemmt" (Prothmann 1989:77f).

In den Erhebungsgesprächen teilten die Befragten diese Sicht nicht. Auch gegenüber inhaltlichen Veränderungen oder Verfremdungen der vorhandenen Brauchformen erhoben sich kaum Bedenken. Gelegentlich brachten die BrauchträgerInnen "neue" rituelle Handlungen in die Mailehenpraxis ein oder sie reaktivierten bereits verschwundene Brauchelemente. In Anlehnung an bereits bekannte Brauchformen wiesen die Implemente häufig konservative Züge des Althergebrachten auf. Das Aufnahmeritual der neuen Vereinsmitglieder ist hierfür ein Beispiel. ${ }^{307}$ Es wurde zu Beginn der 1970er Jahre eingeführt und gilt heute als etablierte Brauchform. Indessen ist der sogenannte "Maibutz" eine Neuerung im Oevericher Brauchgeschehen, die sich nicht auf lokale Traditionen zurückführen läßt. Es handelt sich hierbei um den Kuß des Maikönigspaares als ein öffentlich vollzogenes Ritual. ${ }^{308}$ Während manche Brauchelemente im Laufe der Zeit in Vergessenheit gerieten, wurden andere nicht nur wieder hervorgeholt, sondern auch zunehmend fortentwickelt. Für letzteres spricht die lebensgroße Strohpuppe, die den Kirmesmann bzw. den sogenannten "Zacheies" darstellt und die gewöhnlich bei der offiziellen Beendigung des Festes ein tragisches Ende nimmt. In den 1920er und 1930er Jahren zogen die Junggesellen am letzten Kirmestag mit dem Zachaies durch den Ort und unterwarfen ihn einer

${ }^{306}$ Der Schandmaien wurde nur ein einziges Mal thematisiert, um sogleich seine Bedeutungslosigkeit für das Oevericher Mailehen herauszustellen (Gruppengespräch I 39/23-27/2b:640-652).

${ }^{307}$ Eine detaillierte Beschreibung des Vorganges findet sich in Kap. 4.3.3.

${ }^{308}$ Zum Maibutz siehe unten Kapitel 4.3.5. 
Gerichtsverhandlung, die regelmäßig mit einem Todesurteil endete. Wenn auch in anderer Form, so bestand schon damals der rituelle Abschluß der Maikirmes darin, daß man den Kirmesmann verbrannte. Nach 1945 war diese Figur zunächst aus dem Brauchgeschehen verschwunden, bis sie 1974 neuen Anklang bei den Junggesellen und dem Kirmespublikum fand. Inzwischen gehört die Kirmesmannverbrennung zu einem Ritual mit einer eigenen lokalspezifischen Ausprägung. Die traditionelle Gerichtsverhandlung, bei der gewöhnlich alle im Dorf bekannt gewordenen Schandtaten des Vorjahres dem "Delinquenten" zur Last gelegt werden, wurde ersetzt durch eine markante Bestattungs- und Trauerzeremonie. 309

Der Kommabend konnte sich dagegen in den letzten dreißig Jahren nicht halten. Anfangs machten die Junggesellen von 1966 noch einige Versuche, die von Vorgängern praktizierte wöchentliche Besuchspflicht fortzuführen. Es scheint jedoch so, als habe es unter den Mailehenpaaren zuwenig Zuspruch zu solchen Treffen gegeben. Herr und Frau Beck haben diese Schwierigkeit folgendermaßen geschildert:

Herr Beck: Als wir noch gesteigert haben, da mußte man ja auch donnerstags zu der Mailiehen hingehen. Das ist ja weitgehend auch jetzt gestorben. Das ist ja auch nicht mehr der Fall. Und wer da nicht erschien, der mußte auch ne Strafe bezahlen. Also da wurde jemand beauftragt, der mußte da Kontrolle gehen abends, nicht, und sehen, ob der nun auch ins Haus rein ging oder nicht.

Frau Beck: Oh, is ne blöde Sitte.

Herr Beck: Ja, nun das war eben so - und ich fand das ganz gut. Und wer das nicht gemacht hat, der mußte fünf Mark - oder so - bezahlen. Aber die meisten gingen ja viel zu gern, weil es da ja immer was zu trinken gab.

$J a$, Sie fanden das ganz gut - daß der Junge das Mädchen besuchen mußte.

Herr Beck: Ja, ich find das aus dem Grund schon mal gut, dann konnte man sich doch en bißjen mehr kennenlernen. Heute sieht man sich doch nur an dieser Kirmes, speziell bei dem Festumzug noch. So und dann is Schluß. Un hier: Dann waren (je nach dem, wenn die Kirmes jetzt Ende des Maies war) dann waren drei oder vier Tage (oder jetzt Donnerstag war das denn der spezielle Tag), wo man sich vorher auch schon mal gesehen hat. Und man konnte doch sich en bißjen näher kennenlernen. Man konnte schon mal über die Kirmes reden; oder, wenn auch andere Interessen vorlagen, konnte man dadrübber... Aus dem Grunde finde ich dat schon mal gut. Und je nachdem, wo man jetzt hinkam, wie schon gesagt, da gab es auch immer einiges zu trinken, nicht. Un dat war ja damals auch ne Zeit, da hatte man auch nicht das Kleingeld so, wie die heute das haben, ne. Daß man da schon mal in die Wirtschaft gehen konnte, das war weitgehends auch nicht der Fall. Aus dem Grunde finde ich das gut. [...]

Frau Beck: Aber dieser Kommabend, der hat doch nix gebracht...

Herr Beck: Warum nicht?

Frau Beck: Als der Alfons kam, der war dermaßen schüchtern. Ich glaub, der war immer froh, wenn der Abend wieder vorbei war.

Hat'er dauernd auf die Uhr geguckt?

Frau Beck: Ja, so ungefähr.

${ }^{309}$ Zur Kirmesmannverbrennung siehe Kapitel 4.3.5. 
Eine Stunde war das, ne?

Frau Beck: Das weiß ich garnicht genau, wie dat war.

Herr Beck: Voraussetzung oder überhaupt Pflicht war, daß man überaupt da hinging. Wielange man sich jetzt da aufhielt, das entzieht sich auch meiner Kenntnis jetzt, nicht. Aber das kam ja meistens so, wenn da die zwei en bißjen zusammengepaßt oder harmoniert hann, dann kann ich mir vorstellen, dann hat der Abend länger gedauert, nicht.

Frau Beck: Ja, ja. Das is wahr. Hing auch en bißchen davon ab, was man da für ein Mailehen hat, stimmt. ${ }^{310}$

Das Verschwinden des Kommabends vor etwa dreißig Jahren markierte den Ausgangspunkt für einen allgemeinen Rückgang von Kontakten zwischen den Mailehenpaaren. Formelle Gelegenheiten sich zu treffen, haben sich gegenwärtig auf den Festumzug am Kirmessonntag reduziert. Es war üblich, daß die Mailehen zu diesem Anlaß zu Hause von ihren Ersteigerern abgeholt wurden. Doch diese Bereitschaft verliert anscheinend an Verbindlichkeit ebenso wie die ehemals selbstverständliche Aufforderung zum gemeinsamen Tanz. In den Reminiszenzen der Älteren offenbarte sich das Bedauern über diese Entwicklung, aber auch die Jüngeren äußerten zu diesem Punkt Kritik.

Neben dem allmählich sich vollziehenden Formenwandel, wie er hier zum Ausdruck gekommen ist, gab es aber auch Veränderungen, in denen der Gestaltungswille der Beteiligten unmittelbar erkennbar wurde. Insbesondere die Frauen setzten sich aktiv für eine Belebung des Mailehens ein. Zunächst gelang es denjenigen Frauen, die mit den sogenannten Maimüttern (die Mütter der jeweils herrschenden Maikönigspaare) in Verbindung standen, einen völlig neuen rituellen Raum zu schaffen. Es wurde mitgeteilt, daß aus einer spontanen Idee, sich $\mathrm{zu}$ verabreden, sich $\mathrm{zu}$ treffen, gemeinsam etwas zu unternehmen, gemeinsam zu feiern und die Aktionen jeweils unter ein Thema/Motto zu stellen, sich die rituelle Form des Maimüttertreffens entwickelte. Eine aktive Maimutter, Frau Heuerdorf, berichtete:

Frau Heuerdorf, Sie erzählten noch mit den Frauen so, daß Sie sich da noch mal so zusammentreffen...

...montags?

...und was machen. - Ja.

Mhm. Ja dat ham...

...wie regelmäßig is das denn oder was hat es damit auf sich? Was unternehmen die Frauen denn so...

...nä, net rejelmäßig!

$J a$, jetz, jetz...

...nur Kirmes.

Ja, mein' ich ja.

${ }^{310}$ Frau und Herr Beck (08/8/2b:562-622). 
Ja, Kirmes, dann gehn mer... Dieses Jahr waren mer denn bej der Maikönigmutter. Ich hätt' et auch hier machen können, ne, [Frau Heuerdorf war zum betreffenden Zeitpunkt die "Maiköniginmutter"], aber die hatte sich da angeboten, un da han ich jedaach, da gibste im Zelt eine aus. Dat moß mer joa, ne.

Mhm, dat is so üblich auch?

Dat is so üblich. Un dann, mir gehen dann... Montags tun mir uns dann irjendwo treffen: montags, mittags um 11:00 Uhr, nur Frauen!

Un das is'n ganz harter Kern, oder sin das immer wieder andere, oder kommen auch schon mal nеuе dazu...

...nä, dat is... kommen auch schon mal neue dazu, ne. Also dat sin net immer dieselbe. Dat sin... meistens sin mir so mit 15, 18, 20 "Mann". Un dann tun mir irjendwo... Dat is dann wat abwechselnd, dat wird vorher abjesprochen: du machs Kaffee, mir jin bej dir oder mir kommen bej dich, un dann wird da wat jejessen. Un dann machen mir dann so'n... Dieses Jahr han mir zwei Fahnen jekrich, die Maimutter, von dem König die Mutter und von der Königin die Mutter. Vorne sin mir met der Fahne jegangen un die anderen Frauen dann hinterher, ne. Un dann gehn mir rund dur'jet Dorf un singen wat, un dann gehn mir ent Zelt. Joa, un dann trinke mir dann wat da, so bis um drei, halb vier [15:00-15:30 Uhr], un dann jeht der eine dann, der eine jeht Kuchen holen, der andere jeht Kaffee holen, der andere Schnittchen holen oder der andere kocht Eier, je nach dem. Ja, un dann trinke'mer jemütlich Kaffee, un dann trinke'mer noch eine un tanzen noch, un dann is ja dann Musig schon. Mir ham ja dann en Alleinunterhalter un tanzen wat unternander, wenn keine Männer da sin, ne. Un dann bis abends, meistens sieben, halb acht oder acht, je nach dem, ne, jehn mer dann nach Hause, ziehen uns schnell wat anderes an un dann jeht et widde ab. - Dat is schön!

Dat is aber nur an dem Montag.

Nur an dem Montag, mhm. [...]

Un dat is jetzt mittlerweile auch schon richtig fest etabliert?

Also dat is Montag... Also Montag is der, sar'ich immer, schönste Tag!

Mhm. Un seit wann wird dat jemacht?

Mit den Frauen?

$J a$.

Sechs, sieben Jahr? So jenau weiß ich dat och net. Joa, sechs, sieben Jahr awwer bestimmt. Wir haben et awwer och schon mal so jemacht: Et hät jemand en Traktor jeholt, ne, un dann hät der uns m'em Traktor abjeholt. Also hier, mir ham uns dann hier irjendwo jetroffen, un dann sin mir met der Leiter of de Traktor jeklettert, of de Anhänger met zwanzig "Mann". Un dann sin mer dann durch Oeverich jefahren nach Leimersdorf, da is ja och ne Wirtschaf, un han uns da wat ze essen... ha'mer dann en Suppe jejessen. [...] Ja, dat is ja dat Jaudi: dann met der Leiter von der Kaar widde runter, ne. Un dann sin mer dann da en de Wirtschaft jejangen, han mer wat jejessen, jetrunken und dann sin'mer widder met der Kaar widde hee noa Oevverich jefahren un dann en'et Zelt, ne.

War dat auch so'n Montag, so'n Kirmesmontag?

Dat woar och'n Kirmesmontag, mhm.

Ah, ja. Da wird sich also immer wieder was ausgedacht.

...immer wat ausgedacht. Un vorjes'Jahr da sin'mer... wat hatte'mer dann vorjes'Jahr an? Dies Jahr hatte'mer uns janz normal an. Vorjes'Jahr hatte'mer, glaub ich, alle bunte Röcke an un weiße Blusen. Jahre davor, ich weiß aber jetz net wat für'n Jahr, da han mir uns all als "Wandersmann" anjezore, ne: richtije Wanderschuhe, so'n Knickerbocker, dicke Strümpfe, Rucksack ov'n Rücken. Un dann ha'mer uns in dem Rucksack, ham'er uns ze Trinken, ze Essen 
mitjenommen. Un dann ha'mer uns, in Niederich woar doa so'n kleines Häusjen, da ha'mer uns dann in dat Häusjen jesetzt, un han dann jetrunken un jejessen, en Stunde oder zwei, un sin dann en't Zelt jejangen mit den Klamotten äwwer, ne. Un dann woar och einmal ein Jahr, dat weiß ich, doa woar eine Frau, die woar sehr, sehr sparsam, un dat wußte mir, ne. Un da han'mir jesacht: "Mir kommen Kirmes ze dir Kaffee trinke." Un dat woar ihr gar net recht, mit zwanzig "Mann". Un dat han mir dann owwer och jemacht, ne. Da han mir uns an dem Zelt jetroffen... Nä, mir sin erst in et Zelt jejangen, so. Un dann sin mir so um drei Uhr [15:00 Uhr] sin mir dann met dem janzen Zug sin mir dann bej die Frau Kaffeetrinken jegangen, ne. Un dann han mir se noaher, die Frau mit dem Mann, mit in't Zelt jenommen mit der Fahne voraus, un dann kriechte sie ne Extratour ${ }^{311}$ jespielt un dann han mir die Fahne über sie jedreht. Wissen se, immer so wat, eh, irjendwie jedes Jahr wat anderes. ${ }^{312}$

Das Maimüttertreffen hatte dauerhaften Erfolg. Die Maimütter begehen seit etwa 12 Jahren ihren Kirmesmontagstreff, produzieren jährlich kreative Ideen und haben offensichtlich großen Spaß daran. Die unterhaltsamen Treffs, die ein Teil der weiblichen Mailehen in der Mainacht zusammenführt, wurden zwar eher durch informelle Züge geprägt und sind von der Zugehörigkeit zu bestimmten Personenkreisen abhängig, aber hier könnte sich ein Entwicklungspotential nach dem Muster der Maimütterzusammenkünfte in Zukunft noch entfalten. ${ }^{313}$

Mancherorts scheuten die jungen ledigen Frauen auch nicht davor zurück, die Mailehenversteigerung selbst in die Hand zu nehmen. Nicht nur im entfernten nordhessischen Istha ${ }^{314}$ wurde die im Mailehen üblich gewordene starre geschlechtsspezifische Rollenaufteilung aufgebrochen und umgekehrt. Dieses Beispiel steht nicht alleine. Auch im unmittelbar benachbarten Umfeld der Untersuchungsregion, in Fritzdorf, wurden im April 1995 die Männer durch Frauen ersteigert. Da die Junggesellen an den rituellen Aktivitäten die Lust verloren hatten, nahmen die Frauen die Herausforderung an, die entstandene Lücke wieder zu schließen. Aufgrund ihrer guten Verbindungen zu den FritzdorferInnen gelang es selbst einer Niedericherin, an dieser Versteigerung aktiv teilzunehmen. Diese Prozesse zeigen, daß eine Flexibilisierung der formalen Brauchstrukturen in bezug auf die Geschlechterrollen greifbar und akzeptabel geworden ist. Ein Blick in die Geschichte lehrt, daß die Brauchträgerinnen auch in der Vergangenheit bei der Wahl ihrer Mailehenpartner stärkeren Anteil hatten als es heute üblich ist (siehe Kapitel 2.9). So besehen konnten die Vorstöße der Oevericher Frauen in der Zurückeroberung ihrer traditionellen Rechte vom Junggesellenverein bisher erfolgreich abgewehrt werden. Nach den

${ }^{311}$ Die Extratour ist eine Einlage der Tanzkapelle zu Ehren eines bestimmten Paares.

${ }^{312}$ Frau Heuerdorf (23/15/2a:581-665).

${ }^{313}$ Bei dem Versuch, die geschlechtsspezifischen Dimensionen eines Brauches zu erfassen und gleichmäßig auszuleuchten (vgl. Kapitel 1.1), unterliegen Forscherinnen wie Forscher grundsätzlich der Schwierigkeit, die sich aus ihrer eigenen geschlechtsspezifischen Rolle ergeben. In diesem Fall sei darauf hingewiesen, daß auf dem "Feld" der Maimütter- und Mailehentreffen keine teilnehmende Beobachtung möglich war.

${ }^{314}$ Siehe oben Kapitel 4.1.3. 
Ausführungen von Frau Kruse gab es schon in den 1980er Jahren in Oeverich den Versuch, eine Männerversteigerung durchzusetzen:

Weißt Du, wat'e machen könntest? Die Ricky mal fragen...

...wegen Fritzdorf.

Genau. Die Weiber steigern nämlich dieses Jahr die Männer. Wollte'mir ja auch mal machen, aber da is der janze Jungjesellenverein auf die Barrikaden gegangen.

$J a$, dazu wollt'ich Dich auch mal fragen. Wie kam et denn überhaupt dazu?

Die [Junggesellen] hatten immer voll ihren Spaß, weil mir uns immer: "How Gott, hoffentlich werd ich net Maikönigin! Hoffentlich!" ne, da hatten die immer en Spaß un "Haha!", ne. Un mir so: "Irjendwann machen mir dat mal umgekehrt!" Un in dem Jahr, wo mir diese Jubiläum hatten, han mir jesacht: "Wißt'er wat?! Dies Jahr machen mir dat!" Un die: "Nä, nä, um Gottes Willen! Wer möcht mich dann wohl steijern!?" Da sin die all of die Barrikaden gegangen, un da ha'mir et net jemacht. (lacht) Dat hätte'mir echt durchziejen müssen, ne. Ha! Kannste Dir vorstellen? Die hätten da jesessen: "Owowow" (Ausdruck des Zitterns). (lacht)

Und, weißte noch, wer auf die Idee gekommen is, das mit der Männerversteigerung? Wie das aufjekommen is?

Ja, wir saßen mal wieder zesammen, ne. Un irjendwann ha'mer dat mal... irjendeiner kam auf die Idee. Wer dat jetzt grundsätzlich war, weiß ich nicht.

Aber... praktisch, daß ihr's wirklich machen wolltet, daß war zum Jubiläum?

Joa.

Ihr hattet aber vorher schon praktisch so die Rede davon gehabt? Also Jahre vorher schon mal so rumge...

...ob Jahre, weiß ich nicht, aber vielleicht eins, zwei Jahre vorher schon mal...-

Mal rumgefaxt, oder...

...ja, eben. Man faxt, flachst da mit da rum, ne. Ja, im Endeffekt ha'mer et do'net jemacht. Aber dat hätte'mer machen müssen. Dat wär der Gag gewesen.

Un woran is'et gescheitert?

Ja, weil die Jungjesellen et net wollten. Un ich glaub, wenn mir jetzt unbedingt gewollt hätten, dann hätte'mir et auch durchjezogen, ne. Wat hätten die [Junggesellen ] denn machen können, wenn mir'et gemacht hätten, ne. Aber ich schätze mal, dafür ware mir zewenig, weil die paar "Mann", die mir im Prinzip Essen gegangen sin [s.o. informelles Mailehentreffen], dann hätten mir dat net auf die Beine jekricht. Wenn mir dat richtig durchorganisiert hätten, [dann] glaub ich schonn, aber... ich glaub, da hat der Elan dann nachher doch zu gefehlt, ne. - Aber dat wär der Gag gewesen. Kannste Dir vorstellen, die Männer hätten da so gesessen, so wie mir in de Mainacht. (lacht) Dat wär doch der Gag! Oh Gott! ${ }^{315}$

Aufgrund dieser Hintergründe nimmt es nicht wunder, daß in den Gesprächen fast einhellig die Meinung zum Ausdruck gebracht wurde, daß der Übergang von der Frauen- zur Männerversteigerung sowohl vorstellbar als auch praktikabel sei. Der Druck auf die Junggesellen wird wohl nicht nachlassen, solange jener offensichtliche Widerspruch ungelöst bleibt: wenn also die Frauen am formalen Brauchvollzug genauso beteiligt sein wollen wie die Männer, aber die Mailehenpraxis dagegen

${ }^{315}$ Frau Kruse (31/17/4a:140-187). 
weiterhin durch einen ungleichberechtigten Gebrauch der Brauchformen bestimmt wird.

Nicht nur in der Frage der Wahrung vertrauter Brauchformen drängen sich den BrauchträgerInnen neue Forderungen und Überlegungen auf. Ernsthafte Sorgen machte man sich unlängst über den Standort des Festzelts. Da der langjährig genutzte Kirmesplatz der Baugebietserschließung zum Opfer fiel und zusätzlich Beschwerden von NachbarInnen über den ruhestörenden Lärm der Tanzmusik bei der Kommunalverwaltung eingingen, mußten neue Entscheidungen getroffen werden. 1994 wich man kurzfristig auf ein ortsnahes Grundstück aus, das allerdings ebenfalls in absehbarer Zeit bebaut werden sollte. Von 1995 bis 1999 war es immerhin möglich, die Kirmes an einem festen Ort stattfinden zu lassen. Allerdings mußte auch hier wegen Beschwerden über Lärmemissionen das Feld buchstäblich geräumt werden. Diese Misere hat die Organisation des Maifestes erschwert und bringt damit die Mailehenpraxis in eine prekäre Situation. Es wurde dabei deutlich, wie BrauchträgerInnen daran gehindert werden, für eine strukturelle Stabilität und eine räumliche Verankerung des Dorffestes zu sorgen. Sichtbar wurde auch ein Zwiespalt, der die Ortsbevölkerung in zwei Lager teilt: Einerseits identifiziert sich bis heute ein großer Teil der Bevölkerung mit dem Brauchgeschehen, andererseits sondern sich Dorfangehörige $a b$, indem sie auf die Respektierung ihre Persönlichkeitsrechte pochten. Es sollte erwähnt werden, daß die GegnerInnen der traditionellen Festveranstaltung auch innerhalb des Kreises der Alteingesessenen zu finden sind, so daß die Frage nach den Ursachen nicht einseitig auf dem Rücken der Zugezogenen ausgetragen werden kann. Hängt also die Existenzfähigkeit des Mailehens von der Abwehr eines allgemein feststellbaren Trends zur sozialen Individualisierung ab?316 Traditionelle Mittel sozialer Konfliktbewältigung, wie z.B. Rügebräuche, die gezielt gegen die Abweichler im Dorf eingesetzt wurden, konnten für eine demokratisch orientierte Zivilgesellschaft spätestens seit 1945 keine ernsthafte Handlungsalternative darstellen (siehe Kapitel 2.5, 2.7 und 2.8). Das gilt offensichtlich auch in diesem Fall. Abgesehen von ethischen Überlegungen, welche die Achtung vor Personen angemessen in Rechnung stellt, ${ }^{317}$ bringt auch die jüngere Rechtsprechung kein Verständnis für die überkommenen Instrumente der "Volksjustiz" auf und sanktioniert Übergriffe auf die zugestandenen Individualrechte. Bei der Suche nach Lösungen scheint daher das Ringen um gegenseitiges Verständnis

${ }^{316}$ Eine Orientierung in der Debatte um die Individualisierungsthese bieten z.B. Beck und BeckGernsheim (1994:10-39) oder Heitmeyer (1997:9-26).

${ }^{317}$ Zur Angemessenheit moralischer Entscheidungsfindung und die Bedeutung von gegenseitiger Rollenübernahme, Gerechtigkeit und Wohlwollen siehe Kohlberg et al. (1986:206-208). Lutz (1960:74-88) hat bereits den Konflikt zwischen traditionellen Rügepraktiken und bürgerlichem Recht beschrieben, wobei unter der von ihm verwendeten Begrifflichkeit (Gemeinschaft, Sitte, Ordnung und Volksrecht) die Perspektive auf die Heterogenität der Interessen abhanden gekommen ist. Eine Revision ist durch die Arbeit von Hinrichs (1991:430-463) auf dem besten Wege. 
gefragt zu sein. Und damit steht vor allem das Aufeinanderzugehen und das gemeinsame Gespräch im Vordergrund. ${ }^{318}$

\subsection{Momentaufnahme: Ethnographische Beob- achtungen im Jahre 1993319}

\subsubsection{Dorfmaibaum}

Der Termin für das jährlich wiederkehrende Maibaumholen und -aufstellen in Oeverich wurde von den Brauchtreibenden nicht strikt festgelegt. Gewöhnlich fällt er auf das Wochenende vor dem ersten Mai. Am 24. April 1993, an einem sonnigen Nachmittag trafen sich deshalb die Junggesellenvereinsmitglieder im Ortskern von Oeverich an einer markanten Stelle: der historischen Wasserpumpe. Annähernd zwanzig junge Männer im Alter zwischen 18 und 34 Jahren erschienen in zweckmäßiger Arbeiter- Freizeit- oder Bundeswehrkleidung. Bei einer ersten Flasche Bier vertrieb man sich die Wartezeit mit lockeren Gesprächen. Besonderes Interesse fanden hierbei Themen wie Autos, Motorräder und Bundeswehr. Bald waren fast alle aktiven Vereinsmitglieder einschließlich der in dem Jahr neu aufzunehmenden Junggesellen versammelt. Mit der erforderlichen Ausrüstung machte man sich nun auf den Weg, die vom Förster zugewiesene Fichte aus dem Wald zu holen. Auch wenn der Vereinsvorsitzende nicht an der Spitze des Konvois voraus fuhr, so sorgte er mit seinem Gefährt, einem ausgedienten, alten Traktor mit speziellem einachsigem "Maibaumanhänger", für genügend Aufsehen.

Vor Ort wurde der zukünftige Dorfmaibaum von allen Beteiligten kritisch in Augenschein genommen. Konnte eine vom Sturm entwurzelte Fichte den Ansprüchen und Erwartungen genügen? Würde sie auch den Vorstellungen der Dorfbewohner entsprechen? Zweifelnd und mit etwas gedämpftem Elan schickte man sich an, die

${ }^{318}$ Nach meinen Informationen war während der Erhebungsphase eine Verständigung zwischen den involvierten Konfliktparteien wenig aussichtsreich. Verhärtete Haltungen ließen eine Vermittlung des Ortsvorstehers scheitern. Die Weichen für eine Einigung zwischen BrauchbefürworterInnen und gegnerInnen waren noch nicht gestellt (dazu. z.B. Herr Decker 24/16/1a:431-444). Möglicherweise kann an diesem Punkt auch die volkskundliche Forschung einen Beitrag leisten, indem sie die soziale und kulturelle Stellung des Brauches deutlich macht und damit die Grundlage für den Austausch von Sachargumenten verbreitert. Auf Anfrage wäre auch eine volkskundliche Moderation denkbar, bei der nicht das fragwürdige Ziel, Relikte zu bewahren, verfolgt werden sollte, sondern es ginge darum, die berechtigten Positionen auf allen Seiten zu erkennen und sich einem gemeinsamen Konsens anzunähern, der den Konflikt zwischen Individual- und Kollektivinteressen überwindet. Diese Lösung ist deshalb notwendig, weil es in der dargelegten, immer noch anhaltenden Auseinandersetzung nicht vorrangig um Lärm und Vergnügen geht, sondern um gegenseitige Achtung und sozialen Frieden im dörflichen Lebensraum. Hinzu kommt, daß vergleichbare Auseinandersetzungen in Nachbargemeinden ebenfalls aufgetreten sind (Prothmann 1995:18). Vgl. auch Bausinger (1985:9-21).

${ }^{319} \mathrm{Vgl}$. die Abbildungen im Anhang (7.4). 
notwendigen Vorbereitungen für den Transport $\mathrm{zu}$ treffen. Rasch wurden mit Motorsägen abstehende Äste vom Stamm entfernt; sogar die Krone wurde abgetrennt. Die stark eingetrocknete Rinde erübrigte das mühselige Schälen des zirka fünfzehn Meter langen Restkorpus, der nunmehr mit viel Kraft und Geschick aus dem unwegsamen Waldgelände herausgeschafft werden mußte. Dort, wo der Schlepper wegen des zu engen Baumbestands nicht zum Einsatz kommen konnte, mußten unter der Regie des Vereinschefs alle Männer mit anpacken. Als man den Waldrand erreicht hatte, erhellten sich die roten, verschwitzten Gesichter der jungen Burschen, denn eine Pause und eine Stärkung bei Bier und belegten Brötchen sollten folgen. Jetzt war es nur noch eine Kleinigkeit, den Baum sicher an der Ackerschiene des Traktors und dem originellen zweirädrigen "Maibaumaufleger" festzuketten. Während der einträchtigen Rast setzten sich drei Männer von der Gruppe ab, um einen Ersatz für den abgesägten Baumwipfel aufzutreiben. Zur allgemeinen Zufriedenheit kehrten sie bald mit einer gerade gewachsenen, jungen Tanne in frischem Grün zurück.

Gegen 17.30 Uhr erreichte man schließlich den Platz im Dorf, wo gewöhnlich der mit bunten Papierfähnchen geschmückte Dorfmaibaum den Einheimischen und Durchreisenden die ausgebrochene Fest- und Frühlingsfreude anzeigt. Eine mit Beton ausgegossene Vertiefung stellte sich als eine einfache, durchaus wirkungsvolle Vorrichtung heraus, die nicht nur für den sicheren Stand des hohen Baumes sorgte, sie erleichterte ebenso dessen mühseliges Aufrichten. Durch eine spezielle Führung, die den Maien beim Aufrichten relativ leicht in das mit angesammeltem Regenwasser gefüllte Loch gleiten lassen sollte, konnte ein seitliches Abrutschen des Stammes verhindert werden. Eine massive, senkrecht hinter der Vertiefung aufragende eiserne Stange sorgte ebenso für den nötigen Halt. Sie verhinderte, daß der Stamm mit der entsprechenden Wucht die betonierte Fassung des Maibaumlochs zertrümmerte.

Nachdem also der gesamte Troß von seinem Waldausflug zurückgekehrt war, versuchte man mit der Hilfe eines Radladers, den Stamm in die richtige Position zu bringen. Kurz vor dem Aufrichten wurde die Tanne als Ersatzkrone am oberen Ende des Baumstamms festgezurrt. Augenblicklich versahen einige Junggesellen die grünen Zweige mit zahlreichen farbigen Papierbändern. Jetzt stand einer der heikelsten Momente der Aktion bevor: Der Radlader hob den Maibaum sachte an und schob ihn gleichzeitig millimeterweise nach vorne in die spezielle Vertiefung. Kräftige Schläge mit einem schweren Vorschlaghammer auf das untere Ende des Stammes trugen zusätzlich dazu bei, daß der Baum in der Führung blieb und nicht seitlich abrutschte. Auf diese Weise reckte sich die Maibaumspitze mehr und mehr in die Höhe, bis der Stamm plötzlich mit einem mächtigen Ruck tief in das Loch sackte. Jetzt ragte der Dorfmaibaum halbwegs senkrecht in den Himmel. Einem ungewollten 
Überschlagen des Baumes wurde vorgebeugt, indem der Stamm mit einer starken Eisenkette am hydraulischen Hebearm des Radladers verbunden blieb.

Zwanzig bis dreißig etwa $50 \mathrm{~cm}$ lange, keilartig zugeschnittene Holzstücke hatte man griffbereit an Ort und Stelle aufgeschichtet. In Verbindung mit einem speziellen Eisenring, der nach dem Aufrichten das untere Ende des Stammes umfaßte, dienten die Hölzer der Feinjustierung und endgültigen Stabilisierung des Baumes; möglichst viele solcher Keile trieb man mit dem Vorschlaghammer zwischen Ring und Stamm. Auf diese Weise fixiert, fand der Baumstamm seinen geraden und festen Sitz. Zufrieden betrachteten die Junggesellen gemeinsam mit ein paar schaulustigen Anwohnern das vollendete Werk. Nach über sechs Stunden Plackerei, einschließlich der kräftesammelnden Verschnaufpausen, verabschiedeten sich die ersten Mitstreiter. Aber der überwiegende Teil der Burschen ließ den Abend gemütlich bei einem letzten gemeinsamen Bier ausklingen.

\subsubsection{Maien}

$\mathrm{Zu}$ den wichtigsten Terminen bei der Ausübung des Mailehens zählen der letzte Apriltag und die darauffolgende Mainacht. Das Holen der Maien begann am 30.04.1993 um 16:30 Uhr. Die Junggesellen hatten sich wiederum an der eingangs erwähnten Wasserpumpe in Oeverich verabredet. Sobald jeder auf dem bereitstehenden Anhänger oder Traktor seinen Platz gefunden hatte, wurde ein nah gelegenes, mit jungen Birken bestandenes Waldstück angesteuert. Kaum an Ort und Stelle angelangt, kreischten die Kettensägen, und die ersten Bäume krachten knarrend zu Boden. Die Mehrzahl der jungen Männer war jetzt damit beschäftigt, die einzelnen Birken aus dem Unterholz zu ziehen und zum Wagen zu schleppen. Hier standen zwei bis drei Helfer bereit, die herangeschafften Birken aufzuladen. Knapp zwei Stunden waren vergangen, als man die gewünschte Anzahl von Maien beisammen hatte. An der mühevollen Aufgabe waren 19 Junggesellen beteiligt. Aufgrund einer durchschnittlichen Länge von etwa fünf Metern ragten die Bäume mit ihren grünen Kronen deutlich über das Ende des Anhängers hinaus. Manchmal mußten die selbsternannten Holzfäller von älteren Vereinsmitgliedern angemahnt werden, auf die Dicke und Länge der Baumstämme zu achten. Es sollte vermieden werden, daß schützenswerter Baumbestand Schaden bei dieser Aktion nahm. Man wollte auch keinen Konkurrenzdruck der Junggesellen untereinander schüren, bei dem jeder den größten und schönsten Maien für sich und sein Mailehen beanspruchen würde. Und genauso hielt man jene Mühen für entbehrlich, die das Aufstellen allzu mächtiger Maien bereiten würde. Manche Junggesellen verteidigten jedoch ihre Interessen an einem größeren Baum damit, daß sie zusätzlich noch Maien für ihre auswärtigen Freundinnen benötigten. Mit dem Versprechen, daß derartige Bäume nur außerhalb Oeverichs und Niederichs aufgestellt würden, konnte man sich einigen. Somit kamen 
am Schluß 38 Birken und eine Fichte zusammen. Letztere war für die zukünftige Maikönigin bestimmt, der damit gegenüber den Mailehen eine besondere Ehre zuteil kommen sollte.

Da die Junggesellen an diesem Tag und in der bevorstehenden Nacht noch einige Aufgaben zu bewältigen hatten, hielt man sich nicht viel länger als nötig im Wald auf. Nach einer kurzen, etwa halbstündigen Pause wurde die Rückfahrt angetreten. Im Hof eines Vereinsmitglieds stellte man den Anhänger ab und lud einen kleinen Teil der Maien, nämlich die Birken, die den auswärtigen Verehrerinnen zugedacht waren, auf einen bereitgestellten Kleinlastwagen. Gegen 19:30 Uhr löste sich die Gruppe kurzfristig auf. Die Burschen machten sich für das bevorstehende Treffen in der Dorfgaststätte frisch. Vor dem nächtlichen Aufstellen der Maien mußten noch die neuen Mitglieder in den Verein aufgenommen und die Mailehen versteigert werden (siehe Kapitel 4.3.3 und 4.3.4).

Sechs Stunden später, um 1:30 Uhr, verließen 28 Junggesellen angeheitert ihr Stammlokal. Die Maikönigin und ihr Gefährte sowie die Mailehenpaare standen nunmehr fest. Es galt nun, genau diese Nachricht der Dorfbevölkerung und insbesondere den Betroffenen mitzuteilen. Dazu brachten die Burschen unter einigem Lärm und Aufsehen die Maien an ihren Bestimmungsort. Lautstark wurde mit Traktor, Anhänger und Leiter fast jede Straße abgeklappert. Kam man am Haus eines ersteigerten Mailehens vorbei, zog man einen Maien vom Wagen, schmückte ihn mit bunten Bändern und zurrte ihn mit einigen Drahtschlingen an geeigneten Halterungen (z.B. Regenrohren) fest.

Es verwundert kaum, daß bei diesem Vorgang trotz nächtlicher Stunde in den Häusern bald Licht gemacht, die Haustür geöffnet wurde und die umstehenden Junggesellen $\mathrm{zu}$ einer kleinen Stärkung (Alkohol, Kaffee, belegte Brötchen) hereingebeten wurden. In manchen Häusern schien man auf die eintreffende Burschenschar gewartet zu haben. Woanders hingegen rührte sich nichts. Sicher hätten die Junggesellen für das Maiensetzen einige Stunden mehr einkalkulieren müssen, wenn jede einzelne Familie zu sich ins Haus eingeladen hätte. Zudem stand der krönende Höhepunkt, das Aufsetzen der Fichte für die Maikönigin, noch bevor. Da diese in Niederich beheimatet war und zunächst die Oevericher Straßen abgefahren wurden, rückte dieser Moment eher an den Schluß der Aktion.

Wer den Maibrauch in der Lokalpresse verfolgt, erfährt an einigen Stellen auch etwas über die erhöhte Unfallgefahr während der Mainacht. Riskante Manöver beim Maiensetzen sind hierbei eine Gefahrenquelle, die durch Übermüdung und Alkoholkonsum noch gesteigert werden. Auch im hier beschriebenen Fall kam es zu einem Zwischenfall, der zunächst einen ordentlichen Schreck bei den Beteiligten hervorrief. Gerade am Haus der Maikönigin angelangt, als man sich anschickte den wesentlich größeren 
und schwereren Maien vom Wagen zu heben, geschah es, daß ein Bursche zusammen mit der Fichte vom Wagen herunter auf die Straße fiel und dort reglos liegen blieb. Bekümmert überlegte man, ob schnell ein Arzt zu rufen sei, doch die Situation entspannte sich nach einigen Minuten, nachdem sich der Kreislauf des Gestürzten wieder stabilisierte. Obwohl der junge Mann bald wieder auf seinen Beinen stand, saß der Schrecken bei vielen tief, und man war sich einig darin, daß ein ernster Unfall das Schlimmste sei, daß den Brauchausübenden passieren könne.

Nachdem unter der Regie des Hausvaters der besonders prächtige Maien der Regentin am geeigneten Ort plaziert worden war, gingen alle gemeinsam mit der Maikönigin ins Haus. Nicht jeder fand Platz in der Küche, wo Bier, Kaffee und belegte Brote bereitgehalten wurden. Neben dem besonderen Ehrenbaum, der ausgiebigen Bewirtung der Junggesellen dokumentierte ein weiterer Vorgang die Zusammenfügung von Maikönigin und Maikönig: "Maibutz! Maibutz!" so erschallte lautstark der immer wiederkehrende Appell der Junggesellen an das beisammensitzende Maikönigspaar, sich zu küssen, solange bis dieser Forderung nachgegeben wurde. Vor dem Verlassen der gastfreundlichen Familie sollte das Paar noch öfter die Gelegenheit bekommen, den mit Nachdruck vorgebrachten Wunsch zu erfüllen. Der spontane Zuruf "Maibutz! Maibutz!" begleitete die beiden von nun an durch ihre gesamte Amtszeit. Hierauf achteten insbesondere die Junggesellen und die weiblichen Mailehen, und sie erhielten während der Tanzveranstaltungen oder des Umzugs von der umstehenden Dorfbevölkerung durchaus Unterstützung (s.u.).

Der letzte Maien wurde in ein entfernteres Nachbardorf gekarrt. Er gebührte einem Mädchen, das mit einem Vereinsmitglied fest befreundet war und das sich mit vielen Jungen des Vereins gut verstand. Anscheinend wurden die nächtlichen Besucher erwartet, denn auch hier hatte man wieder für den üblichen Imbiß gesorgt. Während sich ein Teil der Junggesellen bereits auf den Heimweg gemacht hatten, harrten noch acht Burschen bis zum Morgengrauen aus. Um kurz vor 6:00 Uhr traf man in Oeverich ein und stellte gleich am Ortseingang fest, daß ein Mailehen irrtümlich keinen Maien erhalten hatte. Da noch Maien auf dem Wagen übrig geblieben waren, stellte es kein Problem dar, dieses Versehen rasch zu beheben. Obwohl es inzwischen beinahe taghell geworden und der ein oder andere bereits auf der Heimfahrt eingeschlummert war, machten sich noch drei unverzagte Junggesellen daran, ihre auswärts wohnenden Freundinnen mit dem symbolträchtigen Grün zu versorgen.

\subsubsection{Aufnahme neuer Mitglieder in den Jungge- sellenverein}

$\mathrm{Da} ß$ das Oevericher Wirtshaus über ein vom großen Gastraum abteilbares Nebenzimmer verfügte, kam den Junggesellen sehr entgegen, denn nicht alle ihre Aktionen waren unmittelbar für die Öffentlichkeit bestimmt. So zogen sich die jungen Männer 
am Abend des 30.04.1993 hierher zurück, um die Vorbereitungen für die anstehende Mailehenversteigerung zu treffen. Als Zeitpunkt hatte man 20:00 Uhr ausgemacht. Die dreißig Minuten, die damit für jeden nach dem Maienholen verblieben, reichten kaum aus, um sich für den Gaststättenbesuch umzukleiden und herzurichten. Nach und nach wurden die Plätze an der "T-förmig" angeordneten Tafel besetzt. Schließlich mußten einige sich mit der zweiten Reihe zufriedenstellen und wegen der räumlichen Enge auf Tische verzichten. Den ersten Programmpunkt, das gemeinsame Essen, brachte man zügig hinter sich. Dann wurden die beiden Schiebetüren zum großen Gastraum zugezogen, die jetzt nur noch von der Kellnerin geöffnet werden durften. Es folgten ein paar kurze Ansprachen vom Vorsitzenden und von einem der älteren Mitglieder zum allgemeinen Zustand der Vereinsmoral. Erinnert wurde daran, daß im letzten Jahr die Beteiligung an einzelnen Gemeinschaftsaktionen etwas dürftig ausfiel. Gleichzeitig appellierte man an die Anwesenden, den geselligen Umtrunk am 1. Mai bei der Maikönigin diesmal allseits wahrzunehmen.

Derjenige, der das Wort ergriff, beendete seine Rede immer mit einer Freibierrunde, so daß innerhalb kurzer Zeit jeder vier bis fünf kleine Gläser Bier $(0,21) \mathrm{zu}$ leeren hatte. Stetig hatte sich der Alkoholgenuß seit dem Maienholen am Nachmittag erhöht. Hierin mag eine wesentliche Voraussetzung für den weiteren Fortgang des feuchtfröhlichen Abends gelegen haben, denn es entfesselte sich sogleich ein Gesangwettstreit unter jugendlichen Männern, der unter den gewöhnlichen Bedingungen des Alltags und den damit einhergehenden normativen Verhaltensanforderungen nicht stattgefunden oder zumindest andere Formen angenommen hätte. Immer wieder aufs Neue wurde am Ende eines Lieds der folgende Aufforderungsvers gesungen: "Ach, lieber Harald ${ }^{320}$ sing ein Lied, sing ein Lied, sing ein Lied. :|" Wenn der auf diese Weise zum Singen Aufgerufene sich weigerte, erschallte umgehend die Fortsetzung des Verses: "Der liebe Harald kann kein Lied, kann kein Lied. :| Drum gibt der Harald eine Rund, eine Rund." Hin und wieder stieß man bei diesem willkürlichen Auswahlverfahren, in dem jeder irgendwann einmal oder gar mehrfach an die Reihe kam, auf einen, dem kein Lied spontan einfiel oder dem aus anderen Gründen die Stimme versagte. Tendenziell erschienen die Jüngeren hier zurückhaltender, was jedoch nicht dazu führte, daß eine Weigerung tatsächlich zum Spendieren von Freibier verpflichtete. Wenn jemand nicht singen wollte, wurde der Druck auf ihn nicht zusätzlich verstärkt. Hingegen gab es genügend Ambitionierte, die nicht oft genug an die Reihe kommen konnten. Dieser Eifer entwickelte sich aus der puren Lust an der Entgrenzung des Alltagsverhaltens. Schon die Lautstärke des Gesangs genügte, um auf den positiven Widerhall und Beifall der anderen zu stoßen. Der gleiche Übermut fand sich in denjenigen Liedtexten wieder, welche kaum noch

${ }^{320}$ Der eingesetzte Vorname dient hier zur Veranschaulichung, er ist austauschbar und richtete sich nach dem jeweils zum Singen aufgeforderten Junggesellen. 
Tabuzonen des Sexuellen unberührt ließen: So besang man beispielsweise die weiblichen Brüste, tausend nackte Weiber oder auch männliche Geschlechtsteile. Sexuelle Phantasien konnten sich in diesen Liedern artikulieren, ohne von Umstehenden mißbilligt oder sanktioniert zu werden. Letztlich akzeptierte auch die Kellnerin augenscheinlich diese Situation. Bei der Verrichtung ihrer Arbeit ließ sie sich Irritationen nicht anmerken.

Um ca. 22:30 Uhr war das gemeinsame Singen beendet. Die Vorbereitungen für das öffentliche Aufnahmeritual der vier neuen Mitglieder nahmen ihren Lauf. In der Mitte des großen Gastraumes stellte man für jeden einen Stuhl bereit. Darüber hinaus wurde Rasierschaum, eine sogenannte "Hääp", 321 ein Tablett mit Schnapsgläsern, ein Trichter und ein großes zweiteiliges Brett mit vier Löchern benötigt. Die Prozedur begann damit, daß die Köpfe der Initianden in dieses Brett eingespannt wurden, so daß sie wie vier Delinquenten erscheinen mußten, die ihre gerechte Strafe unter Anwendung mittelalterlicher Foltermethoden zu erwarten hatten. Sie nahmen auf den Stühlen vor der versammelten Mannschaft des Junggesellenvereins und jenen Gasthausbesuchern Platz, die das Spektakel mitverfolgen wollten. Die vier Rasierschaumdosen verteilte der Vereinspräsident an vier Junggesellen. Nun ergoß sich der duftige Seifenschaum unaufhaltsam über Haare und Gesichter, solange bis die Physiognomie des einzelnen hinter einer weißen Hülle unkenntlich wurde. Zur allgemeinen Belustigung formten die Einseifer aus den eingeschäumten Haaren abstehende Zöpfe. Dann wurde ein Tablett mit gefüllten Schnapsgläsern angereicht. Mit einem gewöhnlichen Plastiktrichter bekam jeder Initiand den klaren oder goldgelben Inhalt mehrerer Gläschen eingeflößt. Schließlich übernahm ein betont grimmig wirkender Junggeselle die noch ausstehende Rasur mit der "Hääp", die eher einem Mordinstrument als einem Hygieneartikel ähnelte. Das Initiationsritual gipfelte in einem gemeinsam ausgeführten, gewagten Sprung der neuen Mitglieder von ihren Stühlen. Das Tückische bestand darin, daß die Hälse immer noch in dem Lochbrett eingezwängt blieben. Hiermit war die Aufnahme erfolgreich vollzogen. Die Burschen konnten wieder auf freien Fuß gesetzt werden, sie bekamen ein paar Minuten, um sich frisch machen und um sich dann dem eigentlichen Höhepunkt des Programms zuwenden zu können.

\subsubsection{Mailehenversteigerung}

Die Mailehenpaare, Maikönigin und Maikönig wurden in Oeverich und Niederich durch die Mailehenversteigerung ermittelt. Am 30.04.1993 wurden die vom Schriftführer des Vereins auf einer Liste aufgeführten Frauen um ca. 23:30 im Anschluß an die Aufnahme der neuen Vereinsmitglieder meistbietend ersteigert. An die weibliche Mailehenwürde waren bestimmte Bedingungen geknüpft. Jede $\mathrm{zu}$ ersteigernde

${ }^{321}$ Altes, scharfes Haumesser (vgl. Prothmann 1989:51). 
Ortsbewohnerin mußte älter als sechzehn Jahre sein, sie durfte nicht verheiratet oder geschieden sein und ihr Wohnort sollte in Oeverich oder Niederich liegen. So kam eine Liste mit 29 potentiellen Mailehenkandidatinnen zustande.

Sobald das Spektakel des Initationsrituals beendet war, zogen sich die Burschen wieder in den Nebenraum des Wirtshauses zurück. Der Präsident sorgte für Ruhe und erklärte in wenigen Sätzen die Regeln für das Ersteigern des Maikönigtitels. In Oeverich stößt man dabei auf eine interessante Eigenart der Brauchausübung. Während vielerorts der Maikönig durch das absolute Höchstgebot bestimmt wird, das im Laufe einer Mailehenversteigerung fällt, bieten die Vereinsmitglieder hier separat auf den Königstitel. An jenem Abend stand der Titel bei einem Mindestgebot von 200 Talern (entspricht 20,- DM) zur Disposition. Sobald ein entsprechendes Angebot und kein Gegengebot vorläge, stünde der Maikönig fest. Daher besteht für den Verein eine Gefahr darin, daß der Königstitel ohne nennenswerten Gewinn veräußert werden kann. Spannende Bietgefechte und hohe Ersteigerungssummen sind nur dann zu erwarten, wenn mindestens zwei Bewerber den Maikönigstitel anstreben. Wenn es aber unter den Junggesellen an einer sie drängenden Motivation, Maikönig zu werden, mangelt, so bedingt dieser ungewöhnliche Versteigerungsmodus ein freieres Bieten auf dasjenige Mailehen, das man ersteigern möchte. Denn das sonst vorhandene Risiko, durch ein hohes Gebot ungewollt Maikönig zu werden, ist bei einer Trennung von Titel- und Mailehenversteigerung weggefallen. Bei dem Oevericher Verfahren wird folglich derjenige Junggeselle Maikönig, der es auch werden möchte. Nachdem er den Zuschlag erhalten hat, darf er sich aus allen zur Verfügung stehenden Mailehen eines auswählen, das er zu seiner Maikönigin machen möchte.

Überdies verdient in diesem Zusammenhang eine zusätzliche Sonderregelung des Oeverich-Niedericher Versteigerungsverfahrens Beachtung, die bereits angesprochen wurde (siehe Kapitel 4.2.4). Um einen zusätzlichen Anreiz zu bieten, der die Junggesellen dazu bewegen könnte, das herrschaftliche Repräsentationsamt zu übernehmen, schafft man finanzielle Vorteile durch das sogenannte "Bier op de Maikönig" (Bier auf den Maikönig). Dabei offerieren einzelne Junggesellen gewissermaßen ein Anrecht auf eine bestimmte Menge (Liter) Bier. Wenn ein Maikönig gefunden wird, kann dieser seinen Anspruch auf den Warenwert des angebotenen Bieres geltend machen. 1993 besaß ein Liter Bier den Wert von drei D-Mark. Der Schriftführer notiert den Anbieter zusammen mit dem genannten Betrag in Litern Bier. Gibt es keine oder nur schwache Anzeichen, für einen Titelinteressierten, so steigen gewöhnlich die Literbeträge. Der Schriftführer muß dann die Literzahlen stetig aktualisieren bzw. kumulieren. Hin und wieder ermittelt und verkündet er das Gesamtguthaben. Dieses kann der künftige Maikönig bei seinen "Sponsoren" einlösen. Dabei wird der Literbetrag in den entsprechenden DM-Betrag umgerechnet 
und ausgezahlt. Auf diese Weise ist es den Junggesellen gelungen, die finanzielle Belastung, die auf einen Maikönig zukommt, erheblich zu mindern und untereinander $\mathrm{zu}$ verteilen.

Folgen für den Ablauf der Versteigerung hat eine weitere außergewöhnliche Regel: Der "Usklöppe" (Ausklopfer bzw. Auktionator) muß bei der Ausübung seines Geschäfts auf jedes kleinste, flüchtigste Handzeichen, auf jegliche Gestik oder Körperbewegung achten, die in irgendeiner Weise als Gebot interpretiert werden könnten. Mit dem Augenblick des Angebotsaufrufs kehrt augenblicklich eine ungewöhnliche, spannungsgeladene Ruhe ein. Denn unter Umständen mag eine unkontrollierte, unbeabsichtigte Gebärde als Gebot, das den Zuschlag erhält, aufgefaßt werden.

Nur vor dem Hintergrund dieser Besonderheiten läßt sich der Ablauf der Oevericher Mailehenversteigerung in der Nacht zum 1. Mai 1993 verstehen. Die Wahl des "Usklöppe" war auf einen jungen Mann gefallen, der aufgrund seiner bevorstehenden Verehelichung als prädestiniert für die Ausübung dieses Amts galt. Da sein Austritt aus dem Verein feststand, ging man davon aus, daß er ohne eigene Ambitionen die Versteigerung möglichst neutral durchführen könne. Gewöhnlich wird bei Versteigerungen die Annahme eines Gebots durch drei laute Hammerschläge signalisiert, die von dem Ruf "zum Ersten, zum Zweiten und zum Dritten" begleitet werden. Den Zuschlag zögert der Auktionator etwas heraus, indem er nach dem zweiten Schlag einen Moment innehält, um einem Mitbieter eine letzte Chance zur Erhöhung des Gebots zu gewähren. Mit geringfügigen Abweichungen, nämlich dem Hammer, den der "Usklöppe" durch zwei scheppernde Topfdeckel ersetzte, fand sich diese bewährte Praxis auch in Oeverich.

Schleppend nahm die Auktion ihren Lauf. Ein Junggeselle, der bereits vor einigen Jahren den Maikönigtitel ersteigert hatte, sorgte mit seinem Gebot von 250 Talern dafür, daß seine Genossen erleichtert aufatmen konnten. Hierdurch wurden drei Mitstreiter zu weiteren Geboten angeregt. Zum Erstaunen der Runde beteiligte sich der Ex-Maikönig allerdings weiterhin an dem sich nunmehr entfachenden Bietgefecht und trieb damit den Preis in die Höhe. Zusehends führte dies zu Unmut und Aufregung unter einigen Anwesenden. Daß jemand sich ernsthaft ein zweites Mal um den Titel bemühte, wurde kritisiert und letztlich mißbilligt. Endlich kam es zum Zuschlag, nachdem der Ex-Maikönig einlenkte und man bei mehreren tausend Talern und einigen hundert Litern "Bier op de Maikönig" angelangt war. ${ }^{322}$

${ }^{322}$ Die genauen Zahlen werden hier nicht mitgeteilt, da ich den Wunsch der Beteiligten auf Vertraulichkeit respektiere. 
Ein Moment der Spannung lag in der Bekanntgabe der Maikönigin. Doch der Maikönig schien die Anwesenden nicht sonderlich zu überraschen, als er den Namen seiner Wunschkandidatin preisgab. Die meisten wußten wohl, daß das soeben bestimmte Regentenpaar zwar nicht in einem Liebesverhältnis, aber doch freundschaftlich zueinander stand und zusammenpaßte.

Bevor jetzt die Mailehenpaare im weiteren Fortgang der Versteigerung ermittelt werden sollten, folgte eine Unterbrechung, in der das neue Maikönigspaar den Gaststättenbesuchern bekannt gemacht wurde. Gleichzeitig mußte ich den Kreis der Junggesellen bis zum Ende der Versteigerung verlassen, da man diese Veranstaltung in ihrer Intimität bewahren wollte. Eine Ausnahme oder ein Präzedenzfall, die später immer wieder Quelle von Querelen sein könnten, galt es zu vermeiden (siehe Kapitel 4.1.3).

Nach etwa einer Stunde, es war gegen 01.30 Uhr, beendeten die Junggesellen ihre Auktion, und man schickte sich an, die bereits oben beschriebene letzte Aufgabe für diese anstrengende Nacht zu erfüllen: das Aufsetzen der Maien vor den Häusern der ersteigerten Mailehen und der Maikönigin.

\subsubsection{Maikirmes}

In Oeverich steht die Ausübung des Mailehenbrauchs in enger Verbindung zur Kirmes. Schon die Bezeichnung Maikirmes legt einen deutlichen Akzent auf den jahreszeitlich wiederkehrenden Maibrauch gegenüber dem Aspekt der Kirchweihe als Erinnerungsfeier an den Weihe- und Patronatstermin der Urbanus-Kapelle. Zu verschiedenen Gelegenheiten rücken die Junggesellen und die unverheirateten Frauen als BrauchträgerInnen in den Mittelpunkt des Ortsfests. Bei der Durchführung der Kirmes schenkt die Dorfbevölkerung somit der Generation der Jugendlichen ein außerordentlich hohes Maß an Aufmerksamkeit. Dies beginnt bereits bei den Vorbereitungen: Nur wenige Minuten, nachdem der "Usklöppe" in der Nacht zum 1.5.93 den zukünftigen Maikönig ausgerufen und dieser der Junggesellenrunde seine Auserwählte bekanntgegeben hatte, wurde das Versteigerungsergebnis durch die Wirtshausbesucher weiterverbreitet. Auch die Aktion des oben beschriebenen Maienaufstellens trug dazu bei, daß die Bevölkerung informiert wurde, wer während der Kirmestage über die beiden Dörfer herrschen wird. Die vor den elterlichen Häusern der Maikönigin und der Mailehen errichteten Maien zeugen unverkennbar von der Präsenz der jungen Männer und Frauen, die zusammen in jährlicher Regelmäßigkeit die Maibräuche begehen.

Sobald das Maikönigspaar und das Mailehengefolge feststehen, mußten rasch weitere Vorkehrungen für einen erfolgreichen Ablauf der Kirmes getroffen werden. Sie bestanden z.B. im Zeltaufbau (um die Kosten gering zu halten, unterstützten Vereins- 
mitglieder hierbei den beauftragten Zelteverleih). ${ }^{323}$ Doch neben derart technischen Problemen, die zu lösen waren, erforderte der Brauch des Mailehens noch ein Treffen der Junggesellen bei der Maikönigin. Dieses Treffen findet gewöhnlich gleich am 1. Mai statt.

Obwohl man die Mainacht bis in die frühe Morgenstunde mit dem Maiensetzen verbracht hatte, sollten daher die Junggesellen am Nachmittag des 01.05.1993 zu einem Besuch bei der Maikönigin erscheinen. Vorab hatte man sich für 14:00 Uhr wieder in der Gaststätte verabredet, wo am Abend zuvor die Versteigerung stattgefunden hatte. Als achtzehn Junggesellen eingetroffen waren, entschied man sich für den Aufbruch zur Maikönigin. Eine gewisse Aufregung war dem Maikönig anzumerken, schließlich stand er und seine Auserwählte im Mittelpunkt des bevorstehenden Programmpunkts.

Gemeinsam mit ihren Eltern und Geschwistern hatte die Regentin für einen kleinen Empfang (bei Bier und belegten Brötchen) ${ }^{324}$ gesorgt. Bei der angenehm sommerlichen Witterung konnte man Tische und Bänke auf der Terrasse aufstellen, so daß es bei der erwarteten Anzahl der Gäste keinerlei Probleme mit der Unterbringung geben mußte. Bei der Begrüßung überreichte der Maikönig seiner Gefährtin einen Blumenstrauß, den er zuvor in Ahrweiler besorgt hatte, und wurde mitsamt seiner Begleitung freundlich ins Haus gebeten. Die Junggesellen waren ohne ihre Mailehen erschienen. Man setzte sich an die Tische, wurde von den Angehörigen der Maikönigin bewirtet und unterhielt sich mit den Tischnachbarn. Erst gegen 18:00 Uhr begann sich die gesellige Runde aufzulösen. Das Königspaar war die meiste Zeit Seite an Seite und mußte seine Gespräche hin und wieder durch jene beharrlich vorgebrachten "Maibutz! Maibutz!"-Rufe unterbrechen; nur durch unmittelbare Einlösung der Forderung ließen sich die ungeduldigen Burschen wieder zur Ruhe bringen.

Vom 21. bis zum 24. Mai 1993 fand die Maikirmes statt. Eine Woche vor Pfingsten beginnt gewöhnlich die Oevericher Maikirmes. Dabei stehen gesellige Unterhaltung und Tanz im Festzelt im Vordergrund. Mit dem Diskoabend am Freitag, bei dem ein professioneller Discjockey die Tanzmusik unter der Berücksichtigung aktueller internationaler Hitlisten bestimmt, nimmt das Feiern seinen Lauf. Techno-Rhythmen und dazu passende Solotänze trafen den Geschmack des überwiegend jugendlichen Publikums. Für den Maibrauch hatte dieser Abend jedoch kein entscheidendes

\footnotetext{
${ }^{323}$ Einige Vorbereitungen mußten dagegen schon Monate vorher geplant und angegangen werden. Insbesondere die Verpflichtung einer stimmungsvollen, qualitativ ansprechenden Tanzkapelle, war ein großes Anliegen des Vereins und wurde in der Regel möglichst frühzeitig, d.h. mehrere Monate vor der eigentlichen Veranstaltung vertraglich abgesichert.

${ }^{324}$ Infolge der spontanen Unterstützung eines Bäckers und eines Metzgers war es trotz Feiertag möglich, in weniger als 24 Stunden Vorbereitungszeit die nötige Menge an Brötchen und genügend Aufschnitt zu erhalten.
} 
Gewicht. Es bestand für das Maikönigspaar, die Junggesellen und die Mailehen keine Repräsentationspflicht. Da der Abend vom Junggesellenverein organisiert wurde, traf man auf einige Vereinsmitglieder, die verschiedene Aufgaben übernommen hatten. So wurde die Abendkasse, der Bonverkauf und der Ausschank untereinander verteilt. Die gesamte Kirmeszeit stand für die Junggesellen somit nicht nur im Zeichen des ausgelassenen Feierns, sondern auch in der Einhaltung des vereinbarten Dienstplans.

Der erste öffentliche Auftritt des Maikönigspaares fand am Samstag, dem 14. Mai 1993, im großen Festzelt statt. Als Eröffnungsball hatte der Verein dieses Ereignis auf Plakaten angekündigt. Um 20:00 Uhr war Einlaß ins Zelt. Auswärtige Besucher, aber in der Mehrzahl Eingesessene aus Oeverich und Niederich trafen ein, so daß schon bald ein großer Teil der Sitzplätze vergeben waren. Im Gegensatz zum Vorabend herrschte jetzt eine lockere Zusammensetzung aus jüngeren wie älteren Gästen vor. Das Eintrittsgeld belief sich auf 10,- DM. Die Tanzkapelle "Les Bermudas" sorgte für die musikalische Unterhaltung, und ein Junggeselle übernahm die Moderation. Nach einer guten halben Stunde kündigte er die Eröffnung der Kirmes und damit auch die Freigabe des Tanzbodens durch das neue Maikönigspaar an. Dazu wurden zwei Bänke mitten auf der Tanzfläche aufgestellt. Während auf der einen Bank das diesjährige Maikönigspaar plaziert und mit vollen Sektgläsern versorgt wurde, fanden auf der zweiten Bank die Amtsvorgänger ihren Platz. Die Kapelle spielte nun mehrere Ehrenlieder, wobei die Paare ihren Sekt austranken. Sobald die Musikinstrumente verstummten, erklang aus dem Publikum der allseits bekannte Maibutz-Ruf. Nach einem ersten Kuß folgte bald ein weiterer. Die hoheitlichen Paare gaben dem lautstarken Drängen der Zuschauer nach einer "Zugabe" sehr schnell und widerspruchslos nach. Dann waren die vier zu einem Walzer ("Der Mai ist gekommen") aufgefordert. Schließlich bekam das aktuelle königliche Paar seine eigene sogenannte Extratour. Dabei tanzte es unter der vom Fähnrich geschwenkten Fahne des Junggesellenvereins. Somit war die Maikirmes mit einer Tanzveranstaltung, die bis in die frühen Morgenstunden des nächsten Tages andauern sollte, offiziell eröffnet. Viele Kirmesbesucher nutzten die Möglichkeit zum Tanz. Dabei spielte die Band in erster Linie aktuelle, vorwiegend deutschsprachige Schlagermusik, zu der Foxtrott getanzt wurde. Hin und wieder wurde das gebotene Repertoire durch Walzer, Rock 'n Roll, oder Twist erweitert. Um die allgemeine Stimmung zu steigern, wurden kölnische Karnevalslieder erfolgreich eingesetzt. Ermunterungen zum Schunkeln, zum Bilden von Polonaisen, zum Mitsingen und klatschen griff das Publikum bereitwillig auf. In gewisser Regelmäßigkeit - meist nach drei gespielten Musiktiteln - wurde eine zehn- bis fünfzehnminütige Pause eingelegt, so daß dem Publikum immer wieder Gelegenheit zur Unterhaltung, Stärkung und Erfrischung gegeben war. Die Junggesellen, die abwechselnd an der Theke, im Service und an der Kasse ihre Pflicht zu erfüllen hatten, sorgten für das leibliche Wohl mit alkoholischen und alkoholfreien Getränken. Am Imbißwagen vor 
dem Zelt wurden Pommes Frites, Bratwürstchen und dergleichen verkauft. In Zusammenarbeit mit den Mailehen betrieben die Junggesellen eine von jungen Leuten gut besuchte Sektbar. Diese war vom Hauptraum des Festzelts ein wenig abgeschirmt. Die Sektbar war auch der Ort, wo sich der sogenannte harte Kern, die besonders ausdauernden Kirmesgäste, bis in die frühen Morgenstunden zurückzogen. Die meisten Besucher verließen zwischen 24:00 und 2:00 Uhr das Fest. Abgesehen von einer Rangelei zweier junger Männer, die allerdings durch das Eingreifen der Junggesellen rasch beendet wurde, verlief der Abend ohne störende Zwischenfälle.

Wer nach diesem Festvergnügen noch überschüssige Energien besaß, traf sich mit anderen zusammen bei einer starken Tasse Kaffee im Freundeskreis. Für einen Teil der Junggesellen war allerdings der Dienst noch nicht beendet. Durch schlechte Erfahrungen in der Vergangenheit sah man sich gezwungen, eine Zeltwache einzurichten, die darauf achten sollte, daß Musikanlage und Getränkevorräte während der Nacht vor Diebstahl gesichert waren.

Am Kirmessonntag traten die Junggesellen erst um 16:00 Uhr wieder vollzählig in Aktion, als der Moment für den Festzug gekommen war. Der Umzug führte annähernd durch jede Straße beider Ortschaften. Gebildet wurde er durch die Fähnriche des Vereins, die an der Spitze den Zug anführten, darauf folgten das Tambourcorps, das Maikönigspaar, die Mailehenpaare und der Kirmesmann, eine lebensgroße Strohpuppe, die auf einer als Bahre umfunktionierten alten Leiter lag und von ehemaligen Junggesellen getragen wurde. Im Festzug zeigte sich also erstmals in der Öffentlichkeit, welcher Junggeselle welches Mailehen ersteigert hatte. Arm in Arm eingehakt zogen die Paare hinter der Königskutsche her. Der Vereinspräsident übernahm mit seinem Mailehen die Position unmittelbar hinter der Kutsche. Darauf folgten in willkürlicher Reihenfolge die anderen. Manche Burschen führten dabei gleich zwei oder drei Frauen mit sich.

Bevor der Zug sich in Bewegung setzte, hatten sich Fähnrich, Spielmannszug und Mailehenpaare am Festzelt versammelt. Einige Junggesellen hatten ihre Partnerinnen zu Hause abgeholt. Schon an der Kleidung der Teilnehmer und Teilnehmerinnen ließ sich unschwer erkennen, daß sich alle auf ihren Auftritt in der Öffentlichkeit vorbereitet hatten. Der Ausdruck von Festlichkeit im äußeren Erscheinen konnte zwar sehr individuell interpretiert werden, doch ihre jugendliche Alltagskleidung hatten die Beteiligten zu diesem Anlaß augenscheinlich nicht hervorgeholt. Trotz bzw. wegen des fehlenden einheitlichen Gesamteindrucks hatte der Umzug ein lebendiges, präsentables und durchaus feierliches Gepräge. Als nun außer dem Maikönigspaar alle versammelt waren, brach man unter der Marschmusik des Tambourcorps auf, um zunächst den Maikönig und dann die Maikönigin abzuholen. Durch die Trommelschläge und Klänge der Pikkoloflöten konnte der Maikönig das Herannahen 
des Zuges von weitem hören. In seinem dunklen Anzug präsentierte er sich seinen Freunden und zog die neugierigen Blicke der Öffentlichkeit auf sich. Während seine Familie dafür sorgte, daß die Umstehenden mit einem Glas Sekt oder sonstigen Getränken versorgt wurden, spielte man ein Ehrenlied für den Maikönig. Dazu schwenkten die Fähnriche die Vereinsfahnen. Nach einer Weile bestieg der Herrscher seine mit üppigen Blumenarrangements geschmückte Kutsche, die sich alsdann in Richtung Niederich in Bewegung setzte, um dort die Maikönigin abzuholen. Während der Fahrt grüßte er freundlich die Umstehenden, ließ sich durch Zurufe, Photographen und Videofilmer würdevoll feiern. In seiner Hand hielt er einen Blumenstrauß für seine Auserwählte bereit. Manche Häuserfronten waren mit frisch belaubten Birkenreisern geschmückt. Auch wenn die Straßen nicht von Zuschauern dicht gesäumt waren, so verfolgten viele Anwohner von ihren Balkonen, offenen Haustüren oder Fenstern das Treiben auf der Straße. Ein Teil der Leute begleitete den Zug. Von weitem signalisierte der mit bunten Bändern gezierte Maien das zweite Etappenziel, das elterliche Haus der Maikönigin. Auch hier wurde man freundlich mit der üblichen Bewirtung empfangen. Der Maikönig übergab den Handstrauß, der das optische Erscheinungsbild des Regentenpaares abrundete. Ein edles, knöchellanges Ballkleid schmückte die junge Frau und unterstrich auf unverkennbare Weise ihre herausgehobene Position bei dieser Veranstaltung. Der Spielmannszug ließ nun im Dreiviertel-Takt das Lied "Der Mai ist gekommen" erklingen, worauf das Königspaar einen Walzer unter dem geschwenkten Vereinsfähndel tanzte. Noch bevor die FlötistInnen ihre Instrument vom Mund abgesetzt hatten, wiederholte sich das Maibutz-Ritual. Unermüdlich nutzten die ZuschauerInnen jegliche Gelegenheit, die sich während des Umzuges bot, jene Aufforderung zum Küssen mit Nachdruck zu wiederholen.

Der Zug setzte sich nun in Bewegung. Dabei wurde eine Schleife durch Niederich gezogen. Einen kleiner Zwischenhalt legte man noch vor dem Haus des Ortsvorstehers ein. Das Maikönigspaar tanzte abermals unter der Vereinsfahne, und erneut wurde Sekt ausgeschenkt. Endziel des Zuges war das Festzelt. Doch bevor es erreicht wurde, mußten noch ähnlich ablaufende Unterbrechungen am Gasthaus und an der Kapelle eingelegt werden. Nach knapp zwei Stunden zog der Spielmannszug gegen 18:00 Uhr mit donnernden Paukenschlägen im Gleichschritt ins Zelt ein, worauf die jungen Paare folgten. Die MusikantInnen spielten zum Abschluß noch drei Lieder und verabschiedeten sich vom Publikum.

Während einige unter den weiblichen Mailehen sich kurz nach dem Ende des Umzuges bereits von ihren Brauchpartnern verabschiedeten, blieben die anderen noch in einer geselligen Runde zusammen. Man setzte sich an einen langen Tisch zum Maikönigspaar. Jetzt wiederholte sich im wesentlichen das Programm vom Vorabend. Die Musikkapelle, die am Kirmessamstag auftrat, sorgte nun auch für 
stimmungsvolle Tanzmusik, zu der ältere wie jüngere sich gleichermaßen hingezogen fühlten. Wieder wurde dem Maikönigspaar besondere Ehre und Aufmerksamkeit zu Teil, indem es einige Extratouren alleine auf der Tanzfläche zu absolvieren hatte. Nach dem bekannten Ritual hatte das Paar auf einer Bank Platz zu nehmen, die mitten auf die Tanzfläche geschoben worden war. Vor und nach den Extratouren gab es den üblichen Sekt und die üblichen "Maibützchen". Abgesehen von einer geringeren Besucherzahl verlief der sogenannte große Kirmes-Ball am Sonntag nach demselben Muster wie der Eröffnungsball.

Der letzte Tag der Oevericher Maikirmes ist der Kirmesmontag. Das offizielle Ablaufschema des Junggesellenverein für den 24.05.1993 hatte zwei Programmpunkte vorgesehen: ein Frühschoppen mit Musik und einen Abschlußball. Da der Kirmesmontag lediglich ein lokaler Feiertag ist, sind vor allem Einheimische von diesem Angebot angesprochen. Aber auch sie sind an einer Teilnahme am Frühschoppen oft bereits durch die Berufsausübung gehindert. Während des Abschlußballes am Abend war das Festzelt wieder gut besucht. Kurz vor 20:00 Uhr starteten die "Les Bermudas" erneut ihr Unterhaltungsprogramm mit den speziellen Einlagen für das Maikönigspaar. Obwohl die Musik und das Publikum nicht entscheidend von denen der Vortage abwich, hatte sich an der allgemeinen Stimmungslage doch merklich etwas verändert. Die Kleidung war bei vielen weniger festlich und kam dem alltäglichen Freizeitlook nah. Selbst das Maikönigspaar schien in seinen Repräsentationspflichten erheblich entlastet. Statt Anzug und Krawatte genügte Jeans und T-Shirt, statt knöchellangem Ballkleid genügte ein sommerliches Kleid den Ansprüchen. Gemeinsames Klatschen, Singen und das Bilden endloser Polonaisen waren Ausdruck einer angeheizten, ausgelassenen Feierlaune; es schien, als hätten die Oevericher und Niedericher bewußt ihre Kräfte für diesen Augenblick aufgespart. Mit der Gewißheit, am nächsten Morgen wieder in das normale Alltagsleben zurückfinden zu müssen und der Vergänglichkeit eines herausragenden, vielleicht einzigartigen Erlebnisses wurden diese Stunden besonders genossen.

Anteil hieran hatte auch die bevorstehende Kirmesmannverbrennung. Der Kirmesmann ist eine lebensgroße Strohpuppe, welche das gesamte Fest begleitet. Seine zeremonielle Verbrennung um Mitternacht stellt den Schlußpunkt der Oevericher Mai-Kirmes dar. Es begann damit, daß eine Gruppe von jungen Männern, die alle mit weißen Umhängen und schwarzen Hüten bekleidet waren, auf die Tanzfläche traten. Einer von Ihnen trug ein Kreuz vor sich, ein anderer führte einen Eimer Wasser und eine Toilettenbürste mit sich. Schließlich trat ein älterer Herr mit schwarzem Anzug hinzu, der aus einem Gebetbuch unverständliche Beschwörungs- oder Segensformeln rezitierte. Im Kerzenschein wurde der Kirmesmann, der noch dicht unter der Decke baumelte, ganz langsam mit einem Seil auf den Boden herabgelassen. Während der gesamten Prozedur wiederholte die Band unablässig als Klage- und Trauerlied den 
Refrain des Schlagertitels "Mamy Blue" (Interpret: Ricky Shayne), zu dem die Zuschauerschar sang. Dieser äußerst stimmungsvolle Moment zog offensichtlich alle Anwesenden in ihren Bann. Der genannte Refrain wirkte aufgrund der stetigen Wiederholung meditativ. Die sakral anmutende Monotonie glich der von gregorianischen Chorälen oder indischen Raga. Begleitet von dieser Musik trugen die weißgewandeten Männer die Puppe, nachdem man sie auf einer Bahre (Leiter) gelegt hat, mehrere Runden durch das Zelt. Schließlich bildete sich hinter ihnen ein immer größer werdender Zug von Menschen, der den Kirmesmann nach draußen zur letzten Station, zu seiner Feuerbestattungsstelle brachte. Nicht weit entfernt vom Zelt legte man die Puppe ab und entzündete sie. Dies gelang jedoch nicht auf Anhieb. Der oftmals mit der triefend nassen Toilettenbürste erteilte Segen führte dazu, daß nicht nur das versammelte Publikum Wasserspritzer abbekommen mußte, auch der Kirmesmann blieb von diesen Schauern nicht verschont. Das Stroh, aus dem die Puppe im wesentlichen bestand war daher nicht mehr trocken und konnte erst mit einigen Mühen entflammt werden. Nachdem man sich noch einige Minuten das Feuer anschaute, löste sich die trauernde Kirmesgemeinde auf und verschwand nach und nach wieder auf ihren Plätzen im Festzelt. Hier spielte die Musikkapelle erneut zum Tanz auf. Das Ende der Veranstaltung lag bei 2:00 Uhr, doch die letzten Kirmesbesucher und die Junggesellen harrten noch aus. Während die einen sich nicht von dem gelungenen Fest trennen konnten, hatten die anderen noch genügend Arbeit mit dem abschließenden Aufräumen und anfänglichen Vorbereitungen zum bevorstehenden Zeltabbau.

\subsection{Gespräche: Die Braucherlebnisse}

$\mathrm{Daß}$ die Stimmen der Betroffenen in der Mailehenforschung kaum zu Wort gekommen sind, wurde aus den vorangegangenen Kapiteln deutlich. Die oberflächliche Beschäftigung mit der Ethnographie des Mailehens wurde nicht nur als Defizit, sondern auch als Ursache für eine fehlgeleitete Mailehendeutung angeführt. Selbst schlüssig scheinende, intelligible Erklärungsmodelle mußten daran zerbrechen, daß sie sich auf Forschungsergebnisse stützten, denen die Nähe zur Brauchpraxis fehlte. Ein wesentliches Ziel dieser Arbeit bestand deshalb darin, die Kluft von Außen- und Innensicht zu überbrücken. Es sollte Raum für die Perspektive der Betroffenen gewonnen werden. Freilich unterliegt auch dieses neu eröffnete Feld zwangsläufig erkenntnisleitenden Begrenzungen. Durch den Forschungsrahmen und die schriftliche Veröffentlichung der Ergebnisse werden von vornherein eine Reihe limitierender Faktoren wirksam (siehe Kapitel 1 und 4.1). Zudem wurde schon darauf hingewiesen, daß die empirische Erhebung nicht eine Dopplung der Realität anstrebt. 
Vielmehr geht es um ein ethnologisches Hineindenken, Verstehen und Vermitteln von kultureller und sozialer Praxis.

Die folgende ausführliche Wiedergabe eines Gruppengesprächs von ehemaligen Mitgliedern des Junggesellenvereins soll dieses Hineindenken unterstützen. Sie kann dazu verhelfen, ein Bild von der Verschiedenartigkeit der Positionen zu gewinnen, die bei der Ausübung des Brauches eingenommen werden konnten. Bei der sich anschließenden Analyse zeigt sich, daß der Disput, der sich vorrangig um die Motivlage bei der Wiederbelebung des Mailehens in den 1960er Jahren dreht, auf entscheidende Kernpunkte des persönlichen Zugangs zur Brauchpraxis hinführt. ${ }^{325}$

Angestoßen wurde die Diskussion durch die von mir gestellte Frage:

Ja, was würden Sie denn sagen, was der Reiz war [früher am Junggesellenvereins- und Brauchgeschehen]?

Herr Keller: Ja, das is letzten Endes immer die Fraue.

Herr Fischer: Wat, die Fraue!? Am Jungjeselleverein die Fraue!?

Herr Hagen: Nä.

Herr Fischer: Im Jungjeselleverein doch net!

Herr Keller: Direkt de Jungjeselleverein net, aber dat Steijere un dat alles. Letzten Endes jing doch...

Herr Kastner:...et war teilweise die gemeinsame Festlichkeit.

Herr Hagen: Ja, ja.

Herr Fischer: Dat woaren doch net die Fraue in der Zit un Mädsche, die am meiste interessiert han!

Herr Keller: Es hatte net jeder en Auto. Et jing mehr um die Gesellschaft, dat Zusammensein. Weil, meistens hatt mer, wenn man mal met'm Auto rous fuhr, hatte man immer dat janze Auto voll. Heute fahrn se jeder mit'm Auto.

$[\ldots]$

Herr Fischer: Ja, der Reiz?

Herr Böhm: Dat woar die Kameradschaft unter Umständen.

Herr Fischer: Ja, dat würd ich och sagen.

Herr Keller: Ja, un wie jesagt, et hätt net jeder n'Auto, et woar net jeder mobil.

Herr Fischer: Ja, dat hätte mer och ohne Verein jehat.

Herr Keller: Ja, dat schon.

Herr Böhm: Vor allen Dingen jing man jemeinsam schon mal of andere Kirmesse zosammen mi'm Jungjeselleverein: "Hee, häst keen Lost? jonn mer zosammen..." un so weiter un so fort.

Herr Hagen: Nä, mi'm Jungjesellenverein sin mir selten jeschlossen...

${ }^{325}$ Anzumerken ist, daß Gruppengespräche nicht zwangsläufig durch Probleme der Meinungsführerschaft, der sozialen Akzeptanz, der verhärteten Vorurteile oder ähnlichem gestört, manipuliert, nivelliert und inhaltlich bedeutungsschwach werden. 
Herr Böhm: ...net esu. Äwwer mir sin schon öfter zosamme... Dat woaren och die... Da sin ja och Freundschaften entstanden, die sin nachher so zusammenjehalten worden.

Herr Hagen: Vereinstreffen han'mir och net jemach - höchst selten.

Herr Fischer: Han mir jarnet jemaat.

Herr Keller: Ja.

Herr Böhm: Joa, aemoal em Joahr ham'er noaher ahnjefange... ha'mer die Mailehn ehnjelade un han dann jemeinsam Ovendaesse ${ }^{326}$ noa de Kemess jemaat.

Herr Keller: Ja.

Herr Kastner: Ja, Jeselligkeet woar dat...

Herr Fischer: Kameradschaft.

Herr Kastner: Jeselligkeet.

Herr Hagen: Bekanntschaft sou ze treffe, hatte mer net nütich - hatte mer net nütich ${ }^{327}$. Dat kunnte mer sou.

Herr Fischer: Da kunnte mer uns och sou en de Wiertschaft treffe.

Herr Kastner: Et war ja och sonst keine andere Festlichkeit im Ort, ne. Et woar joa jarnix. Also mir waren praktisch die einziste, die wat jemacht han. Denn damals hätt die Feuerwehr och noch nix jemaacht, ne.

Herr Böhm: Nä, nä.

Herr Kastner: Die hat ja erst viel, viel später wat jehat. Dat heißt, mir woarn der einziste, der überhaupt wat jemacht hat, ne.

Herr Fischer: Ist das so? Aus dem Motiv? Die Kameradschaft hätten wir och jehat ohne Verein! Mir hättn uns in de Wiertschaft treffe künne!?

Herr Keller: Dat sowieso.

Herr Böhm: Äwwer dodurch, dat mir jemeinsame jearbeit hatte, also dat Ziel, die Kirmes zu machen un dodadurch dat man jemeinsam jearbeitet hat, is dat doch e bisjen enger zosammejeschweißt.

Herr Kastner: Richtig, dat stimmt.

Herr Keller: Letzten Endes hatten mir joa och viel wenijer Jeld als die hök hatten. Un dodurch kräschte mir Jeld in die Kass rinn un kunnten och Fahrte mache. Sunst kunnte mir wahrscheinlich keen Fahrt maache...

Herr Hagen: ...hätte'mer keen jemaat...

Herr Keller: ...doa woar och wahrscheinlich eijensinnijes [eigennütziges] Denke 'bej, dat mir Jeld ennoahme.

Herr Böhm: Ja, dat koam joa doazo, arwer Jeld...

Herr Keller: ...ja, ja. Dat wued net nur jemaat, dat hee Kirmes woar. Mir woallte och Jeld hann.

$[\ldots]$

Herr Keller: Mir wollt'n Jeld han von der Lök. ${ }^{328}$

Herr Hagen: Dat stimmt schon.

326"Ovendaesse": Abendessen.

327 "nütich": nötig.

328 "von der Lök": von den Leuten. 
Herr Keller: Mir wollt'n net nur arbedde.

Herr Hagen: Doafür sag ich dat joa: Umsonst kann man dat vun keinem verlange. Dat is unmöglich.

Herr Keller: Nä, nä - soll'n die och net.

Herr Hagen: Nä, wie er jetzt sagt, "Weshalb hatt'er dann jesteijert? Um an die Mädschjer ranzukumme?" Mädschjer - da bruch ma nur noa Neuenahr ze fahre. Doa joaf et suveel Mädsche, dat et d'bang wued em Auto, ne Pitte.

Herr Fischer: Ja, doafür brud'e mer och net ze steijere - Mädsche net. Dat woar kee Argument für de Verein.

Herr Kastner: Na ja, mir ha'm uns aber damals och op die Geschichte gestützt. Et waren ja noch alte Akten da, wo der Verein bestanden hat. Un der hätt ja doamals och jesteijert, oder net, wenn ich mich noch recht entsinne.

Herr Keller: Jedenfalls hung dat awwer all doamet zesamme... do weeß och jenau, dat zwei un drei Mann sich jedriwwe ${ }^{329}$ un jedriwwe un jedriwwe hann. Die Sache woar schon doa, die Interesse an de Mädschje woar schon da.

Herr Hagen: Ja schon, et woar joa imme jet doa. Et joaf joa keene, sag'mer ma, wenn ma jetzt achzig oder hundert Mark usführ, wenn de jar keen Interesse jehat hätt. Dann hätt jesagt direk', dann kreje mer kahl Bier ${ }^{330}$ doafür. Jet Interesse wiead joa imme jeweas sin...

Herr Keller: ...ja klar...

Herr Hagen: ...nä dat... su janz afstriede äwwer ne. Äwwer für'n Bekanntschaft kennezeliere?

Herr Keller: Nä, nä. Für dat Mädschje zu hierodde joa net, dat es klar. Äwwer dat es bei mir vielleech och noch jeweas damals.

Herr Hagen: Maach sinn.

Herr Kastner: In der Regel is ja ne jewisse Sympathie da, wenn du jemand steijern willst, dann is er ja dir net unsympathisch, sondern du hast ne jewisse Sympathie für den. Un von der Sicht usjesehn is dat janz normal. Ob derjenije, der et nohher jesteijert hätt, ob der dann noch die Sympathie hat? Oft wurd dat ja och jemmat, um denjenijen hochzubringen un irjendwann hätt der dann jesagt, "Weeßte wat: L-m-a-A!" un dann bleef der doadroff seatze, ne.

Herr Böhm: Et is awer och esu: Et woar en Blamage, wenn ma keen jetzt jesteijert hätt - op deutsch jesagt, ne.

Herr Keller: Ja, ja. Mir han hernoah de Stroawe och huh jesatzt. Wenn die keent hatten, mooten joa hohe Strafen zahlen. [...] Ich glöv, der moot fuffzig Mark bezahle, wer keent hat oder noch mieh.

Herr Hagen: Jetzt?!

Herr Keller: Damals. Wer net jeseteijert hat, der mooßt vial Jeld bezahle.

Herr Hagen: Äwwer kä zwanzig Mark...

Herr Keller: Nä, nä, nä, nä...

Herr Hagen: So hoch aower net...

Herr Fischer: ...iader zwanzig.

Herr Kastner: Fünf Mark, fünf Mark anfangs...

329"jedriwwe": getrieben.

330"kahl Bier": kaltes Bier. 
... es war sehr wenig [Strafgeld] am Anfang, und weil so wenige gesteigert haben, wurd's dann hochgesetzt später...

Herr Keller: ...ja, ja, dat weiß ich ganz jenau, daß es bestimmt fuffzig Mark jeweas...

Herr Hagen: ...ich hann et nie bezahle möße, derweje weeß ich dat net.

Herr Keller: Die durften anschließend net ens met'm Zoch joahn, die mooten noch im Zelt Dienst maache.

Herr Kastner: Also et wurd jedenfalls damals och deswejen jemacht, damit überhaupt em Dorf noch wat is, ne.

Herr Hagen: Sons brauchste keene Festzoch ze maache, wenn net jesteijert woar.

Herr Kastner: Ne Kirmes wurd einfach deswejen och jemaat, damit em Dorf überhaupt jet veranstaltet is. Also ne reine Geldsache deswejen war dat net.

Herr Keller: Doch.

Herr Fischer: Meenste mir hättn doumals so jedaach? So...

Herr Keller: ...nä...

Herr Fischer: ...so für de Jemeinschaft jeddach?

Herr Kastner: Doch! Hann mir. Doch, Pitte, hundertprozentig! Denn wir haben ja damals noch die fuffzig Mark Einlage bezahlen müssen, damit wir über die Runden kommen. Also et hätt doch keene jedaach ... nur für en Reibach zu mache.

Herr Keller: Doch ... nur, nur.

Herr Kastner: Aber du hättest doch die Kirmes anschließend och noch jemaach, ob de jetzt nachher tausend Mark wenijer hattest oder net.

Herr Keller: Dat hätte mer joa...

Herr Böhm: ...de zweite Jedanke, möglichst noch Jeld ze maache, äwwer de ieazte Jedanke woar, de Kirmes ze kreje.

Herr Keller: ... äwwer do siehs, dat se jetz nimmie doafür sinn, weil se winnijer ennemm. Net weil die Ärweet... - die Ärweet is doa, ja, jenau wie och wenn veel Lök da wäre oder vielliech och e bisje winnije. Et Jeld fehlt jetz un derwejen wolln die die Kirmes och jet anders maache. Un mir hann damals och nur an dat Jeld jedaach... ${ }^{331}$

Herr Fischer: ....an dat Jeld jedaach.

Herr Böhm: Nein.

Herr Kastner: Nä, nä.

Herr Keller: ...doa woar zwar Tradition debei, weil...

Herr Kastner: ...nä. Würd ich net sagen...

Herr Keller: ...doch hundertprozentig...

Herr Böhm: Nein, nein.

Herr Kastner: Nä. Also vom Ursprung her net. Wir haben wohl nachher, wie mir dat Dinge moa jemaat hann, oder im zweiten Jahr hann mir natürlich versucht, dat noch besser zu mache un mehr Geld rauszuholen. Aber dat sinn zwei ganz verschiedene Dinge...

Herr Keller: ...dat is doch nachher automatisch kunn, mir hann doch nix jemaach...

331 "nimmie": nicht mehr; "winnijer ennemm": weniger einnehmen; "Ärweet": Arbeit. 
Herr Kastner: ...nä, nä automatisch net. Also ich weeß, dat mir zum Beispiel den Bierlieferanten gewechselt haben...

Herr Keller: ...mir hann doch nix besonderes jemaat?!

Herr Böhm: ...die tollste Musikkapelle hann mir jeholt, den Maizoch hann mir enjeführt, mir hann dat Dorf jeschmück un su jet, dat woar alles en Verbindung, Lök en dat Zelt rinzekrije.

Herr Kastner: Ja.

Herr Böhm: Dat hong alles doamet zesamme.

Herr Keller: Dat maach joa letzten Endes sinn, ja, äwwer wie jesaacht, öm Jeld ze maache, öm Jeld ze maache...

Herr Hagen: Mir hann et jedohn om jewisses Jeld...

Herr Fischer: ...öm Jeld ze kreje?

Herr Hagen: Ja.

Herr Kastner: Nä. Dat würd ich och net sage. Also vom Anfang her un och nachher.

Herr Böhm: Et joang om die Kirmes ... Kirmes ze maache.

Herr Kastner: ...von der Tradition her allein vielleich och net, sondern weil ma jesacht hätt...et es..

Herr Keller: ...un och net die Ärbeed ze maache. Die hätt nämlich keene jern jedoahn...et jing nur um et Jeld.

Herr Kastner: ...et es, et es sons am Ort nix mehr da, weil ja sonst gar nix mehr jewesen wäre.

Herr Böhm: Motivation war, Kirmes ze maache...

Herr Kastner: Dat würd ich och sagen, doch.

Herr Fischer: Dat wird bei jedem unterschiedlich jewesen sein.

Herr Böhm: ...un doabei noch Jeld met ze maache, dat woar der Idealzustand.

Herr Keller: Ja, dann hättste joa Bier für et halwe Jeld verkoofe künne. Da wärn vielliech noch'n paar mieh Lök kunn...

Herr Kastner: ...nä, nä. Dat is klar. Mir hann natürlich dann versucht, dat entsprechende Jeld zu machen, um dann ne Tour oder wat zusammen zu machen. Dat woar schon so.

Herr Böhm: Da hätt uns dat Bengen en de Nas drin jestochen: Die Bengener hann joa moa schwer Jeld met dem Wald- und Wiesenfest jemaach. Die fuhren [gemeinsam in Urlaub] un da hann mir jesacht, su wie die Bengener möchte mer och noch.

Herr Keller: Ja, ja, jaja.

Herr Kastner: Äwwer der Grund woar joa, diesmal Kirmes ze maache...

Herr Keller: Ja, ja

Herr Böhm: ...dat woar joa die Grundvoraussetzung, ne.

Herr Keller: Ja, dat is klar.

$[\ldots]$

Herr Kastner: Aber dat wir dat nur aus Geldgründen, dat war nich so...

Herr Fischer: ...also ich weeß meen Motiv nimmie.

Herr Böhm: Mee Motiv woar: Doa woar ne Verein, doa woall ich och erenn.

Herr Fischer: Jenau dat woar meen Motiv: Doa woar ne Verein, doa woll ich debeesinn. 
Herr Kastner: Richtig.

Herr Keller: Ja, ja.

Herr Böhm: Ma jehört dezoh, jenau. Un dat es och dat hauptsächliche Motiv, wat vermutlich die andere Lök och hann un dann doarinnwaase, ne.

Herr Kastner: Is dat joa och gewesen; sage mer mal, der Verein is ja zuerst mal jegründet worden, und erst dann die Kirmes jemacht worden. So - aber dat mer natürlich aus der Kirmes nachher möglichst viel rausholt is doch...

Herr Böhm: ...dat is doch logisch.

Herr Kastner: ...weil mer ja ne jemeinsame Tour machen wollte. ${ }^{332}$

Die Beantwortung der Frage nach dem Reiz des Mailehens löste ein vielstimmiges Streitgespräch aus. Aufgrund der vergeblichen Bemühungen, im scheinbar wirren Diskussionsverlauf zu einem Konsens zu kommen, fand Herr Fischer zu der Überzeugung, daß die Motive zur Brauchausübung grundsätzlich bei jedem Befragten verschieden sein dürften. In der Tat brachte die empirische Erhebung eine Vielzahl von differenten Äußerungen und Beobachtungen hervor. Bei der Analyse konnten sich die reaktivierten subjektiven Empfindungen und kognitiven Reflexionen der GesprächspartnerInnen zu Erlebnis- und Bedeutungsfeldern zusammenfassen lassen. Eine aufmerksame Betrachtung der Argumente, die in der oben ausgeführten Kontroverse vorgebracht wurden, führt unmittelbar zu inhaltlich relevanten Schwerpunktthemen. So stritten die Diskutanten über den unspezifizierten Eigenwert der Brauchaktionen in Abgrenzung zur ökonomischen Verwertbarkeit der Kirmesorganisation. Ferner klang die herausgehobene Stellung sozialer Kontakte und einer besonderen Rollenübernahme an. Auch der Aspekt der ortsgeschichtlichen Verbundenheit schien dem mailehenspezifischen Treiben ebenso einen Sinn zu verleihen. Diese Spur wird in den folgenden Abschnitten zu verfolgen sein, um ein verdichtetes Bild von den Erlebnissen, den Erlebnisweisen und den persönlichen Auseinandersetzungen $\mathrm{zu}$ erhalten, aus dem sich der Erfahrungsraum Mailehen derzeit konstituiert und sich realitätsnah erfassen läßt.

\subsubsection{Voreheliche Kontakte}

Soziale Kontakte sind bei der Durchführung des Mailehens stets konstitutiv gewesen. Von dem Aufstellen des Dorfmaibaums bis zur Kirmesmannverbrennung traten die Mitglieder einer lokalen Gemeinschaft in einen Handlungszusammenhang, der durch den Brauch seinen äußeren, formellen Rahmen erhielt. Gruppen oder Paare wurden gebildet, um Rituale vorzubereiten und durchzuführen. Ferner kamen Familienangehörige, FreundInnen, Bekannte, auswärtige Kirmesgäste und Fremde im Namen des Dorffestes zusammen. Vereint unter dem Dach des Festzelts begegnete man sich bei Musik, Tanz, Unterhaltung und Beköstigung. Abgesehen von diesen allgemeinen Situationsbedingungen wurde das Mailehen vor allem mit der Suche

${ }^{332}$ Gruppengespräch II (50/33-37/3a:556-696). 
nach LebenspartnerInnen in Verbindung gebracht. Die herkömmliche Deutung des rituellen Geschehens als vorehelicher Kontaktbrauch hat an Aktualität wenig eingebüßt, auch wenn in dem oben ausführlich wiedergegebenen Gruppengespräch Zweifel laut geworden sind. Mit dem Argument, daß es bereits in den sechziger Jahren an Gelegenheiten keinesfalls gemangelt habe, sich mit interessanten Frauen der Umgegend zu befreunden, hat man versucht, die Sichtweise eines ehemaligen Mitstreiters aus dem Junggesellenverein zu entkräften. Jener hatte auf die Frage nach dem entscheidenden Antrieb zur Brauchausübung die Frauen an oberster Stelle erwähnt. Wenn nach den tieferen Sinn- und Erlebnisschichten gesucht wird, die in der Mailehenpraxis eine Rolle spielen, dann erscheint die Klärung des Widerspruchs zwischen symbolischer Verkupplung unverheirateter Paare im Brauch und real erfahrener Liebesbeziehung im Alltag von Bedeutung. An diesem Punkt stellt sich das Problem, ob das Brauchleben vom realen Leben scharf zu trennen ist oder ob und welche Verbindungslinien zwischen beiden Seiten gezogen werden müssen. Vergegenwärtigt man sich, daß nur ein geringer Anteil der rituell ermittelten Paare sich in der Folge auch zu Ehepaaren zusammengeschlossen hat, so erhält die Argumentation der Kritiker anscheinend eine empirische Beweiskraft. Selbst für diejenigen, die geheiratet haben, gilt nicht unbedingt, daß ihre Beziehung auf jener persönlichen Involvierung im Brauchgeschehen aufbaute. ${ }^{333}$ Bis in die Gegenwart hinein kam es selten vor, daß sich Freundschaften direkt auf die Ergebnisse einer Mailehenversteigerung zurückführen ließen. Dabei ist es unerheblich, ob man die Biographien von Maikönigs- oder Mailehenpaaren verfolgt.

Aufgrund des Erhebungsmaterials eröffnen sich zwei Perspektiven, um die voreheliche Bedeutung des Mailehens zu erkennen. Die eine reflektiert das Konfliktpotential, welches das Mailehen im Vorfeld der Verehelichung in bereits bestehende feste Bindungen von Liebespaaren hineintragen kann. Die andere läßt sich auf unmißverständliche Aussagen der Betroffenen zurückführen, die bestätigen, daß die vorgefallenen Preistreibereien und Ersteigerungen am Maiabend nicht nur von dem Alkoholkonsum, der finanziellen Liquidität oder der Lust und Laune des Ersteigerers beeinflußt wurden. Oft verbarg sich dahinter ein ernsthafter Versuch des Junggesellen, einen intensiveren Kontakt zur Auserwählten herzustellen.

\subsubsection{Paare im Widerstreit}

In Gesprächen betrachteten Frauen die Tatsache, daß sie von einem Junggesellen ersteigert und zum Mailehen oder zur Maikönigin gemacht wurden, nicht selten als Quelle von Eifersucht, Konflikten oder gar Trennungen. Damit kam der Mailehenoder Maikönigschaft, als einer Art ritueller Alternative zur selbstbestimmten festen Liebesbeziehung, ein irritierendes, wenn nicht destabilisierendes Potential zu, das den

${ }^{333}$ So äußerte sich Frau Heuerdorf (23/15/2a:121-160). 
Anstoß geben konnte, die voreheliche Lebensplanung $\mathrm{zu}$ hinterfragen, $\mathrm{zu}$ durchdenken und ihr eventuell eine neue Richtung zu geben. Eine harmlose Form dieser speziellen Belastungsprobe, die durch das Mailehen ausgelöst werden konnte, spiegelt sich in folgender Passage wider:

Der einzige, der skeptisch war, war halt mein Freund, verständlicherweise auch irgendwo. Der wußte auch gar nicht, was auf ihn zukommt. Und dann saßen die dann sonntags hier: alle nur Männer, leicht angetrunken und müde.

Und ihr Freund hat das alles mitgemacht?

Nee, hat sich dann ganz rausgehalten. Er war dabei, als sie mich hier abgeholt haben und an dem Sonntag, am ersten Mai, war er ein Stündchen dabei. $\mathrm{Zu}$ seinem Glück damals stand er kurz vor einer Prüfung und hatte viel zu büffeln. Und während ich dann unterwegs war, hat er gebüffelt. Nee, es hat ihm überhaupt nicht gefallen. Auch dann im Festzelt mit den Freunden zusammen, dann ist er auch nach der halben Stunde ist er dann auch mitgetigert. Er kam sich deplaziert vor, einfach. Ein bißchen dumm kam er sich vor, als Freund. Er hat das sowieso nicht ganz verstanden: "Das kann man doch nicht machen, wenn man ne feste Beziehung hat!" Dabei hatte ich mir dann weniger gedacht: "Is halt en Brauch." 334

Hier kommt eine typische Konstellation von Haltungen und Verhaltensweisen zum Vorschein: Die Freundin eines Mannes wurde zur Maikönigin gekürt. Als Neubürgerin war Frau Pfeiffer nach anfänglicher Überraschung stolz und erfreut. Ihr Engagement wurde zudem von ihrer Familie unterstützt. Dagegen konnte sich ihr Lebenspartner nur schwer mit den Brauchaktivitäten abfinden. Für ihn war die Situation unverständlich und vor allem deshalb kaum zu ertragen, weil der Brauch die Junggesellen legitimierte, von außen in seine Zweierbeziehung einzugreifen. Während Frau Pfeiffer das ganze Geschehen als unverdächtig und als Möglichkeit ansah, den Status der Ortsfremden zu überwinden, geriet ihr Freund mit den Implikationen der rituellen Paarbildung in Konflikt. Nicht er, sondern jener rituell legitimierte Konkurrent traf die Vorbereitungen, um an der Seite der Liebsten den festlichen Umzug in der repräsentativen Kutsche zu begehen, die zahllosen Extratouren zu tanzen und schließlich auch den Aufforderungen zum Maibutz in aller Öffentlichkeit nachgeben zu dürfen. Frau Pfeiffer blieb letztlich auch nicht verborgen, daß ihr Maikönig mit seiner Amtsübernahme und der Auswahl seiner Mitregentin bestimmte Absichten verfolgte:

Ich weiß nicht, wieso er mich [als Maikönigin] ersteigert hatte: vom Sehen her gekannt und irgendwie kam das dann.

Und das ergab sich vom Jahr vorher [als sie zusammen ein Mailehenpaar waren] nicht ein näherer Kontakt?

Nein. Ja, so ab und zu, wenn man sich mal sieht oder so, dann unterhält man sich mal etwas näher. Nee, näherer Kontakt eigentlich nicht. Dadurch, daß er zu der Zeit auch beim Bund war, schon gar nicht.

Hatte er auch keine Andeutung gemacht, daß er möglicherweise Sie im Auge...

${ }^{334}$ Frau Pfeiffer (46/32/1a:440-462). 
...doch! Doch, doch das schon. Ja, ja. Deswegen war er ja auch so eifrig und fordernd: "Jetzt mußt du aber machen!" und so, das schon. Aber er wußte auch von Anfang an, daß ich en festen Freund hatte. Also das wußte er schon. ${ }^{335}$

Die unterschiedlichen Positionen treten nun klar hervor: Der Brauch eröffnete dem Maikönig die Möglichkeit, seinen persönlichen Neigungen zur rituell ermittelten Gefährtin nachzugehen und Ausdruck zu verleihen. Dies hinderte die Maikönigin keinesfalls daran, die Konditionen ihrer Bereitschaft zur Teilnahme am Brauch deutlich zu machen. Daß sie ihre bestehende Liebesbeziehung nicht gefährden wollte, hatte der Maikönig zu akzeptieren. Das Beispiel von Frau Pfeiffer hat gezeigt, daß eine Ankündigung von vorehelichem Werbungsverhalten im Rahmen des Mailehens nur dann erfolgversprechend sein kann, wenn gleichgerichtete Interessen der Akteure vorauszusetzen sind. ${ }^{336}$

Das Aufeinandertreffen der verschiedenen, subjektabhängigen Erwartungen und die Konfrontation von rituellen und realen Mann-Frau-Beziehungen stellten sich nicht immer so harmlos dar wie im obigen Beispiel. Die Erfahrungen von Frau Kruse, die das Brauchtreiben über mehrere Jahre aktiv mitverfolgte, haben die Problematik deutlich gemacht:

Was ich immer schade finde (okay, ich war nie Maikönigin), aber die meisten, die Maiköniginnen wurden - die können ja praktisch gar nichts dafür, die werden ausgesucht, und dann is es so -, aber die haben Krach mit ihren Freunden.

Während der Zeit?

Während der Zeit. Wie ich es erste Mal mitgesteigert worden bin, ist auch ne Freundin von mir mitgesteigert worden. Die ist direkt im ersten Jahr Maikönigin geworden. Die hatte den ganzen geschlagenen Mai Krach mit ihrem Freund. Die hatte den ganzen Monat Vorhaltungen von ihrem Freund gekriegt, ne. Also dat versteh ich einfach nicht. Auch damals mein ehemaliger Freund: "Du wirst doch net Maikönigin!? Du wirst dat doch wohl ablehnen, wenn du wirst!?" Ich sag: "Ich würd dat im Lebtag net ablehnen!" Obwohl ich ja nie Maikönigin war, hatten mir immer, bis daß es raus war, wer Maikönigin wird, Krach - schon vorher. Ich war ja nie Maikönigin, aber dann die Zeit so vorher so: "Es is bald Kirmes, Mainacht, mal gespannt wer Maikönigin wird, du wirst es!" - "Nä, du wirst es!" - "Nä, ich werd es auf gar keinen Fall!" und so. Und dann: "Wie, du wirst doch kein Maikönigin!?" Und dann hatten mir schon Krach. Also furchtbar! ${ }^{337}$

Die Kirmes und der Maibrauch eigneten sich auf diese Weise als Prüfkriterium der Stabilität einer vorehelichen Beziehung. Sie erlaubten vielfältige menschliche Begegnungen und Einblicke in die Mechanismen von gegenseitigem Vertrauen und gegenseitiger Achtung. Hieran entspann sich nicht selten ein destruktiver Wettstreit zwischen Eifersucht auf der einen, ausgelassener Lebensfreude auf der anderen Seite. Ein erprobtes Mittel, die Beziehungskrisen während der Kirmestage zu begrenzen,

${ }^{335}$ Frau Pfeiffer (46/32/1a:340-351).

${ }^{336} \operatorname{Im}$ Gruppengespräch I (39/23-27/2b:654-660) hieß es, daß die ledigen Frauen, die einen festen Freund besaßen, nicht mehr gesteigert worden seien.

${ }^{337}$ Frau Kruse (25/17/1a:602-630). 
schien in der Abstinenz der argwöhnenden Partner zu liegen. Wer gegen seine Eifersucht nicht ankäme, habe sich von den Feierlichkeiten fernzuhalten und den Spaß derer nicht $\mathrm{zu}$ verderben, die manchmal über das ganze Jahr hinweg in erwartungsvoller Vorfreude auf diese Kirmeslustbarkeiten geblickt haben. ${ }^{338} \mathrm{Da} 3$ aber die Verläßlichkeit und Treue des eigenen Partners hier durchaus realen Gefahren ausgesetzt sein konnten, wurde in Gesprächen bestätigt. Lediglich gefestigte, "hundertprozentige" Freundschaften waren hiervor anscheinend geschützt. Das Erlebnis des Mailehens offenbarte sich an dieser Stelle als eine Gratwanderung, bei der die anregenden und spannenden Elemente des zwischenmenschlichen Umgangs gleichzeitig mit den soliden und beständigen Werten der Zweierbeziehung korrespondierten. Hierzu Herr und Frau Kruse:

Herr Kruse: Is natürlich so ne Sache. Es sind schon sehr viele Beziehungen kaputtgegangen durch so wat. Ich kenn auch selber welche: Sie hatte nen festen Freund, ja, un dann war dat halt so, dat sie gesteigert wurde von jemandem. Und sie fand den auch ganz interessant und er sowieso sie schon vorher, sonst hätt er sie auch net jesteigert. Okay, dat muß net immer sein. Et gibt och so Kumpels, wie jetzt der Michael mit der Hanne, obwohl der ja an für sich och schon mal was mit der hatte. Aber trotzdem, ne. Da sind auch schon Beziehungen gescheitert, ne, an so wat. Und ich glaube, dat kann man manchmal auslegen wie man will; so ganz grundlos is es nich.

Frau Kruse: Aber so ne Beziehung, die muß doch so wat in't Vertrauen setzen, oder?

Herr Kruse: Ja, dat ja. Aber trotzdem is et kaputt gegangen.

Frau Kruse: Dann war et aber nie so richtig hundertprozentig!

Herr Kruse: Boa - dat würd ich net sagen.

Frau Kruse: Ich weiß net, irgendwann steigert sich dat. [...] Und irgendwann is dann Schluß. Ich glaub auch, wenn alle gedacht haben, es klappt alles, mir verstehen uns so gut. Aber ich glaub, wenn dann so ne Beziehung dadurch auseinandergeht durch so ne Kirmes - okay, et gibt Frauen wie Männer, die dazu geneigt sind, fremdzugehen. Die sagen: "Wat heißt 'fremdgehen'?" Die sehen dat locker; die sehen dadrin noch kein "Fremdgehen". Aber ich glaub, ne richtige, feste Beziehung, die kann so was aushalten, wenn man eben halt ein paar Tage Kirmes feiert. Okay, man muß en gewisses Vertrauen haben, ne. Es is klar, Flirten tut man. Also... wenn ich sagen würd, ich würd mit keinem flirten, da würd ich lügen. Aber ich mach mit keinem rum. Un dat is en Unterschied, ne, ob man mit jemandem flirtet oder ob man da richtig anbaggert. Aber die kriegen auch ein passendes Wort gesagt, ne. Un es gibt auch immer so en anbaggern un so en. Manche fangen ja so richtig an zu Grapschen und so weiter. Das is ja widerlich, ne.

Herr Kruse: Das sin die Schattenseiten, ne. ${ }^{339}$

Diese Diskussion hat gezeigt, daß dem Mailehen durchaus eine Bedeutung in der vorehelichen Kontaktaufnahme zukam, und zwar in zweierlei Hinsicht: Unter der Voraussetzung gleichgerichteter Interessen konnten die jungen Männer und Frauen sich von bestehenden Liebesbeziehungen lösen und aufgrund der rituellen Paarzu-

${ }^{338}$ Frau Kruse (25/17/1a:648-666).

${ }^{339}$ Herr und Frau Kruse (25/17/1a:630-715). Vgl. auch Frau Gebhard (41/28/1a:552-567), die die Meinung von Frau Kruse teilt, daß die Ursachen für Beziehungskrisen häufig nicht auf das Mailehen zurückzuführen seien. 
teilung zueinander finden. Darüber hinaus eignete sich die Brauchausübung zum affektgeladenen Flirt, der die festen Freundschaften nicht unbedingt gefährdete. Im Gegenteil, die positiv überstandene Belastungsprobe erschien innerhalb der vorehelichen Beziehung als eine Form des gegenseitigen Vertrauensbeweises. Der Mailehenbrauch bereitete den Raum, die Zeit, die sozialen und kulturellen Umgangsformen wesentlich vor, welche die konkreten Kontakte zwischen AkteurInnen leiteten, und zwar unabhängig davon, ob es sich um Maikönigs- oder Mailehenpaare handelte oder ob es um langjährige Freunde des lokalen Umfeldes oder um zufällige Kirmesbekanntschaften ging. Jene Kontakte konnten dazu geeignet sein, bestehende längerfristige Bindungen zu gefährden oder neue erwachsen zu lassen, wie sich anhand der Äußerungen von Frau Eder ablesen läßt:

Aber dann hier die eine: ein Junggesell is der ihr Freund seit'm Mai. Die sind schon so lange zusammen seitdem.

Der hatte die ersteigert?

Nä, aber so sieht man auch, daß so manche zusammenkommen, obwohl sie sich vorher gar nicht kannten, ne. Durch den Mai, durch die Kirmes haben sie sich gut kennengelernt und sind dann zusammengekommen. Ist doch schon schön, was das alles bewirken kann, so ne Kirmes.

Und dein Maikönig, der hat sich wahrscheinlich dich ausgesucht, weil er dich...

...weil ich ihm gefalle.

...ganz gut fand - oder hast du ne andere Erklärung?

$\mathrm{Ja}$, ich mein, ich hab seit über zwei Jahren en Freund, mit dem ich schon so lang zusammen bin. Ich mein, er is en total lieber Kerl, aber ich würd ja nicht deshalb mit meinem Freund Schluß machen. Es is en lieber Kerl, ehrlich, aber ich hab ja meinen Freund. Wenn ich vielleicht keinen Freund hätte, wär's vielleicht was anderes, aber so. Das geht ja net.

Und dein Freund, wie hat der sich dazu...

...der is ja die ganze Kirmes... Nicht einmal war der hier. Und der hatte gesagt, das könnt er sich nicht angucken. Er wäre zu eifersüchtig dafür. Tja... könnte er sich nicht angucken. ${ }^{340}$

Die Optionen, die das Mailehen im Vorfeld vorehelicher Kontakte für die einzelnen generierte, treten hier nochmals klar hervor. Der Brauch trug dazu bei, daß junge Frauen und Männer sich kennenlernten und einander näher kommen konnten. Es gelangte aber auch ins Bewußtsein, daß die Konventionen partnerschaftlicher Bindungen, wie zum Beispiel gegenseitige Zuverlässigkeit und Treue, durch die Brauchausübung nicht außer Kraft gesetzt werden sollten.

\subsubsection{Perspektiven der Ersteigerer}

Ich hab während der ganzen Zeit [der Vereinsmitgliedschaft] nie ein Mädchen ersteigert, kein einziges. Es war keins dabei, das mir gefallen hätte, und ich konnte es nicht, mit irgend einem Mädchen gehen, das mir nicht zusagte, nicht. ${ }^{341}$

${ }^{340}$ Frau Eder (21/14/1a:238-265).

${ }^{341}$ Herr Fischer (33/20/2a:103-109). 
Hätte eine Mehrzahl der Junggesellen ähnlich empfunden und wäre $\mathrm{zu}$ denselben Schlußfolgerungen gekommen wie Herr Fischer, dann würde man das Mailehen wohl kaum noch in Oeverich antreffen. Das Zitat macht auf die persönlichen Voraussetzungen der Mailehenersteigerer aufmerksam. Für Herrn Fischer war eine Beteiligung an Bietgefechten ausgeschlossen, solange kein tiefergehendes Interesse sein Verhältnis zu den potentiellen Brauchpartnerinnen bestimmte. Dieser Zusammenhang zwischen persönlicher Zuneigung und ritueller Zuteilungspraxis ließ sich zudem dort bemerken, wo die Emotionen und Affekte die Preistreibereien beherrschten. Die Feststellung, daß der Maikönig sein besonderes Interesse zu einer jungen Dorfbewohnerin aufgrund der rituellen Auswahl zum Ausdruck bringen konnte, findet sich schon in einer Beurteilung früherer Brauchpraxis durch Herrn Selm:

Und mit dem Mailehenschreiben: Da weiß ich auch nicht. Da hieß es: "Der Sowieso oder die Sowieso is Maikönigin!" - "Ja, wer hat sie denn geboten?" - "Och, der Sowieso." - "Ja, ja. Die haben ja auch sonst schon ganz gut... zusammen hat man die manchmal gesehen." Ja. Aber alles, alles harmlos. ${ }^{342}$

Auf diese Weise nahm die Dorfbevölkerung in den 1930er Jahren Anteil an der Wahl des Maikönigs. Sie beurteilte, ob das Regentenpaar zusammenpaßte. Dadurch, daß die beiden bisweilen miteinander in Kontakt standen, war die rituell erzeugte Zweierkonstellation für Außenstehende schlüssig. Die gegenseitige Bekanntschaft war der Garant dafür, daß die beiden etwas miteinander anfangen und miteinander klar kommen konnten. Vielleicht erwies sich ja eine gegenseitige Zuneigung, welche die Betreffenden zur Lebenspartnerschaft zusammenschloß. Genau an diesem Punkt lehnte sich Herr Selm vorsorglich gegen den Verdacht auf, daß der Brauch zu Unsittlichem verführen könnte. Er stellte heraus, daß alles harmlos gewesen sei, denn uneheliche Kinder seien ihm nicht bekannt geworden und die Pille zur Schwangerschaftsverhütung habe es damals nicht gegeben. Die Abfolge menschlicher Biographien von der Jugend zur Eheschließung und zur Familiengründung schien insoweit unmißverständlich vorgezeichnet. Daß das Mailehen hierbei gewissermaßen eine wichtige Tür öffnen konnte, stand für Herrn Stein unabweisbar fest, der die unmittelbare Nachkriegszeit als Junggeselle erlebt hat:

Un dann waren ja och junge Leute, die sich wirklich... Jungjesellen, die sich in e Mädschje verlieben, verknallt hatt'n, ne. Un die han schon im Winter anjefangen ze sparen, ze sich selbst jesacht: "Meine Freundin, die steijere... die mache ich dies Joahr zur Maikönijinn!" ne. Un im Grunde jenommen waren die Mädels da alle stolz drof. Egal was da ov der Versteijerung jequasselt wurd, ne, alle stolz drof, Maikönijin zo werden oder zomindeste en hohes Anjebot ov se jemacht wurden, ne. ${ }^{343}$

${ }^{342}$ Herr Selm (42/29/1b:51-66).

${ }^{343}$ Herr Stein (12/11/1b:341-350). 
Das Ersteigern wurde hier als Liebesbeweis angesehen. In dem Zusammenhang sollte der Brauch aber nicht mißinterpretiert werden. Das Mailehen diente nicht unmittelbar der Eheanbahnung. Es war kein derart monokausales oder folgenschweres Ritual. Im Gegenteil, es sollte als ein impulsiver, jugendlicher Spaß aufgefaßt werden, wie Herr Stein zu verstehen gegeben hat:

Manche erfuhren andern tags, erfuhrn die erst, dat se zwei oder drei Mailehn jesteijert hatt'n, ne. Och, da war'n och welche, die hatt'n in jedem Arm eine, ne. Aber da ham die Mädchen sich nicht beleidigt gefühlt, dat zwei oder so. Man hatte es eben als Brauch, aber doch net... Es wurde ja niemand verpflichtet, sein Mailehn zu heiraten, und umgekehrt wurden die Mädels ja och net verpflichtet, den ze heiraten. Aber viele han... [...] Also ne janze Anzahl - jetz fallen se mir jetz net so all mehr ein, die sich durch diese Mailehnversteijerung kennenjelernt han, darüber liebenjelernt und dann jeheiratet han. Also is oft so, aber umjekehrt gibt's och bestimmt mehr, han nich jeheiratet, ne. ${ }^{344}$

Auch hier herrschte wieder die Überzeugung vor, daß die Mailehenversteigerung durchaus von den vorehelichen Ambitionen der Ersteigerer getragen wurde. Zugleich wurden aber die reellen Chancen und Grenzen einer vielversprechenden Lebenspartnerschaft, die sich aus dem Brauch hätten ergeben können, stark relativiert. Ehen kamen zumeist auf andere Weise zustande. ${ }^{345} \mathrm{Da}$ sich unter der Ausübung des Maibrauchs Paare fürs Leben finden ließen, ist aber dennoch einem jüngeren Gesprächspartner, Herrn Decker, bewußt gewesen. Er bemerkte, daß sich in jüngerer Zeit ein Wandel abzeichne, der nur noch wenig Optimismus in dieser Frage zulasse:

Früher muß man sagen - grad en Oeverich - da sin zwei die ich mit Bestimmtheit noch weiß, wo der Maikönig und die Maikönijin och später jeheiratet han. Un dat is en den letzten Jahren och net mehr. Also die machen nur diese Steijerungen und die Mädchen jonn noch met, aber die meiste hann zur Zeit schon feste Freunde. Also diese Verbindungen, wie die früher waren, die sin och nemmehr; also wat da noch wat nach koam, ne. Awwer et waren zwei zu meiner Zeit noch, da hat der Maikönig un die Maikönijin, die han da später jeheiratet un han en Familie jegründet.

Is dat denn über den Brauch gelaufen, oder haben die sich...

...nä, die ham sich da kennenjelernt. Über den Mai ham die sich kennenjelernt. Et is ja so: Der Maikönig, der holt sich ja ne Maikönigin, die ihm och sympathisch is. So, dat sin Freundschaften, die im Mai entstanden sin und dann noch, sag mer, die Nachwehen, und dann nachher haben sie jeheiratet. [...] Das is aber heut... also in den letzten Jahren hab ich dat nemmehr erlebt. Also noch nemmehr, woll mer mal sagen, dat die Mailehen, also dat die praktisch doa... also nachher noch irjenswie wat mehr war, ne.

Und das erklären Sie sich dadurch, daß die vorher schon Freundinnen, feste Freundinnen haben - die Junggesellen?

Jetzt? Jetzt? Ja, jajaja.

War das denn früher nicht auch ähnlich?

\footnotetext{
${ }^{344}$ Herr Stein (12/11/2b:445-462).

${ }^{345}$ Prothmann (1982:302) hat berichtet, daß man in Oeverich ortsfremde EhepartnerInnen bevorzugt habe.
} 
Ja, aber man muß doch sagen - ich mein, wenn wir von früher reden, muß man natürlich dreißig Jahre zurückrechnen, ne - da hatten die Mädchen mit sechzehn Jahren kein feste Freundschaften. Dat woar ja alles viel älter, jenau wie die Jungen och. Awwer heut, heut han die Mädchen ja mit fuffzehn Joahr, dann han se schon feste Freunde - die Jungens och, ne. Dat woar joa damals net esu. Hätten die Eltern ja, die hätten ja offjepaß wie en Luchs. ${ }^{346}$

An diesem Punkt ist es nützlich, eine weiter unten zitierte Aussage einer jungen Frau heranzuziehen. Die Informantin war in den 1990er Jahren Maikönigin und vertrat die Ansicht, daß ihr Ersteigerer durchaus auf ihre Gegenliebe hätte treffen können, wäre sie nicht zu jenem Zeitpunkt mit einem anderen Jungen fest befreundet gewesen. Die Interpretationen männlicher und weiblicher Brauchakteure gelangen damit zu demselben Schluß: Frühe Liebesverhältnisse unter Jugendlichen stehen der vorehelichen Kontaktaufnahme im Rahmen der Mailehenausübung entgegen. Diese Folgerung erscheint auf den ersten Blick einleuchtend. Angesichts anderer Stimmen bedarf sie aber einer zusätzlichen Konkretisierung. So machten die befragten Frauen darauf aufmerksam, daß ihre Chancen, einen Maikönig oder ein Mailehen nach ihrer Wahl zu bekommen, generell unberechenbar gewesen seien. Die Feststellung, noch nie habe eine Maikönigin durch die Mailehenversteigerung ihren Wunschkandidaten erhalten, hat mir eine Dorfbewohnerin am Abend der Versteigerung im Wirtshaus mitgeteilt. Ähnliche Desillusionierungen waren meinen Gesprächspartnerinnen nicht fremd. Man gab zu bedenken, daß der weibliche Einfluß auf die rituelle Paarzuteilung von zu geringem Gewicht sei, als daß sich feste Beziehungen aus dem Mailehen hätten ergeben können. 347 "Aber so... ich mein, der Maikönig, der hätte gern met mir wat anjefangen. Aber der jefiel mir net", bemerkte Frau Heuerdorf, die in den Nachkriegsjahren zur Maikönigin gekürt wurde. ${ }^{348}$ Nach anfänglichem Widerwillen beugte die damals Sechzehnjährige sich dem Druck des Vaters, erfüllte ihre Repräsentationspflichten bei den Bällen und war erleichtert, als die Kirmestage endlich ein Ende gefunden hatten.

Diese in den Nachkriegsjahren herrschenden Verhältnissen verloren in jüngerer Zeit keinesfalls an Bedeutung. Frauen nachfolgender Generationen haben gleichfalls von Junggesellen berichtet, die mit der Maikönigschaft die Hoffnung verbanden, einen engeren Kontakt zu der Erwählten herzustellen. Frau Dietz erinnert sich:

Wie hast Du dann erfahren, daß Du Maikönigin geworden bist? Wie war das?

Die [Junggesellen] kamen dann, und ich wußte es ja auch schon durch die Tanne und dann wie gesagt, weil mein Bruder es mir gesagt hatte. Aber ich könnte jetzt nicht sagen, daß ich mich überschwenglich gefreut hätte, ich könnt auch nicht sagen, daß ich... ja, das war nun mal halt eben so, ne, so war es jetzt. Ich denk, daß sind in dem Moment och zu viele Sachen...

...und der Maikönig?

\footnotetext{
${ }^{346}$ Herr Decker (24/16/1a:569-598).

${ }^{347}$ Siehe unten Kapitel 4.4.2.2.

${ }^{348}$ Frau Heuerdorf (23/15/2a:140-153).
} 
...die auf einen zu kommen, ne. Ja, also ich denke schon, daß der Maikönig damals - ich weiß net, ob das jetzt unbedingt hier rein gehört -, daß der also auch ganz andere Ambitionen hatte. Der hatte sich vielleicht auch mehr davon versprochen, daß er dachte: "Ach ja, kannste irgendwie mit der anbändeln oder so." Ich denke schon, daß so aus dem Verhalten heraus, so wie ich ihn kenne, [...] daß er das schon - ja, was heißt positiver - aber sich mehr darauf gefreut hatte, ne. Ich denke, daß mein Gefühl mich doch nicht allzu sehr getäuscht hat. Denn man merkt das ja dann doch schon: Is das mehr so... Vielleicht war mir das alles deswegen alles so... Ich war, wie gesagt, froh als das ganze rum war und war abgeschlossen, ne.

Daß du das Gefühl hattest, daß es doch nicht so auf Gegenseitigkeit...

... nein. Von ihm aus dann schon, aber von meiner Seite nicht, ne. Vielleicht ist das dann auch noch so ne negative Begleiterscheinung. [...] Aber andererseits denk ich auch, wenn en Maikönig sich en Mädchen aussucht, dann wird ihm das ja och wohl gefallen, denn sonst... Der wird ja dann nicht irgend jemanden von den anderen nehmen. Also vermut ich mal. ${ }^{349}$

Die Strukturen und Erfahrungen im Zusammenhang vorehelicher Kontaktaufnahme durch das Mailehen waren über Jahrzehnte vergleichbar. Sie waren an die prinzipiellen Vorbedingungen der Brauchausübung geknüpft. Die Tatsache, daß unverheiratete Frauen kaum Einfluß auf die Partnerwahl ausüben konnten, verringerte bis zur Gegenwart noch oft die Chance der vorehelichen Kontaktaufnahme durch das Mailehen.

\subsubsection{Anbahnung sexueller Beziehungen}

Der tabuisierte Bereich vorehelicher Sexualität spielte in der Auseinandersetzung mit dem Mailehen schon in der Frühen Neuzeit eine Rolle (siehe Kap. 3.6). Auch in Oeverich beschäftigte man sich mit diesem Thema. Im vorangegangen Abschnitt berichtete ein Informant, Herr Selm, davon, daß die Zusammengehörigkeit der unverheirateten Maipaare durch das Brauchprozedere öffentlich wurde. Dennoch hätten sich die Jugendlichen stets den damaligen Sittlichkeitsanforderungen des sozialen Umfeldes verpflichtet gefühlt. Man sei weit davon entfernt gewesen, einer triebhaften Begierde zu verfallen. Er beteuerte, früher sei "alles, alles harmlos" verlaufen, und dementsprechend habe es auch keine unehelichen Nachkommen gegeben. ${ }^{350}$ Damit wurden die Brauchtreibenden zumindest für die Zeit bis zum Zweiten Weltkrieg von dem häufig kursierenden Verdacht ${ }^{351}$ freigesprochen, daß sie die rituellen Gelegenheiten durchaus genutzt hätten, Normen der ländlichen Sexualmoral zeitweilig außer Kraft zu setzen.

Ebenso ist sich diejenige Generation, deren Jugend in die frühen Nachkriegsjahre fiel, darüber einig, daß man damals libidinösen Versuchungungen standhaft widerstehen mußte. Vor allem Eltern und Pastoren wachten darüber, daß sich die Heranwachsenden unter keinen Umständen zu weit hervorwagten und mahnten deshalb

\footnotetext{
${ }^{349}$ Frau Dietz (02/03/1b:7-30 und vgl. 02/03/1a:691-713).

${ }^{350}$ Herr Selm (42/29/1b:51-64).

${ }^{351}$ Siehe Kap. 3.6.
} 
eindringlich: "Wenn du mit'm Könd anjezore küß...!"352 Die Betroffenen hielten sich an diese bruchstückhafte, aber wirkungsvolle Drohung. Sexuelle Enthaltsamkeit schützte nicht nur vor unerwünschter Nachkommenschaft, sondern auch vor der sozialen Marginalisierung. Die Zeiten hätten sich allerdings geändert, so lautet das gemeinsame Credo im Gruppengespräch. Auf die sexuelle Domestizierung von damals sei inzwischen eine Freizügigkeit gefolgt, die zu erheblichen Verständnisschwierigkeiten zwischen den Generationen führe:

War man denn an den Kommabenden unter Aufsicht der Eltern?

Herr Schmitz: Och, watt. Och, watt.

Frau Marx: Nee.

Frau Rosen.: Wir waren noch so brav, wir brauchen keine Aufsicht. [...]

Herr Marx.: Das hatte mit den Eltern nichts zu tun.

Also das gab's eigentlich nicht, daß man sich da näher gekommen ist?

Herr Schmitz: Dat maach et och ejenn han.

Frau Rosen: Ja, wenn... nä; so nicht, glaub ich nicht.

Frau Marx: Soviel wie ich weiß, nicht.

Frau Rosen: Heinrich, sin mir uns näherjekommen?

Herr Marx: Dat is at lang her.

Frau Rosen: Do weeß et nimmie?! Ich weeß et awwer noch. E Küssje, dat woar et awwer dann.

Herr Marx: E Bützje un dann en jod Taat ${ }^{353}$. [...] Es wurde vor allen Dingen immer gut gegessen...

Frau Rosen: ...aufgewartet, aufwarten, das mußte man wohl. Das war das A und O, wenn der Junge mit Nachhaus kam. Egal, ob das was Festes oder hier so ne lose Beziehung [war], ne Aufwartung mußte jemacht werden. Dat war et wenigste. [...] Et woar alles halb so wild.

Herr Marx: Et war ne ganz andere Je... et war janz anders.

Frau Rosen: Alles zesamme war ne janz harmlose Anjelejenheit...

Herr Marx: ...Das kann man sich heute gar nicht mehr vorstellen.

Frau Rosen: ...total harmlos. Anders kann ich't net saare.

Herr Schmitz: ...ne janz andere Zeit.

Herr Marx: Ne ganz andere Zeit, ach du lieber Gott.

Deswegen find ich's so wichtig, daß Sie darüber mal erzählen.

Frau Marx: Unsere Kinder, die denken, mir wären net normal jewesen.

Herr Marx: Die sagen, mir sin Bekloppte.

Frau Marx: Mir sin wirklich nicht normal jewesen in der Jurend, nicht normal.

Frau Rosen: Weeste wat meen Cousin jesaat hät? "Edith, ich soat ich weeß jar net, ich han nur der Franz jehat. Doa woar vürher keene, doa woar während keene, doanoah keene." Ich saat:

${ }^{352}$ Gruppengespräch I (39/23-27/2b:41-105).

353 "en jod Taat": eine gute Torte. 
"Annegret, da sin ich sou unmodern wie duo. Ich han och nur meenge eene jehat." Da sin mir total unmodern.

Frau Marx: Ja, ehrlich!

Frau Rosen: Doa laachen die junge Löck drüvver.

Herr Schmitz: Ja, klar. [...]

Frau Marx: In der damaligen Zeit hat man uns für dumm verkauft, und heute ist es...

Herr Marx: ...is et übertrieben.

Frau Marx: ...übertrieben. Aber den goldenen...

Frau Rosen: ...die jonn von eenem Extrem en't annere.

Frau Marx: ...Mittelweg findet man nicht. ${ }^{354}$

Gespräche über jene vorehelichen Intimitäten, die anscheinend durch die Brauchausübung zustande gekommen sein sollen, haben in der retrospektiven Zusammenschau bemerkenswerte Parallelen zutage gefördert. Festzuhalten ist dabei ein generationenspezifisches Muster: Immer wieder trifft man bei den Älteren auf die Vorstellung, daß das Treiben der Heranwachsenden als ungezügelt, maßlos und geradezu exzessiv eingeschätzt werden müsse. Aus meiner Sicht wurde diese unvermutet starre Deutungsstruktur verstärkt durch eine tiefwurzelnde Logik des Generationenaufbaus mit einer Fürsorgepflicht der Reiferen gegenüber den Emporstrebenden. Der kontinuierlich unterstellte Sittenverfall bestätigte die Annahme, daß die ältere Generation über eine moralisch gefestigtere Haltung verfüge als die nachfolgende Generation. Nicht zuletzt der Einfluß der Massenmedien hat sich bei der Beurteilung des Wandels der Sexualmoral Geltung verschafft, wie die Äußerungen von Herrn Stein nahelegen:

Man hat sich da [während des Kommabends] unterhalten. Da waren meistens die Eltern debej, un da jingen die, nachher jingen die schlafen, ne. Un, joa, da hat man sich noch'n bißchen unterhalten. Ja, un dann jing mer wieder nach Haus. - Ja, das war damals nicht so wie das heute ist. Ich weiß nicht, ich will es nicht behaupten, aber wenn man Zeitungsberichten und och hier im Fernsehen, ne, also daß die meisten Achtzehnjährigen schon Jeschlechtsverkehr han jehabt, ne. Also das war damals och hier un zomal auf'm Land nicht so. Ich weiß nicht, wie es in den Städten war, ne. [...] Ja, un da gab's ja och noch keine Pille un kein Kondom - ja, die gab's och schon, ne, aber dann hätte man von hier nach Bonn fahren müssen. Die konnte man hier ja in keinem Geschäft kaufen und so, ne. ${ }^{355}$

Die heutige Elterngeneration hat die Meinung vertreten, daß im Gegensatz zu den aktuellen Verhältnissen die damaligen Auffassungen zur Sexualmoral so streng gewesen seien, daß voreheliche intime Kontakte über den Mailehenbrauch als absolut abwegig gegolten hätten. ${ }^{356}$ Der Vorwurf, das Mailehen verführe zu unsittlichen Beziehungen, traf augenscheinlich immer nur die gerade Jungen, während sich die Verheirateten, die Eltern- und Großelterngenerationen auf die zeitbedingte strenge Erziehung und die gesellschaftlich repressiveren Zustände zurückzogen.

${ }^{354}$ Gruppengespräch I (39/23-27/2b:423-565).

${ }^{355}$ Herr Stein (14/11/2b:497-526).

${ }^{356}$ Herr Decker (24/16/1a:569-598). 
Infolgedessen drängt sich die Einschätzung auf, daß die gegenwärtigen sozialen und familiären Verhältnisse dazu beigetragen haben, die sittlichen Schranken aufzubrechen. Die rezente Berichterstattung der rheinischen Tageszeitungen zum Brauch hat $\mathrm{zu}$ einer Verfestigung dieser Sichtweise geführt. ${ }^{357}$ Aus der Fülle von Belegstellen sei folgendes Beispiel angeführt:

"Zum Beispiel Jürgen: seit 20 Jahren ist er immer feste dabei. 13 Mal hat er mitgesteigert, einmal davon den Maikönigstitel, der die freie Auswahl im Mädchensortiment garantiert. 'Sechs von den 13 hab ich vernascht', verriet der graumelierte Mittdreißiger mit verklärtem Augenausdruck ..." (General-Anzeiger, 02./03.04.1994).

Der Verdacht gegenüber der Gefahr der sexuellen Entgrenzung im Rahmen der Mailehenausübung wurde über Jahre auf diese oder vergleichbare Weise erhärtet. Glaubwürdigkeit und die Übertragbarkeit der zitierten Aussage auf andere Mailehenbeziehungen sind von den BerichterstatterInnen nahegelegt worden, aber die Überprüfbarkeit der Informationen gehörte nicht zwangsläufig zu den Prämissen journalistischer Veröffentlichung. ${ }^{358}$ Die vielfachen Anspielungen auf das Moment vorehelicher Intimität in Mailehenbeziehungen sollten daher im empirischen Teil der Untersuchung mit der tatsächlichen Situation konfrontiert werden. Zunächst ließ sich feststellen, daß die wenigsten unter den Befragten das Thema Sexualität und Brauch von selbst ansprachen. Mit dieser Reaktion war zu rechnen, nicht weil die sexuellen Kontakte von vornherein hätten ausgeschlossen werden können, sondern aufgrund der Brisanz des Gegenstands. Gesellschaftliche Tabubereiche oder die persönliche Intimität gehören nicht unbedingt in den Zusammenhang eines volkskundlichen Fragenkatalogs über Maibräuche, und insofern hatten die GesprächspartnerInnen diese Themen wohl kaum erwartet. Indirekte Möglichkeiten der Erkenntnisgewinnung konnten hier behutsam genutzt werden. Wenn der Gesprächsverlauf es erlaubte und es sinnvoll erscheinen ließ, wurde den Befragten das obige Zitat des Zeitungsartikels vorgelegt, mit der Bitte, es zu kommentieren. Zumeist reagierte man mit Befremden auf den Textauszug. Eine Verquickung von sexuellen Kontakten und Brauchhandlungen widersprach weitgehend den Erfahrungen und Vorstellungen der InformantInnen. Fast alle hielten dies für abwegig und glaubten, in der Äußerung des Berrenrather Junggesellen - sofern sie überhaupt wahrheitsgemäß wiedergegeben sei - eine Übertreibung zu erkennen, die zu einem verbreiteten männlichen Imponiergehabe passe. Vor dem Hintergrund eigener Erfahrung war es den GesprächspartnerInnen unmöglich, eine nachvollziehbare Erklärung zu diesem Fall der rituell ausgelösten seriellen Monogamie ${ }^{359}$ beizusteuern. Schnell wurden Zweifel über die Seriösität der Berichterstattung laut. Ober-

${ }^{357}$ Dazu Wey (1999).

${ }^{358}$ Vgl. Schmidt (1994:190-193) zu journalistischen Berichterstattungsmustern und der Konstruktion von sozialer Wirklichkeit.

${ }^{359}$ Zur seriellen Monogamie (bzw. sukzessiven Polygamie) s. Vivelo (1988:237 Fn. 2). 
flächliche Recherche und Voreingenommenheit der Reporterin galten als Ursache für eine Aussage, die den Brauch geradezu entstelle. In einem Gespräch mit Frau Thiel führte die Betroffenheit und das Unverständnis über eine derartige Darstellung des Mailehens schließlich dazu, daß der Vater hinzugezogen wurde, um eine Stellungnahme abzugeben:

Frau Thiel: Meine Güte! Dat darf ja wohl net wahr sein! Dat is ja... Also, also kann ich nun wirklich net sagen. Also zum Beispiel bei uns in der Generation is noch keiner mit dem Junggesellen zusammengeblieben, un ich hab och noch so noch nix von Techtelmechtel oder so mitgekriegt. Un von vernaschen kann man... Meine Güte!

Aber das, was der Jürgen sagt, das zitiert sie [die Journalistin] ja, das soll er wirklich gesagt haben.

Frau Thiel: Ja, da wird bei denen ja einiges los sein. Ich mein, vielleicht is dat bei denen ja wirklich so, also wenn die dat ja so alles schreibt. Also ich kann mich mit den Sachen also gar net so identifizieren. Anscheinend muß bei denen ja einiges los sein - bei denen in Berrenrath. [...] Nä, da kann man fast überhaupt kein Vergleich ziehen zu uns. Also die hat da anscheinend wirklich en Angeber erwischt, der, der da alles das erzählt hat.

Vater: Also dat is ja wirklich en unverschämter Bursche.

Frau Thiel: Ja. Also find ich nämlich auch. Ich bin da wirklich entsetzt drüber.

Vater: Also echt, wenn der sou jet preis jäb, also da wär er hier aber erledigt. Also der würde auch nicht mehr zum Steijern zujelassen. Also da sin die knallhart die Jungen. Dat is ja e stark Stück dat.

Frau Thiel: Ich bin och tatal baff...

Vater: ...der Jung, der wär für mich Luft.

Frau Thiel: Ich find dat ganz schlimm, weil der damit so'en schönen Brauch echt in'nen Dreck zieht. Also es is wirklich en schöner Brauch. Also er macht den... durch den Text hier wird der ganz schön fertig gemacht. ${ }^{360}$

Aus den Gesprächen mit aktiven Mitgliedern des Junggesellenvereins ergibt sich in diesem Punkt kein einheitliches Bild. Nicht verlegen, aber etwas unsicher urteilt ein junger Vereinsangehöriger, Herr Winzer, über die Beobachtungen der Journalistin zur Verführbarkeit ersteigerter Frauen:

Würdest Du sagen da is was dran?

Pwwh... Doch.

Teilweise?

Teilweise schon, ja. Meinste jetz: "sechs von dreizehn hab ich vernascht" ne?

Mmh.

Könnte sein, ja. Was ich von früher aus Erzählungen was mal ich gehört hab. Jetzt, dieses un letztes Jahr haben so paar erzählt: "Also früher der un der..." Die heute schon über dreißig sind und fünfunddreißig, da hab ich schon gehört... manchmal kommt es mir so vor... Also ich

${ }^{360}$ Frau Thiel (05/05/2a:275-346). 
bekomm das dann nur halbwegs mit, auf einmal sind se weg, ne. Doch. Das sind aber nur einige wenige. ${ }^{361}$

Dagegen laufen die abwägenden Formulierungen von Herrn Weiden auf eine andere Einschätzung des Zusammenhangs von Brauchausübung und vorehelicher Sexualität hinaus:

Tja, dazu kann ich dir auch nichts sagen, dat liegt ja an den Mädchen un Männern selber. Aber ich glaub et net, dat et so weit kommt, et sei denn, et is en Freund, der seine Freundin steigert oder sonst wat. Also ich kann et mir net vorstellen, weil irgendwie wär man ja auch en bisjen dumm, ne, weil wat hat dat dann damit ze tun, ne, auch wenn ich die steigere oder sonst wat, dann hat dat ja nix damit ze tun, dat ich die vernaschen will. ${ }^{362}$

Eine Anbahnung intimer vorehelicher Beziehungen ging demnach von Voraussetzungen aus, die nicht im formellen Brauchablauf, sondern unabhängig davon in persönlichen Neigungen begründet lagen. Sexuelle Zügellosigkeit, die in der Mailehenpraxis besonders zur Entfaltung käme, ist aber als Chimäre anzusehen und wurde insbesondere als solche unter den Einwirkungen der Medien und der älteren Generationen wachgehalten. Noch ein weiterer Aspekt kommt hinzu, den Herr Fischer zur Sprache gebracht hat und der zur Klärung jenes zählebigen Unsittlichkeitsvorwurfs beitragen kann:

Ich überlege gerade, welche Motive hat man, ein Mailehen zu ersteigern. Welche Motive? Also für mich waren sie nicht ausreichend genug. Ja, also bei Junggesellen in dem Alter ist die sexuelle Motivation natürlich sehr groß. Daran kann ich mich noch genau erinnern, oh ja. Die sexuellen Dinge spielten eine überragende Rolle. Darüber haben wir sehr viel gesprochen. Das war auch immer das Ziel unserer Ausflüge, das Ziel des Besuchs von irgendwelchen Veranstaltungen. Ob das beim Mailehen auch der Fall war? Joa, sicher auch. ${ }^{363}$

Sexuelle Themen waren also häufig Gegenstand der Besprechungen unter den jungen Männern. Der Informant betont die allgemeine Verbreitung solchen Verhaltens. Insofern ist es auch verständlich, daß Frau Gebhard, Frau Randow und Frau Jansen mit Gelassenheit auf die Aussage des Berrenrather Junggesellen von den "sechs vernaschten Mädchen" reagiert und sie als geschlechts- und altersspezifische Prahlerei abgetan haben. Dazu Frau Gebhard:

Dat is bestimmt net so, dat en Mädchen mit einem en't Bett geht, nur weil er die halt gesteigert hat. Wahrscheinlich wollte derjenige en bißchen angeben. ${ }^{364}$

Frau Randow:

Ja, is ja toll: sechs von dreizehn, Klasse.

Glauben Sie, daß das en Thema is?

\footnotetext{
${ }^{361}$ Herr Winzer (07/07/1b:586-595).

${ }^{362}$ Herr Weiden (18/12/2b:465-472).

${ }^{363}$ Herr Fischer (34/20/3b:676-692).

${ }^{364}$ Frau Gebhard (41/28/1b:462-471).
} 
Is bestimmt übertrieben. Is wahrscheinlich große Klappe. Ja, das mit der freien Auswahl das stimmt ja wirklich, ne. Also wer soviel geboten hat, daß er Maikönig wird, der kann ja wirklich nehmen was er will, aber "sechs von dreizehn hab ich vernascht" bezweifle ich sehr. ${ }^{365}$

und Frau Jansen:

Ja, doch. Ja, doch. Joa, joa, daß er dann regelmäßig immer eine die oder die andere... ob's stimmt weiß ich nicht. Kann nur sein, daß er das erzählt hat. Joa, joa. "Joa, da haste Auswahl un doa kannste die... un oh, janz toll!" klar. Mhm. Ob es jetzt stimmt, weiß man net. Ich mein, dat steht auch wieder auf 'nem anderen Blatt. ${ }^{366}$

Mit diesen Aussagen ist nochmals deutlich geworden, daß die Hartnäckigkeit, mit welcher der Verdacht auf mailehenbedingte sexuelle Entgrenzungen aufrechterhalten wurde, am wenigsten auf konkrete moralische Verfehlungen der Jugendlichen zurückgeführt werden kann. Unter bestimmten Voraussetzungen konnte der Brauch dazu führen, daß die sozialen Kontakte zielgerichtet intensiviert wurden. Für manches Maipaar konnte dabei die Frage im Raum stehen, ob der rituell ermittelte Partner nicht zugleich ein Lebensgefährte sein könnte. ${ }^{367}$ Gegenseitige Sympathien verwandelten dann die rituellen $\mathrm{zu}$ freundschaftlichen Beziehungen. Wenn es schließlich auch zu intimen Verhältnissen kommen konnte, so gründete die betreffende Zweierbeziehung auf einer gemeinsam zurückgelegten Entwicklung, bei dem das Mailehen möglicherweise den Ausgangspunkt, wohl kaum zugleich den Endpunkt markierte.

\subsubsection{Soziale Rollen und die Erschließung anderer W e 1 t e $n$}

Ich weiß net, ob ich mir als Kind so gewünscht hab: "Oh, bald kannste auch mit gehn!" Daran kann ich mich echt ne'mehr erinnern. Wahrscheinlich schon, weil ich dat ja damals so toll fand. Ja, und dann bin ich mit fünfzehn zum ersten Mal gesteigert worden. Die Mädchen werden ja ab sechzehn, Jungs ab achtzehn.

Und wurdest Du praktisch in dem Jahr dann sechzehn oder wieso warst Du mit dabei?

$\mathrm{Mhm}, \mathrm{ja}$. Aber et is normalerweise net so. Mhm.

$J a$, und wie war das dann für Dich?

Ach ich mein... also ich hatte überhaupt keine Lust. Und ich hab mit Schrecken an das Wochenende gedacht, weil ich kannt ja auch keinen mehr von den Jungen und die einzigsten, mit denen ich noch was im Ort zu tun hatt, das war halt die Lisa. Die war in meiner Klasse un dann noch zwei andere Mädchen aus Oeverich. Die waren auch in meiner Klasse. Und sonst die, die kannt ich ne'mehr, weil mir ham uns och ne'mehr gegrüßt oder so. Dat hat sich dann ja irgendwann verloren gehabt. Ja, un dann hab ich nur gedacht: "Ach nä, wie ätzend. Da hängste nur da rum un weiß net, mit wem du reden sollst." Weil: die sin mir auch all viel älter vorgekommen. Die waren dann schon alle am arbeiten in meinem Alter...

...achtzehn...

${ }^{365}$ Frau Randow (45/31/1b:534-542).

${ }^{366}$ Frau Jansen (53/38/2a:406-414).

${ }^{367}$ Vgl. die Kapitel 4.4 einleitende Wiedergabe des Gruppengesprächs II (50/33-37/3a:556-696). 
...nä, oder auch so die Mädchen, die halt en bißchen älter waren als ich. Dat war irgendwie ne ganz andere Welt, so. Na ja...

...ach, selbst die Mädchen...

...ja, ja. Aber dat war dann doch schön. Also war ich überrascht. Dat hat echt Spaß gemacht. Konnt man Sekt trinken zwischendurch. Dat war ja dann auch toll in dem Alter. ${ }^{368}$

Den Eintritt in die aktive Brauchgestaltung schilderte Frau Gebhard als eine Berührung mit einer "anderen Welt". Schon im Alter von fünfzehn Jahren wurde sie in den Kreis der unverheirateten, zu ersteigernden Mädchen und Frauen aufgenommen. Dabei stellte man sie vor vollendete Tatsachen: Der Maibaum, den die Burschen ihr vor das Haus gesetzt hatten, war ein Zeichen für den über die Mainacht vollzogenen Statuswechsel. Mit der Forderung nach gleichgerichteter Aktion und Brauchträgerschaft unter Heranwachsenden ließ sich ein bis dahin argloses Unbeteiligtsein nicht länger behaupten. Auch wenn der Zeitpunkt hierfür sowohl den allgemeinen Gepflogenheiten als auch den Erwartungen der Betreffenden widersprach, so waren die Signale eindeutig, die bereits mit der Versteigerung ihr Gewicht, ihre Legitimation und Dringlichkeit erhalten hatten. Eine Abweisung der ehrenvollen Rolle, welche durch die Junggesellen trotz der nicht erreichten Altersvoraussetzungen der Informantin zugebilligt wurden, hätte als grundsätzliche Ablehnung gegenüber dem Tun der BrauchträgerInnen verstanden werden können. Diesem sozialen Druck, der durch die Eltern und das soziale Umfeld verstärkt werden konnte, war die Heranwachsende ausgesetzt. Ihr bangte vor dem gesetzten Termin, zu dem sie mit ihrem Mailehen den Festumzug begehen sollte. Die formale, rituelle Pflichterfüllung war dabei nicht einmal die schwierigste Hürde, sondern das Zusammentreffen mit einem Kreis von Leuten, der ihr fremd geworden war. An dieser Stelle kommt der Gedanke von der "anderen Welt" zum Vorschein, der zunächst Züge der Desorientierung und des Risikos trägt: Womit soll die rituell verfügte Zeit unter den fremden und fremdgewordenen Leuten ausgefüllt werden? Was erwarten die anderen von einem? Worüber soll man reden? Derartige Fragen beschwerten das fünfzehnjährige Mädchen unmittelbar vor ihrer ersten Teilnahme am Mailehen. Am Ende wich der Schrecken den Verlockungen der "anderen Welt": nicht nur daß der Umgang mit der Dorfjugend intensiviert wurde, auch der Verzehr von Sekt steht für mehr als eine Befriedigung naiver Konsumgelüste, nämlich für den Zugewinn von Autonomie, die sonst nur Erwachsenen zugebilligt wurde.

Unabhängig von Geschlecht und Alter findet sich diese Sichtweise auch bei anderen Befragten. Auffällig ist allerdings, daß Frauen die Schwierigkeiten, die mit dem Eintritt in die Welt des Mailehens verbunden waren, stärker thematisierten. Hieraus zu schließen, Probleme der Desorientierung, der Verhaltensunsicherheit, der mühseligen Integration in neue Bezugsgruppen seien im Hinblick auf die männlichen

${ }^{368}$ Frau Gebhard (41/28/1a:125-151). 
Kandidaten gänzlich unbedeutend, ist jedoch nicht gerechtfertigt, wie unten noch zu zeigen ist.

Die ersten Schritte abseits des überschaubaren Terrains kindlicher Orientierungen und Handlungsmöglichkeiten fielen zeitlich oft mit dem Mailehen zusammen. Herr Stein rekapitulierte die Alternativen jugendlicher Entgrenzung und zunehmender Erschließung der Erwachsenenwelt vor dem Hintergrund der 1930er Jahre:

Als Kind hat man da erst so mit zwölf, dreizehn Jahren... vorher mußte man ja Maiabend, wenn diese Mailehenversteigerungen waren, dann mußte man ja ins Bett. Und hier gegenüber da war ne Gastwirtschaft [...] Dann ham wir denn vorne auf der Straße, als Dreizehn-, Vierzehnjährige, als wir im siebten, achten Schuljahr waren, ne, dann waren wir dann auf der Straße, und dann kamen ab und zu die Jungjesellen raus, und dann ham wir denn jehört, wie die da drenn ov ne Trommel schlugen. Da hatten die so ne Dose, und dann hatten die so en Holzhammer, un dann han se denn jesteijert. Einer macht dann so - wir sagen hier - de Ausklöpper, also der Verkaufsmann. Ja, un dann ham mir dann jelauscht, ne un jehört, ne, wat die dann über die einzelnen Mädchen... die wurden dann da versteigert hier im Dorf, die Mädchen, ne. ${ }^{369}$

Von den verhaltenen Annäherungen älterer Schulkinder an die Aktionen der nächst höheren Altersklassen ist hier die Rede. Zwischen den Zeilen ist noch etwas von der Spannung und Neugier der Jüngeren zu spüren, die es wohl kaum erwarten konnten, bis sie selbst an der Reihe waren und das Versteigerungsspektakel aus nächster Nähe mitverfolgen und -bestimmen konnten. Auf diese Weise zeichnete sich ein Vorstadium $a b$, in dem die heranwachsende Junggesellengeneration einen Teil ihrer zukünftigen Aufgaben antizipierte. Gerade von diesem Orientierungs- und Lernverhalten zeugen auch Darstellungen gegenwärtiger BrauchträgerInnen. Der ausführliche Bericht von Herrn Weiden hinterläßt ein eindrückliches Bild:

Also früher war et für uns Jugendliche oder Kinder sozusagen immer et Größte, wenn halt eben die Junggesellen et Zelt aufgebaut haben, und mir konnten halt eben da sozusagen mitwirken, wenn wir dat durften; weil zeitweise waren se halt eben doch mal schlechter gelaunt, und dann durften wir uns halt eben net zu nah ans Zelt ranwagen, sag ich mal. Ja, und so ging dat eigentlich von den Jahren aus immer weiter. Da hat man eigentlich so mit dem Maibrauch selber gar net soviel zu tun gehabt, ne. Tja, und da ging dat halt eben so weit nachher, dann war et zum Beispiel, wenn die früher gesteigert haben, oder so, dann ha'm wir uns vor die Fenster gehockt, hier an de Wirtschaft auch, um zu hören, wer wen dann halt eben steigert. Halt eben, wenn man ne ältere Schwester hat oder so, um denen dann zu sagen, der und der hat dich halt eben gesteigert, ne. Un dann halt eben erster Mai war halt eben meistens bei der Maikönigin. Morgens ging dat schon los: durch et Dorf gefahren, gucken, wo die Tanne steht, wer is Maikönigin. Mußten wir halt eben wissen. Vor allen Dingen die Eltern waren meistens neugierig. Und dann, nachmittags, wenn die Junggesellen halt eben dann da waren, hat uns eben immer sehr interessiert, wat da halt eben so los war. Aber reinkommen, konnten wir net. Und dann konnten wir halt eben nur dat Gegröle hören, je besoffener se wurden. Ja, und so ging dat dann von Jahr zu Jahr, sag ich mal. Nachher ging et sogar so weit, wenn die in den Wald fuhren, fuhren wir meistens mit Fahrrädern und mit'm Moped schon mal hinterher, um zu sehen, wat da halt eben so abläuft, wenn die die Bäume abmachten. Tja, und dann selber kam man dann halt eben irgendwann mal in den Junggesellenverein rein. Ich sag mal, zu meiner Zeit war dat noch selbstverständlich, in dem Jahr, wo man achtzehn wurde, ging man da rein. Dat is

${ }^{369}$ Herr Stein (13/11/1a:13-46). 
heutzutage leider ne'mehr so. Die meisten haben keine Lust mehr daran. Die sagen sich halt eben: "Alkoholtrinken hab ich keine Lust drauf." Un bei uns sag ich mal, is dat halt eben wie gesagt Maibrauch: In der Mainacht gibt et kein Cola, Limo, Wasser oder sonstiges, ne. ${ }^{370}$

Ein Verlangen der Jungen, an den Aktionen der Brauchträger zu partizipieren, war über Jahrzehnte vorhanden, und bis heute existierte eine gewisse Durchlässigkeit der alters- und statusbedingt differenzierten Interaktionsbereiche. War die Laune der Junggesellen nicht auf einem Tiefpunkt, so konnte man als Fünfzehnjähriger hoffen, daß man geduldet wurde und bei einigen Brauchvorbereitungen mithelfen durfte. Herr Winzer schilderte, wie man dadurch sich aus nächster Nähe einen authentischen Eindruck vom Vereinsleben verschaffen konnte und man war entsprechend vorbereitet, wenn wenige Jahre darauf der eigene Eintritt erfolgen sollte:

Dann näherte sich so der Termin, Junggeselle zu werden. Wie war das? Wie kommt man in den Verein überhaupt rein? Wie kommt überhaupt dann die Entscheidung zustande, daß ich da reingehe und so?

Also für mich war das irgendwie auch gar keine Entscheidung; das war... das muß einfach sein. Das is normal, daß man da reingeht. Und ich wollte auch gerne da rein, weil jetzt alle... en paar ältere Freunde, die sind da drin; [die sind] so ein paar Jahre früher reingekommen. Denen gefiel das dann auch alles ganz gut. Und dann war das normal, daß man da reingegangen is. Dann is man eben... So vor'm ersten Mai fing das dann an: "Jetzt muß man langsam schon mal ein bißchen üben!" Dann waren wir eben ein paar Mal in der Kneipe hier, und dann die, die im Verein waren, auch schon. Und dann haben die einen dann auch schon gefragt, ob man überhaupt auch da reinkommt, und dann war das auch ganz klar. [Die] waren dann alle ziemlich freundschaftlich dabei, und dann war das auch kein Problem. Und in dem Verein hier sind auch keine drin, weswegen ich da nicht reingegangen wär. Das gibt's ja auch, daß da ein paar im Dorf sind, da sind'n paar drinnen, die mögen sie nicht, und deswegen gehen sie nicht da rein. Aber das war bei mir kein Problem. Und ne besondere Sache war das eigentlich nicht, weil wir waren ja auch schon ein bißchen bekannt in der Kneipe. [Da] war das nix mehr Besonderes, so viel. Die, die dies Jahr reingekommen sind, die waren sozusagen das erstes mal richtig in der Wirtschaft, haben da es erste Mal was getrunken, und, ich glaub, da is es schon was anderes. Aber so war das einfach: Zusammensetzen mit Freunden und dann eben nur die Prozedur danach mit dem Einseifen. Aber sonst war das ne ganz normale Sache. ${ }^{371}$

In diesem Fall sind alle Voraussetzungen für eine Mitgliedschaft im Junggesellenverein schon Wochen vor der Mainacht erfüllt, sieht man einmal von dem Aufnahmeritual ab. Der Statuswechsel des Burschen erscheint im Grunde als vorweggenommen: man pflegte bereits freundschaftliche Kontakte $\mathrm{zu}$ den Vereinsmitgliedern, traf sich in einem bestimmten Stammlokal, gewöhnte sich an die gängigen Umgangsformen ebenso wie an den Geschmack von Bier, dem Standardgetränk der Junggesellen. Schritt für Schritt fügte man sich auf diese Weise in die neue Rolle hinein. Dieser Vorgang, der hier einem Automatismus ähnelte, erschien manchmal geradezu als etwas Naturgegebenes, wenn nämlich von der Natürlichkeit des Hineinwachsens die Rede war. ${ }^{372}$ Der Prozeß der Identifikation mit dem neuen

${ }^{370}$ Herr Weiden (17/12/1a:16-64).

${ }^{371}$ Herr Winzer (07/07/1a:144-175).

${ }^{372}$ Siehe oben die Kapitel 4.4 einleitende Wiedergabe des Gruppengesprächs II (50/33-37/3a:556696). 
Status, den damit verbundenen Pflichten und Rechten lief bei männlichen Jugendlichen oft glimpflicher ab, als dies bei der weiblichen Referenzgruppe der Fall war. Die Tatsache unterschiedlicher Bildungswege zeigte an diesem Punkt deutliche Auswirkungen. Nicht nur bis zum Hauptschulabschluß blieben die Jungen häufig untereinander in Kontakt, auch die Berufsausbildung in der Nähe des Heimatortes führte dazu, daß man sich nicht aus den Augen verlor. Dagegen förderte die höhere schulische Ausbildung eine soziale Trennung der Jugendlichen. Nach Beendigung der Grundschule wurde man frühzeitig auseinandergerissen. ${ }^{373}$ In dem neuen sozialen Umfeld entwickelten sich rasch neue Freundschaften und andere Interessen. Ferner trug der lange Schultag mit dem hohen Hausarbeitenpensum dazu bei, daß für die Betreffenden kaum noch Freizeit übrig blieb. ${ }^{374}$ Der ausführliche Rückblick von Frau Randow hat diesen Entwicklungsprozeß nachgezeichnet:

Wie immer geht's damit los, daß man sich zurückversetzt, daß Sie sich an Ihre Kindheit erinnern und mal versuchen, zu überlegen, wann das war, wann Sie zum ersten Mal Berührungspunkte hatten zu dem Brauch - speziell zu den Maibräuchen hier im Ort, zur Maikirmes; was Ihnen dazu einfällt, wie das damals war?

Ja, da war ich eigentlich noch ganz klein. Früher haben wir halt praktisch direkt um die Ecke von dem Platz gewohnt, wo die Kirmes ausgerichtet worden ist. Und ja, früher fand ich das alles toll, ne. Da hatte ich halt auch viele Freunde, mit denen ich im Kindergarten zusammen war. Und das war auch irgendwie noch so richtig schön mit Karussell, und es gab halt noch total viel damals so, ne. Also es war schon alles lustig.

Das heißt, Sie haben sich praktisch auch auf die Kirmes so gefreut, oder...

...ja, das war halt schon was Besonderes einmal im Jahr. - Ja, damals fand ich das noch schön.

Welches Alter war das?

Ja, ab dem Alter, wo man laufen kann so ungefähr; ab Kindergarten, Grundschule so.

Was verbinden Sie mit dieser Zeit? Was haben Sie da mitbekommen: Den Umzug vielleicht?

Ja, klar. Ja, das fand ich immer ne tolle Sache. Das war halt wirklich was Besonderes. Das ging ja hier durch Oeverich und Niederich. Und dann halt diese Maikönigin mit diesem tollen Kleid, und die Musik und so. Und je nachdem, wenn's dann ne Kutsche war, dann noch mit Pferden also das war echt aufregend immer, ne. Und halt für die Kinder auch mit Karussell und allem. Dann das Tanzen im Festzelt. Also wir sind da tausendmal durchgerast, und dann konnte man durch diese Zeltvorhänge da praktisch rausklettern und drumherum. Und der Spielplatz war direkt in der Nähe. Also es hat halt ne Menge Spaß gemacht, so. Auch die ganzen Aufbauarbeiten, ne. Es ging ja Tage vorher los.

Das haben Sie auch schon mitgekriegt?

Ja, klar. [...] Oder nachher halt, dann durften wir mal helfen, im Zelt irgendwie was fegen oder die Bänke aufstellen, oder Getränke so verkaufen. Das war einfach, ja, ne Abwechslung, ne. War mal was los. Kamen ja auch Leute von überall hierher, aus den ganzen Nachbardörfern. Und allein die Disko; das war's natürlich halt auch, ne. Ja, das war ganz schön.

Aber is das nicht jetzt schon später?

Ja, das ging... Disko, sicher das war später. Ja, ab zehn vielleicht, ne.

${ }^{373}$ Vgl. Anhang 7.2, Tabelle 7.3: Übergangsquoten zur Sekundarstufe.

${ }^{374}$ Frau Evers (03/04/1a:176-201). 
Mit zehn wurde schon die Disko interessant?

Ja, ja. Ja, klar. Man hat ja dann auch seine Flammen in der Grundschule gehabt, mit denen mußte dann getanzt werden. Das lief da dann halt.

Und war das nicht ein bißchen spät, so 20.00 Uhr, oder wann fingen die mit der Disko an?

Das weiß ich gar nicht mehr. Aber im Grunde genommen, es war ja immer den ganzen Tag über schon Musik da. Und es war etwas los: Die Buden waren offen, und alle waren halt irgendwie um das Zelt rum. Ja, ich weiß gar nicht mehr, wann die so offiziell aufgemacht hat, die Disko, aber da wurd das halt eh dann lockerer gesehen, ne. Meine Eltern waren dann auch oben. Von daher war das irgendwie nie so das Problem.

Dadurch, daß Sie direkt am Zeltplatz gewohnt haben?

Ja. - Das mußte ja nicht bis in die Nacht gehen. Hauptsache man hat ein bißchen davon gehabt. Und sonst. - Also jetzt direkt was das jetzt alles mit so'nem Brauch zu tun hatte, mit Junggesellen und so, das wußte ich halt damals nicht; hat mich auch nicht interessiert. Hauptsache es war halt mal was hier gebacken.

Und mit den Freunden hat man sich dann verabredet, dahin zu kommen? Oder, das war klar, man geht dahin und dann trifft man die anderen?

Ja, das war ganz klar, ja. Ich glaub, Nierendorf hat noch irgendwann mal im Jahr so'ne Kirmes, ne. Das war's aber so - vielleicht Ringen noch. Und von daher, dann kamen halt immer alle zusammen. Wir waren in Leimersdorf in der Grundschule und sämtliche Leute, die halt dann da waren, sind dann natürlich hier zur Kirmes gekommen. [...] Ja, früher fand ich das schön.

Hatte man vorher schon so'ne Vorfreude auf die Kirmes?

Ja. Ja, klar. Unsere Verwandeten, die sind dann auch immer zu Besuch gekommen. Dann ha'm wir hier schwer Kaffee getrunken und so. Es gab natürlich Kirmesgeld für die Kinder, damit wir dann losziehen konnten. Das war immer schon so das Ereignis des Jahres hier.

Bis wann ging das so?

Wo es mir Spaß gemacht hat?

$J a$.

Ich glaub so, bis in die Zeit, wo das dann anfing, daß man dann diesen Maibaum gesetzt bekam und dann damit versteigert wurde. Also ich glaub, mit sechzehn war das. Aber es ging eigentlich schon vorher los, daß ich mich hier also mehr vom Dorf gelöst hab. Weil ich bin als einzige hier aus der Grundschulklasse, bin ich nach Ahrweiler ins Gymnasium gekommen. Die anderen sind alle mit nem anderen Bus in die Hauptschule gefahren, und da hab ich dann halt einen ganz anderen Freundeskreis gehabt, ne, und war dann halt viel in Neuenahr und Ahrweiler unterwegs. Und das hat sich dann irgendwie hier verlaufen. Aber ich bin halt trotzdem immer noch zur Kirmes gegangen, ne, weil da sind die Ahrweiler halt auch gekommen. Das war dann auch ganz witzig. Und dann mit der Disko, das wurde natürlich dann auch immer besser, je älter ich wurde; da konnte ich auch länger dableiben. Aber dann irgendwie mit dieser Junggesellenversteigerungsgeschichte, das gefiel mir dann nicht. ${ }^{375}$

Die Freude an der Kirmes als ein unvergeßliches Fest, bei dem sich die Kinder austoben konnten, wurde aus männlicher wie weiblicher Sicht hervorgehoben. In der Erinnerung nahm das Treiben im Festzelt einen besonderen Stellenwert ein. Hier wandelte sich die passive Rezeption eines sich alljährlich wiederholenden Brauches in eine aktive, schöpferische Teilnahme für beide Geschlechter. Aus staunenden, eher stummen Begleitern der Rituale und Geselligkeit von Erwachsenen wurden

${ }^{375}$ Frau Randow (45/31/1a:28-169). 
"rasende", "kletternde", "tanzende", "spielende" und schließlich auch "helfende" AkteurInnen. Das Tanzen und Mitwirken barg bereits eine gewisse Vorbereitung der heranwachsenden Kinder auf ihre künftige Rolle im Brauchgeschehen, wenn ihnen zum gegebenen Zeitpunkt eine Übernahme des Brauches angedient wurde. Gelegenheiten zum ausgelassenen Tollen und Spielen sorgten zudem dafür, daß die gesamte Veranstaltung in einem für Kinder überaus attraktiven Licht erscheinen mußte. Die typischen Kirmesattraktionen für den Nachwuchs, wie die Verkaufsbuden und das Karussell, gerieten daher leicht in den Hintergrund. Sie wurden zwar auch immer wieder erwähnt, aber nur selten verband man mit ihnen ein vergleichbar schwärmerisches, positives Erinnerungsgefühl.

Es zeigte sich, daß auch die Mädchen genauso Anteil an leichten Hilfsarbeiten wie die Jungen hatten. Voller Eifer unterstützten sie die Organisatoren. Die später bedeutsame Differenzierung der Geschlechterrollen fand vorerst noch keinen nennenswerten Niederschlag im Braucherlebnis. Mit zunehmendem Alter verlor diese gleichsam unterschiedslose Geschlechterrollensozialisation ihre Wirkung. Während fünfzehnjährige Jungen den Anschluß zu den älteren, im Verein organisierten Geschlechtsgenossen suchten, lag es den Mädchen fern, spezielle Kontakte zu Brauchträgern und Brauchträgerinnen herzustellen. Als Sechzehnjährige, wenn sie gewöhnlich zum ersten Mal auf der Versteigerungsliste der Junggesellen auftauchten, machte sich bei einigen die Kluft bemerkbar, die in der zwischenzeitlichen Entwicklung begründet war. Die Metapher vom Hineinwachsen, der sich einige männliche Informanten im Zusammenhang der Brauchsozialisation bedienten, war für die Frauen oftmals belanglos. Den Mädchen war der Brauch über die Zeit fremd geworden, und daher fiel es ihnen manchmal schwer, wenn mit einem Mal die Übernahme der rituell zugedachten Rolle von ihnen erwartet wurde. Dies ist im weiter oben dargestellten Falle der ein Jahr $\mathrm{zu}$ früh ersteigerten Informantin offensichtlich. ${ }^{376}$ Aber auch andere Gesprächspartnerinnen sahen sich von dem äußerlich zuerkannten Statuswechsel überrascht. Selbst wenn in der Kindheit ein intensiver Kontakt zum Kirmesgeschehen nach der oben geschilderten Art und Weise bestand, war damit die Übernahme von mailehenspezifischen Pflichten und Rechten noch nicht sichergestellt. ${ }^{377}$

\subsubsection{Männerwelten}

Was war denn überhaupt der Reiz am Junggesellenverein für Sie und nicht nur am Verein, sondern auch an den Bräuchen?

An den Bräuchen? - Also am Junggesellenverein war es die Geselligkeit mit den anderen. Und an den Bräuchen - ich kann von mir gar nicht sagen, daß ich die irgenwie genossen habe oder für wichtig hielt, obwohl ich, glaube ich, derjenige war, der das Aufnahmezeremoniell

${ }^{376}$ Frau Gebhard (41/28/1a:125-151).

${ }^{377}$ Frau Randow (45/31/1a:127) und Frau Evers (03/04/1a:30). 
eingeführt hat, das ja vorher gar nicht da war, nicht. [...] Damals war das das Leben in der Freizeit. Wir haben uns ja regelmäßig in der Woche zwei, drei Mal in der Gastwirtschaft getroffen.

\section{Die Junggesellen?}

Ein Großteil der Junggesellen war da. Wir konnten ja nicht aus dem Dorf raus, das heißt, ne ganze Reihe hatten schon Autos. Ich hatte auch schon relativ früh en Auto. Aber... das war eine vertraute Gemeinschaft, nicht. Nach der Arbeit traf man sich dann, lachte und erzählte zusammen, trank Bier und rauchte Zigaretten.

Also so über den Junggesellenverein...

...nö, wir hätten uns auch getroffen, selbst wenn... wir trafen uns da nicht als Mitglieder des Junggesellenvereins, aber alle in unserem Alter waren im Junggesellenverein. Wir ham uns sicher häufiger getroffen, als heute sich die Jugendlichen in der Gastwirtschaft treffen.

\section{Hat der Junggesellenverein das denn belebt?}

Nein. Der spielte da während dieser Zeit gar keine Rolle. Wir haben natürlich dann immer wieder über den Junggesellenverein gesprochen: über das, was geschehen war und das, was für die Zukunft geplant war. Aber das war gar keine Vereinsangelegenheit. Also das war der Spaß da mit Gleichaltrigen, allen möglichen, obwohl ich ja - auch bei diesem ganzen Jux, der da gemacht wurde, Blödsinn, der gemacht wurde, immer derjenige war, der immer das nur miterlebte, aber das nicht angeführt hat. Das waren andere. Das war der Herbert Jäger [...] Das war also ein ganz toller Vogel, der Stimmung brachte und Hansen auch, oh ja. Und ich war auch nie bei denen, die da das Wort geführt haben. Ich war immer derjenige, der zugehört hat.

Und nochmal auf die Bräuche zurückzukommen, das war Beiwerk, nebensächlich?

Tja, Lassen Sie mich mal gerade - vielleicht kommen mir dann etwas mehr Gedanken dazu diese Bräuche hintereinander aufführen: Also das begann mit dem Baumholen, mit dem Holen des Maibaumes - ja? War das besondere Freude? Das war ne Pflicht, das gehörte einfach dazu, daß im Mai ein Baum im Dorfe stand; und der mußte geholt werden. Ich glaub, das hat uns allen so großen $\mathrm{Spa} ß$ eigentlich gar nicht gemacht. --

Und vielleicht ne gewisse Risikofreude daran, weil das wird ja beschrieben, daß es nicht immer so ganz legal war, die Bäume aus dem Wald zu holen?

Nee. Da hatten wir auch gar keine Hemmungen, hatten auch keine Angst. Nein, nein, das nicht.

Also Risiko- oder Abenteuerlust spielte da keine Rolle?

Nein, nein, ganz und gar nicht. - Ja, anschließend das Holen der Maien, also der Birken. Ja, das war... also für mich war das... war's eine Pflicht? Nein, es gehörte einfach dazu. Aber daß ich irgendwelche freudigen Gefühle gehabt hätte? Nee, wüßte ich nicht. Aber auch keine negativen Gefühle.

Es waren jetzt auch nicht die Momente, wo die Geselligkeit besonders nochmal in Schwung gekommen...

....also gesellig war's ja anschließend, nicht. Obwohl wir auch schon in den Wald... ich weiß nicht, ob's anfangs war, aber zuletzt nahmen wir auch schon en Kasten Bier mit in den Wald, und dann wurd dann dazwischen immer Mal wieder ne Pause gemacht. Aber gesellig wurd's ja erst anschließend dann. Ja, das war immer schön. Und das ist dann natürlich auch besonders schön, wenn man vorher etwas gearbeitet hat, nicht wahr. - Joa, und dann erfolgte das Steigern. $\mathrm{Da}$ hab ich mich sowieso auch immer zurückgehalten. Ich war auch nie jemand, der ausgesteigert hat - also der Auktionator. Das war der Hagens Stefan, der das sehr gut konnte hab ich mich also auch zurückgehalten. Obwohl ich mich... ich hab teilgenommen, mitgelacht und mich gefreut. Das war, das war... also das ist immer ein, ein wirklich spannendes Ereignis. Was da an Urwüchsigkeit zum Vorschein kam, an Witzen hin- und herflogen, das ist erstaunlich, nicht. Das war - und das ist auch heute sicher noch so - eine Sache, da haben wir 
uns wirklich totgelacht, viel Freude gehabt. Das war wirklich ein Höhepunkt. Deshalb ist es wahrscheinlich auch noch weitergeführt worden, weil es einfach so etwas Lustiges, so was Ausgefallenes, so was Jeckes, so was Verrücktes war, und so etwas wollen die Jugendlichen in dem Alter. Also keiner von uns hatte damals irgendein Interesse, einen alten Brauch weiterzuführen, hat überhaupt keinen interessiert, nicht. Das war einfach nur was, was Verrücktes. Nun gut, was war denn sonst noch? Ja, dann wurden die Bäume ausgefahren in der Nacht. Da war auch immer Spaß bei, war aber auch immer anstrengend; daran kann ich mich schon erinnern - bis zum frühen Morgen manchmal. [...] Ob ich jetzt lieber in der Gastwirtschaft sitzen geblieben wäre, oder ob es mir solchen Spaß machte, die Bäume da ans Haus zu stellen? Ja. Ich weiß auch nicht, ob immer alle mitgefahren sind; da hatte sich schon der ein oder andere verdünnisiert zwischendurch.

Vielleicht konnte der ein oder andere auch nicht mehr...

...und konnte auch nicht mehr. Jaja. Naja, die wurden aber trotzdem mitgeschleppt. Die schliefen dann auf dem Wagen. Die konnten auch gar nicht mehr mithelfen. Das war ja auch gar nicht so schlimm.

Früher war das mit dem Alkohol auch noch en bisjen stärker, könnte ich mir vorstellen.

Ja.

Also diese scharfen Sachen wurden ja wahrscheinlich auch getrunken.

Ja. Irgendwann wurden sie verboten. Es kann sein, daß wir schon sie an diesem Abend verboten haben, und es durfte nur noch Bier getrunken werden. Stellen Sie sich mal vor, da hielten sich auch alle dran. [...] Ja, aber es wurde natürlich sehr viel Bier getrunken, und davon kann man ja auch bis zur Erschöpfung müde sein. - Ja, also diese weiten Fahrten, die wir manchmal gemacht haben, das war schon recht anstrengend, nicht.

\section{Mit dem Traktor?}

Immer mit dem Traktor. Der Traktorfahrer war natürlich nüchtern. Darauf ham wir schon geachtet. Da fand sich eigenartigerweise immer jemand. Im übrigen war das mit dem Alkohol und der Polizei damals noch nicht so schlimm wie heute. [...] Tja, also Spaß, Freude, Geselligkeit mit Gleichaltrigen - und das ist doch das, was viele von uns auch heute in der freien Zeit suchen, und ich mein, das ist auch ne tolle Sache, nicht. ${ }^{378}$

"Spaß, Freude, Geselligkeit mit Gleichaltrigen" rückten in den Vordergrund, als Herr Fischer von dem Antrieb der Jugendlichen bei den Vereins- und Brauchaktivitäten sprach. Allerdings war damals eine formale Grundlage für die Zusammenkunft anscheinend vernachlässigbar. Viele Treffen von Vereinsmitgliedern erfolgten ohne offiziellen Anlaß. Unzählige Stunden wurden unterhaltsam im Wirtshaus verbracht. Einen Moment drängte sich an dieser Stelle die Vermutung auf, daß ein ersatzloser Wegfall des Vereins und des Mailehens den jungen Männern womöglich nicht als Verlust vorgekommen wäre. Das Wirtshaus als Domäne der Männer schien bereits einer wichtigen formalen Zugehörigkeitsbeschränkung und damit einem homogenen Aufbau eines Junggesellenvereins zu entsprechen. ${ }^{379}$ Bei eingehender Betrachtung des Brauchablaufs wurde allerdings die besondere Attraktivität des Mailehens aufgedeckt. Diese trug zum Erhalt der Aktionen bei. Die Verantwortlichkeit der

${ }^{378}$ Herr Fischer (33/20/2a189-356).

${ }^{379}$ Hierzu äußerten sich Herr und Frau Beck (08/08/2a:312-332) sowie Herr Fischer (34/20/3a:434440). 
Burschen für das rituelle Geschehen ging teilweise mit einem hohen körperlichen Einsatz einher. So erforderte die Errichtung des Dorfmaibaums, das Maienholen und -aufstellen einen entsprechenden Aufwand, der Herrn Fischer zwar nicht als Bürde, aber immerhin als Pflicht erschien. Diese Pflicht erledigte man ohne große Überlegungen. Insofern wurden die genannten Brauchelemente als indifferente Bestandteile einer Gesamtaufgabe aufgefaßt. Vor dem Hintergrund eines Wechsels von anstrengenden und geselligen Phasen wurde der körperlichen Verausgabung eine wichtige positive Eigenschaft zugemessen: Die gemeinsame Plackerei erhöhte den Wert der darauffolgenden ausgelassenen Vergnügungen. ${ }^{380}$ Arbeiten und Spaßhaben gingen im Mailehen offenbar eine vorteilhafte Verbindung ein. Die Organisation und die Durchführung der Kirmes und Bräuche erforderten einerseits die Disziplin und das Verantwortungsbewußtsein der Jugendlichen. Jeder einzelne wurde über Anwesenheitsprüfungen und Dienstpläne persönlich in die Pflicht genommen. Mangelndes Engagement von Mitgliedern ging zu Lasten der gesamten Gruppe. Den Delinquenten wurde daher bei der nächsten Gelegenheit nachdrücklich ins Gewissen geredet. Andererseits barg das Brauchgeschehen auch genügend Raum für ein entgrenztes, transzendiertes Lebensgefühl, das nach Meinung von Herrn Fischer vor allem im Rahmen der Mailehenversteigerung an Ausrucksmöglichkeiten gewann.

Die im Mailehen begründeten Pflichten und Verlockungen repräsentierten aus meinem Blickwinkel die beiden Pole, die den neuen Status und die neue Rolle für die Burschen im Junggesellenverein maßgeblich beeinflußten. Sie entfalteten ein ambivalentes Spannungsverhältnis, welches bereits ganz zu Anfang der jugendlichen Brauch- und Vereinskarriere wirkte. Denn das Aufnahmeritual symbolisierte in überzeugender Weise den Statuswechsel und die situationsabhängige Neudefinition geltender sozialer Rollen, Werte und Normen. Das Ritual forderte letztlich die bedingungslose Unterwerfung des einzelnen unter die willkürlichen Forderungen des Kollektivs. So gipfelte die Aufnahmezeremonie in einem sichtbaren Vollzug der Rollenübernahme. Dabei standen vor allem die Grenzen des persönlichen Durchhaltevermögens auf dem Prüfstand. Reichlicher Konsum von Alkohol und das publikumswirksame Einseifen des Kopfes mit Rasierschaum mußten die Kandidaten überstehen. Persönliche Überwindung und Hingabe waren unerläßlich. Die Hürde der Initiation markierte einerseits den Stolz und die Furchtlosigkeit der Initierten, andererseits aber auch die Ehrfurcht und den Schrecken der Initianden. Die gegenüber den künstlich erzeugten physischen und psychischen Streßfaktoren der Aufnahmeprüfung aufgewendete Härte war charakteristisch für den artifiziellen Männlichkeitsbeweis, der letztlich zum Zugang männerbündischer Gruppierungen

${ }^{380} \mathrm{Vgl}$. oben die Kapitel 4.4 einleitende Wiedergabe des Gruppengesprächs II (50/33-37/3a:556696).Die Äußerungen der Herren Decker (24/16/1a:343-359), Lange (29/19/2a:476-488) und Winzer (07/07/1b:268-278) zielen in die gleiche Richtung. 
berechtigte. ${ }^{381}$ Unausgesprochen stand hinter der Prozedur wohl auch der Glaube an die geteilte Stärke: Wer diese Prüfung bestehe, der verfüge auch über die nötige Standhaftigkeit zur gemeinsamen Bewältigung zukünftiger Herausforderungen.

Aber noch ein weiterer Aspekt ist sichtbar geworden. Die vorausgegangene gedankliche und verbale Affirmation des Junggesellendaseins fand durch die Initiation eine materialisierte, physische Ausprägung. Der Initiand unterwarf sich dem Zeremoniell und erkannte dabei die ungeschriebenen Regeln des Vereins und die Befugnisse der Vereinsmitglieder an. Er konzentrierte seine persönlichen Einsichten und Aktionen auf das, was im Moment der Initiation seiner Aufnahme dienlich war. Anders gesagt, er signalisierte seine bedingungslose Unterstützungsbereitschaft, er opponierte nicht gegen die Fragwürdigkeit des Alkoholexzesses, er monierte nicht die autoritären Strukturen, die er andernorts ablehnte, sondern er erkannte die Machtverhältnisse an und übergab sich der heteronomen Gewalt.

Jene Unterwerfung unter die Machtstrukturen des Vereins konnte im Prozeß der Identifikation mit der Gruppe wiederum als Gewinn von Autonomie erfahren werden: nicht, daß der einzelne frei über sich hätte verfügen können, aber daß es immerhin innerhalb der Gruppe möglich erschien, Verhaltensspielräume zu entdecken, die vorher unerreichbar erscheinen mußten. Somit ergab sich die paradoxe Situation, in der das eigene Handlungsspektrum zuerst verkürzt werden mußte, um anschließend auf einer neuen Ebene zu weitreichenderen Kompetenzen vorzustoßen. Statuswechsel und Rollenübernahme eröffneten neue Betätigungsfelder. Die Aussicht auf einen Zugewinn an Verantwortung und Handlungsmacht mag dabei den männlichen Brauchträgern ein angemessener Anreiz für die Billigung von Nachteilen in bezug auf die bisherige persönliche Integrität gewesen sein. Kurz, die symbolische Erniedrigung durch den Trinkzwang, durch das Einseifen mit Rasierschaum, durch Hänselei und durch die gebotene Unterordnung ließ sich mit Blick auf den zu erwartenden Statusgewinn leichter ertragen.

Die Mailehenversteigerung, die im Ablauf unmittelbar der Aufnahmezeremonie folgte, hat jenes ambivalente Verhältnis von be- und entgrenzenden Wirkungsweisen veranschaulicht. Sie eröffnete dem erfolgreich initiierten Brauchträger die Chance, zum ersten Mal ein Mädchen oder eine junge Frau zu ersteigern. Dabei konnte er gleichberechtigt mit den anderen Junggesellen in einen harten, agonalen Preiskampf um seine Favoritin eintreten, wie aus den Erinnerungen von Herrn Fischer hervorgeht:

Und dann gab es bei der Versteigerung auch immer Eifersüchteleien, oh ja. Ganz sicher. Und manche feste Freundschaften, daß dann jemand noch versuchte, da nochmal anzubandeln an

${ }^{381}$ Dazu Herr Beck (09/08/2a:418-431) und Herr Weiden (17/12/1a:653-674). Siehe auch Kapitel 4.3.3. 
anderer Stelle. Und es passierte immer wieder, wenn jemand auf ein Mädchen besonders scharf war - mir fällt im Moment kein anderer Ausdruck ein - und die anderen wußten das, dann wurde er hochgetrieben. Ist es nicht dem Hansen auch passiert? Ich glaube, der Gerd Schauf war das, der hat dem ganz böse mitgespielt, und das hat dann nachher auch bei dem Mädchen Stimmung erzeugt. Ja, das war eine solche Preistreiberei, ganz gemeine Preistreiberei, verdammt nochmal. Da hat er irgendwann gesagt: "Verdammt noch mal, du kannst mich mal. Jetzt bezahlst du auch das Geld!" Ich weiß auch nicht, wie ich mich da verhalten hätte. Hätte ich wahrscheinlich vorher zuerst überdenken müssen: "Machst du das wirklich: bieten, wenn die anderen dich auf paar hundert Mark treiben?" Ja, also so etwas passierte durchaus, obwohl der andere ja gar nichts davon hatte. Er konnte ja auch bei dem Mädchen in aller Regel dann nicht auf großes Entgegenkommen stoßen. ${ }^{382}$

Die Preistreiberei machte das Austesten von Grenzen gleich mehrfach deutlich. Es kam hierbei zu einem öffentlichen Gefecht um das Anrecht auf ein bestimmtes Mailehen. Wo sonst in aller Regel die Werbung um die Gunst der Auserwählten nur die Betroffenen anging, wurde hier das gemeinsame Buhlen aufgrund der Mailehenversteigerung gleichsam in einer Arena der Kampf- und Schaulustigen präsentiert und vorweggenommen. Auch bereits bestehende Paarbeziehungen waren nicht vor den Offensiven der rivalisierenden Mitstreiter gefeit. Gerne testete man in solchen Fällen die Grenzen der Zahlungswilligkeit aus. Wenn dabei nicht der Freund des zu ersteigernden Mailehens, sondern sein Kontrahent den Zuschlag erhielt, dann konnte dies zu einer Zerreißprobe von sozialen Beziehungen führen.

$\mathrm{Da} \beta$ die Junggesellen die Mailehenschaft als Chance betrachteten, um sich einen näheren Zugang zu der ersteigerten Favoritin zu verschaffen, wurde bereits eingehend behandelt. ${ }^{383}$ Die Versteigerung initialisierte danach ein männliches Rollenverhalten, das zielsicher auf eine voreheliche Kontaktaufnahme gerichtet war. Gleichsam als Eheleute würden die Mailehen-, besonders aber die Maikönigspaare erscheinen, hieß es bei einer ehemaligen Maiköniginnenmutter:

Dat war wie ne Hochzeit. Wie als wenn ne Hochzeit wär. Als wenn man ne Hochzeit hätt. Claudia woar awwer och sehr aufjeregt. Is joa och net esu einfach, ne, wenn da draußen... Och wat woaren da Menschen. Was war hier ein Menschenvolk. Doch, awwer et war schön. ${ }^{384}$

Weder Titel, Kleidung, Auftritte noch Handlungen der Regenten widersprachen den Vorstellungen des Publikums von einem Traumpaar. Demgegenüber konnte aber aufgezeigt werden, daß es sich bei der Brauchausübung nur selten um eine vorweggenommene Traumhochzeit handelte. Diese Tatsache ändert jedoch nichts an Initialisierung einer gedanklichen Auseinandersetzung der BrauchträgerInnen mit dem Thema Verehelichung. So machte das Mailehen in sinnfälliger Weise die Beteiligten auf den gesellschaftlich vorgesehenen und zukünftig anzustrebenden Familienstand aufmerk-

\footnotetext{
${ }^{382}$ Herr Fischer (34/20/3b:606-658).

${ }^{383}$ Siehe Kapitel 4.4.1.

${ }^{384}$ Frau Heuerdorf (23/15/2a:430-439). Dazu auch Frau Pfeiffer (46/32/1b:391-413).
} 
sam. Hierin liegt ebenso ein entgrenzendes Potential, das den Brauchträgern beiderlei Geschlechts in der Ausübung ihrer neuen Rollen erschlossen wurde.

Entgrenzung manifestierte sich in der Mailehenversteigerung auch dort, wo das Ereignis als ein immenses, einzigartiges Spektakel aufgefaßt wurde und den "größten Spaß im ganzen Jahr" bedeutete, wie Herr Goltz betonte:

Also et gibt immer noch welche, die net steigern?

Joa, joa. Meistens sin et die, die viellech neu renkunn. Die viellech noch jet Angs han et ieaschte Joar. Äwwer et sin imme zwei, drej debej oder... die viellech net steijere. Äwwer et es de grüßte $\mathrm{Spa} ß$ em janze Joar. Also ich han dat jern jemaat: die Löck jetriewe un jet. Also dat woar imme en häre Saach. ${ }^{385}$

Die Versteigerung diente hier sowohl dem ausgelassenen Vergnügen als auch der männlichen Herausforderung. Manche Vereinsmitglieder, vor allem die jungen, müßten demnach erst die nötige Kompetenz im Umgang mit dem Medium erwerben, um es dann den anderen gleichtun zu können. Das Treiben wurde explizit als "en häre Saach" - als eine "herrliche" Angelegenheit unter Herren - verstanden. Auch junge Nachwuchskräfte im Verein gelangen zu solchen Sichtweisen und haben offenbar ähnliche Empfindungen bei der Brauchausübung, wie die folgenden Ausführungen von Herrn Winzer illustrieren:

Ich find das Beste von allem das Steigern. Das find ich das Schönste, darum unterscheidet sich das dann auch eben zum Normalen (wenn man normal zusammensitzt), daß man dann eben, joa, die Mädchen im Dorf steigert. Das ist das Einziste was, wenn man da mit'm Jungjesellenverein was mit den Mädchen zu tun hat, mit der Kirmes, mit dem Steigern, und das is eben das Schönste. [...] Und im ersten Jahr war das auch gut, fand ich, wenn man das so mitmacht.

Hatt'ste da auch schon eine ersteigert?

Jaja. Ja. Würd ich auch jedes Mal machen, nämlich fünfzig Mark Strafe zahlen, um dann n'Thekendienst Sonntagnachmittag zu machen, das is nicht der Sinn irgendwie und das macht auch keinen Spaß. Das muß dann sein, mit im Zug zu gehen mit'm Mädchen; dann die janze Musik, is schon was Schönes. ${ }^{386}$

Daraus kann allerdings nicht die Schlußfolgerung gezogen werden, daß nur diejenigen Spaß an der Mailehenversteigerung hatten, die sich an den Bietgefechten und Preistreibereien beteiligten. Auch wer kein Mailehen ersteigerte und deswegen zur Zahlung der Strafgebühr verpflichtet war, konnte als Zuschauer ebenfalls auf seine Kosten kommen. ${ }^{387}$

Die Textbeispiele zur Mailehenversteigerung haben veranschaulicht, daß die Mailehenversteigerung weitaus mehr als eine formale Lösung der rituellen Paarzuteilung

\footnotetext{
${ }^{385}$ Herr Goltz (19/13/1b:681-688).

${ }^{386}$ Herr Winzer (07/07/1a:268-286).

387 Darauf hat eine zitierte Gesprächssequenz bereits am Anfang dieses Unterkapitels aufmerksam gemacht Herr Fischer (33/20/2a:288-305).
} 
beinhaltete. Entschieden äußerte Herr Fischer den Standpunkt, daß der Brauch keineswegs aus der Rückbindung an die tradierten Vorgaben erfahren und erhalten worden sei, sondern rein aus der Lust an der völligen Entgrenzung, dem Anomalsein, der entfesselten Spontaneität im Hier und Jetzt. Der Brauch wurde als "etwas Verrücktes" erlebt (s.o.). Dabei gewährte die Mailehenversteigerung den passenden äußeren Rahmen für das Bedürfnis, die Normalität des Alltäglichen zu durchbrechen und seine gewohnten Umgangsformen und konventionellen Verhaltensweisen durch rituell enthemmte Varianten $\mathrm{zu}$ ersetzen. $\mathrm{Zu}$ den Bedingungen gehörte, daß die Junggesellen für eine gewisse Zeit unter Ihresgleichen bleiben konnten, daß sie währenddessen keinen störenden Einflüssen von außen ausgesetzt waren. Als empfindliche Beeinträchtigung wertete man nicht nur die Ambitionen eines Junggesellenvaters, interne Brauchabläufe filmisch festzuhalten oder die des Forschers, den rituellen Prozeß möglichst vollständig teilnehmend $\mathrm{zu}$ beobachten, sondern auch die weibliche Dorfjugend wurde stets bei den Versteigerungen ausgeschlossen (siehe auch Kapitel 4.1.3). Den für das persönliche Erleben relevanten psychosozialen Eigensinn einer für Frauen und Mädchen unzugänglichen Gruppierung findet seine explizite Bestätigung in einem Beitrag eines ehemaligen Junggesellenmitglieds, Herrn Decker. Gegenstand der betreffenden Passage war wiederum die Frage nach dem Reiz der Brauchausübung:

Allein wejen der Tour machen die Junge dat net. - Dat is irjens wiedde wat... Och vielleich, vielleich, dat is joa och bej uns erwachsene Männer och so: Et is joa schon mal janz schön, wenn nur Männer unnerwees sin. Dat werden die Fraue jenauso saren. Die saren och: "Wenn unser Kaffeekränzjen..." - oder wat et is - "Mir sin och emaol froh, wenn mir en paar Stunde allein sin." Un so seh ich dat hier och, ne. Dann kann man sich schon mal anders benehmen, als wenn mer ewig de Frau debej hat. Un so is dat bej Jungjeselle, saren ich. Dann könne mer uns moal en bissjen anders ovführen oder... oder wat erzählen oder weiß der Deuwwel wat se maache eben, ne, ohne dat dereck de Freundin debei is, ne. Un dat is der Reiz. ${ }^{388}$

Für die männlichen Brauchträger ergaben sich neue beziehungsweise andere Verhaltensspielräume; ein anderes Lebensgefühl entfaltete sich aus dem episodischen Abtauchen in ein rituell geschütztes Refugium. Wiederum hat die Analyse an dieser Stelle das paradoxe Wechselspiel von Isolation und Entgrenzung zum Vorschein gebracht. Die gewöhnlichen Situationen im Alltag und der übliche mitmenschliche Kontakt erforderten augenscheinlich eine gewisse Zurücknahme verborgener persönlicher Handlungspotentiale, die nur unter bestimmten Voraussetzungen auftreten konnten. Günstige Bedingungen zu einer Transzendierung dieser in der Normalität blockierten Verhaltensoptionen garantierte das Mailehen. Innerhalb der Brauchausübung akzeptierte das soziale Umfeld Überschreitungen der im Alltag zu erwartenden Umgangsformen. Alkoholexzesse, autonomer Widerstand gegen lokale Autoritäten, enthemmte Mißachtung von gesellschaftlichen Tabuthemen sind

${ }^{388}$ Herr Decker (24/16/1a:358-369). 
wiederkehrende Beispiele für die jugendliche Berauschung an einem Freiheitsgefühl, das in der Entgrenzung des Normen- und Wertgefüges begründet war.

Trügerisch ist in diesem Zusammenhang der Anschein einer rituell bedingten Autonomie des einzelnen Akteurs, da stets bedacht werden muß, worauf diese scheinbare Autonomie basierte. Der Rückzug aus dem Alltag, aus den Herkunftsfamilien, aus der Partnerbeziehung, aus den Freundes- und Kollegenkreisen mündete für den einzelnen keineswegs in die uneingeschränkte Selbstbestimmung. Weiter oben wurde festgehalten, daß der Initiand, sich von alten Fesseln lösend, zugleich in neue Abhängigkeiten begab. Der Statuswechsel verlangte die vorübergehende Preisgabe erprobter sozialer Sicherheiten zugunsten neuer Verhaltenszumutungen und Erwartungen. Aus dieser Anforderung erwuchs eine Umorientierung, zu der nicht jeder potentielle Kandidat bereit war. Da der Vereinsbeitritt auf Freiwilligkeit beruhte, lag die Entscheidung letztlich bei den jungen Burschen selbst. Das Problem der Ablehnung der Vereinsmitgliedschaft wurde zwar für die Vergangenheit immer wieder als marginal eingestuft, aber es zeigte dennoch, daß nicht jeder gewillt war, den Preis des Rollenwechsels zu zahlen. Ein heute über neunzigjähriger Gesprächspartner, Herr Selm, erklärte, warum er sich dem vereinsmäßigen Treiben seiner Alters- und Geschlechtsgenossen entzog und nicht dem Weg seiner älteren Brüder folgte:

Ich war nicht Mitglied im Junggesellenverein. Warum nicht? Das war mir zu dumm. Nicht, weil ich dann mit Dummen zusammen war, sondern deshalb in die Wirtschaft gehen, um mir das anzuhören, so was. Das hat mir einfach nicht gelejen. Da war ich halt ein Außenseiter, vorher schon in jeder Hinsicht und wurde auch als solcher anjesehen. Aber nicht, nicht... mit allen Leuten hab ich mich gut verstanden. 389

Die getroffene Entscheidung war nicht gegen irgendwelche Personen gerichtet. Im alltäglichen Leben pflegte der Informant einen harmonischen Umgang mit der Dorfbevölkerung. Er wollte sich lediglich an den Treffen im Wirtshaus nicht beteiligen. Die Themen, welche dort zur Tagesordnung gehörten, waren ihm offensichtlich unangenehm. Gespräche, die in diesem Rahmen stattfanden, wollte er weder mitverfolgen, geschweige denn selbst initiieren und in Gang halten. Auf dieser Grundlage läßt sich auch seine Parteinahme für den Kampf des Pastors gegen die Mailehenversteigerung verstehen: 390

Ich hab gelesen, daß der Pastor Knopp damals nicht begeistert war von den Maibräuchen.

Ganz recht. Hatte er recht. Warum? Das hing nämlich davon ab, ob es einen im Dorf gab, der das in einer Form bringen konnte - das Anbieten der Mädchen an die Burschen als besondere Freundschaft und Tanzpartner der jungen Achtzehn-, Neunzehn- und Zwanzigjährigen - in einer Form und beim Bier bringen konnte, daß auch Eltern und andere doa hätten zuhören können. Das wird das jewesen sein. Das is es auch bei mir jewesen. Da hab ich mir jedacht:

${ }^{389}$ Herr Selm (42/29/1a:347-359).

${ }^{390}$ Siehe Kapitel 4.2.2. 
"Da seh ich mir keinen für aus, keinen." Denn ich kannte die Dorfjenossen, die kannt ich doafür doch. ${ }^{391}$

Lag es nun doch an den besonderen Charaktereigenschaften oder -schwächen der Dorfburschen, daß die Mailehenversteigerung, wie sie zu der Amtszeit des Pfarrers Knopp praktiziert wurde, den Unmut von Unbeteiligten aus dem sozialen Umfeld heraufbeschwören mußte? Wäre eine gemäßigtere rituelle Paarzuteilung denkbar gewesen, so daß jeder andere hätte zuhören können, ohne peinlich berührt zu sein? Diese Überlegungen stehen zunächst einmal im Widerstreit mit den Äußerungen des Informanten selbst. Herr Selm hatte ausdrücklich betont, daß der damalige Kreis der Junggesellen, zu dem auch zwei seiner Brüder gehörten, ganz gewöhnliche Jungen waren, die sich im Alltag unauffällig verhielten. Dagegen sah Herr Selm sich selbst in einer gesellschaftlichen Außenseiterposition. Von daher ist der Gedanke an eine "gezähmte" Mailehenversteigerung, welche auch die Kritik des damaligen Kirchenmannes hätte entkräften können, letztlich substanzlos und fußt in einer unrealistischen Vision von einer moralisch geläuterten Brauchpraxis. Die Gegenthese scheint mir hingegen plausibel und von der empirischen Seite hinreichend abgesichert: Der Statuswandel vom Jungen zum Junggesellen und Brauchträger erforderte gleichzeitig einen merklichen Rollenwandel. Wenn die männlichen Akteure das Interesse an der Aufrechterhaltung von gewöhnlichen Umgangsformen im Rahmen ihrer Zusammenkünfte verspürt hätten, dann hätten sie sicherlich auch den Willen aufbringen können, die Mädchen und jungen Frauen in einer Weise anzubieten, bei der niemand hätte Anstoß nehmen müssen. Es ist offenkundig, daß viele Männer, die das Mailehen mitgemacht haben, gerade jene Entgrenzung der alltäglichen Verhaltensregeln als Anreiz für ihr Engagement betrachtet haben. Wenn sich die rituell legitimierten und statusbezogenen Handlungsmöglichkeiten nicht voll entfalten konnten, zeichneten sich sogleich Frustrationen der Beteiligten ab, wie sie im folgenden, von Herrn Winzer wiedergegebenen Fall sichtbar wurden:

Das is ja doch ne ziemliche Prozedur, in den Verein reinzukommen, oder?

Das fand ich auch gar nicht so schlimm, fand's lustig. Außerdem: dann hatte ich ja schon sowieso was getrunken, un dann is das lustig, würd ich sagen.

Steigert sich das nicht jedes Jahr?

Es wird jedes Jahr schwächer, würde ich sagen. Das hab ich jetzt nur so gehört von den Älteren im Verein. Das war früher viel schlimmer. Da ham'se viel mehr getrunken auch hier Schnaps und so was - nicht nur die den eingetrichtert bekommen haben, sondern auch die Älteren, und dann waren so viele gar nicht mehr fähig, dann die Bäume zu stellen; sind die vorher gegangen. Auch mit dem Einseifen: Bei uns war das noch so ne richtig schöne Prozedur, aber wenn man jetzt sieht dieses Jahr: Der eine is überhaupt nicht mehr eingeseift worden, der andere nur en bißchen. Also das wird irgendwie lascher. Auch mit dem Liedersingen: Die Älteren, die kennen dann noch tausend Lieder, aber jetzt die Jüngeren, die kennen die eben nicht und dann können die auch nicht mitsingen. Und dann is eben die Stimmung gar nicht mehr so gut, wie das in den Jahren davor war. Oder wie - das hab ich jetzt gemerkt - von letztem Jahr auf dieses Jahr, daß

${ }^{391}$ Herr Selm (42/29/1b:652-666). 
das viel... weil das is überhaupt nicht mehr was Besonderes geworden. Da war das dann einfach so wie ne bessere Versammlung, bis eben auf das Einseifen da und auf das Steigern. ${ }^{392}$

Aufgrund von Unterhaltungen mit älteren Vereinsmitgliedern konnte Herr Winzer den Eindruck gewinnen, daß einzelne, ihm wesentlich erscheinende Merkmale der Junggesellenrolle über die Zeit regelrecht verkümmert sein mußten. Die enorme Trinkfestigkeit, das ausdauernde Singen von Stimmungsliedern und die Aufnahmezeremonie sah er vom Zerfall bedroht.

Zeichen des Niedergangs glaubten einige ältere Gesprächspartner auch vor dem Hintergrund der rezenten Versteigerungspraxis zu erkennen. In einer Diskussionsrunde kamen die ehemaligen Vereinsmitglieder zu der Ansicht, daß die Brauchtreibenden ihrer Rolle wohl kaum gewachsen seien, wenn sie es mittlerweile nur mit Mühe und unter hohen finanziellen Anreizen schafften, den Maikönigstitel zu versteigern:

Herr Keller: Tja, wenn die noch souvial jenn mösse, ${ }^{393}$ dann is joa och veel Jeld dann fott...

Herr Fischer: ...mhm...

Herr Keller: ...dat et überhaupt ene wiid. ${ }^{394}$

Herr Kastner: Wie: "Jenn mösse, dat ene wid?"

Herr Fischer: Tousend Mark, dat ene Maikönig wid.

Herr Keller: De Maikönig krit tousend Mark hök.

Herr Kastner: Joa, is doch Unsinn sou watt.

Herr Keller: Tja, is awwer sou.

Herr Hagen: Joa, ber hätt die da... Dat is äwwer en Sach!

Herr Kastner: Dat is mir vollkommen neu.

Herr Hagen: Joa, bat maat der met den tousend Mark?

Herr Keller: Da deet der sich vür enkleede.

Herr Böhm: Schwatze Anzug koofe.

Herr Hagen: Joa, dat sin joa Saache hee. Doa kunn ich äwwer net met.

Aber dat hängt ja met dem Versteigern zusamme, ne.

Herr Keller: Das hängt damit zusammen, daß keiner mehr Maikönig werden will.

Aber auch wie die Versteigern mit dem "Bier op de Maikönig".

Herr Keller: Nä, nä.

Herr Hagen: He, hüür moal, dann han se keene mieh, der versteijere kann.

Herr Kastner: Würd i awwer och sare.

Herr Hagen: Ich donn der moal erzelle...

392 Herr Winzer (07/07/1a:238-267).

393 "souvial jenn mösse": soviel [Geld] geben müssen.

394"dat et überhaupt ene wi(i)d": daß es überhaupt einer wird [Maikönig]. 
Herr Keller: ...mir han doch imme jesaat henoah, et ieascht wid de Maikönig ersteijert.

Herr Hagen: Joa, dat han mir joa och at jedoan.

Herr Keller: Wenn nu keene, nu keene e Jebott maat?

Herr Hagen: Joa, doa ham'er et dran jejen. Doa muoß mer souviel ehrlich jejenanner sin... - dat kann ich de sare, nämlich wie et Jäjers Lenchje Maikönijin jewuure is...

Herr Fischer: ...mem Jupp.

Herr Hagen: ... un mem Jüpp. Un wenn doa ene alles durchlurt ${ }^{395}$ doa woar vürher Maikönig, de Schneiders Fried on meng Schwester, un met de Steijerei jingt net wigger, ${ }^{396}$ doa han ich doa klipp un kloar jesaat: "Dann wiedd dat all jestriche, riiße mer dat Papier kapott, mir han uns jet jezänk, hee sin wat Wöört jefalle, no mööt'er euch üwwerläje, wöllt er noch Maikönig widdeh han oder wöllt er'n net han?" Un do han mer nöj ahnjefange ze steijere. Do wurd dat Papier fott un do is nöj ahnjefange ze steijere. Un do sin widdeh vernünftije Sache eruskumme. Do sin doa Spitzenbeträje eruskumme widdeh. Do muoßten die se joa üwwerläje: "Maach ich met oder maach ich net met?"

Herr Keller: Dat is joa och: Hät ene jet jetroank, hät ene nix jetroank?

Herr Hagen: Ja, dat hät joa met'm Drinke...

Herr Keller: ... doch!

Herr Böhm: ... hät dat och ze dohn. Mancher saat, wenn er besofe is, schnell joa.

Herr Hagen: ... sou doll... dat is sou en Saach. Dat is nur en Saach, wat sich jewisse Lök in däm Jungjesselleverein en der Saach net durchsetze. Doa muoß mer met denne vürher, net wie mir dat doamals jemaach hätte. Ich well net sare, wat dat richtig woar, wat jemaach is wure. Äwwer et wued net jesteijert un et koam nix erus un sou jaar nix. Et leevst nix. Die Tour. Doa han mer us noch Jezänk wie verrök noaher un do han ich jesaat: "Eens mööt'e wesse: Entwede et wid richtig gesteijert oder et wid net jesteijert. Entwede ihr dood beede oder dood net beede. Wenn't er net beede dood, dann jett dat Krömchje draan. ${ }^{397}$ Dann jenn mir dat draan. Net nur eins zwei Mann sollen doa bezahle. Sou un sou. Un doa han mer nöj ahnjefange un doa hät dat widdeh wunderbar hinjehaue.

Herr Kastner: Also ich muß sare, dat System is natürlich schwachsinnig.

Herr Keller: Ja, ja. Dat halt ich o'net...

Herr Kastner: ... dat is awer tödlich so'n System - dat is tödlich so'n System.

Herr Fischer: Wat die jetzt machen?

Herr Keller: Ja, ja. Met den tousend Mark.

Herr Hagen: Dat is mir nöj. Dat is et ieaschte Moal, dat ich dat hüüre.

Herr Kastner: Dat is mir also och vollkommen neu.

Herr Hagen: Die han keine en der Laare, der versteijere kann?

Herr Keller: Ich weeß dat net. Ich han et och nur vum hüre.

Herr Hagen: Ich kann dir doa Saache erzelle, wenn ich doa hök... sare mer, ich kenne die Leut joa, die Mädchjer joa jar nimmie, die doa versteijert wern. Dann han se käne, der versteijere kann, oder keene, der dat maat. Doa moaßte ochens üwwer Saache, üwwer denge Schatte drüvversprenge. Un ene der doa beet, un do meens et wär net huh jenoch, un dann moaßte at en

395"durchlurt": durchblickt.

396 "jingt net wigger": ging [es] nicht weiter.

${ }^{397}$ Wenn ihr nicht bietet, dann gebt die Sache [den Kram] auf. 
Zahl sare, die jebodde is, die jar net jebodde is un dann wied widdeh jebodde. Un wenn dat ene net maat oder net deet oder er hät Angs am Schluß - der versteijert hät - ich han selwer jet ze bezahle am Schluß. Dat is dat imme. Ich hat imme och janz schöne Summe am Schluß och selwer ze bezahle.

Herr Kastner: Ich muoß och sare, dat sollte - em Grunde jenommen - sollte dat Janze joa e bisje Lustijes och sin.

Herr Hagen: Dat woar och lustig; oder woar et net lustig?

Herr Fischer: Doch.

Herr Kastner: Ich sach ja, dat Ganze soll joa och irjendwo wat Lustijes sin. Sare mer och der Maikönig selewst. Deswejen han ich zum Beispiel damals, han ich joa als Ausnahme diesen Zylinder jeholt un so weiter...

Herr Hagen: ...dä häste jenomme, weil de Aujust der och vröher jehat hat.

Herr Kastner: ...un weil de Aujust den och jehat hat. Dat hät mir sou joot jefalle.

Herr Hagen: Dat is och jet schön.

Herr Böhm: Is et och, ja.

Herr Kastner: Un daraufhin han ich nach sounsoviel -zig Jahren han ich mir och den Zylinder jehoalt. [...] Aber dat is ja keen Kostenfaktor in dem Sinne. Sare mer, ich han dat ja net jemaat, weil mir ene jetz viellech tausend Mark joab oder sou jet. Dat macht doch keene Spaß, dat is doch uninteressant, ne. Man kann jetz sare: "Jut..." wenn er [der Maikönig] die Auslare für den Sekt un sou jet... oder der kann dat net allein finanzieren, dat der Jungjeselleverein saacht: "Jut, dat maache mer."

Herr Hagen: Heinrich, no sej moal ierlich, bat hät da vröher de Maikönig dich jekos ${ }^{398}$ ?

Herr Keller: Och, net vial: ne Aanzoch on ...

Herr Hagen: ...joa de Aanzoch häste joa imme, ne.

Herr Keller: Joa, nä. Dat weeß ich net, ob de....

Herr Hagen: ... vröher moaßte joa ne dunkle Aanzoch han, hök kannste met em rude Sakko joan, met em jälle, met em wiiße un en dunkel Hos hät jede oder en hell Hos oder sou jet, ne.

Herr Keller: Anjekleed sin die all nöj...

Herr Hagen: ...sin die all. Dat loaßen sich die Äldere joa net nemme. Äwwer wenn dat heute sou is, ne, dann solln se dat Steijere draan jewwe...

Herr Kastner: ...dat würd' i awer och sare.

Herr Hagen: Solln se dat Rasiere ens dran jewwe. Dann is doa jet verkiert jelaufe. Dat is äwwer net von heute, die hök draan sin. Dann is dat schon met Jahre is dat joa allmählich emoal renjebröckelt...

Herr Kastner: ...jenau sou is'et.

Herr Hagen: ...en die Saach. Dann han se keine em Verein...

Herr Keller: ...fang jetz noch an, dat se doadurch ene draanspringt.

Herr Kastner: Ja, aber dat is doch och nix. Sare mer, dat Janze soll doch irjenswo e bisje Spaß un e bisje Freud oder sou jet maache.

Herr Keller: Spaß un Freud han die hök och.

Herr Kastner: Un wie jesaacht, damals och. - Joa juut, awer... is doch schwachsinnig. ${ }^{399}$

398"jekos": gekostet. 
Nach dem hier zum Vorschein kommenden Rollenverständnis haben sich über die Jahre hindurch erhebliche Probleme in die gegenwärtige Versteigerungspraxis eingeschlichen. Die Meinung der einzelnen Diskussionsteilnehmer wies zwar graduelle Differenzierungen auf, aber es herrschte Übereinstimmung darüber, daß das Anbieten des Maikönigtitels mit Hilfe jenes nachträglich eingeführten Instruments, dem "Bier op de Maikönig", ${ }^{400}$ eine schwerwiegende Fehlentwicklung sei. Hohe Geldbeträge konnten bei der Einlösung der Biergebote zugunsten des zukünftigen Maikönigs zusammenkommen. Ein derartiger finanzieller Anreiz für die Entgegennahme des höchsten Repräsentationsamtes der Brauchträger wurde als widersinnig angesehen. Offenbar standen die eigenen Erlebnisse und das damalige Selbstverständnis von Vereinsmitgliedern im Widerstreit zum aktuellen Brauchvollzug und zur aktuellen Rolle der Brauchträger. Die Verantwortlichen von heute konnten in diesem Punkt die Erwartungen ihrer Vorgänger nicht erfüllen. Das Pathos, welches der Mailehenversteigerung von den Diskutanten unterlegt, welches durch Witz und Wortgewalt, durch Risikobereitschaft und Entschlußkraft oder auch durch Enthemmtsein und Alkoholgenuß charakterisiert wurde, erschien durch das monetäre Tauschgeschäft merklich ramponiert. Und dennoch gestand man den heutigen Akteuren zu, daß sie immer noch genügend Spaß an der Versteigerung hätten.

Wohlgemerkt trugen nicht nur Aufnahmeritual und Mailehenversteigerung dazu bei, die Rolle der Junggesellen zu konturieren. Auch andere Aufgaben aus dem rituellen Kanon des Mailehenbrauchs waren nach Herrn Weidens Erfahrungen geeignet, die entscheidenden und stets wiederkehrenden Momente des statusbezogenen Handelns zu aktivieren:

Es is immer die Versteigerung der Mailehen, was du immer so gerne sehen möchtest, [das] finde ich überhaupt net so gut, weil das is meistens en ziemlich ödes Thema, weil jeder versucht, dat so schnell wie möglich runterzukriejen, damit der Puss weg is, weißte, weil dat wird nachher alles ze lang hinten in dem Raum drin, un dann ham'se meisten keine Lust mehr dazu. Da is einfach irgendwie nix Gutes dran, weißte, wat halt eben so lustig sein sollte oder sonst wat.

Ich hätte gedacht, daß das relativ spannend is, wenn da sich gegenseitig hochgesteigert wird.

Et Spannendste an sich is et Maikönigssteigern. Un der Rest dat is halt eben... dat läuft nachher halt eben alles so ab, weil - wie gesagt - jeder weiß ja wen er ungefähr ersteigern will, un damit hat sich der Fall. Un meistens is et Lustiste am ganzen Mai et Dorfmaibaumovstelle. Da freuen sich die meisten drauf. [...] Weil da trinken die meisten auch dann ziemlich viel, und dann ham mir echt ne Feier draus jemacht dieses Jahr, dat war schon bald ne'mehr normal. Mer sin um zwei Uhr in den Wald gefahrn, ham mer den Baum dann aufjestellt, un dann so um fünf Uhr rum sin mer in de Wirtschaft, un nachts um drei Uhr sin mer dann nach Haus. Dat war natürlich ziemlich hart, aber wat wir an dem Tag gelacht haben da und wer da alles mitgegangen is, einfach super. ${ }^{401}$

${ }^{399}$ Gruppengespräch II (49/33-37/2b:296-379).

${ }^{400}$ Siehe dazu auch Kapitel 4.2.4 und 4.3.4.

${ }^{401}$ Herr Weiden (18/12/2a:636-657). 
Das intensive Gruppenerlebnis unter Gleichgesinnten tauchte immer wieder als ein wesentliches Element des Handelns auf. Man genoß die vertraute Atmosphäre, das gesellige Miteinander und die gemeinsamen Anstrengungen, die zum reibungslosen Gelingen des Mailehens beitrugen. Abseits vom Alltagsleben bot der Brauch den jungen Männern offensichtlich die Möglichkeit, einen besonderen sozialen Zusammenhalt zu finden.

Etwas anders erfuhr man dieses männliche Wir-Gefühl in Krisensituationen. Das gemeinsame Arbeiten, Lachen, Trinken, Feiern mußte durch den gemeinsamen Kampf für den Erhalt des Brauches erweitert werden. Als Gegner des Mailehens traten in den 30er und 50er Jahren des 20. Jahrhunderts strenge Kirchenmänner auf. ${ }^{402}$ Es entfesselte sich ein Machtkampf zwischen zwei ungleichen Parteien: Den gestandenen Pfarrern mit ihrer weitreichenden Autorität standen die trotzigen Burschen gegenüber. Herr Stein gibt den Verlauf des Streits folgendermaßen wieder:

Also außer der Pastor damals - wie hieß er noch: Geisen - der war da jejen die Versteijerung. Aber wir haben uns da net erweichen lassen, ne. Ich hab ihn einjeladen. Ich hab ihm geschrieben: "Der Jungjesellenverein lädt ihn zur Versteijerung ein. Er dürfte sojar teilnehmen als Lediger", hab ich ihm jeschrieben, ne. Da hat er natürlich sonntags jepredigt vun: "Nu besitze die Jungjeselle och noch die Frechheit...", sagt er, un predigt un hat er jetobt dann, ne, un met beiden Fäusten jeklopp, ne. Aber die Leute han zwar net jelacht, heute würden se ja lachen dadrüwwer, ne, aber damals waren das Autoritäten auf'm Dorf, ne, un da hat niemand jewaacht, was ze sagen, ne. Un das... Wie der nahher versetzt wurde, da kam en anderer Pfarrer, ne, un der hat das... der hat uns jebeten, aber nich so doll unter die Jürtellinie zu jehen, ne, die Mädchen hätten ja auch ihre Würde und so weiter, ne. Aber der hat wieder nichts jesagt, ne. Da war dat janz unterschiedlich, wurd das jehandhabt un ausjelegt. - Ich hab mir och doa nichts wejen jemacht. Der is an mir minnestens e Vierteljahr vorbeijejangen. Da ging er spazieren, der Pfarrer, dann hat er, wenn er mir entjejen kam, ne, dann hat er in ne Tasche jegriffen un hat's Jebetbuch jenommen, dann hat er ins Jebetbuch, als wenn'e im Jebet war. Un wenn er an mir vorbei war, dann hat er's Jebetbuch wieder in die Tasch jesteckt un jing ohne Jebetbuch, ne. Na, ich hab ihn aber och nich in seiner Andacht jestört. Ich bin dran vorbeijejangen, hab "Juten Tach!" jesacht, er hat mir keene Antwort jejen, hab i aber och mir nix draus jemacht, ne.

Und die Bevölkerung im Dorf: Hat die dann den Junggesellenverein unterstützt, in dem was er dann weiter gemacht hat? Die hat den Zwist ja auch mitjekriegt.

Ja, ja, die han das mitjekriegt, ne, un... ah, das war teils, teils: Da waren die meisten... ach, die Männer, die han all jesacht: "Laßt euch net verrückt machen! Macht, wie et früher jewesen is!" Un da waren einije Frauen, ne. Wir han die damals in... Wir hatten dann hier so ne Anzahl Frauen, un das waren so dem Pfarrer seine Mitarbeiterinnen, ne. Wir han se hier im Volksmund "Westdeutscher Rundfunk" jenannt, ne, weil die, wenn mal irjendwo en Ehekrach war, was in jeder Familie mal vorkommt, un da liefen die morjens zum Gottesdienst, un dann anschließend bej de Pastor: "Wir müssen für die un die beten. Da war die Nacht en Krach..." un so wat, ne. Un das waren diejenijen, die han dann gejen die Mailehnversteijerung jewettet [sic], ne. Un meistens och noch sou Fuffzig-, Sekzigjährije Juffele - wie mir hier saachte - also Jungfrauen, also die keinen mitjekriegt, keinen Mann mitjekriegt hatten, ne. Aber sonst die Masse der Bevölkerung... 403

${ }^{402} \mathrm{Vgl}$. Kap. 4.2.2 und 4.2.3.

${ }^{403}$ Herr Stein (13/11/1b:360-413). 
Je stärker die Autorität der Kirche in der damaligen Zeit erlebt wurde, um so ehrenvoller klingt selbst heute noch der gewonnene Kampf um den Erhalt des Brauches. Er erscheint hier als Kristallisationspunkt adoleszenter Selbstbehauptung. Und in der Wahrung der Autonomie konnte sowohl das Selbstwertgefühl der einzelnen als auch das Wir-Gefühl des Kollektivs aus dieser Konfrontation gestärkt hervorgehen. Mit dem entsprechenden Rückhalt aus der Bevölkerung wurde hier das am Junggesellenstatus gebundene Machtpotential in einem konkreten Fall erfahren. Insofern bot die kollektive Brauchausübung auch im Umgang mit einflußreichen Dorfgrößen eine Transzendierung des bisher gewohnten Wirkungsbereichs der Heranwachsenden.

Ein letzter Aspekt der Entgrenzung und Horizonterweiterung, der bisher nur kurz gestreift wurde, rückt nun ins Blickfeld. Gemeint ist der Zugewinn an Fertigkeiten technischer und organisatorischer Art. Mit der Übernahme der Verantwortung für die Kirmes und das Mailehen ergaben sich Anforderungen an die Jugendlichen, das große Dorffest den Erwartungen der Allgemeinheit entsprechend $\mathrm{zu}$ organisieren. Planerische, logistische, führungsspezifische Qualitäten standen ebenso auf dem Prüfstand wie handwerkliche oder technische Fähigkeiten. Die Vereinszugehörigkeit und die Brauchausübung konfrontierten den Heranwachsenden mit handfesten Aufgaben, für die er persönliche Verantwortung und Einsatz aufbringen mußte. Fällen und Aufstellen von ansehnlichen Maibäumen oder das Auf- und Abbauen großer Festzelte waren solche Arbeiten. Mitunter konnte das Einüben von Tätigkeiten verlangt werden, mit denen ein Achtzehnjähriger bislang keine Berührung hatte. Das Können des einzelnen und der gesamten Mannschaft wurde der Dorfbevölkerung mit einer gelungenen Kirmes sinnfällig unter Beweis gestellt. Hierdurch stieg das Ansehen der Brauchträger im Ort. Ferner konnte ein Junggeselle, der bislang tagein, tagaus nur die Arbeit im landwirtschaftlichen Betrieb seiner Eltern verrichtete, zum Beispiel im Thekendienst eine vorteilhafte Abwechslung und persönliche Bereicherung erkennen. Auf der Grundlage des Status- und Rollenwandels mündete die Übernahme brauchspezifischer Pflichten gleichermaßen in einer persönlichen Herausforderung und einem persönlichen Gewinn. Dazu Herr Lange:

Ich meen, ich han och jern an der Theke jedes Jahr so zwei-, dreimal Dienst gemacht, ne, aber berufsmäßig hätt ich das nie gemacht, ne. Oder jetzt, wenn de Feuerwehrtag is... Ich wial gern so wat aushelfe, ich mach so gern so wat Thekendienst an nem Tag, wenn man unabhängig is un macht dann en Tag oder zwei oder sou, ne. Dat han ich och jern jemaach. Darum muß ich sare, woar et och met'm Verein nie für mich ein Würgnis oder sou, ne. 404

Wenngleich hier die dauerhafte, alltägliche Verpflichtung zum Bewirten von Gästen keine Alternative zur eigentlichen Berufsausübung sein konnte, so genoß der befragte Jungbauer zumindest an den Kirmestagen die Gelegenheit, kurzfristig in die Rolle eines Wirtes zu schlüpfen. Ein stärkerer Anreiz als die Mithilfe beim Bierausschank

${ }^{404}$ Herr Lange (29/19/2a:476-484). 
boten Herrn Lange vor allem aber die mehrtägigen Vereinsfahrten, welche die Junggesellen meist in Zweijahresabständen unternahmen. Bus-, Zug- und Flugreisen mit Zielen in Süddeutschland, Österreich, Italien und Spanien führten ihn aus der heimatlichen Umgebung und der Enge des Gewohnten heraus:

Der Reiz - also für mich muoß ich sare - wat der Jungjeselleverein mir geboten hatte, hätt ich sonst niemals erleben können, und zwar mein ich damit die Fahrten. Ich mein, am Anfang war't mal en Ausflug nach Dürkheim. Dat war, glaub ich, et erste, Wurstmarkt, ne, Tagesfahrt mit'm Bus. Dann war's nachher en Wochenende Konstanz. Dat woaren drei Tage, dann wurd's nachher ne ganze Woche alle zwei Jahre. Un dat sin Fahrten, die ich sonst, wenn ich nicht im Junggesellenverein gewesen wär, niemals gemacht hätte, wär ich niemals hingekommen, das hätt ich niemals erleben können. Et war halt eben... ich muoß dazusagen, ich hatte Landwirtschaft, man fuhr net in Urlaub. Bei den Jugendlichen damals war dat auch net so, dat die praktisch privat so fuhren, ne. Äwwer dat woar jet, mer dät zwar zwei Jahre Kirmes arbeiten oder mußte zwei Jahre Kirmes dafür arbeiten, hatten doafür alle zwei Jahre so ne Fahrt. Un in dem Fall, wenn der Verein fuhr, da wurd et halt och oft so gelegt, wann die meisten konnten damals waren noch mehrere Landwirte drin. [...] Et wurd so gelegt, dat die meisten fahren konnten. Et wurd och praktisch von meinen Eltern aus toleriert, so, dann fiehrt de Verein, un die Woche dann wurd dat toleriert un akzeptiert, ne. Wojejen, wenn ich sonst gekommen wär: "So, ich fahren met däm Sammersch Paul oder met dem Meiersch en Woch doa un doa hin" dann hätten se mich jefroach, ob ich noch normal wär, ne. Wie dat bei den anderen Jurendlichen, die jetzt en anderen Beruf haben, die ihre Woche Urlaub haben, wie dat da is, kann ich net beurteilen. Für mich muß ich saren, mir hät der Verein veel jejen, wie ich eben schon sagte, ich hätte diese Fahrten - dat woaren joa nun etliche - nie machen können, wenn ich net em Verein woar. ${ }^{405}$

An dieser Stelle endet und gipfelt die Darstellung von Herrn Lange über die außerordentliche Erweiterung des persönlichen Erlebnishorizontes im Kollektiv der Junggesellen. Resümierend läßt sich festhalten, daß das zu Beginn aufgedeckte Spannungsverhältnis aufgrund der Mechanismen der zweckgerichteten Eingliederung in die Gruppe der unverheirateten Burschen keineswegs nur zu Lasten der Individuen gehen mußte. Die Tatkraft und Leistungsfähigkeit, die vielfach enthemmten Interaktionen und Möglichkeiten zum Exzeß sowie letztlich auch die Berührung mit der Macht, die mit der Einnahme der neuen sozialen Position für die männlichen Heranwachsenden greifbar wurden, dienten dem positiven Erleben des ambivalenten Junggesellenstatus. Bisher galt es als Ausnahme, sich diesem Status zu verweigern. Setzt man eine Orientierung am Dorfgeschehen voraus, so dürfte ein wichtiger Grund für die Rekrutierung neuer Vereinsmitglieder das überwiegend positive Gefühl gewesen sein, das mit der Rollenübernahme einherging und von Herrn Winzer in der folgenden Formulierung zusammengefaßt wurde:

Wenn man im Jungjesellenverein is, das is schon en bißchen anerkannt sozusagen, das hebt einen irgendwie en bißchen höher. ${ }^{406}$

${ }^{405}$ Herr Lange (29/19/2a:353-402).

${ }^{406}$ Herr Winzer (07/07/1a:59-63). 


\subsubsection{Frauenwelten}

Im Vergleich zum Status der Brauchträger wurden beim weiblichen Pendant grundsätzlich andere Bedingungen wirksam. Es wurde bereits gezeigt, daß die Eintrittsvoraussetzungen des Junggesellenvereins von der Ortszugehörigkeit, dem Familienstand und vom Alter bestimmt wurden. Im wesentlichen hingen sie aber von einer affirmativen Haltung der aufzunehmenden Mitglieder ab. Das heißt, daß ein Vereinseintritt nicht automatisch vollzogen wurde, wenn ein Junge aus Oeverich oder Niederich das Alter von achtzehn Jahren erreichte. Seine Absicht, im Verein mitwirken zu wollen, mußte man vorbehaltlos kundtun und durch das Prozedere des Aufnahmerituals besiegeln. Erst dann wurde der neue Status manifest. Nach der soziologisch gebräuchlichen Terminologie wurde in diesem Zusammenhang vom erworbenen im Unterschied zum zugeschriebenen Status gesprochen. ${ }^{407}$ Letzterer ergibt sich folgerichtig aus der Erfüllung festgelegter Merkmale, die vom Subjekt nicht oder nur kaum zu beeinflussen sind. Die weibliche Mailehenschaft entspricht dem Konzept vom zugeschrieben Status. Eine äußerliche Erfüllung von Kriterien genügte, um unversehens auf der Versteigerungsliste aufgenommen zu werden. Auf eine Affirmation der als Mailehen angepriesenen Mädchen und jungen Frauen legten die Junggesellen während der Mailehenversteigerung keinen großen Wert. Bis in die Gegenwart hinein betrachteten die Männer die Auktion als ihr Ressort. Einen Anlaß, irgend jemanden außerhalb dieser homogenen Gruppierung an der Auflistung der versteigerungsfähigen Frauen zu beteiligen, sah man nicht. Jegliche Einmischung auf diesem Feld hätte den Junggesellen als Einschränkung ihrer bislang unangefochtenen Stellung und Kompetenzen vorkommen müssen. Die Zuschreibung des Status, welcher der weiblichen Dorfjugend die Teilhabe an der Brauchträgerschaft bescherte, erfolgte letztlich über das eindeutige Ergebnis der Mailehenversteigerung und somit ohne das Zutun der betroffenen Frauen. Diese prinzipielle Zurücksetzung der Frauen durch die gegenwärtige Brauchpraxis wurde von den Beteiligten durchaus wahrgenommen. Frau Evers hat sich dazu folgendermaßen geäußert:

Aber irgendwie is das schon en komischer Brauch, wo man wirklich noch merkt, daß er aus der Zeit stammt, wo eben die Frauen sich zu fügen hatten, ne. Der Mann sucht sich ne Frau aus, und sie muß sich fügen, ne, wie das eben früher auch so war. Die Frauen hatten nichts mitzusprechen, ne. ${ }^{408}$

Über Jahrzehnte hinweg lag die Entscheidungsbefugnis unangefochten in der Hand der Junggesellen. Insofern mußte ein durch die Frauen erhobener Einwand als inakzeptabler Eingriff in die Angelegenheiten der Männer verstanden werden, wie die Erlebnisse von Frau Gebhard illustrieren:

${ }^{407}$ Vgl. Hradil ( $\left.{ }^{7} 1988: 1260\right)$.

${ }^{408}$ Frau Evers (03/04/1a:418-426). 
Ich wollt zum Beispiel, als die mich et erste Mal gesteigert han, bin ich dann zu denen dahingegangen und gesagt: "Ich hab keine Lust mitzugehn." Un dat hat net gezählt. Un beim zweiten Mal bin ich vorher hingegangen und hab ihnen gesagt: "Ich hab keine Lust mehr." Dat hat auch net gezählt. Die steigern einen dann trotzdem. Dat find ich auch dann net okay.

Du bist einfach gesteigert worden, obwohl Du...

...ja, ja klar. Die nehmen da kein Rücksicht drauf.

Du warst beim Vorsitzenden oder wo?

Mhm. Un normalerweise is dat so, dat man Mädchen freikaufen kann. Also wenn dat en Freund hat, kann der dat freikaufen; un dat ging aber net. Ich hatte damals nämlich en Freund, und der hat noch denen en Kasten Bier hingestellt. Un die ham mich trotzdem gesteigert, den Kasten Bier mitgeholt un... is denen egal.

Also das war en auswärtiger Freund?

Ja.

Das heißt, es war denen egal, Du hast Deinen Maibaum gekriegt und Du wurdst abgeholt?

$\mathrm{Ja}$, ja. Mhm. Kasten Bier trotzdem einkassiert.

Aber Du hättest Dir auch nicht überlegt: "Gut, dann bin ich einfach nicht da an dem Tag!"

Nä, dat find ich bescheuert so wat. Also dat find ich echt doof, wenn der Junge dann kommt un klingelt un steht dann da. [...] Ja, da kann man nix machen. ${ }^{409}$

Verbales Kontern gegen die sich hier auswirkende männliche Definitionsmacht und Verfügungsgewalt war nach den Erfahrungen von Frau Gebhard zwecklos. Die Einmischungen wurden nicht zugelassen, und so wurde jede Ortsansässige, wenn sie die Kriterien annähernd erfüllte, zum Kreis der Mailehen hinzugezählt. Hierunter konnten sich selbst Fünfzehnjährige befinden. Insbesondere wenn davon auszugehen war, daß auf die Betreffenden hohe Auktionssummen entfallen würden und damit "gutes Geld" in die Vereinskasse fließen würde. ${ }^{410}$ Obwohl die Brauchausübung in diesem Punkt den subjektiven Ansichten über die persönlichen Rechte und Möglichkeiten der Selbstverwirklichung widersprach und obwohl sie als unzeitgemäße Fortführung patriarchaler Strukturen aufgefaßt wurde, sahen sich die Betroffenen außerstande, ihrer eigenen Position im Mailehen mehr Gewicht zu verleihen. Willkür und Fremdbestimmung sah man im Grunde als unannehmbare Vorgänge im gesellschaftlichen Leben an. Die Vorstellungen von freizügigen Persönlichkeitsrechten wurden vor dem Hintergrund der Brauchausübung durchkreuzt, relativiert und herabgesetzt. Mädchen und junge Frauen mußten sich dem rituell zustandegekommenen und insoweit legitimierten Verdikt der organisierten, achtzehn- bis etwa fünfunddreißigjährigen Junggesellen fügen. Ihre Mitsprache erübrigte sich. Eine Entbindung von Pflichten, die sich im Anschluß an den Statuswechsel aufdrängten, schien aussichtslos. Selbst bestehende Liebesbeziehungen und die Bemühungen des festen

${ }^{409}$ Frau Gebhard (41/28/1a:371-397). Vgl. Herr Lange (29/19/2b:611-617) und Herr Goltz (20/13/2a:91-94).

${ }^{410}$ Dazu Herr Goltz (19/13/1b:547-559), Frau Kruse (26/17/2a:258-264). 
Freundes, den Junggesellenverein mit einem Kasten Bier für das Losbinden von rituellen Verpflichtungen zu entschädigen, blieben ohne Wirkung.

Im Statuswechsel erlebten die beiden oben zu Wort gekommenen Betroffenen eine Zurücknahme ihres gewohnten Selbstverständnisses. Erwartungen, Verhaltensweisen, Werte und Rechte, die ihnen im Alltag vertraut waren, hatten durch das Mailehen einen Teil ihrer Gültigkeit verloren. Versuche, kommunikativ seine Position gegen die männliche Verfügungsgewalt durchzusetzen, scheiterten. Dort, wo im Rahmen der Brauchausübung Menschen und Personengruppen unter sozialen Druck gerieten, dem sie sich nicht ohne weiteres entziehen konnten, erhielt das Mailehen eine spürbare Brisanz, welche rasch in den Blick von Außenstehenden geraten konnte. Die Analyse stößt hier auf kritische Fragen: Wie erklärt sich die Diskrepanz zwischen Urteilsvermögen und Verhalten von Betroffenen? Warum widersetzten sich die unfreiwilligen Brauchträgerinnen nicht mit der ganzen Kraft ihrer Persönlichkeit und mit der gebündelten Macht gleichgesinnter Mitstreiterinnen den Mechanismen der Unterwerfung? Warum konnten männliche Brauchträger anscheinend mühelos am gewohnten Ablauf des Mailehens und an der ungleichen Rollenverteilung festhalten?

Es wäre leichtfertig und $\mathrm{zu}$ vereinfachend, wenn die Deutung sich darauf beschränkte, den im Mailehen sichtbar gewordenen geschlechtsspezifischen Rollenantagonismus auf eine ungleiche Machtverteilung unter den BrauchträgerInnen zu beziehen. Verkürzend und damit unbrauchbar wäre der Schluß, daß Frauen ohnmächtig der männlich dominierten Brauchausübung ausgeliefert seien. In zahlreichen Passagen ließen die Betroffenen erkennen, daß sie mit den restriktiven Verhaltenszumutungen umzugehen wußten. Der bestehende Eindruck von der weiblichen Willen- und Wehrlosigkeit erforderte somit eine Korrektur. Eine Zuspitzung des Braucherlebnisses auf rein zwanghafte, normerfüllende, sanktionsabwehrende Facetten konnte sich lediglich auf eine einseitige Perspektive stützen. ${ }^{411}$ Gewiß muß man bedenken, daß die Betroffenen handfesten Entfremdungsmechanismen ausgesetzt waren. Dennoch konnte die negative Seite der Brauchausübung durch Bereiche individuell erfahrbarer Entgrenzung, welche auf die Brauchträgerinnen ähnlich wirkten wie auf ihre männlichen Mitstreiter, teilweise aufgewogen werden. Daher wird die weibliche Rolle erst verständlich, wenn man auf das Spannungsfeld von positiven wie negativen Begebenheiten, Gefühlen und Gedanken eingeht, die sich am individuellen Braucherlebnis festmachen lassen. Das Fazit von Frau Gebhard lautete:

Also ich muß sagen, also für mich war'et eigentlich ganz gut un so. Aber et gibt halt so zwei Seiten: Einerseits so en Druck dahinter, andererseits halt natürlich auch positive Seiten. ${ }^{412}$

${ }^{411}$ Siehe Kapitel 3.2 und Wey (1999).

${ }^{412}$ Frau Gebhard (41/28/1a:369-371). 
Wie bei der Rollenübernahme durch die Junggesellen kommt auch hier eine spezifische Ambivalenz zum Ausdruck, die die Beteiligung am Mailehen charakterisierte. Ein dichotomes Verhältnis von Autonomie und Heteronomie war für die männliche Rolle kennzeichnend und fiel in der Bilanz positiv aus. Augenscheinlich hat die mailehenspezifische Frauenrolle zu ähnlichen Erlebnisweisen geführt. Auch hier konnten jene Einschränkungen, welche die Brauchträgerinnen mit der Rollenübernahme in Kauf nahmen, durch außergewöhnliche Transzendierungen von Verhaltensmustern entschärft werden.

Anders als im Junggesellenverein, wo dem Unterschied von Funktionsträgern und gewöhnlichen Mitgliedern kaum eine herausgehobene Bedeutung zugemessen wurde, ${ }^{413}$ machten sich bei der Beurteilung der weiblichen Rollenübernahme die bestehenden Differenzierungen nach Maikönigin, Mailehen und Rummel stärker bemerkbar. Aufgrund der Repräsentationspflichten der Maikönigin drängten sich die speziellen Verhaltenszumutungen in verstärktem Maße auf. Dagegen wog die Anforderung an die Mailehen, während des Festumzugs vor die Öffentlichkeit zu treten, deutlich leichter. Selbst wenn ein Mädchen dieser Pflicht nicht entsprach, mußten keine gravierenden Sanktionen und kein großes Aufsehen befürchtet werden. In den sogenannten Rummel kamen diejenigen, für die keine Ersteigerer gefunden wurden. ${ }^{414}$ Gegen Ende der Auktion sah der Vereinsvorsitzende es allerdings als seine Pflicht an, den Rummel en gros zu übernehmen. Unter diesen Unversteigerten konnte er sich dann ein Mailehen auswählen. ${ }^{415}$ Mädchen, die dem Rummel angehörten, erhielten einen Maien wie die ersteigerten Mailehen und waren insofern nicht völlig vom Brauchgeschehen ausgeschlossen.

Eine eingehendere Betrachtung der einzelnen Rollenausprägungen macht die Unterschiede sehr deutlich. Beginnen wir mit den Innenansichten bei der Maikönigin. Frau Dietz berichtete eindrücklich von persönlicher Bestätigung einerseits und Unterwerfung andererseits, die ihre Erfahrungen als höchste Amtsinhaberin gleichzeitig prägten:

Es war früher natürlich auch irgendwo schön, wenn man Maikönigin wurde, weil eben nicht jede die Möglichkeit hatte, Maikönigin zu werden, ne. Daher war es - so hab ich es damals zumindest gesehen - och irgendwo was Positives, ne. Aber so diese ganzen Begleiterscheinungen waren mir dann nachher... dat war mir also mehr unangenehm, als daß ich sagen würde, es wäre schön gewesen.

${ }^{413}$ Herr Fischer (33/20/2a:134-149) und Herr Weiden (17/12/1a:550-567) haben betont, daß die Übernahme des Präsidentenamtes schon mehrfach zum Problem geworden sei, weil es den Mitgliedern an der Motivation fehle, sich den Verpflichtungen zu stellen. Der mit der Funktion verbundene Aufwand scheint somit nicht mit dem Zugewinn an sozialem Status in einem ausgewogenen, anreizbietendem Verhältnis zu stehen.

${ }^{414}$ Zum Rummel siehe auch Kapitel 4.3.4.

${ }^{415}$ Dazu Herr Beck (09/08/2a:605-612) und Herr Goltz (19/13/1b:673-681). 
Und welche Begleiterscheinungen meinst Du da jetzt so konkret?

Ja, jetzt mit diesem Maibutz und dann mußtest du tanzen, obwohl du mußtest ja praktisch fast den ganzen Abend tanzen, ne. [...] Und vor allen Dingen, dat war dann ja noch so: Wie gesagt, die Bank wurde in die Mitte von der Tanzfläche geschoben, un dann mußtest du also Sekt trinken. Un dann mußte das Glas leer sein, obwohl du den Sekt vielleicht gar nicht mochtest, oder, ne, wenn das Glas leer war, dann mußtest du schon das nächste trinken. Also in Anführungszeichen eine "Vergewaltigung", ne. [...] Und das waren eigentlich och so die unangenehmen Begleiterscheinungen, ne, wo ich da sagte. Und ich kann mich also einmal daran erinnern (zumal ich dat och nicht gewohnt war, zuviel Alkohol zu trinken), daß wir zu dem Maikönig nach Hause gegangen sind und daß ich da also Wurst und Käse gegessen hab, um irgendwo einigermaßen klar zu werden, ne. [...] Also ich weiß einen Abend, ich hatt also richtig en Schwipps, und mir war es richtig schlecht und übel, und ich hätte mich also irgendwo in die Ecke stellen können: immer von diesem Tanzen und das Trinken und... Ich weiß, es gibt vielleicht Typen, denen macht das nichts, ne, aber mir ging dat irgendwo nachher so gegen den Strich, daß ich also auch, wie ich anfangs schon sagte, froh war, als es wirklich nachher rum war, ne, als ich den Montag dann geschafft hatte.

Also, ja, das wird mir schon klarer: Der Maibutz und diese Tanzverpflichtungen...

...ja, ja auch dieses Trinken dann immer. Dieses, ja, was man da also verkonsumieren sollte, ne. Ich mein, das war dann zwar immer - war es zweimal am Abend oder haben sie's einmal gemacht - aber dann halt eben... Also ich kann mich erinnern, also es wurde dann ne Flasche Sekt aufgemacht, und ich mußte also einmal zwei Gläser Sekt praktisch so hintereinander wegtrinken, ne. Und ich denke, och grad so Sekt, den kann man nicht so schnell dann wegtrinken, ne. Ich weiß nicht, ob das vielleicht auch war, die Hemmungen zu nehmen, oder keine Ahnung. Aber so dieser Brauch, das ging mir also schon dermaßen gegen den Strich. Vielleicht wenn es auch jetzt mit dem Trinken nicht so gewesen wäre, wenn man mal genippt hätte, so wie man vielleicht wollte, ne. "Trink leer! Trink leer!" und dann, ja, wurd das Glas schon wieder vollgeschüttet, ne. Und dann hieß es: "Du hast das Glas noch nicht leergetrunken!" - "Ja, ich möchte aber jetzt nicht mehr!" - "Nein, du mußt das Glas leertrinken!" Also schon... man fühlte sich also schon in die Enge gedrückt, ne. Und wenn man dann so jung is, hat man auch - glaube ich - nicht so die Kraft, dagegen anzugehen, ne. ${ }^{416}$

Positive wie negative Erlebnisse wog Frau Dietz aus der Retrospektive gegeneinander ab. Bei ihrer Wahl zur Maikönigin fühlte sie sich zwar umschmeichelt, aber dieses positive Gefühl wurde letztlich durch die "negativen Begleiterscheinungen" überschattet. Jene Nebenwirkungen geben Aufschluß über Verhaltenszumutungen, die mit der Rollenübernahme einhergingen. Aufforderungen zum Maibutz, zur ständigen Tanzbereitschaft und zum übermäßigen Alkoholkonsum wurden angesprochen. Für die Betroffene gab es kein Entrinnen aus der öffentlichen Repräsentationspflicht, weshalb das Küssen, Tanzen und Trinken vor versammeltem Publikum $\mathrm{zu}$ einem unangenehmen Zwang werden konnten. Zur königlichen Herrscherin gekürt, als anmutige Schönheit bewundert, gefeiert und zugleich von dem Gefolge und den Schaulustigen bedrängt, so präsentierte sich das zwiespältige Dasein einer Maikönigin.

Beim Vergleich mit weiteren Fallbeispielen tritt hervor, daß sich andere Brauchträgerinnen mit denselben widerspruchsvollen Zusammenhängen beschäftigten. Unübersehbar ist allerdings dabei, daß die Bewertungen der Rolle nach subjektiven Kriterien

416Frau Dietz (02/03/1a:164-219). 
und spezifischen Erlebnissen erfolgte. Trotz der erwähnten Zumutungen blieb das Erlebnis oftmals in positiver Erinnerung. Von dieser Seite zeigte sich in einem ausführlichen Bericht von Frau Pfeiffer die Bilanz der durchlebten Brauchkarriere:

Ja, und dann ging das nachts los, daß es hier bimmelte um zwei Uhr morgens, und die Mädels standen vor der Tür und schrieen nur "Maibutz, Maibutz!" Und das erste, was ich dachte: "Oh Gott, ich bin Maikönigin!" und rannte runter zur Tür, und: "Ja, Maikönigin..." Und da war ich erst'mal voll schockiert; konnte auch nicht mehr schlafen. Aber ich hab seltsamerweise keine Minute dran gedacht, daß irgendwie... zu sagen: "Nee, hab ich keine Lust." oder so. Also das wollt ich schon mitmachen, wenn's mir auch sehr komisch war. Ja, und dann wurd halt die Maitanne aufgestellt, und, wie Sie wahrscheinlich wissen, wird man dann vom Vorsitzenden des Junggesellenvereins gefragt, ob man das mitmachen möchte oder nicht. Und ich hab auch zugesagt. [...] Ja, und dann erfaßte unsere ganze Familie die Panik, daß ja die Junggesellen hier ankommen, und wir wußten nicht, wo die Getränke herzunehmen sind. Mein Vater hat sämtliche Tankstellen abgeklappert, weil der Kaufmann an dem Tag auch nicht da war, also der Lebensmittelmarkt, der sonst dafür zuständig war. Ja, und dann ging das hier los. Und das Schlimmste fand ich eigentlich am Anfang mit dem Maibutz. Das fand ich schon komisch. Mein Freund saß dann dabei, und der fand das dann auch so etwas seltsam. [...] Ja, und dann wurd halt geplant, was ich für ein Kleid kaufen soll. Und ich fand das schrecklich, daß es en langes sein mußte. Und die Vorgaben wurden halt gemacht, wie das so ungefähr abläuft. [...] Ja, und dann ging die Rennerei los. Daran kann ich mich noch gut erinnern: Die Rennerei nach dem Kleid, das war furchtbar. Also ich wollt es auch perfekt haben, irgendwie. [...] Meine Eltern, die sind wahnsinnig geworden. Wir waren überall. Dann hab ich doch nicht gefunden, was ich wollte. Ja, das war prägend irgendwie. [...] Ja, dann ging's halt weiter. Darauf die Woche, da war's halt blöd mit Vatertag und dann das Wochenende danach, es sind ja dann immer die Festivitäten. Da hatte ich nur so kurz Zeit, das Kleid zu kaufen - war für mich damals ungeheuer wichtig.

Ihr Mutter war da sicherlich auch engagiert.

Auch, ja klar. Die Mütter sind da sowieso sehr... war alles sehr aufregend.

Das war ja auch alles neu für die.

Ja, komplett neu. Die haben mich noch nervöser gemacht als ich eh schon war. Und dann den Samstag war der Eröffnungstanz hier. Ja, und dann sonntags gings halt los mit dem Abholen, und ich war am zittern vor Aufregung. Als ich einmal in der Kutsche saß und den ersten Tanz hinter mir hatte, dachte ich: "Gut." Da hat's auch Spaß gemacht. Ich muß sagen, ich bereue nichts, also um das vorweg zu sagen. Also ich würd's wieder machen, zurückgerechnet. Doch, muß ich sagen, war schön. Und ich hab auch en anderes Verhältnis zu den Oevericher Junggesellen bekommen, auch zu dem ganzen Fest als solches. Früher war das für mich UmptattaMusik und heute? Weiß nicht, wahrscheinlich durch die Integrierung, ich weiß es nicht. [...] Ja, und dann das Übliche: Festzug und danach Tanz. Und an dem Montag war mein Maikönig wieder beim Bund, da hat er kein Frei bekommen und da weiß ich noch, daß ich es bedauert habe, daß ich nicht mehr den Abschlußtanz mit ihm gemacht habe und da mein Amt schon erledigt war, nachdem das Schlimmste vorüber war. - Ja.

Was war das "Schlimmste"?

Das war für mich von vorneherein der Festzug. Das war das Aufregendste, sagen wir so. Da wußte ich so gar nicht - uh - so im Mittelpunkt stehen. Es war schon komisch. Aber hat mir dann im nachhinein gefallen, muß ich auch zugeben. Doch, war schön, hat Spaß gemacht. ${ }^{417}$

Verben und Adjektive, in denen Fassungslosigkeit, Verwirrung und Aufregung zum Ausdruck kommen, beherrschen den Text bis zu seinem letzten Drittel. Dann

${ }^{417}$ Frau Pfeiffer (46/32/1a:97-240). 
verschaffen sich gegenläufige Effekte Geltung: Fiebern und Unbehagen kulminierten zu Beginn des öffentlichen Auftritts und verwandelten sich nach der ersten Bewährung beim Tanz in positives Erleben. Frau Pfeiffer beschrieb damit einen Prozeß der Einfindung in die Rolle der Maikönigin. Was sie anfangs schockierte und ihr den Schlaf raubte, was sie immer wieder komisch, aufregend und schlimm fand, war am Ende mehr als ein schönes Erlebnis. Die Beteiligung am Brauch veränderte ihre Position als Zugezogene im Dorf. Die Bevölkerung honorierte das Engagement jener jungen Frau, welche die in sie gesetzten Erwartungen ganz besonders gut erfüllen wollte. Dieser Ansporn zeigte sich sehr deutlich bei den Vorbereitungen zum Umzug. Daß das gekaufte lange Festkleid nicht ganz ihren Vorstellungen entsprach, beschäftigte sie dabei noch lange. In diesem Beispiel bot die Identifikation mit der rituell zugewiesenen Rolle die Möglichkeit zur gewünschten sozialen Integration. ${ }^{418}$ Daher traten die spannungsgeladenen Momente, wie sie zum Beispiel im Maibutz und der Repräsentationspflicht zum Vorschein kamen, in den Hintergrund der Erinnerungen.

Persönlichen Voraussetzungen muß bei der Übernahme und Bewertung der Brauchträgerinnenrolle eine beachtliche Bedeutung zugemessen werden. Die beiden vorangegangen Fälle haben veranschaulicht, daß die Rolle der Maikönigin zwar formal ähnlich, inhaltlich aber entgegengesetzt beurteilt wurde. Während die Eingesessene die Auswirkungen sozialer Repression hervorhob, relativierte sich im Vergleichsfall der erlebte Druck unter dem Einfluß der gewonnenen gesellschaftlichen Partizipationsmöglichkeiten. Darüber hinaus muß berücksichtigt werden, daß in diesem speziellen Fall von der Geltung gewisser Sonderrechte ausgegangen werden kann. Die Bedingungen, unter denen die zugezogene Informantin Maikönigin wurde, erschienen so, als hätte für sie die freie Wahl bestanden, ihr Amt anzunehmen oder abzulehnen. Zum damaligen Zeitpunkt ging die Betroffene jedenfalls freimütig davon aus, daß sie über ihre Teilnahme selbst entscheiden könne, wohingegen die im Ort aufgewachsene Frau Thiel keinerlei Zweifel über die alternativlose Pflicht zum Amtsantritt hegte:

Ich glaub, wenn mer bei uns jetzt ablehnen würde, daß man Maikönigin wird, also ich glaub, da wär bei uns wirklich was los. Da bräuchte man sich Kirmes gar nicht mehr blicken zu lassen. Also da wär man wirklich unten durch. Also da könnt man sich bei uns nicht mehr blicken lassen. ${ }^{419}$

Ohne die Erfahrung dieser Ausweglosigkeit war die Rolle der Maikönigin weniger prekär, als sie sich unter den gewöhnlichen Umständen den potentiellen Kandidatinnen darbot. Nach den Erfahrungen von Frau Kruse setzte sich ein Teil der

${ }^{418}$ Siehe unten Kap. 4.4.4.

${ }^{419}$ Frau Thiel (04/05/1a:586-589). 
betreffenden Mädchen und Frauen am Abend der Versteigerung zusammen, um dem Druck gemeinsam zu widerstehen:

Ja, die ersten Jahre war'et ganz schlimm, oh Gott, un vor allen Dingen so in der Mainacht. Wenn du nur gesteigert wirst, is dat ja in Ordnung. Weil... dann is et ja auch mehr oder weniger egal, wer dich steigert, ne. Aber wenn du Maikönigin wirst, dann han mir gedacht: "Gott, wat is, wenn der oder der mich steigert?" ne. Un: "Oh nee! Der will ich um Gottes Willen net!" Et gibt ja halt eben so Typen, wo du denkst: "Oh!" - Gott, für uns war dat immer en Graus, wenn der eine dich steigert und du mußt den dann noch küssen. Wenn du Maikönigin wirst, dann mußt du den ja küssen. Für die Astrid war dat ja sehr gut, ne. Un et Sonja war damals auch total glücklich, dat et de Marco war, aber war trotzdem entsetzt, dat et überhaupt Maikönigin war. Un dat waren so Situationen, wenn de dann Maikönigin warst: "Hah, du hast'et geschafft!" Dann war der Rest mehr oder weniger egal, ne. ${ }^{420}$

Vor allem zwei Dinge schienen die Brauchträgerinnen in Unruhe zu versetzen: Erstens, zum Unzeitpunkt Maikönigin zu werden und zweitens, nicht den erhofften Partner zu bekommen. Trafen beide Konstellationen zusammen, dann war die Maiköniginnenschaft für die Betroffene ausgesprochen unangenehm. Mit zunehmendem Alter konnte Frau Thiel mehr Gelassenheit gewinnen und brauchbedingte Befürchtungen abbauen:

Es is immer spannend, wer Maikönigin wird. Besonders wenn man ganz jung is, dann is es echt sehr spannend, weil man dann auch irgendwie nicht will. Und je älter man wird, dann denkt man sich: "Och, is ja egal."

\section{Und warum wolltest Du nicht Maikönigin werden?}

Tja, ich weiß auch net, wenn mer so jung is, dann will mer dat irgendwie net. Da hat man so Schamgefühle. Nä, dat is wirklich net so schön. Also wirklich, je älter man dann wurde, um so... man wird einfach freier un sieht das dann gar nicht mehr so ernst. So zum Beispiel, wenn man so jung is un dann so mit dem Maibutz, dann sieht mer das halt so ernst: "Oh Gott!" Dann hat man vielleicht noch so en Schamgefühl. Un nachher, wenn mer so en bisje älter is, dann sieht man das halt nicht mehr so ernst, ne. Dann denkt man sich: "Och, es is einfach en Maibutz" und das war's dann, ne; vielleicht deswegen.

Also irgendwann is das dann so umgeschwenkt.

Ja, nicht direkt umgeschwenkt. Also man is dann auch nicht direkt so scharf dadrauf: "Oh, ich will das werden!" oder so, sondern es is einem... wenn's passieren würde, is es einem egal. Oder halt so mit'm Uli, da hab ich mich auch drüber gefreut. Also mit'm Uli da hab ich mich echt drüber gefreut. Vielleicht mit'm anderen, wär's mir egal, aber mit'm Uli... wie ich das gehört hab, hab ich gedacht: "Ach ja, wird lustig!"421

Entsprechend den Ausführungen stellte sich die eigene Brauchkarriere im nachhinein ganz glücklich dar. Frau Thiel wurde erst mit gut zwanzig Jahren zur Maikönigin ersteigert. Zu dem Zeitpunkt konnte sie die Aufforderung zum Maibutz nicht mehr in die Bredouille bringen. Dadurch, daß der Maikönig aus ihrem engeren Freundeskreis stammte, empfand sie den rituellen Statuswechsel weder als bedrückende Bürde noch als hinzunehmende Pflicht. Die Zeit, in der sie das höchste Amt der

${ }^{420}$ Frau Kruse (26/17/2a:261-281).

${ }^{421}$ Frau Thiel (04/05/1b:70-116). 
Brauchträgerinnen bekleidete, verging ihr im Grunde viel zu rasch, da sie mit dem Maikönig, den Junggesellen und ihren Mailehen sowie einem großen Teil der Kirmesgäste vergnügliche Stunden in einer "Superstimmung"422 verbrachte:

Ja, und am Aufregendsten ist es dann, wenn mer die Musik hört, dann bekommt man Bauchkribbeln. Dann geht's los.

Beim Umzug?

Ja, genau. Dann sind dann immer alle dran: "Da hörst'de? Musik kommt, Musik kommt!" Ja, und dann is man wirklich sehr aufgeregt. Ja, und dann... - Tja, und dann geht alles so schnell vorbei. Das is wirklich Wahnsinn. Es war einfach schön. ${ }^{423}$

"Hah, du hast'et geschafft!"424 konnten sich die ehemaligen Maiköniginnen sagen. Sie waren von dem mulmigen Gefühl des Ausgeliefertseins befreit, daß sie zuvor in den Mainächten plagen konnte. Während es in den frühen Nachkriegsjahren aufgrund des Versteigerungsverfahrens durchaus möglich war, daß einer unverheirateten Dorfbewohnerin mehrmals das königliche Repräsentationsamt angetragen werden konnte, so wurde in jüngerer Zeit auf diese Variante verzichtet. ${ }^{425}$ Vor dem Hintergrund einer überaus gelungenen und positiv erlebten Rollenübernahme wurde verständlich, daß der Anspannung, welche die Mailehenversteigerung verursachte, auch positive Seiten abgewonnen werden konnten. Rückblickend stellte Frau Thiel fest:

Un es is auch irgendwie schön, wenn man erst später Maikönigin wird, vielleicht auch weil immer die Aufregung da is, weißt de. Dann in der Nacht so: "Bist'et jetzt geworden? Bist'et net geworden?" oder so. Oder: "Wer könnte denn Maikönig geworden sein?" Und auch so der Spaß dabei, weißt de, zum Beispiel der is jetzt vorbei, ne. ${ }^{426}$

Die Furcht, den Status der Maikönigin ungewollt $\mathrm{zu}$ erhalten, verquickte sich demnach leicht mit einem aufmunternden Nervenkitzel. Allerdings geschah es wohl häufiger, daß der Maikönig den Erwartungen seiner Erwählten weniger entsprach als im soeben erörterten Fall. Die Ersteigerer konnten aufgrund ihrer Gebote eine gezielte Auswahl vornehmen und waren dadurch im Vorteil. Während sie die Chance hatten, ihren persönlichen Neigungen Ausdruck zu verleihen, sahen sich die potentiellen Kandidatinnen oftmals einer zwiespältigen, folgenreichen Sympathiebekundung ausgeliefert. ${ }^{427}$ Indem von außen darauf gedrängt wurde, den rituellen Ablauf des Mailehens nicht zu gefährden, waren Reaktionen der Maiköniginnen auf derartige Offerten eingeschränkt. Diese Zusammenhänge machte das Gespräch mit Frau Evers deutlich sichtbar:

\footnotetext{
${ }^{422}$ Frau Thiel (04/05/1a:566-569).

${ }^{423}$ Frau Thiel (04/05/1a:128-138).

${ }^{424}$ Frau Kruse (26/17/2a:261-281).

${ }^{425} \mathrm{Vgl}$. Kapitel 4.2.4.

${ }^{426}$ Frau Thiel (04/05/1b:133-140).

${ }^{427}$ Siehe Kapitel 4.4.1.2.
} 
Hattest Du für Dich damals gedacht, Maikönigin zu werden?

Is klar, das wünscht man sich ja, ne. Man möchte natürlich mal die Auserwählte sein, ne, in dem Sinne, ne. Das wünscht man sich schon, ne.

Ja, und dann kam's dazu...

...Ja, ich weiß jetzt gar nicht mehr genau, ob ich das jetzt von meinem Bruder erfahren habe oder ob ich zuerst die Tanne am Haus gesehen hab. Ja, und dann natürlich die erste Frage: "Wer ist der Maikönig?" ne, ist klar, daß das einen interessiert, ne. Und daß man stolz ist, ist eigentlich auch klar, daß der Maikönig einen selbst als diejenige auserwählt hat, die ihm am besten gefällt, ist ja auch verständlich, ne. Aber auf der anderen Seite wiederum, wenn man dann dem Maikönig nicht ähnliche Gefühle entgegen bringt, ist es och wieder ne verzwickte Situation, ne.

Und wie würdest Du die Wahl entscheiden?

Ja, ablehnen, das macht man ja ohnehin nicht, ne. Das... das gehört sich nicht, ne. Ich mein, is klar, da würd man denjenigen ja auch verletzen. Ich mein, die paar Tage, die gehen auch rum, ne. Macht man eben ne gute Miene zu bösem Spiel, ne. ${ }^{428}$

$\mathrm{Da}$ eine designierte Maikönigin ihre Wahl ablehnte, war für viele undenkbar. Indes trug sich in der Oevericher Brauchgeschichte ein einziges Mal ein solcher Zwischenfall in den 1970er Jahren zu. Er sorgte im Junggesellenverein und in der Bevölkerung für Aufregung. Ohne Komplikationen fand man aber einen Ersatz für das ausgeschiedene Paar. Somit war der rituelle Ablauf der Maikirmes nicht gefährdet. Die Begründung für diesen einzigartigen Vorfall ist aufschlußreich. Nach den Schilderungen lag die damalige Entscheidung über die Verweigerung der Teilnahme nicht bei der Maikönigin selbst, sondern bei ihren Eltern, die sich einer rituellen Legitimation der vorehelichen Verbindung ihrer Tochter widersetzten. ${ }^{429}$ Wieder zeigte sich die Wirksamkeit der Fremdbestimmung bei den weiblichen Brauchträgerinnen. Rituelle Regeln konnten anscheinend verletzt werden, und dem daraus resultierenden öffentlichen Druck konnte man standhalten, solange nicht die Betroffene selbst, sondern die höhere Autorität der elterlichen Gewalt auftrat und eine Beteiligung ablehnte.

Bemerkenswert sind daneben Berichte von Maiköniginnen, die von dem Versuch der Gegenwehr und Selbstbehauptung zeugen. Sie decken einen markanten Verhaltensspielraum auf, der das weibliche Rollenmuster prägte. Am Anfang steht ein Erlebnis von Frau Heuerdorf. Ihre Vorstellungen über die Handlungsspielräume einer Maikönigin gingen zu weit; deshalb wurden sie korrigiert:

Nee, Nee. Also der Maikönig jefiel mir jar net, der ich hatt. Der woar och he von Oeverich. Dat weiß ich noch jod. Ja, da sin mir dann och he durch dat Dorf jefahren, ne. Wie heute och. Un da sin mir dann unten in den Saal tanzen jejangen. Dann sin ich dann um zehn Uhr nach Hause jekommen; da hab ich jesagt: "Ich geh nicht mehr!" Der jefiel mir net, der Maikönig. Sagt minge Vatter: "Mach bloß dat de runterkommst!" Sagt er: "Du bis Maikönijin, un du muoß met

${ }^{428}$ Frau Evers (03/04/1a:111-143).

${ }^{429}$ Herr Beck (08/08/1b:492-515), Frau Dietz (02/03/01a:469-482) und Herr Fischer (32/20/1b:669$679)$. 
dem Jung tanzen!" Joa, doa sin ich wieddr runterjejangen. Joa, han ich dann anstandshalber, ne... Das is ja och nicht jedermanns Sache; also wenn die Mädchen die Jungen net Leiden wollen. Oder is ja heute noch. Also mir jefiel der Maikönig net.

Un dann war's eher ne Tortour?

Ja, ja. Et woar ne Tortour. Dat is doch klar, ne, wenn se den Jung net möjen, un sollen dann drei Tage doa mit dem Tanzen. Nä, also der jefiel mir net. ${ }^{430}$

Durch die Mailehenversteigerung war die designierte Maikönigin zwar in aller Regel unweigerlich zur öffentlichen Teilnahme am Brauchgeschehen verpflichtet, dagegen verblieb ihr aber ein Rückzugsort, der ihre emotionale Beteiligung im Verborgenen halten konnte. Die Zugewandtheit des Maikönigs mochte problematisch, vielleicht auch bedrängend sein. Abgewiesene Sympathiebekundungen erhöhten den Druck auf die Maikönigin. Im oben geschilderten Fall führten sie dazu, daß die Informantin versuchte, sich ihrer rituellen Aufgabe und damit der Nähe zu ihrem Maikönig zu entziehen. Dieses Verhalten widersprach allerdings der ihr zugedachten Rolle. Ihre Familie und das soziale Umfeld kümmerten sich in diesem Moment nicht so sehr um die emotionalen Vorlieben und Aversionen einer Schlüsselfigur des Mailehens. In diesem Falle hatte die Betroffene lediglich die Aufgabe, den Schein zu wahren und dem Publikum eine repräsentative Maikönigin vorzuspielen. Als Frau Heuerdorf ihre äußerliche Fassung wiedergefunden hatte, war es ihr wieder möglich, den Anforderungen gerecht zu werden. Die rituelle Rollenübernahme stellte auf diese Weise ein Lernfeld für vergleichbare Situationen im Alltagsleben dar, bei der eine hohe Anpassungsleistung des handelnden Subjekts vom sozialen Umfeld erwartet wird. ${ }^{431}$

Es hat sich gezeigt, daß besonders die Rolle der Maikönigin mit sozialem Druck und Zwängen behaftet sein konnte. Soziale Spannungen lockerten sich zunehmend, wenn die betreffenden Paare einen wechselseitig freundschaftlichen Umgang pflegten oder zumindest die gegenseitige Akzeptanz gewannen. Selten traten die hiermit verbundenen Probleme derart in den Vordergrund wie im obigen Fall. Gefühle blieben eher im dunkeln. Die Maikönigin unterwarf sich dabei den Vorgaben und arrangierte sich mit ihrem Brauchpartner, solange die zeitliche Verpflichtung dazu bestand. Einige Frauen versuchten, den möglichen Eingriff in die persönliche Integrität von vornherein zu minimieren und sorgten für eine unmißverständliche Grundlage der rituellen Beziehung:

Frau Rosen: ...ja, manchmal, manchmal war der Junge meinetwegen nicht angenehm, aber das mußte die vier Wochen im Mai in Kauf genommen werden...

Herr Marx: ...dat jing ja wieder vorbei...

Frau Rosen: ...wenn die Kirmes vorbei war, war das ja vorbei, ne. Woar ja nur für ne jewisse Weile. Hab ich ja eben gesagt, mit dem Franz, der Junge der mich gesteigert hatte, da war

${ }^{430}$ Frau Heuerdorf (23/15/1a:275-299).

${ }^{431}$ Dazu auch Frau Dietz (02/03/1a:41-62; 1b:36-80) und Frau Evers (03/04/1a:440-453). 
absolut gar nichts. Un ich hab dem jesagt, beim Tanzen (mir mußten ja die Ehrentänze absolvieren) sacht ich: "Franz, do kannst mache wat'te willst, un ich dohn et och!" Ich wollt ja net irjendwie in Abhängigkeit reinkumme, ne. ${ }^{432}$

Das Brauchgeschehen und die Verbindung zum Maikönig wurde hier von der Maikönigin lediglich als äußerer Rahmen betrachtet. Gewisse Regeln waren einzuhalten, Tänze mußten absolviert werden, ansonsten aber galt es, die eigene Unabhängigkeit $\mathrm{zu}$ fordern und zu behaupten. Maiköniginnen, die mit einer ähnlichen Ausgangslage konfrontiert waren, sahen sich gerade in diesem Punkt tendenziell überfordert. Die Gründe dieser Überforderung lagen in dem geringen Alter, der Unerfahrenheit und dem Hin- und Hergerissensein zwischen dem schmeichelnden Gefühl der Umwerbung und dem bitteren Geschmack jener Zwänge, die nicht selten die Erlebnisse begleiteten, welche mit der exponierten Rolle der Maikönigin einhergingen. Alkoholtrinken, Tanzen und Maibutzgeben zählten hier zu den Verhaltenszumutungen, die durch die Übernahme der Maiköniginnenrolle gegen den eigenen Willen der Brauchträgerin erzwungen wurden.

Welche Struktur von Verhaltenszumutungen und Reaktionsweisen lassen die bisherigen Ausführungen erkennen? Wie ist der Kern beschaffen, den die Rolle der Maikönigin beschreibt und welche Gestaltungsmöglichkeiten zeichnen sich ab? Ausgangspunkt der Analyse war die Zwiespältigkeit der rituellen Verpflichtung. Positive wie negative Eigenschaften der Rollenübernahme wurden festgestellt. Grundlegend erschien zunächst der Modus des Statuswechsels. Daß der Maiköniginnentitel durch die Junggesellen vergeben wurde, erzeugte einen äußeren Druck und eine brisante Stimmung unter den Kandidatinnen. Das rituell legitimierte asymmetrische Verhältnis von Ersteigerern und Ersteigerten verschärfte diese Situation. Einem Jungen wurden Optionen offengehalten, welche den Eintritt in den Junggesellenverein oder die Beteiligung an der Versteigerung betrafen. Dagegen wurde eine weibliche Heranwachsende in die Rolle hineingedrängt. Sie hatte der Herausforderung entgegenzutreten, sich zusammen mit dem Ersteigerer als ein repräsentatives, würdevolles Paar der Öffentlichkeit zu zeigen. Gebote der Geselligkeit mußten insbesondere auf der weiblichen Seite beherrscht werden. Erwartet wurde das frohgestimmte Mitmachen sowohl im überschaubaren Kreis der Junggesellen, als auch vor einer teils anonymen Menschenmenge, die beim Festzug die Straßen säumte.

Die Rollenübernahme bedeutete eine Loslösung von vertrauten Orientierungen und Verhaltensweisen. Gleichzeitig erforderte sie eine gewisse Einordnung in einen gesellschaftlich und rituell vorgezeichnetes Aktionsfeld. Diese Einordnung vollzog sich nicht immer reibungslos. Immer wieder bekundeten Brauchträgerinnen ihr

${ }^{432}$ Gruppengespräch I (39/23-27/2a:538-558). Vgl. Frau Pfeiffer (46/32/1b:520-537) und Herr Stein (14/11/2b:445-470). 
Unbehagen an der vom sozialen Umfeld geforderten, rituell legitimierten Vereinnahmung ihrer Person. Die meisten haben erfahren, daß die Rollenübernahme gewisse Handlungen erzwingen konnte, die ohne den Statuswechsel und unter alltäglichen Bedingungen unterblieben wären. ${ }^{433}$

Freilich gab es auch den Glanz des in der Öffentlichkeit bewunderten und bespiegelten jugendlichen Anmuts, der aus dem Status des Mailehen- und insbesondere des Maikönigspaares schöpfte. Er forderte jedoch seinen Tribut in der Befolgung der dargelegten, im Brauch geltenden Spielregeln. ${ }^{434}$ Hochgefühl und positive Erfahrungen verschwiegen die Maiköniginnen keineswegs. Man sprach von der ausgelassenen Feststimmung, der ausgelebten Tanzleidenschaft und den anregenden Kontakten. Überhaupt konnte die zwischenmenschliche Begegnung, die Neu- oder Wiederaufnahme von vielfältigen Beziehungen zur Altersgruppe sowie generell zur Dorfbevölkerung bedeutsam werden. Da die Maikönigin an exponierter Stelle der Kirmesfeierlichkeiten stand, war eine allgemeine Aufmerksamkeit des Publikums auf sie gerichtet. ${ }^{435}$ Leicht konnte sich hieraus ein allgemeines Interesse am näheren Kennenlernen der Regentin ergeben. ${ }^{436}$ Vor diesem Hintergrund ist es durchaus nachvollziehbar, daß der Maiköniginnenstatus das persönliche Ansehen steigern konnte. Die Dimensionen gesellschaftlicher Achtung und Anerkennung konnten überwältigend sein. Das Selbstwertgefühl wurde hierdurch bestärkt. Eine ähnliche Wirkung ging von der Tatsache aus, die Auserwählte des Maikönigs zu sein und vor anderen potentiellen Kandidatinnen den Vorzug zu genießen.

Im Unterschied von Alltag- und Brauchgeschehen machte sich ein weiteres Potential positiver Transzendierung persönlicher Verhaltensspielräume bemerkbar. Dadurch, daß sich das Mailehen vom Alltäglichen abhob, gewann es einen eigenständigen Charakter: Gewöhnlich geltende Regeln, Werte, Normen und Erwartungen wurden gewissermaßen in Vorzeichen gesetzt und neu bewertet. Dies führte zu einer distanzierteren Betrachtung der eigenen Person, des sozialen Umfelds und der auftretenden

433"Und das Schlimmste fand ich eigentlich am Anfang mit dem Maibutz. Das fand ich schon komisch. Mein Freund saß dann dabei, und der fand das dann auch so etwas seltsam", äußerte bereits an anderer Stelle Frau Pfeiffer (46/32/1a:128-137), deren Erlebnis des Mailehens aufgrund des Status der Zugezogenen nicht so sehr unter der Aufforderung des Mitmachens stand. Ihr erschien dieses Ritual auch mit Blick auf ihren Liebsten als schwer erträgliche Zumutung. Der Kuß als symbolische Form der Zuneigung verlangte nunmehr eine Neudefinition: Er wurde zum Symbol der Publikumsmacht über das Maikönigspaar. Dazu auch Frau Thiel (04/05/1b:70-116), Frau Dietz (02/03/1a:164-213), Frau Evers (03/04/1a:453-551), Frau Gebhard (41/28/1b:288-295), Herr Winzer (07/07/1a:653-669).

${ }^{434}$ Herr Stein (14/11/2b:550-565) hat von Brauchregeln gesprochen.

${ }^{435}$ Ausdruck dieser Beachtung sind zudem die unzähligen Zeitungsberichte mit den jeweils aktuellen Photos von Maikönigspaaren (Wey 1999).

${ }^{436}$ Frau Pfeiffer (46/32/1b:418-427) berichtete, daß sie über Jahre hinweg von unbekannten Leuten auf ihren Auftritt als Maikönigin angesprochen worden sei. 
Interaktionen. Der gewonnene Abstand brach Bahn für die spielerische Variation eigener Verhaltensweisen. Auf diese Weise bestand eine außergewöhnliche und günstige Situation, sein eigenes Verhalten und sein Selbstverständnis aus einem veränderten Blickwinkel zu betrachten, neu zu ergründen und neu zu positionieren. Hier entwickelte das Brauchgeschehen seine markante Eigendynamik und Spontaneität. Entgegen der Ernsthaftigkeit und Authentizität der gewohnten Lebenswelt konnten im Brauch die spielerischen Verwandlungskünste auf der rituell begründeten Bühne des Mailehens zum Zuge kommen. Die positive Nutzung dieser Entgrenzung hing allerdings entscheidend von der inneren Einstellung der Betroffenen zum Mailehen $\mathrm{ab}$. Wenn es jemandem sehr schwer fiel, die ambivalenten Rahmenbedingungen zu akzeptieren, dann blieb der potentielle Spielraum zur Entgrenzung eher verschlossen.

Die Mailehenrolle unterstreicht aus einem anderen Blickwinkel nochmals die Wirkungsweise der bisher dargestellten Zusammenhänge. Da sich die Pflicht hierbei im Grunde darauf beschränkte, daß die Ersteigerte zusammen mit ihrem Ersteigerer am Festzug teilnahm, wurden die sozialen Erwartungen in weitaus geringerem Maße als Verhaltenszumutung empfunden. Inhaltlich wie formal waren die Anforderungen im Vergleich zur Maiköniginnenrolle erheblich gemindert. Gleichgültigkeit und Belanglosigkeit kennzeichneten beinahe durchgängig die Einschätzung des Mailehenstatus. Durch die sanftere Form der rituellen Verpflichtung sah man zuweilen auch eine Möglichkeit des Hineinwachsens in den rituellen Prozeß und den Kreis der BrauchträgerInnen, wie aus den Erinnerungen von Frau Thiel hervorgeht:

Wie - würdste denn sagen - wie war das denn, Mailehen zu werden? - Also mit sechzehn?

Ja, das war eigentlich ganz in Ordnung. Also - weil - das war ja auch nicht weiter schlimm, da passierte ja auch so nichts. Da war man ja auch wieder in der Gemeinschaft. Man is halt zusammen mit den anderen Leuten im Zug gegangen. Da war man halt auch net so ne Einzelperson, die so herausgehoben wird, ne. Und da konnt mer sich das ja auch erst mal in Ruhe angucken. Aber dann die Angst, daß man es direkt wird, die Maikönigin, das is schon blöd. ${ }^{437}$

Die Mailehenrolle wurde von den Gesprächspartnerinnen als harmlos erlebt und eingestuft. Daher erklärt sich auch der feststellbare Sinneswandel von Frau Gebhard, die sich in der Anfangsphase gegen eine Aufforderung zur Teilnahme gewehrt hatte. Auf die Bedeutung der Mailehenversteigerung angesprochen, äußerte sie:

...ja, darüber hab ich mich auch immer total drüber aufjeregt, daß das schon 'steigern' heißt, weil man steigert ja auch Kühe und so. Und da hab ich mich immer schon drüber aufgeregt, daß da noch die Mädchen gesteigert werden. Das is ja im Prinzip dann dasselbe. Aber heute sehe ich dat ne'mehr so. Na ja. Ich glaub dat war auch früher net so, dat man dat halt so vergleichen kann, wie wenn jetzt Tiere ersteigert werden. Früher war dat ja halt so, ham die Mädchen en Jung kennengelernt, also praktisch ihren späteren Ehepartner. Un heute is dat halt... Ach, ich find et eigentlich net schlecht, weil man so mit denen noch mal wat zu tun hat. Und für mich war'et halt auch total schön, weil: mir ham uns ja mit den meisten net gegrüßt.

${ }^{437}$ Frau Thiel (04/05/1b:123-134). 
Ich kannte von den meisten auch gar net die Namen. Und seit dem Fest so, dann ham wir abends immer einen gut getrunken und so, seitdem hab ich mich auch mit manchen wieder ziemlich gut verstanden. Mit denen hab ich zwar heute auch noch nix zu tun, aber wir sagen wenigstens 'Hallo' oder grüßen uns. Und dat fand ich vorher auch total doof, dat die nur einen Ort weiter wohnen und ich die ne'mals kenne un die sin vielleicht drei, vier Jahre älter nur als ich. Un dat is schon schön. Also so gesehen, hat et auch en guten Zweck gehabt. Mhm.

Das is schon dann auch mit durchs Mailehen gekommen?

$\mathrm{Ja}$, also wenn man mal mitgemacht hat, dann is es et eigentlich okay. Bloß halt immer so kurz vorher, dann denk ich jetzt noch... mhm. Un ich bin auch froh, daß ich jetzt ne'mehr mitmache. ${ }^{438}$

Durch die konkreten Berührungen mit der Brauchausübung verringerten sich die vorhandenen Bedenken von Frau Gebhard. Da es bei der Brauchausübung nicht um einen "Besitzerwechsel" unverheirateter Frauen ging, wurde eine pejorative Verbindung zwischen Tierauktion und ritueller Paarzuteilung nunmehr als unzutreffend erachtet. Letztlich konnte der alljährlich wiederkehrenden Rollenübernahme auch etwas Positives abgewonnen werden: Kontakte zur Dorfjugend wurden über das Mailehen wirkungsvoll belebt.

Die Kehrseite des sichtbar gewordenen Integrationsprozesses unter den BrauchträgerInnen bildete demgegenüber der sogenannte Rummel. Auch dazu äußerte sich Frau Gebhard:

Du bist also praktisch, seitdem Du fünfzehn warst, immer auch gesteigert worden?

Ja. Wird ja auch jedes Mädchen gesteigert bis auf eins und die will so gern gesteigert werden. Un darüber ärgere ich mich auch jedes Jahr, weil das wissen die Jungen. Un die Jungen steigern ja sowieso... die meisten steigern nur irgend en Mädchen, net en bestimmtes, weil sie et gut leiden können, sondern dat die Mädchen halt wegkommen. Un dann is halt dat eine Mädchen, dat wird nie gesteigert und wünscht et sich aber schon seit Jahren. Un die sitzt dann jedesmal im Fenster un guckt sehnsüchtig zu. Un dat find ich auch total zum Kotzen, dat die sich net da mal... Dat sich net ein Jung mal überwinden kann, die da mitzusteigern, weil so phh...

Gibt's da en Grund für?

Ja, dat is halt so et "Dorftrampel", kann mer sagen. Und da macht sich jeder drüber lustig, aber so is die eigentlich ganz nett. Ob man jetzt mit einem da rumgeht, mit dem man sich vielleicht net so toll unterhalten kann, aber immerhin en bißjen oder mit einem rumgeht, der sowieso da so ne Flappe zieht, weil er keine Lust hat, denk ich, kommt auf et Gleiche raus. ${ }^{439}$

Die potentiellen Mailehenkandidatinnen, denen die Junggesellen bei der Versteigerung den Status des Rummels zuschrieben, übernahmen gewissermaßen eine Rolle auf der Hinterbühne der rituellen Aktion. Trotz der Ersteigerung des Rummels durch den Vereinsvorsitzenden und der Verteilung von Maien an alle betroffenen Frauen konnte über die soziale Ausgrenzung nicht hinweggesehen werden. Frau Dietz berichtete, daß sie dieses Brauchelement als zusätzliches Druckmittel erfahren habe:

${ }^{438}$ Frau Gebhard (41/28/1a:260-292).

${ }^{439}$ Frau Gebhard (41/28/1a:297-315). 
Und man hörte dann auch "Die is net jesteigert worden! Die hat kein Mailehen!" oder "Der Mailehen, der hat de janze Rummel!" Der hatte dann sechs oder sieben Frauen, ne. Dat war also dann irgendwo, daß man denkt: "Eh, Rummel muß joa och nich gerade sein." Wobei ich denke, wenn man ein dickeres Fell gehabt hätte, hätte man sich vielleicht och nachher jesagt: "Weißt du, Rummel, wat soll's?!" Heutzutage denk ich da och anders drüber. Dat war vielleicht einfach so diese Erziehung und wenn du im Rummel bist, dann... ja, dat is irgendwo... bist du also en Mensch zweiter Klasse. So sprachen die Leute aber auch dadrüber, ne, weil ja... "Der is im Rummel un der is im Rummel!" als ob das irgendwo was Negatives wäre. Aber wie gesagt, ich glaube, das kommt irgendwo noch von viel, viel früher her; vielleicht die vorherige Generation meiner Mutter noch. Ich weiß es nicht. [...] Man wollte sich dann ja auch nicht unbedingt mit so einer Frau [aus dem Rummel] vergleichen. Dann denkt man: "Da wirst du auch auf so eine Ebene gestellt." Wobei das Mädchen nichts dafür konnte. [...] Damit hat man sich dann irgendwo och immer identifiziert, daß man gesagt hat: "Ach ne, dat..." Und deswegen, wenn man ersteigert wurde, daß war eigentlich..., fand ich also gar nicht schlimm. ${ }^{440}$

Der Rummel wirkte also sozial disziplinierend. Die potentiellen Kandidatinnen konnten sich geehrt fühlen, wenn sie von ihren männlichen Mitstreitern ersteigert und zu Maiköniginnen oder Mailehen gemacht wurden. Unkonformes Verhalten, wie etwa die Auflehnung gegen die eingeführte Brauchpraxis, konnte dem Ansehen in der Dorföffentlichkeit abträglich sein. Möglicherweise litt auch das eigene Selbstverständnis, solange die Zugehörigkeit zum Rummel als ein Zeichen der Unbeliebtheit im Kreis der Junggesellen interpretiert wurde.

\subsubsection{Soziale Brauchökonomie: Verdienen und Verdienste}

Man muß halt eben sehen, dat immer en gewisses Geld in de Kasse bleibt. Et könnt ja och mal en Jahr schiefgehen, ne.

Von der Kirmes her...

...ja. Un dat is halt doch eben en Unkostenfaktor. Dann geht et an't Eingemachte. Wenn ich die Kirmes verbock, ne, dann bezahl ich dat ja net alleine. Dat geht ja auf jedes Vereinsmitglied. Un wenn et mal um denen ihr Geld geht, dann sieht'et doch schon anders aus, ne.

Wie sieht dat denn aus? Also et kommen an Gelder rein: die Mitgliedsbei...

...-beiträge, dann kommt dat Geld rein vom Steigern un dat, wat halt eben von unserer Kirmes übrigbleibt.

Das is es.

Mehr kommt net rein.

Wie hoch is denn der Mitgliedsbeitrag?

Den Mitgliedsbeitrag ham'mer hochgesetzt auf 24 Mark im Jahr. Vor drei Jahren war er bei zwölf Mark. Ja, dat is... den Beitrag wollte'mer net so hoch setzen. Die meisten Achtzehnjährigen gehen mittlerweile noch zur Schule oder sin grade in de Lehre oder sonst wat, un denen schmerzt dat dann doch schon ganz schön, ne. Un die ham dann och noch viele andere Interessen. Dann gehen se - wat weiß ich - noch Fußballspielen, müssen da ihren Jahresbeitrag zahlen. Dat muß man alles mal sehen, ne. Un so ham'mer dat eben net so hoch gesetzt, ne.

Und was kommt durch die Versteigerung so rein?

${ }^{440}$ Frau Dietz (02/03/1a:364-440). 
Ouwh... Dat is meistens sehr verschieden. Dat sin auch, ich sag mal, Geldbeträge, die sin eigentlich sehr verschwiegen, ne. Also dazu möchte ich mich eigentlich nicht äußern.

Also in der Festschrift, da steht ja mal ne Zahl drin. So um 3500 Mark oder so... ${ }^{441}$

... die sin et auf jeden Fall ne'mmer, weil - wie gesagt - et geht auch von Jahr zu Jahr zurück, weil immer mehr ham mehr Interessen. Je mehr Interessen die jüngeren Leute haben, um so mehr Geld geben se och aus. Um so wenijer Geld bleibt och für so wat übrig dann, ne. Da kannste och nix dran machen. Muß man halt eben sehen, dat die Kirmes durch et organisieren her, dat de billigere Sachen einkäufst oder sonst wat un halt eben, dat da en bisjen mehr dran hängenbleibt.

Un was kommt da im Schnitt bei raus?

Dat is meist auch sehr verschieden. Da kannste auch sagen, et gibt Jahre, da haste - wat weiß ich - schon mal 4000 Mark kannst auch schon mal sechs haben. Wenn du bedenkst für die ganze Arbeit und so weiter, wieviel Stunden dat alles is, is dat net viel. Da gibt et Feste, da kommt einiges mehr bei rum. Aber da kannste halt nix dran machen.

Ihr müßt dann immer auch was vorhalten, damit ihr die Kirmes finanzieren könnt.

Die Unkosten, dat kommt ja alles erst nach de Kirmes, ne. Un deswegen, dat Vorhalten, dat mache mer halt eben nur, falls... et könnt ja zum Beispiel mal en Jahr kommen, wo zum Beispiel wenig Besucher kommen oder sonst wat. So, aber dann kommt die Musik, die will ihr Geld haben, der Zeltverleiher will sein Geld haben un dafür mußte halt immer noch en bisjen auf Seite legen. Du mußt halt eben doch en bisjen vorsichtig sein. ${ }^{442}$

Der Junggesellenverein hat vermieden, genauere Informationen über seine Konten und Bilanzen in die Öffentlichkeit zu tragen. Indessen konnte es nicht im Verborgenen bleiben, daß der Verein, die Kirmesorganisation und das Brauchgeschehen auch von wirtschaftlichen Erwägungen und Handlungen durchdrungen wurde. Aufgrund der Mitgliedsbeiträge, der brauchspezifischen Auktionen und der gastronomischen Aktivitäten flossen Gelder in die Kasse des Junggsellenvereins. Da neben den Einnahmen jedes Jahr auch Ausgaben zu verbuchen waren, ergaben sich Überlegungen, wie mit den finanziellen Mitteln wirtschaftlich umzugehen sei. Die Durchführung der Kirmes war stets mit abzuwägenden Risiken verbunden, die durch umsichtige Vorsorgemaßnahmen eingedämmt wurden. Besucherzahlen ließen sich nicht vorhersagen. Trotzdem mußten beispielsweise die hohen Kosten der Zeltmiete oder der Musiker unabhängig vom Erfolg der Veranstaltung aufgebracht werden. Der rationelle Umgang mit den Vereinsgeldern nach dem Prinzip der Kosten- und Nutzenabwägung ermöglichte den Junggesellen immerhin Gewinne, die in gemeinsame Urlaubsfahrten eingebracht werden konnten. Bereits in den 1950er Jahren wurde von dieser Möglichkeit Gebrauch gemacht. Diese Reisen wurden von der Dorfbevölkerung immer aufmerksam mitverfolgt, zeigten sie doch, daß es um den Verein und den Fortbestand der Kirmes gut bestellt war. Nachdem die Urlaubsziele immer weiter in den Süden gerückt waren, festigte sich die Ansicht im Dorf, daß die Junggesellen über beträchtliche Einnahmen verfügen müßten. Dieser Meinung folgte

${ }^{441}$ Der in der Festschrift genannte Betrag lag noch höher: Im Jahre 1987 wurde die "Rekordsumme von 5.352 DM" erzielt (Prothmann 1989:101).

${ }^{442}$ Herr Weiden (17/12/1b:506-557). 
die Gegenreaktion der Brauchträger, die ihre wirtschaftliche Lage gerne verschwiegen und ihre Touren als angemessene Entlohnung ausgegeben haben. Dazu Herr Weiden:

Die Mädchen kriegen vielleicht ihren einzelnen Betrag raus. Dat mag sein. Aber wat da halt eben beim Steigern herausgekommen is an sich, ne, dat is doch vereinsintern un dat geht auch nirjendswo raus, ne. Weil - dat sin dann doch manche Gelder, sag ich mal, von wegen dat braucht net... der sagt dann morgen im Dorf: "Tja, hier die ham dat un dat vom Steigern. Dies Jahr brauchen die an Kirmes net ze viel ze verdienen!" oder wat. Dat geht halt eben überhaupt keinen normalerweise wat an. Auch wie jetz hier mit der Kirmes mit dem Geld. Wenn mich einer fragt: "Wat nehmt'er an der Kirmes ein?" da sag ich: "Wat geht dich dat überhaupt an!?" ne, weil dat hat halt eben normalerweis überhaupt keinen zu interessieren. Mir machen unsere Arbeit dafür un haben halt eben och viel Ärger deswegen; un wenn mir jetzt da in Urlaub fliegen, dann is dat halt eben unser Verdienst, ne.

Also der Urlaub, kann man sagen, der is finanziert dadurch...

...teilfinanziert. Also dat Taschengeld un en gewisse Beitrag muß jeder dazutun, weil sonst, sag ich mal, ganz tragbar is dat net mehr. Ich sag mal, en Drittel muß von den Reisekosten - vom Flug un vom Hotel - mindestens jeder dazutun. Ansonsten müßte dat wieder so weit ausweiten, da könnste eventuell alle drei, vielleicht auch erst alle vier Jahre vielleicht einmal fliegen. Un da gibt et ja manchmal Fälle, die kommen mit achtzehn rein, heiraten mit einunzwanzig; die wären dann zum Beispiel niemals dabeijewesen, ne. Oder du mußt natürlich dann Reisen machen, die dann dementsprechend billiger sind. Aber dat wollen se auch net. Se wollen wenn, irjendswo hin, wo se och wissen, dat gutes Wetter is un dat se ihren Spaß haben können. Un dann mußte halt eben, wie gesagt, schon in den Süden fliegen, weil, sonst gibt et da eigentlich keine oder kaum Alternativen, ne.

Gran Canaria, ne?

Ja, fliegen wir dies Jahr. Sieben Tage. Vor zwei Jahren waren wir in Teneriffa un vor drei Jahren - da sind wir zwei Jahre hinterenander mal geflogen - da waren'mer auch in Gran Canaria im selben Hotel auch. ${ }^{443}$

Bevor der Junggesellenverein 1967 nach etwa achtjähriger Pause wiederbelebt wurde, ${ }^{444}$ waren die Geschäfte an der Kirmes zwischen Verein und den ortsansässigen Gastwirten nicht strikt getrennt. So gab es einen Tag, an dem die Junggesellen den Eintritt und das Tanzgeld einnehmen konnten, während der Wirt für die Überlassung des Saales das sogenannte "Stoppejeld" kassieren durfte. Dieses System führte allerdings zu Problemen. Weder der Wirt noch die Junggesellen konnten mit ihren Einnahmen zufrieden sein. Die Burschen zogen sich zurück und überließen die Ausrichtung der Kirmes dem Gaststättenbetreiber, dessen Profite in den 1960er Jahren so gering gewesen sein mußten, daß er schließlich dem sich neu formierenden Junggesellenverein die Kirmesveranstaltung vollständig überließ. Damals übernahmen die motivierten Jungen von ihren Vorgängern nur dreißig Mark Vereinskapital, so daß zusätzlich von jedem Mitglied ein Vorschuß von fünfzig Mark Startkapital eingezogen werden mußte, das allerdings nach der ertragreichen Beendigung des Festes wieder an jeden zurückgezahlt werden konnte. Nach der

${ }^{443}$ Herr Weiden (17/12/1b:604-641).

${ }^{444} \mathrm{Vgl}$. Kapitel 4.2.4. 
Einschätzung von Herrn Beck hat das dauerhafte Erfolgsrezept der Kirmes in einer vollständigen Trennung der Verantwortungsbereiche gelegen:

Der Wirt wollte an diesem Fest verdienen und der Junggesellenverein auch, nicht. Und das war ja bei uns nicht der Fall. Wir haben alles übernommen: die Unkosten, wir haben natürlich auch nachher den Verdienst daran gehabt. Wir brauchten mit keinem zu teilen, ob es so oder so ausgegangen wäre, nicht. Und ich kann mir vorstellen, daß das auch en Grund dafür war, daß die Sache vorher nicht mehr so harmoniert hat zwischen Wirt und Junggesellenverein, daß die überhaupt noch Lust hatten, so was durchzuführen. Und dann hat in diesem Saal unten und in der Wirtschaft auch dauernd oder alle paar Jahre der Wirt gewechselt. 445

Die Kirmes fand seit dieser Zeit regelmäßig in einem Festzelt statt. Die gesamte Organisation erforderte von den Jugendlichen ein beachtliches Engagement und unternehmerische Fähigkeiten. Preisvergleiche von Getränkelieferanten und Zeltverleihern gehörten von nun an ebenso selbstverständlich zum Aufgabengebiet der Brauchträger wie die publikumswirksame Reklame für die bevorstehenden Kirmestage. Vor allem die Mailehenversteigerung wurde anfänglich als eine stützende Einnahmequelle betrachtet. Ihre wirtschaftliche Bedeutung schien in dem Maße abzunehmen, wie die Erlöse aus Eintrittsgeldern und dem Getränkeverkauf zunahmen. Herr Kastner bemerkte dazu:

Als wir wat Jeld zur Verfüjung hatten, da woar nachher die Steijerei, dat woar joa nur noch dat Jaudi in der Kneipe, dat woar Spielerei, ne. Dat iearzte Steijerei, doa woarn mir daran interessiert, Jeld in die Kasse reinzekriejen, ne. ${ }^{446}$

Augenscheinlich wurde der beschriebene Wandel und die hohe Motivation der Burschen von der Bevölkerung begrüßt und mit dem Zuspruch der Besucher belohnt, wie die folgende Passage aus einem Gruppengespräch verdeutlicht:

Herr Böhm: Un dat eigentümliche woar joa, je voller dat Zelt woar, um so mehr wollten auch rein, ne.

Herr Kastner: Dat hing awwer och zusammen damit, dat och viele damals kamen un ham einfach gesacht: "Wir müssen den Verein unterstützen!" Ich kann mich zum Beispiel an Schulzes Leni oder sou je...

Herr Böhm: ...ja, ja.

Herr Kastner: Hundertprozentig. Die einfach aus der Sympathie heraus, dat überhaupt mal wieder jemand da war, der wat gemacht hat, dat die hinjejangen sin, han jesacht: "Mir müssen die unterstützen un jonn doavür also och eruß!" Ich weeß also Bauers Mia un sou weeder, damals - die janzen Joare - is dat immer dajeweas. Dat is ja nun nur mal jetzt als Beispiel jenomm für viele, die dann erußjejange sin, die sons normal nie erußjejange sin. [...] Dat waren so einije, die mir hök esou dann enfalle, un wo mer sare muß, die ham dat tatsächlich aus Sympathie jetan. Un nachher wie die Kassen voller waren, dann han die jesacht: "Ihr müßt awwer och mal wat für die Kirche spenden!" un so weiter. Dat koam. Dat kann ich mich och noch dran erinnere, dat die Leute sich dadrüwwer ovjerächt han, dat also sounsoviel Jewinn doawoar un etliche tausend un davon dann Urlaub oder sou jet jemach wued, dat se jesaat han:

${ }^{445}$ Herr Beck (08/08/1a:575-583).

${ }^{446}$ Gruppengespräch II (49/33-37/2a:275-278). 
"Joot, dann künnt'er awwer och moal jet spenden, wenn mir schun erußjonn un für dat Dorf oder für den Verein wat tun, dann kann der Verein och mal dafür wat tun!"447

Die Diskussion weist auf eine wechselseitige Beziehung zwischen den Festorganisatoren und -besuchern hin. In der Aufbauphase des Vereins genossen die Junggesellen anscheinend bedingungslos die breite Unterstützung aus dem Dorf. Später, als mit den erwirtschafteten Gewinnen regelmäßig Urlaubsfahrten gemacht wurden, erhielten sie die Aufforderung, mit den finanziellen Mitteln auch einmal das Gemeinwesen zu stärken. Dementsprechend flossen Gelder in die fällige Erneuerung der Kapellentür.

Der Vorwurf, daß die Burschen die Veranstaltung der Kirmes dazu benützten, auf leichte Weise enorme Summen an Geld zu verdienen, lag auch in jüngerer Zeit immer wieder nahe. Flugreisen auf die Balearen und Kanaren galten als sicheres Indiz für die gefüllte Vereinskasse und die Konsumorientierung der Vereinsmitglieder. Doch der Kritik der Außenstehenden schien der Blick für die mühselige, vergleichsweise gering entlohnte Leistung der Brauchträger entgangen zu sein. Jedenfalls bestärkten ehemalige Vereinsmitglieder die jüngeren Generationen in ihrem Treiben. Sie betonten aus eigener Erfahrung, daß der Mai für die Veranstalter der Kirmes stets eine enorme Belastung gewesen sei. Schließlich gab Herr Fischer zu bedenken, daß der Lohn so gering ausfalle, daß eine andere Tätigkeit für die Betroffenen finanziell in jedem Falle lukrativer wäre:

Glauben Sie mir, das ist eine verdammte Rackerei. Das können sie nur in jungen Jahren machen. Das ist schon ne Schufterei. Heute in dem Maße nicht mehr, weil es so viele Mitglieder sind.

Jetzt meinen Sie, das Fest auszurichten?

...dieses Fest auszurichten. Also ich glaube, sie würden mehr verdienen, wenn die ganzen Mitglieder irgendwo versuchten, Geld zu verdienen. Und in dieser Zeit könnten sie, glaube ich, mehr Geld zusammentragen als durch das Ausrichten der Kirmes. ${ }^{448}$

Eine derart profitorientierte Zielsetzung des Vereins wurde bislang nicht verfolgt. Es erscheint als abwegig, das Engagement der Junggesellen aus rein wirtschaftlichen Motiven erklären zu wollen. Die oben angesprochenen Opportunitätskosten waren vorsorglich gegen jene Kritiker gerichtet, welche die Kirmesmacher lediglich unter dem Licht von finanziellen Vorteilen betrachteten. Hier sei nochmals an die kontroverse Diskussion der Junggesellen von 1966 angeknüpft:

Herr Keller: Mir hann et jedohn om jewisses Jeld...

Herr Fischer: ...öm Jeld ze kreje?

Herr Keller: Ja. 449

${ }^{447}$ Gruppengespräch II (48/33-37/1a:412-441).

${ }^{448}$ Herr Fischer (34/20/3b:390-398).

${ }^{449}$ Gruppengespräch II wiedergegeben in der Einführung zum Kapitel 4.4. 
Diese apodiktische Haltung eines ehemaligen Vereinsmitglied wurde von den Mitstreitern vehement angefochten. Den Stellenwert des Ökonomischen eindeutig zu bestimmen, bereitete unter den Informanten Schwierigkeiten. Hatte die Gewinnerwirtschaftung Priorität bei der Brauchausübung oder war sie lediglich ein angenehmer Nebeneffekt? Die Gegenthese lautete, man hätte auch ohne den vulminanten wirtschaftlichen Erfolg damals die Kirmes weitergeführt:

Herr Fischer: Meenste mir hättn doumals so jedaach? So...

Herr Keller: ...nä...

Herr Fischer: ...so für de Jemeinschaft jeddach?

Herr Kastner: Doch! Hann mir. Doch, Pitte, hundertprozentig! Denn wir haben ja damals noch die fuffzig Mark Einlage bezahlen müssen, damit wir über die Runden kommen. Also et hätt doch keene jedaach ... nur für en Reibach zu mache.

Herr Keller: Doch ... nur, nur.

Herr Kastner: Aber du hättest doch die Kirmes anschließend och noch jemaach, ob de jetzt nachher tausend Mark wenijer hattest oder net.

Herr Keller: Dat hätte mer joa...

Herr Böhm: ...de zweite Jedanke, möglichst noch Jeld ze maache, äwwer de ieazte Jedanke woar, de Kirmes ze kreje. ${ }^{450}$

Doch hätten die Verfechter des idealistischen Gemeinschaftsgedankens kaum bestreiten können, daß Verluste aus dem Kirmesgeschäft nicht auf Dauer tragbar gewesen wären. Insofern scheint eine Bewertung nach Prioritäten, d.h. eine Gewichtung jener Ambivalenz zwischen ökonomischen und sozialen, zwischen eigennützigen und gemeinnützigen Handlungsmotivationen, am Kern des Brauchgeschehens vorbeizugehen. Am treffendsten erschien demgegenüber die Einordnung dieser widerstreitenden Grundmotive, wenn sie in einer wechselseitigen Abhängigkeit interpretiert wurden; so Herr Lange:

Et woar sou, et muoß jet jemaach weere, et soll jet annersch sin wie wie andere Kirmesse. Man wollt joa och die Leute ansprechen, man wollte ja voll haben, man wollte ja wat verdienen. Irjendwie war dat en Kreislauf. 451

\subsubsection{Innerdörfliche Beziehungen}

Die Erkenntnis, daß Bräuche in Verbindung mit öffentlichen Festveranstaltungen Raum für die zwischenmenschliche Begegnung geschaffen haben, liegt zweifellos auf

${ }^{450}$ Gruppengespräch II wiedergegeben in der Einführung zum Kapitel 4.4.

${ }^{451}$ Herr Lange (29/19/2a:703-706). Dazu auch Herr Gerber (P/01/8:1): "Der allgemeine wirtschaftliche Aufschwung war für die Wiederbelebung des Junggesellenvereins, der Kirmes und der Gewinne aus der Kirmesveranstaltung nicht nur eine Gleichzeitigkeit, sondern auch eine Bedingung. Wenn das nicht geklappt hätte, wäre der Junggesellenverein wohl untergegangen. So konnte auch der Dienst besser verkraftet werden; ich meine jetzt das Gefühl, Dienst tun zu müssen, wenn andere feiern. Daneben war der Maibrauch ein zusätzliches Element, um die Kirmes attraktiv zu machen." 
der Hand. Mit der nachfolgenden Analyse wird dieser Zusammenhang bekräftigt. Es wird aber auch deutlich, daß sich hinter der scheinbar trivialen Selbstverständlichkeit des Sachverhalts diffizile Grundvoraussetzungen des sozialen Kontakts bzw. die konkreten Umstände der Interaktionen und deren Prozeßhaftigkeit verbergen. Einer problembewußten kulturwissenschaftlichen Analyse kann es gelingen, dem wenig Hinterfragten überraschende Einsichten zu entlocken und somit zu klären, welche brauchgebundenen Verhaltensformen geeignet sind, die innerdörflichen Beziehungen zu modellieren. Sofern diese Gestaltungsmöglichkeiten zumindest von einem Teil der Betroffenen als sinnvoll angesehen wurden, erlangt die gefestigte Position des Brauches im Inventar lokal tradierter Verhaltenszumutungen weiterhin ihre Plausibilität.

"Das Alleinsein ist ja eigentlich weg"452 - mit Bezug auf die Partizipation am Brauchgeschehen verweist diese Feststellung von Frau Weiß bereits auf den Kern der Problematik und gibt einen Anstoß zu einer kritischen Durchmusterung der Beiträge zum Thema. Denn durch eine in dem Wörtchen "eigentlich" liegende Einschränkung wurde der Widerspruch zu der vordergründigen brauchspezifischen Normalität des Geselligen oder Integrativen greifbar. Freilich führte das Braucherlebnis zu einer Kontaktsituation, die das Alleinsein aufhob. Allerdings sollte nicht darauf verzichtet werden, die Art des Erlebnisses eingehender zu bestimmen, um gleichzeitig den Blick für die Qualität des brauchbedingten Geselligseins zu öffnen. Die wortreichen Erklärungen, welche die Gesprächsaufzeichnungen im Hinblick auf eine Affirmation der sozialen Integrationsleistung des Mailehens lieferten, sollten daher die oft etwas leiseren, hintergründigen Nebenbemerkungen zum Segregationspotential keineswegs übertönen.

In den Äußerungen der GesprächpartnerInnen trat die Ansicht hervor, daß die Brauchausübung eine hervorragende Möglichkeit für zwanglose, lockere, unverbindliche Zusammenkünfte mit Brauchtreibenden und Kirmesgästen darstelle. Während die überwiegende Zeit im Jahr jeder mit sich selbst, seiner Familie, seiner Arbeit und seinen speziellen Interessen beschäftigt sei, so könne das Dorffest als ein Ort der Begegnung, des Wiedersehens und einer gemeinsam erfahrenen, ausgelassenen Festtagsfreude erachtet werden. Gerade vor dem Hintergrund vielfältiger Störquellen, welche die Akzeptanz des Dorffestes beeinträchtigen und eine Beteiligung daran fraglich machen würden, empfanden einige InformantInnen den Aspekt der periodisch begangenen und rituell abgesicherten kollektiven Geselligkeit als ein wertvolles, überaus schützenswertes kulturelles Gut. Gefährdungen für den erfolgreichen Fortbestand des Brauches wurden dabei oft in der überbordenden Fülle von individuell wahrnehmbaren Freizeit- und Unterhaltungsangeboten gesehen. Im

${ }^{452}$ Frau Weiß (01/02/1b:338-343). 
Grunde seien an jedem Wochenende die verschiedensten, miteinander konkurrierenden Fest- oder Tanzveranstaltung für jeden erreichbar. Diskotheken stellten zudem noch in weiter räumlicher Entfernung eine Bedrohung für das heimische Fest dar, indem sie das jugendliche Publikumspotential zunehmend absorbierten. Die individuelle Mobilität der Dorfjugend habe durchweg zugenommen. Auch sei die Verfügbarkeit eines Autos geradezu eine Selbstverständlichkeit. ${ }^{453}$ Die Beschäftigung mit dem eigenen Fahrzeug in der Freizeit trage gegenwärtig zur adoleszenten Selbstverwirklichung bei. Doch nicht nur das veränderte Freizeitverhalten, auch die allgemeine Interessenlage innerhalb der Dorfbevölkerung führe zu Problemen. Der Wunsch, ein gemeinsames Ortsfest zu begehen, verkümmere. Jugendliche würden sich nicht mehr zur Vereinsmitgliedschaft oder zur Brauchträgerschaft animieren lassen. Computer, schulische Werdegänge mit ihren speziellen Anforderungen, die Ausweitung des sozialen Handlungshorizonts würden dazu führen, daß sich ein großer Teil der Aktivitäten nicht mehr im gemeinsamen Dorfverband abspiele. Der örtliche Zusammenhalt werde somit bereits frühzeitig im Kindesalter geschwächt. Genauso würden sich die steigenden Einwohnerzahlen auswirken. ${ }^{454}$ Zugezogene ließen sich kaum integrieren. Sie betrachteten ihre Wohnortwahl vornehmlich aus Eigeninteressen. Während die relativ günstigen Baukosten auf dem Land und die Ruhe der ruralen Zurückgezogenheit den ehemaligen Stadtbewohnern besonders attraktiv erscheinen würden, träte die Bedeutung des Kennenlernens der Nachbarn, Erlebens dörflicher Lebensgewohnheiten und die punktuelle Erduldung der jährlich wiederkehrenden kirmesbedingten Ruhestörungen in den Hintergrund.

Integrationsunwillige Zugezogene seien ein ernstes, aber nicht das einzige Problem in diesem Zusammenhang. An einem derart segregierenden Verhaltensmuster würden sich auch zunehmend Teile aus der angestammten Bevölkerung orientieren. Einhergehend mit dem Verzicht auf die Pflege sozialer Kontakte würde die Tanzmusik auch für sie dann zu einer Lärmbelästigung (siehe Kapitel 4.2.4). In den eigenen Reihen und Altersgruppen spürte man dieselbe Misere des Wertverlustes in bezug auf den sozialen Zusammenhalt auf. Wie sonst erkläre sich beispielsweise, daß bei einigen bereits der terminierte private Urlaub die Teilnahme an den Kirmesfeierlichkeiten verhindere. Die meisten InformantInnen ordneten die vor Ort gemachten Erfahrungen einem Prozeß gesamtgesellschaftlicher Entwicklung zu. Dabei unterstellte man den Hang zur Befriedigung egoistischer Einzelinteressen und die damit einhergehende Vereinzelung und Vereinsamung. Insbesondere mit Blick auf diese Einschätzung gesellschaftlicher Faktoren und der Prognose unmittelbar bevorstehender Wandlungsprozesse trat das in den Gesprächen häufig anklingende Gemeinschaftserlebnis im Mailehen in seinen positiven Konotationen besonders

${ }^{453} \mathrm{Vgl}$. Fn. 237.

${ }^{454}$ Vgl. Anhang 7.2., Tabelle 7.1 (Einwohnerzahlen) bzw. 7.3 (Übergangsquoten zur Sekundarstufe). 
deutlich hervor. Nach dieser allgemeinen Einschätzung über die innerdörflichen sozialen Beziehungen werden im folgenden die einzelnen Stimmen Gehör finden, um Anhaltspunkte dafür zu gewinnen, wie berechtigt die Sorge über die attestierten Auflösungserscheinungen sein könnte.

\subsubsection{Kommunikation und Brauch}

Wenn in den Gesprächen auf den tieferliegenden Sinn des Mailehenbrauchs eingegangen wurde, dann verwiesen Befragte häufig auf ein vitales Verlangen nach zwischenmenschlichen Begegnungen. Im Zusammenhang mit dem Brauch wurde unterstellt, daß die privaten Kontakte in der Familie, im Verwandten- und Freundeskreis oder im Beruf nur unzureichend dem Anspruch des einzelnen genügen könnten. Sie müßten um weitere soziale Austausch- und Zugangsmöglichkeiten zu NachbarInnen und zur Dorfbevölkerung vermehrt werden. Vom Nutzen des Maibrauchs für eine bisweilen zusammenhängende lokale Residenzgruppe war man in vielen Punkten überzeugt. Frau Weiß, die das verbreitete Singledasein als Errungenschaft des "modernen Menschen" beschrieben hat, sieht gerade in der Schaffung von Kommunikationsmöglichkeiten eine vorrangige Funktion der Brauchausübung:

Und wie würdest Du das jetzt erklären, daß Du grundsätzlich positiv zum Brauch eingestellt bist?

Ja, Brauchtum is was... Ja, ich sehe im Brauchtum was Gutes, was man beibehalten sollte, was... Ich bin der Meinung, was für die Leute früher gut war, für uns heute auch nicht von Nachteil ist. Und... ja, gut. Man könnte sagen: "Ich brauche das nicht." Ich brauche das auch nicht. Aber das ist so die... oft die Einstellung des modernen Menschen, daß er sagt, "Ich brauche das nicht." Aber auf der anderen Seite, es fehlt dem modernen Menschen auch vieles, ne. Und in dem Moment, wo ich sage, ich brauche das nicht, dann brauche ich aber ja etwas anderes, was wahrscheinlich auch in diese Richtung geht oder was diese Bedeutung hat. Weil irgendwie Brauchtum is etwas Überliefertes und was von früher kommt. Das gibt meiner Meinung nach auch Halt. Und der moderne Mensch, der sucht ja auch immer etwas, wo er sich dran halten kann, was für ihn gut ist. Und ich seh ja diese, diese Brauchtümer ja sowieso in erster Linie als Kommunikation - egal jetzt in welcher Weise oder in welcher Art man das sieht, oder?

Kannst Du das nochmal genauer erklären, inwieweit Du das als Kommunikation siehst?

Ja, ich hab ja schon mal gesagt, wegen der sozialen Kontakte. Soziale Kontakte braucht jeder. Heutzutage is es zwar so, daß die Single-Haushalte zunehmen - und is ja auch schön als Single zu leben, muß ich sagen - aber trotzdem, man muß, solange man jung ist oder solange man keine Einschränkung hat... Wenn ich jung bin und gesund, kann ich machen, was ich will, ne. Aber in dem Moment, wo ich mal, sei es nur eine Grippe habe, merke ich schon, daß ich als Single alleine bin. [...] Und von daher is das Überlieferte, die Familien, die Großfamilien, wie sie früher waren auch nicht schlecht, ne: man muß sich auf andere Menschen einstellen, man muß auch öfter mal nachgeben, was man als Single ja nicht so braucht, ne. [...]

Und wenn Du jetzt nochmal den Bogen spannst zu den...

...zu den Brauchtümern.

...das Kommunikative daran. 
Für mich jetzt ist das natürlich das Gespräch oder... ja, halt sind das die sozialen Kontakte, daß ich Leute kennenlerne oder auch daß ich jetzt... Ich seh auch schon mal gerne, wenn jemand tanzt. [...] Jetzt, von wegen der Kommunikation, ja, dann kommt da hinzu Brauchtum, Tanz, Bewegung, ne. So die menschliche Nähe, die Kommunikation, die sozialen Kontakte, die sind im Brauchtum sehr stark vertreten, ne. [...] Wo ich schon erzählt hab von der Kirmes: Es kommt Besuch, es wird eingeladen. Das sind ja soziale Kontakte. Oder, wie das dann... früher, hab ich ja auch gesagt, war das ja so, daß jetzt auf einem Dorf oder in einem Ort die Kirmes stattfand. In den übrigen Dörfern war ja dann nichts. Also kamen ja die jungen Leute in dieses Dorf auf die Kirmes zum Tanz. Sind ja soziale Kontakte, ne? Also ich seh das schon so. Ich finde, das is was Schönes und das braucht auch der moderne Mensch. Der moderne Mensch braucht auch soziale Kontakte. ${ }^{455}$

Diese Äußerung entfaltet ihr Gewicht, je deutlicher man sich die anhaltende Diskussion über eine zunehmende Sinnentlehrung tradierter Brauchhandlungen in volkskundlichen Fachbeiträgen vor Augen führt. ${ }^{456}$ Sie legt nämlich den Gedanken nahe, daß besonders dem Menschen in der gegenwärtigen Lebenswelt der Brauch als Mittel zur Förderung sozialer Beziehungen zugute kommt. Auch wenn die Mittel des Mailehens das gesellige Leben im Dorf anzuregen und aufrechtzuerhalten, einem Außenstehenden relativ unwirksam erscheinen mögen (z.B. Besuchsmöglichkeit, Tanz), so ist aus dem Blickwinkel der GesprächspartnerInnen ein Zweifel an prinzipiellen interaktiven Möglichkeiten, die sich aus dem Brauch heraus ergeben, unbegründet.

In die gleiche Richtung führt die Interpretation von Herrn Gerber. Von ihm wurde der Brauch als strukturbildendes Gerüst sozial integrierender Handlungen bewertet:

Das Verschwinden der Maibräuche wäre für die Junggesellen schlecht: die Struktur für die Kirmes wird dann ärmer, es käme zu weniger Treffen. Zum gemeinsamen Feiern braucht man irgendein Gerüst, bei dem man sich vorstellen kann, das dieses oder jenes Spaß machen kann.

Weiter heißt es:

Bei dem Brauch ist die breite Teilnahme der Dorfbevölkerung wünschenswert. Wenn mehr mitmachen, bewegt sich eher etwas. Das Zusammen-Spaß-haben ist wichtig, nicht nur einer oder viele. Der Brauch ist deshalb auch austauschbar: wenn es einen Brauch gäbe, wo viele zusammen Spaß haben, dann wäre der genauso gut. ${ }^{457}$

Aus dieser Perspektive traten die spezifischen Brauchhandlungen vor dem eigentlichen Sinn und Zweck des Mailehens in den Hintergrund. Der Brauch hatte lediglich dafür zu sorgen, daß er Anlässe schafft, an denen sich möglichst alle Betroffenen an einem Ort treffen und die gemeinsam gefundene Zeit zur geselligen Unterhaltung nutzen können.

Während auf der einen Seite die Austauschbarkeit jenes sozialstabilisierenden Gerüstes betont wurde, stellten andere gerade auf eine basale Originalität oder

\footnotetext{
${ }^{455}$ Frau Weiß (01/02/1b:180-308).

${ }^{456}$ Siehe Kapitel 3.2; ferner z.B. Kramer (1988:127-142).

${ }^{457}$ Herr Gerber (P/01/10:1-3).
} 
Einmaligkeit und damit in gewisser Weise auch auf die Unersetzbarkeit der Brauchhandlungen ab. Der Wegfall des ortsüblichen Maibrauchs wurde dementsprechend als eine einschneidende Einbuße innerhalb der lokalen Lebenswelt gewertet. Möglichkeiten sozialer Kompensation blieben bei dieser Betrachtung unberücksichtigt. Der Niedergang traditioneller Bräuche und Feiern erweise sich als konsequente Fortführung der gegenwärtigen Zersetzung dörflich geprägter Sozialstrukturen oder gar Kultur. Das postulierte homogene dörfliche Gefüge, so Herr Decker, sei gerade in den letzten Jahren maßgeblich durch den enormen Zuzug von Neubürgern beeinträchtigt worden:

Wie ist denn so allgemein die Beteiligung an den Bräuchen, an den...

...also hier die Beteiligung bei uns is gut, dat muß man sagen. Dat is och et einziste em ganzen Jahr, ne. Da is sonst nix. Früher waren hier die Säle. Da waren die Gaststätten, die hatten ihre Säle. So, da war Fastnacht, da war eben en Ball oder Pfingstball un Kirmes - aber dat is all nemehr. Also dat is praktisch... et einziste is hier die Kirmes in Oevverich.

Und da gehen alle hin.

Da gehen alle hin.

Wie is dat mit den Zugezogenen...

...ich sag ja... also die größte Aufgabe, sag ich, dat is, die Neubürger zu integriere. Nur et is schwer. Die Grafschaft is ja ne Zuwachsgemeinde, un durch die neue Baujebiete kommen die Leute all doahin. Also vor allem in Oeverich und Leimersdorf sind da in den letzten fünf, sechs Jahren über fuffzig Prozent sind also Neubauten. [...] Un dat is natürlich die Jefahr. Ich mein, früher dat war hier, woll'mer sare, jewachsene Dörfer, ne, wo prakisch die Urahne, die Enkele, alles dablieb un dann et Jahr eins, zwei wurden Häuser jebaut. Da kamen Neubürjer, so die ham'mir schnell... die jingen dann in de Feuerwehr souwat. Da waren die drin. Aber heut, heut die Masse, da kennt fast einer der andere ne'mehr, ne. Un dat krejn se och net hin, ne. Ich meen, dat is ne große Aufjabe. Ich hab och jesat, wir müssen die Leut, wenistens mal, dat se an die Vereine rankumme, nämlich sonst krijen se joa jar keene Kontakt. Aber et es ze schwer. Ich hab dat Jefühl, et sin viele, die han hier et Land jekauft und die saren: "Et is preiswert." So, die gehen dann auswärts arbeiten nur dat se dann abends, wie mir dann saren: "Die Schlaftouristen und Wochenendtouristen." Die Leute wollen ihre Ruhe haben, dat kann mer joa och verstehen, ne. Und dann sin die Schwierigkeiten, ne. ${ }^{458}$

Aber auch in den eigenen Reihen seien gravierende Änderungen am Werke, fährt Herr Decker fort. Die Junggesellen unterlägen der Gefahr, den eigenen Interessen einen höheren Wert beizumessen, als sich den Werten der Dorfgemeinschaft zu verpflichten:

Wie war so dat Miteinander im Junggesellenverein

Also da jibbet, also ich muß saren, da jibbet keine Streitigkeiten - wenistens in dem Monat [an dem die Kirmes stattfindet]. Dat is och sehr, sehr wichtig, ne, dat die Leutchen, dat die Jungjesellen sich treffen, net jeder läuft seine eijene Weg, un wenn se sich nur eine Monat treffen. Früher war'et noch anders. Wenn mir rausfuhren, ich mein, da waren ja och verschiedene Gruppen, awer sonntags, abends, ham mir uns all... da kamen die um zehn, elf Uhr aus allen Ecken un Kanten, un dann waren mir widder eins, zwei Stunden zesammen. Dat is natürlich

${ }^{458}$ Herr Decker (24/16/1a:208-268). 
heut net esu. Un dat is joa och bedingt durch die Mobilität. Jeder hat e Auto. Un der eine sagt: "Ich fahr moal schnell dahin" der andere: "[Ich fahr] dahin" ne. ${ }^{459}$

Zugezogenen und zunehmend auch Alteingesessenen falle es demnach schwer, vom interaktiven Angebot des Mailehens Gebrauch zu machen. Gerade angesichts einer wachsenden Vereinzelung dörflicher Familien und Haushalte könnte sich das jährlich wiederkehrende Dorffest mit seinen Beteiligungsmöglichkeiten als Gegenmittel zur sozialen Isolierung par excellence darstellen. Nach der Einschätzung von Herrn Weiden führe der teilweise dürftige Zuspruch einzelner Bevölkerungskreise zu Problemen, und zwar nicht nur in bezug auf das sichere Fortbestehen der Bräuche, sondern auch allgemein im Hinblick auf das Dorfleben:

Et gibt Leute, die Du net kennst-aus'm Ort?

Ja, dat hier sind ja Leute - gu'mal hier von '71 [beim Durchgehen der in der Festschrift angeführten Liste der Vereinsmitglieder], ${ }^{460}$ da war ich ein Jahr alt, ne. Un wenn die... die sind meistens kurz danach weggezogen oder so wat. Wie hier bei dem Hundertjährigen [Jübiläum des Junggesellenvereins], wo manche Leute mit'm Zug mitgegangen sind, also die kannt ich ja net mal vom Sehen her, ne. Et sin auch jetzt noch Leute im Dorf, die Zugezogene oder so, kann ich dir net sagen, wo die hier wohnen - beim besten Wille net. Et is och: Die siehst de... Guck mal, momentan is et ja och wieder so: Morgens fahr ich auf de Arbeit, abends komm ich heim. Normalerweise bin ich jetzt noch am Arbeiten, ne. Ja!? Dat einziste, wo ich halt eben rausgehe, is am Wochenende in de Disko oder sonst wohin; da seh ich die auch net. Oder hier in de Wirtschaft, da gehen die net hin. Un deswejen is et äußerst selten, wenn de irgendwen hier überhaupt mal triffst un überhaupt mit denen dann mal och en Wort redest. Dat kann dir höchstens, wie gesagt, an Kirmes passieren. Wenn de mit denen eventuell an der Theke nebenenander stehst un trinkst mit denen en Bierchen, dann kommste vielleicht mit denen mal in de Verzäll. Sonst wirst du hier keinen kennenlernen von den Neuen. Das is et beste, et beste Fest, um irjenswelche Kontakte zu schließen. Hier hinten wohnen zum Beispiel auch welche [...], die siehste et ganze Jahr im Dorf net. Et einziste wann de die siehst: Kirmessamstag sin die im Zelt.

Dat sin Zugezogene?

Mhm. Sonst siehste die nie. Im Auto siehst du sie schon mal fahrn, aber Kirmessamstag sind die jetzt jedes Jahr im Zelt.

Und da hamn se auch Kontakt?

Jaja. Dann reden die schon mal mit dem. Da geht die Frau schon mal mit dem tanzen oder er geht schon mal mit'ner anderen Frau tanzen, und so kriegen die halt eben dann ihren Kontakt, ne. Nur dadrübber.

Un andere, die, die beteiligen sich net?

Sag'mer mal, dat sin halt eben... Manche Leute, die wollen halt eben, wie gesagt, mit'm Dorfleben gar nix zu tun haben, ne. Die ziehen aus der Stadt raus, wolln hier halt eben ihr Haus bauen, ihre Ruhe haben un der Rest interessiert halt einfach alles net, ne. Un dat is halt eben... durch solche Fälle geht halt eben auch dat ganze Dorfleben kaputt, ne. Tja. Aber daran ändern kannste auch nix. ${ }^{461}$

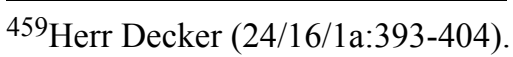

${ }^{460}$ Siehe Prothmann (1989:62-64).

${ }^{461}$ Herr Weiden (18/12/2b:555-583). 
Die Äußerungen von Herrn Weiden sind geprägt von der Befürchtung, daß die dörflichen Kontakte sich in einem allmählichen Auflösungsprozeß befänden. Lediglich das für alle zugängliche Ortsfest würde dieser Entwicklung etwas entgegensetzen. Von den Beteiligten konnte es als Angebot begriffen werden, die innerdörfliche Isolation aufzubrechen und über die Zusammenkunft, das Aufeinanderzugehen, das Miteinanderreden und schließlich das Tanzen die zwischenmenschliche Begegnung zu modellieren. In dieser Weise verfügte der Brauch sowohl über initiierende als auch interaktionsleitende Momente, die zweckgerichtet den sozialen Kontakt unter den Kirmesbesuchern und den Brauchtreibenden selbst beeinflußten. Dafür hat Herr Winzer ein Beispiel gebracht:

Ich find's schöner, wenn ich da mit den anderen Junggesellen zusammensitze und einen hebe oder was; macht mehr Spaß als Maikönig zu sein. Aber das is auch bei uns so: Da geht irgendwie gar nix anderes, weil die ganzen Mailehen, die ganzen Mädchen im Dorf, die haben so gar nicht soviel mit dem Dorf zu tun, und deswegen bleibt einem gar nix anderes übrig.

Wie meinst Du das jetzt?

Also es könnt ja auch sein, daß man dann mit den Mailehen im Zelt sitzt und daß die nicht nur Sonntagnachmittag da sind, sondern auch am Samstag oder am Montag. Aber das is eben nicht der Fall. Und deswegen bleibt einem gar nix anderes übrig, als nur mit den Junggesellen und den anderen Leuten aus dem Dorf dann zusammenzusein.

Also der Kontakt zu den Mailehen...

...zu den Mädchen is nicht so gut allgemein.

Auch zu den Gleichaltrigen?

Auch die vorher bei mir in der Klasse waren, in der Grundschule oder so. Die seh ich zwar und dann grüß ich se, aber das war's auch schon. Die hab ich dann seit der Grundschule nicht mehr so richtig gesehen. Das is auch meistens so, daß die nicht oft im Dorf so selber sind, und dann hat mer gar keinen Kontakt mehr zu denen. Also die haben meistens mit den Klassenkameraden und Klassenkameradinnen zusammen.

Ach so, die gehen dann noch weiter auf die Schule?

Ja, das war jetzt so, daß die ganzen Mädchen auf'm Gymnasium waren, und dann waren die mit neunzehn noch in der Schule. Die haben... auch so allgemein haben die Mädchen nicht soviel Kontakt im Dorf. Aber jetzt hat sich's schon... bei'n paar hat es sich geändert, seit der Kirmes. [...] Denen hat das dann ziemlich gut gefallen, die waren auch an anderen Tagen noch dabei. Aber das sind kaum welche. [...]

Jetzt gibt's aber doch für die Mädchen die Möglichkeit, zu sagen: "Hier, ich ruf den Vorsitzenden an und sag: 'Streich mich von der Liste!'"

Mhm, gibt's.

Aber da wird dann nicht so von Gebrauch gemacht. Also die nehmen dann trotzdem teil.

Ja, machen se. Ja, die gehen dann eben nur im Zug mit, und dann sitzen se noch ne Stunde em Zelt und dann war's das für die auch. Und so schlimm is das ja für die bestimmt auch nicht, glaub ich. Vor allem steigert man wenn, dann die, die man besser kennt. Also ich hab jetzt zum Beispiel nur die gesteigert letztes Jahr, mit der hab ich mich in'n Grundschuljahrn immer gut verstanden und so was. Von daher hab ich vielleicht die gesteigert. Ich glaub, daß is denen auch 
ganz recht, wenn die von Gleichaltrigen gesteigert werden, nicht daß dann irgendne Sechzehnjährige von nem Ende Zwanzigjährigen gesteigert wird; wär bestimmt nicht recht. ${ }^{462}$

Diese ausführliche Gesprächspassage ist aufschlußreich, weil sie einerseits den Prozeß eines fast zwangsläufigen Auseinanderdriftens von im Kindesalter gepflegten Freundschaften nachzeichnet, andererseits das im Brauch liegende Potential der Wiederbelebung derartiger Verbindungen aus der Grundschulzeit eindeutig benennt. 463 Während der Eintritt in den Junggesellenverein einen großen Teil der männlichen Jugend hauptsächlich über die gemeinsame Ausrichtung der Kirmes eng zusammenband, war der integrative Effekt der Mailehenschaft weitaus weniger wirksam (vgl. Kap. 4.4.2). Das Beispiel zeigte aber zumindest die reale Chance, abgebrochene oder gestörte soziale Beziehungen aufzufrischen und zu beleben. Und dabei ließ sich der Impuls für das wiedererwachte Interesse und die damit einhergehende Aktion ausschließlich auf das Mailehen zurückzuführen.

Die Reaktivierung von Beziehungsgefügen aus der Kindheit mußte keineswegs eine einseitige Angelegenheit von männlichen Jugendlichen sein. Wenn das Mailehen unter den Brauchträgern und Brauchträgerinnen einen kommunikativen Sinn erfüllte, dann war es in jedem Fall auf die reziproke Schließung von Handlungsketten angewiesen. ${ }^{464}$ Der initialen Begegnung mit den weiblichen Mailehen gingen die Mailehenversteigerung und das Maienstellen als aktive Einsätze der Junggesellen voraus. Doch eine geglückte Kontaktaufnahme erforderte eine Reaktion, eine Erwiderung, die über das schematische, passive Sich-Einfügen in die Brauchrolle hinausgehen mußte. Der folgende Bericht von Frau Eder zeugt davon, daß die Wiedergewinnung oder der Zugewinn sozialer Kontakte über das Mailehen daher auch positiv empfunden werden konnte:

Du hast gesagt, am Anfang hättest Du überhaupt nicht so en Draht zur Kirmes gehabt. Wodur...

...weil ich die Leute ja auch irgendwie nicht kannte. Ich kannte ja nicht die Junggesellen. Ich mein, mit den Jungen hatten wir... hab ich ja nie irgendwie was zu tun gehabt - so von früher, die sin ja alle schon viel älter. Und halt da lernt man die alle erst mal richtig kennen un so; un merkt richtig, wie lieb die alle sin. Un dann kommt man denen auch schon irgendwie en bißjen näher.

Also Du kanntest praktisch keinen von denen oder vom Sehen...

...vom Sehen schon, aber nicht so vom Charakter her, so wie die sin un so. Das hat sich da eigentlich...

...hattest Du Dich nicht mit denen vorher schon mal getroffen oder unterha...?

462 Herr Winzer (07/07/1a:347-399).

${ }^{463}$ Während in den 1970er Jahren noch zwei Drittel der Grafschafter SchülerInnen gemeinsam die Hauptschule besuchten, sind die GrundschulabgängerInnen in den 1990er verstärkt auf die Realschule und das Gymnasium gewechselt (siehe Anhang 7.2, Tabelle 7.3: Übergangsquoten zur Sekundarstufe).

${ }^{464} \mathrm{Vgl}$. dazu die explizierten Grundannahmen sozialer Interaktion in Kap. 1.1 und in Wey (1999:313$315)$. 
...nä, gar nicht. Aber jetzt, im Gegenteil. Jetzt - so Wochenende in Diskos - ja, sehen mer uns un so. Ich mein, es hält auch irgendwie das Dorf schön zusammen. Jetzt so cliquenmäßig sin mer och immer ganz lustig.

Also es hat sich schon was verändert dadurch...

...doch es hat sich schon was verändert.

Also würdste sagen, schon als Du's erste Mal Mailehen warst oder...

...doch das war... ja doch, da hat's auch schon angefangen. Da hab ich mich auch schon wieder gefreut auf die nächste Kirmes un jetzt auch schon wieder auf die nächste Kirmes und dat is total schön un so - doch. Aber das wird immer... von jedes Jahr wird dat immer intensiver. 465

Über das Mailehen bekam Frau Eder den Anschluß an eine Clique von Dorfjugendlichen, nachdem der von ihr eingeschlagene Bildungsweg zu einer Abkoppelung geführt hatte. Einmal in Gang gesetzt, verstärkten sich die Kontakte von Jahr zu Jahr. Die fortschreitende Festigung der sozialen Kohäsion ließ sich daran ablesen, daß eine schemenhafte Wahrnehmung von Personen derselben lokalen Herkunft in eine affektbestimmte Zuneigung überging, und die Wertschätzung, die man für den eigenen Wohnort aufbrachte, wandelte sich mit der Zugehörigkeit zur Gruppe der Brauchträger. Das Gefühl der Indifferenz oder Ablehnung wich einer positiven Einstellung. Denn durch das gemeinsam begangene Mailehen konnte Oeverich zu einer Identifikationsfigur werden. Eine allmählich zunehmende Ergriffenheit von diesem Integrationsprozeß zeigte sich bei Frau Eder:

Hast Du Dir schon mal überlegt, wozu der Brauch gut is?

Vielleicht irgendwie, daß das Dorf irgendwie doch noch mal irgendwie sich mal trifft oder irgendwie zusammenhält - halt noch, ne. Ja, so hab ich mal so gedacht. Vielleicht, daß man sich dann mal wenigstens mal irgendwie amüsieren kann un mit dem Dorf zusammenkommt; um die Gemeinschaft dann irgendwie zu erhalten.

Glaubst Du, das is heute auch noch der Grund?

Doch. - Vielleicht... also ich mein, zum größten Teil schätze ich schon. Aber manche gehen vielleicht nur dahin, um sich irgendwie einen anzutrinken oder was weiß ich. Doch die älteren Leute, glaub ich, die kennen... schätz ich doch mal, daß die noch irgendwie... Aber ich mein, die Jüngeren vielleicht nicht mehr so, daß die Jüngeren vielleicht nur mehr dahin gehen, um sich zu amüsieren. Aber die Älteren vielleicht doch noch, die Gemeinschaft sich irgendwie zu erhalten. So, vielleicht ist das so geteilt.

Und was macht für Dich den Reiz aus - so an dem Brauch?

Ja, halt zum Beispiel die Leute, die ich halt nicht jeden Tag sehe oder so, daß ich die dann auch mal wieder, halt von den jüngeren Leuten - so wie in unserem Alter oder zwanzig, vierundzwanzig oder - halt sich mit denen richtig amüsieren können. Also Kirmes is dann halt die Zeit, um sich irgendwo richtig auszuleben.

Und wie ist so allgemein die Beteiligung im Dorf an den Bräuchen?

Also von den älteren Leuten her ist die Beteiligung eigentlich ziemlich groß, aber dann halt von den jüngeren? Dann so ab sechzehn vielleicht wieder, weil mer dann halt in diesen Maidings, in die Mailehen da aufgenommen wird, daß dann... dann fängt das vielleicht wieder an, so langsam wieder. [...]

${ }^{465}$ Frau Kruse (21/14/1a:130-205). 
Würdest Du da Unterschiede sehn bei Leuten, die noch nicht so lange im Dorf wohnen, daß die sich eher raushalten oder...

...oh nö, will ich nich sagen. Dieses Jahr sin ja auch schon ziemlich viele hier hingezogen. Ich hab auch schon ziemlich viele Leute gesehen, die ich noch nie gesehen hab, die ich noch nicht kannte und hab dann immer erfahren, die sin neu zugezogen in Oevverich. Un ich mein, find ich so eigentlich ganz gut, daß sie sich dann halt doch der Gemeinschaft dann irgendwie anschließen wollen un so, ne. Die Kirmes is fürs Dorf immer en ganz großes Ereignis, un da trifft sich alles, da trifft sich echt dat ganze Dorf.4 ${ }^{46}$

Die eigenen Erfahrungen mit dem Mailehen, was das Knüpfen freundschaftlicher Beziehungen betraf, gipfelten letztlich in der Anschauung, daß sich aufgrund des Brauchgeschehens das ganze Dorf zu einer harmonischen Einheit formiere. Das Mailehen entsprach damit einem idealen Gemeinschaftsmodell, in dem sowohl Heranwachsende mit zeitweilig ablehnender oder desinteressierter Haltung, begeisterte BrauchträgerInnen, arglose ZuzüglerInnen als auch die Alteingesessenen, die sich um den sozialen Zusammenhalt bemühen, ihren Platz fanden. Diese Gruppen mit ihren unterschiedlichen Motivlagen vereinigten sich in der gemeinsam begangenen Kirmes.

\subsubsection{Sozialer Kontakt}

$\mathrm{Da} ß$ das Mailehen nicht nur als ein "Gerüst" zur Ausbildung innerdörflicher Kontakte fungierte, sondern auch von zentraler Bedeutung für das vitale Zusammengehörigkeitsgefühl war, wurde in den Gesprächen ausdrücklich bemerkt. So wurde der Brauch präsentiert als das Ereignis, als das beste oder einzige Fest, um im Ort Leute $\mathrm{zu}$ treffen und kennenzulernen. In einem weiteren Analyseschritt stellt sich das Problem, wie dieses brauchspezifische Angebot in der Praxis genutzt wurde. Hierauf gaben die bislang zitierten Gesprächspassagen erste Anhaltspunkte: Gäste wurden zur Kirmes eingeladen, fremde Tanz- und GesprächspartnerInnen wurden gesucht, und die Mailehenversteigerung erzeugte den Impuls, ehemalige Schulfreundschaften wieder aufzufrischen. Diese Hinweise über die konkrete Kontaktsituation täuschen allerdings leicht darüber hinweg, daß das Mailehen tatsächlich nicht mehr und nicht weniger als ein "Gerüst" zur Kontaktaufnahme sein konnte. Durch formalisierte, erwartbare Verhaltensweisen, auf die weiter unten noch näher eingegangen wird, konnten jene Anstrengungen und Unsicherheiten, die sich mit jeder Art von Kommunikation verbindet, teilweise entschärft werden. ${ }^{467}$ Aber auch die rituell unterstützte Interaktion lebte letztlich von einer Eigendynamik, die die Beteiligten selbst ins Spiel bringen mußten. Die folgende Aufzeichnung des Gesprächs mit Frau Kruse gibt hierfür ein anschauliches Beispiel:

${ }^{466}$ Frau Eder (21/14/1a:528-578).

${ }^{467}$ Vgl. Luhmann (1987:216f). 
Und wie hat sich das herauskristallisiert. Du sagtest ja am Anfang so, bevor Du überhaupt so Mailehen geworden bist, da hättest Du ja manche... da wärst Du nicht so mit zurechtgekommen...

...jaja...

...jetzt im Laufe der Jahre so hat sich da ja was getan, da biste ja praktisch an die Leute was rangekommen und hast se kennengelernt... 468

Ja, das is... Manche kennste halt eben auch gut, ne, wie der Uli. Der is so alt wie ich. Der war halt eben auch im Junggesellenverein. Un durch den, den kannte ich halt, da hab ich mich dann halt eben an die Leute gehalten, die ich gut kannte, wie ich anfangs dadrin war. Un ganz am Anfang, ich weiß, et erste Jahr, wie die Steffi Maikönigin war un ich war dann bei der, wie die ganzen Junggesellen da saßen, un, ja, ich mit sechzehn, ja, da hab ich den Mund net aufjekriegt, ne. Da hab ich immer dat Gefühl gehabt, dat die einen verarschen, ne, wo du debejstehst, ne. Und mit den Jahren da kriegt man auch en Mundwerk und kann dann auch antworten, ne. Wenn die dann ne dumme Frage stellen, da gibste halt ne dumme Antwort zurück. Und so nach und nach lernste dann halt eben die Leute kennen, weil die ja auch die Mailehen zum Essen einladen, ne. Dann sitzt de dann irgendwie wieder... da sitzt en anderer dir gegenüber, bei dem de eigentlich denkst: "Oh Gott, dat darf doch net wahr sein, der sitzt dir gegenüber?!" Und so'n... und dann nachher denkste: "Och, so verkehrt is er ja garnet." Dat kommt dann halt eben... wenn, wie jetzt anfangs, wie vierzehn, fuffzehn, da fing dat dann an, dat ich dann Leute kennenlernte, ne, wo man Fremden gegenüber ja dann doch noch en bißjen fremd, also zurückhaltend is. Un nachher is dat, wie... Wenn ich heute die Leute kennenlern, dann bin ich offen, ne. Och, dann erst mal redeste dann, dann merkste nachher... kannste dann nachher noch sagen: "Mit dem kannste nix anfangen" oder "Mit dem kannste dich gut unterhalten." Dat merkt man nachher halt eben. Früher hat man dann doch viel nach'm Aussehen oder nach der Art der Leute, äh, is mer da gegangen, ne. Un, is klar, mit so drei... vierzehn, fünfzehn vielleicht auch noch sechzehn, ne, da weiß mer halt eben net, wie mer mit den Leuten umzugehen hat, ne. Un nach un nach lernt mer die halt eben kennen, ne, un dat is dat Schöne dadran, ne. ${ }^{469}$

Frau Kruse schilderte die Passagen ihrer Integration in die Gruppe der Brauchträger. Ihr junges Alter, ihre Fremdheit, Unerfahrenheit und Schüchternheit machte sie dafür verantwortlich, daß sie sich anfangs nur zögerlich an den Treffen beteiligte. Zunächst war es für sie wichtig, daß ein Bekannter ihr den Einstieg in die Gruppe erleichterte. Offensive Einschüchterungsversuche seitens der Brauchträger schreckten sie dennoch ab. Die Euphorie über das soziale Erleben des Mailehens wuchs erst mit den Jahren, in denen die Kontakte stabiler und die auftretenden Verhaltensweisen berechenbarer wurden. Zudem fand sie Strategien zur Selbstbehauptung. Dabei wurde sichtbar, daß die zunehmende Integration gleichzeitig mit einer persönlichen Entwicklung einherging, die einen offeneren, vorurteilsfreieren Umgang in den zwischenmenschlichen Beziehungen erlaubte. Die regelmäßige Wiederkehr des Brauches bot die

468 Die Fragestellung bezieht sich auf die folgende Bemerkung von Frau Kruse (25/17/1b:217-229): "So manche in dem Junggeselleverein, wie ich noch net in dem Junggeselleverein drin war, wie ich so dreizehn, vierzehn, fünfzehn war - vom Sehen her kennt man so Leute - so paar spezielle, wenn ich die gesehen hab, dann bin ich Laufen gegangen. Die mochte ich absolut nicht die Leute. Wenn ich die gesehen hab, da dacht ich: "Oh Gott, wie ka'ma nur?" ne. Mittlerweile, man hat die Leute kennengelernt, wenn die kommen, wir grüßen uns "Hallo! Wie geht et?" ne, weil man die Leute auch kennengelernt hat, ne."

${ }^{469}$ Frau Kruse (25/17/1b:585-647). 
Gelegenheit, die eigenen Hemmungen zu überwinden, Kontakte aufzubauen und gleichzeitig die dazu nötige soziale Kompetenz $\mathrm{zu}$ trainieren und $\mathrm{zu}$ verfeinern. Bezeichnend ist unter diesem Blickwinkel auch ein Vergleich des Mailehens mit den Großdiskotheken des Umlandes, den Frau Kruse anstellt:

Nä, also Kirmes... Dat is eben halt dat Schöne, mer lernt immer mehr Leute... ich glaub, die erste Kirmes (kann ich mich zwar so net mer hundertprozentig dran erinnern), aber ich weiß, dat ich mich da so doch en bißjen verloren vorkam, ne. Man hatte zwar so die Leute, die man so kannte, ne, aber so andersherum kam man sich so en bißjen fremd vor. Un wenn mer jetzt durch et Zelt... geht mer: "Hallo! Hallo! Hallo! Hallo! Hallo!" ne. Dat geht ja nur... mer is ja nur Leute am begrüßen, ne. Weil: Auch mit so sechzehn, kennt mer die älteren Leute auch gar net so - okay, manche schon vom Sehen her, ne, aber so... oder die Eltern von denen, die im Junggesellenverein sin, kennt mer... die lernt mer ja erst kennen mit der Zeit, ne. Un dat is dann doch schon interessant, ne. Und ich muß sagen, dadurch wird man vielleicht auch lockerer, ne, weil ich kann mir net vorstellen, wenn ich jetzt in ner Großstadt großgeworden wär und würd in so ne große Diskothek gehen, sagen mer wie in Godesberg et "Octagon" oder Koblenz et "Extra", dat man dann so en lockeren Kontakt bekommt. Okay, man lernt Leute kennen, is klar; man wird irgendwo immer mal angesprochen, egal von wem. Aber net so der Kontakt, ne (dat mer sagen kann, dat is en guter Kumpel oder so, oder mit dem kannste Blödsinn machen), der kann in so'ner großen Diskothek oder so nie aufgebaut werden. Schon allein, weil mer sich ja gar net unterhalten kann, ne. Un auf so'ner Dorf... [-kirmes], ja, da geht mer wat trinken, et is auch zum Beispiel net so teuer, wenn mer jetzt in de Diskothek, ne, da bezahlste schon fünf Mark un hier ne Mark achtzig oder so wat für et Bier oder so. Da geht dat auch viel schneller: "Trinkste wat?" oder so, ne: "Gehste mal mit mir tanzen?" ne, weil dat dann gar net so auffällt. In so'ner Diskothek will jeder vornehm sein, jeder schnieke, ne. Auf so'ner Kirmes geht dat alles wesentlich lockerer zu, ne. ${ }^{470}$

Auf der Kirmes sei demnach alles viel lockerer, man bekäme dort lockeren Kontakt und würde selber auch lockerer. Das entscheidende Merkmal, das in diesem Plädoyer den Vorteil des althergebrachten, ländlichen Mailehens gegenüber der zeitgemäßen, städtischen Diskothek begründete, tauchte gleich dreimal im Text auf. Für die Gesprächspartnerin bereitete der Brauch offensichtlich eine ungezwungene Atmosphäre, in der die Kommunikation mit Unbekannten wesentlich erleichtert wurde. Solchen vorteilhaften Bedingungen widersprach augenscheinlich das in Diskotheken gängige Stilrepertoire, das sich aus Selbstbeherrschung, sozialer Etikette und Äußerlichkeiten zusammensetzte. Es scheint gerade der graduelle Verzicht auf diese andernorts geltenden Konventionen zu sein, der im Erleben des Brauches bei Frau Kruse als besonders befreiend und schätzenswert empfunden wurde und der den positiven Wert des Mailehens nachvollziehbar werden läßt:

Da kennst du so viele Leute [auf der Kirmes]. Du triffst manchmal et ganze Jahr die Leute nicht, aber bei uns auf Kirmes ja. Und dann erzählste mit dem, und dann erzählste da, und dann siehste ja wieder eine, ne, un da wieder. Un da willste ja auch net nur Hallo sagen und gehst weiter und willste auch net andauernd Händchen in Händchen mit deinem Freund dann da stehen. Und wenn et dein eigene Kirmes is, dann möchteste richtig mal dahin un mit dem tanzen un mit dem tanzen oder da en bisje erzählen, ne, auch wenn et net nur fünf Minuten

${ }^{470}$ Frau Kruse (26/17/2a:64-107). 
sind; und wenn et auch mal ne Stunde wird oder auch zwei, ne. Und dat is halt dat Schöne: $\mathrm{Du}$ stehst da zusammen, dat is spontan, dat is net so gekünstelt, ne. ${ }^{471}$

\subsubsection{Verständigungsbarrieren}

Auch wenn in den vorangehenden Abschnitten der geglückte soziale Austausch im Vordergrund der Diskussion stand, so wurde zumindest an manchen Stellen deutlich, daß sich dieser Erfolg nicht zwingend aus der Partizipation am Brauchgeschehen ergab. Gerade die Ausführungen von Frau Kruse haben dargelegt, daß vielfältige Faktoren für einen gelungenen Integrationsprozeß verantwortlich waren. Neben den wert- und normsetzenden Verhaltensmustern, die auf den Begriff des Lockerseins hinausliefen, traten vor allem gruppenspezifische Zusammenhänge und psychosoziale Dispositionen der AkteurInnen hervor. Alter der Beteiligten und der Vertrautheitsgrad untereinander beeinflußten deshalb die Kommunikation ebenso wie eine wesensmäßige Verschlossenheit. Die Verwobenheit von brauch-, gesellschaftsoder persönlichkeitsbedingten Einflußfaktoren wurde damit aufgedeckt. Mögliche Störungen, die beim Aufbau sozialer Kontakte im Rahmen des Brauchgeschehens auftreten konnten, müßten sich demzufolge auf diese Determinanten zurückführen lassen. Entsprechend wäre das Braucherlebnis durch eine Gefährdung der lockeren Atmosphäre, durch auftretende Widersprüche zum dörflichen Zusammengehörigkeitsgefühl oder durch einen erkennbaren persönlich begründeten Widerwillen mehr oder minder stark beeinträchtigt. Im Umkehrschluß würde das Ausbleiben solcher Irritationen zu einem ungeschmälerten Braucherlebnis führen. Es müßten dann die sozial integrativen gegenüber den segregierenden Momenten überwiegen.

Zur Überprüfung dieser Interpretation liefern die Erlebnisse und Gedanken von Herrn Franken eine Fülle von detaillierten, relevanten Informationen:

Wie gestaltete sich dann [nach Ihrem Zuzug] der Kontakt mit den Dorfbewohnern?

Ja, erst mal so über die direkte Nachbarschaft, wo man sich natürlich vorgestellt hat. [...] Es war damals auch noch so: Oeverich war Anfang der Achtziger noch vergleichsweise unberührt. Die Grafschaft explodiert en bißjen in den letzten Jahren, weil die Gemeinde sehr viele Baugebiete neu ausweist. Da war man als Neuzuziehender auch einfach ne Novität im Dorf. Es gab nur ne ganz kleine Neubauecke, wo en paar Leute wohnten, ansonsten war jeder Neue, der wurde noch registriert. Mittlerweile, glaube ich, is das en bißjen verloren, weil sehr viele jetzt neu dazuziehen. Wenn dann so en Schwung kommt, dann verliert sich das Interesse natürlich auch und das Kenntnisnehmen der Neuen, ne. Bei mir war einfach so ne Kenntnisnahme auch da, ne. Und dann entpuppte sich hinterher, daß ich Leute auch kannte, die im Dorf wohnten [...] und dann gab's dann auch schon so Vereinfachungs... Vereinfachungspunkte letztlich. Ja, und dann eben über den alten Hausbesitzer, der mich dann auch schon mal mitnahm ins Festzelt anläßlich der Maifeste, daß man also dann so praktisch eingeführt wurde - in Anführungszeichen "eingeführt". Man hatte einfach auch so... so en Anhänger, der einen dann

${ }^{471}$ Frau Kruse (25/17/1a:667-676). 
da mitzog oder so ne Zugmaschine, die einen als Anhänger mitnahm, ne. Vielleicht is ja doch auch immer psychologisch für einen auch ne Überwindung, sag ich mal, in so en Festzelt zu gehen, wenn man da völlig fremd ist und weiß, die kennen sich alle, die treffen sich einmal im Jahr, zum Teil kommt dann auch noch die Verwandtschaft aus weiterer Entfernung zusammen - bewußt, um da ins Festzelt zu gehen. Und von daher hatte ich eigentlich immer da einfachen Zugang, aber auch - wie gesagt - Glücksache, ne. Das is eben so.

Wann hat sich das mit dem Festzelt ergeben?

Ja, schon eigentlich im ersten Jahr. Direkt wurd ich dann dahin mitgenommen, hab mir das angeguckt, fand das zwar ganz witzig, aber persönlich hat's mich so super sehr nicht angesprochen, weil... kommt auch drauf an wahrscheinlich, an welchem Tag man auch da is. An dem Tag, als ich da war, is mir nur aufgefallen, daß sehr viele stark Alkoholisierte da waren. Das war dann doch etwas derber insgesamt. "Na ja", dachte ich, "na ja, okay, so is das eben auf'm Land." Aber das is mehr wertfrei zu sehen, war einfach nur so, daß ich dachte: "Na ja, okay. Bin nie der Typ gewesen, der sich groß besoffen hat" und von da hab ich da weniger Zugang zu. Und zu diesen Maifesten gehört doch so ein etwas heftiger alkoholischer Zuspruch wohl dazu, ne, hab ich den Eindruck.

Speziell bei was? Bei der Kirmes oder...

...ja, bei der Kirmes, auch bei den Umzügen, ne, ist dann...Alle dreihundert Meter wird da an einem Schnaps genossen. Also ich weiß nicht, irgendwie hab ich's damit nicht. Also ich würd wahrscheinlich da nach drei Schnäpsen, sofern ich Maikönig wäre, irgendwo in der berühmten Gosse liegen.

Den Ablauf, haben sie auch schon mitbekommen - wie das...

...ja, so ganz im Groben weiß ich, wie dat abläuft. Wie gesagt, der Junggesellenverein, das Maikönigspaar, was dann auch durch's Dorf zieht. Und Höhepunkt is eben auch der Umzug im Dorf mit dem wunderbaren Begriff "Maibutz". Als ich den es erste Mal hörte, wußte ich gar nicht, worum es eigentlich geht, obwohl ich Rheinländer bin und das Wort "Bützjen" kannte. Aber mit Maibutz konnte ich erstmal nix anfangen, bis ich dann eben rauskriegte, daß sich dann das erkorene Paar eben öffentlich zu küssen hat und alle applaudierend drumrumstehen und der Fähndelschwenker sein Fähnchen schwenkt.

Das heißt, Sie haben schon mal dabeigestanden...

Ja, doch, weil die auch durchs Dorf ziehen. Auch wenn sie das Dorf früher überall geschmückt ham, [...] is man einfach dazugegangen. Ich mein, wenn man schon sieht, daß man sich traditionell bemüht - wie immer das von dem Hintergrund auch an dem Tag dann auch selber sein mag, man sieht, daß manch einer mehr hackebreit als hackeschmal is - muß man dann doch erkennen, daß so ne Pflege, wo man sich bemüht, das Dorf zu schmücken, doch irgendwo auch en positiven Bezug hat bei den Leuten selber. Ich mein, wenn die da... nur zum Saufen könnten die sich auch in die nächste Kneipe setzen; das wär ja auch relativ einfacher. Also bin ich auch immer dazugegangen, und dann hat man natürlich auch applaudiert und gewunken und das Übliche, daß die Leute also auch nicht das Gefühl hatten: "Der ignoriert uns jetzt da." Das hätte ich also nicht für gut gefunden, besonders gerade dann, wenn der Zug auch mehr oder weniger am Haus vorbeigeht, dann sollte man sowat nicht tun. Würd ich für taktlos empfinden.

Ergibt sich das mehr zufällig? Also, weil sie jetzt grade mitkriegen, daß die Musikkapelle vorbeizieht...

...ja, eigentlich ja...

..."Jetzt geh ich raus!" oder sehen Sie im Kalender dann und dann is Kirmes?

Ja, ich weiß das mittlerweile. Im Laufe der Jahre wächst so was ja zu. Aber es is nicht so, daß ich derjenige bin, der jetzt das Jahr über sich auf die Maikirmes freut. Dazu muß man wahrscheinlich auch viel länger in diesen familiären Bindungen auch im Dorf sein, um auch wie andere das machen - um auch die Verwandschaft einzuladen. Die haben dann montags 
zum Teil frei, wenn Kirmes is. Also dat hab ich nie gemacht. So viel Bezug hab ich dazu nicht. Schon mal dann abends ins Festzelt gehn, klar, mal en Bierchen trinken, sich mit en paar Leutchen unterhalten, das ja, aber nicht darüber hinaus. Also es is keine in dem Sinn aktive Einbindung, is so'n passives Mitnehmen, Beteiligtsein im Rahmen auch dessen, wo ich das Empfinden habe: "Da kannste dich beteiligen, ohne hier in Konflikt meiner eigenen Wertvorstellung zu kommen" weil, ich sag mal, darüber hinaus, mich jetzt da wirklich drei Tage ins Festzelt zu hocken und mir die Hacke voll zu trinken, das wär irgendwie nicht so das Thema.

Und da ergeben sich dann zufällige Kontakte im Festzelt auch...

...ja.

...mit den Leuten...

...ja, genau. Jaja. Dann spricht einen auch schon mal so einer an dann, is so. Dat is dann... dann sin wieder alkoholbedingt oftmals ja auch die Umgangsformen wieder etwas lockerer und dann auch die Gesprächsbereitschaft wahrscheinlich höher. Ich bin aber immer - das muß ich klar sagen - eigentlich immer freundlich angesprochen worden. Dat war eigentlich immer ganz angenehm. Es is also nicht so, daß man angepöbelt worden is oder so wat. [...]

Aber es is nicht so, daß Sie jetzt schon angesprochen werden: "Hier, dann und dann is Kirmes und dann gehen wir zusammen ins Festzelt oder treffen uns da!?"

Nee, wie gesagt, außer damals über den Hausbesitzer, als der noch lebte, dann ja, aber sonst in der Form eigentlich nicht. Weiß ich auch gar nicht, wie weit das auch sonst im Dorf stattfindet. Dat is einfach... da geht man halt hin. Das Dorf is ja kleiner. Man muß das doch mehr in Relationen sehen. Das is nicht wie ne Kirmes in der Stadt, wo ne Prozentzahl vielleicht bei... wenn da fünf Prozent Leut hingehen, is diese Kirmes rappelvoll. Diese Kirmes is nur voll, wenn da die Hälfte des Dorfes auch hingeht, ne. Von daher kriegt das vielleicht auch en anderen Bezug zum Verständnis der Leute. Also von daher kann ich mich nicht erinnern. [...] Na ja, ansonsten - wie gesagt - so im Festzelt... Wenn man da sieht, die Nachbarn, die freuen sich dann so... doch Nachbarn ham mich auch schon mal so nach...: "Ich würd ja auch ins Festzelt kommen!?" ne, aber mehr so beiläufig, ne. Das ist dann schon stattgefunden.

Und daß Sie dann praktisch Ihrem Bekanntenkreis Bescheid sagen: "Hier dann und dann is...

...hat sich en paarmal zufällig ergeben, weil wir gerade Besuch hatten. Sind wir also auch mit dem Besuch ins Festzelt gegangen. Wobei ich da sagen muß, ich hatte immer so en seltsames Gefühl dabei. Die Leute, die aus der Stadt kommen und das Dorf überhaupt nicht kennen, legen witzigerweise oftmals dann en gewisses elitäres Verhalten an den Tag. Warum, weiß ich nicht, aber es ist so nach dem Motto: "Och, da feiern die Doofen" ne. Ich weiß nicht, dat fand ich immer so... Selbst bei guten Freunden hab ich das so gespürt. Vielleicht ist dat auch nur en Film von mir, ich weiß nicht. Aber ich hatte...

...aber den Eindruck...

...den Eindruck hatte ich immer, den konnte ich nie so ganz abwehren und... Den Eindruck hatten vielleicht auch andere. Man merkt das ja schon, wenn jemand so am Tisch sitzt und so sich eigentlich unsicher, unwohl umschaut, dann is dat eigentlich so en Zeichen dafür, daß er irgendwas an dieser Situation nicht positiv empfindet, und von daher hab ich dat also nie zum Thema gemacht, da irgendwen jetzt zur Maikirmes dann bewußt einzuladen. Hätte man vielleicht durch intensive Pflege anders erreichen können. Aber, ich sag, so viel Bezug hab ich dann auch wieder selbst nicht dazu, daß ich also diesen Anspruch hätte, jetzt hier pädagogisch, erzieherisch tätig zu werden.

Und - ich weiß nicht, ob Sie das noch dann wissen - ob das dann auch ne andere Situation war im Festzelt mit den Freunden und Bekannten, als wenn Sie jetzt selber oder im Kreis ihrer Familie ins..

...ja, es war eine andere, wie gesagt, weil auch die... ich sagte dat eben, wenn man schon so ne Gruppe hat, die so ne scheinbare Unzufriedenheit eigentlich mit sich herumträgt oder so en 
Unwohlempfinden, merken es auch die Umstehenden. Die meisten Menschen artikulieren ja ihre Gefühle nicht, sondern verarbeiten die ja eigentlich unbewußt. Und da merkte man schon, man war dann auch im Festzelt ne isolierte Gruppe, ne. Also da war's dann praktisch gar nicht so, daß einer einen angesprochen hat, außer vielleicht grade mal, wat weiß ich, hier der Betreiber des Dorfladens, der natürlich jeden grüßte, ne. Aber ansonsten merkte man schon, das hat irgendwie... hat nicht das Empfinden, wie wenn man alleine hingeht und eben als Dorfmitbewohner vielleicht denn auch den Eindruck vermittelt, daß man vielleicht en bißjen Kontakt sucht, ne. Denn sonst würde man den Leuten ja vielleicht auch unterstellen, dat se völlig blind wären, wenn also einer alleine kommt, daß se den dann irgendwo in die Ecke stellen. Ich sag ja, dat findet eben nicht statt, sondern, daß man dann doch schon positiven Zugang bekommt. ${ }^{472}$

Zunächst stellte sich heraus, daß Herr Franken einen verhältnismäßig einfachen Start hatte, um den Kontakt zu seinem sozialen Umfeld und den dortigen Gepflogenheiten aufzunehmen. Das von ihm bewohnte Haus lag mitten im alten Ortskern. Somit war der nachbarschaftliche Zugang zu Alteingesessenen nicht von vornherein durch die Wohnlage eingeschränkt. Bemerkenswert erscheint vor allem die etwas weitergehende Bekanntschaft zum ehemaligen Hauseigentümer. Dieser führte nämlich den Neuling in den Kreis einer vermeintlich festgefügten Kirmesgesellschaft ein - ein Erlebnis, das als Überschreiten einer kritischen Schwelle und als psychische Herausforderung anschaulich wiedergegeben wurde. Die Gefühle von Fremdheit, Isolation und Desorientierung verstärkten sich durch die Vorstellung der Kirmes als ein formeller Zusammenschluß von DorfbewohnerInnen mit ihren engsten Angehörigen. Die Partizipation an dieser Veranstaltung schien nur über die Mitwirkung eines auf den Brauch eingeschworenen Dritten möglich. ${ }^{473}$ Der Verlauf der Integration wurde entsprechend der Schilderung überwiegend positiv erlebt. Gleichwohl zeichneten sich Grenzen der Identifikation mit der Art des kollektiven Feierns ab. Der Verzehr von Alkohol nahm an diesem Punkt einen teilweise kritischen, polarisierenden Stellenwert ein. Alkohol konnte beschwingen, entkrampfen und enthemmen. Demnach eignete sich ein gemäßigtes Trinkgelage dazu, das Aufeinanderzugehen und damit die zwischenmenschlichen Kontakte zu erleichtern. Die Wirkung von Alkohol konnte aber auch bedrohliche Energien freisetzen. Pöbeleien von Betrunkenen waren zwar unüblich, dennoch existierte aufgrund des exzessiven Alkoholkonsums eine gewisse Gefährdung der brauchbedingten Kontaktsituation. Herr Franken sah den Sinn des Brauches in dem Moment in Frage gestellt, wo unkontrollierte Derbheiten die soziale Interaktion nachhaltig stören könnten.

Im Zusammenhang mit dem Alkoholverzehr deutete der Betroffene eine weitere Verständigungsbarriere an. Das zünftige Trinken zählte zum Brauchablauf dazu und hat sich auch mit dem Selbstverständnis der brauchausübenden Gruppe verbunden. Daher mußte einem Nicht- oder Wenigtrinker der Zugang zum Brauch schwerfallen,

${ }^{472}$ Herr Franken (44/30/1a:240-425).

${ }^{473}$ Hierzu auch Frau Pfeiffer (46/32/1a:186-192), Frau Jansen (52/38/1b:316-327), Frau Gebhard (41/28/1a:162-175), Frau Eder (21/14/1a:200-219) und Herr Winzer (07/07/1a:148-173). 
denn sein Verhalten stand in einem Widerspruch $\mathrm{zu}$ der virulenten Trinkaufforderung. Die Auflösung dieses Widerspruchs verlangte nach einer für die Gruppenmitglieder akzeptablen Rechtfertigung, wenn die Abstinenz und damit der anhaltende Verstoß gegen eine Gruppennorm nicht als grundsätzliche Hinterfragung identitätsstiftender Wertvorstellungen erachtet werden sollte. Andererseits durfte der Alkoholgenuß auch nicht zu regelmäßigen Ausschreitungen führen. Schwerwiegende Entgleisungen und Entladungen aggressiver Spannungen, z.B. in Form von Schlägereien, hätten sowohl den Gruppenzusammenhalt geschwächt als auch die Attraktivität des Mailehens als Ort sozialer Begegnung gemindert. Für den Befragten war das Verhältnis noch im Lot: man konnte mal ein "Bierchen" trinken, man kam mit Leuten ins Gespräch, ohne angepöbelt $\mathrm{zu}$ werden, und alles spielte sich dabei ohne die Verletzung eigener Wertvorstellungen ab. Dadurch, daß die Grenzen des kommunikativen Austauschs nicht überschritten wurden, konnte man über harmlose Diskrepanzen hinwegsehen. Der von Junggesellen betriebene Aufwand bei der Brauchausübung konnte uneingeschränkt honoriert werden, solange eine gegenseitige Achtung der Beteiligten spürbar wurde.

Daß die Modellierung sozialer Kontakte maßgeblich von der Einhaltung des Prinzips der gegenseitigen Anerkennung abhing, hat Herr Franke in einem weiteren Teil seiner Ausführungen dargelegt, als er über die gescheiterten Begegnungen von Stadtund LandbewohnerInnen berichtete. Die pejorative Bedeutung der Begriffe dörflich, ländlich, provinziell trat im sozialen Umgang mit den befreundeten Städtern mehr oder weniger hervor. Offenbar führten Unsicherheiten und das Vorteil vom hinterwäldlerischen, zurückgebliebenen Dasein auf dem Lande zu einer gewissen elitären Arroganz gegenüber der Art des geselligen Feierns, wie sie sich im Mailehen präsentierte. Gleich in mehreren Fällen hatte der Befragte dieses Verhaltensmuster erkannt. Verwundert über diese stereotypen Abgrenzungsmechanismen, sah er nunmehr keinen Anreiz, Freunde aus der Stadt zur Kirmes einzuladen, um diese dann aufklärerisch und praxisnah mit ihren Vorurteilen zu konfrontieren.

\subsubsection{Strukturen des sozialen Austauschs}

Konzentrieren wir uns abschließend auf die Strukturen des sozialen Austauschs, die sich bereits in der obigen Darstellung abzeichneten. Es zeigte sich, daß fünf Aspekte bei der innerdörflichen Kommunikation im Mailehen eine maßgebliche Rolle spielten. Im einzelnen ging es dabei um:

1) den Brauch als erkennbares soziales Zeichen, das den initialen Impuls zur Kommunikation auslöste;

2) den Beteiligungswillen der Betroffenen;

3) die Vermittlung von Kontakten durch eingeweihte Dritte bei der Einführung 
neuer InteraktionspartnerInnen;

4) objektive Affinität unter den Beteiligten, d.h. die Übereinstimmung äußerer Merkmale (z.B. die Ableitung einer gemeinsamen lokalen Bindung);

5) subjektive Affinität unter den Beteiligten, d.h. die Übereinstimmung ideeller Merkmale (z.B. die Ableitung eines gemeinsamen Geschmacks).

\section{Soziales Zeichen}

Daß sich die Aktionen nicht im verborgenen abspielten - sieht man einmal von der Mailehenversteigerung ab -, war eine Vorbedingung dafür, daß das Brauchgeschehen für die DorfbewohnerInnen sozial produktiv werden konnte. Es bedurfte einer publikumswirksamen Darbietung, die möglichst reichhaltige Anreize zu einer breiten Beteiligung der lokalen Öffentlichkeit hervorbrachte. Auf diese Weise erschien der Brauch als ein kulturelles Angebot, das einen potentiell offenen kommunikativen Anschluß für die Beteiligten gewährte. Die Entzifferung des sozialen Sinns beim Mailehen als eine Einladung zu einem öffentlichen unterhaltsamen Treffen lieferte sogleich den Impuls für eine brauchbedingte innerdörfliche Kommunikation. Wie stark der hiermit in Gang gesetzte Austausch auf eine konkrete Brauchhandlung angewiesen war, wurde in einem Gruppengespräch sichtbar:

Was is jetzt der Reiz gewesen an diesem Brauch?

Frau Rosen: Das kann man eigentlich gar nicht beantworten. Das war einfach schön un...

Herr Marx:...die Gestaltung einer Kirmes. Denn ohne Jungjeselleverein...

Frau Rosen:...lief ja gar nichts.

Herr Schmitz:...wurde ja praktisch keine Kirmes jehalten. Un da wieder [nach 1945] ein Verein da war, wurde wieder Kirmes jehalten. Un dieser Brauch mußten wir ja dann haben, das Steigern...

Frau Rosen:...eigentlich de Grundlage, dat war die Grundlage vum Ganze wieder. Joa, mir brauchten die zum Fiere, um ins Feiern reinzukommen. ${ }^{474}$

Es scheint somit offensichtlich, daß der Brauch die zur geselligen Zusammenkunft nötigen, dechiffrierbaren Signale aussendete. Bereits das Herrichten des Ortes mit dem Dorfmaibaum und den Maien oder die laut schallende Musik des Tambourcorps während des Festumzugs durch die Straßen lenkte die Aufmerksamkeit der Bevölkerung auf das Kirmestreiben. Dadurch war jeder einzelne implizit dazu aufgefordert, am Gelingen des jährlich wiederkehrenden Dorffestes teilzuhaben. Da die Kirmes die einzige lokale Großveranstaltung in Oeverich darstellte, wurde der Stellenwert des Brauchgeschehens und der Beteiligung daran zusätzlich gesteigert. Herr Goltz äußerte sich dazu folgendermaßen:

$J a$, jetzt würd mich noch interessieren: Die Beteiligung der Dorfbewohner, so. Und dat Verhältnis der Dorfbewohner zum Junggesellenverein und zu den Bräuchen?

${ }^{474}$ Gruppengespräch I (40/23-27/3a:230-241). 
Also hee in Oevverich: sehr jut! Also et is... Iaschtens saren moal die Eldere vun de Jungjeselle zeejen also voll met, ne. [...] Dat heescht, die Dorflök, die kunn, verstehste. Et is keene Saal me hee, et is... eemoal em Joahr is Danz hee em Dorf, dat is de Kirmes, verstehste. Un dann is normalerwees alles op de Been. Un dat is dat, wat de jetz grad weasse wollst, verstehste. Un sou sin die Lök och enjestellt, ne. Un wenn de, sare mer moal, in de Wiertschaav hiers: "Ah, wat war dat Kirmes jot. Doa ham'mir doa un doa jesäß, un hee un dat un dat. Un weeßte noch, wie mer an de Sektbar jestande han, un dat un dat" verstehst, un, un, un. Un die Lök sin och widde doa für die nächste Kirmes. Un sin am Organisiere, ejal wat dat is, verstehste. Hee jet Ümzöch met e paar Fraue ${ }^{475}$ un doa jet, verstehste. Die maachen noch met. ${ }^{476}$

Auch wenn hier in einer überhöhenden Verallgemeinerung der Anschein erweckt wurde, daß die Kirmes die gesamte Dorfbevölkerung mobilisierte, hatte die Aussage doch für die breite Masse der Betroffenen ihre Berechtigung. Die Junggesellen hätten das unternehmerische Risiko der Kirmesveranstaltung kaum übernehmen können, wenn nur wenig Zuspruch aus dem Ort selbst gekommen wäre. ${ }^{477}$

Die Beliebtheit der Kirmes erwuchs für viele aus der Tatsache, daß hier die seltene Chance genutzt werden konnte, Bekannte wiederzusehen. Die Kirmes war damit nicht nur ein Treffpunkt, an dem neue Kontakte entstanden, sondern bestehende Beziehungen konnten auch gepflegt werden. ${ }^{478}$ Gleichzeitig boten die Festveranstaltungen qualitativ andere Möglichkeiten als beispielsweise der zufällige Kontakt auf der Straße, wie die Erfahrungen von Frau Pfeiffer zeigen:

Ich fänd's auch schade, wenn der Junggesellenverein aufgeben müßte.

Und zwar jetzt aus welchen Gründen?

Ehm. Ich würd das Fest vermissen, weil dann kann man wieder en bißjen engere Kontakte schließen zu Dorfmitbewohnern.

Während des Festes?

Während des Festes. Ja. So, spricht man mal auf der Straße, und das war's dann eigentlich.

Wie sieht das auf dem Fest aus, wenn Sie dahin gehen?

Ehm. Ja, irgendwie... Man spricht eher mal. Man spricht länger vielleicht. Doch - ehm - den Thomas Görtz, ich weiß nicht, ob Sie den kennen, mit dem hatte ich dann nähere Kontakte auch mal danach. Also ne gewisse Freundschaft hatte sich dann doch schon mal... das wäre sonst auch nie zustande gekommen. Man is lockerer vielleicht auf dem Fest. Da schließt man eher mal festere (was heißt festere... richtig festere Freundschaften haben wir im Dorf eigentlich gar nicht) Bekanntschaften. ${ }^{479}$

Die aus dem konkreten Braucherlebnis gewonnene Sicht verdeutlicht einmal mehr die Bedeutung, die dem Mailehen im Rahmen der sozialen Kontaktaufnahme zukam. Der Brauch ermöglichte das zwanglose Zusammentreffen und gesellige Beisammensein

475Über die Hintergründe der Aktionen der Maimütter siehe Kapitel 4.2.4.

${ }^{476}$ Herr Goltz (20/13/2a:354-429).

${ }^{477}$ Dazu auch Gruppengespräch II (49/33-37/2a:544-563).

${ }^{478}$ Vgl. etwa Frau Eder (21/14/1b:157-165), Frau Thiel (04/05/1b:688-695) und Frau Kruse (25/17/1b:594-619).

${ }^{479}$ Frau Pfeiffer (46/32/1a:529-540). 
in einer außergewöhnlich lockeren Atmosphäre. Dieser Zusammenhang wurde weiter oben bereits als wesentlich herausgestellt. Das Mailehen sollte gewährleisten, daß günstige Bedingungen als "Gerüst" - um den von Herrn Gerber eingebrachten Begriff zu gebrauchen - zur Erleichterung der Kommunikation für jeden verfügbar würden. Die Kontinuität der Mailehenausübung schaffte Verläßlichkeit, sie stabilisierte und förderte die soziale Interaktion. Aus dieser Perspektive erhellte Frau Weiß ihr Verständnis von der Brauchtradition:

Traditionen sind etwas, wo man sich dran halten kann, was schon immer war. Gut, das Brauchtum war immer - aber es is ja auch immer wieder etwas Neues in dem Moment. Die Kirmes ist ja jedes Jahr wieder wat Neues. [...]

Was bleibt dann noch von der Tradition übrig?

Indem sie regelmäßig gehalten wird, diese Kirmes und daß so bestimmte Dinge beibehalten werden. Beispielsweise ein Zelt, das ist wichtig in der heutigen Zeit, ne, weil dat gehört einfach so zur Kirmes. Viele haben ja schon zum Geburtstag en Zelt oder für ne Hochzeit oder wat. Also Zelt is immer wieder wat Besonderes - heutzutage noch, ne. En Zelt gehört auch schon mehr oder weniger zur Kirmes.

Obwohl es eigentlich ne neue Sache is...

...ja genau, mhm. Aber da siehste ja auch, daß das Brauchtum sich auch, daß das Brauchtum sich auch wandeln muß; also es darf nicht zu sehr an den Traditionen festkleben, sondern es muß sich auch en bißjen der Zeit anpassen. Ja, was dazugehört... Getränke, Tanz, Trinken und auch Essen gehört dazu, wie diese Frittenbuden oder Grillfleisch, Reibekuchentradition hier im Rheinland, ja, und Tanz. Ich glaube schon, wenn da so bestimmte Regeln beachtet werden und aktive Leute da sind, daß das Brauchtum dann erhalten bleibt. ${ }^{480}$

Folglich offenbarte sich das Mailehen als ein zeitlich und räumlich relativ festgefügter Rahmen, in dem die Bereitstellung von Getränken, Speisen und Tanzmusik, einen sicheren Platz einnahm. Weitere brauchspezifische Attribute wurden mit dem Merkmal der Austauschbarkeit verbunden. Betrachtet man insbesondere die variablen Ausprägungen aus dem Formenbestand des Mailehens, so stellte sich für den ein oder anderen Betroffenen die Frage nach ihrer speziellen Beschaffenheit. Waren diese dazu geeignet, den sozialen Sinn des Brauches zu unterstützen? Hieraus ergeben sich interessante Einsichten in die Fragilität des brauchbedingten Kommunikationsprozesses. Oben konnte man bereits eine Vorstellung davon bekommen, wie wichtig die Rolle des Alkohols in diesem Zusammenhang war. Er wurde als Mittel zur Senkung sozialer Hemmschwellen benannt. Gleichzeitig konnte aber ein allzu exzessives Trinken problematisch werden, wenn der Alkoholrausch die Einhaltung gewisser Verhaltens- und Kommunikationsregeln verhinderte. ${ }^{481}$

Die Lautstärke der Tanzmusik brachte bei Herrn Stoll einen ähnlichen Zwiespalt hervor:

${ }^{480}$ Frau Weiß (01/02/1b:351-410).

${ }^{481}$ Siehe hierzu die Ausführungen zu Pöbeleien bzw. zu sexueller Belästigung bei Herrn Franken (44/30/1a:307-382), Frau Kruse (25/17/1a:630-715) und Frau Randow (45/31/1a:388-397). 
Ja, nu muß ich dabeisaren, ich bin schon en paarmal in den letzten paar Jahren nachhaus jejangen, weil mir einfach die Musik zu laut war. Weil ich jesacht hab, dat is kein Kirmes, dat es nur Radau. Un wenn ich Kirmes hab, dann treff mer uns mit Bekannten oder ich lade soujar Leute Kirmes ein - also dat tun wa ja, abends komme'mer op de Kirmes und so weiter. Un ich bin met ihnen am sprechen un so weiter un die fangen an zu spielen, un dann is einfach nichts mehr möglich, et is einfach keine Unterhaltung mehr möglich. Da wird sich nur anjeschrieen. Dat is für mich kein Kirmes. [...] Das hab ich auch für die Kinder gesagt. Ich sachte: "Hört e'mal. Ihr braucht euch doch gar net ze wundere, daß es so viel Ehescheidungen jibt. Ihr lernt euch doch jar nicht kennen. Ihr lernt euch doch jar nich... Wenn ihr in den Diskos jeht, da versteht ihr nicht euer eijenes Wort." Sach ich: "Da sind sieben Jungen auf der Tanzfläch un drej Mädschjen, un da sin die sich am bewejen un sin doa dran." Sach ich: "Ihr könnt euch selber net mehr verstehn, un dann, wenn die Musig aufjehört hat, dann habt ihr ne schöne Konversation, ihr seid euch am Unterhalten, un", sach ich, "un da fängt de Musig an, un dann is wiedde alles... Un da saat'er noaher: 'Ö̈h, wo woare mer'ewens, ööh, dran stehn jebliewwe? Ööh, wie woar dat noch?"' Saat ich: "Wollt ihr sou e Jespräch aufrechterhalte?" Sare ich: "Wenn mir e Mädschje kennejeliert hatten, mir jingen in de Beethovenhall sunntachsnoamentachs ov de Tanztee oder in de Rheinhotel Dreesen un da täte mer uns e Deschelche söke, ${ }^{482}$ wo vier Persone oder grad zwei Persone dranjinge un dann ha'mir verzällt." Sare ich: "Un da tät de Fred König, der fing widde an ze spille mit singem Danzorschester. Un dann ha'mer ose Walzer, dann ha'mer ose Tango, dann ha'mer ose langsame Walzer..." Sare ich: "Doa ha'mer uns kennejeliert." Ich sare: "Durch das kleinjesprochene... durch dat kleine Wort, wat jesproche wiad, doadurch liert ihr eur Lök, ihr Partner kenne un net durch der Radau!"483

Der Zusammenhang von sozialer Kommunikation und Brauch gewinnt in dieser Passage einen bedeutenden zwischenmenschlichen und gesellschaftlichen Stellenwert. Aber abgesehen davon, wurde nochmals gezeigt, wie sehr eine gelungene Kirmesveranstaltung von einer angenehm lockeren Gesprächsatmosphäre abhing. So, wie der Alkohol zu dieser Stimmung seinen Beitrag leistete, trug auch die Tanzmusik dazu bei. Beide "Ingredienzien" bedurften allerdings einer ausgewogenen Dosierung.

Ein weiterer Aspekt zielte gewissermaßen auf eine Verfeinerung jener "Zutaten" ab, die das kommunikative Miteinander noch verstärkten. So wurde in der Runde ehemaliger Junggesellen die zunehmende Verflachung der musikalischen Animation beklagt:

Herr Fischer: Hät sich do jet jeändert dran, an de Musig?

Herr Keller: Ja, der Rhythmus hät sich vieleech schon net jeändert, äwwer sons hät sich doch nix jeändert.

Herr Kastner: Doch, würd ich schon saren. Dat hät sich insofern jeändert, wie zum Beispiel die Musik hier, die Musig is gut. Dat kan mer ja net saren [daß die schlecht sei]. Für diejenijen... dat kütt ja drov an, hät jeder en anderes Jespür. Nur die müßten in meinen Augen die Leute viel mehr einbinden. Dat han die vröher jemacht.

Herr Fischer: Dat han verschiedene och jemaat vröter in Verjangenheit. Düss Moal net. Is mer och ovjefalle. Dat stimmt.

482"e Deschelche söke": ein Tischchen suchen.

${ }^{483}$ Herr Stoll (12/10/3a:142-202). 
Herr Kastner: Die ham die Leute einjebunden. Dat heißt also, die haben och irjendwo moal jemaat, wat woar dat, so Art Spiele oder sou wat, ne, wo jeder och dann moal en Fremden in den Arm nahm un derartije Dinge. Dat fehlt bei der Musig hier.

Herr Fischer: Dat fehlt bei der düss Joar...

Herr Kastner: ...dat is och Fürschjoar sou jeweas.

Herr Fischer: Da kütt dat Temperament vun der... vun der Musig.

Herr Kastner: Ja, eben. Ne, dat heest also, do hast dann automatisch schon mal ne fremde Frau em Arm oder sou jet, ne, bei dieser Spielerei, weil do jewechselt wurde oder sons wat...

Herr Böhm: ...Polonaise-Stückchen wued och'ens avenszo jemaat, ne.

Herr Kastner: Richtig. Un hatts dann automatisch schon mal irjendwie der Kontakt dazu [zu den Fremden], ne, un dat fehlt heute. Dat is net gut, wat die maache. - Sons spielen die toll, dat muß ich sare, also jedenfalls etliche Saache. ${ }^{484}$

Von einer engagierten Musikkapelle war demzufolge mehr zu erwarten als die Wiedergabe gefälliger Tanzmusik. Sie sollte die Fähigkeit besitzen, das Publikum spielerisch in zwischenmenschliche Kontaktsituationen zu verwickeln.

Aber auch bei der Ausführung der Brauchhandlungen, die unmittelbar der Verantwortung der BrauchträgerInnen unterlagen, wurde nicht immer das volle Potential ausgeschöpft, um den sozialen Austausch zu fördern:

Herr Kastner: Joa, richtig, der Extradanz für de Jungjeselleverein. Äwwer der machen se hök och ni'mie.

Herr Keller: Maachen se ni'mie?

Herr Kastner: Nä. Han ich mich och... Dat woar nämich wat ich am Anfang sachte... Also ne Musig, die moaß dat maache.

Herr Böhm: Für die Jungjeselle un en Extradanz für die ehemalije Mitglieder des Jungjesellevereins, da häste at zwei Dänz...

Herr Keller: ...hernoah sitzen die Lök en halev Stunn doa un dürfen net danze. Dat es och nüüs.

Herr Kastner: Och, sou zwischendurch at moal, sare mer, dat mer dann en Extradanz für die Jungjeselle macht. Dat woar doch immer schön oder net, oder net.

Herr Keller: Ja, dat schon.

Mit den Mailehen dann?

Herr Kastner: Richtig.

Herr Hagen: Dohn die dat ne'mie?

Herr Kastner: Nänänä.

Herr Fischer: Un die sedzen och ni'mie wie mir vröter ...

Herr Kastner: ...an einem Disch.

Herr Fischer: ...an eenem Disch zesamme.

Herr Kastner: Is mir auch aufjefallen.

Herr Fischer: Do stonden dann Blome drov für die Maikönigin.

${ }^{484}$ Gruppengespräch II (49/33-37/2a:382-397). 
Herr Kastner: Richtig.

Herr Hagen: Mir soaßen all an däm gruße Disch.

Herr Keller: Doch, doch.

Aber nur am Sonntag.

Herr Fischer: Am Sonntag?

Herr Keller: Ja, ja.

Herr Fischer: Am Sonntag woar ich net doa.

Herr Keller: Noa'm Zuch han die och all zesammenjesesse.

Herr Kastner: Äwwer doch abends un so weiter ne'mehr.

Herr Keller: Nä, oamends net.

Herr Kastner: Joa, dat ham mir äwwer. Dat weeß ich äwwer, dat dat immer sou woar.

Aber trotzdem nur an dem einen Tag?

Herr Kastner: Nä, net den einen Tag, alle Tare.

Alle Tage?

Herr Kastner: Aber immer, ja. Un et wued och jede Ovend en Extradanz jespillt für die Jungjeselle un sou weiter, ne - mit Mailehn. Owwer hundertprozentig. ${ }^{485}$

Neben den Extratänzen für die Mailehenpaare an allen Kirmestagen war in den 1960er und 1970er Jahren das Zusammensitzen am langen Tisch ein weiteres wichtiges Brauchelement, das zur geselligen Unterhaltung der Mailehen untereinander beitrug. Das gemeinsame Essen der Brauchakteure im örtlichen Speiselokal war damals ebenso ein herausragendes kommunikatives Ereignis. Es gewann seine Intensität dadurch, daß die Junggesellen am ersten Mai durchs Dorf zogen, in die Häuser der Mailehen einkehrten und ihre Partnerinnen abholten:

Herr Hagen: Mir hatten äwwer och anjefange de iaschte Mai hinejoan.

Herr Keller: Ja, dat wird ja hök nu janz jroß jemaat.

Herr Hagen: Ja, dat... Äwwer nur bej de Maikönigin.

Herr Keller: Ja, ja...

Herr Hagen: ...großmächtig; do jingen mir äwwer doch sons vun...

Herr Keller: ...de janze Daach von morjens zehn bis ovends zehn.

Herr Hagen: ...vun eenem Huus, de janze Daach, vun einem en et andere. Do woare mer baal klinisch duut hee.

Mit allen Junggesellen?

Herr Hagen: Mit allen Junggesellen överall hin. [...] Wo jinge mir all hin?! Mir jingen joa bej jede Mailehen hin. Doa kräscht jede vürjestallt, hee.

Und wurd da auch "Maibutz" gerufen?

Herr Hagen: Joa, kommt drauf an, meistens, meistens. [...] Un dann ha'mer die affjehoalt, sare mer, die jesteijert wuade, un jingen doamet oamends in de Wiatschaft. [...]

${ }^{485}$ Gruppengespräch II (50/33-37/3b:415-431). 
Herr Keller: Mir sin joa teelwees och met denne, met de Mailien op andere Kirmesse jefahren.

Herr Hagen: Joa, dat schon, dat koam joa drov an. Dat woan jewisse Klübche. Wenn, soa moal, mir zwei hatten jetzt jet jesteijert und die zwei Mädchje woarn befreundet, ...

Herr Keller: ...ja, dann wued doch ovends dann noch ov annere Kirmesse jefahre.

Herr Hagen: ...dann joav dann noch woannerscht hinjefahre. ${ }^{486}$

Zwölf Stunden vergingen, bis die brauchtreibende Dorfjugend damals ihr Ziel, die Gaststätte, erreichte. Unterdessen hatte sie einen einzigartigen Einblick in viele der ortsansässigen Familien erhalten. Gleichzeitig fanden spontane Bewirtungen und ein reger innerdörflicher Austausch statt.

Jüngere DorfbewohnerInnen registrierten die eingeschränkten Kontaktmöglichkeiten im heutigen Brauchverlauf mit einigem Bedauern. Nachdem der Versteigerungsakt mit den Paarzuteilungen eine nähere Verbindung unter den Jugendlichen initiierte, brachte der Brauch letztendlich kaum Möglichkeiten hervor, die rituell bedingten Beziehungen zu intensivieren. So bemängelte Frau Gebhard diesen Zustand:

Dat is eigentlich nur halt der Sonntagnachmittag, wo mer wat zusammen machen muß. Dat find ich auch en bißchen schade, weil danach verläuft sich dat alles wieder. ${ }^{487}$

Hieraus ergab sich der Wunsch nach einer reicheren Formensprache des Brauches, welche die soziale Interaktion fördern könnte. Demgegenüber stand die einschlägige Erfahrung hauptverantwortlicher Brauchorganisatoren. Deren Möglichkeiten, die potentiellen BrauchträgerInnen $\mathrm{zu}$ animieren und zu aktivieren, waren begrenzt. Aufgrund des zurückgehenden Interesses an Kommabenden und ähnlichen Aktivitäten auf breiter Front ging ein Teil des mailehenbedingten Formenrepertoires allmählich verloren (siehe Kapitel 4.2.4).

\section{Beteiligungswillen}

Die persönliche Beteiligung am Brauchgeschehen war somit neben dem zeichenhaften Aufforderungscharakter des Mailehens von entscheidender Relevanz für das Zustandekommen eines sozialen Austauschs. Eine freie Entscheidung zum Dabeisein und Mithelfen erschien Herrn Goltz als wesentlicher innerer Antrieb:

Jetzt noch mal zu den Zugezogenen. Du hattest ja da so en Beispiel, wo dat ganz gut geklappt hat, wo einer im Verein auch mitgemacht hat. Wie siehst Du dat jetz so generell so zum Brauch, zur Kirmes, zu den Junggesellen...

...dat is janz eenfach: wenn doa eener Loast un Interesse daran hat, der meet doa jern met; un wenn eene kein Interesse daran hät, der denkt in Anführungsstriche: "Loss mich en Rooh, un ich han doa keen Loast dran, un ich joan leewer en de Disko oder ich joan Angele" oder wäs de Deuwel wat en mät, verstehst. Doadran liegt dat. Jedem dat Interesse. Wenn eene Loast hat, is et jot, verstehste. ${ }^{488}$

${ }^{486}$ Gruppengespräch II (49/33-37/2b:506-573).

${ }^{487}$ Frau Gebhard (41/28/1a:192-195).

${ }^{488}$ Herr Goltz (20/13/2a:460-470). 
Die Lust und das Interesse mußten demnach der Beteiligung am Brauch vorausgehen. Damit wurde der Stellenwert persönlicher Neigungen deutlich herausgestrichen. Unter den Befragten äußerten manche an dieser Stelle ihre Bedenken. So wurden beispielsweise Zweifel am brauchbedingten ethischen oder intellektuellen Anspruchsniveau spürbar. In diesen Momenten rekurrierten die GesprächspartnerInnen häufig auf hohen Alkoholkonsum, verhaltensauffällige Derbheiten und belanglose Gesprächsthemen, an denen sie keinerlei Interesse hegten. ${ }^{489}$

In anderen Fällen zeigte sich, daß allein die affirmative Haltung gegenüber den Brauchaktivitäten nicht ausreichte, um den sozialen Austausch zu garantieren. In einem Abschnitt zur Oevericher Mailehengeschichte (4.2.1) kam Frau Theisen zu Wort, deren Leben stark von den beruflichen und familiären Erfordernissen eingegrenzt wurde. Aus Zeitmangel war ihr eine aktive Beteiligung am Mailehen verwehrt, wie die entsprechende Stelle noch einmal unterstreicht:

Siste, wie Ende der 40er, da war die Regina, der Peter klein, ne un jet, un jeboren. Nä, da sin mir jarnet doa, ja überhaupt jarnet doazo kunn, für noa Oefferich ze joan, ne. Heut sinn dat die "Pampers". Doa hatte mir ken Zitt für. Mir hann noch schön Windeln jewaschen, ne. 490

Von anderer Qualität als alle hier genannten Begleitumstände, die das Zustandekommen eines zwischenmenschlichen Kontakts im Rahmen der Brauchausübung unterstützten, war das Moment der sozialen Reziprozität. In der unten wiedergegebenen Gesprächspassage läßt sich im Detail verfolgen, daß das Interesse für das Brauchgeschehen, die zur Verfügung stehende Freizeit und die ersten Integrationsversuche nicht unmittelbar in eine gelungene Interaktion münden mußten:

Um nochmal auf den Mailehenbrauch zurückzukommen: Mit sechzehn war ja dann das erste Mal...

...ja, genau.

War das neu für Sie oder...

Das war ganz neu, kannte ich gar nicht so. [...] Einmal hab ich den [Maien] dann gestellt bekommen.

Wie war das dann? Ich mein, wenn man den Brauch überhaupt nicht kennt...

Ja, war komisch. Ja, die Mama sagte mir dann irgendwie am anderen Tag: "Ja, da waren die Junggesellen, die ham dir en Baum gestellt." Ich dachte: "Wie?! Quatsch!" Sagte ich: "Wieso sollen mir die Jungs en Baum stellen?" Ja, bin ich raus gucken gegangen - ja, stand das Ding da vor der Tür. Ja, hab ich mir nix weiter bei gedacht. Ich bin auch nicht durchs Dorf gerannt "Oh, ich hab en Maibaum. Hier, ich bin toll!" Nä, war irgendwie komisch. Ja, un irgendwann hat man dann über drei, vier Ecken dann rausgekriegt, wer einem den Baum dann da hingestellt hat, einer von den Junggesellen, der mich dann da praktisch gesteigert hat und der mir den Baum gesetzt hat, ne. War irgendwie komisch. Aber daß jetzt irgendwie einer gesagt hätt: "Ja hier, Marina, das is so un so und unser Brauch eben halt is: wir ersteigern eben halt die

${ }^{489}$ Hierzu Herr Selm (42/29/1a:347-359) und Frau Randow (45/31/1a:388-397).

${ }^{490}$ Frau Theisen (06/06/1a: 415-424). 
Mailehen und derjenige, der dich ersteigert hat, der setzt dir eben halt auch'n Baum." [...] Das war irgendwie komisch, ganz was Neues. So etwas kannte ich überhaupt nicht. [...]

Und Ihren Ersteigerer ham Sie nicht kennengelernt?

Nee. Neenee.

Der hat sich nicht zu erkennen gegeben?

Neenee, der hat sich nicht zu erkennen gegeben. So ungefähr wußt ich's, aber...-

Aber er selber hat nicht gesagt: "So, hier ich hab dich ersteigert un..."

...neenee, hat er nicht.

Weil - es is ja auch so, daß beim Umzug die Paare ja durchs Dorf ziehn?

Mhm, ja, die Ersteigerten praktisch - die Jungs, die dann die Mailehen ersteigert ham. Also da bin ich eigentlich nie mitgegangen. [...] War irgendwie komisch. Hab mich auch nicht, ehrlich gesagt, auch nicht besonders wohl da in der Gemeinschaft gefühlt, ne, immer irgenwie so als Außenseiter. Weiß nich.

Also diese Erinnerung is recht stark.

Jaja. Is... Ja, doch. Ich sags so, wie's is, was soll ich Ihnen jetzt irgendwie beschönigen, was nicht da war. Das war als Kind schon so und das hat sich bis ins Jugendalter geprägt. Und ich mein, wenn's einem irgendwo nicht gefällt in der Jugendgemeinschaft oder mit den Junggesellen, dann geht mer automatisch nicht mehr hin, ne. Und wie gesagt, als Kind kam ich mir wie so ne Notlösung vor, und irgendwann hab ich das schnell drangegeben. Dann gehe ich auch eigentlich nicht später mit den Jugendlichen und Erwachsenen auch nicht mehr weg. Das ist für mich eigentlich dann klar, daß ich dann da in der Richtung keinerlei Interessen mehr habe, ne. Ich mein, für so was war ich mir eigentlich früher un heute noch zu schade, als Notlösung irgendwie zu dienen - so.

Und war das irgendwie dann doch - ich versuch, mich da en bißjen reinzuversetzen - irgendwie ne schwierige Entscheidung zu sagen: "So, okay, ich geb das auf, ich entscheide mich für'n anderen Freundeskreis"?

Nö, überhaupt nicht. Nee, gar nicht, weil ich hatte ja keinerlei Bezug hier oben. Es wär ja was anderes gewesen, wenn ich jetzt hier mit den Jugendlichen nen guten Kontakt gehabt hätte, mit denen abends weggegangen wär, wenn wir zusammen weggefahrn wärn und, wie gesagt im Mai, ich hätte, wat weiß ich, jeden Mai vielleicht mal en Maibaum gekriegt un wär in der Gemeinschaft so drin, das wär vielleicht was ganz anderes; aber so... Nö, keinerlei Schwierigkeiten. [...]

Und so die Vorstellung, einmal - weil man das ja dann wahrscheinlich jedes Jahr auch irgendwie mitkriegt...

...ach so, als Maikönigin und dann irgendwie dazustehen?

Ja, genau.

Hatte ich eigentlich keine Ambitionen, jetzt als Maikönigin. Ich mein, gut, es is schön: dann fahren die mit der Kutsche durch die Gegend und'n Riesentamtam und so, aber... Nö, hatte ich eigentlich...

...so, auch aus der früheren Sicht, als Sie jünger waren?

Ja. Nö, ich fand das irgendwie en bisjen... Es war für mich immer wie so'n Theater, wie so'n Theaterstück. Dann ziehn die hier durchs Dorf. Das war für mich nix. Ich kannte das nicht un war für mich irgendwie normal... Keinerlei irgendwie Interesse dazu gehabt, jetzt irgendwie Maikönigin zu werden. Nee. ${ }^{491}$

${ }^{491}$ Frau Jansen (52/38/1a:399-517). 
Das Beispiel zeigt, daß ein Brauch, der im Grunde den sozialen Austausch untereinander fördern sollte, seine kommunikative Bedeutung vollständig einbüßen konnte, wenn die Chancen einer Eingliederung lediglich vorgespielt wurden und damit auch nur fiktiv vorhanden waren. In dem von Frau Jansen selbst benutzten Bild vom Theater wurde dies besonders anschaulich. Obwohl der Brauch ihr eine aktive Rolle als Mailehen zuwies, konnte eine Rollenübernahme nicht stattfinden, da es aus ihrer Sicht keine wirkliche Gelegenheit zum aktiven Austausch gab. Ihre Situation als verhinderte Brauchträgerin bestätigte die Diskrepanz, die zwischen ihr als Zugezogener und den Alteingesessenen als Brauchausübende lag. Da die rituell bedingten, kommunikativen Beteiligungsmöglichkeiten blockiert waren, konnte das Mailehen auch nicht zu einer sozialen Annäherung führen. Dagegen kam es zu einer wiederholten Bestätigung der vorhandenen Verständigungsbarrieren. Hierzu Frau Jansen:

Ja, man hat irgendwie gemerkt so, daß ich irgenwie dann doch nicht dazugehöre - so die Abgrenzung. Ich war zwar mit den Jugendlichen alle irgendwie so bekannt, und ich kannte die auch so ziemlich alle, aber ich konnte keinen Bezug zu den Leuten jetzt finden, ne. [...] Ich weiß nicht, hat mir irgendwie nicht so gefallen. Ich mein, ich fand das zwar lieb, daß die mich dann eingeladen haben und daß die mir dann en Maibaum da gesetzt haben, ne, aber ich weiß nicht, ich konnt da... man hat da irgenwie immer zu spüren gekriegt: "Man is kein richtiger Oevericher, ne Zugezogene." Hat man irgendwie immer zu spüren gekriegt. Das is schon immer so gewesen. 492

Die Äußerungen zeigen, wie das im Ansatz vorhandene Engagement ins Leere führen konnte, wenn es von den beteiligten InteraktionspartnerInnen nicht positiv wahrgenommen wurde und sich in einem weiteren Schritt zu einem gegenseitigen Interesse an den handelnden Subjekten kommunikativ ausbaute. Die sozial integrative Potenz des Mailehens wurde also nur in dem Maße wirksam, wie die handelnden Personen bereit waren, aufeinander zuzugehen. Soziale Kommunikation basierte wesentlich auf jener wechselseitigen Öffnung und Anteilnahme. Wenn das Mailehen ein vitales Miteinander unter allen Beteiligten ermöglichen sollte, konnte von dieser Reziprozität nicht abgesehen werden.

\section{Vermittlung}

Offensichtlich schien ein Hemmnis für den sozialen Austausch darin zu liegen, daß es für Neulinge, wie Herrn Nolden, schwer war, sich in bereits vorhandene Kommunikationsstrukturen einzubringen:

Wir sind ja "Ausländer", so sagt man. Ich meine, die [Alteingesessenen] wissen, wer ich bin un: "Der määt un der tut..." Aber Einheimischer sind sie nicht, ne. Sie bleiben... Ja, die sagen, wir sollen auf sie zukommen, aber gehen sie doch mal irjendwohin und saren: "Ja, wie is et dann, wat maat..." ne. Also et gibt Leut, die können das. Das muß man auch können. Un dann: Jetzt weiß ich net, wie nimmt der das auf, ne, wenn se dahinkommen, ne.

Kann ja auch aufdringlich...

${ }^{492}$ Frau Jansen (52/38/1a:227-252). 
...ja, kann ja auch meinen, du wärst aufdringlich. ${ }^{493}$

Schon öfter war von der psychosozialen Barriere die Rede, wenn man sich vor die Aufgabe gestellt sah, Zugang zu einem bestehenden Gruppenverband zu erlangen. Dazu folgte dann meistens ein Hinweis auf die entscheidende Hilfeleistung eines Vermittlers. In der Regel vertrauten sich die Betreffenden einem Dorfbewohner an, der bereits auf den Brauch und dessen sozialen Sinn eingeschworenen worden war. Der Vermittler stellte somit ein Bindeglied dar zwischen den Brauchunerfahrenen und -erfahrenen. Durch seine Existenz gewannen beide Parteien eine relativ stabile Vertrauensgrundlage: Die Neulinge wußten, daß sie in kritischen Situationen nicht ganz auf sich alleine gestellt waren. Zugleich unterlag der längst formierte Kreis der Brauchtreibenden nicht einem ständigen Beobachtungs- und Rechtfertigungsdruck von außen, den die rituell legitimierten Verhaltensauffälligkeiten provozieren konnten. Das Aufeinanderzugehen war am ehesten unter der gewissermaßen treuhänderischen Aufsicht eines Dritten möglich, welche die aufeinanderstoßenden, möglicherweise kontroversen Interessen in den Hintergrund treten ließ. Insofern war auch der Wahrung der persönlichen Integrität gedient. Die Notwendigkeit des Vermittlers stand dabei keineswegs in einem direkten Verhältnis zum lokalen Status des Brauchunerfahrenen. Wie in vorangegangenen Abschnitten ausführlich dargelegt (4.4.4.2/3), berichteten sowohl Zugezogene als auch Einheimische von der Bedeutsamkeit vertrauter Personen im Prozeß der sozialen Einbindung ins Brauchgeschehen.

\section{Objektive Affinität}

Vielfach wurde die Überzeugung laut, daß einer stabilen Bindung an den Ort und den Kreis der Alteingesessenen eine gewichtige Bedeutung im sozialen Austausch beizumessen sei. Lokale Verwurzelung und Verwandtschaftsbeziehungen würden sich durchaus positiv auf eine soziale Eingliederung durch das Mailehen auswirken. Dagegen würde mit dem Attribut der Ortsfremdheit die Gefahr von gemeinschaftsstörenden und -zerstörenden Kräften assoziiert. Nicht nur, daß klassifizierende Begriffe wie "Ausländer", "Immis" und "echter Oeffericher" zur Bezeichnung des residentiellen Status kursierten, sondern auch die in der Interaktion liegende Ausgrenzung schuf Probleme für manchen Gesprächspartner. Der soziale Sinn des Mailehens wurde deshalb an dieser Stelle fragwürdig. Die Erlebnisse von Frau Jansen sprechen für diese Sichtweise:

Ich hab erst einmal en Maibaum gekriegt - wahrscheinlich auch, weil ich mich auch nie so großartig mit den Leuten... hier so mit den Jugend... so früher ham wir zwar so zusammen gespielt, aber so ne richtig enge Freundschaft hab ich eigentlich mit den anderen nie so gehabt. So gespielt ham'wir früher miteinander schon, aber waren auch oft Keilereien, wo wir uns gestritten ham, was eigentlich auch normal is, so ziemlich, ne. Aber das mir jetzt irgendwie ne engere Freundschaft... war eigentlich nie, weil die waren ja alteingesessen hier, die ham schon

${ }^{493}$ Herr Nolden (37/22/1a:468-479). 
zusammen gewohnt, sind praktisch miteinander aufgewachsen. Und wir kamen vor Jahren hierhin, und ich war dann wie so en Eindringling, ne. Das wechselte dann meistens: wenn die einen Krach hatten, dann mit mir gespielt, ja, und dann wieder so umgekehrt. Ja, und Maibräuche - großartig? Ja, wie gesagt, ein einziges Mal. ${ }^{494}$

Der lokale Status vermittelte Frau Jansen das bleibende Gefühl einer Außenstehenden. Ihren Kontakt zu der gewachsenen, homogenen Gruppierung der Alteingesessenen sah sie daher als nicht erwünscht und aussichtslos. Unter diesen Voraussetzungen konnte sich die soziale Wirkkraft des Mailehens nicht entfalten. Die Wohndauer und mehr noch die lokale Herkunft stellen auf diese Weise Merkmale dar, die von außen objektiv an die Betroffenen herangetragen wurden und die die Ausgangsposition innerhalb des sozialen Austauschs mitbestimmt haben. Besonders aussichtslos erschien zum Beispiel die Aufnahme in den Kreis der BrauchträgerInnen, wenn die NeubürgerInnen aus der Stadt zugezogen waren; dazu die Angaben von Herrn Winzer:

Eben meintest Du, es gäbe welche [Jugendliche], die nicht reingegangen sind [in den Junggesellenverein]?

Mhm. Ja, das sind oft so Leute, die vorher auch nix mit'm Dorf zu tun hatten. Ich hab jetzt en ziemlich großen Freundeskreis schon vorher im Dorf gehabt. Hier meine Eltern kommen ja auch hier aus'm Dorf. Und dann sind das eben meistens Leute, die entweder vor paar... vor zwanzig Jahren oder so zugezogen sind oder gerade zugezogen und dann gar keine Bekannten im Dorf haben oder vielleicht gar kein Interesse haben am Junggesellenverein. Vielleicht komme se auch noch aus der Stadt oder so was, und dann is da meistens gar nix los. Das sind nämlich jetzt die, die dieses Jahr oder letztes Jahr zum Teil auch reinkommen könnten. Die ha'mer nämlich gefragt, und die hatten absolut kein Interesse. Die kannte auch keiner vorher, wer das überhaupt war. Den Namen kannte keiner. Die sieht man vielleicht en paar Mal, aber das war's dann vielleicht auch schon.

Also ihr habt praktisch nur vermutet, daß die jetzt im richtigen Alter sein könnten, ihr kanntet die gar nicht und seid dann auf die zugegangen: "Hier, habt ihr schon mal was vom Junggesellenverein gehört?"

Ja, aber das hab ich gar nicht so mitbekommen. Das hat alles der Präsident dann gemacht. Der hat die dann gefragt, ob sie wollen oder nicht, mal erklärt, was da so läuft. Das war außerdem nur bei drei Leuten. Ja, und dann kam da ne Absage.

Ham die das erklärt, warum nicht?

Weiß ich gar nicht. Er hat uns nur gesagt, die kommen nicht rein und das war's.

Und das waren ausschließlich Zugezogene?

Mhm. Einer ist aus der ehemaligen DDR rübbergekommen und der andere... ja, das sind dann immer so Leute, die waren dann früher schon so isoliert. Die ham keinen Freundeskreis im Dorf, nur in anderen Dörfern oder wo sie dann gerade sin, aber mit dem Dorf haben die gar nix zu tun.

Aber Du sagtest ja eigentlich, daß Du ja auch nicht so'n Kontakt hattest zu den Junggesellen...

...zu den Junggesellen nicht, aber das ist wieder die Sache, wenn man en Freundeskreis hat und dann kommt man mit Freunden gleichzeitig rein, als wenn...-

Als wenn man alleine reingeht...

${ }^{494}$ Frau Jansen (52/38/1a:103-129). 
...ja, genau. Und darum braucht man so viele aus dem Junggesellenverein gar nicht zu kennen. Das gibt dann meistens den Ausschlag, wenn man mit Freunden da reingeht. Aber ich würd sagen, wenn ich jetzt auch alleine gewesen wär, ich wär reingegangen. Das is eben so die Sache: es muß alles... Man muß meistens hier aufgewachsen sein, Freunde im Dorf haben, Verwandtschaft und so was, dann is das en Muß, dann verpaßt man was, wenn man nicht reingeht. ${ }^{495}$

Hier wurde der Eindruck nochmals bestätigt, daß eine erfolgreiche Kontaktaufnahme zwischen Einheimischen und Zugezogenen keine Selbstverständlichkeit war. Das Vorhandensein unterschiedlicher Interessen und Freundeskreise würde die Aussichten auf Kontakte begrenzen. Für den Eintritt in den Junggesellenverein seien lokale Herkunft, verwandtschaftliche und freundschaftliche Beziehungen zu Alteingesessenen durchaus von Bedeutung gewesen. Wenn diese Voraussetzungen erfüllt waren und das Mindestalter der Brauchausübenden erreicht war, dann stand der Übernahme der Brauchträgerrolle kaum noch etwas entgegen. Dementsprechend sahen einige der Befragten diese Entwicklung als einen natürlichen Prozeß an. Aufgrund der augenscheinlichen äußeren Affinität war eine Entscheidung darüber, ob man sich am Mailehen beteiligen wolle, bereits obsolet: man wuchs in das Brauchgeschehen hinein, so Frau Thiel:

\section{Wolltest Du Maikönigin werden?}

Also gewollt hab ich's da auch noch... Also "wollen"? Es is halt einfach auf mich zugekommen, aber...-

Aber Du hättest jetzt auch nie gesagt: "Nee, das is mir jetzt zu viel. Ich ruf den Präsidenten an und sag..."

...nä, auf keinen... Das nich. So extrem... ganz bestimmt nicht. Nee.

Das kam Dir überhaupt nicht in den Sinn?

Nä. Weil ich mich ja auch mit den Junggesellen oder halt die, die in meinem Alter waren, ja auch immer gut verstanden hab und so.

Und die waren da drin.

$\mathrm{Ja}$, und die waren im Junggesellenverein un meine Geschwister waren drin. Das war ja immer so. Man is da halt einfach mit reingewachsen und das war halt ganz normal. Das fängt auch jetzt erst an, daß halt viele Mailehen sagen: "Ich möchte nicht." Früher hab ich's halt nicht so gemerkt. Es wird immer vereinzelt welche gegeben haben. Das sind dann aber auch die, die sich schon immer abgekapselt haben vom Dorf, ne. Das wird aber jetzt immer mehr, daß die Leute sich halt abkapseln vom Dorf, weil es ja auch viel mehr Möglichkeiten gibt, andere Dinge zu tun. Deswegen gehen ja auch so Bräuche halt kaputt, weil viel zu viele Angebote da sind.

Was denkste, was die jetzt mehr haben oder was Du an Angeboten weniger hattest?

Tja, die sind ja damit glücklich geworden, und ich also fand das toll. - Das kann ich jetzt nicht so sagen. Also ich war damit zufrieden, so wie's war. Also mir hatten immer sehr viel Spaß. Es wird jedes Jahr... Also es is wirklich ne tolle Erinnerung. Tja. Das müssen die... Die haben dann ja auch en ganz anderen Bekanntenkreis, sind vielleicht auch auf ne andere Schule gegangen, haben ganz andere Ansprüche und so, sind vielleicht selber Zugezogen, daß die Eltern nicht so Kontakt haben mit den anderen. Bei uns war das immer... Wir haben immer alle

${ }^{495}$ Herr Winzer (07/07/1a:194-238). 
zusammen gespielt. Entweder waren wir immer alle in Oeverich auf'm Spielplatz oder wir waren in Oeverich auf'm Bolzplatz. Wir waren immer alle zusammen, und dadurch kam das, is man da reingewachsen, war das was ganz Normales. 496

Das äußere Kennzeichen der lokalen Herkunft fand zwar an dieser Stelle auch Berücksichtigung, aber Frau Thiel räumte ein, daß der soziale Austausch zunehmend durch weitere Faktoren beeinflußt wurde. Wenn es zu ihrer aktiven Zeit kaum auffiel, daß sich einige Dorfjugendliche vom Mailehen abwendeten, so schien in jüngerer Zeit die lokale Herkunft kaum noch als Garant für das geforderte Engagement in der Brauchausübung. Der Einbindung ins lokale Geschehen würde insbesondere auch ein vitales Interesse an sozialen Beziehungen im Ort vorausgehen. Die Zersplitterung von Altersgruppen wurde in diesem Zusammenhang als Problem angesehen. War die Dorfjugend in den Grundschulklassen noch vereint, so trennten sich die Wege oft bei der Auswahl der weiterführenden Schulzweige.497 Auch die individuelle Beeinflussung durch die verschiedenen Möglichkeiten der Freizeitbeschäftigung als Auslöser für den Verlust des sozialen Zusammenhalts hat Frau Thiel in dem Gespräch anklingen lassen.

\section{Subjektive Affinität}

Die Tatsache, daß individuelle Entscheidungen über den Besuch einer bestimmten Schule, über die Wahl des eigenen Freundeskreises und über die bevorzugte Freizeitbeschäftigung für den Grad der Beteiligung am Mailehen von Bedeutung waren, zeigt, daß hier neben objektiven auch subjektive Affinitätsmerkmale wirksam waren. Eine Bestätigung über die nötige innerlichen Orientierung am Ziel der Begegnung und sozialen Kommunikation im Brauch kommt in den folgenden Äußerungen von Frau Thiel zum Ausdruck:

Also es is wie gesagt so, es ganze Jahr über man sieht sich mal und sagt: "Hallo!" aber man is halt nie so intensiv zusammen [mit den anderen Jugendlichen aus dem Ort]. Und dann is Kirmes und dann is man wieder zusammen, und dann halt is Kirmes vorbei und dann sind die Interessen wieder verschieden. Aber es trifft sich halt Kirmes - is immer wieder toll, weil mer auch weiß, da sind die Leute, die man vielleicht schon lang nicht mehr gesehen hat oder so. Das is immer schön. ${ }^{498}$

Obwohl jeder im Alltag seine eigenen Wege ging, wurden die unterschiedlichen Interessen während der Kirmeszeit bewußt unterdrückt. Das Zusammentreffen und der soziale Austausch wurde möglich, weil die Beteiligten sich zeitweilig füreinander öffneten. Diese innere Öffnung hatte das Ziel, eine gemeinsame Affinität unter den Beteiligten herzustellen und tauchte in anderen Zusammenhängen immer wieder auf. Die Eindrücke von Frau Eder, daß man sich zu Beginn der Einstiegsphase innerlich dem Brauch verschlossen habe, konnten einige GesprächspartnerInnen teilen. Durch

\footnotetext{
${ }^{496}$ Frau Thiel (04/05/1b:256-294).

${ }^{497}$ Vgl. oben Kapitel 4.4.4.1.

${ }^{498}$ Frau Thiel (04/05/1b:684-696).
} 
diese Barriere war es vielen zunächst nicht möglich, das kommunikative Potential des Mailehens zu erschließen:

Und vorher [vor der Mailehenschaft] hat Dich das gar nicht interessiert? Als so Vierzehn-, Fünfzehnjährige warst Du da überhaupt schon mal auf der Kirmes oder so?

Ja, schon vielleicht mal so abends kurz, aber auch net oft. Das hat mich irgendwie auch nie interessiert, so die Leute un so - ich kannte die auch alle nicht. Ja, und jetzt komm ich halt mit denen eigentlich total gut aus un so. Das macht dann auch irgendwie Spaß, wenn man dann die Leute dann kennt und sich mit denen dann irgendwie zu amüsieren. ${ }^{499}$

Mit sechzehn Jahren erfuhr Frau Eder, obwohl sie die sozialen Verhältnisse in Oeverich relativ gut kannte, durch den Brauch eine qualitativ andersartige Integration in das soziale Dorfgefüge. Entscheidend für das Gelingen dieser neuartigen Einbindung war nicht alleine das Vorhandensein des Brauches und die Absolvierung des kurzen Auftritts beim Festumzug der Mailehenpaare, sondern vor allem die Veränderung der inneren Einstellung:

Die Vierzehn-, Fünfzehnjährigen, die denken: "Komm, is Scheiße. Komm, brauchen wir net hinzugehen. Is sowieso nur im Dorf." Vielleicht so ab sechzehn wird's erst spannend. ${ }^{500}$

Der konstatierte Gesinnungswandel muß allerdings nicht auf das Alter festgelegt werden. Die Umstände für eine plötzliche Öffnung konnte auch mit zufälligen Ereignissen zusammenhängen. So berichtete Frau Pfeiffer, daß sie als Zugezogene zwar schon früh in das Brauchgeschehen hineingezogen wurde, ihr aber lange Zeit die tieferen Zusammenhänge verborgen blieben. Wenn sie ersteigert worden war, sah sie sich lediglich dazu aufgefordert, den Umzug mitzumachen. Da weder großes Interesse von ihr ausging, den Brauchablauf im Detail kennenzulernen, noch von den eingeschworenen BrauchträgerInnen die brauchbedingten Interaktionsmöglichkeiten deutlicher gemacht wurden, mußte der soziale Sinn des Mailehens vorerst im Verborgenen bleiben:

Bis zum dritten Mal wußte ich also gar nicht, daß das [Mailehen] mit Ersteigern und so was überhaupt etwas zu tun hat. Das hat mir erst der Thomas [Maikönig] erklärt und deswegen hatt' ich das gar nicht so ernstgenommen. ${ }^{501}$

Nachdem Frau Pfeiffer das Amt der Maikönigin zugefallen war, änderte sich die innere Einstellung zum Brauch und das Verhältnis zu den BrauchakteurInnen grundlegend. Mit diesem Moment ergriff sie die Gelegenheit, eingehendere Kontakte zur Dorfbevölkerung aufzubauen, die für sie bis in die Gegenwart von Bedeutung blieben:

\footnotetext{
${ }^{499}$ Frau Eder (21/14/1a:196-205).

${ }^{500}$ Frau Eder (21/14/1a:553-559).

${ }^{501}$ Frau Pfeiffer (46/32/1a:84-91).
} 
Bei den Junggesellen hat man den Eindruck, die freuen sich das ganze Jahr drauf. Am Montag sind se dann zwar auch wieder froh, wenn se das Zelt wieder abbauen können, aber ich glaube, denen macht das auch schon Spaß.

Und sonst - wie beurteilen Sie das sonst so fürs Dorf?

Ja, da hab ich jetzt zwei Sichten: Früher, hat mich das nicht interessiert groß, da hab ich aber auch nicht gewußt, worum es geht.

Es wär für Sie kein Verlust gewesen...

...wär für mich... Heute ja, aber damals nicht. Ich weiß auch nicht, wie es überhaupt mit den Dazugezogenen ist, ob die dadurch schneller integriert werden durch dieses Fest. Höchstens, wenn man halt gesteigert wird und wenn man es dann mitmacht, ne. Oder wenn man in der Nähe des Festzelts vielleicht wohnt, daß man dann eher mal hingeht. Wir waren ja immer weitab; das war ja immer am anderen Ende des Dorfes. Haben wir immer nur die Musik gehört, die Bässe.

Die kamen noch bis hierher?

$\mathrm{Ja}$ - mitten in der Nacht noch. Mein Mann wußte dann auch immer: "Jetzt bald kommt sie nach Hause, die Musik wird leiser." Ja, ich war dann auch immer bis zum Ende dabei. [...] Man ist bekannter geworden dadurch - im ganzen Dorf. Mich kannten danach sehr viele, obwohl ich se auch noch nicht so kannte. Aber man kam öfter ins Gespräch mit jemandem. Doch - man ist schon integrierter seitdem. Wir sind integrierter, nicht nur ich, sondern meine ganze Familie; und das ist auch schön. Ich möcht auch nicht mehr weg aus dem Ort. ${ }^{502}$

Das Mailehen führte in diesem Fall zur geglückten sozialen Einbindung von Dorfangehörigen, weil es eine kommunikativ hochwirksame Dimension zwischen bisher getrennten Personenkreisen eröffnete. Der Brauch erlaubte eine Begegnung auf Augenhöhe, bei der die üblichen Abgrenzungspotentiale abgebaut werden konnten. Der lokale Status, die soziale Herkunft, die geringe Vertrautheit spielte in dem Augenblick keine Rolle mehr als klar war, daß man gemeinsame Interessen verfolgte. Frau Pfeiffer erinnerte sich an die folgende Situation:

Anfangs dachte ich mal, was ich eben ganz kurz ansprach, daß man sich vorkommt, man is jetzt zum Spaß der anderen das Maikönigspaar - aber nicht nur die Frau, sondern auch der Mann so aus Jux und Dollerei für die anderen, ne. Aber das hat sich dann auch direkt gegeben, das Gefühl eigentlich, weil es einem selber auch Spaß gemacht hat. ${ }^{503}$

Die gleichberechtigte Beziehung untereinander, der reflexive Austausch und die Orientierung an Handlungszielen, die nicht mit den Interessen anderer KommunikationspartnerInnen kollidierten, erscheinen in den Ausführungen von Frau Pfeiffer als wesentliche Kriterien bei der erfolgreichen Modellierung der zwischenmenschlichen Beziehungen. Demgegenüber stand die Gefahr des Abbruchs der brauchbedingten Kontakte, wenn die Beteiligten auf die Einhaltung dieser basalen Reziprozitätsprinzipien zu wenig achteten. Dies wird im Zusammenhang mit den Erlebnissen von Frau Jansen klar:

${ }^{502}$ Frau Pfeiffer (46/32/1a:480-523 vgl. auch 1b:272-276).

${ }^{503}$ Frau Pfeiffer (46/32/1b:549-557). 
Also wie gesagt, ich hab nur einmal einen [Maien] gekriegt. Da hat sich wahrscheinlich einer erbarmt (lacht herzhaft) - keine Ahnung. (lacht) [...] Ich glaub, ich war da so sechzehn. Meine Mutter... dat war total lustig. Da kann ich heut noch drüber lachen: Irgendwie nachts Remydemy und ich war mit meiner Freundin noch unterwegs und ich kam nachts spät Nachhause. Un - meine Mutter ging dann raus und die waren den [Maien] dann wohl am Festmachen, also an der Dachrinne irgendwie. Und meine Mutter geht dann raus: "Was machen sie denn hier?!" weil total schlaftrunken, ne. Weil die es... die hat en leichten Schlaf. Die hört das direkt, wenn hier irgendwas is. Und dann ham die gesagt: "Ja, wir kommen von der Baumschule. Wir wollen den Baum hier bringen" ne. Das war irgendwie total komisch. Ich mein, gut, ja dann kamen die Jugendlichen nachher an un ham gesagt: "Komm mit!" Dann nach Oeverich Essengehen un so. [...] Ja, un dann bin ich da mit hin un, wie ich Ihnen das vorher schon gesagt hatte, das hat man immer irgendwie zu spüren gekriegt, daß man irgendwie doch nicht zur Gemeinschaft gehört, ne. Un dann hab ich eigentlich auch keinerlei Ambitionen gehabt, dann mich da irgendwie in irgend'ner Art zu bemühen, ne. ${ }^{504}$

In diesen Erfahrungen war kein Platz für ein mitleidiges Gefühl aufgrund einer scheinbar verpaßten Jugendzeit. Abseits des vitalen Brauchgeschehens ihres Heimatortes führte der jugendliche Erlebnisdrang von Frau Jansen auf andere Weise zu vielfältigen menschlichen Begegnungen und zu innerer Befriedigung. Dennoch veranschaulicht dieses Beispiel gerade in dem bewußtgewordenen Fehlschlag ein Potential der innerdörflichen Kommunikation, das die am Mailehen Beteiligten hätten freisetzen können.

\subsection{Kennzeichen der Mailehenpraxis: Präsen- tation und Wirkung}

Das Bild, das man von den Ausprägungen und der Entfaltung des Mailehenbrauchs in Oeverich erhält, fügt sich ohne Mühe in die überregional und historisch vergleichende Darstellung (siehe Kap. 2.5 bis 2.8) ein. Aus dem 19. Jahrhundert liegt ein sicherer Beleg vor, der über die Existenz des Mailehens in der ehemaligen Bürgermeisterei Gelsdorf Auskunft gibt. Im Jahre 1869 wiederholte sich für den Landkreis Ahrweiler der gleiche Vorgang, den wir nur vier Jahrzehnte zuvor im benachbarten Siegburger Verwaltungsbezirk feststellen konnten. Hier wie dort bemühte sich die Kirche unter der Beeinflussung weltlicher Machthaber, gegen das Mailehen vorzugehen - in beiden Fällen ohne nachhaltigen Erfolg. Am Beispiel Oeverich ließ sich darüber hinaus zeigen, wie die zuständigen Pfarrer noch in der zweiten Hälfte des 20. Jahrhunderts versuchten, die Jugendlichen von der alljährlich stattfindenden Mailehenversteigerung abzubringen. $\mathrm{Da} \beta$ diesen Reglementierungsbestrebungen nicht nur der Widerstand der Junggesellen entgegenschlug, ging aus den lebhaften Erinnerungen der Betroffenen hervor. Damals erhielten die Heranwachsenden die breite Unterstützung der Dorfbevölkerung.

${ }^{504}$ Frau Jansen (52/38/1a:260-287). 
Neben den kirchlichen Zugriffen mußte man sich auch anderer Einflußnahme widersetzen bzw. entziehen, was nicht immer gelang. Mehrmals kam die Brauchausübung zum Erliegen. Die Gründe sind nicht immer ersichtlich. Nachdem sich 1889 der Junggesellenverein formiert hatte, vermutlich aus dem informelleren Zusammenschluß der sogenannten "Männerreih", war mit amtlicher Registrierung, schriftlich festgesetzten Statuten und einem hierarchischen Führungsprinzip ein hoher Organisationsgrad der männlichen Brauchträgerschaft erreicht. Dennoch verhalf dieser Schritt nicht zu einer dauerhaften Sicherung der Brauchpraxis. Schon wenige Jahre nach der Wende zum 20. Jahrhundert wurde eine Neugründung des Vereins fällig. Auch während der beiden Weltkriege war das Vereins- und Brauchleben zum Stillstand gekommen, und in den 1960er Jahren führten Spannungen zu einer weiteren Störung der rituellen Abläufe. Mangelnde Motivation, Querelen bei der Kirmesdurchführung und der Verteilung von Einnahmequellen während des Festes zwischen Gastwirten und Junggesellen wurden als Gründe genannt.

Der ideologische Impetus der Nationalsozialisten auf die Brauch- und Festgestaltung wurde in Oeverich spürbar, wobei seine konkreten Auswirkungen in den Erinnerungen nur noch ein blasses Bild hinterließen. Ähnlich wie bei der Kirche richteten sich die Vorgaben der weltlichen Machthaber gegen die Mailehenversteigerung. Man hielt die Junggesellen dazu an, die Würde der Frau zu respektieren, und daher sahen sich die Burschen dazu gezwungen, skatologische Anspielungen oder Auswüchse bei der Anpreisung der einzelnen Mailehenkandidatinnen zu unterlassen. Die weitere Gestaltung des Mailehens scheint von dem ideologischen Gedankengut und Formenrepertoire relativ unberührt geblieben zu sein. ${ }^{505}$

Die Verhältnisse nach 1945 sind den GesprächspartnerInnen deutlich im Gedächtnis geblieben. Die Betroffenen haben einen regelrechten Drang, wenn nicht eine Gier geschildert, mit der die offensichtlich kriegsbedingt verhinderte Jugendzeit nachgeholt werden sollte. Nicht ohne Stolz verwies man auf den damals erforderlichen Pioniergeist, der zunächst dazu beitrug, daß die organisatorischen Strukturen und damit auch die Bräuche wiederhergestellt wurden. Alkohol, Tanz und Amüsement bis in die frühen Morgenstunden zeichneten das Mailehen in gewisser Weise als Fluchthelfer und Seelentröster der Jugendlichen aus, weil es als Anlaß galt, dem Ärger mit strengen Eltern oder der persönlichen Erfahrung materieller wie psychischer Not zeitweise zu entgehen.

${ }^{505}$ Die Erinnerungen an die Erlebnisse während des Dritten Reichs ist mit spezifischen Problemen der lebensgeschichtlichen Reflexion behaftet. Hierauf einzugehen, wäre eine Herausforderung, der sich eine eigenständige Folgeuntersuchung intensiv zu widmen hätte, um ein tieferes Verständnis z.B. über den Zusammenhang von dem oberflächlichen Bild damaliger Medienberichterstattung und der Situation der damals Betroffenen zu erhalten. Vgl. dazu Korff (1984:280f). 
1966 mußte eine Gruppe von zwölf Oeverichern den Junggesellenverein erneut aufbauen. In den Folgejahren wurde daran gearbeitet, eine neue, professionelle Festorganisation $\mathrm{zu}$ etablieren, die den Vereinsmitgliedern nicht zuletzt eine wirtschaftliche Basis für gemeinsame Urlaubsfahrten gewähren sollte. Das Konzept trug Früchte. Terminliche Änderungen, das große Festzelt, der hinzugewonnene Diskoabend, die neue Sektbar, die intensiven Werbemaßnahmen, die Verpflichtung geeigneter Tanzkapellen, aber auch das Engagement der Jugendlichen vom Zeltaufbau bis zum Thekendienst verhalfen dem Oevericher Maifest zu neuem Ansehen und dem Junggesellenverein zu einer respektablen Einnahmequelle. Der unternehmerische Erfolg war die Basis gemeinsamer Ausflüge. Spektakuläre Reiseziele an der adriatischen Küste oder auf kanarischen Inseln gelten bis heute als Lohn für den kollektiven Einsatz der Junggesellen im Mai.

Es könnte hier leicht der Eindruck entstehen, daß für das eigentliche Mailehen im Rahmen der Tanzfeierlichkeiten heute kein Platz mehr ist. Tatsächlich war das Lager der Junggesellen gespalten, als es 1966 um die Wiedereinführung der Mailehenversteigerung ging. So gab es eine Partei, welche die Kirmes ausrichten wollte, ohne dabei den rituellen Rahmen zu berücksichtigen. Allerdings verfügten die "Traditionalisten" über die meisten Stimmen, so daß 1968 wieder gesteigert wurde. Das Oevericher Mailehen blieb jedoch von Anpassungsnotwendigkeiten nicht verschont. Der Kommabend ließ sich nicht mehr aufrechterhalten. Die inzwischen bestehenden Möglichkeiten, sich in der Freizeit häufig zu treffen, hatten das Bedürfnis nach einem rituell verbindlichen Termin deutlich herabgemindert, so daß die Institution des Kommabends kaum noch Anhänger fand. Die Zusammenfügung der Mailehenpaare wurde auf diese Art jedoch in ihrer Bedeutung geschwächt, da sich die gemeinsamen Pflichten reduzierten. Demgegenüber blieb der recht hohe Erwartungsdruck, dem das Maikönigspaar ausgesetzt war, bis in die Gegenwart hinein bestehen. Tendenzen der Zurückweisung des Maikönigs, wie sie Faber und Ziegler (1979/80:170) in Bonner Vororten beobachten konnten, waren den Oevericher Kandidatinnen nahezu unbekannt. Einmal kam es zu einer Situation, bei der die designierte Maikönigin ihr Amt ablehnte. Dies wurde jedoch von einem großen Teil der Befragten als ein bedauerlicher Einzelfall betrachtet. Für viele der unverheirateten Frauen waren daher die Stunden der Mainacht immer noch spannungsreich und für manche schicksalsträchtig, wenn sich herausstellte, daß die Wahl auf sie gefallen war.

Die rituell bedingten Anforderungen wurden nicht immer positiv erlebt. Fast alle Gesprächspartnerinnen standen einer verfrühten Forderung zur Übernahme des Maiköniginnenamts skeptisch gegenüber. Denn man könne etwas Zeit zur Eingewöhnung in die Gesellschaft der Brauchträger und Brauchträgerinnen gut gebrauchen. Oft entstand für die Maikönigin eine schwierige Situation, wenn sie die Sympathiebezeugung des rituellen Partners nicht erwidern konnte. Dann wurde ein 
recht hohes Maß an Gelassenheit von ihr gefordert, um eine Hypostasierung und das Gefeiertwerden als Paar zu bewältigen. Jeder Auftritt in der Öffentlichkeit verlangte nach einer schauspielerischen Leistung, da die "Hoheiten" sich dem Publikum als ein würdiges, einträchtiges Gespann präsentieren mußten. Insbesondere der sogenannte Maibutz stieß hier auf einen deutlichen Widerwillen. In einer Situation, in der das Maikönigspaar nicht zusammenpaßte, konnte das Braucherlebnis dennoch zu einem persönlichen Gewinn führen. Die Voraussetzungen dafür waren günstig, wenn es den ProtagonistInnen gelang, jenen zunächst ernst gemeinten Hintersinn der Verpaarung und das deutlich gewordene Interesse des Ersteigerers, die Bande zur Auserwählten enger zu knüpfen, in einen anderen Interaktionszusammenhang zu stellen.

Die Verteidigung der tradierten Brauchformen trat im Fallbeispiel Oeverich dort hervor, wo die Mailehenversteigerung, das Mailehen und somit auch das Besondere an der Maikirmes gegenüber der massiven Kritik der Pfarrer in Schutz genommen werden mußte. Darüber hinaus gefährdeten soziostrukturelle Umbrüche das rituelle Treiben. Schon in den 1920er Jahren hat Hilberath (1931:67f) die allgemeinen gesellschaftlichen Umwälzungen ins Auge gefaßt, von denen die tradierten sozialen Beziehungen im Dorf betroffen sein konnten. Insbesondere von veränderten Erwerbsstrukturen, von sich wandelnden Geschlechterrollen oder von der Urbanisierung war dabei die Rede. Seither sind die zentrifugalen Kräfte einer modernen, semiurbanen Gesellschaft keineswegs zum Stillstand gekommen. Im Gegenteil, es bestehen inzwischen radikal erweiterte Interaktions- und Kommunikationsmöglichkeiten, die auf einer erhöhten Mobilität, auf der Diversifikation der Arbeits- oder Bildungschancen, auf einer Überfülle von Freizeit-, Unterhaltungsangeboten oder Konsumgelegenheiten und schließlich auch auf der digitalisierten Informationsübertragung via Internet beruhen. So stellt sich die Frage, was heute den Reiz des Brauchgeschehens in einer postmodernen Lebenswelt ausmacht. Welche Bedeutung hat das Erlebnis des "Überlebten" vor dem Hintergrund einer gegenwärtigen Normenpluralisierung? Wodurch kann das Mailehen seinen Stand behaupten gegenüber der zunehmenden Entgrenzung von Erlebnis- und Konsummöglichkeiten, die zahllose individuelle Orientierungsalternativen zu versprechen scheinen $?^{506}$

Die Literatur des 19. und 20. Jahrhunderts hat das Mailehen immer wieder als eine Institution der Heiratsvermittlung herausgestellt. Als Beleg für diese Sichtweise genügte nicht selten jener Zuteilungsspruch beim Lehenausrufen, der als Folge der

${ }^{506}$ Luckmanns (1972:191-197) Aufsatz über Zwänge und Freiheiten im Wandel der Gesellschaftsstruktur macht bereits auf diese Trends gesellschaftlicher Entwicklung aufmerksam. Sie können heute mit Beck (1986:20) pointiert als Freisetzungsprozeß charakterisiert werden. Hierbei wird der Mensch aus den vertrauten Lebenszusammenhängen herausgelöst und entwickelt sich damit zum "homo optionis" (Beck/Beck 1994:16). Vgl. die Aufsätze in Heitmeyer (1997) v.a. Lüdtke (1997:376), Heitmeyer (1997:12-16), Friedrichs (1997:478-484). Über den Zusammenhang von Entritualisierung und Individualisierung siehe Schäfer und Wimmer (1998:20-23). 
rituellen Verpaarung die Eheschließung in der Frist eines Jahres verhieß. In dem Tanzlied bei Wittenwiler wurde schon davon gesungen, daß dem Burschen die zu erheischende Tanzpartnerin "ze fröden seinem leben" gelten sollte, was schließlich die lebenslange Perspektive einer vorstellbaren Ehebeziehung einschließen konnte. Allerdings artikulierte man auch Skepsis gegenüber einer derart offensichtlichen Wirkungsweise des Mailehens. Das spielerische Element im Brauch harmonierte nicht mit der Ernsthaftigkeit matrimonialer Strategien im bäuerlichen Milieu, wo Besitz, Ansehen und Tüchtigkeit wichtige Entscheidungsfaktoren darstellten (vgl. Kapitel 3.3/3.5). Wenn also die rituelle Verpaarung Auswirkungen im Heiratsverhalten der Jugendlichen nahelegte, dann konnte es sich hierbei lediglich um indirekte Konsequenzen handeln, die dazu führten, daß heiratsfähige Jungen und Mädchen einander besser kennenlernten und Spaß zusammen hatten. Genauso hatte es Herr Stein zum Ausdruck gebracht, als er seine Junggesellenzeit in den Jahren nach 1945 rekapitulierte (siehe Kapitel 4.4.1.2).

In dem Moment, als die Selbstverwirklichungschancen für den einzelnen über den gewohnten Rahmen der dörflich-bäuerlichen Existenzform hinauswuchsen, schien das Interesse an einer brauchgeleiteten Zusammenführung der Jugendlichen gänzlich verlorenzugehen. Grasmück (1989:32) und Schrick (1992:39) haben unter Hinweis auf die Motorisierung sowie die Vielfalt von Freizeit- und Kontaktmöglichkeiten diesen Gedanken in die heutige Zeit übertragen. Sie haben daher auf einen Funktionswandel des Mailehens verwiesen, bei dem das voreheliche Werben keine Rolle mehr spiele. Im Kontrast dazu stehen allerdings die Aussagen der AkteurInnen. Nicht selten ergriffen die Maikönige die Gelegenheit, um sich der bewußt ausgewählte Regentin zu nähern. Eifersuchtsszenen, in denen die festen Freunde der Maiköniginnen pikiert dem rituell legitimierten Konkurrenten das Feld überlassen mußten, konnten deshalb ernsthafte Partnerschaftsprobleme auslösen.

Sieht man einmal ab von Sonderformen, wie z.B. dem frühneuzeitlichen Kölner Beispiel, so war für das Mailehen die Paarbildung zwischen heiratsfähigen Frauen und Männer durchweg konstitutiv. Die Funktion einer direkten Vermittlung von EhepartnerInnen erscheint in diesem Zusammenhang abwegig, weshalb die Rede vom "Heirathsbureau des platten Landes"507 irreführend ist. Dagegen hat sich der Brauch aber bewährt, die Jugendlichen auf einen bevorstehenden Statuswechsel vorzubereiten. Im Rahmen des Mailehens sind die jungen Frauen und Männer in einen Interaktionszusammenhang getreten, der die Gedanken auf eine potentielle Lebenspartnerschaft richtete und der darüber hinaus aus der virtuellen Paarbeziehung eine ungewohnt sinnfällige Erfahrung ermöglichte.

${ }^{507}$ Siehe Kapitel 3.3. 
Die subjektbezogene Wiedergabe der Braucherlebnisse machte deutlich, daß das Mailehen über eine rituelle Anbahnung der Ehe weit hinausging. Die von den Jugendlichen übernommenen Brauchrollen deuteten auf einen symbolischen Statuswechsel hin, der für alle sichtbar vollzogenen wurde. Die Junggesellen hatten in den 1970er Jahren das Aufnahmeritual eingeführt, das den Übergang besonders markierte: An dem einen Ende des Initiationsprozesses wurde die Loslösung vom Kindsein, von familiären Bindungen oder der Autorität der Eltern sichtbar, an dem anderen Ende vollzog sich der Einstieg in die Gruppe der unverheirateten Männer und die Anerkennung der gruppenspezifischen Verhaltensnormen. Mit der neuen Situation einhergehende Unsicherheiten und Einschränkungen für den Initianden ließen sich kompensieren. Unmittelbar nach der Aufnahmezeremonie war für alle Vereinsmitglieder die Beteiligung an der Mailehenversteigerung erlaubt. Die vollzogene Initiation ermöglichte somit den Zugang zu vereins- und brauchspezifischen Aktionsfeldern, in denen sowohl dionysische Aufwallungen als auch die Übernahme von verantwortungsvollen Aufgaben zur Geltung kamen. ${ }^{508}$

Auch aus der Perspektive der Frauen wurde durch das Mailehen ein Übergang in eine "andere Welt" geschaffen. Mit sechzehn Jahren veränderte sich in der Regel die Beziehung der Mädchen zum Brauch und zur Maikirmes abrupt. Von nun an kamen die Mädchen ohne ihr Zutun auf die Versteigerungsliste. Geschlechtszugehörigkeit, Alter, Ortsansässigkeit genügten, um diesen Statuswechsel auszulösen. Im Vergleich zum männlichen Initiationsritual zeigt sich demzufolge ein grundsätzlich anderer Mechanismus sozialer Transformation. Während die Jungen die Entscheidung der Teilnahme aktiv steuern konnten, gehörten die Mädchen zwangsläufig zum Kreis der Brauchträgerinnen, sobald sie die genannten Voraussetzungen erfüllten. Dem zugeschriebenen weiblichen Status stand ein erworbener männlicher Status gegenüber.

Dieser Tatbestand stieß bei den betroffenen Frauen auf Argwohn. Mit unterschiedlichen Mitteln und unterschiedlichem Erfolg wurde versucht, gegen die Einschränkung der eigenen Freiheiten vorzugehen. ${ }^{509}$ Eine Gesprächspartnerin (Frau Gebhard) schilderte eingehend ihre anfängliche Abneigung gegen das Mailehen, von dem sie dachte, daß die Mädchen wie Vieh versteigert würden. Sie berichtete, wie sie sich dagegen wehrte, daß sie bereits mit fünfzehn Jahren ersteigert wurde. Das folgende

${ }^{508}$ Vgl. die Kapitel 3.3, 3.6 und 3.7.

${ }^{509}$ Die soziale Ungleichheit zwischen den Geschlechtern, die an diesem Punkt erkennbar wurde, erzeugte problematische Deutungen. Frauen wurden häufig von vornherein in einer absolut passiven Rolle gesehen. Eine positive Identifikation der Brauchträgerinnen mit ihrer Rolle blieb entweder unerkannt oder wurde als unemanzipiert abqualifiziert (vgl. insbes. Kapitel 3.2 und 3.6). Dagegen ließ sich zeigen, daß man den sozialen Beziehungen und den im Brauch wirksamen Einflußmöglichkeiten nur auf die Spur kommen kann, wenn man eine auf der geschlechtsspezifischen Statusdifferenz basierende Passivitätsideologie mit kritischer Distanz betrachtet.

Einen ähnlichen Weg hat Nadig (1986:138f) beschritten, als sie die Situation der Frauen in Mexiko unter dem herrschenden Machismo zu ergründen versuchte. 
Jahr setzte sie sich vorsorglich vor dem 30. April mit dem Junggesellenverein auseinander und erklärte, daß sie dem Mailehen nicht zur Verfügung stehe. Als der Freund der Informantin mit einem Tribut - der Ablieferung eines Kasten Biers an den Junggesellenverein - den Freikauf ermöglichen wollte, schlugen die Bemühungen ein drittes Mal fehl. Die Sache erscheint damit relativ eindeutig: Die Junggesellen wehrten sich beharrlich gegen eine Einmischung in "ihre" Angelegenheiten. Vor diesem Hintergrund dürfte eine völlige Abkehr der Betroffenen vom Brauchgeschehen als verständlich erscheinen. Doch bemerkenswerterweise nimmt die Darstellung an diesem Punkt ihre Wende. Letztlich sah Frau Gebhard im Mailehen eine gute Möglichkeit, die Kontakte im Dorf aufzufrischen, und zog damit aus den ambivalenten Auswirkungen des Brauches eine positive Bilanz. In anderen Fällen ist häufig ein ähnliches Muster sichtbar geworden. Einerseits wurden die Einschränkungen aufgrund der männlichen Dominanz bei der Paarzuteilung klar artikuliert, andererseits stand der Kritik am Brauchgeschehen die positiv erfahrene Erweiterung des eigenen Handlungsspektrums gegenüber. Das Zusammentreffen mit den Jugendlichen, das ausgelassene Geselligsein bis in die frühen Morgenstunden, der unkontrollierte Alkoholkonsum oder das ausgiebige Tanzen fielen dabei ins Gewicht. ${ }^{510}$ Soziale Kommunikation und Interaktion verbunden mit einer dionysischen Entgrenzung waren bei der Beurteilung des Mailehens aus weiblicher Sicht durchaus von Bedeutung. Eine derart kreative Zugangsweise widerspricht einer Passivitätsideologie, welche die Frauen als gefügige Anhängsel in der Mailehenrezeption fast durchweg an den Rand der Brauchpraxis gedrängt hatte. Sicherlich kann kaum übersehen werden, daß die Junggesellen eine maßgebliche Stellung erlangt haben bei der formalen Organisation des Brauchablaufs. Hier wäre vor allem die Mailehenversteigerung zu nennen. Aber es kann ebensowenig übersehen werden, daß der inhaltliche Bedeutungsgehalt jedes einzelnen Brauchelementes, an dem die Frauen beteiligt waren, aus dem interaktiven Zusammenwirken aller beteiligten Subjekte entsprang. Genau an diesem Schnittpunkt formaler und inhaltlicher Brauchgestaltung zeigt sich, daß eine Brauchforschung, die ein differenziertes Bild von der Wirklichkeit erhalten möchte, weder einem geschlechts- noch subjektneutralen Code unterliegen sollte (siehe Kapitel 1.1).

Um dieses wichtige Merkmal der Mailehenpraxis konkret zu veranschaulichen, kann eine besonders klare, bereits oben zitierte Stelle nochmals herausgegriffen werden. Frau Rosen erinnerte sich daran, welche persönliche Herausforderung für sie in der Klärung der rituellen Paarbeziehung lag:

[...] mit dem Franz, der Junge der mich gesteigert hatte, da war absolut gar nichts. Un ich hab dem jesagt, beim Tanzen (mir mußten ja die Ehrentänze absolvieren) sacht ich: "Franz, do

${ }^{510}$ Auf den Zusammenhang von Alkoholkonsum, Fest und Adoleszenz ist unlängst Rolshoven (2000:29-50) in einer zusammenfassenden Darstellung über die kulturelle Bedeutung des Rausches eingegangen. 
kannst mache wat'te willst, un ich dohn et och!" Ich wollt ja net irjendwie in Abhängigkeit reinkumme, ne. ${ }^{511}$

Die Argumentation von Frau Rosen macht den Grat zwischen formellem und inhaltlichem Handlungsvollzug, auf dem sich die Akteurinnen und Akteure bewegt haben, sehr deutlich. Die Darstellung bezieht sich auf das Jahr 1946. Vor dem Hintergrund der gesamtgesellschaftlichen Entwicklung macht diese Angabe darauf aufmerksam, daß im Brauchgeschehen sozialpolitische Einflußfaktoren, wie die geschlechtsspezifische Emanzipation, von nachrangiger Bedeutung waren. Entscheidend bei der von der Informantin artikulierten Distanzwahrung zum Maikönig war hingegen die persönliche Durchsetzungskraft. Das Mailehen präsentierte sich demnach als Lernort, und zwar nicht nur für die Zurschaustellung männlicher Dominanz, sondern auch für die weibliche Selbstbehauptung. $\mathrm{Da}$ diese Funktion auch von den Beteiligten wahrgenommen wurde, konnte an vielen Stellen der Arbeit aufgezeigt werden.

Ein wichtiger Aspekt, die Modellierung innerdörflicher Beziehungen, ergänzt die erkennbaren Wirkungsbereiche des Mailehens. Im Zeitalter der Globalisierung von Kommunikations- und Interaktionsmöglichkeiten und der anscheinend unermeßlichen Erweiterung des persönlichen Handlungsfeldes mag die Beteiligung an einem Brauch, der sich hauptsächlich auf die Bewohner und Bewohnerinnen eines Ortes und auf einen relativ festgefügten Aktionsradius begrenzen läßt, generell nicht mehr zeitgemäß erscheinen. Doch dieser Annahme widerspricht die weitreichende Unterstützung der Brauchträgerinnen und Brauchträger bis in die Gegenwart hinein. Auch die Versuche einzelner, das Kirmesgeschehen z.B. durch Einwendungen gegen die Lärmemissionen zu hintertreiben, blieben bislang erfolglos. Zustimmung zum Mailehen gab es aus allen Richtungen: von Alteingesessenen wie von Zugezogenen, von Menschen, die in direkter Nähe zu den BrauchträgerInnen standen, aber auch von denjenigen, die sich ausgegrenzt fühlten. Somit stellte sich die Frage nach den Gründen für jene breite Akzeptanz und die Beliebtheit des Brauches.

Es zeigte sich, daß im überschaubaren Rahmen des Mailehens geradezu ein Ausgleich zu den modernen Zeiterscheinungen gesucht wurde. Das relative Vertrautsein mit den lokalen Gegebenheiten, dem Publikum und dem Festablauf bot anscheinend ideale Bedingungen für einen Ort der Begegnung. Da dieses Zusammentreffen unter bestimmten Voraussetzungen stattfand, kann hier von einem institutionalisierten Begegnungsfeld gesprochen werden. So, wie der Brauch als "Gerüst" (Herr Gerber) für den zwischenmenschlichen Kontakt angesehen wurde, kann man ihn auch als Institution bezeichnen, die den sozialen Austausch effektiv gefördert hat. Im Mailehen sah man also ein Instrument gegen den zunehmenden Individualismus oder die Desintegration und für die Stärkung sozialer Kohäsion und gestaltbarer Ortsverbundenheit.

${ }^{511}$ Gruppengespräch I (39/23-27/2a:552-558) vgl. auch Kapitel 4.4.2.2. 
Dem Gedanken an eine modellierbare Gemeinschaft, die durch den Brauch gestärkt würde, hingen nicht nur die Befragten der im Dorf eingewurzelten Familien an, sondern auch diejenigen aus der Peripherie der Neubaugebiete. Alle Beteiligten entdeckten im Brauch ein schätzenswertes Integrationspotential. Die integrative Kraft des Mailehens entfaltete sich insbesondere dann, wenn ein strukturelles Prinzip eingehalten wurde, das sich über fünf Ansatzstellen steuern ließ: Erstens, der zeichenhafte Charakter des Brauches mußte präsentiert, wahrgenommen und entschlüsselt werden. Auf diese Weise konnte das Engagement der Dorfbewohner geweckt werden. Zweitens, die formale Offerte, bedurfte einer Antwort. Die Werbung um die Teilnahme am Mailehen löste zwar nötige Impulse aus, um den Willen an einer Beteiligung und die damit verbundene Zeit aufzubringen, maßgebend war aber die konkrete Entscheidung der Zielgruppe. Drittens, auch der Kontaktvermittlung kam eine wichtige Aufgabe zu. Der Vermittler konnte dafür sorgen, daß das Gefälle des Andersseins zwischen den fremden Parteien gemindert wurde. Viertens zeigte sich bei den BrauchanhängerInnen eine objektbezogene Affinität, welche die Beteiligungschancen am Brauchgeschehen beeinflussen konnte. Stabile Bindungen zum Dorf, die sich in der lokalen Herkunft, den Verwandtschafts- und Freundesbeziehungen innerhalb des Ortes manifestierten, führten gewissermaßen zu einem "natürlichen" oder "normalen Hineinwachsen" in den Kreis der Brauchtreibenden. Dieser Aspekt macht allerdings auf ein Problem aufmerksam, das die gesamte Integrationswirkung wiederum in Frage stellt. Denn solange die Partizipation am Mailehen eine pseudohereditäre Qualifikation vorauszusetzen scheint, bleiben Abseitsstehende (etwa Zugezogene, Städter oder Einzelgänger) mehr oder weniger ausgegrenzt. Ein fünftes strukturbildendes Moment wirkte gegen dieses letztgenannte Prinzip der endogamen Selbstbezogenheit alteingesessener BrauchteilnehmerInnen. Im Braucherleben konnte eine subjektbezogene Affinität wirksam werden, welche die Erfüllung der vorgenannten Kriterien durchaus in den Hintergrund drängen konnte. So stellte sich heraus, daß z.B. Zugezogene in den Kreis der Brauchbeteiligten aufgenommen wurden, wenn sie bereit waren, in unvoreingenommener Weise auf die bestehende Gemeinschaft der Brauchausübenden einzugehen. Dies gelang allerdings nur, wenn auch umgekehrt die Alteingesessenen die gleiche Unvoreingenommenheit und Bereitschaft zur Aufnahme der Neuen, Fremden oder Abseitsstehenden aufbrachten. Es konnte gezeigt werden, daß das Mailehen den formalen Rahmen zu einer Modellierung innerdörflicher Beziehungen vorgibt. Dieser Rahmen bezweckte nicht mehr - aber auch nicht weniger - als eine Hinführung zu einer zwischenmenschlichen Begegnung. Letztlich entschied die inhaltliche Ausgestaltung sozialer Beteiligung darüber, ob das Mailehen positiv als Medium sozialer Integration genutzt wurde. 


\section{$5 \quad$ Res ümee}

\subsection{Das Mailehen als Medium}

Un warum hoffen Sie, dat et so [mit dem Mailehen] weitergeht?

Joa, dat e bisje Tamtam in de Jejend darüm is. ${ }^{512}$

Frau Theisens Antwort klingt am Ende einer Erkundung der Mailehenpraxis ernüchternd. In den Gesprächen sind immer wieder vergleichbare Äußerungen gefallen, wie z.B. der Brauch sollte beibehalten werden, damit sich in dem Ort wenigstens einmal im Jahr etwas ereigne. Manchmal wurde auch darauf hingewiesen, daß der Brauch als etwas Selbstverständliches gelte, als ein Muß, als eine alternativlose Attraktion. Daß solche Ausführungen in der Befragungssituation ein leichtes Unbehagen in mir auslösen konnten, dürfte verständlich sein. Ich hoffte, daß die GesprächspartnerInnen ihre Ausführungen im Fortgang des Gesprächs präzisieren würden und ahnte damals noch nicht, daß mit schlichten Worten der Kernpunkt des Mailehens angesprochen worden war: das rituelle Geschehen war in erster Linie nicht auf spezifische Funktionen ausgerichtet, sondern es diente in der Tat der Gewinnung von Möglichkeiten zum sozialen Austausch, indem es einen formellen Rahmen der Begegnung schuf. Das Mailehen wurde damit zu einem wichtigen Medium der zwischenmenschlichen Begegnung. Der Verlauf und das Ende dieser Begegnung entwickelte sich während der Brauchausübung und nahm bei der Interaktion Gestalt an.

Diese Sichtweise ist unter den Befragten sehr verbreitet. Sie findet sich bei Frauen und bei Männern, bei Jüngeren und bei Älteren, bei Alteingesessenen und bei Zugezogenen und überdies bei KritikerInnen der Brauchpraxis. ${ }^{513}$ So schlug im Falle von Frau Jansen die negative Erinnerung an die unzureichenden Gelegenheiten und Bedingungen der Partizipation nicht in eine grundsätzliche Ablehnung des Brauches um. Frau Jansen differenzierte deutlich zwischen dem Medium und ihren AnwenderInnen:

Gab's denn andere Mädchen im Dorf, die in 'ner ähnlichen Situation waren, daß sie nicht so recht am Brauch beteiligt waren?

Nä, wüßte ich eigentlich nicht, daß irgendwie en anderes Mädchen jetzt so in der Situation war jetzt wie ich. Könnt ich nicht sagen.

Und das hat Sie nicht so gestört, daß Sie dadurch praktisch ausgeschlossen sich vorkommen konnten, weil alle anderen Mädchen dabei waren?

Nö, war gar nicht so schlimm, weil ich hatte ja woanders meinen Freundeskreis. [...]

${ }^{512}$ Frau Theisen (06/06/1b:90-94).

${ }^{513}$ Siehe Abschnitt 4.4.2 und insbesondere 4.4.4. 
Weil... Ich könnte mir vorstellen, daß das nämlich'n Grund sein könnte, warum man sagt: "Nee, also da bin ich gar nicht böse drum, wenn es tatsächlich dazu kommen sollte...

...daß der Maibrauch ganz verlorengeht?

Ja. Mhm.

Nöö, deswegen kann ich das nicht von vorneherein verurteilen. Weil: Wenn die Leute jetzt so sind - sagen wir mal, die Menschen - deswegen muß man die Sache ja noch lang nicht verurteilen, ne. Also jetzt sprich: den Maibrauch. So stehe ich jetzt eigentlich dazu, ne..$^{514}$

Das Mailehen stellte Beziehungen unter den Brauchbeteiligten her. Diese Beziehungen waren trotz der Ritualisierung keineswegs festgelegt; entscheidend war die inhaltliche Ausgestaltung des vorgegebenen Rahmens. Vor allem, wenn das Mailehen dazu führte, soziale Kontakte anzubahnen oder zu intensivieren, sinnvolle Lernfelder sozialen Handelns zu eröffnen, zusätzliche Verdienstmöglichkeiten herzustellen, das profane Verlangen nach Konsum oder das dionysische nach Aufwallung und Entgrenzung zu befriedigen, dann wurde die positive Wirkung der Brauchpraxis subjektiv erfahrbar und prägte entsprechend der Intensität der Erlebnisse bald die Erinnerungen, bald die Persönlichkeit der Beteiligten. Das Mailehen konnte innerhalb eines zeitlichen Rahmens einen sozialen Austausch zwischen den beiden Geschlechtern oder zwischen den Generationen, den DorfbewohnerInnen und den auswärtigen Kirmesgästen fördern. Über die Aufstellung des Dorfmaibaums und der Maien, über die Positionierung des Festzeltes und vor allem den Umzug durch die menschengesäumten Straßen bzw. Gassen war es dem Kreis der Brauchausübenden möglich, eine symbolische territoriale Inbesitznahme des Ortes zu vollziehen. Das Vorhandensein dieser sozialen, zeitlichen und räumlichen Koordinaten der Brauchpraxis war eine Herausforderung für die örtliche Bevölkerung, weil sich die persönliche Stellungnahme des einzelnen nicht umgehen ließ: der Achtzehnjährige hatte den Eintritt in den Junggesellenverein, die Sechzehnjährige eine Übernahme der Mailehen- bzw. Maiköniginnenrolle und die DorfbewohnerInnen den Besuch der Maikirmes jeweils für sich abzuwägen. Als Medium war der Brauch prinzipiell kontingent. Er war offen für die Befürwortung oder Ablehnung durch die Beteiligten.

Doch kam der zwischenmenschliche Austausch auch in vollem Umfang zur Geltung? Bei der Berücksichtigung einer prinzipiellen Gestaltbarkeit des Mailehens stellt sich auch die Frage nach störenden Einflüssen, nach einengenden Normen oder sozialen Zwängen. In einer Gruppe, in welcher der Gebrauch eines Mediums verbreitet ist, grenzt sich derjenige zumindest partiell aus, der beharrlich die Annahme des medialen Angebots zurückweist. Eine Fülle von Beispielen ließe sich zur Verdeutlichung dieses Zusammenhangs heranziehen. Aktuell und für viele spürbar sind die Konsequenzen, die sich bei der Verwirklichung einer ubiquitären Computervernetzung privater Haushalte ergeben. Wer den Zugang zum globalisierten Datenaustausch ablehnt, spürt mit zunehmender Verbreitung des Mediums Internet einen gewissen

${ }^{514}$ Frau Jansen (52/38/1b:495-511). 
Grad gesellschaftlicher Isolation. Gerade am Internetbeispiel wird sichtbar, wie sich ein wichtiger gesellschaftlicher Teilbereich mit spezifischen Kommunikationsformen und -weisen ausdifferenzieren kann, der die Außenstehenden quasi zu Analphabeten macht. Die Situation der Ausgrenzung verschärft sich in einem vergleichsweise überschaubaren sozialen Umfeld, wie z.B. in einem Dorf, wo die Nachbarn untereinander Kontakte pflegen. Folglich muß ein Medium vor dem Hintergrund der gesellschaftlichen Einwirkungen und der sozial normierenden Verhaltenskontrolle betrachtet werden. Es konnte gezeigt werden, daß nicht nur übergeordnete Machtzentren, wie kirchliche oder staatliche Obrigkeiten, sondern auch Eltern, Geschwister, PartnerInnen, Freunde und NachbarInnen versuchten, direkt oder indirekt Einfluß auf die persönliche Entscheidung zur Mitwirkung am Brauch zu nehmen. Manche Brauchträgerin, mancher Brauchträger sahen sich zur Medienübernahme bedrängt, andere hingegen empfanden den Übergang als "normale", wenn nicht "natürliche" Folge der eigenen Biographie. Aufgrund der im Brauch ausdifferenzierten Statusunterschiede zwischen Jungen und Mädchen wurde es den männlichen Initianden relativ einfach gemacht, sich dem rituellen Geschehen fernzuhalten. Dagegen blieben den jungen Frauen in den meisten Fällen nur informellere Verhaltensstrategien, um sich zu entziehen.

Kehren wir an diesem Punkt zu der Frage zurück, die in der Einleitung der Arbeit aufgeworfen wurde: Wer erhält bei der Brauchausübung was von wem geborgt, wozu und unter welchen Bedingungen? Bei einer oberflächlichen Betrachtung kam man zu dem Schluß, daß das Mädchen dem Jungen über das brauchbedingt zugestandene Recht vom Junggesellenverein zugewiesen wird. Die Burschen nähmen so ihre gesellschaftlich gebilligte Machtposition ein und der männlichen Überlegenheit könne sichtbar Ausdruck verliehen werden. Diese Argumentation erzeugte Unglauben, weil sie ein starres Modell von männlicher Dominanz und weiblicher Fügsamkeit postulierte. Stereotyp orientierte es sich an einem enthistorisierten asymmetrischen Machtverhältnis der Geschlechter. Die hiervon ausgehende Diskrepanz zur sozialen Wirklichkeit führte wohl dazu, daß einige Autoren die These vom baldigen Verschwinden des Mailehens aufstellten. Doch die Rede vom Reliktcharakter, vom Anachronismus oder dem antizipierten Niedergang konnte über die Zeit jenen Unglauben lediglich verstärken. Mehr als hundert Jahre sind vergangen, seit man das Mailehen totgesagt hat. Die Prognosen sind nicht eingetreten. Trotzdem hat es vor dem Hintergrund der jährlich wiederkehrenden Meldungen der Lokalzeitungen zum Brauchgeschehen den Anschein, als habe sich der pathologische Zustand des Mailehens weiter zugespitzt (Wey 1999).

Der mediale Charakter des Mailehens trägt dazu bei, daß die Relikt- oder die Untergangsthese jeglicher Grundlage entbehrt. Zum Relikt könnte das Mailehen sich nur dann entwickeln, wenn der soziale Austausch innerhalb des Dorfes nicht mehr 
gefragt wäre. Die Folge davon wäre ein Niedergang der Brauchausübung. Daß der offene Anwendungscharakter genuin mit dem Mailehen verbunden und demnach stets vorauszusetzen ist, scheint mir in der Rückschau unabweislich. Überall, wo diese brauchtypische Charakteristik unberücksichtigt blieb, tauchten Verständnisschwierigkeiten auf. Rituelle Handlungsformen, welche die Familienmitglieder, Bediensteten und Freunde eines frühneuzeitlichen Patrizierhaushaltes enger zusammenschließen konnten (Kapitel 2.3), lassen sich mit den in dieser Arbeit ergründeten strukturellen Grundzügen des Mailehens mühelos zusammenbringen. Aber sie fügen sich nicht der von Zender (1979:837) vorgezeichneten Entwicklungslinie, in deren Verlauf ein "magisch-bestimmte[r] rituelle[r] Brauch" zu einem mehr oder minder nachrangigen "Schaustück" auf säkularen Boden herabsinkt.515 Auch an anderen Beispielen konnte gezeigt werden, daß Deutungen in die Irre geführt haben, weil sie konkrete ethnographische Befunde, die sozialen, zeitlichen und räumlichen Bezüge ignoriert haben bzw. weil sie von spezifischen Interessen geleitet waren, welche den Brauch in ein ideologisches Raster zwangen.

Betrachtet man dagegen das Mailehen von einer anderen Ausgangsposition, bei der den weiblichen Beteiligten im Rahmen der Brauchpraxis nicht sämtliche Handlungsoptionen von vornherein beschnitten werden, ergibt sich eine andere Antwort auf die oben formulierte erkenntnisleitende Frage: Das Mädchen und der Junge stellen eine wechselseitige Beziehung auf der Basis einer überlieferten Zuteilungsform her, um daraus einen kommunikativen und interaktiven Austausch zu entwikkeln. ${ }^{516}$ Damit unterliegt man nicht dem Kardinalfehler vorangegangener Maileheninterpretationen, welche den Aspekt der Versteigerung ins Zentrum der Betrachtung gestellt haben. Der Zuteilungsmodus erhält hier lediglich formale Bedeutung, wohingegen die inhaltliche Ausgestaltung der Paarbeziehung in den Vordergrund rückt. Daß von dem Mailehen selbst keine Gewähr über die Sinnhaftigkeit der Brauchpraxis ausgehen kann, liegt bei einer Unterstellung der medialen Wirkungsweise auf der Hand. So wie Sprache, Schrift oder Kunstwerke in ihren Ausgestaltungen eine außerordentliche Fülle von Informationsmöglichkeiten zulassen, läßt auch

${ }^{515} \mathrm{Vgl}$. auch die Typisierungen unter dem Begriff "Spielbrauch", die ebenso auf jene Degeneration von einer ernsthaften zu einer substanzloseren Brauchpraxis hindeuten. Dazu Weinhold ( ${ }^{3} 1882: 285$ Fn. 1) und Zender (1977:135); vgl. auch Schwedt (1989:146).

${ }^{516} \mathrm{Am}$ Rande fügen sich hier zwei Hinweise von GesprächspartnerInnen zu sprachlichen Besonderheiten in diese Perspektive ein:

1. Es wurde mehrfach gesagt, daß sowohl das Mädchen als auch der Junge als Mailehen bezeichnet werden. Dies deutet trotz formaler Unterschiede bei der Paarzuteilung auf den einheitlichen Status der Brauchträgerinnen und Brauchträger hin (vgl. Fn. 3).

2. So wurde im Gruppengespräch I geäußert, daß die Mailehenversteigerung mit dem allgemeinen Auktionsgeschäft nicht vergleichbar sei. Deswegen sei auch der Gebrauch der Verben ersteigern oder versteigern im Zusammenhang mit dem Mailehen unangemessen. Dagegen spreche man von "steigern" (z.B.: Der Junge hat das Mädchen "gesteigert"). In dem Wort versteigern wurde eine pejorative Bedeutung gesehen, welche dem Verständnis der Brauchpraxis zuwiderlaufe. 
das Mailehen eine Vielzahl von sozialen Begegnungsmöglichkeiten zu. ${ }^{517}$ Genau darum ging es meines Erachtens in den Gesprächen, wenn die Betroffenen bei der Frage nach dem Reiz des Brauchgeschehens immer wieder auf den Punkt zu sprechen kamen, daß das Mailehen, das einzige sei, was auf einer relativ offenen, zweckfreien Weise zu einem innerdörflichen Zusammentreffen führe. Frau Pfeiffer bemerkte hierzu:

Ich fand's einfach schön, so ne dörfliche Einheit zu erleben. "Einheit" ist jetzt übertrieben, aber - daß man sich versteht und... - versteht? Auch Quatsch! Daß man zusammenkommt, das ist schön. Das Zusammenkommen - mal. Sich näher kennenlernen - mal. Daß es diese Gelegenheit gibt - das ist jetzt nicht zu den Maiköniginnen, sondern jetzt zu dem Fest allgemein - das finde ich schön! 518

Um diese gewonnene Einsicht über die Gestaltbarkeit des Mailehens rückblickend nochmals in der Empirie zu verankern und das Abstrakte wieder im Konkreten aufgehen zu lassen und die Schwere kulturwissenschaftlicher Analyse ein wenig mit der Leichtigkeit der Brauchpraxis zu versöhnen, sei die Aufmerksamkeit auf folgende Szenen des Mailehens gelenkt:

Frau Kruse: Ah, wat ha'm wir da schon erlebt. Nach der Musik, wenn wir dann alle Mann in der Sektbar sind, dann singen mir dann. Ein Lied nach dem anderen. Das ist so richtig Volksmusik für uns.

Herr Kruse: Dann werden die Geister wach, ne. Und wenn se vielleicht sonst auf Sat 1 immer auf die Volkshitparade schimpfen...

Frau Kruse: ...ach, "Heidi", ne oder "Biene Maya". Also das ist die letzten Jahre "Heidi" und "Biene Maya" der Hit. Ja, und dann singt einer immer vor und wir immer nach. Der Rainer, der immer vorsingt, kommt dann so aus sich raus. Der brüllt manchmal so laut, daß da kein Ton mehr rauskommt. [...]

Ein Jahr ging et da drum. Die Männer, die eben beim Junggesellenverein waren, die haben dann gebrüllt: "Was trinken wir? Bier! Was trinkt der Junggesellenverein? Kaba, Kaba hält sie gesund!". Und da kamen die in einem Jahr mit der Milchkanne an, nem ganzen Paket Kakao und ha'm dat darein geschüttet. Da mußte der Junggesellenverein sich anstellen und mußte dann den Kakao trinken, oh nee. [...].

Herr Kruse: Teilweise kommen die Sachen auch alle spontan aus solchen Dingern dann. Und das ist das Schöne an so'ner Kirmes dann, ne, wo dann auch die - ich will mal sagen jetzt - die Völker sich unterander so total auch verstehen. Kommen Auswärtige dahin, ne, die waren dann vielleicht auch bei denen auf'm Junggesellenfest, ha'm se besucht und dann kommt halt so'was spontan irgendwie, ne. Kommt einer auf die Idee, sagt er: "Weißte wat, wir machen en Gag und holen da ne Milchkanne, tun mer Milch rein, dann geben mir den andern Kaba dann."

${ }^{517}$ Von der archaischen Höhlenmalerei bis zur postmodernen Videoinstallation hat die Kunst neben einer Fülle von Inhalten auch zu einer Fülle von Ausdrucksformen geführt. Beim Mailehen war der Formenbestand dagegen überschaubar. Aber auch hier wurde mit rituellen Handlungsprozessen experimentiert. So erfolgte ein Wandel vom Lehenausrufen zur Mailehenversteigerung. Inzwischen häufen sich die Anzeichen für eine weitere Umwälzung des formellen Brauchablaufs. Gemeint ist die Männerversteigerung (vgl. Kapitel 4.2.4). Ob diese Tendenzen der Brauchinnovation sich durchsetzen werden, wird sich in der Zukunft erweisen. In jedem Falle ergeben sich aus der anbahnenden Entwicklung interessante Anknüpfungspunkte für die weitere Mailehenforschung.

${ }^{518}$ Frau Pfeiffer (46/32/1b:120-134). 
Aber dat hier war vom Jahr davor, oder wie?

Frau Kruse: Da war also nicht die Ellen Maikönigin. Das ist schon länger her, ne.

Genau. Aber ich mein hier, die Milchkanne kam ein Jahr später, nachdem vorher schon irgendwas mit der Milch und den Sprüchen gelaufen war?

Frau Kruse: Nä, dat kam spontan. Der Spruch, der wurde da in dem Jahr dauernd gesungen, ne. Un dann natürlich die Gegenwehr: "Was trinken wir? Bier! Was trinken die Männer? Kaba, Kaba!", ne. Dat wurd dann immer so gegenseitig, um die halt eben zu foppen, zu zanken, ne.

Un dann kamen die Männer...

Frau Kruse: ...dann kamen dann Bauern, "Hee, weißte wat, ich hol jetz ne Kanne Milch!", so in etwa, ne. Un dann Kaba wurd dann irgendwoher... ich weiß net, wie dat zustande kam. Auf jeden Fall hatten die dann auf einmal ne Kanne Milch auf der Tanzfläche stehen, ne. ... Un da ha'm mir, da ha'm mir jegrölt. -

Oder, wie ne Bekannte von uns, die is ja mit nem Musiker verheiratet, die haben acht Jahre, glaub ich, bei uns auf Kirmes Musik gemacht. Un klar, man kennt die nachher, un Sprüche: "Na, wie is'et" und so, ne. Und da ha'm mir denen... nachher ha'm mir denen sogar geholfen, abbauen, zwar mehr schlecht als recht. Un da hat einer von denen gesagt, "Kommt doch mal zu uns. Wir haben auch Maikirmes." [...] Da sind wir dann hingefahren, und dadurch is sogar ne Bekannte mit nem Musiker durch unsere Kirmes zusammen. Sind mittlerweile verheiratet, haben ein...

...also eine Oevericherin und...

Frau Kruse: ...ja, und der wohnt mittlerweile auch in Oeverich. Die haben mittlerweile auch en Kind. Und der holt sich mittlerweile auch für Oeverijer Kirmes frei. Der is Musiker und der sagt: "Also Oeverijer Kirmes mach ich keine Musik", ne. Dat Wochenende hält der sich frei, ne. Schon so is der mit in diese Kirmes einverleibt, ne. Also is Wahnsinn, ne. -

Oder, das war in dem Jahr, wie der uns eingeladen hat zu sich auf Kirmes, und die haben ihre Sachen in das Büsjen gebracht, und da standen draußen zwei Dreirädchen (Kinder nachmittags stehenlassen, ne). Ha'm die die reingebracht, ne. Einer hat sich draufgesetzt, ne, die Beine über't Lenkrad und dann von unten gelenkt. Un der andere hat geschoben, ne. Ja, die Junggesellen hatten natürlich gut einen geschüttet, ne: $a b$ ! Und da war einer, der Olaf, der hatte ne helle Hose an. Und wenn ma dann an den Tischen nicht mehr lenken konnte, [dann gab es] noch mal en guten Schubs und ab durch die Tische und Bänke, ne. Also es hat sich wohl keiner weh getan, aber die Hose die war nachher kohlrabenschwarz. [...] Dat ging da so richtig durchs Zelt, ne, so richtig Wettrennen: zwei Dreirädchen durchs Zelt; war ja leer, ne. Gott, war da ein Theater! -

Oder, ein Jahr hatten wir sogar en Sofa im Zelt stehen, wo Montag, nachmittags, die Männer drauf saßen und haben gut - ich weiß gar net, wo dat Sofa herkam, ne.

War dat da richtig in Szene gesetzt, oder wie?

Frau Kruse: Ne, einfach so. Ich weiß net, wo dat stand. Irgendwo haben die dat hergehabt. Ob denen die Bänke zu hart waren, ich weiß net. Auf einmal, ich kam in't Zelt rein, da hatten die da so en altes Sofa drinstehen. -

Oder, mittlerweile die Frauen, die Mütter von den Junggesellen, ne, die machen ja jetzt auch jeden Montag was, ne.

Jetzt auch im ganzen Jahr über oder meinst Du Kirmesmontag?

Frau Kruse: Nä, die Kirmes, Kirmesmontag. Die haben jedes Jahr en anderes Motto. Ich weiß, et erste Jahr, glaub ich, hatten die alle lange Kleider an, wo ich mich so dran erinnern kann. Et Jahr drauf, glaub ich, da is hier dem bisherigen Junggesellenvorsitzenden seine Mutter mit'm Traktor mit Anhänger gekommen, ne. Sind die durch Oeverich, Niederich gefahren und ha'm die ganzen Frauen abgeholt, ne. Die Frau Keck konnt halt eben Traktorfahren und dann der Anhänger dran und dann allen Mann Frauen, da standen Bänke drauf, ne. Und die ziehen da ja 
gut ab, ne, also die schlucken da ja einiges, ne. Und da hatten se en Jahr, da haben sich alle Wanderklamotten angezogen: Knickerbocker, Stiefel und dann ab. Und ich glaub, in dem Jahr wo die Birgit Maikönigin war, da ha'm se gesagt, ziehen sie alle Hüte an. Die ha'm also jedes Jahr... Un die Treffen sich dann immer bei der Maiköniginsmutter und dann wird dann Kaffee und Kuchen, ne, und dann gehen die in't Zelt. Und teilweise nehmen sie dann auch schon mal da Kuchen mit, und dann geht et so richtig rund, ne.

Herr Kruse: Aber nur die Frauen, ne?

Frau Kruse: Nur die Frauen.

Und was sind das für Frauen? Wie sind die so zusammengekommen?

Frau Kruse: Die von den Mailehen, also von den Mädchen, die gesteigert werden und die von den Junggesellen die Mütter. So alle...

Herr Kruse: ...dadurch wird dat so ne Gemeinschaft, ne?

Frau Kruse: Mhm. Wie auch oftmals, wenn ich meine Mutter frage: "Wat machste denn Weiberfastnacht?" "Ja, mir gehen mit den Frauen weg.", ne, "Mir treffen uns mit den Frauen.", dat sinn dann meistens die. [...]. Wie die letzten Jahre, wenn ich dann kirmesmontags frei hatte, da sagt meine Mutter: "Kannst du dann kochen?" ne, weil die ist dann weg. [...] Dann sinn die dann weg. Aber finde ich aber irgendwo gut. Mittlerweile ist das schon richtiger Brauch, daß die sich treffen, ne.

Seit wann is das denn praktisch so gang und gäbe?

Frau Kruse: Tja - ich würd sagen, die letzten fünf, sechs Jahre.

Hat sich so herausentwickelt?

Frau Kruse: Mhm. Also is mittlerweile schon... Gehört dazu, ne. Und dat war mehr oder weniger durch en Zufall. Ich schätze mal, weil die sich immer unverabredet getroffen haben im Zelt, ne. Klar, dann bilden sich immer Klübchen, ne. Und dann irgendwann: "Ja, da müßten wir ja wat richtiges draus machen!?" Und irgendwann ha'm die dann gesagt: "Komm, gehen wir nach Haus und ziehen uns lange Kleider an oder sonst irgendwat!". Un dann ha'm die sich dann mit den letzten Jahren schon vorher verabredet und haben gesagt: "Dann und dann machen wir das und das", ne. Das find ich irgendwo, find ich gut. - Da sin dann so die Mütter, teilweise sin da sogar Frauen dabei, wo die Kinder noch zu klein sind, daß sie mitgesteigert werden. So einige Frauen...

...die dann mitgerissen werden, sozusagen...

Frau Kruse: ...Mhm. Genau. ${ }^{519}$

Mit den wachen Erinnerungen an die kreative Aneignung des Mailehens führt die Gesprächspassage aus, was oben unter der Metapher des "Tamtam" angedeutet worden war. Ob das ausgelassene Singen des sogenannten "harten Kerns" am Ende des Tanzabends, die spöttische Inszenierung des Kakaotrunks der Junggesellen, die folgenreiche Kontaktaufnahme zwischen Musikern und Kirmesgästen, das improvisierte Dreiradwettrennen, das alte Herrensofa im Festzelt oder der Treff der Maimütter, alle Beispiele gehen zurück auf ein gemeinsames Medium, das sie ermöglicht hat: das Mailehen. Und alle Beispiele zeugen von einer Vitalität, von einer Erlebnisdichte, wie sie unter gewöhnlichen Umständen kaum anzutreffen ist. Insofern liegt ein Eigenwert des Brauches tatsächlich darin, solche unplanmäßigen und imponder-

${ }^{519}$ Frau und Herr Kruse (25/17/1a:335-503). 
ablen Erlebnisse gleichsam magnetisch anzuziehen. Daß die Möglichkeit zum Agieren für den einzelnen geschaffen wurde, das ist das entscheidende Moment, und dafür bot das Mailehen einen festen äußeren Rahmen. Dieser war offenbar überaus effektiv, denn in ihm entstanden diejenigen Handlungen, die von vielen Brauchbeteiligten gewünscht und erwartet wurden. Dies konnte - wie im Beispiel des Maimüttertreffens - so weit gehen, daß aus spontanen Aktivitäten rituelle Handlungen geboren wurden, die dem Mailehen in Oeverich ein neues Brauchelement zur Seite gestellt haben.

\subsection{Brauchforschung und das Erlebnis des " Üb e rlebte n"}

"Das Dilemma ist 'hausgemacht' und bedarf einer Lösung" - damit hat Bimmer (21994:392) nochmals jener Forderung Nachdruck verliehen, daß die Brauchforschung einer erkenntniskritischen Revision unterzogen werden müßte, um den Ansprüchen von Wissenschaftlichkeit zu genügen. Überholte Begrifflichkeiten, einseitige methodische Zugänge, fehlgeleitete Ausgangspositionen oder gar der Mangel einer Theorie des Brauches wurden seit annähernd drei Jahrzehnten als Indikatoren einer ins Abseits driftenden volkskundlichen Teildisziplin benannt. ${ }^{520} \mathrm{Da}$ eine umfassende Bearbeitung der angesprochenen Probleme weiterhin aussteht, ist nach den Gründen der anhaltenden Zurückhaltung $\mathrm{zu}$ fragen. Kommen die Erwartungen an eine Erneuerung der Brauchforschung einer unerfüllbaren und daher unannehmbaren Herausforderung gleich oder liegen die Ursachen eher in einer sich wandelnden Präferenzstruktur volkskundlicher Gegenstandsbereiche, bei der die Beschäftigung mit Bräuchen nahezu ausgedient hat? ${ }^{521}$ Freilich kann eine Lösung des Dilemmas nur von einer breiten materialvergleichenden Auseinandersetzung zu dieser Thematik erwartet werden. Deshalb sollen hier lediglich Anregungen in die stockende Diskussion eingebracht werden, die aus der Beschäftigung mit dem Mailehen weiter an Plausibilität gewonnen haben.

Die Analyse des Mailehens erforderte die Beschäftigung mit der Fachgeschichte. Seit dem 19. Jahrhundert wurde von namhaften Volkskundlerinnen und Volkskundlern wertvolles empirisches oder historisches Faktenmaterial ans Tageslicht gebracht, das den Grundstock für detaillreiche phänomenologische Beschreibungen und scharfsinnige Erklärungsversuche bildete. Die "hohen Schreibtische" einer distanzierten

${ }^{520}$ Siehe z.B. Weber-Kellermann (1973:I-V; 1984:23-29 und 1985:10-17).

${ }^{521}$ In Parenthese gesteht auch Hartinger (1992:37) den Bedeutungsverlust der Brauchforschung ein: "Über den hohen Stellenwert der Brauchtumsforschung innerhalb des Faches ist sich die (besonders ältere) Volkskunde einig". 
Lehnstuhl-Ethnologie verhinderten jedoch den Blick und den Zugang auf das ins Brauchgeschehen involvierte Subjekt (Kaschuba 1986:502). Anders gesagt, die Wahrnehmung der AkteurInnen verflüchtigte sich unter den spezifischen Erkenntnisinteressen und Konstrukten der Forschenden. Dabei trieb man die Analyse zuweilen so weit, daß die aufgestellten Behauptungen der Brauchpraxis diametral entgegen standen. Deshalb lassen sich in den mythologischen Ansätzen kaum noch Bezüge zum konkreten Braucherlebnis wiederfinden. Die Maikönigspaare treten hier nicht als Menschen, sondern als Inkarnationen von Gottheiten bzw. Dämonen und damit als die TrägerInnen einer Idee auf.

Die subjektlosen Brauchanalysen mußten einer realtitätsnahen Forschung im Wege stehen. Und tatsächlich war die Spurensuche im historisch überlieferten Quellenbestand fast aussichtslos, weil nur in Ausnahmefällen fundierte Hinweise auf die Brauchbeteiligten gegeben wurden, geschweige denn auf das soziale Umfeld. Hinzu kommt, daß ebenso selten unmittelbare Zeugnisse von den Betroffenen anzutreffen sind. So begnügte man sich in der Mailehenforschung über weite Strecken mit spekulativen Deutungen. Implizit oder explizit war oftmals von der rigiden Sitte die Rede, die zu einer fraglosen Anwendung der Brauchformen führen würde. Damit wurden die Handelnden, zugespitzt formuliert, zu Ausführenden, die offenbar bedingungslos den ungeschriebenen Gesetzen einer sozialen Mechanik folgten. Sie wurden in letzter Konsequenz $\mathrm{zu}$ vorherbestimmbaren Objekten, die sich dem Brauchrhythmus in aller Regelmäßigkeit auslieferten. Reflektierendes Bewußtsein, Gedanken, Gefühle, Eigensinn, Kreativität und Spontaneität, Dinge, welche die Persönlichkeit eines Menschen im Innersten kennzeichnen, wurden von der Brauchforschung älterer Machart ignoriert. Hier war für die Mailehenforschung eine folgenschwere Lücke zu schließen. Im Vordergrund stand nun die Perspektive der vom Brauch Betroffenen, und damit wurde die Chance verbunden, vermeintliche Anachronismen und asymmetrische Rollenzuweisungen zu verstehen. Die Gefahr der Ansammlung zusammenhangsloser Einzelaussagen erwies sich als unbegründet. Die soziale und kulturelle Ordnung wurde gerade im subjektiven Erleben sichtbar. Dort erlangte sie eine zentrale Stellung, wenn auch nicht die einer determinierenden ahistorischen Übermacht (vgl. Lipp 1988:33-35).

Damit ergeben sich nach meiner Sicht Anknüpfungspunkte für eine Neuorientierung der Brauchforschung. Das beharrliche Festhalten an der Sitte/Norm-BrauchMechanik kann weder das Ziel einer historisch noch empirisch orientierten Brauchforschung sein. Für beide Zugangsweisen muß die Aufdeckung der dynamischen Beziehungen zwischen Brauch, Individuum und Gesellschaft bzw. das wechselseitige Verhältnis von Brauchform und -inhalt erkenntnisleitend sein. Daß diese Forderung insbesondere für die Vergangenheitsbetrachtungen schwer zu erfüllen ist, wurde hinreichend expliziert. Dennoch lohnt es sich, mit der aufzubietenden detektivischen 
Akribie, die subjektiven Zugänge zu den historischen Lebenswelten zu erschließen. In jedem Falle darf der Mangel an Daten, die für eine angemessene Interpretation notwendig sind, nicht dazu verleiten, in dem Brauchgeschehen der Vergangenheit per se einen Reflex auf die gesellschaftliche Normierung zu erkennen. Und was die jüngeren Entwicklungen der Brauchpraxis betrifft, wäre es ebenso verfehlt, hinter den publikumsbezogenen, folkloristischen oder kommerziellen Zügen rezenter Brauchausübungen nur noch die Auflösung sozialer Verbindlichkeiten festzustellen. Die "Endphase des Brauchtums" (Kramer 1988:127-142) einzuläuten, wirkt daher nicht weniger abwegig als jene Prognosen aus dem 19. Jahrhundert, die dem Mailehen das Etikett des Überlebten anhefteten.

Aus dem hier beschrittenen Weg der Brauchanalyse wurde der Blick frei für eine mediale Substanz der Brauchpraxis. Dem außenstehenden Betrachter erschien das Mailehen seit Mitte des 19. Jahrhunderts als Anachronismus, weil er die Formen der Brauchausübung nicht in Beziehung zu den gewandelten sozialen, räumlichen und zeitlichen Gegebenheiten setzen konnte. Der tiefere Sinn des rituellen Geschehens mußte im Verborgenen bleiben, solange die Dimension der Performanz nicht genügend ins Blickfeld geriet.522 Die Berücksichtigung der Performanz mündet einerseits in eine lebendige, praxisnahe Ethnographie, sie drängt aber andererseits auch zu einer Erneuerung von Brauchforschungsansätzen, bei der eine angemessene Gewichtung der Relationen zwischen dem Brauch als kultureller Objektivation, dem Individuum als handelndem Subjekt mit eigendynamischer Potenz und dem sozialen Bezugsrahmen stattfindet. Die Orientierung bisheriger Erklärungsversuche an relativ starren Brauchformen führte $\mathrm{zu}$ einer Vereinseitigung der Argumente und endete allzu oft in einer spekulativen Ursprungssuche, einer werturteilsgeleiteten Traditionsrhetorik oder in Entstellungen durch die Perpetuierung falscher Grundannahmen, die mit der Brauchpraxis nur wenig gemein hatten. Beschreibt man dagegen das Mailehen als Medium, so entfernt man sich von einer einseitig formalisierten Objektzentrierung, da der Sinn des Brauches aus einer dynamischen Beziehung erwächst, welche die Beteiligten aus der sozial und kulturell eingebetteten Anwendung des Mediums entwickeln und welche das Braucherlebnis wesentlich prägt. Die Klärung dieser relationalen Beziehung erfordert die Analyse der inhaltlichen Seite der Brauchausübung. Und damit müssen die subjektspezifischen Hintergründe der Beteiligung $\mathrm{zu}$ einem leitenden Thema der Brauchforschung werden.

${ }^{522} \mathrm{Im}$ Rahmen der Erzählforschung gelang es Barre Toelken (1981:39-49), überzeugend nachzuweisen, wie wirklichkeitsentstellend eine Interpretation von Volksliedern ausfallen kann, bei welcher die "dynamische, menschliche und kulturelle Situation, in der die Überlieferung tatsächlich stattfindet" (1981:39), nicht berücksichtigt wird. Der hiermit angesprochene Performanzaspekt kann auch bei der Brauchanalyse keineswegs folgenlos übergangen werden. 


\section{Quellen- und Literaturverzeichnis}

\subsection{Archivalien}

Amt für rheinische Landeskunde Bonn: T-170 (Accuratissimi extractus ex protocolis; Impekovener Mottekopp).

Landeshauptarchiv Koblenz: Bürgermeister-Rechnung der Stadt St. Goar vom Jahr 1562. Bestand 638, Nr. 77.

Volkskundliches Seminar der Universität Bonn: Rheinischer Fragebogen Nr. 1665 Bengen und Nr. 1546 Leimersdorf 1922.

\subsection{Gedruckte Quellen und Materialien}

Bous, Robert und Klein, Hans-Georg: Quellen zur Geschichte der Stadt Ahrweiler (856-1812). Bad Neuenahr-Ahrweiler 1998.

Cardauns, Hermann und Müller, Reiner (Hrsg.): Die rheinische Dorfchronik des Joan Peter Delhoven aus Dormagen (1783-1823). Dormagen 1966.

Geist, Monika; Müllenbach, Konrad und Stolz, Hans: Entwicklungsprogramm für den Landkreis Ahrweiler. St. Augustin 1977.

Frick, Hans: Quellen zur Geschichte von Bad Neuenahr. Bad Neuenahr 1933.

Herodot: Geschichten und Geschichte. Buch I-IV. Übersetzt von Walter Marg. Zürich u.a. 1973.

Herodotos: Buch I. Erklärt von Heinrich Stein. Mit einer Einleitung über Leben, Werk und Dialekt Herodots und einer Karte. 8. Auflage. Dublin u.a. 1968.

Kaiser, Joh. Bapt. (Hrsg.): Das Archidiakonat Longuyon am Anfange des 17. Jahrhunderts. Visitationsbericht von 1628-1629. Erster Teil: Die vier wallonischen Dekanate. Heidelberg 1928.

Kreisverwaltung Ahrweiler: Serviceteil: Aktuelle Daten und Fakten. (Beilage in: Dies.: Dienst Leistung - Zukunft). Bad Neuenahr-Ahrweiler 1999a.

Kreisverwaltung Ahrweiler: Dienst - Leistung - Zukunft: Produkte, Positionen und Profile. Bericht der Kreisverwaltung Ahrweiler für den Zeitraum von 1996 bis 1999. Bad Neuenahr-Ahrweiler 1999b.

Landkreis Ahrweiler Wirtschaftsförderung: Wirtschaft in Zahlen (Faltblatt) o. J.

Meisen, Karl: Eine volkskundliche Beschreibung von Jülich und Berg. In: Annalen des historischen Vereins für den Niederrhein. 126(1935)77-107.

Pfeilstücker, Heinrich (Hrsg.): Sammlung der allgemeinen und für den Regierungsbezirk Trier besonders gültigen Polizeigesetze und Verordnungen. Nebst einem Anhange, enthaltend die für die einzelnen Bürgermeistereien des landräthlichen Kreises Saarbrücken bestehenden LokalPolizei-Verordnungen. Saarbrücken 1841.

Prothmann, Ottmar: Chronik der Bürgermeisterei Gelsdorf. Meinerzhagen 1988.

Prothmann, Ottmar: Festschrift zum 100jährigen Bestehen des Junggesellenvereins OeverichNiederich 1889-1989. Oeverich 1989.

Prothmann, Ottmar: Das dörfliche Leben der Gemeinde Grafschaft im Umbruch. Gedruckte Vortragsfassung (verkürzt gehalten in Eckendorf am 28. November 1995). O.O. 1995. 
Prothmann, Ottmar: Chronik von Nierendorf. Nierendorf 1998.

Redlich, Otto: Jülich-Bergische Kirchenpolitik am Ausgange des Mittelalters und in der Reformationszeit. Bd. 2.1 Visitationen und Berichte. Jülich (1533-1589). Bonn 1911.

Sammlung der wichtigsten allgemeinen Verordnungen und Bekanntmachungen seit der Wiedereinrichtung der Erzdiozöse Köln. Köln 1837.

Scotti, J. J.: Sammlung der Gesetze und Verordnungen, welche in dem vormaligen Churfürstenthum Cöln (im rheinischen Erzstifte Cöln, im Herzogthum Westphalen und im Veste Recklinghausen) über Gegenstände der Landeshoheit, Verfassung, Verwaltung und Rechtspflege ergangen sind, vom Jahre 1463 bis zum Eintritt der Königl. Preußischen Regierungen im Jahre 1816. 4 Bde. Düsseldorf 1830-1831.

Scotti, J. J.: Sammlung der Gesetze und Verordnungen, welche in dem vormaligen Churfürstentum Trier über Gegenstände der Landeshoheit, Verfassung, Verwaltung und Rechtspflege ergangen sind, vom Jahre 1310 bis zur Reichs-Deputations-Schlussmäßigen Auflösung des Churstaates Trier am Ende des Jahres 1802. Düsseldorf 1832.

Statistisches Jahrbuch für Rheinland-Pfalz. Herausgegeben vom Statistischen Landesamt RheinlandPfalz. Bad Ems 1959ff.

Weiler, Joachim: "Bildung muss das Mega-Thema unserer Gesellschaft werden". In: Kreisverwaltung Ahrweiler: Dienst - Leistung - Zukunft. 1999, 48.

Weinsberg, Hermann von: Das Buch Weinsberg. Kölner Denkwürdigkeiten aus dem 16. Jahrhundert, hrsg. von Konst. Höhlbaum (Bd.1-2), Fried. Lau (Bd. 3-4) und Jos. Stein (Bd.5). 5 Bde. Leipzig, Bonn 1886-1926.

Wießner, Edmund: Kommentar zu Heinrich Wittenwilers Ring. Leipzig 1936.

Wießner, Edmund (Hrsg.): Heinrich Wittenwilers Ring. Nach der Meininger Handschrift. Leipzig 1931.

Wittenwiler, Heinrich: Der Ring. Frühneuhochdeutsch/Neuhochdeutsch. Nach dem Text von Edmund Wießner ins Neuhochdeutsche übersetzt und herausgegeben von Horst Brunner. Stuttgart 1991.

Vollständige Sammlung ...: Vollständige Sammlung deren die Verfassung des Hohen Erzstifts Cölln betreffender Stucken, mit denen benachbahrten Hohen Landes-Herrschaften geschlossener Concordaten und Verträgen, dann in Regal- und Cameral-Sachen, in Justiz- Policey- und Militär-Weesen vor- und nach ergangener Verordnungen, und Edicten. Aus Gnädigstem Befehl Ihrer Churfürstlichen Gnaden zu Cölln Maximiliani Friderici zusammen getragen, und zum Druck befördert. 2 Bände. Cölln am Rhein 1772/-1773.

\subsection{Wörterbücher}

Deutsches Wörterbuch von Jacob und Wilhelm Grimm. 16 Bde. Leipzig 1854-1960.

Frankfurter Wörterbuch herausgegeben von Wolfgang Brückner. 6 Bde. Frankfurt am Main 19711985.

Hessen-Nassauisches Volkswörterbuch von Luise Berthold. (mehrbändig). Marburg 1927ff.

Pfälzisches Wörterbuch. Bearbeitet von Julius Krämer. (mehrbändig). Wiesbaden $1965 \mathrm{ff}$.

Rheinisches Wörterbuch bearbeitet und herausgegeben von Josef Müller. 9 Bde. Berlin 1928-1971.

Schweizerisches Idiotikon. Wörterbuch der schweizerdeutschen Sprache. Bearbeitet von Friedrich Staub und Ludwig Tobler [u.a.]. (mehrbändig). Frauenfeld $1881 \mathrm{ff}$.

Südhessisches Wörterbuch. Begründet von Friedrich Maurer und bearbeitet von Rudolf Mulch. (mehrbändig). Marburg 1968ff. 


\subsection{Filmverzeichnis}

Das Jungenspiel in Würselen 1979. 16mm, farb, Lichtton, 351m, 32 Min. (24 B/sek), prod. 1979 (Verleih Nr. 3245303 Amt für rheinische Landeskunde Bonn oder Landesbildstelle Rheinland Düsseldorf) Gabriel Simons, Bonn.

Maibaum und 1. Mai. Eine Dokumentation. (Fernsehserie "Tradition und Gesellschaft in Hessen"). 16mm, farb, ton, 308m, 28 Min. 12 Sek. (24 B/sek), prod. 1969/70, publ. 1971. (Verleih Nr. W 2034 IWF Göttingen [Videoband]). Ingeborg Weber-Kellermann, Marburg und Harald Schäfer (HR, Ffm). 1971.

Maibräuche in Körrenzig. Maibaumaufsetzen - Balbieren der Neulinge - Maienstecken. 16mm, farb, Lichtton, 307m, 28 Min. (24 B/sek), prod. 1979 (Verleih Nr. 3245011 Amt für rheinische Landeskunde Bonn oder Landesbildstelle Rheinland Düsseldorf). Gabriel Simons und Ayten Fadel, Bonn.

Maifest in Bornheim bei Bonn - Bornheim 1962. 16mm, farb., ton., 143m, 13 Min. (24 B/sek), prod. 1962 (Verleih Nr. 3344557 Amt für rheinische Landeskunde Bonn oder Landesbildstelle Rheinland Düsseldorf). Gabriel Simons 1962.

Die Pfingsteierkrone - Küdinghoven/Bonn 1984. 16mm, farb, Lichtton, 461m, 42 Min (24 B/sek), prod. 1984 (Verleih Nr. 3245129 Amt für rheinische Landeskunde Bonn oder Landesbildstelle Rheinland Düsseldorf). Gabriel Simons und Ayten Fadel, Bonn.

Versteigerung der Mailehen beim JGV Gemütlichkeit in Gielsdorf/Vorgebirge am 10. April 1976. 16mm, farb, Lichtton, 351m, 32 Min. (24 B/sek), prod. 1976 (Verleih Nr. 3245109 Amt für rheinische Landeskunde Bonn oder Landesbildstelle Rheinland Düsseldorf). Gabriel Simons, Bonn.

\subsection{Literaturverzeichnis}

Anonymus: Mädchen=Lehn, Mai=lehn auf dem Lande in der Rheingegend. In: Gemeinnützige und unterhaltende Rheinische Provinzial=Blätter N.F. 3(1836a)3-5.

Anonymus: Seltsamer Gebrauch in der Gegend von Uelmen. In: Gemeinnützige und unterhaltende Rheinische Provinzial=Blätter N.F. 3(1836b)122-123.

Anonymus: Mädchen= oder Mai=lehen in der Eifel. In: Gemeinnützige und unterhaltende Rheinische Provinzial=Blätter N.F. 3(1836c)82-86.

Assion, Peter: Historismus, Traditionalismus, Folklorismus. Zur musealisierenden Tendenz der Gegenwartskultur. In: Jeggle, U. et al. (Hrsg.): Volkskultur in der Moderne. 1986, 351-362.

Arbeitsgruppe Bielefelder Soziologen (Hrsg.): Alltagswissen, Interaktion und gesellschaftliche Wirklichkeit, Bd.1: Symbolischer Interaktionismus und Ethnomethodologie. Reinbek 1973.

Arbeitsgruppe Bielefelder Soziologen (Hrsg.): Alltagswissen, Interaktion und gesellschaftliche Wirklichkeit, Bd.2: Ethnotheorie und Ethnographie des Sprechens. Reinbek 1976a.

Arbeitsgruppe Bielefelder Soziologen (Hrsg.): Kommunikative Sozialforschung. Alltagswissen und Alltagshandeln; Gemeindemachtforschung; Polizei; Politische Erwachsenenbildung. München 1976b.

Arbeitsgruppe volkskundliche Frauenforschung (Hrsg.): Frauenalltag - Frauenforschung. Beiträge zur 2. Tagung der Kommission Frauenforschung in der Deutschen Gesellschaft für Volkskunde, Freiburg, 22.-25. Mai 1886. Frankfurt am Main u.a.1988.

Aubin, Hermann: Agrargeschichte. In: Gesellschaft für Rheinische Geschichtskunde: Geschichte des Rheinlandes. 2. Band. 1922, 115-148. 
Aubin, Hermann; Frings, Theodor und Müller, Josef: Kulturströmungen und Kulturprovinzen in den Rheinlanden. Geschichte - Sprache - Volkskunde. Mit einem Vorwort zur Neuausgabe von Franz Petri und Nachworten zum geschichtlichen und volkskundlichen Beitrag von Hermann Aubin und Matthias Zender (reprographischer Nachdruck der Ausgabe Bonn 1926). Bonn 1966.

Back, Friedrich: Die evangelische Kirche im Lande zwischen Rhein, Mosel, Nahe und Glan bis zum Beginn des dreißigjährigen Krieges. 3 Bde. Bonn 1872-74.

Back, Friedrich (Hrsg.): Chroniken der Pfarreien der Ämter Birkenfeld und Frauenberg vom Ende des 16. und dem Anfang des 17. Jahrhunderts. Aus dem Nachlasse des Superintendenten D. Friedrich Back. Birkenfeld 1899.

Ballhaus, Edmund: Auf wissenschaftlichem Diskurs - Land in Sicht? Dörflicher Alltag im volkskundlichen Film. In: Becker, S. et al (Hrsg.): Ländliche Kultur. 1989, 150-185.

Barlen-Ebert, Sigrid: Mailiedausrufen und Jungenspiel in einem Ort des Aachener Raumes. In: Hessische Blätter für Volkskunde 51/52(1960)5-28.

Bauer, F.: Die Mädchenversteigerung in der Pfalz. In: Pfälzisches Museum 21(1904)147.

Baur, Ludwig: Das Liehn- oder Lehn-Ausrufen. In: Archiv für Hessische Geschichte und Alterthumskunde 8(1856)567-569.

Bausinger, Hermann; Jeggle, Utz; Korff, Gottfried und Scharfe, Martin: Grundzüge der Volkskunde. Darmstadt 1978.

Bausinger, Hermann: Volkskunde. Von der Altertumsforschung zur Kulturanalyse. Unveränderter Nachdruck der Ausgabe 1971. Darmstadt 1979.

Bausinger, Hermann: Zur Spezifik volkskundlicher Arbeit. In: Zeitschrift für Volkskunde 76(1980)121.

Bausinger, Hermann: Brauchtradition - Erhaltung, Veränderung, Mitgestaltung. In: Beiträge zur Volkskunde in Baden Würtemberg. 1(1985)9-21.

Bausinger, Hermann: Volkskultur in der technischen Welt. Frankfurt am Main u.a. 1986.

Bausinger, Hermann: Name und Stereotyp. In: Gerndt, H. (Hrsg.): Stereotypvorstellungen im Alltagsleben. 1988, 13-19.

Beck, Rainer: Illegitimität und voreheliche Sexualität auf dem Land. Unterfinning, 1671-1770. In: Dülmen, R. v. (Hrsg.): Kultur der einfachen Leute. 1983, 112-150.

Beck, Ulrich: Risikogesellschaft. Auf dem Weg in eine andere Moderne. Frankfurt am Main 1986.

Beck, Ulrich und Beck-Gernsheim, Elisabeth: Individualisierung in modernen Gesellschaften Perspektiven und Kontroversen einer subjektorientierten Soziologie. In: Dies. (Hrsg.): Riskante Freiheiten. 1994, 10-39.

Beck, Ulrich und Beck-Gernsheim, Elisabeth (Hrsg.): Riskante Freiheiten. Individualisierung in modernen Gesellschaften. Frankfurt am Main 1994.

Becker, Albert: Die Mädchenversteigerung in der Pfalz. In: Pfälzisches Museum. Monatsschrift für heimatliche Literatur und Kunst, Geschichte und Volkskunde 21(1904)121-122.

Becker, Albert: Frauenrechtliches in Brauch und Sitte. Programm des K. Hum. Gymnasiums Zweibrücken 1912/13. Zweibrücken 1913.

Becker, Albert: Volkskundliches aus der Reformationszeit. In: Oberdeutsche Zeitschrift für Volkskunde 13(1939)28-33.

Becker, Siegfried und Bimmer, Andreas C. (Hrsg.): Ländliche Kultur. Internationales Symposion am Institut für Europäische Ethnologie und Kulturforschung, Marburg, zu Ehren von Ingeborg Weber-Kellermann. Göttingen 1989.

Becker, Thomas Paul: Konfessionalisierung in Kurköln. Bonn 1989. 
Becker, Thomas: Brauchtum. In: Faust, A. (Red.):Nordrhein-Westfalen. ${ }^{2} 1994,70-75$.

Bell, Catherine: Ritual Theory, Ritual Practice. New York 1992.

Bell, Catherine: Ritualkonstruktion. In: Belliger, A. et al. (Hrsg.): Ritualtheorien. 1998, 37-48.

Belliger, Andréa und Krieger, David J.: Einführung. In: Dies. (Hrsg.): Ritualtheorien. 1998, 7-33. Belliger, Andréa und Krieger, David J. (Hrsg.): Ritualtheorien. Ein einführendes Handbuch. Opladen u.a. 1998. Bellinghausen, Hans: Winningen. Ein deutsches Heimatbuch. 2 Bde. Coblenz 19231925.

Berg, Eberhard und Fuchs, Martin (Hrsg.): Kultur, soziale Praxis, Text. Die Krise der ethnographischen Repräsentation. Frankfurt am Main 1993.

Berliner Geschichtswerkstatt (Hrsg.): Alltagskultur, Subjektivität und Geschichte. Zur Theorie und Praxis von Alltagsgeschichte Münster 1994.

Bimmer, Andreas C.: Vom "-tum" in der Volkskunde. In: Österreichische Zeitschrift für Volkskunde 93, N.S. 44(1990)150-173.

Bimmer, Andreas C.: Brauchforschung. In: Brednich, R.W. (Hrsg.): Grundriß der Volkskunde. ${ }^{2} 1994$, 375-396.

Biundo, Georg: Kirchenvisitationsprotokoll des Oberamtes Lichtenberg 1544. In: Blätter für pfälzische Kirchengeschichte und religiöse Volkskunde 18(1951)53-55.

Biundo, Georg: Die Leiningen-Westerburger Kirchen- und Poizeiordnung vom Jahre 1566. In: Blätter für pfälzische Kirchengeschichte und religiöse Volkskunde 27(1960)1-22.

Bothe, Friedrich: Brauch und Sitte im alten Frankfurt. Frankfurt am Main 1941.

Bourdieu, Pierre: Die feinen Unterschiede. Kritik der gesellschaftlichen Urteilskraft. Frankfurt am Main 1982.

Bourdieu, Pierre: Sozialer Sinn. Kritik der theoretischen Vernunft. Frankfurt am Main 1987.

Bourdieu, Pierre: Was heißt sprechen? Die Ökonomie des sprachlichen Tausches. Wien 1990.

Bourdieu, Pierre: Rede und Antwort. Frankfurt am Main 1992.

Bourdieu, Pierre: Narzißtische Reflexivität und wissenschaftliche Reflexivität. In: Berg, E. et al. (Hrsg.): Kultur, soziale Praxis, Text. 1993, 365-374.

Bourdieu, Pierre und Wacquant, Loic J.D.: Reflexive Anthropologie. Frankfurt am Main 1996.

Bracke, Erika: Fruchtbarkeitskult und Männerbund im Maibrauchtum. (masch.schriftl. Diss.). Wien 1943.

Breckner, Roswitha: Von den Zeitzeugen zu den Biographen. Methoden der Erhebung und Auswertung lebensgeschichtlicher Interviews. In: Berliner Geschichtswerkstatt (Hrsg.): Alltagskultur, Subjektivität und Geschichte. 1994, 199-222.

Brednich, Rolf Wilhelm: Zum Stellenwert erzählter Lebensgeschichte in komplexen volkskundlichen Feldprojekten. In: Ders. et al. (Hrsg.): Lebenslauf und Lebenszusammenhang. 1982, 46-70.

Brednich, Rolf Wilhelm: Quellen und Methoden. In: Ders. (Hrsg.): Grundriß der Volkskunde. ${ }^{21994,}$ 73-96.

Brednich, Rolf Wilhelm (Hrsg.): Lebenslauf und Lebenszusammenhang, Autobiographische Materialien in der volkskundlichen Forschung. Vorträge der Arbeitstagung der Deutschen Gesellschaft für Volkskunde in Freiburg i. Br. vom 16. bis 18. März 1981. Freiburg i. Br. 1982.

Brednich, Rolf Wilhelm (Hrsg.): Grundriß der Volkskunde. Einführung in die Forschungsfelder der europäischen Ethnologie. 2., überarb. und erw. Aufl. Berlin 1994.

Bremer, J.: Das kurkölnische Amt Liedberg. Mönchengladbach 1930. 
Brooks, Nelson: Teaching culture in the foreign language classroom. In: Foreign Language Annals 1(1968)204-217.

Brückner, Wolfgang: Hans Mosers Bedeutung für die Volkskunde. In: Moser, H.: Volksbräuche im geschichtlichen Wandel. 1985, X-XI.

Brückner, Wolfgang: Trachtenfolklorismus. In: Jeggle, U. et al. (Hrsg.): Volkskultur in der Moderne. 1986, 363-382.

Brunner, Horst: Siehe unter gedruckte Quellen: H. Wittenwiler. 1991.

Caduff, Gian: Die Knabenschaften Graubündens. Eine volkskundlich kulturhistorische Studie. Chur 1932.

Chernoff, John M.: African Rhythm and African Sensibility. Aesthetics and Social Action in African Idioms. Chicago u.a. 1979.

Christmann, Helmut; Hempenstall, Peter und Ballendorf, Dirk Anthony: Die Karolinen-Inseln in deutscher Zeit. Eine kolonialgeschichtliche Fallstudie. Münster u.a. 1991.

Cicourel, Aaron V.: Methode und Messung in der Soziologie. Frankfurt am Main 1974.

Conrath, Karl: Der Brauch des Mai Lehenausrufens. In: Saarheimat. Zeitschrift für Kultur, Landschaft, Volkstum 5. Jahrgang, Heft 6, 1962, 4-5.

Cox, Heinrich L.: Volkskundliche Kulturraumforschung im Rhein-Maas-Gebiet (1920-1990). In: Rheinisches Jahrbuch für Volkskunde (1989/1990)29-67.

Cromberg, Hans Ekhardt: Die Knabenschaftsstatuten der Schweiz. Spiegelbild von Sitte, Brauchtum und Recht. Winterthur 1970.

Devereux, Georges: Angst und Methode in den Verhaltenswissenschaften. 3. Aufl. Frankfurt am Main 1992.

Dierker, Friedrich: Das rheinische Mailehen nach seinem Wesen, seiner Verbreitung und seiner Stellung in der Gemeinschaft. Wuppertal-Elberfeld 1939.

Dietz, Josef: Raue Sitten bei der Mailehenversteigerung. In: Rheinisch-westfälische Zeitschrift für Volkskunde 3(1956)94-99.

Doering-Manteuffel, Sabine: Die Eifel. Geschichte einer Landschaft. Frankfurt am Main u.a. 1995.

Duden, Barbara: Genus und das Objekt der Volkskunde im Licht der neueren Körpergeschichte. In: Köhle-Hezinger, C. et al. (Hrsg.): Männlich. Weiblich. 1999, 66-74.

Dülmen, Richard van (Hrsg.): Kultur der einfachen Leute. Bayerisches Volksleben vom 16. bis zum 19. Jahrhundert. München 1983.

Dülmen, Richard van und Schindler, Norbert (Hrsg.): Volkskultur. Zur Wiederentdeckung des vergessenen Alltags (16.-20. Jahrhundert). Frankfurt am Main 1984.

Dünninger, Dieter: Wegsperre und Lösung. Formen und Motive des dörflichen Hochzeitbrauches. Ein Beitrag zur rechtlich- volkskundlichen Brauchtumsforschung. Berlin 1967.

Dünninger, Josef: Brauchtum. In: Stammler, W. (Hrsg.): Deutsche Philologie im Aufriß. 2. Aufl. Berlin u.a. 1962, 2571-2640.

Dünninger, Josef und Schopf, Horst (Hrsg.): Bräuche und Feste im fränkischen Jahreslauf. Texte vom 16. bis zum 18. Jahrhundert. Kulmbach 1971.

Eckertz, G.: Chronik der Stadt Sinzig: In: Annalen des Historischen Vereins für den Niederrhein, Heft 13/14 (1863/64) 256-270.

Edelstein, Wolfgang und Nunner-Winkler, Gertrud (Hrsg.): Zur Bestimmung der Moral. Philosophische Beiträge zur Moralforschung. Frankfurt am Main 1986. 
Emge, Carl August: Über die unechte Alternative zwischen dem Kollektiv und dem Einzelnen. In: Akademie der Wissenschaften und der Literatur: Abhandlungen der geistes- und sozialwissenschaftlichen Klasse. Heft Nr. 10. Wiesbaden 1953.

Ennen, Edith und Wiegelmann, Günter (Hrsg.): Festschrift Matthias Zender. Studien zur Volkskultur, Sprache und Landesgeschichte. Bonn. 1972.

Erikson, Erik Homburger: Jugend und Krise. Die Psychodynamik im sozialen Wandel. München 1988.

Faber, Michael H.: "Zum ersten, zum zweiten und zum dritten". Frauenauktionen im Rheinland. In: Völger, G. et al. (Hrsg.): Die Braut: Geliebt, verkauft, getauscht, geraubt. Zur Rolle der Frau im Kulturvergleich. 2 Bde. Köln. 1985, 440-448.

Faber, Michael H. und Ziegler, Torsten: Junggesellenvereine und ihre Aktionen im Mai. Ergebnisse empirischer Untersuchungen in drei Stadtteilen des rechtsrheinischen Bonn. In: Rheinischwestfälische Zeitschrift für Volkskunde 25(1979/1980)147-197.

Fabre, Daniel: Burschen, Mädchen und das Volksfest. In: Levi, G. et al. (Hrsg.): Geschichte der Jugend. 1997, 56-96.

Faust, Anselm (Red.): Nordrhein-Westfalen. Landesgeschichte im Lexikon. 2. Aufl. Düsseldorf 1994.

Fischer, Hans: Zur Theorie der Feldforschung. In: Schmied-Kowarzik, W. et al. (Hrsg.): Grundfragen der Ethnologie. 1980, 63-78.

Fox, Nikolaus: Sitten und Bräuche. In: Zeitschrift des Rheinischen Vereins für Denkmalpflege und Heimatschutz 22(1929)236-258.

Fox, Nikolaus: Fastenfeuer und Lehenausrufen an der Saar. In: Unsere Heimat. Blätter für saarländisch-pfälzisches Volkstum. 7(1935/36)194-199.

Fox, Nikolaus: Stand der Volkskunde in der Saargegend. In: Abhandlungen zur Saarpfälzischen Landes- und Volksforschung. 1(1937)178-185.

Frazer, James George: The Golden Bough. A Study in Comparative Religion. 2 Vols. London 1890. (zitiert nach der 3. Auflage London 1920-1922).

Freyaldenhoven, F.: Maikauf im Jülicher Lande. In: Deutschland. Zeitschrift für Heimatkunde und Heimatliebe 5(1914)252-253.

Friedrichs, Jürgen: Methoden empirischer Sozialforschung. 12. Aufl. Opladen 1984.

Friedrichs, Jürgen: Normenpluralität und abweichendes Verhalten. Eine theoretische und empirische Analyse. In: Heitmeyer, W. (Hrsg.): Was treibt die Gesellschaft auseinander? 1997, 473-505.

Fröhlich, H.: Die Kirchenvisitationsprotokolle des Pfalz=Zweibrückischen Oberamts Lichtenberg aus den Jahren 1538, 1544 und 1553. In: Monatshefte für rheinische Kirchengeschichte 28(1934)257-263, 321-334 und 353-362.

Fuchs, Peter und Göbel, Andreas: Einleitung. In: Dies. (Hrsg.): Der Mensch - das Medium der Gesellschaft? Frankfurt am Main 1994, 7-14.

Fuchs, Peter und Göbel, Andreas (Hrsg.): Der Mensch - das Medium der Gesellschaft? Frankfurt am Main 1994.

Fuchs, Werner: Möglichkeiten der biographischen Methode. In: Niethammer, L. (Hrsg.): Lebenserfahrung und kollektives Gedächtnis. 1985, 436-470.

Gadamer, Hans-Georg und Vogler, Paul (Hrsg.): Neue Anthropologie. Dritter Band: Sozialanthropologie. Stuttgart 1972.

Gansen, P.: Zur Geschichte des Mai-Lehens im Siegkreis. In: Heimatblätter des Siegkreises 7(1931)18-19.

Garz, Detlef und Kraimer, Klaus (Hrsg.): Qualitativ-empirische Sozialforschung. Konzepte, Methoden, Analysen. Opladen 1991. 
Gennep, Arnold van: Les rites de passage. Étude systématique des Rites. Paris 1909.

Gerndt, Helge: Vierbergelauf. Gegenwart und Geschichte eines Kärtner Brauchs. Klagenfurt 1973.

Gerndt, Helge: Vorüberlegungen zur Funktion des Rechts. Ein Betrachtungsmodell. In: Köstlin, Konrad et al. (Hrsg.): Das Recht der kleinen Leute. 1976, 34-49.

Gerndt, Helge (Hrsg.): Stereotypvorstellungen im Alltagsleben. Beiträge zum Themenkreis Fremdbilder - Selbstbilder - Identität. München 1988.

Gierlichs, Hubert: Kirmesbräuche in den Rheinlanden. In: Rheinische Geschichtsblätter. Zeitschrift für Geschichte, Sprache und Altertümer des Mittel- und Niederrheins 1(1895)361-362.

Giersberg, Heinrich Hubert: Geschichte der Pfarreien des Dekanats Grevenbroich. Köln 1883.

Ginzler, Hildegard: Bräuche im Kreis Ahrweiler. In: Landkreis Ahrweiler (Hrsg.): Der Kreis Ahrweiler im Wandel der Zeit. 1993, 233-250.

Gluckman, Max: Rituale der Rebellion in Südost-Afrika. In: Kramer, F. et al. (Hrsg.): Gesellschaften ohne Staat. 1983, 250-280.

Grasmück, Gisela: Das Lehenausrufen im Saarland. In: Schwedt, H. (Hrsg.): Brauchforschung regional. Untersuchungen in Rheinland-Pfalz und im Saarland. Stuttgart. 1989, 17-33.

Grebel, Alexander: Aus St. Goar. In: Zeitschrift für deutsche Kulturgeschichte (1857) 92-96.

Grimm, Jacob: Deutsche Mythologie. Göttingen 1835.

Grimm, Jacob: Auswahl aus den kleineren Schriften. Berlin 1871.

Hahn, Heinrich: Lehnausrufen, Hagelfeier, Räderschieben, Johannisfeuer, Eierpicken und einiges andere. In: Back, F. (Hrsg.): Chroniken der Pfarreien der Ämter Birkenfeld und Frauenberg vom Ende des 16. und dem Anfang des 17. Jahrhunderts. Birkenfeld. 1899, 45-67.

Hartinger, Walter: Religion und Brauch. Darmstadt 1992.

Heeger, Fritz: Feuer im Brauchtum des ehemaligen Kurfürstentums Mainz. In: Hessische Blätter für Volkskunde 65(1965)100-102.

Heimatjahrbuch Kreis Ahrweiler. Herausgegeben vom Landkreis Ahrweiler. Bad NeuenahrAhrweiler.

Heitmeyer, Wilhelm: Einleitung: Auf dem Weg in eine desintegrierte Gesellschaft. In: Ders. (Hrsg.): Was treibt die Gesellschaft auseinander? 1997, 9-26.

Heitmeyer, Wilhelm (Hrsg.): Was treibt die Gesellschaft auseinander? Bundesrepublik Deutschland: Auf dem Weg von der Konsens- zur Konfliktgesellschaft. Frankfurt am Main 1997.

Hermanns, Harry: Das narrative Interview in berufsbiographisch orientierten Untersuchungen. (Arbeitspapiere des Wissenschaftlichen Zentrums für Berufs- und Hochschulforschung an der Gesamthochschule Kassel; Nr.9). Kassel 1981.

Hezel, Francis X., S.J. und Berg, M.L. (Eds.): Micronesia: Winds of Change. A Book of Readings in Micronesian History. Saipan 1980.

Hilberath, Leo: Der Junggesellenverein in der Eifel. Ein Beitrag zur Soziologie der Männerbünde, Altersklassen und der Geschlechter. Köln 1931.

Hildebrandt, Helmut: Historische Feldsysteme in Mitteleuropa. In: Geschichtliche Landeskunde. (Das Dorf am Mittelrhein. Fünftes Alzeyer Kolloquium). 30(1989)103-148.

Hinrichs, Ernst: "Charivari" und Rügebrauchtum in Deutschland. Forschungsstand und Forschungsaufgaben. In: Scharfe, M. (Hrsg.): Brauchforschung. 1991, 430-463.

Hoffmann-Krayer, E.: Knabenschaften und Volksjustiz. In: Schweizerisches Archiv für Volkskunde 8(1905)81-99, 161-178. 
Hofmann, Winfried: Hermann Weinsberg und die kölnische Fastnacht im 16. Jahrhundert. In: Rheinisch-westfälische Zeitschrift für Volkskunde 10(1963)82-98.

Hradil, Stefan: Sozialer Status. In: Staatslexikon. Recht, Wirtschaft, Gesellschaft. Herausgegeben von der Görres-Gesellschaft. 7. völlig neu bearb. Aufl. Bd.4. Freiburg u.a. 1988, Sp. 1260-1262.

Hugger, Paul: Volkskundliche Gemeinde- und Stadtteilforschung. In: Brednich, R.W. (Hrsg.): Grundriß der Volkskunde. ${ }^{2}$ 1994, 273-292.

Humphrey, Caroline und Laidlaw, James: The Archetypal Actions of Ritual. A theory of ritual illustrated by the Jain rite of worship. Oxford 1994.

Hurth, H.: Maitag und Mailehenversteigerung. In: Die Eifel, Mai 1935, 55.

Jeggle, Utz: Volkskunde im 20. Jahrhundert. In: Brednich, R. W. (Hrsg.): Grundriß der Volkskunde. 21994, 51-72.

Jeggle, Utz; Korff, Gottfried; Scharfe, Martin und Warneken, Bernd Jürgen (Hrsg.): Volkskultur in der Moderne. Probleme und Perspektiven empirischer Kulturforschung. Reinbek 1986.

Jernigan, Earl Wesley: Lochukle. A Palauan Art Tradition. Ph.D., Univ. of Arizona, Tuscon 1973.

Kaschuba, Wolfgang: Mythos oder Eigen-Sinn. "Volkskultur" zwischen Volkskunde und Sozialgeschichte. In: Jeggle, U. et al. (Hrsg.): Volkskultur in der Moderne. 1986, 469-507.

Kaschuba, Wolfgang: Einführung in die Europäische Ethnologie. München 1999.

Kellenbenz, Hermann: Wirtschafts- und Sozialentwicklung der nördlichen Rheinlande seit 1815. In: Petri, F. et al. (Hrsg.): Rheinische Geschichte. Bd. 3. 1979, 1-192.

Keussen, Hermann: Die Kirchen-Visitation in der Gegend von Krefeld im Jahre 1641. In: Die Heimat. Mitteilungen des Vereins für Heimatkunde in Crefeld. 2(1922)146-150 und 3(1924)34-38.

Kinkel, Gottfried: Die Ahr. Landschaft, Geschichte und Volksleben. Zugleich ein Führer für Ahrreisende. Bonn 1846.

Kischkewitz, Hubertus: "Wir haben keine andere Chance" - Das Trumpf-As der Gemeinde Grafschaft ist die Gewerbeansiedlung. In: Heimatjahrbuch Kreis Ahrweiler 47(1989)37-38.

Klein, J.: Maispielfeier in den rechtsrheinischen Nachbarorten Cölns. In: Zeitschrift des Vereins für rheinische und westfälische Volkskunde 6(1909)127-136.

Klersch, Joseph: Volkstum und Volksleben in Köln. Ein Beitrag zur historischen Soziologie der Stadt. 3 Bde. Köln 1965.

Koch, Walther: Die Vorgeschichte der Zweibrücker Kirchenordnung von 1557. In: Blätter für Pfälzische Kirchengeschichte und Religiöse Volkskunde. 24(1957)85-105.

Köhle-Hezinger, Christel; Scharfe, Martin und Brednich, Rolf Wilhelm (Hrsg.): Männlich. Weiblich. Zur Bedeutung der Kategorie Geschlecht in der Kultur. 31. Kongreß der Deutschen Gesellschaft für Volkskunde, Marburg 1997. Münster u.a. 1999.

König, Maria: Bäuerliche Burschenschaften. Ein Beitrag zur deutschen Volkskunde. Bremen 1938.

König, René: Zur Einführung. In: Völger, G. et al (Hrsg.): Männerbande - Männerbünde. Bd.1, 1990, XXVII-XXXII.

Köstlin, Konrad und Sievers, Kai Detlev (Hrsg.): Das Recht der kleinen Leute. Beiträge zur Rechtlichen Volkskunde. Festschrift für Karl-Sigismund Kramer zum 60. Geburtstag. Berlin 1976.

Kohlberg, Lawrence; Boyd, D R und Levine, C: Die Wiederkehr der sechsten Stufe. Gerechtigkeit, Wohlwollen und der Standpunkt der Moral. In: Edelstein, W. et al. (Hrsg.): Zur Bestimmung der Moral. 1986, 205-240.

Koll, Bernhard: Agrarlandschaftsveränderungen in der östlichen Hocheifel vom Ende der frühneuzeitlichen Anbauperiode (ca. 1580) bis zum Jahre 1830. Bonn 1984. 
Korff, Gottfried: "Heraus zum 1. Mai". Maibrauch zwischen Volkskultur, bürgerlicher Folklore und Arbeiterbewegung. In: Dülmen, R. v. et al. (Hrsg.): Volkskultur. 1984, 246-281.

Korth, L.: Volkstümliches aus dem Kreise Jülich. In: Zeitschrift des Aachener Geschichtsvereins 14(1892)72-130.

Krämer, Augustin: Palau. Teilband 3 (Abteilung V: Stoffliches und Abteilung VI: Geistige Kultur). Ergebnisse der Südsee-Expedition 1908-1910 herausgegeben von Georg Thilenius. Hamburg 1926.

Krämer, Dom.: Hoch! Blomendahler Gelogsjongen on Mailehen. In: Heimatkalender des Eifelkreises Schleiden. 1958, 23-24.

Kramer, Fritz und Sigrist, Christian (Hrsg.): Gesellschaften ohne Staat. Gleichheit und Gegenseitigkeit. Frankfurt am Main 1983.

Kramer, Karl-S.: Die letzten hundert Jahre - Endphase des Brauchtums? Erinnerungen und Lesefrüchte. In: Wandel der Volkskultur in Europa. Festschrift für G. Wiegelmann Bd. 1. Münster. 1988, 127-142.

Krebs, Friedrich: Verbot des Maiensteckens und des Lehenausrufens 1569. In: Rheinisch-westfälische Zeitschrift für Volkskunde 20(1973)228.

Kreuter, Karl: Die Hauensteiner Mailehenversteigerung. In: Der Pfälzerwald. Organ des PfälzerwaldVereins u.a. 11(1910)184-185.

Kriegk, G.L.: Deutsches Bürgerthum im Mittelalter. Nach urkundlichen Forschungen und mit besonderer Beziehung auf Frankfurt am Main. Frankfurt am Main 1868.

Künßberg, Eberhard Freiherr von: Rechtsgeschichte und Volkskunde. In: Zeitschrift für Deutschkunde 36(1922)321-335.

Kyll, Nikolaus: Maienbrauch in der Trierer Landschaft. In: Neues trierisches Jahrbuch 1975, 69-78.

Lamnek, Siegfried: Qualitative Sozialforschung. Band 1: Methodologie. München u.a. 1988.

Lamnek, Siegfried: Qualitative Sozialforschung. Band 2: Methoden und Techniken. München u.a. 1989.

Landau, Georg: Gebräuche, Aberglauben und Sagen aus Hessen. In: Zeitschrift des Vereins für hessische Geschichte 2(1840)272-281.

Landkreis Ahrweiler (Hrsg.): Der Kreis Ahrweiler im Wandel der Zeit. Landschaft, Geschichte, Kunst und Kultur, Brauchtum, Landwirtschaft, Weinbau, Wirtschaft und Verkehr. Bad NeuenahrAhrweiler 1993.

Lange, Wilhelm Chr.: Land und Leute auf der Schwalm. In: Festschrift der deutschen Anthropologischen Gesellschaft zur XXVI. allgemeinen Versammlung zu Cassel gewidmet von der Residenzstadt Cassel. Cassel. 1895, 39-88.

Langenbucher, Wolfgang R.; Rytlewski, Ralf und Weyergraf, Bernd (Hrsg.): Kulturpolitisches Wörterbuch Bundesrepublik Deutschland, Deutsche Demokratische Republik im Vergleich. Stuttgart 1983.

Laven, Ph.: Das Lehenausrufen in Saarhölzbach 1834.

Leclerc, Gérard: Anthropologie und Kolonialismus. München 1973.

Leiris, Michel: Die eigene und die fremde Kultur. Ethnologische Schriften 1. Frankfurt am Main 1977.

Lenger, Friedrich: Sozialgeschichte der deutschen Handwerker seit 1800. Frankfurt am Main 1988.

Levi, Giovanni und Schmitt, Jean Claude: Einleitung. In: Dies. (Hrsg.): Geschichte der Jugend. 1996, 9-20. 
Levi, Giovanni und Schmitt, Jean Claude (Hrsg.): Geschichte der Jugend. Band 1: Von der Antike bis zum Absolutismus. Band 2: Von der Aufklärung zur Gegenwart. Frankfurt am Main 1996 und 1997.

Lindner, Rolf: Die Angst des Forschers vor dem Feld. Überlegungen zur teilnehmenden Beobachtung als Interaktionsprozeß. In: Zeitschrift für Volkskunde 77(1981)51-66.

Lipp, Carola: Überlegungen zur Methodendiskussion. Kulturanthropologische, sozialwissenschaftliche und historische Ansätze zur Erforschung der Geschlechterbeziehung. In: Arbeitsgruppe volkskundliche Frauenforschung (Hrsg.): Frauenalltag - Frauenforschung. 1988, 29-46.

Lipp, Carola: Alltagskulturforschung in der empirischen Kulturwissenschaft und Volkskunde. In: Berliner Geschichtswerkstatt (Hrsg.): Alltagskultur, Subjektivität und Geschichte. 1994, 78-93.

Lipp, Carola: Frauenforschung. In: Brednich, R.W. (Hrsg.): Grundriß der Volkskunde. ${ }^{2} 1994,311$ 334.

Lipp, Wolfgang: Männerbünde, Frauen und Charisma. Geschlechterdrama im Kulturprozeß. In: Völger, G. et al. (Hrsg.): Männerbande - Männerbünde. 1990, 31-40.

Löber, Ulrich: Umfragen zu den dörflichen Burschenvereinigungen in den Gemeinden der "Marburger Landschaft". Marburg/Lahn 1972.

Löffler, Klara: Aus den Handwerksgeheimnissen - Über ein wissenschaftliches Genre. In: KöhleHezinger, C. et al. (Hrsg.): Männlich. Weiblich. 1999, 99-114.

Lövkrona, Inger: Gender and Sexuality in Pre-Industrial Society: Erotic Riddles. In: Fabula. Zeitschrift für Erzählforschung 34(1993)270-279.

Lucius, Robert von: Der Weiße Kreis. In: Völger, G. et al. (Hrsg.): Männerbande - Männerbünde. Bd.2, 1990, 373-380.

Luckmann, Thomas: Zwänge und Freiheiten im Wandel der Gesellschaftsstruktur. In: Gadamer, H.-G. et al. (Hrsg.): Neue Anthropologie. 1972, 168-198.

Lüdtke, Alf: Einleitung: "Sicherheit" und "Wohlfahrt". Aspekte der Polizeigeschichte. 1992, 7-33.

Lüdtke, Alf (Hrsg.): "Sicherheit" und "Wohlfahrt". Polizei, Gesellschaft und Herrschaft im 19. und 20. Jahrhundert. Frankfurt am Main 1992.

Lüdtke, Hartmut: Entgrenzung und Kontrollverlust in Freizeit und Konsum. In: Heitmeyer, W. (Hrsg.): Was treibt die Gesellschaft auseinander? 1997, 368-413.

Luhmann, Niklas: Soziale Systeme. Grundriß einer allgemeinen Theorie. Frankfurt am Main 1987.

Lutz, Albert: Jünglings- und Gesellenverbände im alten Zürich und im alten Winterthur. Affoltern am Albis 1957.

Lutz, Gerhard: Sitte, Recht und Brauch. Zur Eselshochzeit in der Eifel. In: Zeitschrift für Volkskunde 56(1960)74-88.

Maffesoli, Michel: Der Schatten des Dionysos. Zu einer Soziologie des Orgiasmus. Frankfurt am Main 1986.

Malinowski, Bronislaw: Argonauts of the Western Pacific. An Account of Native Enterprise and Adventure in the Archipelagoes of Melanesian New Guinea. London 1922.

Mannhardt, Wilhelm: Wald- und Feldkulte. Erster Teil: Der Baumkultus der Germanen und ihrer Nachbarstämme. Mythologische Untersuchungen. Zweiter Teil: Antike Wald- und Feldkulte aus nordeuropäischer Überlieferung erläutert [zit. nach der 2. Aufl. Berlin 1905]. Berlin 187577.

Mauss, Marcel: Die Gabe. Form und Funktion des Austauschs in archaischen Gesellschaften. Frankfurt am Main 1968.

Mayring, Philipp: Einführung in die qualitative Sozialforschung. Eine Anleitung zu qualitativem Denken. München 1990. 
Medick, Hans: Spinnstuben auf dem Dorf. Jugendliche Sexualkultur und Feierabendbrauch in der ländlichen Gesellschaft der frühen Neuzeit. In: Scharfe, M. (Hrsg.): Brauchforschung. 1991, 380-417.

Menzel, Wolfgang: Das altdeutsche Sonnenlehen. In: Germania. Vierteljahresschrift für deutsche Altertumskunde. 1(1856)63-81.

Mering, Friedrich E. von: Geschichte der Burgen, Rittergüter, Abteien und Klöster in den Rheinlanden und den Provinzen Jülich, Cleve, Berg und Westphalen nach archivarischen und andern authentischen Quellen. (4 Hefte). Cöln u.a. 1833-37.

Meves, Karl: Das Maispiel im Dorfe Körrenzig (Kr. Erkelenz, Rheinprovinz). In: Deutsche Dorfzeitung. Wochenblatt für ländliche Wohlfahrts- und Heimatpflege. 15(1912)139-140.

Meyer, A.: Der Mai ist gekommen! Eine volkskundliche Betrachtung. In: Das Rurland. Geschichtsund Heimatblätter für das alte Herzogtum Jülich. 2(1934)65-67.

Milkereit, Gertrud: Wirtschafts- und Sozialentwicklung der südlichen Rheinlande seit 1815. In: Petri, F. et al. (Hrsg.): Rheinische Geschichte. Bd. 3. 1979, 193-328.

Moser, Dietz-Rüdiger: Bräuche und Feste im christlichen Jahreslauf. Brauchformen der Gegenwart in kulturgeschichtlichen Zusammenhängen. Graz u.a. 1993.

Moser, Hans: Maibaum und Maienbrauch. Beiträge und Erörterungen zur Brauchforschung. In: Ders: Volksbräuche im geschichtlichen Wandel. 1985, 199-268.

Moser, Hans: Volksbräuche im geschichtlichen Wandel. Ergebnisse aus fünfzig Jahren volkskundlicher Quellenforschung. München 1985.

Müller, Josef: Beitrag zur Geschichte der Mädchen- oder Mailehn. In: Zeitschrift des Vereins für rheinische und westfälische Volkskunde 4(1907)208.

Müller, Josef: Zum Mailehen. In: Zeitschrift des Vereins für rheinische und westfälische Volkskunde 8(1911)72-76.

Müller, Josef: Rheinisches Maibrauchtum. In: Westdeutsche Zeitschrift für Volkskunde 33(1936)1232.

Müller, Rainer: Jungfrau für 2000 Mark. In: neues rheinland. Jg. 20, Heft 5 (1977)6-7.

Müller, Wolfgang: Das Mailehn. In: Hocker, N.: Deutscher Volksglaube in Sang und Sage. Göttingen 1853,215

Mütter, K.: Das Maieierholen und das Versteigern der Mädchen. In: Zeitschrift des Vereins für rheinische und westfälische Volkskunde 9(1912)100-104.

Nadig, Maya: Die verborgene Kultur der Frau. Ethnopsychoanalytische Gespräche mit Bäuerinnen in Mexiko. Frankfurt am Main 1986.

Nellessen, Wilhelm: Mailehen und Maibrauch im Ländchen an der Wurm und die SalmanusVerehrung in Würselen und Broichweiden. In: Rheinische Heimatpflege N.F. 11(1974)134137.

Niessen, Heinrich: Sagen und Geschichten des Saarthales. Saarlouis 1900.

Niessen, Heinrich: Die Mädchen- oder Mailehen. In: Zeitschrift des Vereins für rheinische und westfälische Volkskunde 4(1907)62-67.

Niethammer, Lutz (Hrsg.): Lebenserfahrung und kollektives Gedächtnis. Die Praxis der "Oral History". Frankfurt am Main 1985.

Oellers, Norbert: Geschichte der Literatur in den Rheinlanden seit 1815. In: Petri, F. et al. (Hrsg.): Rheinische Geschichte. Bd. 3. 1979, 553-696.

Oster, Peter: Geschichte der Pfarreien der Dekanate Prüm-Waxweiler. Trier 1927.

Pabst, Eduard: Der Maigraf und seine Feste. Reval 1865. (Reprint 1971). 
Parin, Paul: Der Widerspruch im Subjekt. Ethnopsychoanalytische Studien. Neuauflage. Hamburg 1992.

Parmentier, Richard J.: The Sacred Remains. Myth, History, and Polity in Belau. Chicago. u.a. 1987.

Petri, Franz und Droege, Georg (Hrsg.): Rheinische Geschichte. 3 Bde. Düsseldorf 1979.

Peuckert, Will-Erich: Ehe. Weiberzeit - Männerzeit - Saeterehe - Hofehe - Freie Ehe. Hamburg 1955.

Platvoet, Jan: Das Ritual in pluralistischen Gesellschaften. In: Belliger, A. et al. (Hrsg.): Ritualtheorien. 1998, 173-190.

Pommerin, Reiner: Sterilisierung der Rheinlandbastarde. Das Schicksal einer farbigen deutschen Minderheit 1918-1937. Düsseldorf 1979.

Pop, Mihai: Neue Wege der Brauchforschung. In: Zeitschrift für Volkskunde 80(1984)30-39.

Probst, Peter: Beobachtung und Methode. J.S. Kubary als Reisender und Ethnograph im Spiegel seiner Briefe an Adolf Bastian. In: Baessler-Archiv N.F. 31(1983)23-56.

Prothmann, Ottmar: Landleben in der Voreifel. Oeverich um 1910. Köln 1982.

Prothmann, Ottmar: Geschichte des Dorfes Niederich. Oeverich 1990.

Prothmann, Ottmar: Pfarrgeschichte von Leimersdorf. Festschrift zum 200jährigen Bestehen der Pfarrkirche im Jahre 1992. Leimersdorf 1992.

Radermacher, Karl: Alte Sitten und Gebräuche (Maisitten) am Rhein. In: Zeitschrift des Bergischen Geschichtsvereins. 22(1886)149-168.

Radermacher, Karl: Maisitten am Rhein (in sechs Teilen). In: Am Urquell. Monatschrift für Volkskunde. 4(1893)227-232 und 237-241; 5(1894)17-19, 57-59 und 111-113; 6(1896)85-87.

Raschke, P. und Opp de Hipt, M.: Verein. In: Langenbucher, W. et al. (Hrsg.): Kulturpolitisches Wörterbuch. 1983, 712-718.

Reinsberg-Düringsfeld, Otto Freiherr von: Das festliche Jahr. In Sitten, Gebräuchen und Festen der Germanischen Völker. Leipzig 1863.

Reulecke, Jürgen: Das Jahr 1902 und die Ursprünge der Männerbund-Ideologie in Deutschland. In: Völger, G. et al. (Hrsg.): Männerbande - Männerbünde. 1990, 3-10.

Revel, Jacques: Geschlechtsrollen in der Geschichtsschreibung. In: Neue Rundschau 99 (3), 1988, 523.

Rockenbach, Klaus: Das Mailehen in der Eifel. Ein Beispiel für altes Heimarbrauchtum in europäischen Zusammenhängen. In: Heimat-Kalender Schleiden. 1954, 25-27.

Roeck, Bernd: Außenseiter, Randgruppen, Minderheiten. Fremde im Deutschland der frühen Neuzeit. Göttingen 1993.

Rolshoven, Johanna: Der Rausch. Kulturwissenschaftliche Blicke auf die Normalität. In: Zeitschrift für Volkskunde 96(2000)39-49.

Rosenbaum, Heidi: Formen der Familie. Untersuchungen zum Zusammenhang von Familienverhältnissen, Sozialstruktur und sozialem Wandel in der deutschen Gesellschaft des 19. Jahrhunderts. Frankfurt am Main 1982.

Rosenthal, Gabriele: Die erzählte Lebensgeschichte als historisch-soziale Realität. Methodologische Implikationen für die Analyse biographischer Texte. In: Berliner Geschichtswerkstatt (Hrsg.): Alltagskultur, Subjektivität und Geschichte. 1994, 125-138.

Ruland, Josef: Brauchtum und Sitte im Kreise Ahrweiler. In: Heimatchronik des Kreises Ahrweiler von Kurt Broicher et al. Köln 1968, 231-242.

Ruland, Josef: Vom Winzerleben an der Ahr. In: Ennen, E. und Wiegelmann, G. (Hrsg.): Festschrift Matthias Zender. Studien zur Volkskultur, Sprache und Landesgeschichte. Bonn. 1972, 609632. 
Ruland, Josef: Das Mailehen. In: Studienbuch Landkreis Ahrweiler. Bd. 1. (Beiheftreihe zum Heimatjahrbuch Kreis Ahrweiler "Studien zu Vergangenheit und Gegenwart"). Bad NeuenahrAhrweiler 1987, 130-136.

Schäfer, Alfred und Wimmer, Michael: Einleitung: Zur Aktualität des Ritualbegriffs. In: Dies. (Hrsg.): Rituale und Ritualisierungen. 1998, 9-47.

Schäfer, Alfred und Wimmer, Michael (Hrsg.): Rituale und Ritualisierungen. Opladen 1998.

Schannat, Johann Friedrich: Eiflia illustrata oder geographische und historische Beschreibung der Eifel herausgegeben von Georg Bärsch. Köln 1824-1855.

Scharfe, Martin: Zum Rügebrauch. In: Hessische Blätter für Volkskunde 61(1970)45-68.

Scharfe, Martin: Geschichtlichkeit. In: Bausinger, Hermann et al.: Grundzüge der Volkskunde. 1978, 127-203.

Scharfe, Martin: Einführung (III. Abschnitt: Ungleichzeitigkeiten). In: Jeggle, U. et al. (Hrsg.): Volkskultur in der Moderne. 1986, 347-350.

Scharfe, Martin: Einleitung. In: Ders. (Hrsg.): Brauchforschung. 1991, 1-26.

Scharfe, Martin (Hrsg.): Brauchforschung. Darmstadt 1991.

Schell, O.: Bergische Hochzeitsgebräuche. In: Zeitschrift für Volkskunde 10(1900)37-48.

Schindler, Norbert: Spuren in die Geschichte der 'anderen' Zivilisation. Probleme und Perspektiven einer historischen Volkskulturforschung. In: Dülmen, R. v. et al. (Hrsg.): Volkskultur. 1984, 13-77.

Schindler, Norbert: Die Hüter der Unordnung. Rituale der Jugendkultur in der frühen Neuzeit. In: Levi, G. et al. (Hrsg.): Geschichte der Jugend. 1996, 319-382.

Schmidt, Siegfried J.: Kognitive Autonomie und soziale Orientierung. Konstruktivistische Bemerkungen zum Zusammenhang von Kognition, Kommunikation, Medien und Kultur. Frankfurt am Main 1994.

Schmied-Kowarzik, Wolfdietrich und Stagl, Justin (Hrsg.): Grundfragen der Ethnologie. Beiträge zur gegenwärtigen Theorie-Diskussion. Berlin 1980.

Schmitz, Ferdinand: Volkstümliches vom Siebengebirge. In: Rheinische Geschichtsblätter. Zeitschrift für Geschichte, Sprache und Altertümer des Mittel- und Niederrheins 3(1896/97)104-114.

Schmitz, J. H.: Sitten und Bräuche, Lieder, Sprüchwörter und Räthsel des Eifler Volkes nebst einem Idiotikon. 2 Bde.Trier 1856-1858.

Schrick, Annette: "Im Dorfkrug blüht immer noch der Mädchenhandel!" Zum Mailehenbrauchtum im Rheinland. In: KulTour. Mitteilungsblatt des Volkskundlichen Seminars der Universität Bonn Jg. 3, Heft 1. 1992, 32-46.

Schuegraf: Ueber das Tanzen der Deutschen überhaupt, insbesondere über die vielerlei Arten ihrer Tänze. In: Zeitschrift für deutsche Kulturgeschichte 1(1856)447-476.

Schümann, Carl-Wolfgang: Vivat, crescat, floreat. In: Völger, G. et al. (Hrsg.): Männerbande Männerbünde. Bd. 2, 1990, 381-384.

Schütz, Eduard: Meine Heimat. 2000 Jahre Lantershofen. Lantershofen 1935.

Schug, Peter: Geschichte der zum ehemaligen Ahrgaudekanat gehörenden Pfarreien der Dekanate Adenau, Ahrweiler und Remagen. Trier 1952.

Schulte, O.: Kirchweih im Vogelsberge. In: Hessische Blätter für Volkskunde 1(1902)65-86.

Schurtz, Heinrich: Altersklassen und Männerbünde. Eine Darstellung der Grundformen der Gesellschaft. Berlin 1902. 
Schwall, Anton: Vom Maigelog in Mayschoß a.d. Ahr. In: Zeitschrift für Heimatkunde des Regierungsbezirkes Coblenz und der angrenzenden Gebiete von Hessen-Nassau. 3(1922)52$53 ; 78-79$.

Schwedt, Herbert: Geschlechterrollen, Macht und Brauch. In: Köhle-Hezinger, C. et al. (Hrsg.): Männlich. Weiblich. 1999, 160-170.

Schwedt, Herbert (Hrsg.): Brauchforschung regional. Untersuchungen in Rheinland-Pfalz und im Saarland. Stuttgart 1989.

Schwedt, Herbert und Schwedt, Elke: Bräuche zwischen Saar und Sieg. Zum Wandel der Festkultur in Rheinland-Pfalz und im Saarland. Mainz 1989.

Schwedt, Herbert und Schwedt, Elke: Burschen- und Schützenvereine. In: Völger, G. et al. (Hrsg.): Männerbande - Männerbünde. 1990, 119-124.

Schweizer, Thomas: Männerbünde und ihr kultureller Kontext im weltweiten interkulturellen Vergleich. In: Völger, G. et al. (Hrsg.): Männerbande - Männerbünde. 1990, 23-30.

Schwibbe, Gudrun und Spieker, Ira (Hrsg.): Der Hahn im Korb. Allerneueste Geschichten um Rolf Wilhelm Brednich. Festschrift zum 60. Geburtstag. Göttingen 1995.

Scribner, Bob: Reformation, Karneval und die "verkehrte Welt". In: Dülmen, R. v. et al. (Hrsg.): Volkskultur. 1984, 117-152.

Sels, Leo: Mädchen ersteigert. Von einem alten Volksbrauch des Jülicherlandes. In: Rur=Blumen. Heimat-Wochenschrift zum Jülicher Kreisblatt. 17(1938)163-164.

Selter, Bernward und Wischermann, Clemens: Land- und Forstwirtschaft. In: Faust, A. (Red.): Nordrhein-Westfalen. ${ }^{2}$ 1994, 244-249.

Simrock, Karl: Schlußwort. In: Schmitz, J.H.: Sitten und Bräuche. Bd.2. 1856-58, 145-152.

Simrock, Karl: Handbuch der Deutschen Mythologie mit Einschluß der nordischen. 5. verbesserte Aufl. Bonn 1878.

Staab, Franz: Verfassungswandel in rheinhessischen Dörfern zwischen dem 12. und 14. Jahrhundert. In: Geschichtliche Landeskunde. (Das Dorf am Mittelrhein. Fünftes Alzeyer Kolloquium). 30(1989)149-174.

Stein, Heinrich: Einleitung. In: Herodotos: Buch I. ${ }^{8} 1968$, XXVI-XXXI.

Streckenbach, Klaus: Die Delhoven-Tagebücher aus Dormagen. In: Dormagener Historische Beiträge herausgegeben von Heinz A. Pankalla. Band 1. 1992, 113-137.

Steuten, Ulrich: Das Ritual in der Lebenswelt des Alltags. Gießen 1998.

Theme, J.T.: Der Mai im Brauchtum rheinischer Heimat. In: NS Lehrerbund. Mitteilungsblatt Gau Köln-Aachen 5(1938)87-88.

Thiel, Josef Franz: Quellen der Ethnologie und ihre Rezeption. In: Schmied-Kowarzik, W. et al. (Hrsg.): Grundfragen der Ethnologie. 1980, 79-92.

Thomas, Robert: Geschichte des Ortes und der Bürgermeisterei Oedekoven. Oedekoven 1979.

Thompson, Edward P.: "Rough Music". Le charivari anglais. In: Annales. Économies, Sociétés, Civilisations. 27(1972)285-312.

Toelken, Barre: Zum Begriff der Performanz im dynamischen Kontext der Volksüberlieferung. In: Zeitschrift für Volkskunde 77(1981)37-50.

Trümpy, Hans: Sphären des Verhaltens. Beiträge zu einer Grammatik der Bräuche. In: Rheinisches Jahrbuch für Volkskunde 20(1970)226-233.

Turner, Victor: Dramas, Fields and Metaphors. London 1974.

Uhland, Ludwig: Werke. Hrsg. von Hartmut Fröschle und Walter Scheffler. 4 Bde. München 1984. 
Usener, Hermann: Über vergleichende Sitten- und Rechtsgeschichte. In: Hessische Bläter für Volkskunde. 1(1902)195-228.

Vivelo, Frank Robert: Handbuch der Kulturanthropologie. Eine grundlegende Einführung. München 1988.

Völger, Gisela und Welck, Karin v. (Hrsg.): Die Braut. Geliebt, verkauft, getauscht, geraubt. Zur Rolle der Frau im Kulturvergleich. 2 Bde. Köln 1985.

Völger, Gisela und Welck, Karin v. (Hrsg.): Männerbande - Männerbünde. Zur Rolle des Mannes im Kulturvergleich. 2 Bde. Köln 1990.

Wacquant, Loïc: Auf dem Weg zu einer Sozialpraxeologie. Struktur und Logik der Soziologie Pierre Bourdieus. In: Bourdieu, P. et al.: Reflexive Anthropologie. 1996, 17-94.

Warneken, Bernd Jürgen und Wittel, Andreas: Die neue Angst vor dem Feld. Ethnographisches research up am Beispiel der Unternehmensforschung. Zeitschrift für Volkskunde 93(1997)1-16.

Weber, Hans: Die Hauptgruppen der rheinischen Maibräuche in kulturgeschichtlicher und kulturgeographischer Betrachtung. Köln 1935.

Weber-Kellermann, Ingeborg: Brauch und seine Rolle im Verhaltenscode sozialer Gruppen. Eine Bibliographie deutschsprachiger Titel zwischen 1945-1970. Marburg 1973.

Weber-Kellermann, Ingeborg: Die Sprache der Bräuche. In: Zeitschrift für Volkskunde 80(1984)2329.

Weber-Kellermann, Ingeborg: Saure Wochen frohe Feste. Fest und Alltag in der Sprache der Bräuche. München u.a. 1985.

Weber-Kellermann, Ingeborg und Stolle, Walter: Volksleben in Hessen. Göttingen 1971.

Weinhold, Karl: Die deutschen Frauen in dem Mittelalter. 3.Aufl. Wien 1882.

Weltz, Gisela: Moving Targets. Feldforschung unter Mobilitätsdruck. In: Zeitschrift für Volkskunde 94(1998)177-194.

Westphal, Hannelore: Die Liebe auf dem Dorf. Vom Wandel der Sexualmoral und der Prostitution auf dem Lande. Braunschweig 1988.

Wey, Hans-Willi: "A mesei a delal a telid" - "Das Tarofeld ist die Mutter unseres Lebens". Eine Untersuchung zur kulturellen und wirtschaftlichen Bedeutung von Taro auf den Palau-Inseln (westliche Karolinen, Mikronesien). Unveröff. MA-Arbeit. Göttingen 1992.

Wey, Hans-Willi: Offenheit, Transparenz und Differenziertheit. Ein Beitrag zum Aufbau eines interkulturellen und interdisziplinären Dialogs. In: Zeitschrift für Heilpädagogik 45(1994)892894.

Wey, Hans-Willi: "Erhaltet Palau, liebe deutsche Landsleute!" Tourismus als Katalysator von Umwelt und Kultur. In: Schwibbe, G. et al. (Hrsg.): Der Hahn im Korb. 1995a, 211, 215-218.

Wey, Hans-Willi: Imponderabilien auf östlichen Erkundungswegen. Reflexionen über ein Forschungsprojekt zur Intensivierung des deutsch-deutschen Austauschs. In: Schwibbe, G. et al. (Hrsg.): Der Hahn im Korb. 1995b, 44-48.

Wey, Hans-Willi: "Bei den Jungen geht's rund ...". Medienwirksame Fabrikation und Simplifizierung der Geschlechtsdifferenz im Mailehenbrauch. In: Köhle-Hezinger, C. et al. (Hrsg.): Männlich. Weiblich. 1999, 301-324.

Wiegelmann, Günter; Zender, Matthias und Heilfurth, Gerhard: Volkskunde. Eine Einführung. Berlin 1977.

Wikman, Karl Robert Villehad: Die Einleitung der Ehe. Eine vergleichende ethnosoziologische Untersuchung über die Vorstufe der Ehe in den Sitten des schwedischen Volkstums. Åbo 1937.

Wirtgen, Philipp: Das Nette- und das Brohltal und Laach. Natur, Geschichte, Sage. Bonn 1864. 
Wirth, Hans-Jürgen: Die Schärfung der Sinne. Jugendprotest als persönliche und kulturelle Chance. Frankfurt am Main 1984.

Wolfram, Richard: Prinzipien und Probleme der Brauchtumsforschung. Wien u.a. 1972.

Wrede, Adam: Rheinische Volkskunde. Leipzig 1919.

Wrede, Adam: Rheinische Volkskunde. 2. verbesserte und vermehrte Auflage. Leipzig 1922.

Wrede, Adam: Eifeler Volkskunde. Frankfurt a.M. 1983 (1923).

Wrede, Adam: Rheinischer Volksbrauch im Kreislauf des Jahres. Düsseldorf 1934.

Wrede, Adam: Deutsche Volkskunde auf germanischer Grundlage. Die nationalsozialistische Erziehungsidee im Schulunterricht. Osterwieck/Harz. (2. Aufl.) 1938.

Wrede, Adam: Eifeler Volkskunde. Dritte völlig neubearbeitete Auflage. Bonn 1960.

Zender, Matthias: Rez. zu Leo Hilberath: Der Junggesellenverein in der Eifel. In: Rheinische Vierteljahresblätter 3(1933)374-376.

Zender, Matthias: Dörfisches Vorfrühlingsbrauchtum in der Eifel und auf dem Hunsrück. In: Rheinische Blätter. Deutsche kulturpolitische Zeitschrift im Westen 15(1938)104-108.

Zender, Matthias: Die volkskundliche Struktur des Kreises Schleiden. In: Rheinisch-westfälische Zeitschrift für Volkskunde 1(1954)19-31.

Zender, Matthias: Eigenart und Entwicklung des Festtagsbrauchtums im Raum Euskirchen. In: 650 Jahre Stadt Euskirchen (1302-1952). Der Festschrift zweiter Band. Herausgegeben von Josef Franke im Namen der Stadt Euskirchen. Euskirchen 1955, 279-298.

Zender, Matthias: Das Brauchtum als Zeugnis für Wesensart und innere Gliederung des Mosellandes. In: Zeitschrift für Volkskunde 54(1958)12-43.

Zender, Matthias: Das Volksleben als Zeugnis für die kulturelle Zuordnung und Bedeutung der Stadt Siegburg und ihrer Umgebung. In: Heimatbuch der Stadt Siegburg. Bd.1. Siegburg 1964, 551573.

Zender, Matthias: Nachwort zum Abschnitt Volkskunde. In: Aubin et al.: Kulturströmungen und Kulturprovinzen. 1966, 232-241

Zender, Matthias: Das Kölnische "Niederland" in Gestalt und Sonderart seines Volkslebens. In: Rheinische Vierteljahresblätter 36(1972)249-280.

Zender, Matthias: Glaube und Brauch. Fest und Spiel. In: Wiegelmann, G. et al. (Hrsg.): Volkskunde. 1977, 132-197.

Zender, Matthias: Das Volksleben in den Rheinlanden seit 1815. In: Petri, F. et al. (Hrsg.): Rheinische Geschichte. Bd. 3. 1979, 759-875.

Zerwas, Hans-Jörg: Freiheit, Arbeit, Ehre. Männerbünde im Handwerk. In: Völger, G. et al. (Hrsg.): Männerbande - Männerbünde. 1990, 33-40.

Zewe, Jak.: Sitte und Brauch im Saargebiet. Saarbrücken 1924.

Zimmermann, Harm-Peer: Sitte und Konvention. Ferdinand Tönnies Version einer Dichotomie von Überlebenslogik und Herrschaftslogik. In: Zeitschrift für Volkskunde 88(1992)67-99 und 229247.

Zinnecker, Jürgen: Metamorphosen im Zeitraffer: Junggsein in der zweiten Hälfte des 20. Jahrhunderts. In: Levi, G. et al. (Hrsg.): Geschichte der Jugend. 1997, 460-505.

Zinzius, H.: Maibräuche im Siegkreis. In: Heimatblätter des Siegkreises 1(1925)43-45.

Zuccalmaglio, Vincenz Jacob von [Montanus]: Die deutschen Volksfeste, Volksbräuche und deutscher Volksglaube in Sagen, Märchen und Volksliedern. Ein Beitrag zur vaterländischen Sittengeschichte. Iserlohn 1854-58. 


\section{$7 \quad \mathrm{ANHANG}$}

7.1 Lageplan zur Untersuchungsregion

7.2 Statistische Daten zur Untersuchungsregion

Tabelle 7.1: Einwohnerzahlen: Grafschaft, Oeverich und Niederich (1961-2000)

Tabelle 7.2: Erwerbstätige in der Gemeinde Grafschaft nach Wirtschafts bereichen (1961-1987)

Tabelle 7.3: Übergangsquoten zur Sekundarstufe: Grafschaft (1973-75) und Leimersdorf (1998-99)

7.3 Materialien zur Durchführung der Gespräche

1) Schreiben zur Werbung potentieller GesprächspartnerInnen

2) Begleitschreiben des Seminars für Volkskunde der Universität Göttingen

3) Beispiele für Entwicklungskurven der persönlichen Einstellung und des persönlichen Einsatzes in bezug zur Mailehenpraxis

4) Auszüge aus einem Artikel der Lokalpresse zum Mailehen (Bonner GeneralAnzeiger 2./3. April 1994)

5) Zeitungsbericht über eine Männerversteigerung in Istha/Nordhessen (Hessische Allgemeine 29. März 1994)

\subsection{Abbildung (1-14)}

1) Mailehenversteigerung des Junggesellenvereins Oeverich-Niederich 1974

2) Aufnahme neuer Mitglieder in den Junggesellenverein OeverichNiederich 1974

3) Festumzug der Mailehen am Kirmessonntag 1973

4) Tanz des Maikönigspaares unter der geschwenkten Junggesellenfahne 1969

5) Aufrichten des Dorfmaibaumes am 24. April 1993 in Oeverich

6) Aufnahme neuer Mitglieder in den Junggesellenverein am 30. April 1993 in Oeverich

7) Rasur der Initianden mit der "Häp" am 30. April 1993 in Oeverich

8) Eröffnung der Mailehenversteigerung am 30. April 1993 in Oeverich

9) Besuch der Maikönigin am 1. Mai 1993 in Niederich

10) Einsetzung des neuen Maikönigspaares in ihr Amt am 14. Mai 1993 in Oeverich

11) Festumzug der Mailehen am 15. Mai 1993 in Oeverich

12) Festumzug der Mailehen am 15. Mai 1993 in Oeverich

13) Kirmesmannverbrennung am 16. Mai 1993 in Oeverich

14) Kirmesmannverbrennung am 16. Mai 1993 in Oeverich 
7.1 Lageplan zur Untersuchungsregion

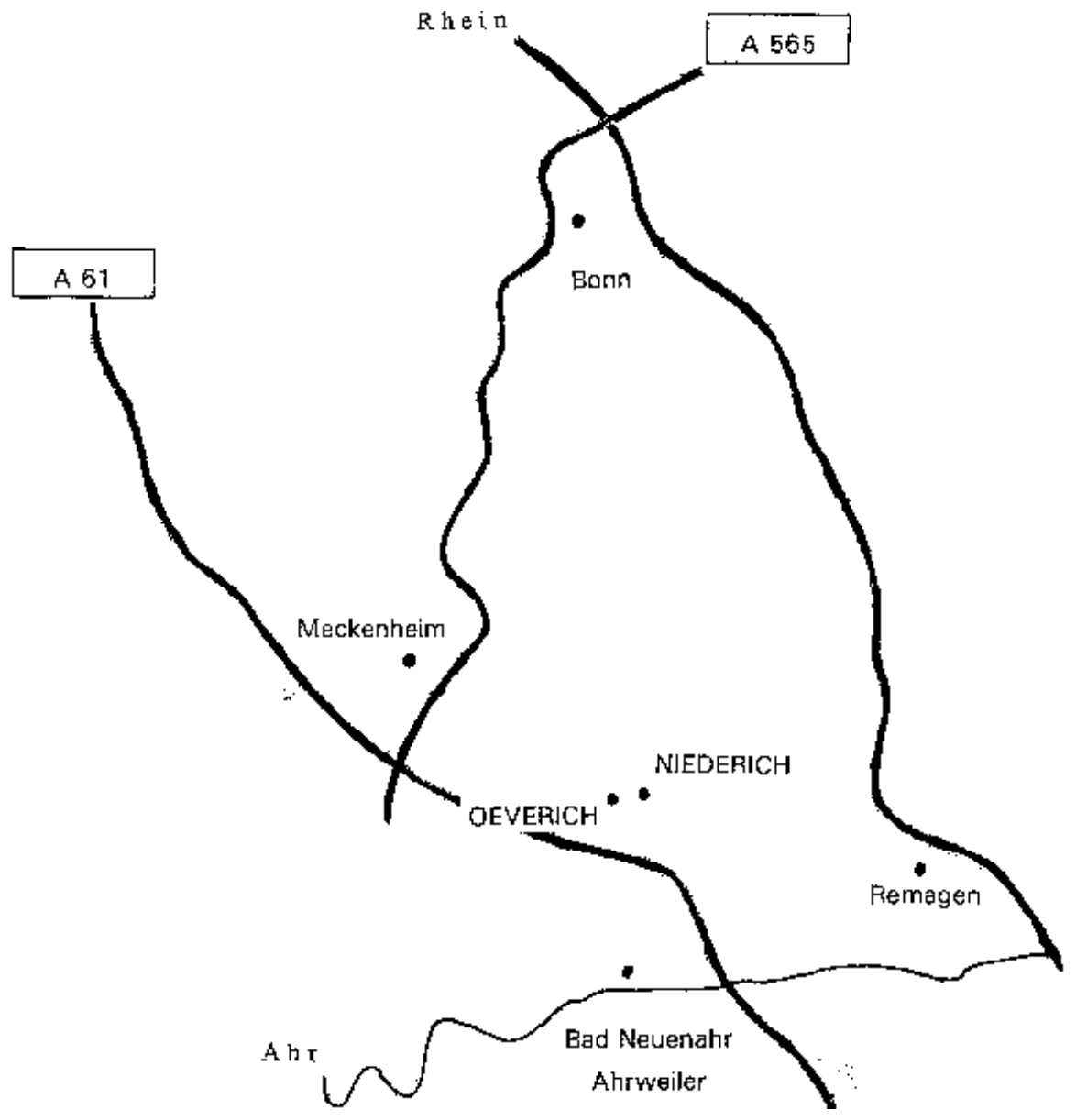


7.2 Statistische Daten zur Untersuchungsregion

Tabelle 7.1)

Einwohnerzahlen: Grafschaft, Oeverich und Niederich $(1961-2000)^{523}$

\begin{tabular}{|c|c|c|c|}
\hline Jahr & Grafschaft & Oeverich & Niederich \\
\hline 1961 & 5.422 & - & - \\
1994 & 9.443 & - & - \\
1996 & - & 510 & 176 \\
1997 & - & 532 & 175 \\
1998 & 10.870 & 572 & 175 \\
1999 & - & 578 & 175 \\
2000 & - & 574 & 184 \\
\hline
\end{tabular}

Tabelle 7.2)

\section{Erwerbstätige in der Gemeinde Grafschaft nach Wirtschaftsbereichen $(1961-1987)^{524}$}

\begin{tabular}{|c|c|c|c|c|c|c|}
\hline \multirow[b]{2}{*}{ Jahr } & \multicolumn{2}{|c|}{ Landwirtschaft u. Forsten } & \multicolumn{2}{|c|}{$\begin{array}{c}\text { produzierendes } \\
\text { Gewerbe }\end{array}$} & \multicolumn{2}{|c|}{$\begin{array}{l}\text { Dienstleistungs- } \\
\text { bereich }\end{array}$} \\
\hline & abs. & (\%) & abs. & (\%) & abs. & (\%) \\
\hline 1961 & 909 & 35,20 & 1023 & 39,70 & 648 & 25,10 \\
\hline 1970 & 427 & 17,60 & 998 & 41,00 & 1006 & 41,40 \\
\hline 1987 & 33 & 3,80 & 314 & 36,40 & 515 & 59,70 \\
\hline
\end{tabular}

Tabelle 7.3)

\section{Übergangsquoten zur Sekundarstufe) \\ A) Grafschaft (1973-75) ${ }^{525}$ \\ B) Leimersdorf (1998-99) $)^{526}$}

\begin{tabular}{|c|c|c|c|c|c|c|c|c|c|c|}
\hline \multirow[b]{2}{*}{ Gemeinde } & \multirow[b]{2}{*}{ Jahr } & \multirow{2}{*}{$\begin{array}{c}\text { Abgänge } \\
\text { insgesamt } \\
\text { abs. }\end{array}$} & \multicolumn{2}{|c|}{ Hauptschule } & \multicolumn{2}{|c|}{ Realschule } & \multicolumn{2}{|c|}{ Gymnasium } & \multicolumn{2}{|c|}{ Sonst. } \\
\hline & & & abs. & (\%) & abs. & $(\%)$ & abs & $(\%)$ & abs. & (\%) \\
\hline A) & $1973-75$ & - & - & 67,3 & - & 13,1 & - & 19,6 & - & - \\
\hline B) & 1998 & 39 & 8 & 20,51 & 15 & 38,46 & 15 & 38,46 & 1 & 2,56 \\
\hline B) & 1999 & 36 & 9 & 25,00 & 9 & 25,00 & 17 & 47,22 & 1 & 2,78 \\
\hline
\end{tabular}

${ }^{523}$ Quellen: Geist et al. (1977) und Gemeindeverwaltung Grafschaft (schriftl. Auskunft).

${ }^{524}$ Quellen: Geist et al. (1977) und Kreisverwaltung Ahrweiler Wirtschaftsförderung (o.J.).

${ }^{525}$ Quelle: Geist et al. (1977).

${ }^{526}$ Quelle: Auskunft Grundschule Leimersdorf. 


\title{
7.3 Materialien zur Durchführung der Gespräche
}

1) Schreiben zur Werbung potentieller GesprächspartnerInnen

\author{
Hans-Willi Wey M.A. \\ Michaelstraße 7 \\ $53111 \mathrm{BONN}$ \\ Telefon: 0228 / 691788
}

Betrıff: Gespräch über die dörnlchen Bräuche (Kirmes, Malbrł̆ ucbe)

Sehr verehrte Dame, sehr geelirter Her.

dank der freundlichen Uwlerstützang ion Hern Pastor Vơssing erreicht Sie heute mein Brief mit der herdiches Bitte um thre Mithilfe!

Zunăchst mōchte ich nuch, mein Asliegen und meine Arbeit thnen vorstellen:

Mein Name ist Haus-Willi Wey, ich hin 30 Jalure alt und wohne zusammen mit meiner Frau

in Bonn. Nach dem Abschluß meines rollskondlichen Studiuns suchte ich nach einem geeigneten Thema für eine Doktorarbeit. Bald wurde ich auf die teils noch lebendigen Gebräuche im Rheinland aufinerksam. In der Grafschaft und vor allem in den Orten Oeverich und Niederich fand ich ein Gebiet, in dem Bräuche um das Mailehen und die Kirmes itber viele Jahre hinweg blühten und bis heute alljährlich stattfinden. Da ich selbst in der Eifel aufgewachsen bin, war mir die Region von vomberein etwas vertraut.

Gamz besonders wichtig ist es, fir meine Arbeit Mensehen ou finden, die sich in die frithere Zeit zurückerinnern wollen und von ihren persönlichen Erlebnissen und Gedanken in einem Gespräch crählen möchten. Welche Erlebnisse, Gedanken oder Gefühle fallen Thnen ein, wezn Sie an die Brăuche in threm Dorf denken? Welche Rolle spielten für Sie diese Bräuche von Hrer Kindheit an bis heute? Mit îhren Antworten kömute die Volkskunde ein richtig lebendiges Bild gewinnen, von dem, wie die Briuche in vergangenen Tagen erlebt wurdea. Und spannend wird es sein, zu seher, was sich bis heute alles getan hat, was sich verändert hat oder was ăhnilich geblieben ist.

Wenn Sie sich zur Mithilfe entschließen, wenn Sie ein wenig die Bereitschaft zum Erzäłlen verspüren und sich ein odet vielleicht zwei Stunden Zeit nehmen können, dann steht einem arregenden gemeirsamen Gespräch wirklich nichts entgegen. Es versteht sich von selbst, daßi Ihre Auskünfte ganz nach Ihren eigenen Wünschen vertraulich belandelt werden.

Setur nett wäre es, wenn Sie recht bald die bejgefügte Postkarte an mich zurūcksenderl, danit ich mich mit lhnen in Verhindung setzen kans. Sie kōnnen mich aluch einfach unter der oben angegeben Telefonummer ereichen.

Für Thre Unterstützung wäre ich Ihnen in jedem Falfe sehr dankbar!

Mit herzlicliem Grruß 
2) Begleitschreiben des Seminars für Volkskunde der Universität Göttingen (Seite 1)

\section{GEORG-AUGUST-UNIYERSITAT GUTTNGEN SEMINAR FOK WOLKSKUNDE}

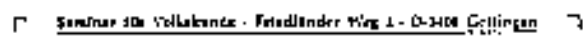

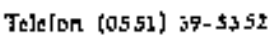

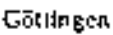

$15.94-1994$

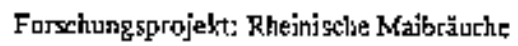

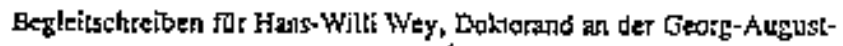

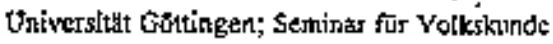

\section{Sthr pechne Damen und Hestenl}

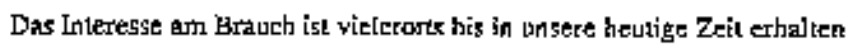

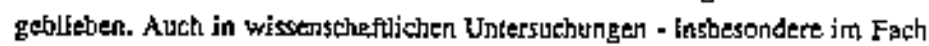

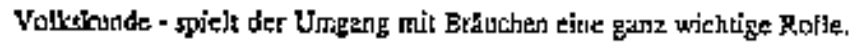

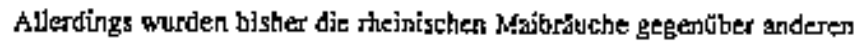

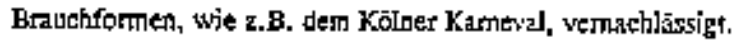

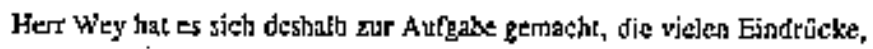

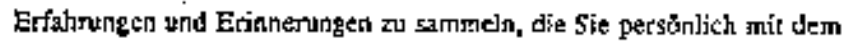
theirtischen Maibraudh vebindar.

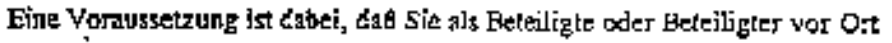

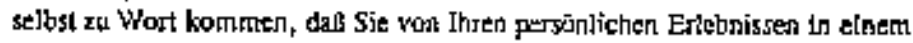

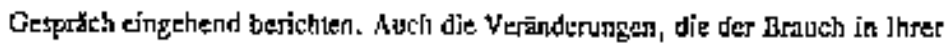

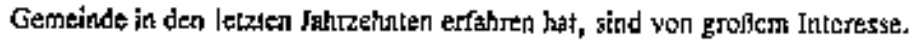

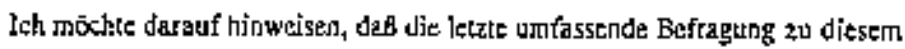

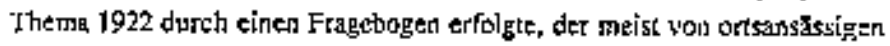

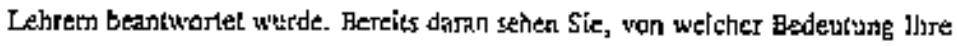

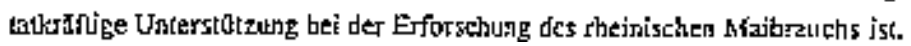


Fortsetzung (Begleitschreiben des Seminars für Volkskunde der Universität Göttingen, Seite 2)

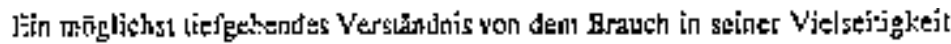

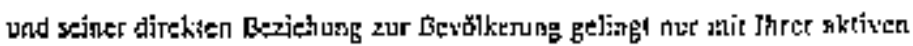
hfjlhj]니

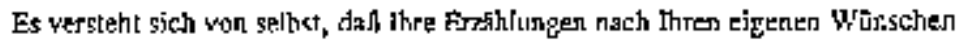

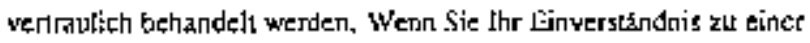

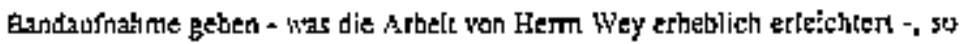

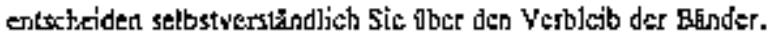

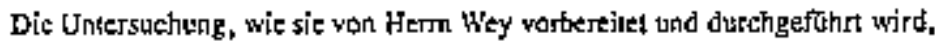

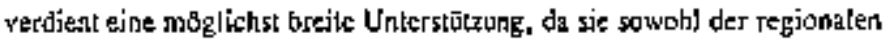

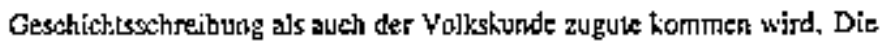

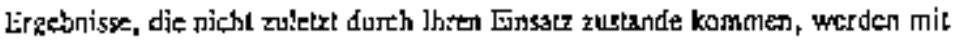

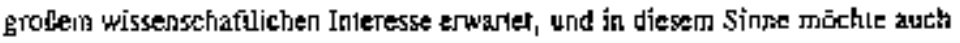
ich Ihren theinen herlichosen Dask ausproches!

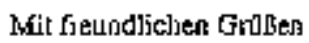

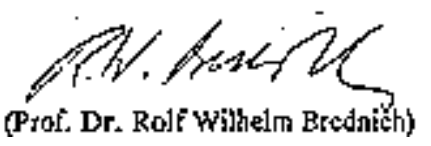


3) Beispiele für Entwicklungskurven der persönlichen Einstellung und des persönli chen Einsatzes in bezug zur Mailehenpraxis

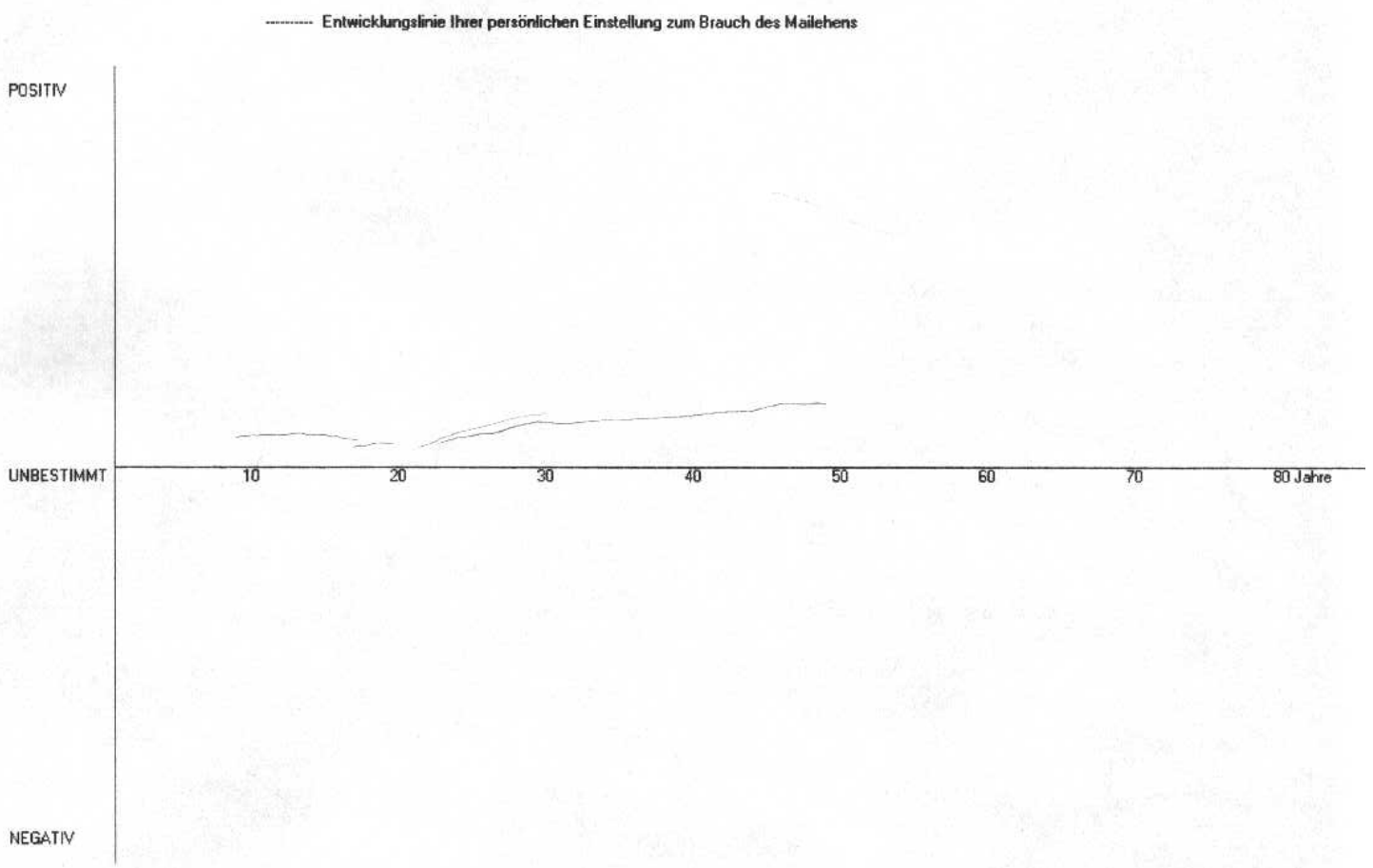

-. Entwicklungslinie lhres persönlichen Einsatzes für die Ausibung des Mailehenbrauchs

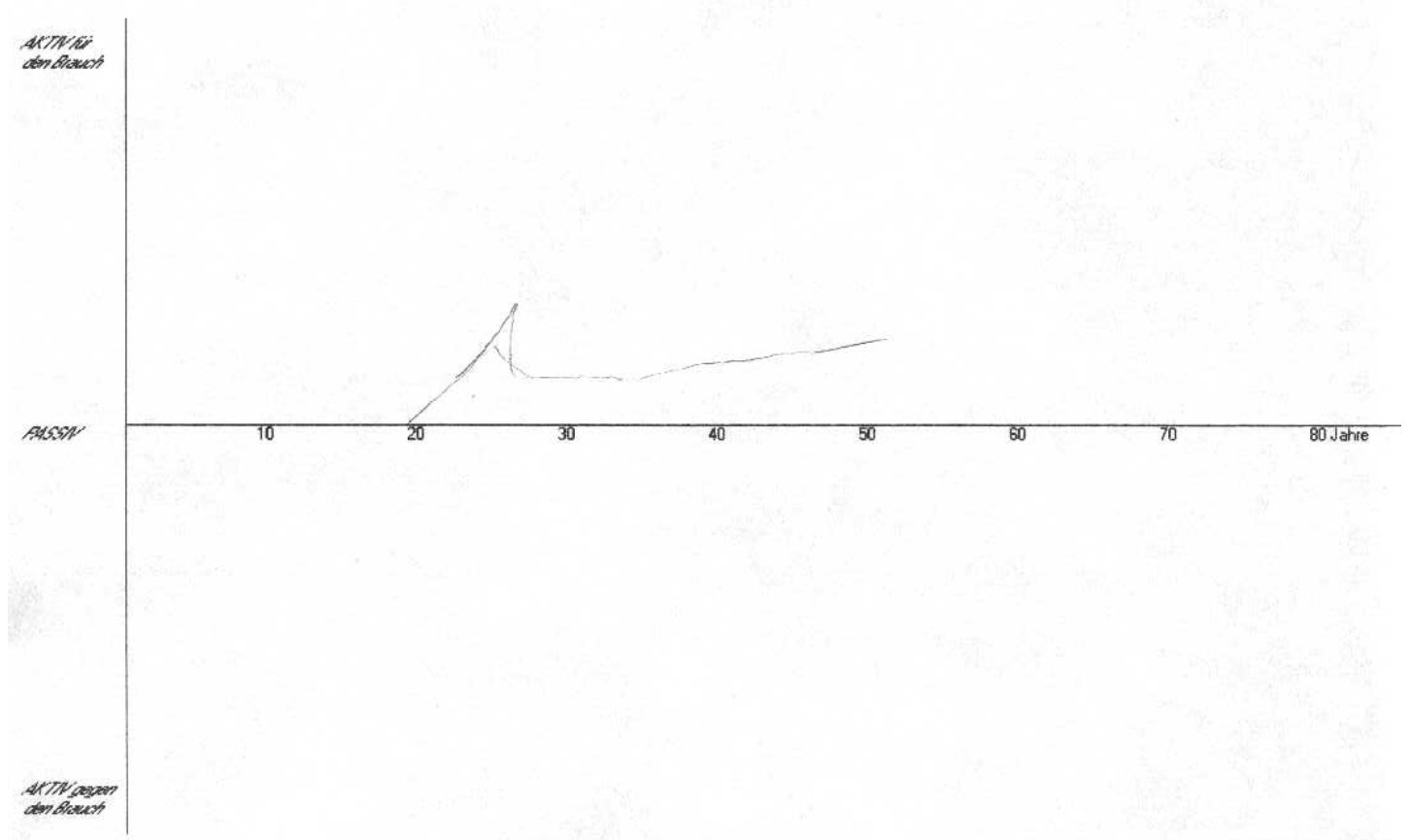


4) Auszüge aus einem Artikel der Lokalpresse zum Mailehen (Bonner GeneralAnzeiger 2./3. April 1994)

\section{König im Mai}

Berrenrather Brauch und Traurn: Mit Krone und Schärpe über die Lendstrafle

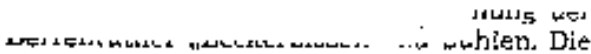
Jungs tragen Cowboysticial, Jean.5, I,ejnemJackets - hien urd da blitzt airse goldene Creole am Ohr - und haiten sich trotz Bauct, assate, wurgtfingerת ured eurh sonst richt geracle Repflegtesten Auftetens für den Näbel der We]l Ko Mín Firoschnulze "La Boum - Die Fete" kennt. Auch sie tröumen von Strapsen und ge-

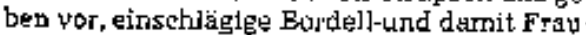
enerfabrungen zu labber. Hepte allerdings kaufen sie sich brave Mädchen, dj ivgeistert sind von dieser Tradjtion. Jn Simt und Sejte

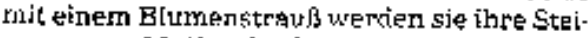
grcer s.uml Maifest begleiten und gich bewur-

dern legsen auf der zam Laufsteg urfunktioriexter Lendstrabe.

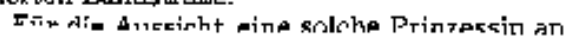

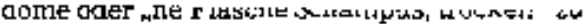
erzattern. Drat \$erh vor der Titr harren der. weil die einfactien Mairelien fiebernd de: ErGebrisse. Auch weng der Falgche"gezahlt hat. nimut Freu es hin Gadz seiten nelur wird ain

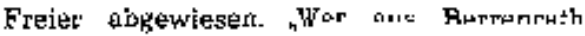

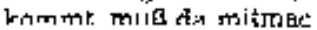

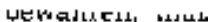

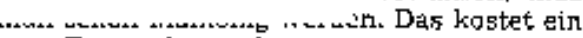
para Taldsender, and die misisen bar auf den Tisch. "Mar sinat aicht ja ponst michts" urd

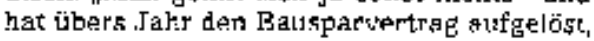

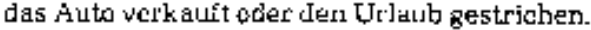

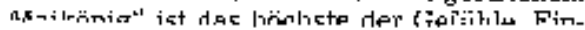

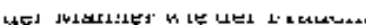

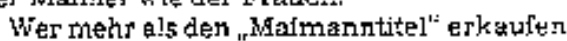
itill, sich also die Frauen von der Juggfraurs. Ljote Irei wajuen kanw, hat meist echor vorher die Angebetete dariber informiert low.r

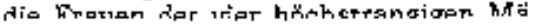

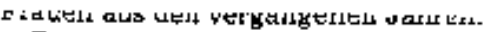

Zum Beispiel Jürgan: soit 20 Jahren is er isntrer feste datei. 13 hal hat ar mitgesteigert. alnogl dawon den Wikönjgstitel dor die freie Auswahl in Mädoher-Sortitent garantiort.

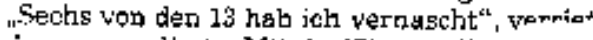

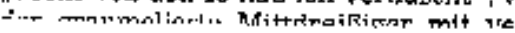

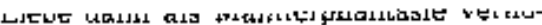
rta Hjer geht es darum, ab eine "Den knarki-

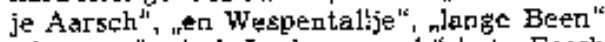
oder en bippigch Loclreopraach" hat. "Fesch möde se sin, un met 2 wan zistoh eg dat doch allt

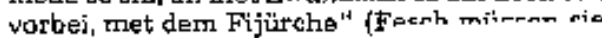

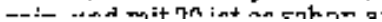


5) Zeitungsbericht über eine Männerversteigerung in Istha/Nordhessen (Hessische Allgemeine 29. März 1994)

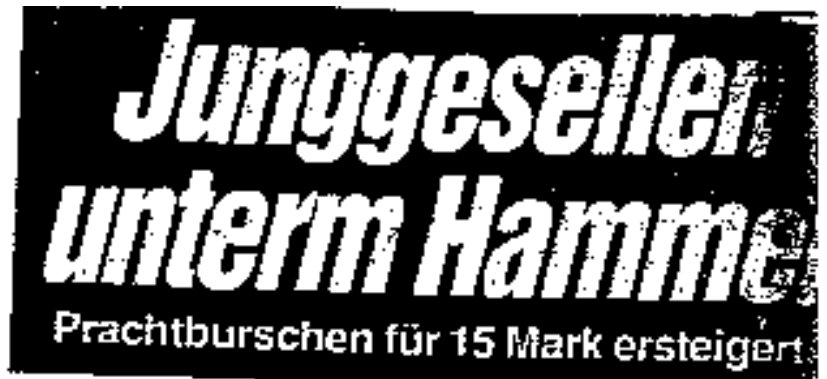

Isthy tra "Dis Airltionatorin bimmelt mit der Glocle ond Petre Lichelt. Für nur 15 Mart hat se ein hübsches Kerlchen entetgert: 1,77 Meter grob, 22 Jahre ait

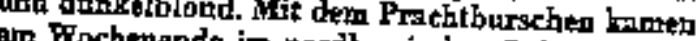
alr Fochendende in tordilessischen Istha nooh 44

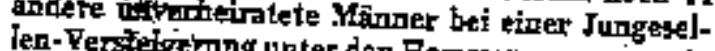
unter dep Fammer.

Eì Otetraus mact's mōglich. Sejt vielen Jajren trerder die ledigen Fruen des Ortes 1" werztejgetr", ietat dresten die Shoer cen Spies :mo . Wir Frauen heber uns th Eiser Gegenaystion trommengetan",

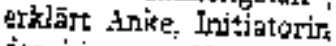
der bizacten Veransca'thig. Māaner haben daber késen Zutritt. Die Narer eler zu rersteaender Jugggereiler bleibgr goicelej, r.J. is! Augsecter Lind einge ihre: Elgonschaften verden berhringer.

It Astektol sird eis

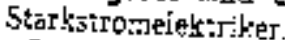
der Leiler cer "Liondfond-

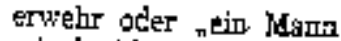
mit danirlen Eocken, de Fublenl spielt und Eadybuilding wackt" Doch

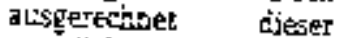

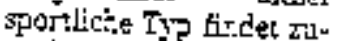
rächat bejine Ioteragseotir. Eshc spāter für eí pas Grosches weg. Mit dem P̈rlis der sultion wrod am shend ejne Fejet finanjiert, むl ter auch die Hänger ktcmsjen cürfer Doch dje haben erst mal xelo ALEer tïr ibre neug

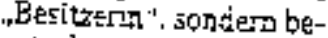

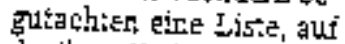

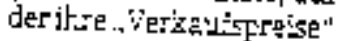

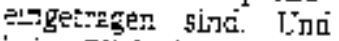
bein 马lok idareui zejpt zits harcher Sicailesaris

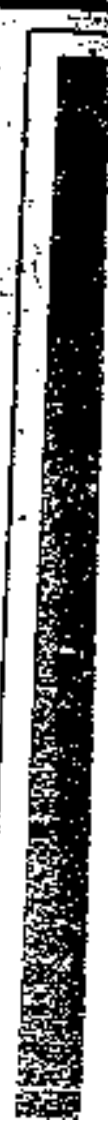


7.4 Abbildungen

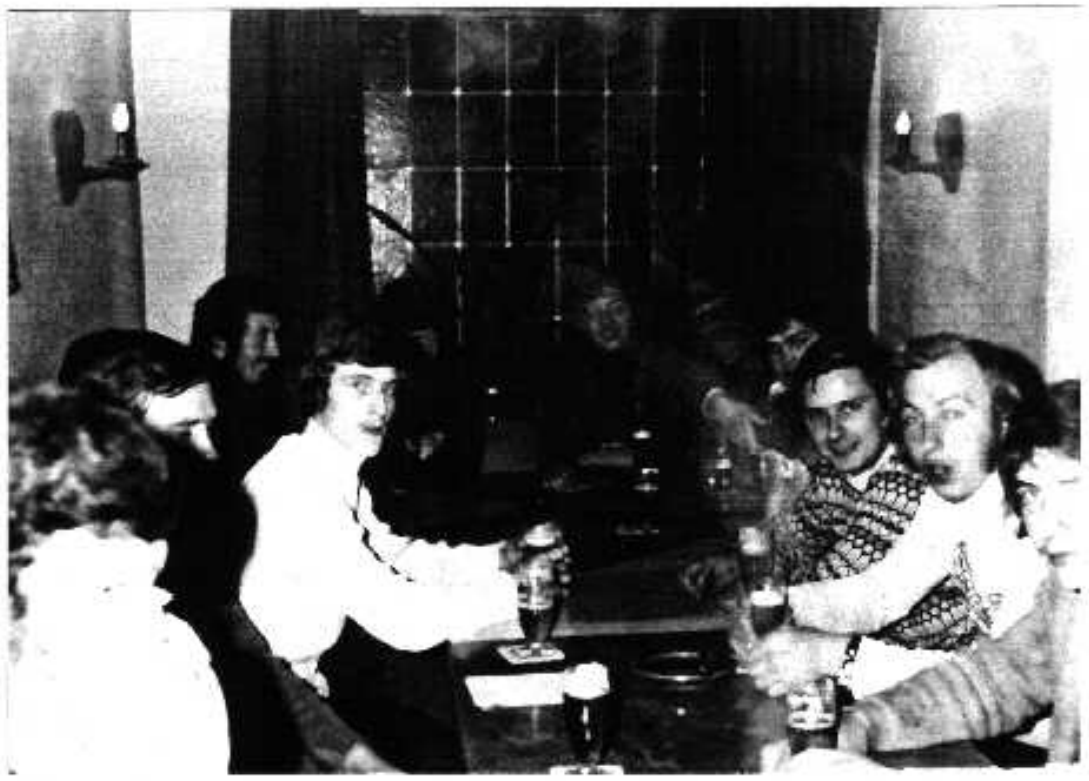

Abbildung 1: Mailehenversteigerung des Junggesellenvereins Oeverich-Niederich 1974 (Photo: Junggesellenverein Ocverich-Niederich)

Abbildung 2; Aufnahme neuer Mitglieder in den Junggesellenverein Oeverich-Niederich 1974 (Photo: Junggesellenverein Oeverich-Niederich)

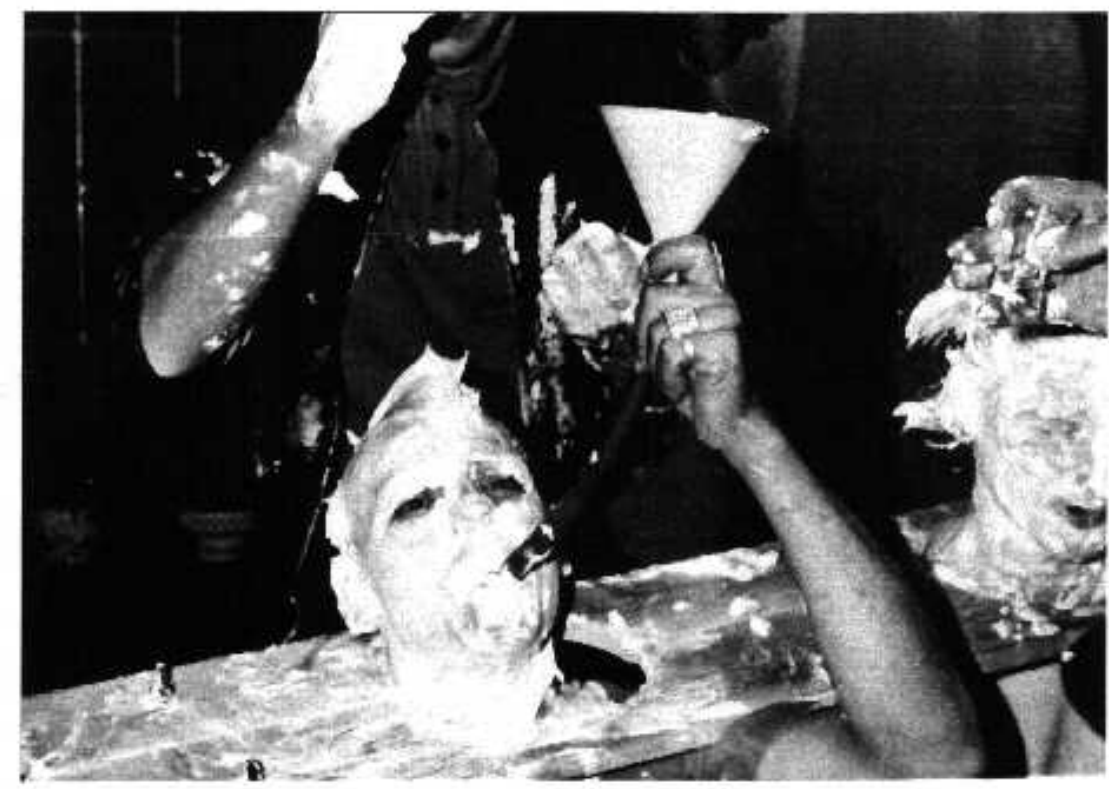




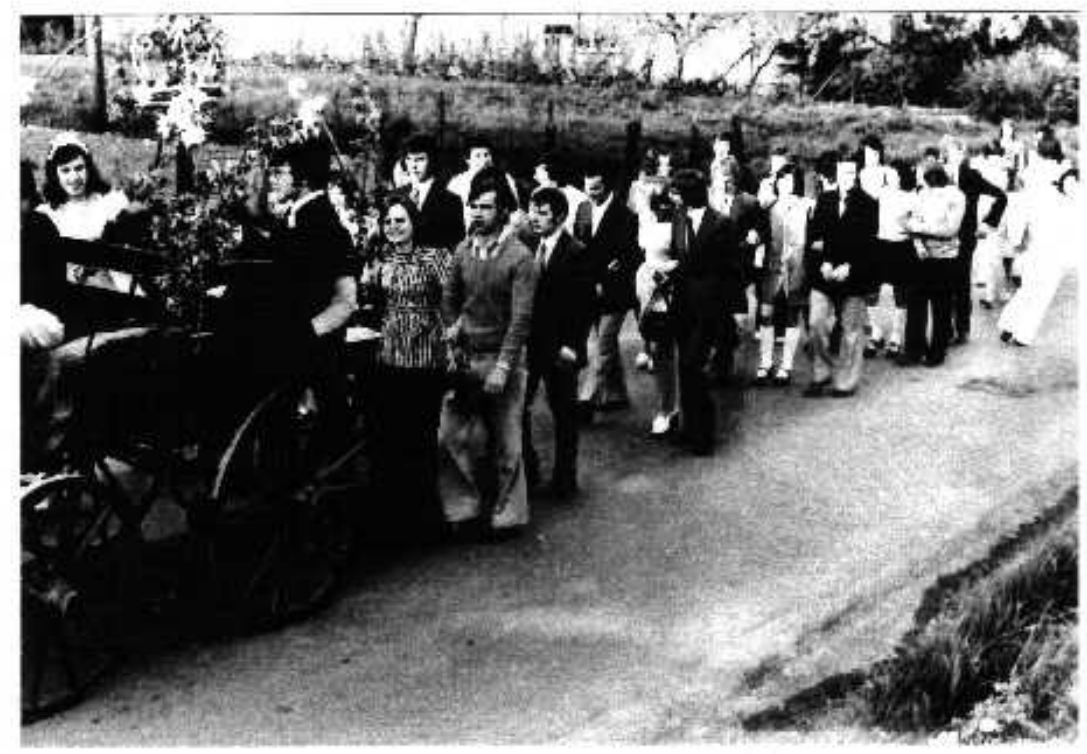

Abbildung 3: Festumzug der Mailehen am Kirmessonntag 1973

(Photo: Junggescllemverein Oeverich-Niederich)

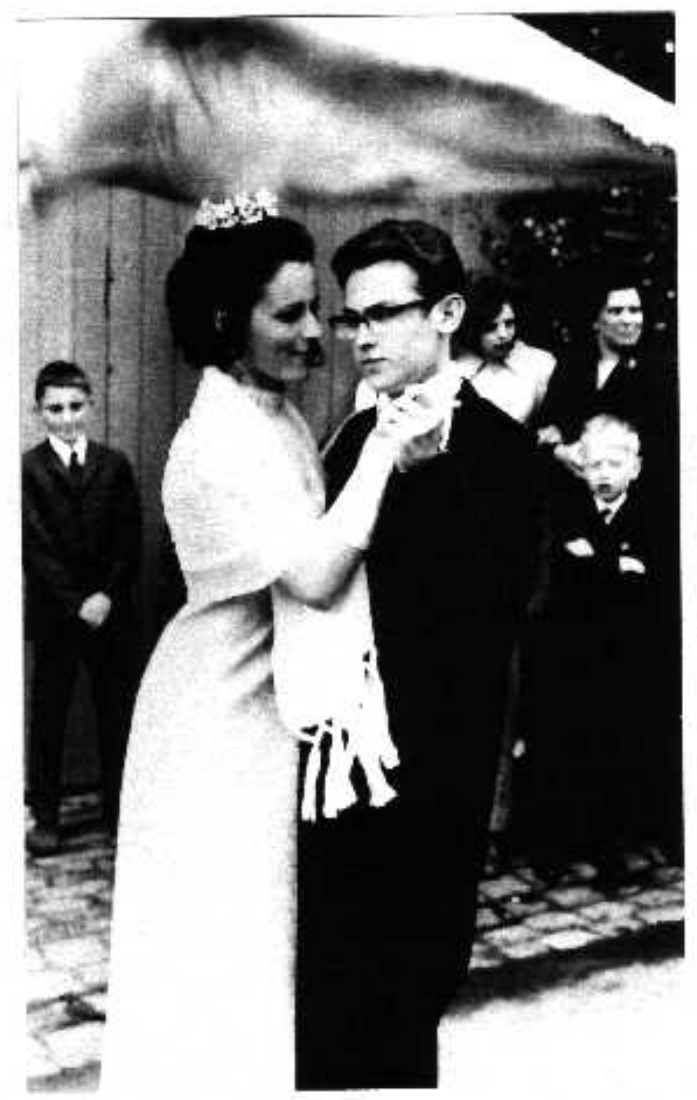

Abbildung 4:

Tanz des Maikönigspaares unter der geschwenkten Junggesellenfahne 1969 (Photo: Junggesellenverein OeverichNiederich) 


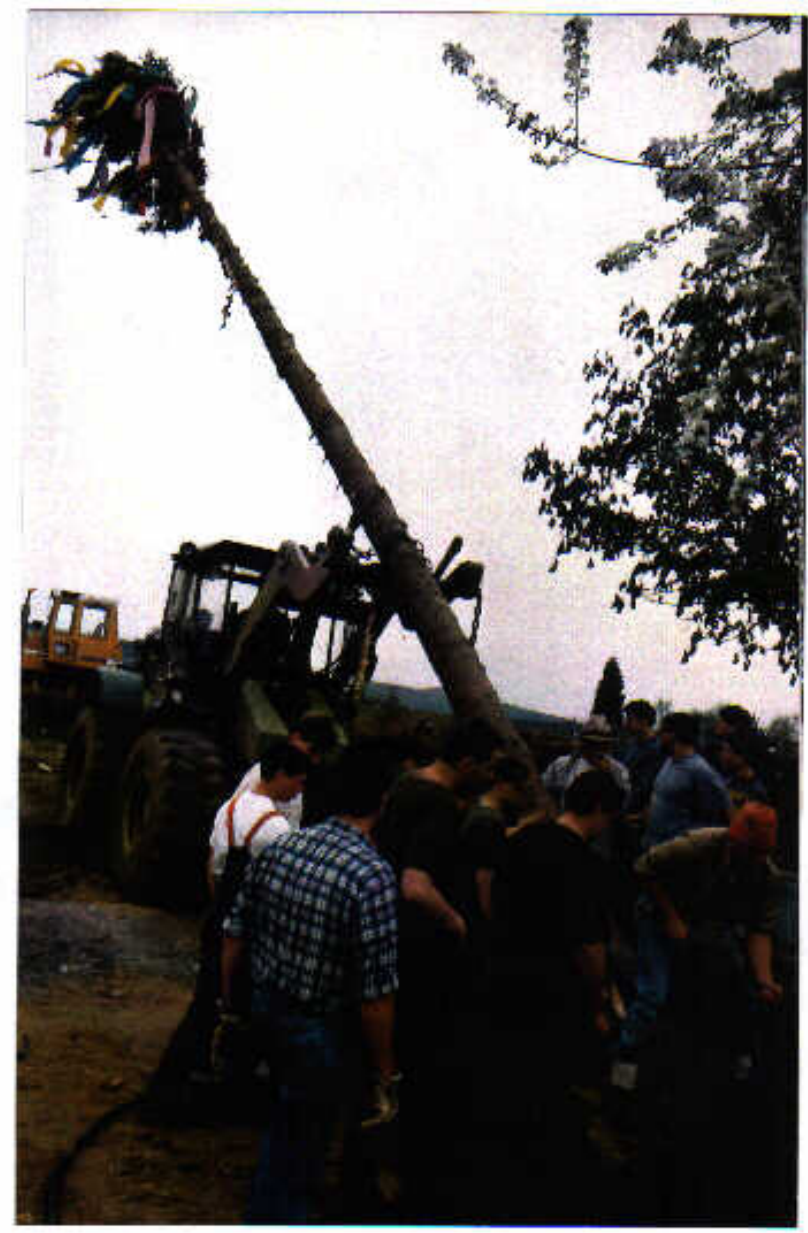

Abbildung 5:

Aufrichten des Dorfmaibaumes am 24. April 1993 in Oeverich (Photo: H.W.W.)

Abbildung 6: Aufnahme neuer Mitglieder in den Junggesellenverein am 30. April 1993 in Oeverich (Photo: H.-W.W.)

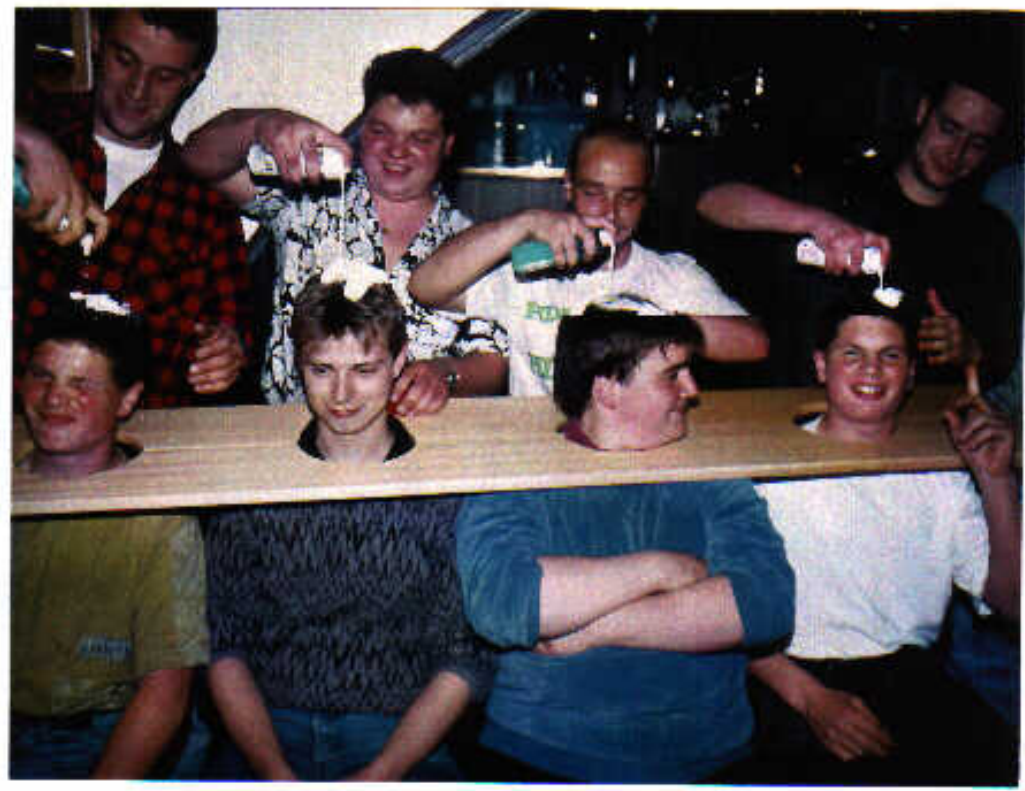




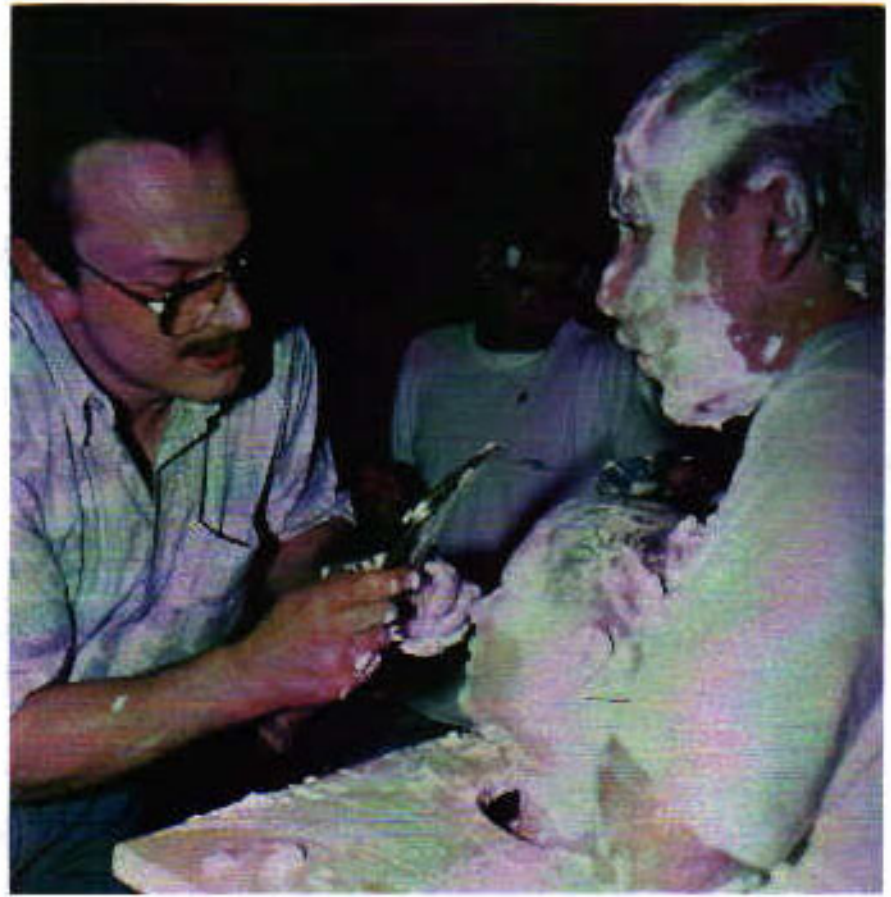

Abbildung 7: Rasur der Initianden mit der "Hääp" am 30. April 1993 in Oeverich (Photo: H, W.W.)

Abbildung 8: Eröffnung der Mailehenversteigerung am 30. April 1993 in Oeverich (Photo: H.W.W.)

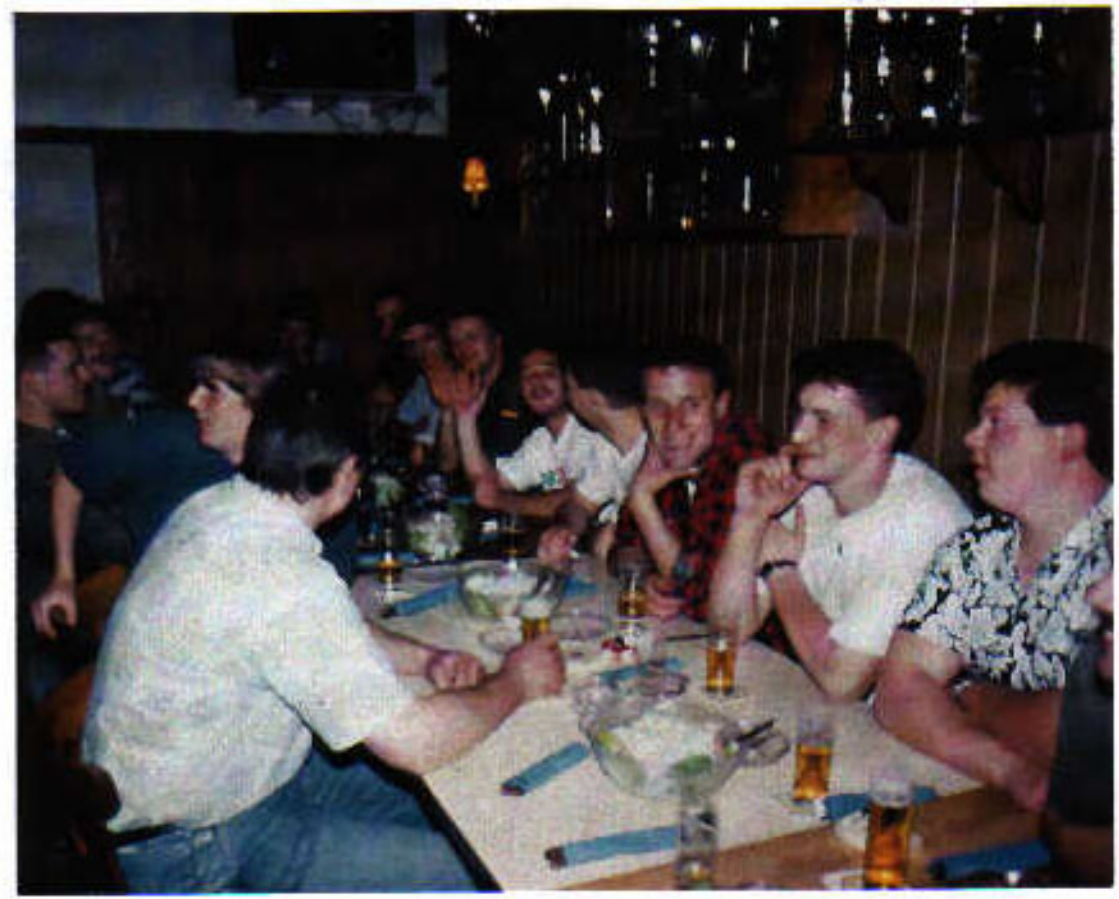




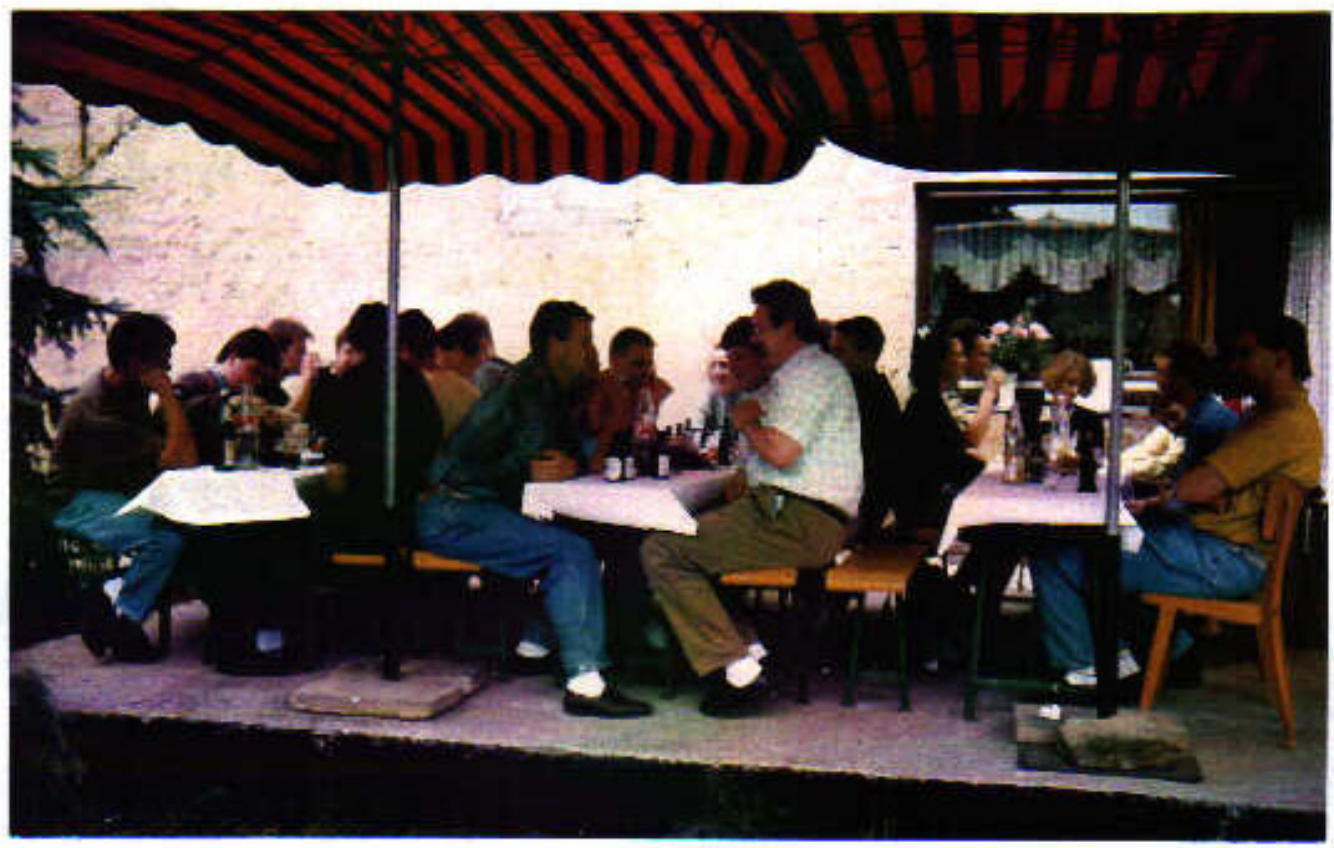

Abbildung 9: Besuch der Maikönigin am 1, Mai 1993 in Niederich (Photo: H.W.W.)

Abbildung 10: Einsetzung des neuen Maikönigspaares in ihr Amt am 14. Mai 1993 in Oeverich (Photo: H,-W,W.)

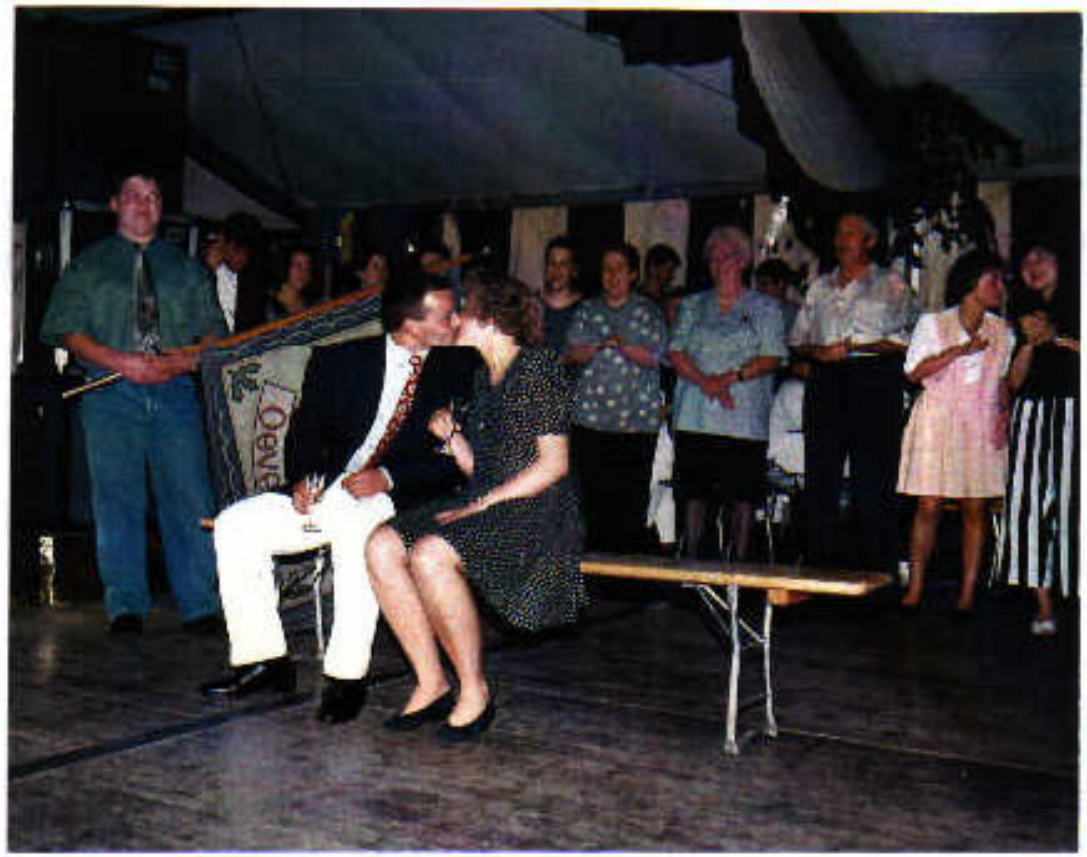




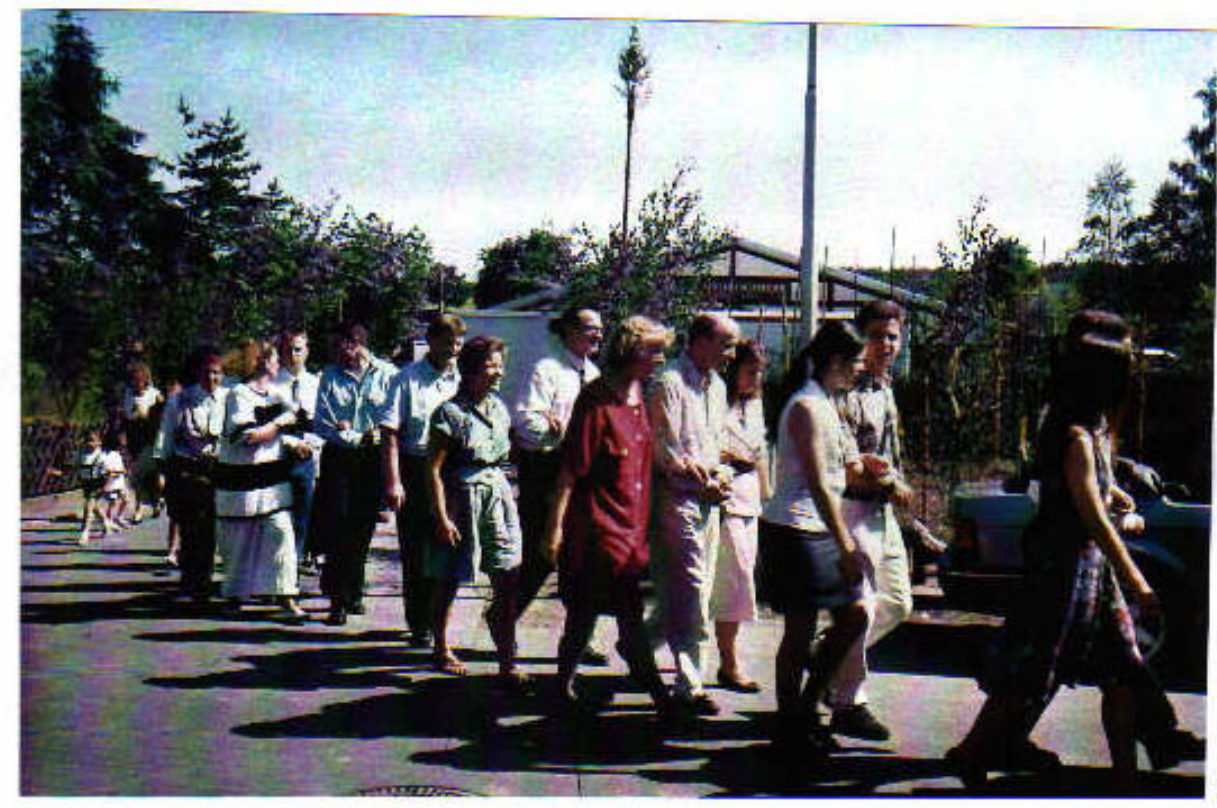

Abbildung 11: Festumzug der Mailehen am 15. Mai 1993 in Oeverich (Photo: H.W.W.)

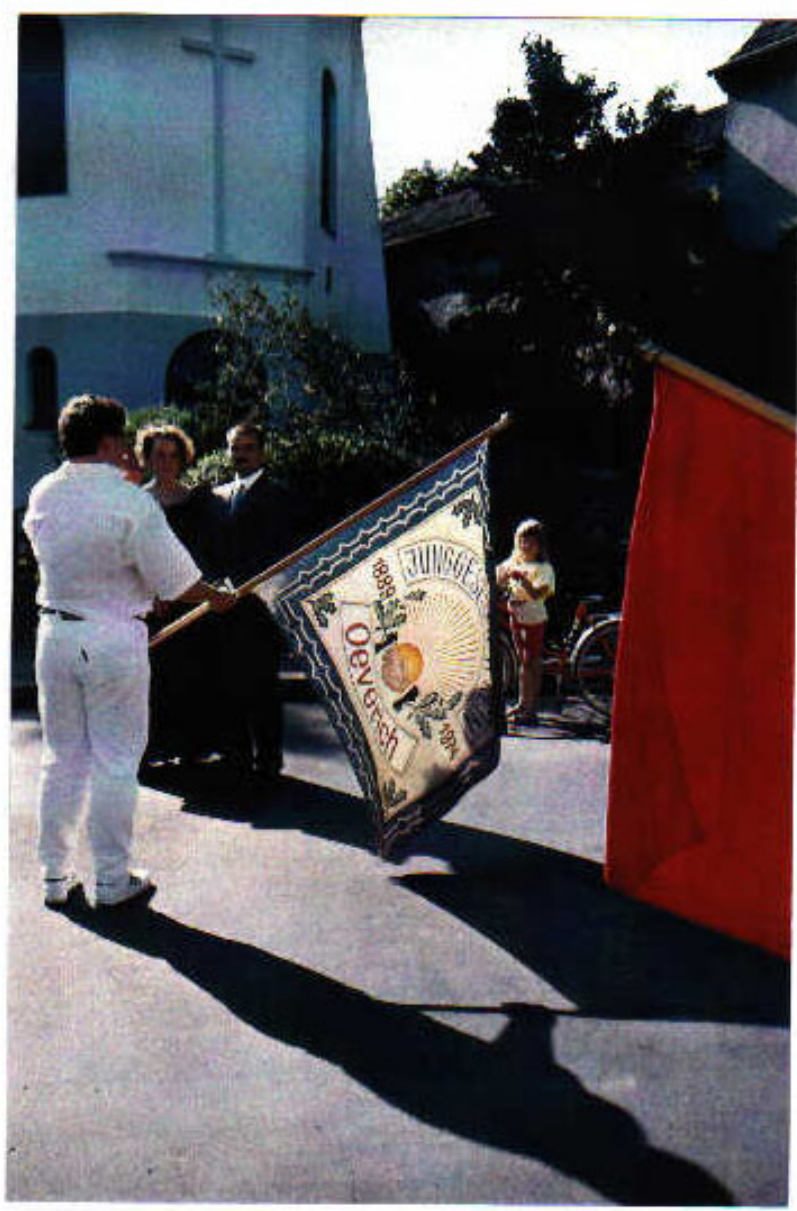

Abbildung 12:

Ehrung des Maikönigspaares durch das Fähndelschwenken. Festumzug der Mailehen am 15. Mai 1993 in Oeverich

(Photo: H.W.W.) 


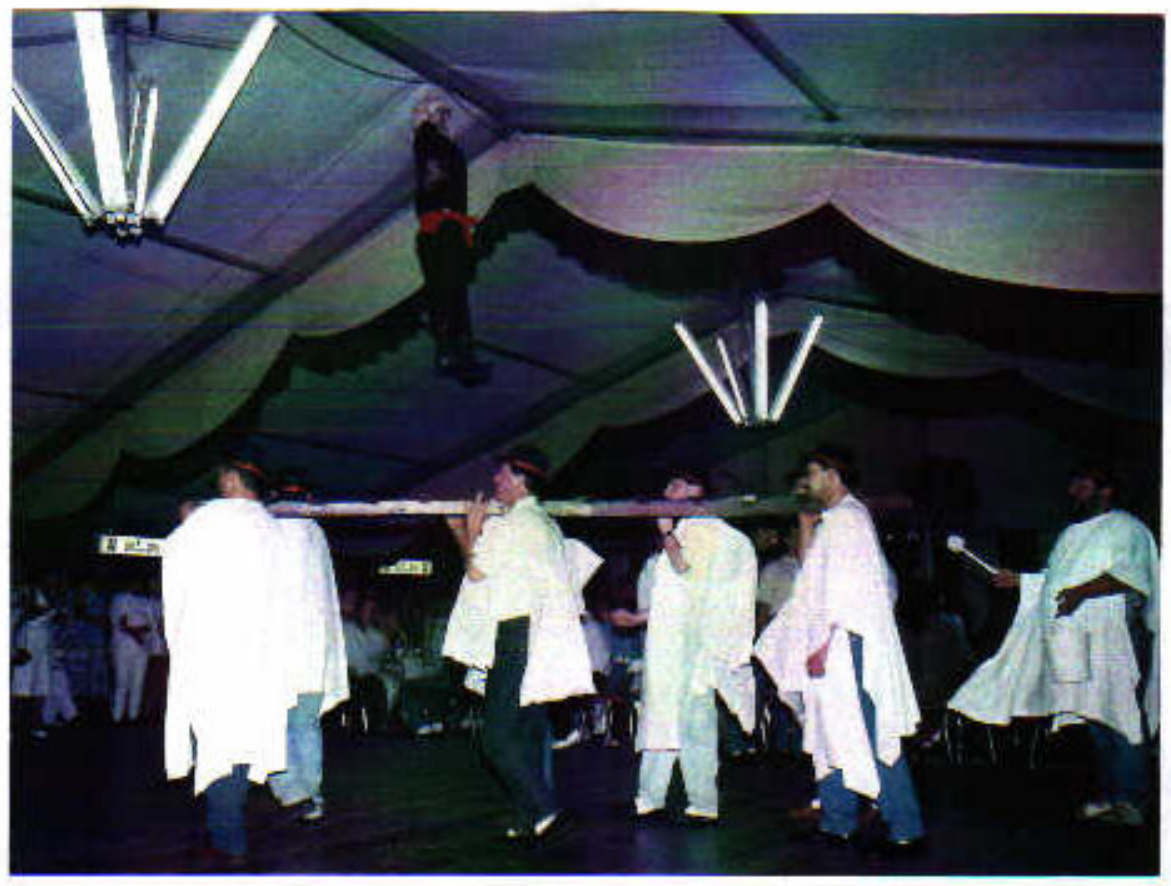

Abbildung 13: Kirmesmannverbrennung am 16. Mai 1993 in Oeverich (Photo: H.-W.W.)

Abbildung 14: Kirmesmannverbrennung am 16. Mai 1993 in Oeverich (Photo: H.-W.W.)

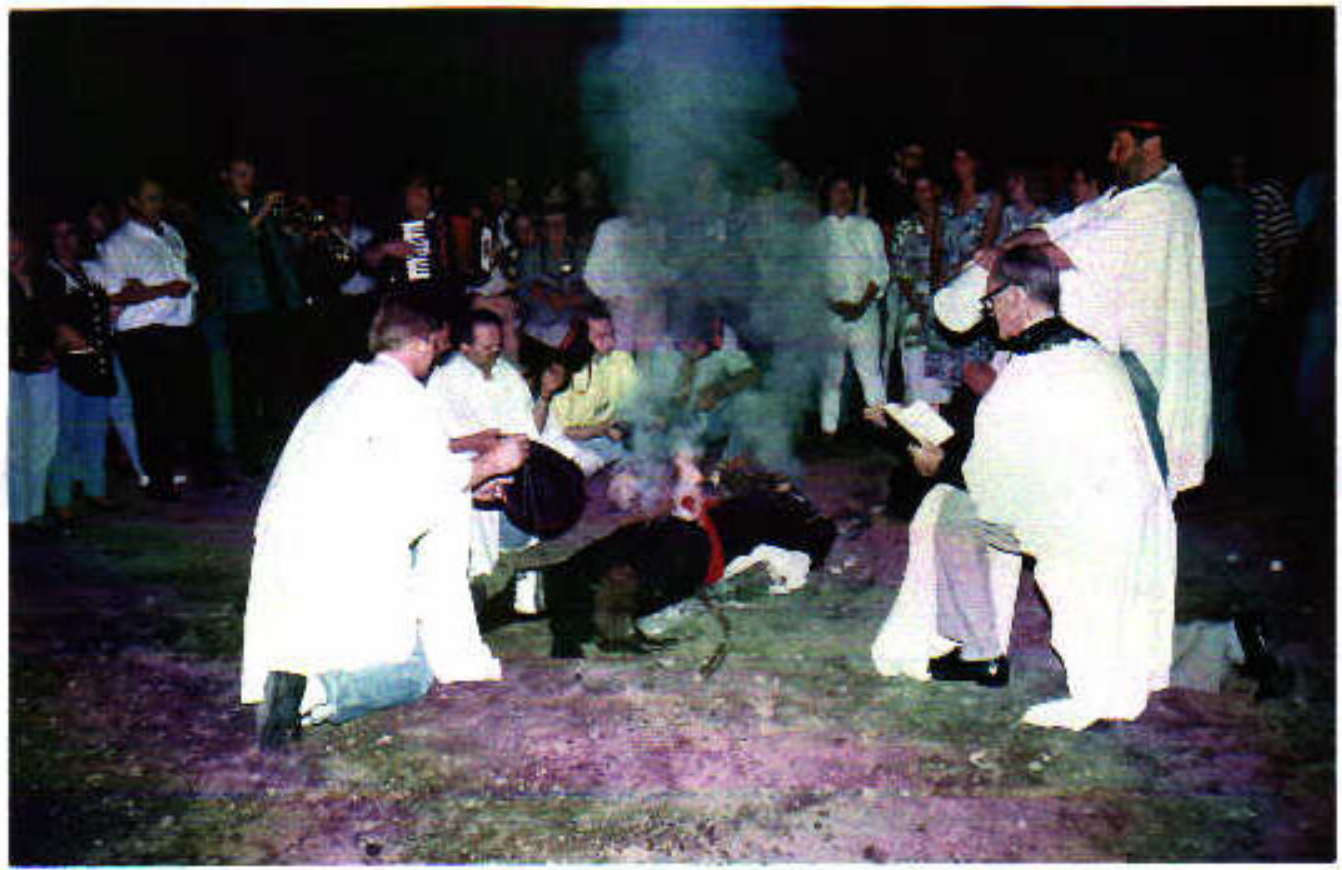

